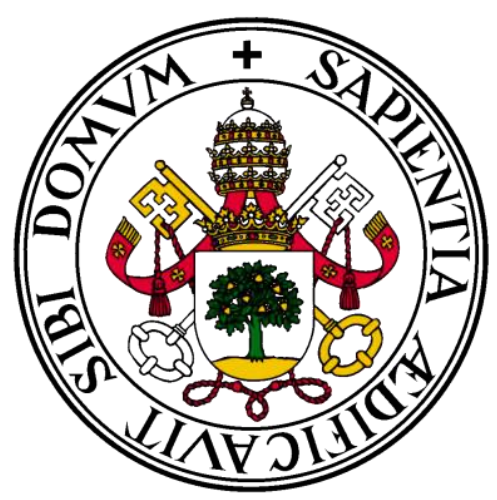

Universidad de Valladolid

Departamento de Física Teórica, Atómica y Óptica

\title{
Análisis del contenido total en columna de vapor de agua atmosférico sobre la Península Ibérica medido con distintas técnicas: radiosondeos, fotómetros solares, y sistema GPS
}

Memoria presentada por

José Pablo Ortiz de Galisteo Marín

Para optar al grado de Doctor en Ciencias

Valladolid, 21 de octubre de 2011 



\section{Agradecimientos}

En primer lugar quiero dar las gracias a mi mujer por su apoyo, compresión y paciencia durante estos largos años que he necesitado para realizar este trabajo, a mis hijos a los que tanto tiempo les he robado, y a toda mi familia en general, especialmente a mis padres por su permanente aliento para que me superara a mi mismo, y que sé que tanta ilusión les hace este momento.

Agradezco de forma muy especial la dedicación y el trabajo de mis directores, Victoria Cachorro y Carlos Toledano, con ellos he aprendido muchísimo. Y por supuesto a Ángel de Frutos que me dio la oportunidad de formar parte del Grupo de Óptica Atmosférica (GOA), donde he podido realizar las tareas de investigación que siempre tanto me han atraído, y a todos los compañeros del GOA, aunque no haya podido pasar mucho tiempo con ellos.

También doy las gracias a todos aquellos que de alguna manera $u$ otra me han apoyado y alentado. Tengo que nombrar a la Agencia Estatal de Meteorología (AEMET) por su programa de fomento de la realización de tesis doctorales entre su personal, a Antonio Labajo, quien me puso en contacto con Victoria y me dio el último empujón necesario para embarcarme en esta aventura que ahora termina su primera escala, a Manuel Lara que me introdujo en el mundo del sistema GPS, y a Juan Pablo Álvarez, por sus oportunas correcciones en los temas de predicción.

Por último quiero expresar mi gratitud a las instituciones de cuyos datos me he servido para realizar este trabajo: Agencia Estatal de Meteorología (AEMET), Instituto Geográfico Nacional (IGE), Universidad de Valladolid, Universidad de Extremadura, Universidad de Valencia, Universidad Politécnica de Cataluña, Universidad de Evora, Instituto Geográfico Portugués, Instituto de Meteorología de Portugal, Servicio Meteorológico de Cataluña, y UK National Weather Service (MetOffice). 



\section{ÍNDICE}

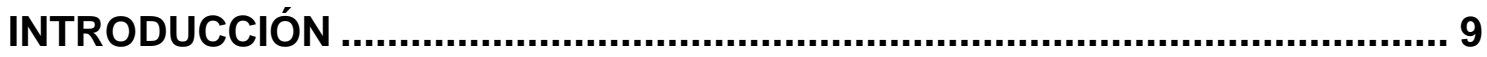

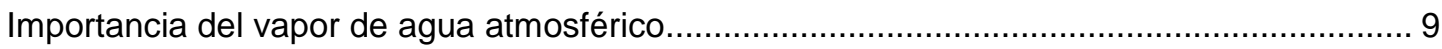

CONCEPTOS GENERALES Y METODOLOGÍA.......................................... 15

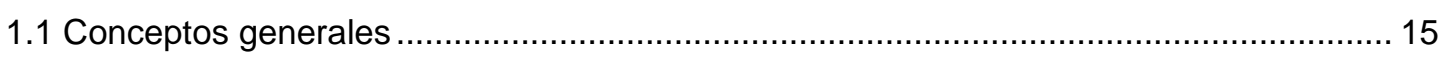

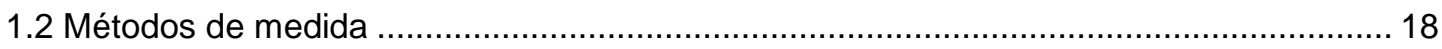

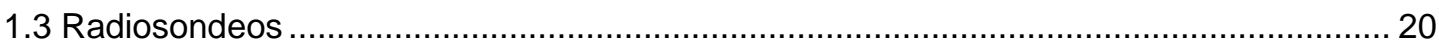

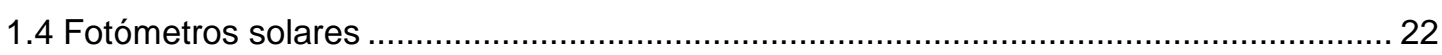

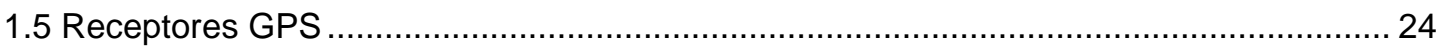

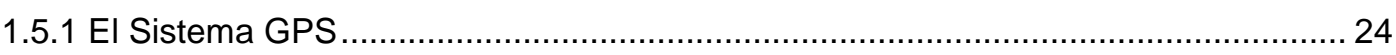

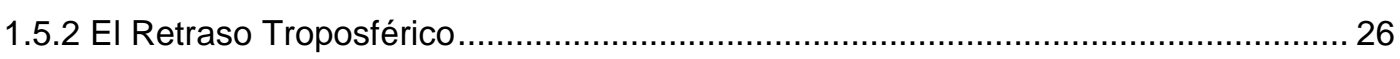

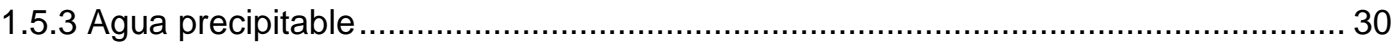

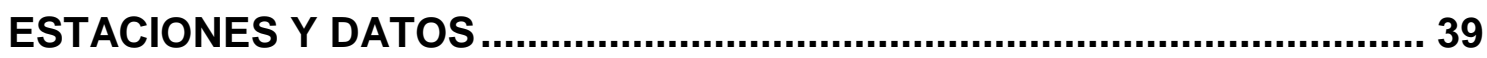

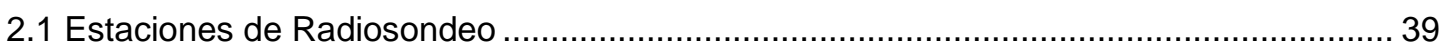

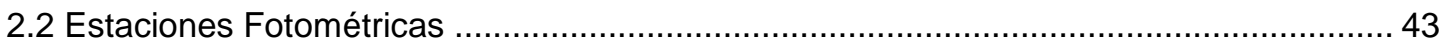

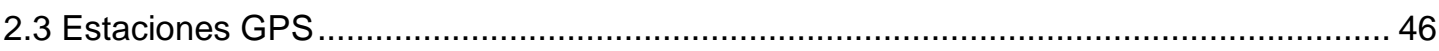

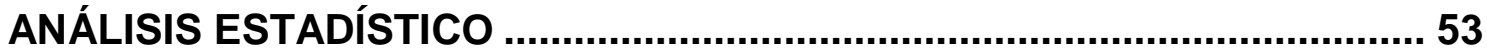

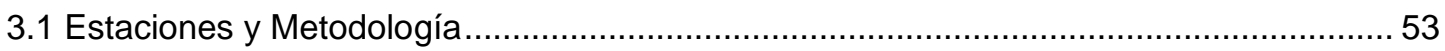

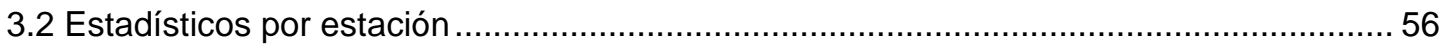

3.2.1 MADRID (aeropuerto de Barajas). Estación de radiosondeo. ................................. 58

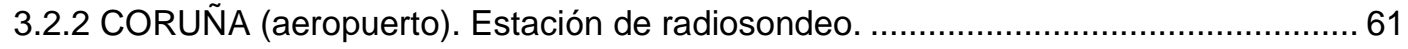

3.2.3 GIBRALTAR (aeropuerto). Estación de radiosondeo. ............................................. 64

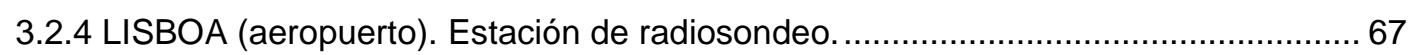

3.2.5 MURCIA (Observatorio Meteorológico). Estación de radiosondeo........................... 70

3.2.6 SANTANDER (aeropuerto). Estación de radiosondeo............................................ 73

3.2.7 ZARAGOZA (aeropuerto). Estación de radiosondeo............................................... 76

3.2.8 EL ARENOSILLO (Huelva, INTA). Estación fotométrica. ..................................... 79

3.2.9 PALENCIA (E.T.S.I.A., Universidad de Valladolid). Estación fotométrica. ................ 82

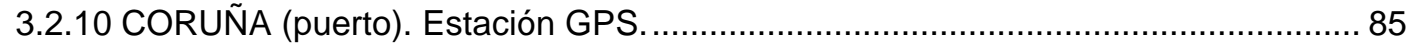

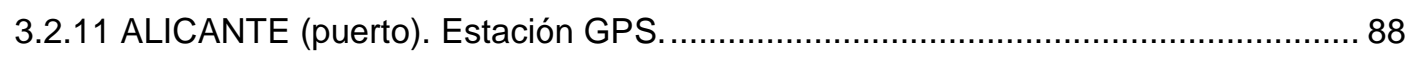

3.2.12 ALMERÍA (Observatorio geofísico). Estación GPS.............................................. 91

3.2.13 CÁCERES (Escuela Politécnica). Estación GPS............................................... 94 
3.2.14 SANTANDER (Escuela Ingenieros). Estación GPS............................................. 97

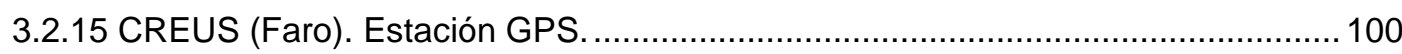

3.2.16 ROQUETES (Observatorio del Ebre). Estación GPS. ....................................... 103

3.2.17 SAN FERNANDO (Observatorio de la Armada). Estación GPS. ........................... 106

3.2.18 VALENCIA (Universidad Politécnica). Estación GPS. ........................................ 109

3.2.19 VILLAFRANCA DEL CASTILLO (Estación de la ESA). Estación GPS...................112

3.2.20 YEBES (Observatorio astronómico). Estación GPS. ............................................ 115

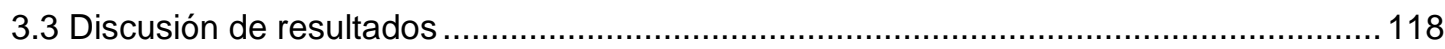

3.4 Distribución vertical del vapor de agua ..................................................................... 123

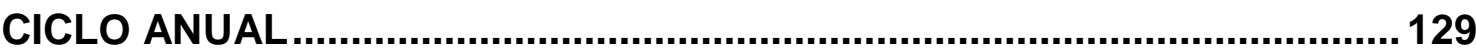

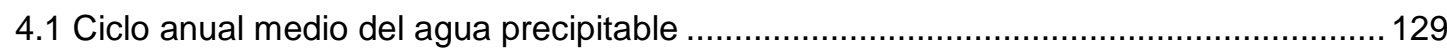

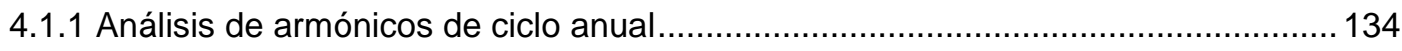

4.1.2 Comparativa entre técnicas del ciclo anual ...................................................... 137

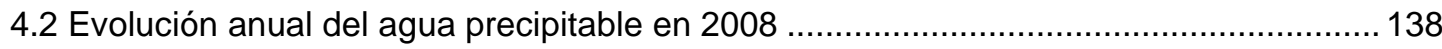

4.3 Evolución anual de la distribución vertical del vapor de agua ...................................... 141

4.4 Mínimo relativo del mes de julio .............................................................................. 147

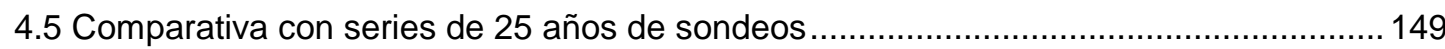

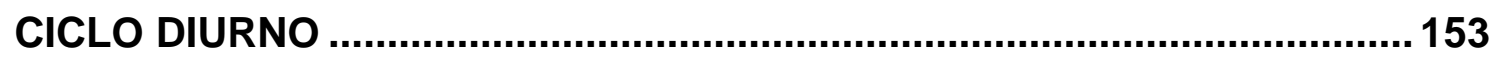

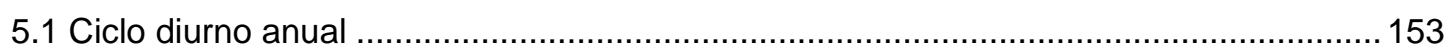

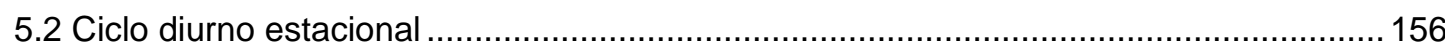

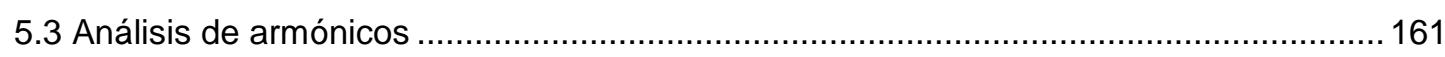

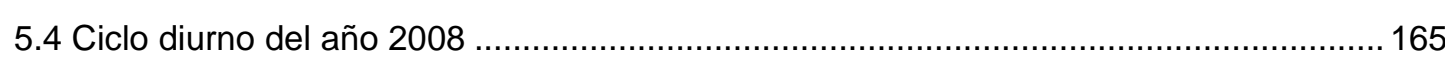

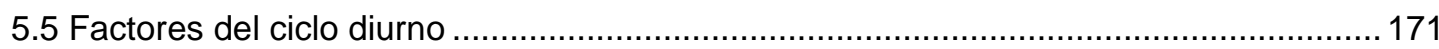

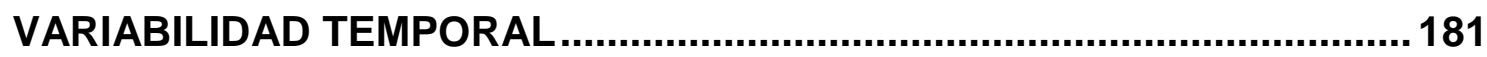

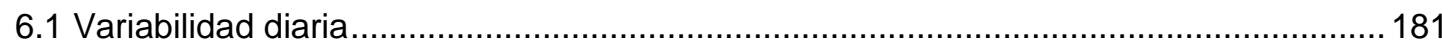

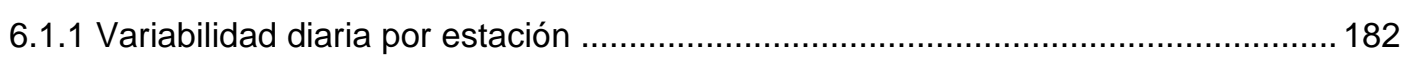

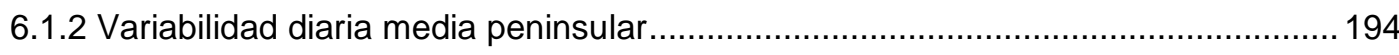

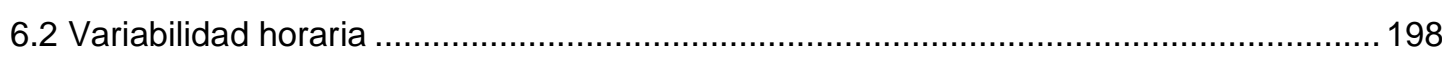

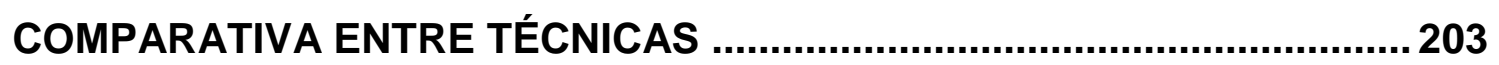

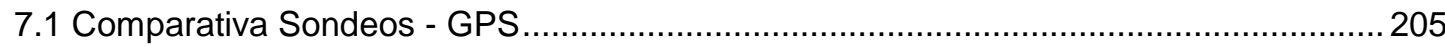

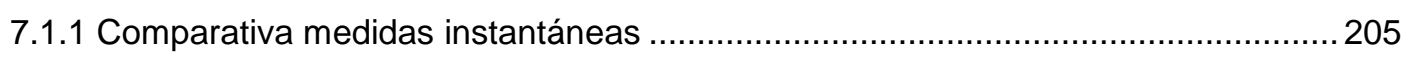

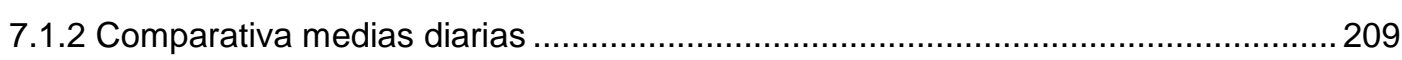

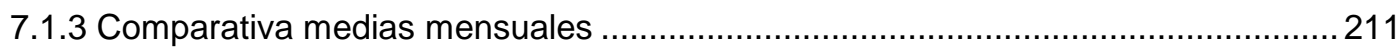

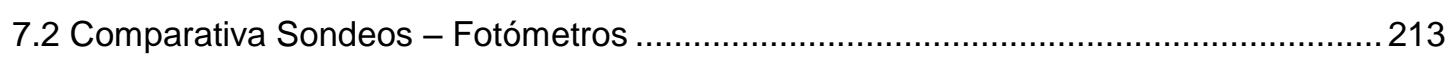

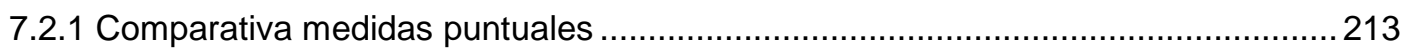

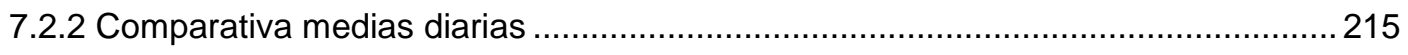

7.2.3 Comparativa medias mensuales …......................................................... 217 


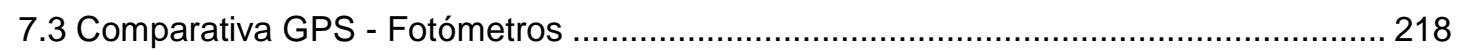

7.3.1 Comparativa medidas instantáneas .......................................................... 218

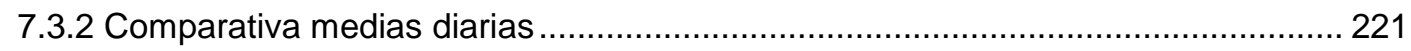

7.3.3 Comparativa medias mensuales ............................................................. 223

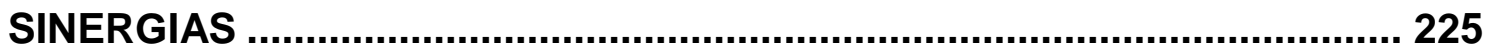

8.1 Diferencia día-noche en las medias de los sondeos ......................................... 225

8.2 Calibración absoluta del centro de fase de las antenas GPS ................................. 228

8.3 Validación de las calibraciones de los fotómetros ................................................ 233

8.4 Sesgo en las medidas de cielo despejado ............................................... 233

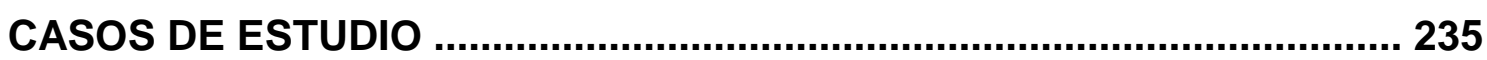

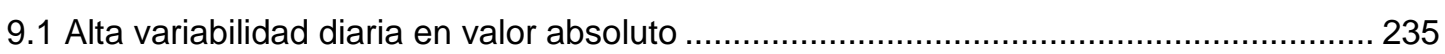

9.2 Alta variabilidad diaria en valor relativo ......................................................... 238

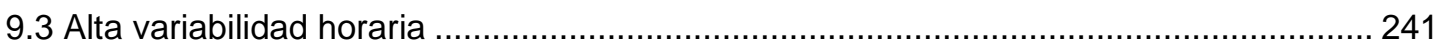

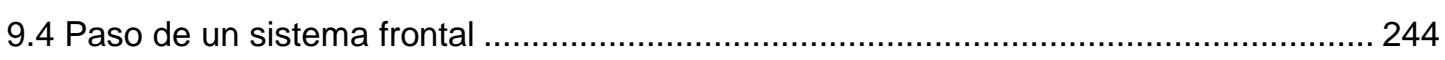

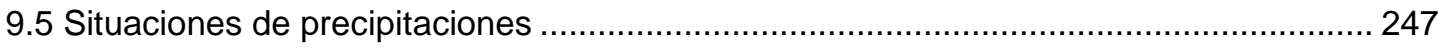

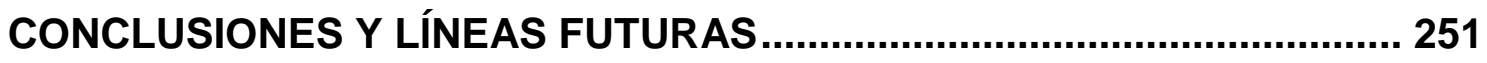

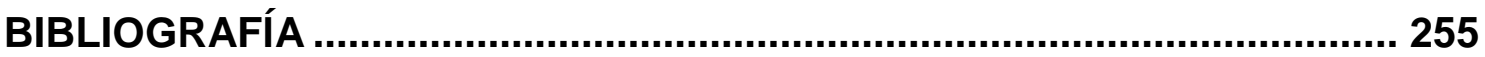

ANEXOS

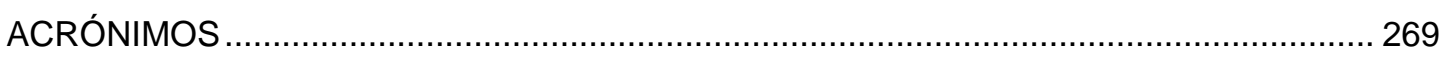

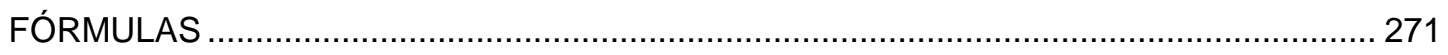

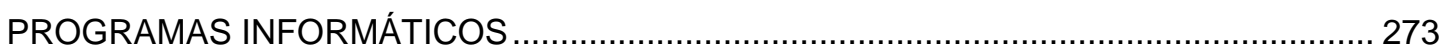

ARTÍCULO I: Improvement in PWV estimation from GPS due to the absolute calibration of

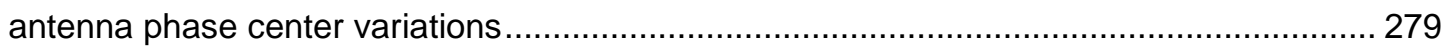

ARTÍ́CULO II: Diurnal cycle of precipitable water vapor over Spain ............................... 289 


$$
-8-
$$




\section{Capítulo 0}

\section{INTRODUCCIÓN}

Esta introducción está dedicada a establecer los objetivos, motivación y contexto donde se enclava esta memoria de trabajo de tesis titulada "Análisis del contenido total en columna de vapor de agua atmosférico sobre la Península Ibérica medido con distintas técnicas: radiosondeos, fotómetros solares, y sistema GPS".

\section{Importancia del vapor de agua atmosférico}

El vapor de agua es uno de los componentes atmosféricos más importante, jugando un papel destacado en muchos procesos de un amplio rango de escalas espaciales y temporales, desde la climatología global hasta la micro-meteorología. Su importancia radica principalmente en el transporte de energía, el balance radiativo, el efecto invernadero, la estabilidad vertical de la atmósfera, y el ciclo hidrológico.

Un mecanismo muy eficaz del balance meridional de la energía a escala global es el transporte de vapor de agua por la circulación general atmosférica, debido al inusual alto valor del calor latente asociado con sus cambios de fase. A bajas latitudes parte de la energía de la intensa radiación solar es utilizada para evaporar agua, que luego es transportada en forma de vapor hacia latitudes más altas donde al condensarse libera gran cantidad de calor (Mockler, 1995).

El vapor de agua interviene muy activamente en el balance radiativo terrestre al ser el principal absorbente en las capas bajas de la radiación infrarroja emitida por la superficie terrestre, siendo el responsable del calentamiento del aire en esas capas. Además, es también el mayor absorbente de la radiación solar (Kiehl y Trenberth, 1997). El conocimiento del balance radiativo y de la distribución del vapor de agua en la atmósfera es necesario para modelizar la atenuación de la radiación solar por la absorción del vapor de agua (Jakobson et al., 2009), lo que permite además mejorar las correcciones atmosféricas de las imágenes de los satélites.

El sistema climático global es muy sensible al contenido de vapor de agua por ser este el componente atmosférico que más contribuye al efecto invernadero, sobre un $60 \%$, mientras que el dióxido de carbono $\left(\mathrm{CO}_{2}\right)$ lo hace con un 26\% (Maurellis y Tennyson, 2003). El contenido de vapor de agua está definido por el Sistema de Observación del Clima Mundial (GCOS) como una de las variables climáticas esenciales para dar soporte a los trabajos que 
llevan a cabo el Panel Intergubernamental para el Cambio Climático (IPCC) y la Convección de Naciones Unidas para el Cambio Climático (UNFCCC). El incremento de la temperatura media del planeta debido al aumento antropogénico de las concentraciones de $\mathrm{CO}_{2}$ en la atmósfera conlleva un aumento en la cantidad de vapor de agua, que a su vez produce un mayor calentamiento (Hall y Manabe, 1999). Los modelos climáticos deben tener en cuenta esta retroalimentación positiva para reducir las incertidumbres en las predicciones del clima futuro. Las diferencias en las proyecciones de la temperatura media del planeta entre los modelos que tienen en cuenta esta retroalimentación (Cubasch et al., 2001) y los que no (Cess et al., 1990) pueden llegar al $70-90 \%$.

Para estudiar los cambios a largo plazo en el contenido de vapor de agua en la atmósfera como consecuencia del Cambio Climático es necesario conocer primero la climatología de esta variable. La mayor parte de los estudios llevados a cabo para determinar la tendencia a nivel global del contenido de vapor de agua, utilizando reanálisis de modelos numéricos (ERA-40 y NCEP) y datos de satélites, apuntan hacia un incremento sobre los océanos que oscila entre $+0.40 \pm 0.09 \mathrm{~mm} /$ década (Trenberth et al., 2005) y $+0.90 \pm 0.06 \mathrm{~mm} /$ década (Brown et al., 2007). Pero para poder confirmar estos valores tan pequeños se necesitan series de datos más largas con una calidad contrastada.

El vapor de agua es un parámetro primordial en la estabilidad vertical de la atmósfera y en la estructura y evolución de los sistemas tormentosos. Así, la distribución del vapor de agua está íntimamente ligada a la distribución de las nubes y a las precipitaciones. Un mejor conocimiento del ciclo diurno del vapor de agua puede ayudar a mejorar las parametrizaciones físicas de los modelos de predicción numérica del tiempo, y así, disminuir las incertidumbres en la predicción de la convección (Vedel et al., 2004; Guerova et al., 2006).

Además, el vapor de agua interviene de manera importante en muchas de las reacciones químicas que tienen lugar en las capas bajas de la atmósfera, donde sus concentraciones son mayores.

Sin embargo, y a pesar de su importancia, este componente atmosférico no está bien caracterizado al no disponerse de medidas con la suficiente resolución para representar su alta variabilidad espacial y temporal, que tiene lugar a escalas mucho más pequeñas (mesoescala o microescala) que otras variables meteorológicas, como podrían ser la temperatura o el viento. Este es el gran problema de las medidas del vapor de agua, de hecho, estas limitaciones son las principales fuente de error de los modelos numéricos de predicción a corto plazo (Kuo et al., 1993; Binder y Schär, 1996).

En Meteorología la variable más estudiada y medida en relación con el contenido de vapor de agua ha sido la humedad (relativa o absoluta). Sin embargo en este trabajo nos centraremos 
en la variable Agua Precipitable (PWV), definida como la masa total de vapor de agua contenida en la columna atmosférica de superficie la unidad. Esta variable se expresa en términos de masa $\left(\mathrm{gr} / \mathrm{cm}^{2}\right.$ ó $\left.\mathrm{kg} / \mathrm{m}^{2}\right)$ o en términos de la altura de la capa de agua resultante si todo el vapor contenido en la columna atmosférica se condensara y depositara sobre la superficie. Según esta definición, el PWV se obtiene por integración de la humedad absoluta en la vertical de la columna atmosférica.

A lo largo de las últimas décadas se han desarrollado una gran variedad de tipos de instrumentación, basados en técnicas distintas, para la medida del contenido total de vapor de agua: sondeos, radiómetros de microondas, lidar, fotómetros solares o infrarrojos, diferentes tipos de sensores satelitales, etc., todos ellos con sus ventajas e inconvenientes. Históricamente los Servicios Meteorológicos Nacionales han utilizado los sondeos aerológicos para determinar el contenido de vapor de agua en la atmósfera. Estas medidas, si bien proporcionan un perfil vertical de la distribución de este componente, son escasas por su alto coste, por lo que datos adicionales provenientes de nuevas técnicas de observación son altamente deseables para alcanzar la adecuada cobertura. Más recientemente, el sistema GPS (Global Position System), diseñado para fines de posicionamiento, se ha revelado como una técnica muy útil para la determinación del contenido total en columna de vapor de agua en la atmósfera (Guerova, 2003; De Haan, 2006). La determinación del vapor de agua con el sistema GPS se basa en el retraso que experimenta la señal de estos satélites al atravesar la atmósfera por la presencia del vapor de agua (Bevis et al., 1992; Bevis et al., 1994). Estos equipos pueden medir de día y de noche y en todas las condiciones de tiempo atmosférico, con buena resolución temporal y espacial.

La calidad de los datos de vapor de agua obtenidos de las redes de GPS ha sido constatada por varios autores por comparación con fotómetros solares (Bokoye et al., 2003; Santangelo et al., 2003; Campmany et al., 2010), con sondeos (Ohtani y Naito, 2000; Wang et al., 2007; Wang y Zhang, 2008), con espectrómetros FTIR (Fourier Transform Infrared) (Schneider et al., 2009), con radiómetros de microondas (Elgered et al., 1997; Emardson et al., 1998; Dai et al., 2002; Morland, 2009), con radiómetros embarcados en satélites como el MODIS (ModerateResolution Imaging Spectroradiometer) (Li et al., 2003), o con los modelos de predicción (Heise et al., 2009), estableciendo todos ellos un error entre 1 y $3 \mathrm{~mm}$, y han sugerido que los datos proporcionados por los GPS son adecuados para estudiar las variaciones diurnas del vapor de agua. Además, la adopción de un modelo de calibración absoluta del centro de fases de las antenas de los satélites y receptores GPS en noviembre del 2006 ha supuesto una gran mejora en la precisión de los datos de vapor de agua (Ortiz de Galisteo et al., 2010).

A la vista de las oportunidades que ofrecía esta nueva técnica, se puso en marcha la acción COST 716 con el objeto de explotar el sistema de estaciones GPS para suministrar observaciones de PWV que pudieran ser asimiladas por los modelos numéricos de predicción. 
Esta línea de trabajo fue continuada por otros proyectos como el MAGIC o el TOUGH, en el que participó el antiguo INM (Instituto Nacional de Meteorología) ahora Agencia Estatal de Meteorología (AEMET). Más recientemente, en el año 2005 EUMETNET (Network of European Meteorological Services) puso en marcha el proyecto E-GVAP, en el que también participó el INM, y que supuso el primer contacto del dotorando con esta técnica.

Aunque hay estudios en la literatura sobre el comportamiento del vapor de agua atmosférico, estos han sido realizados principalmente con datos de sondeos (Reitan, 1960; Gaffen et al., 1991; Gaffen et al., 1992; Ross y Elliott, 1996; Wang et al., 2001), y de satélites (Gao et al., 2004; Dubuisson et al., 2004; Mote y Frey, 2006), que no son suficientes para describir su alta variabilidad espacial y temporal. En estos momentos, el sistema GPS es una de las técnicas más potentes para estudiar el contenido de vapor de agua, como así lo demuestran los numerosos estudios que recientemente se han realizado utilizando datos suministrados por los receptores GPS, tanto a nivel global (Hagemann et al., 2003; Wang et al., 2007; Jin y Luo, 2009) como a nivel regional y local (Dai et al., 2002; Wu et al., 2003; Bastin et al., 2007; Bock et al., 2007; Champollion et al., 2009; Jakobson et al., 2009), pero ninguno de ellos centrado en la Península Ibérica.

El objeto global del presente estudio será el análisis y la caracterización del contenido total en columna de vapor de agua o agua precipitable sobre la Península Ibérica a partir de las medidas de siete años de datos, desde el año 2002 a 2008 ambos inclusive, proporcionadas por la red de receptores GPS de EUREF (European Reference Frame), y complementadas con los datos de las estaciones de radiosondeo y con las medidas proporcionadas por la red de fotómetros solares de RIMA (Red Ibérica de Medida Fotométrica de Aerosoles), red federada con AERONET (Aerosol Robotic Network) (Holben et al., 1998). Estas son las tres técnicas con mayor número de estaciones disponibles sobre la Península.

La motivación para plantearnos realizar este trabajo no es nueva, pues la determinación de esta variable atmosférica como tal surge de forma inmediata cuando se realizan medidas espectro-radiométricas o fotométricas de radiación solar, y éste es el origen de nuestra investigación desde un comienzo en el Grupo de Óptica Atmosférica de la Universidad de Valladolid (Cachorro, 1985; Cachorro et al., 1985, 1986, 1987,1998; Durán, 1997). Las bandas de absorción del vapor de agua en la atmósfera siempre actúan como elementos atenuantes sobre cualquier tipo de radiación del espectro electromagnético, de una forma $u$ otra, desde el rango visible, infrarrojo, o de onda larga o muy larga. Más recientemente, la implantación y extensión de la red de fotómetros AERONET, y en particular de la red RIMA en la Península Ibérica, así como otras redes similares, propicia el análisis de esta variable como un producto más de la misma (Estellés et al., 2004; Torres et al., 2010; Campanelli, 2011). 
Otro tema que también motiva nuestro interés es la interrelación de esta variable con los aerosoles, por la influencia de la humedad de las masas de aire sobre el crecimiento y modificación de las propiedades de estos, tanto las propiedades ópticas (SSA - single scattering albedo, parámetro de asimetría) como físicas (distribución de tamaños), todo ello directamente ligado a la propia composición de los mismos y a su capacidad para absorber agua. Cuestión esta que aún precisa de un amplia investigación y en la cual estamos muy interesados.

Así pues, dentro de este contexto, la implantación en España de un gran número de estaciones GPS por parte del IGN (Instituto Geográfico Nacional) y de diversas comunidades autónomas y otros organismo, y la facilidad de acceder a los datos generados por estos equipos para derivar la variable PWV, nos animó a retomar el estudio de esta variable desde una perspectiva más amplia, con la posibilidad de su estudio en extensas zonas y su comparativa con otras técnicas.

El trabajo de esta tesis se estructura de la siguiente manera: en el capítulo uno se verán algunos conceptos generales y la metodología utilizada para la obtención de los datos de contenido de vapor de agua con cada una de las tres técnicas; en el capítulo dos se describen las estaciones y las fuentes de datos; en el capítulo tres se presentan los resultados del análisis estadístico realizado para cada estación, así como la distribución vertical media del vapor de agua; en el capítulo cuatro se estudia el régimen anual; en el capítulo cinco el régimen diario; en el capítulo seis la variabilidad diaria y horaria; en el capítulo siete se realiza una comparativa entre las tres técnicas; en el capítulo ocho se estudian algunas de las sinergias existentes entre ellas; y en el capítulo nueve se verán algunos casos de estudio de situaciones con importantes variaciones del vapor de agua.

Este trabajo ha dado lugar a los artículos ya publicados que se recogen en los Anexos IV y V. 


\section{Capítulo 1}

\section{CONCEPTOS GENERALES Y METODOLOGÍA}

En este primer capítulo se revisarán algunas definiciones básicas relacionadas con el contenido de vapor de agua en la atmósfera, así como los distintos métodos de medida, y más en profundidad la metodología empleada por la instrumentación utilizada para su determinación en el presente estudio.

\subsection{Conceptos generales}

El aire es una mezcla de gases compuesta principalmente por nitrógeno, oxígeno, y en bastante menor proporción por argón y dióxido de carbono, constituyendo todos ellos un $99,98 \%$ de su volumen, es lo que se llama el aire seco. En la troposfera esta mezcla se distribuye bastante uniformemente por mezcla turbulenta a gran escala. Como resultado, en ella el aire es una mezcla homogénea que se puede considerar que se comporta como un gas ideal, cumpliendo la ley de Dalton sobre presiones parciales. La densidad de cada componente disminuye con la altura, pero no así las relaciones entre ellas, es decir, la densidad de cada componente se mantiene proporcional a la de la mezcla.

Además de los componentes principales, en el aire también se encuentra vapor de agua y otros gases, aunque estos últimos en proporciones muy pequeñas. El vapor de agua constituye hasta el $4 \%$ en volumen (aproximadamente $3 \%$ en peso) en las capas más bajas de la atmósfera, estando prácticamente ausente por encima de la tropopausa (10 a $12 \mathrm{Km}$ ). La mezcla de aire seco con vapor de agua se denomina aire húmedo. Conforme a la ecuación de Clausius-Clapeyron, el contenido máximo de vapor de agua que puede contener el aire, sin que sobrevenga la condensación, es función sólo de la temperatura del mismo, siendo menor cuanto más baja sea esta. Cuando el contenido de vapor aumenta, la presión parcial del mismo también aumenta (según la ley de Dalton) hasta alcanzar la presión máxima o tensión saturante. A partir de ese punto el exceso de vapor se condensa.

A las temperaturas atmosféricas el vapor de agua ejerce unas presiones muy débiles, por lo que se puede considerar que cumple la Ley de Avogadro de los gases. Además, como el crecimiento con la temperatura de su calor específico a presión constante es muy lento, además de gas de Avogadro, se puede considerar también un gas perfecto. El cociente entre la 
constante R de la ecuación de estado del aire y la R' del vapor de agua toma un valor de 0.622 . Es decir, para la misma presión y temperatura el vapor de agua pesa 0.622 veces menos que el aire seco. Por tanto, el aire húmedo es más ligero que el aire seco y tiene mayor calor específico. De ahí, el importante papel que juega el vapor de agua en la estabilidad atmosférica y en el transporte de energía.

El vapor de agua pasa a la atmósfera desde la superficie terrestre por evaporación de las aguas superficiales y la transpiración de las plantas, y vuelve a la superficie por condensación y precipitación. Se difunde de forma más efectiva en las capas bajas por mezcla turbulenta, y en las capas medias y altas por ascensos de masas de aire por inestabilidad y por los movimientos a escala sinóptica. Debido al predominio del aire seco en la mezcla, éste impone al vapor de agua su temperatura y lo arrastra consigo en sus movimientos.

Los principales índices para medir la humedad del aire son:

- La tensión de vapor (e).- Es la presión parcial ejercida por el vapor de agua en la mezcla del aire húmedo, es decir, la contribución del vapor de agua a la presión total. Se mide en $\mathrm{mb}$ o hPa. De acuerdo a la ley de los gases perfectos vendrá dada por,

$$
e=\rho \cdot R^{\prime} T
$$

- Humedad absoluta $(a)$.- Es la densidad del vapor expresada en $\mathrm{gr} / \mathrm{m}^{3}$. Si le tensión de vapor se mide en mb, la humedad absoluta viene dada por la expresión,

$$
a=216,9 \frac{e}{T}
$$

- Proporción de mezcla $(m)$.- Es la masa de vapor por unidad de masa de aire seco. Expresada en función de las presión parcial del vapor $(e)$ y del aire seco $(p-e)$ queda de la siguiente manera,

$$
m=0.622 \cdot \frac{e}{p-e}
$$

- Humedad específica $(q)$.- Es la masa de vapor por unidad de masa de aire húmedo. De la definición anterior, la humedad específica $(q)$ se puede expresar en función de la proporción de mezcla $(m)$ como,

$$
m=\frac{q}{1-q}
$$


Sustituyendo la expresión (1.3) en (1.4) queda,

$$
q \square \frac{5}{8} \cdot \frac{e}{p}
$$

- Humedad relativa $(h)$.- Es la razón entre la tensión del vapor de agua $(e)$ y la tensión saturante o máxima $(E)$ que corresponde a la temperatura del aire.

$$
h=100 \cdot \frac{e}{E}
$$

- Temperatura equivalente $\left(\mathrm{t}_{\mathrm{e}}\right)$.- Es la temperatura que tomaría una masa de aire húmedo si todo el vapor de agua que contiene se condensase y el aire seco absorbiera a presión constante el calor latente desprendido en la condensación,

$$
t_{e}=t+\frac{m \cdot L}{c_{p}}
$$

donde $c_{p}$ es el calor específico a presión constante y $L$ el calor latente de condensación del vapor de agua. Cuanto mayor sea la $t_{\mathrm{e}}$ mayor será el contenido de vapor de agua.

- Temperatura del termómetro húmedo (t').- El agua que una masa de aire puede evaporar vendrá dada por la diferencia entra la cantidad máxima de vapor que puede contener, que es función de su temperatura, y la que realmente contenga. Si el calor necesario para evaporar el agua se extrae de la propia masa de aire, la evaporación produce un enfriamiento. Así, la temperatura del termómetro húmedo se puede definir como la temperatura mínima que una masa de aire puede alcanzar por evaporación de agua en su seno. Cuanto mayor sea t' mayor será el contenido de vapor en el aire, de forma que si t' es igual a la temperatura del aire indicará que éste está saturado.

$$
e(t)=e_{s}\left(t^{\prime}\right)-\frac{P \cdot c_{p}}{622 \cdot L}\left(t-t^{\prime}\right)
$$

- Punto de rocío $(\tau)$.- Es la temperatura a la que hay que enfriar el aire a presión y contenido de vapor constantes para que sobrevenga la saturación. Cuanto menor sea el punto de rocío más seca será la masa de aire.

- Agua precipitable ( $P W V$, del inglés Precipitable Water Vapor).- Es el contenido total de vapor de agua en una columna atmosférica de superficie la unidad. Se expresa en términos de masa $\mathrm{gr} / \mathrm{cm}^{2}$ ó $\mathrm{kg} / \mathrm{m}^{2}$, o en términos de la altura que tendría la capa de agua si todo el vapor contenido en la columna atmosférica se condensará y se colectara en un recipiente 
con la misma superficie que la columna atmosférica. Normalmente en Meteorología se utiliza como unidad de medida el centímetro $(\mathrm{cm})$ o el milímetro $(\mathrm{mm})$. El contenido total de vapor de agua se puede transformar de unidades de masa a unidades de altura dividiéndolo por la densidad del agua líquida. Aproximadamente $1 \mathrm{~mm}$ de agua precipitable equivale a $0,1 \mathrm{gr} / \mathrm{cm}^{2}$ ó $1 \mathrm{~kg} / \mathrm{m}^{2}$ de contenido de vapor de agua. El PWV se obtiene por integración de la humedad absoluta $a$ en la vertical de una columna de superficie la unidad desde la superficie terrestre hasta el límite superior de la atmósfera $h$.

$$
P W V=\int_{0}^{h} a(z) \cdot d z
$$

En niveles de presión $p$ en lugar de niveles de altura $z$ la expresión anterior queda como sigue,

$$
P W V=\frac{1}{g} \cdot \int_{P_{s}}^{0} m(p) \cdot d p
$$

donde $g$ es la constante de la gravedad y $m$ la razón de mezcla (1.3).

EI PWV será precisamente el objeto del presente estudio.

- Espesor óptico de absorción $\left(\delta_{a}\right)$.- Se puede definir la cantidad de vapor de agua contenido en un volumen atmosférico en base a la radiación absorbida por dicho volumen de gas. De acuerdo a la ley de Beer, la relación entre la radiación incidente $I\left(x_{1}\right)$ y la radiación transmitida $I\left(x_{2}\right)$ a través de dos superficie perpendiculares a la dirección de propagación de la radiación se expresa de la siguiente manera,

$$
I\left(x_{2}\right)=I\left(x_{1}\right) \cdot \exp \left(-\delta_{a}\right)
$$

donde $\delta_{a}$ viene dado por la expresión,

$$
\delta_{a}=\int_{x_{1}}^{x_{2}} \sigma(x) \cdot d x
$$

siendo $\sigma(x)$ el coeficiente de absorción en volumen del vapor de agua, que se expresa en $\mathrm{cm}^{-1}$, y en $(\mathrm{cm} \mathrm{atm})^{-1}$ para las condiciones estándar de presión y temperatura ( $P=1013.25$ $\mathrm{hPa}, \mathrm{T}=273.16 \stackrel{\circ}{\circ})$. Dividiendo por la densidad se obtiene el coeficiente de absorción másico $\left(\mathrm{cm}^{2} \mathrm{gr}^{-1}\right)$, y dividiendo por la densidad del número de moléculas se obtiene la sección transversal molecular $\left(\mathrm{cm}^{2}\right)$. La cantidad de material absorbente se expresa en las unidades inversas a las del coeficiente de absorción.

\subsection{Métodos de medida}

Se han desarrollado una gran variedad de métodos para medir el vapor de agua atmosférico, cada uno de ellos con sus ventajas e inconvenientes. Los más destacados son: 
* Observaciones meteorológicas de superficie, la mayor parte de las veces representadas por la humedad relativa. Principalmente se utilizan los psicrómetros, basados en la diferencia entre la temperatura ambiente y la del termómetro húmedo, y los higrómetros, basados en los cambios que experimentan ciertos materiales al absorber moléculas de vapor de agua, como los de haz de cabellos que cambian su longitud o los electrónicos donde cambian las propiedades eléctricas de un componente de un circuito electrónico (resistencia o condensador). Este tipo de medidas sólo proporcionan el valor en la capa junto al suelo, pero no su contenido total en la vertical.

* Radiosondas. Constituyen la fuente principal de observaciones de vapor de agua de los Servicios Meteorológicos. Consisten en sensores electrónicos embarcados en globos sondas que trasmiten vía radio los valores de las variables meteorológicas (presión, temperatura, humedad y viento), medidos conforme el globo va ascendiendo en la atmósfera. La principal ventaja de los sondeos es que suministran un perfil vertical de las variables medidas. Pero debido al alto coste de cada lanzamiento tienen mala resolución horizontal, sobre todo en los países subdesarrollados y en los océanos donde es casi nula, y temporal, limitándose generalmente a dos lanzamientos al día (a las 00 y 12 UTC).

* Medidas satelitales. Consisten en radiómetros embarcados en satélites que trabajan en diferentes rangos de longitudes de onda, según midan radiación infrarroja emitida por el sistema tierra-atmósfera (longitud de onda larga) o bien radiación solar reflejada por éste (longitud de onda corta). En ambos casos la medida depende de la absorción de la radiación por el vapor de agua atmosférico. En el primer caso, al depender la radiación emitida de la temperatura del cuerpo emisor, se obtienen mejores resultados sobre los océanos que sobre tierra, ya que sobre tierra la temperatura es muy variable y difícil de determinar. En el segundo caso se requiere la presencia de radiación solar, por lo que sólo están disponibles durante el día. Los satélites pueden suministrar el contenido total en columna de vapor de agua e información sobre su distribución vertical. Sus medidas abarcan amplias zonas terrestres, con buena resolución espacial en la horizontal, pero mala en la vertical y temporal. Un problema de las medidas satelitales es que necesitan de medidas en tierra para ajustar los complejos algoritmos de transferencia radiativa en los que están basadas.

* Radiómetros de microondas (WVR).

De superficie: determinan el contenido total de vapor de agua en la dirección de observación a partir de las radiancias o temperaturas de brillo medidas sobre el fondo frío del cielo de la radiación de microondas emitida por el propio vapor de agua. La resolución temporal es muy buena (minutos o segundos), pero la resolución espacial es mala al ser 
equipos muy caros. Además, tienen el problema de tener que ser calibrados continuamente, y que los algoritmos usados contienen parámetros que dependen del emplazamiento y la época del año que tienen que ser determinados mediante observaciones independientes. Su efectividad se ve afectada por la presencia de nubes espesas y precipitaciones.

Embarcados en satélites: determinan el contenido total de vapor de agua en la dirección de observación a partir de la absorción en la radiación de microondas emitida por la superficie terrestre por este componente atmosférico. Requieren conocer la temperatura de la superficie terrestre, por lo que su efectividad se deteriora en presencia de nubes y sobre tierra. Tienen buena resolución espacial, pero mala temporal al estar embarcados en satélites de órbita polar que pasan sobre cada punto de la superficie sólo un par de veces al día.

* Fotómetros solares en superficie. Se basan en la comparación entre la radiación solar extraterrestre y la que alcanza la superficie de la Tierra (ley de Beer), medida en longitudes de onda del infrarrojo cercano centradas en una banda de fuerte absorción del vapor de agua. Una vez sustraído el efecto de los aerosoles y la dispersión de Rayleigh, la radiación absorbida puede ser transformada en contenido de vapor de agua mediante modelos de transferencia radiativa. Su funcionalidad está limitada a la presencia de radiación solar directa, por lo que sólo pueden operar durante el día y con cielos despejados en la dirección de observación. Esta metodología se explicará con más detalle más adelante.

* Lidar (radar láser). Determinan el perfil vertical del contenido de vapor de agua a través de los ecos de una señal láser devueltos por el vapor de agua presente en la atmósfera. Tienen una buena resolución vertical y temporal, pero mala horizontal por el coste de dichos equipos.

* Sistema GPS. Basado en el retraso que sufre la señal de los satélites del sistema GPS al atravesar la atmósfera, debida en parte a la presencia de vapor de agua. La proliferación de receptores GPS por su bajo coste proporcionan una densa red que permite determinar el contenido de vapor de agua con buena resolución temporal y espacial en todas las condiciones de tiempo atmosférico. Esta metodología se explicará más adelante en este capítulo.

\subsection{Radiosondeos}

Los sondeos aerológicos mediante globos sondas han sido la herramienta principal de los Servicios Meteorológicos para conocer la distribución vertical del estado de la atmósfera. Las radiosondas constan de una serie de sensores (temperatura, humedad y presión) embarcados 
en un globo relleno de helio que van tomando medidas in situ a distintas altitudes de la atmósfera conforme el globo asciende. Estas medidas son transmitidas vía radio a la estación receptora en tierra, obteniéndose así el perfil vertical de cada una de las variables meteorológica medidas. Además, las modernas radiosondas están dotadas de un receptor GPS que permite determinar la posición del globo en cada instante, de esta información se deduce la velocidad y dirección del viento en cada capa atmosférica sondeada.

Conforme el globo va alcanzando zonas de menor presión se va dilatando hasta que explota, cayendo los sensores a tierra tras alcanzar normalmente altitudes superiores a los $20 \mathrm{Km}$. El hecho de que los sondeos no muestreen toda la columna atmosférica no es un problema para las medidas de PWV, pues el vapor de agua se concentra en las capas bajas. Como se verá en el Capítulo 3, este es prácticamente despreciable por encima de los $9 \mathrm{Km}$ de altitud, límite que es generalmente alcanzado por todos los sondeos.

De las propias medidas de los sensores se pueden calcular índices de estabilidad y variables derivadas. Así, de la temperatura y humedad relativa se obtiene la humedad absoluta conforme a las expresiones vistas anteriormente. El PWV se calcula por integración de la humedad absoluta a lo largo de la trayectoria descrita por el globo. Debido a los vientos reinantes a cada altura, que producen un desplazamiento en la horizontal a lo largo del recorrido del globo, esta trayectoria generalmente no coincide con la vertical del lugar.

De los datos suministrados por las radiosondas es precisamente la humedad relativa la menos fiable, de ahí, que la habilidad de los radiosondeos para proporcional medidas precisas de vapor de agua sea la más limitada (Richner y Phillips, 1982). Así, mientras que las imprecisiones en temperatura son del orden de $0.2{ }^{\circ} \mathrm{C}$, en humedad ascienden al $3.5 \%$, aumentando el error para las regiones frías y secas (Elliot y Gaffen, 1991), en condiciones de precipitación y nubes espesas por problemas de deposición de humedad, por contaminación química del sensor (Wang et al., 2002), y con la altitud por el elevado tiempo de respuesta de los sensores a bajas temperaturas y presiones, lo que limita la utilidad de las medidas de humedad de los sondeos a la troposfera.

Los sensores de humedad de las radiosondas RS80 y RS92 de Vaisala utilizadas en las estaciones de radiosondeo durante el periodo de estudio considerado se corresponden con los modelos A-Humicap y H-Humicap. Estos sensores consisten en un polímero capacitivo que mide directamente la humedad relativa. El fundamento de la medida consiste en la variación que experimenta la constante dieléctrica de una película de polímero con la presión de vapor ambiente, siendo prácticamente una función lineal de la humedad. El modelo $\mathrm{H}$-Humicap que se usa actualmente en la nueva sonda RS92 tiene una incertidumbre del 5\% según el fabricante. Este sensor consiste en dos elementos capacitores gemelos. Durante el vuelo de la sonda uno de los elementos es calefactado de forma alternativa, mientras el otro realiza la 
medición para evitar la contaminación de la medida por la deposición de cristales de hielo dentro de las nubes (Paukkunen, 1995). Aunque la sonda está protegida por un abrigo, tiene el inconveniente de presentar una alta sensibilidad a la radiación solar incidente (Miloshevich et al., 2006), tal y como se verá en el Capítulo 8, lo que produce un sesgo entre las medidas realizadas durante el día y durante la noche.

\subsection{Fotómetros solares}

La determinación del PWV con fotómetros solares se basa en la medida de la transmitancia de la atmósfera en una longitud de onda centrada en un canal de fuerte absorción del vapor de agua, mediante la comparación entre la irradiancia solar directa en el exterior de la atmósfera y la medida en la superficie terrestre (Schmid et al., 1996; Halthore et al., 1997; Cachorro et al., 1998).

Las estaciones de AERONET, cuyos datos se han utilizado en este estudio, están equipadas con fotómetros Cimel. Este fotómetro dispone de una rueda de nueve filtros interferenciales $(340,380,440,500,675,870,936,1020$, y $1640 \mathrm{~nm})$ que se mueven con un motor paso a paso. Los filtros tienen una anchura de banda a mitad de la transmitancia máxima de $10 \mathrm{~nm}$ para los filtros del visible e infrarrojo, menor de $5 \mathrm{~nm}$ para los filtros en el ultravioleta, y $60 \mathrm{~nm}$ para el filtro de $1640 \mathrm{~nm}$. El filtro de $936 \mathrm{~nm}$ se emplea para evaluar el vapor de agua. El resto de filtros están escogidos en zonas del espectro sin apenas absorciones por parte del resto de los componentes atmosféricos (Figura 1.1) para facilitar la obtención del espesor óptico de aerosoles $(A O D)$. El fotómetro dispone también de un sensor de temperatura interior para corregir la dependencia de las medidas en el filtro de $1020 \mathrm{~nm}$ con la temperatura del detector de silicio.

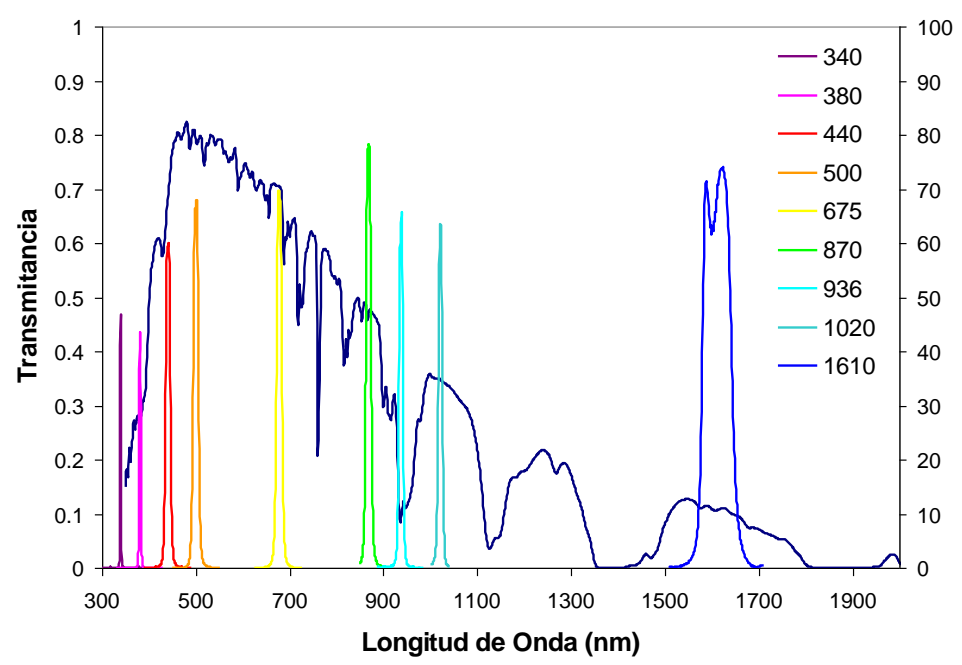

Figura 1.1 - Irradiancia solar al nivel de la superficie terrestre, junto con las funciones filtro del fotómetro Cimel. El filtro de $936 \mathrm{~nm}$ está centrado en una ventana de fuerte absorción del vapor de agua. 
La medida básica 'directa al sol' se compone de tres observaciones espectrales (triplete) tomadas en un intervalo de un minuto, con el fin de detectar y eliminar mediante un proceso de cloud screening las medidas contaminadas por nubosidad. Al ser la variación temporal de las nubes típicamente mayor que la de los aerosoles, la presencia de estas se manifiesta como una variación observable entre las tres medidas que conforman el triplete.

La transmitancia del vapor de agua se obtiene de la transmitancia solar total medida en la banda de los $936 \mathrm{~nm}$, una vez substraídas las contribuciones debidas al scattering de Rayleigh y a la transmitancia de los aerosoles según la expresión,

$$
\tau_{w v} \cdot m_{w v}=\operatorname{Ln} \frac{I_{0}}{l}-\left(\tau_{a} \cdot m_{a}+\tau_{r} \cdot m_{r}\right)
$$

donde $I$ e $I_{0}$ representan la irradiancia solar medida al nivel de la superficie y la extraterrestre respectivamente, $\tau$ el espesor óptico, y $m$ la masa óptica (Kasten y Young, 1989). Los subíndices $w v, a, y$ hacen referencia al vapor de agua, aerosoles y Rayleigh respectivamente.

En la Versión 1 del algoritmo de procesamiento de las medidas de AERONET, el AOD en el canal de los $936 \mathrm{~nm}$ se estimaba por una interpolación entre los valores del AOD en $870 \mathrm{~nm}$ y en $1020 \mathrm{~nm}$, pero debido a la dependencia del filtro de $1020 \mathrm{~nm}$ con la temperatura y a que este canal también está ligeramente afectado por absorción de vapor de agua, en la nueva Versión 2 se ha adoptado por estimar el AOD en $936 \mathrm{~nm}$ por una extrapolación del AOD de los canales desde los 440 a los $870 \mathrm{~nm}$. El espesor óptico de Rayleigh se puede obtener a partir del dato de presión atmosférica en superficie (Bodhaine et al., 1999).

La dependencia de la transmitancia del vapor de agua con el PWV es no lineal, debido a que el proceso de absorción selectiva es un proceso complejo altamente dependiente de la longitud de onda de las líneas espectrales que constituyen la banda de absorción, sobreviniendo la saturación en algunas líneas espectrales a medida que aumenta el camino óptico en la atmósfera. Se han desarrollado distintas expresiones paramétricas para esta dependencia. Algunos autores han experimentado con relaciones del tipo de raíz cuadrada (Reagan et al., 1987), otros sin embargo (Bruegge et al., 1992) han propuesto una relación del tipo,

$$
\tau_{W V} m=a(u \cdot m)^{b}
$$

que incluye la contribución del continuo, donde $u$ es la cantidad de vapor de agua absorbente, y $a$ y $b$ son dos coeficientes que dependen de la longitud de onda, la forma del filtro, el tipo de atmósfera y la distribución vertical del vapor de agua. Estos coeficientes se determinan utilizando modelos de transferencia radiativa línea a línea, es decir, con gran resolución espectral, por ajuste con las transmitancias calculadas en función de la masa óptica para un valor constante de la concentración de vapor. Este tipo de relación ha sido ampliamente estudiada por diversos autores (Michalsky et al., 1995; Schmid et al., 1996; Halthore et al., 1997), y es la utilizada por AERONET. En la Versión 1 del algoritmo de procesamiento se 
asignaban unos valores constantes para los coeficientes $a$ y $b(a=0.655$ y $b=0.574)$ iguales para todos los instrumentos de la red, que habían sido calculados para un filtro genérico de 936 nm utilizando el modelo LOWTRAN 7 (Kneizys et al., 1988) según una atmósfera de verano de latitudes medias. En la nueva Versión 2 estos coeficientes son computados para cada filtro de forma específica usando el modelo de transferencia radiativa LBLRTM (Line by Line Radiative Transfer Model) (Clough et al., 1992).

Las principales fuentes de error asociadas a este procedimiento radican en el modelado de la transmitancia del vapor de agua (Ingold et al., 2000) y en la determinación de la constante de calibración (Reagan et al., 1987; Bruegge et al., 1992). Precisamente, la calibración por el método Langley es más inexacta para el filtro de $936 \mathrm{~nm}$ que para los otros filtros, debido a la rápida variación temporal del vapor de agua. Así, en el procedimiento de calibración, por Langley o por comparación con instrumentos master, al canal de vapor de agua es al que se le exige menos estabilidad. Holben et al. (1998) obtuvo para las calibraciones Langley en Mauna Loa (Hawaii) un coeficiente medio de variación (desviación estándar dividida por la media) de las constantes de calibración del 0.25 al $0.50 \%$ para los canales del visible, del 0.5 al $2 \%$ para los del infrarrojo cercano, y del 1 al $3 \%$ para el del vapor de agua. Otras fuentes de error son la contaminación de las medidas por nubosidad, la forma espectral y la longitud central de los filtros (Bokoye et al., 2006), y el envejecimiento de los mismos (Torres et al., 2010). Estos sufren una degradación por la luz solar del orden del 1 al $5 \%$ en media por año, con una aceleración en el deterioro en algunos canales a partir del segundo año, por lo que deben ser cambiados y calibrados periódicamente. Como la incertidumbre en la calibración es menor que la propia degradación de los filtros, se utiliza una interpolación lineal entre las calibraciones inicial y final de un periodo de instalación del instrumento para obtener los coeficientes de calibración definitivos para ese periodo, recalculando las medidas con los nuevos coeficientes para obtener así la máxima precisión. En el caso de AERONET, el error estimado en la determinación del PWV de los datos fotométricos mediante la técnica de Bruegge es del orden del $10 \%$ (Holben et al., 2001, Smirnov et al., 2004), pero la incertidumbre es muy variable dependiendo de cada periodo e instrumento en concreto.

\subsection{Receptores GPS}

Como ya se ha comentado, la determinación del PWV mediante los receptores GPS se basa en el retraso que introduce la presencia de vapor de agua en la Atmósfera en la propagación de la señal de los satélites de la constelación GPS (Hogg et al., 1981; Resch, 1984).

\subsubsection{El Sistema GPS}

El sistema GPS fue concebido como un sistema de satélites para determinar con precisión posiciones absolutas o relativas sobre el globo terrestre. La constelación de satélites GPS consiste en 24 satélites situados a unos 20200 Km de altura sobre seis orbitas planas, 
separadas entre sí $60^{\circ}$ en el plano del ecuador e inclinadas 55․ Los satélites transmiten en dos frecuencias L1 (1575.42 MHz) y L2 (1227.60 MHz), para lo cual están provistos de un reloj atómico con precisión de hasta $10^{-13}$ segundos que produce una frecuencia fundamental de 10.23 MHz. Las frecuencias portadoras L1 y L2 son generadas multiplicando la fundamental por 154 y 120 respectivamente. Cada satélite transmite sobre las portadoras L1 y L2 dos códigos de ruido pseudo-aleatorios (PRN) propios que sirven para identificarlo, el código C/A o estándar y el código $P$ preciso, junto con las efemérides del satélite, los coeficientes de modelización de la ionosfera, información de estatus, la hora del sistema, y las correcciones horarias al reloj del satélite.

El sistema se basa en la determinación de la distancia entre el receptor en tierra y los satélites mediante la medición del tiempo que tarda la señal de los satélites en viajar hasta el receptor. La posición del receptor se obtiene por una triangulación que sitúa a la estación receptora en la intersección de las esferas con centro en cada satélite y radio la distancia al mismo. Esta distancia puede medirse por tres procedimientos:

* Efecto Doppler. Consiste en determinar la distancia al satélite mediante la variación de la frecuencia emitida por efecto de la velocidad del satélite. Este sistema permite dar una posición imprecisa, pero rápida.

* Medida de Pseudo-distancias. Se obtiene por el desplazamiento temporal necesario para alinear una réplica generada en el receptor del código que emite el satélite. Se habla de pseudo-distancia y no de distancia, porque aunque se conoce el momento de la emisión en el satélite (esa información va en el mensaje), no se sabe el estado preciso del reloj del receptor respecto al del satélite. Si el reloj del receptor y de los satélites estuvieran sincronizados tres satélites bastarían para determinar la posición, sino un cuarto satélite es necesario para eliminar la incertidumbre por el desfase de los relojes.

* Medida de Fase. El fundamento de este método es controlar en fase una emisión radioeléctrica emitida desde la posición conocida del satélite con frecuencia conocida. Una frecuencia de referencia obtenida del oscilador que controla el receptor se compara con la portadora demodulada. Con este método es con el que se obtiene una mayor precisión, y es el empleado para derivar las medidas de PWV.

Las imprecisiones en las medidas de los GPS se deben a:

* Errores del reloj del satélite y del receptor. Los errores en los osciladores de los satélites pueden eliminarse mediante las correcciones calculadas por las estaciones de 
seguimiento, que se envían en el mensaje de navegación que recibe el receptor. Un error de $1 \mathrm{~ns}$ produce una imprecisión de $30 \mathrm{~cm}$ en la distancia.

* Errores orbitales en la posición de los satélites. Las estaciones de seguimiento registran datos de pseudo-distancias y medidas de fase que mandan a la estación de control principal donde se calculan las futuras posiciones orbitales de los satélites, que serán las efemérides transmitidas luego por los satélites. Estas tendrán un error asociado, pues es imposible predecir con exactitud la posición de los satélites. Estos errores se pueden eliminar trabajando con las efemérides precisas que son calculadas a posteriori y pueden obtenerse a tiempo pasado después del postproceso que realiza el International GNSS (Global Navigation Satellite System) Service (IGS). EI IGS calcula las orbitas precisas con una precisión de unos $10 \mathrm{~cm}$ en las coordenadas de los satélites. Estos errores orbitales suponen no más de $0.5 \mathrm{~mm}$ en la distancia relativa receptor-satélite, es decir menos de 0.1 mm en el PWV (Rocken et al., 1993).

* Multipath. Este efecto es causado por múltiples reflexiones de la señal emitida por el satélite en superficies cercanas a la antena.

* Retraso ionosférico. La ionosfera interfiere en la propagación de las ondas de radio introduciendo un retraso en la propagación de la señal. Dicho retraso es proporcional a la densidad de electrones a lo largo del recorrido de la señal, e inversamente proporcional al cuadrado de la frecuencia de la portadora. Este retraso es dispersivo, por lo que puede ser calculado utilizando receptores bifrecuencia (Spilker, 1980; Brunner y Gu, 1991).

* Retraso troposférico. Es debido a la variación del índice de refracción en la troposfera. Para las ondas de radio típicas del sistema GPS este retraso es no dispersivo, es decir, no depende de la frecuencia, por lo que su efecto no se puede eliminar fácilmente como en el caso de la ionosfera. Uno de los puntos claves de los paquetes de software para Geodesia de precisión es el cálculo este retraso para corregir su efecto.

\subsubsection{El Retraso Troposférico}

La presencia de la atmósfera afecta la transmisión de las microondas provenientes de los satélites GPS de dos formas:

1. La velocidad de propagación disminuye; las ondas viajan más lento de lo que lo harían en el vacío.

2. La trayectoria pasa de ser una línea recta a ser una línea curva. 
Ambos efectos producen un retraso en la señal que está determinado por el índice de refracción a lo largo del camino de propagación. Este retardo de la señal puede ser establecido en términos de un aumento equivalente del camino recorrido, que vendría dado por la fórmula,

$$
\Delta L=\int_{L} n(s) d s-G
$$

donde $n(s)$ es el índice de refracción a lo largo de la trayectoria curva $L$ y $G$ es la distancia entre el emisor y el receptor por el camino recto, es decir la trayectoria seguida por las ondas en ausencia de atmósfera. Si $S$ es el camino a lo largo de la trayectoria curva $L$, se obtiene,

$$
\Delta L=\int_{L}[n(s)-1] d s+[S-G]
$$

El primer término de la derecha es debido al efecto de la disminución de la velocidad de propagación, y el segundo término es debido a la curvatura de la trayectoria. Este último término es mucho menor que el primero, siendo sólo del orden de $1 \mathrm{~cm}$ o menor para trayectorias con ángulos de elevación mayores de 15ㅇ․

Generalmente las ecuaciones anteriores se expresan en función de la refractividad $N$ en lugar del índice de refracción $n$, siendo,

$$
N=10^{6}(n-1)
$$

La refractividad de la atmósfera es función de la temperatura, la presión, y el contenido de vapor de agua. Smith y Weintraub (1953) sugirieron la siguiente expresión para la misma,

$$
N=77.6(P / T)+3.73 \times 10^{5}\left(P_{V} / T^{2}\right)
$$

donde $P$ es la presión atmosférica (en mb), $T$ es la temperatura (en ${ }^{\circ} \mathrm{K}$ ) y $P_{v}$ es la presión parcial del vapor de agua. Esta expresión tiene un error de un $0.5 \%$ en condiciones normales. Se dispone de expresiones más precisas como la propuesta por Thayer (1974),

$$
N=k_{1}\left(P_{d} / T\right) Z_{d}^{-1}+k_{2}\left(P_{v} / T\right) Z_{v}^{-1}+k_{3}\left(P_{v} / T^{2}\right) Z_{v}^{-1}
$$

donde $\mathrm{k}_{1}=77.604 \pm 0.014 \mathrm{Kmb}^{-1}, \mathrm{k}_{2}=64.79 \pm 0.08 \mathrm{mb}^{-1}, \mathrm{k}_{3}=3.776 \pm 0.004 \times 10^{5} \mathrm{~K}^{2} \mathrm{mb}^{-1}, \mathrm{P}_{\mathrm{d}}$ es la presión parcial del aire seco, $P_{v}$ la del vapor, y $Z_{d}$ y $Z_{v}$ los factores de comprensibilidad del aire seco y del vapor respectivamente, al no comportarse estos como gases totalmente ideales.

Saastamoinen (1972) demostró que el retraso total troposférico puede ser descompuesto en: retraso hidrostático, asociado con el momento dipolar inducido en la atmósfera y que depende sólo de la presión en superficie; y retraso húmedo, asociado con el momento dipolar permanente del vapor de agua. El vapor de agua es el único gas de la mezcla que compone el aire troposférico con un momento bipolar propio que contribuye a la componente dipolar de la refractividad atmosférica. En el rango espectral de las microondas, la refractividad está dominada por la componente dipolar, siendo aproximadamente 20 veces mayor que la 
componente no dipolar en la mayor parte de la troposfera. Por eso, se considera por separado la componente dipolar debida al vapor de agua, y la componente no dipolar debida al conjunto de todos los gases, incluido también el vapor de agua. Ambos retrasos aumentan de forma aproximada con la inversa del seno del ángulo de elevación, siendo más pequeños para trayectorias orientadas en la dirección cenital. Al ser estos retrasos muy pequeños, del orden de $10^{-8}$ a $10^{-9}$ segundos, en vez de medirse en unidades de tiempo se miden en unidades de longitud, como el espacio que recorrería la luz en ese tiempo. Valores típicos de estos retrasos en la dirección cenital al nivel del mar son:

- Retraso Total Cenital (ZTD, del inglés Zenith Total Delay), del orden de $250 \mathrm{~cm}$.

- Retraso Hidrostático Cenital (ZHD), del orden de $230 \mathrm{~cm}$.

- Retraso Húmedo Cenital (ZWD), del orden de entre 0 y $40 \mathrm{~cm}$.

siendo,

$$
Z T D=Z H D+Z W D
$$

Aproximadamente un centímetro de PWV produce un retraso húmedo de $6.5 \mathrm{~cm}$, pero este factor puede variar hasta en un $20 \%$ dependiendo de la localización, la altitud, la época del año y la situación meteorológica, por lo que tiene que ser determinado para cada medida.

Los receptores GPS no miden en la dirección cenital sino en la de los satélites. Tanto el retraso hidrostático como el húmedo son menores para caminos orientados a lo largo de la dirección cenital, aumentando de forma aproximada con la inversa del seno del ángulo de elevación, con un incremento en un factor de cuatro entre la dirección cenital y una dirección con un ángulo de elevación de 15\%. La mayoría de las expresiones para el retraso a lo largo de un camino con una elevación arbitraria consisten en multiplicar el retraso a lo largo de la dirección cenital por una función de mapeo que describe la dependencia con el ángulo de elevación. Así, el retraso total (TD) para una trayectoria con un ángulo de elevación distinto del cenital, se expresa como,

$$
T D(\theta)=Z H D \cdot M_{h}(\theta)+Z W D \cdot M_{w}(\theta)
$$

donde $M_{h}$ y $M_{w}$ son las funciones de mapeo de la componente hidrostática y húmeda.

Varias expresiones para las funciones de mapeo hidrostático y húmedo han sido propuestas en la bibliografía (Tralli y Lichten, 1990; Rapp-Arrarás y Domingo-Santos, 2008), pero todas ellas son prácticamente iguales para ángulos de elevación por encima de 10 a 15․ Normalmente los receptores GPS utilizan sólo las observaciones de los satélites que quedan por encima de estas elevaciones por estar afectadas de menos imprecisiones, por lo que es posible unificar las funciones de mapeo hidrostática y húmeda en una sola,

$$
T D(\theta)=(Z H D+Z W D) \cdot M(\theta)
$$

Casi todas las funciones de mapeo suponen una simetría azimutal para el retraso, aunque variaciones del $20 \%$ son muy comunes en áreas húmedas (Rocken et al., 1991). Esta 
suposición puede causar errores significativos cuando la troposfera local tiene importantes gradientes de temperatura, presión o humedad (Gardner, 1976; Davidson y Trask, 1985).

Si se disponen de medidas de presión en superficie es posible modelar y calcular el ZHD con precisión de pocos milímetros o menos. Así, si la atmósfera está en equilibrio hidrostático y el barómetro bien calibrado (error $<0.3 \mathrm{mb}$ ), el ZHD se puede determinar con una resolución mejor de $1 \mathrm{~mm}$. El error introducido por la asunción de equilibrio hidrostático es típicamente del orden de un $0.01 \%$ del ZHD, correspondiendo a unos $0.03 \mathrm{~mm}$ de PWV, pero en condiciones extremas puede inducir un error en el PWV tan grande como $1 \mathrm{~mm}$ (Hauser, 1989). El retraso húmedo es más difícil de determinar debido a su alta variabilidad, que generalmente excede en un orden de magnitud a la del hidrostático (Elgered et al., 1991).

Se han desarrollado varias formulaciones y modelos para calcular el ZHD y el ZWD. Destaca la formulación de Elgered et al. (1991), que adoptó un modelo en el cual el ZHD (en milímetros) viene dado por la expresión,

$$
Z H D=(2.2779 \pm 0.0024) P_{s} / f(\lambda, H)
$$

donde,

$$
f(\lambda, H)=(1-0.00266 \cos 2 \lambda-0.00028 H)
$$

es un factor que considera la variación de la aceleración de la gravedad con la latitud $\lambda$ y con la altura $\mathrm{H}$ (en $\mathrm{Km}$ ) sobre la superficie del elipsoide. En esta formulación, el ZWD viene dado por la expresión,

$$
Z W D=10^{-6}\left[k_{2}^{\prime} \int\left(P_{v} / T\right) d z+k_{3} \int\left(P_{v} / T^{2}\right) d z\right]
$$

donde $k_{2}^{\prime}=17 \pm 10 \mathrm{~K} \mathrm{mb}^{-1}\left(k_{3}\right.$ se definió en (1.19)). La expresión anterior se puede aproximar por,

$$
Z W D=(0.382 \pm 0.004) \cdot \int\left(P_{v} / T^{2}\right) d z
$$

Para evaluar esta expresión se requiere conocer el perfil vertical de la temperatura y la presión de vapor, datos de los que normalmente no se disponen. Para eludir este requerimiento se han desarrollado varios modelos para calcular el ZWD a partir de medidas de superficie, pero los resultados no han sido muy buenos comparados con los obtenidos en el cálculo del ZHD (Resch, 1984; Tralli et al., 1988; Baby et al., 1988).

Las últimas técnicas permiten estimar el ZTD por modelización de los propios datos de la red de receptores GPS mediante complejos algoritmos de inversión (Tralli et al., 1988; Herring et al., 1990), de donde restándole el ZHD se obtiene el ZWD. La base física de estas técnicas es la observación simultánea por los receptores de las señales emitidas por los satélites con diferentes ángulos de elevación. En las más recientes, el retraso troposférico se considera como un ruido blanco. Al ser improbable que cambie en un gran cantidad en un periodo corto 
de tiempo, su variación temporal se puede representar por un proceso estocástico, utilizando filtros de Kalman para determinar los parámetros de dicho proceso (Gelb, 1974). La mayoría de los autores consideran que el tipo de proceso estocástico que mejor representa las fluctuaciones del ZTD es un proceso de Gauus-Markov de primer orden (Treuhaft y Lanyi, 1987; Lichten y Border, 1987; Tralli et al., 1988; Herring et al., 1990). Con estas técnicas es posible obtener el ZWD sobre la vertical de cada estación con unas bias y un error cuadrático medio (rmse) menor de $10 \mathrm{~mm}$.

Al utilizar una red de receptores distantes entre sí que conformen una baseline larga ( $>500$ $1000 \mathrm{Km}$ ) en lugar de un único receptor GPS, se puede calcular el ZTD absoluto sobre cada receptor por algoritmos geodésicos de inversión de técnicas diferenciales (Rocken et al., 1993; Duan et al., 1996). En redes con baselines cortas (menor de varios cientos de kilómetros) los parámetros de la inversión para calcular el ZTD están correlacionados, al observar los receptores los satélites bajo unos ángulos de elevación muy similares. El retraso diferencial entre dos estaciones es sensible sólo a los valores relativos de los retrasos cenitales y no a los absolutos. Otros autores (Rocken et al., 1993 y 1995) han obtenido valores relativos del PWV para cada receptor GPS de una red, y han usado un radiómetro de microondas para calcular el valor absoluto del PWV en una estación de referencia, y así determinar la corrección necesaria para transformar el PWV relativo a absoluto en el resto de las estaciones de la red. Con estas técnicas se puede calcular el ZWD con una precisión de 5-20 mm, que equivaldría a precisiones de 1-3 mm en el cálculo del PWV.

\subsubsection{Agua precipitable}

EI PWV se puede estimar de los datos de ZWD a partir de la temperatura media atmosférica pesada por la presión parcial del vapor de agua (Davis et al., 1985),

$$
T_{m}=\frac{\int\left(P_{v} / T\right) d z}{\int\left(P_{v} / T^{2}\right) d z}
$$

Combinando las ecuaciones (1.9), (1.25), (1.27), y la ecuación de estado del vapor de agua, se obtiene la siguiente expresión para el PWV,

$$
P W V=\kappa \cdot Z W D
$$

donde la constante $\kappa$ viene dada por,

$$
1 / \kappa=10^{-6} \cdot\left(k_{3} / T_{m}+k_{2}^{\prime}\right) \cdot R_{v}
$$

siendo $R_{v}$ la constante de los gases específica para el vapor de agua.

Varios son los valores propuestos en la bibliografía para las constantes $k_{3}$ y $k_{2}^{\prime}$ (Smith y Wientraub, 1953; Thayer, 1974). En este trabajo se han utilizado los valores utilizados por Bevis et al. (1994), $k_{3}=3.73910^{5} \mathrm{k}^{2} / \mathrm{mb}$ y $k_{2}^{\prime}=22.1 \mathrm{~K} / \mathrm{mb}$. 
Para calcular del PWV a partir de las expresiones (1.28) y (1.29) hay que conocer la temperatura media de la atmósfera $T_{m}(1.27)$, pero esto implica conocer la distribución vertical del vapor de agua. Otras opciones son usar para la $T_{m}$ unos valores constantes para cada zona y época del año, estimarla de los modelos numéricos de predicción, o de la temperatura en superficie. Como la mayoría del vapor de agua está concentrado en las capas más bajas de la atmósfera $(2-3 \mathrm{Km})$, y la presión de vapor actúa como factor de pesado en la definición de la $\mathrm{T}_{\mathrm{m}}$, es obvio pensar que debe estar correlacionada con la temperatura en superficie. Bevis et al. (1992) llegó a la expresión empírica (1.30) mediante el análisis estadístico de 8718 perfiles de radiosondeos que abarcaban dos años de datos de estaciones en USA en un rango de latitud entre 27 y $65^{\circ}$ y de altitud entre 0 y $1600 \mathrm{~m}$,

$$
T_{m} \approx 70.2+0.72 \cdot T_{s}
$$

Esta relación tiene un $r$ mse de $4.7^{\circ}$ K (error relativo menor del 2\%), que en el peor de los casos induce un error relativo del $4 \%$ en el PWV. Una aproximación más potente, con errores menores del $1 \%$ se obtiene usando el valor predicho por los modelos numéricos de predicción meteorológica (Bevis et al., 1994).

Como la relación (1.30) es empírica y podría ajustarse peor a otras zonas geográficas distintas para la que fue obtenida, en este estudio se ha calculado una relación similar para cada una de las estaciones de radiosondeo con los datos de sus propios sondeos desde el año 2000 al 2008 (Tabla 1.1).

\begin{tabular}{lllrr}
\hline Estación & Recta de Regresión & $\mathbf{R}^{2}$ & rmse & $\begin{array}{c}\text { № } \\
\text { Datos }\end{array}$ \\
\hline Barcelona & $\mathrm{T}_{\mathrm{m}}=0.88 \mathrm{~T}_{\mathrm{s}}+23.24$ & 0.80 & 2.52 & 612 \\
Coruña & $\mathrm{T}_{\mathrm{m}}=0.88 \mathrm{~T}_{\mathrm{s}}+24.74$ & 0.61 & 2.91 & 5468 \\
Gibraltar & $\mathrm{T}_{\mathrm{m}}=0.98 \mathrm{~T}_{\mathrm{s}}-3.87$ & 0.67 & 3.05 & 6434 \\
Lisboa & $\mathrm{T}_{\mathrm{m}}=0.74 \mathrm{~T}_{\mathrm{s}}+65.87$ & 0.70 & 2.77 & 3964 \\
Madrid & $\mathrm{T}_{\mathrm{m}}=0.64 \mathrm{~T}_{\mathrm{s}}+91.17$ & 0.77 & 2.92 & 5396 \\
Murcia & $\mathrm{T}_{\mathrm{m}}=0.69 \mathrm{~T}_{\mathrm{s}}+79.57$ & 0.68 & 3.42 & 5742 \\
Santander & $\mathrm{T}_{\mathrm{m}}=0.89 \mathrm{~T}_{\mathrm{s}}+21.84$ & 0.65 & 2.88 & 5261 \\
Zaragoza & $\mathrm{T}_{\mathrm{m}}=0.64 \mathrm{~T}_{\mathrm{s}}+92.34$ & 0.73 & 3.03 & 4302 \\
\hline
\end{tabular}

Tabla 1.1 - Correlación entre la temperatura media atmosférica $\left(T_{m}\right)$ y la temperatura en superficie $\left(T_{s}\right)$ para cada estación de radiosondeo. Rectas de regresión, coeficiente de correlación $\left(R^{2}\right)$, y error cuadrático medio (rmse).

Para el conjunto de todas las estaciones (Figura 1.2), con un total de 37179 sondeos, se ha obtenido la expresión,

$$
T_{m} \approx 61.92+0.75 \cdot T_{s}
$$

con un coeficiente de correlación $\mathrm{R}^{2}$ de 0.69 , un rmse de 3.19 K, y unas bias de $0.06 \mathrm{~mm}$. 
El error producido en el PWV por la estimación de la $T_{m}$ se puede cuantificar tomando incrementos en (1.29),

$$
\frac{\Delta \kappa}{\Delta T_{m}}=\frac{10^{5} \cdot \frac{k_{3}}{T_{m}^{2}}}{R v \cdot\left(\frac{k_{3}}{T_{m}}+k_{2}\right)^{2}}
$$

Como el segundo término de la suma del denominador (coeficiente $k_{2}$ ) es dos órdenes de magnitud inferior al primero se puede despreciar frente a este, quedando la expresión anterior como sigue,

$$
\frac{\Delta k}{\Delta T_{m}} \approx \frac{10^{5}}{R v \cdot k_{3}}=5.795 \cdot 10^{-4}
$$

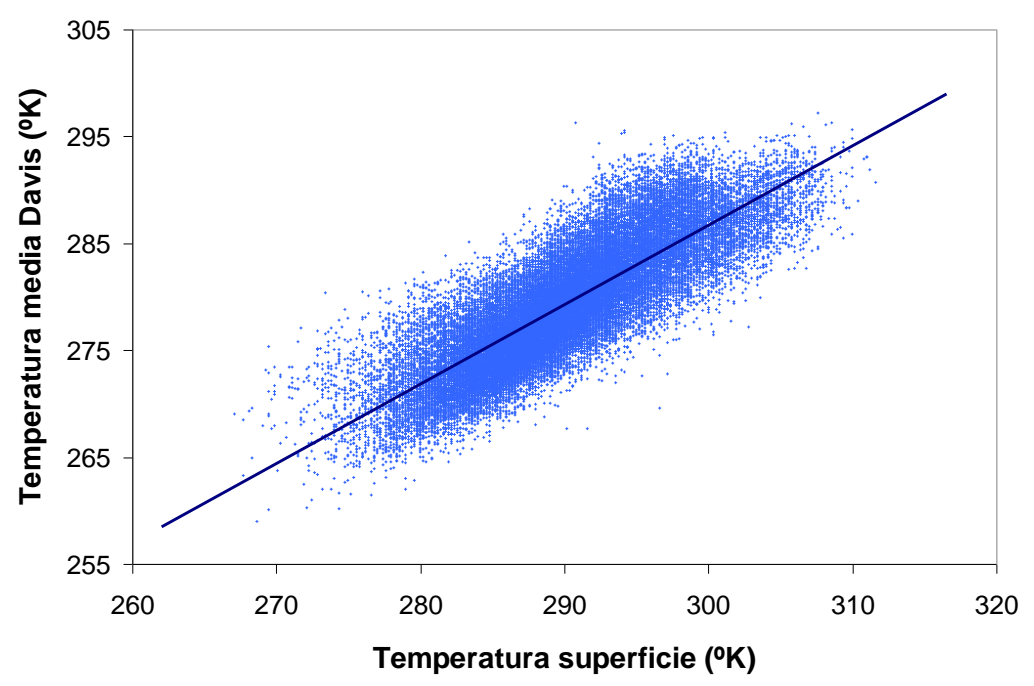

Figura 1.2 - Recta de regresión entre la temperatura media atmosférica $\left(T_{m}\right)$ y la temperatura superficial $\left(\mathrm{T}_{\mathrm{s}}\right)$ para el conjunto de todas las estaciones de radiosondeo.

Tomando incrementos en la expresión (1.28) y sustituyendo el resultado de (1.33) queda,

$$
\Delta P W V \approx 5.795 \cdot 10^{-4} \cdot Z W D \cdot \Delta T_{m}
$$

Para un valor medio típico de $\kappa$ de 6.28 se obtiene,

$$
\frac{\Delta P W V}{P W V}(\%) \approx \frac{5.795 \cdot 10^{-4} \cdot Z W D \cdot \Delta T_{m}}{\kappa \cdot Z W D} \cdot 100 \approx 0.36 \cdot \Delta T_{m}
$$

Con los valores del rmse obtenidos en las regresiones de la Tabla 1.1 (en torno a $3 \stackrel{\circ}{\circ}$ ), se puede decir que el error cometido en el PWV al estimar la temperatura media de la atmósfera a partir del valor de la temperatura de superficie es aproximadamente de un $1 \%$. A este error habría que añadir el cometido en la medida de la temperatura de superficie. Tomando incrementos en la recta de regresión (1.31) tenemos que $\Delta \mathrm{T}_{\mathrm{m}}=0.75 \Delta \mathrm{T}_{\mathrm{s}}$, es decir, una 
sobreestimación de un $1^{\circ} \mathrm{C}$ en la temperatura al nivel de la superficie se traduce en una sobreestimación en el PWV de un $0.27 \%$.

De acuerdo con la expresión (1.35), la diferencia en el PWV para los valores del rmse (Tabla 1.2) obtenidos al estimar la $T_{m}$ por la expresión de Bevis (1.30) o por las obtenidas en este estudio (Tabla 1.1), no supera en el peor de los casos el $1 \%$, siendo de solo un $0.16 \%$ para la expresión (1.31).

\begin{tabular}{lcr|lrr|lrr}
\hline Estación & bias & rmse & Estación & bias & rmse & Estación & bias & rmse \\
\hline Todas & 0.42 & 0.46 & Gibraltar & 1.76 & 2.11 & Murcia & 0.63 & 0.67 \\
Barcelona & -0.45 & 1.01 & Lisboa & 1.52 & 1.52 & Santander & 0.65 & 1.00 \\
Coruña & 0.61 & 0.90 & Madrid & -2.11 & 2.21 & Zaragoza & -0.97 & 1.14 \\
\hline
\end{tabular}

Tabla 1.2 - Bias y rmse entre la $T_{m}$ estimada con la expresión obtenida por Bevis (1.30) y con la obtenida en este estudio para cada estación de sondeo (Tabla 1.1) y para el conjunto de ellas (1.31).

Al no suponer estos rmse diferencias muy significativas en el PWV, y no disponer de una relación entre $T_{s}$ y $T_{m}$ para cada uno de los emplazamientos de los que se dispone de datos de ZTD, se optó por utilizar una única expresión para estimar la $T_{m}$ en todas las estaciones GPS.

Para estudiar si la recta de regresión se ajusta mejor durante el día o la noche se calculó la correlación entre $T_{s}$ y $T_{m}$ para los sondeos las 00 y las 12 UTC por separado del conjunto de todas las estaciones, resultando una correlación ligeramente mayor durante el día (Tabla 1.3).

\begin{tabular}{lccrr}
\hline Hora & Recta de Regresión & $\mathbf{R}^{\mathbf{2}}$ & rmse & № Datos \\
\hline 00 UTC & $\mathrm{T}_{\mathrm{m}}=0.85 \mathrm{~T}_{\mathrm{s}}+35.46$ & 0.70 & 3.12 & 17108 \\
12 UTC & $\mathrm{T}_{\mathrm{m}}=0.76 \mathrm{~T}_{\mathrm{s}}+56.73$ & 0.75 & 2.85 & 18991 \\
\hline
\end{tabular}

Tabla 1.3 - Regresión entre la temperatura media atmosférica $\left(T_{m}\right)$ y la temperatura superficial $\left(T_{s}\right)$ del conjunto de todas las estaciones para los sondeos de las 00 y 12 UTC por separado.

El rmse entre la $T_{m}$ real medida con los datos de los sondeos y la estimada utilizando la expresión (1.31) o una distinta para el día y la noche toma un valor similar para ambos casos. Al mediodía, con la expresión calculada en base sólo los sondeos de las 12 UTC, la $T_{m}$ se subestima en 1.19 K (con un rmse de 3.09), mientras que con la expresión obtenida en base a

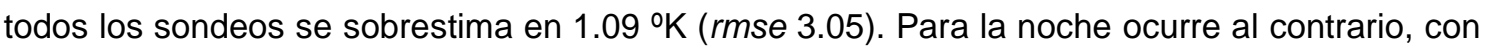
la expresión en base sólo a los sondeos de las 00 UTC la $T_{m}$ se sobrestima en $1.28 \stackrel{\circ}{\circ}$ ( rmse 3.37), mientras que con la expresión de todos los sondeos se subestima en 1.08 $\mathrm{K}$ ( $r m s e$ 3.35). Trasladando estos valores al PWV se puede concluir que al utilizar la expresión (1.31) para todas las horas del día el PWV se sobreestima un $0.38 \%$ al mediodía y se subestima en un $0.39 \%$ a medianoche. Sin embargo, si se utiliza una expresión para el día y otra para la noche los porcentajes se mantienen pero a la inversa, cuando se sobreestimaba se subestima y viceversa, por lo que se optó por utilizar la misma expresión para todas las horas del día. 
De la misma manera se han obtenido las rectas de regresión entre la $T_{m}$ y la $T_{s}$ para cada una de las cuatro estaciones del año (Tabla 1.4). La mayor correlación se da en otoño y la menor en el invierno y el verano, pero en todos los casos los coeficientes de correlación son más bajos que para el conjunto de todos los sondeos del año, del orden de la mitad, sin embargo, el rmse es similar.

\begin{tabular}{llccc}
\hline & Recta de Regresión & $\mathbf{R}^{2}$ & rmse & $\begin{array}{c}\text { № } \\
\text { Datos }\end{array}$ \\
\hline Invierno & $\mathrm{T}_{\mathrm{m}}=0.55 \mathrm{~T}_{\mathrm{s}}+117.58$ & 0.37 & 2.97 & 8965 \\
Primavera & $\mathrm{T}_{\mathrm{m}}=0.70 \mathrm{~T}_{\mathrm{s}}+75.10$ & 0.50 & 3.00 & 9392 \\
Verano & $\mathrm{T}_{\mathrm{m}}=0.55 \mathrm{~T}_{\mathrm{s}}+122.58$ & 0.38 & 3.25 & 9515 \\
Otoño & $\mathrm{T}_{\mathrm{m}}=0.74 \mathrm{~T}_{\mathrm{s}}+63.97$ & 0.62 & 2.91 & 9307 \\
\hline
\end{tabular}

Tabla 1.4 - Regresión entre la temperatura media atmosférica $\left(T_{m}\right)$ y la temperatura superficial $\left(T_{s}\right)$ del conjunto de todas las estaciones para cada época del año.

Comparando las diferencias entre la $T_{m}$ medida y la estimada usando una expresión distinta para cada época del año o la misma para todo el año, no se aprecia una mejora significativa en la estimación de la $T_{m}$ utilizando una correlación diferente para cada época del año. El rmse toma un valor similar en ambos casos para las cuatro estaciones, mientras que las bias son menores cuando se utiliza la recta de regresión propia de cada estación en primavera y verano, y cuando se utiliza la recta anual en invierno y otoño (Tabla 1.5).

\begin{tabular}{lcccc}
\hline & \multicolumn{2}{c}{$\mathrm{T}_{\mathrm{Est}}{ }^{1}-\mathrm{T}_{\text {Med }}$} & \multicolumn{2}{c}{$\mathrm{T}_{\mathrm{Est}}{ }^{2}-\mathrm{T}_{\text {Med }}$} \\
& bias & rmse & \multicolumn{1}{c}{ bias } & rmse \\
\hline Invierno & -1.03 & 3.14 & 0.10 & 3.08 \\
Primavera & -0.14 & 3.00 & 1.11 & 3.20 \\
Verano & 0.39 & 3.27 & -1.01 & 3.53 \\
Otoño & -0.78 & 3.01 & 0.08 & 2.91 \\
\hline
\end{tabular}

Tabla 1.5 - Bias y rmse entre la $T_{m}$ medida y la estimada, usando una expresión distinta para cada época del año $T_{E s t}{ }^{1}$ (izquierda), o con la misma para todo el año $T_{E s t}{ }^{2}$ (derecha).

Con los promedios de los datos de la $T_{m}$ obtenida de los sondeos se ha calculado para cada emplazamiento, hora, y época del año, el coeficiente medio de conversión $\kappa$ de ZWD a PWV (Tablas 1.6, 1.7 y 1.8). Un milímetro de PWV produce un retraso (ZWD) de $1 / \kappa \mathrm{mm}$.

\begin{tabular}{lcc|ccc|lcl}
\hline Estación & $\mathbf{T}_{\mathbf{m}}$ & $\mathbf{1 / \kappa}$ & Estación & $\mathbf{T}_{\mathbf{m}}$ & $\mathbf{1 / \kappa}$ & Estación & $\mathbf{T}_{\mathbf{m}}$ & $\mathbf{1 / \kappa}$ \\
\hline Barcelona & 279.4 & 6.28 & Lisboa & 280.6 & 6.25 & Santander & 278.1 & 6.31 \\
Coruña & 277.7 & 6.32 & Madrid & 277.2 & 6.33 & Zaragoza & 278.1 & 6.31 \\
Gibraltar & 282.0 & 6.22 & Murcia & 281.0 & 6.24 & & & \\
\hline
\end{tabular}

Tabla 1.6 - Temperatura media atmosférica ( ${ }^{\circ} K$ ) y coeficiente de conversión $1 / \kappa$ de PWV a ZWD para cada estación. Para toda la Península se ha obtenido un valor medio de $1 / \kappa$ de 6.28.

Los mayores valores del coeficiente $1 / \kappa$ se dan en las estaciones del interior y en de la costa cantábrica debido a su menor temperatura media atmosférica $T_{m}$ (Tabla 1.6). La diferencia 
entre el máximo valor de $1 / \kappa$ (6.33 de Madrid) y el mínimo (6.22 de Gibraltar) es de 0.11 , es decir, para un mismo valor del ZWD, el PWV es un $1.8 \%$ menor en Madrid que en Gibraltar. La diferencia respecto del valor medio de $1 / \kappa$ del conjunto de todas las estaciones es en el caso de Gibraltar de -0.06 , y en el de Madrid de 0.05 , valores que implican diferencias en el PWV de no más de un $\pm 1 \%$.

\begin{tabular}{ccc}
\hline Hora & $\mathrm{T}_{\mathrm{m}}$ & $\mathbf{1 / \kappa}$ \\
\hline 00 UTC & 279.1 & 6.284 \\
12 UTC & 279.5 & 6.275 \\
\hline
\end{tabular}

Tabla 1.7 - Temperatura media atmosférica (ํ) y coeficiente de conversión $1 / \kappa$ de PWV a ZWD para el día y la noche.

Con los coeficientes obtenidos para las 00 y 12 UTC (Tabla 1.7), los datos de PWV se estarían infravalorando durante el día en aproximadamente un $0.08 \%$ y sobrevalorando en un $0.06 \%$ por la noche al utilizar el coeficiente medio para todas las horas. En cuanto a la época del año (Tabla 1.8), en invierno y primavera el PWV se sobreestiman en un $1,62 \%$ y $0.76 \%$ respectivamente, mientras que en verano y otoño se subestiman en un $2.02 \%$ y $0.19 \%$ respectivamente.

\begin{tabular}{lcc}
\hline & $\mathrm{T}_{\mathrm{m}}$ & $\mathbf{1 / \kappa}$ \\
\hline Invierno & 274.8 & 6.382 \\
Primavera & 277.2 & 6.328 \\
Verano & 285.2 & 6.153 \\
Otoño & 279.9 & 6.268 \\
\hline
\end{tabular}

Tabla 1.8 - Temperatura media atmosférica (K) y coeficiente de conversión $1 / \kappa$ de PWV a ZWD para cada época del año.

A la vista de todo lo comentado anteriormente, se optó por utilizar siempre la expresión (1.31) para estimar la $T_{m}$. Sin embargo, este tipo de relaciones $T_{m}-T_{s}$ pueden introducir un ciclo diurno artificial en el PWV al no tener en cuenta el hecho de que la $T_{s}$ tiene una variación diurna mucho mayor que la $T_{m}$ (Wang et al., 2005). Para eliminar este ciclo artificial se utilizó una temperatura superficial suavizada $\left(T_{s s}\right)$ conforme a la expresión (Morland et al., 2009),

$$
T_{s s}=0.25 \cdot T_{s}+0.75 \cdot T_{s m}
$$

donde $T_{\text {sm }}$ es la temperatura media de cada día al nivel de la superficie.

La otra variable meteorológica necesaria para derivar el PWV de las medidas de PWV es la presión atmosférica al nivel de la estación. Tomando incrementos en la fórmula (1.23) para conocer como la incertidumbre en esta variable afecta al PWV se obtiene,

$$
\Delta Z H D=\frac{2.2779}{f(\lambda, H)} \cdot \Delta P
$$


Trasladando este incremento al PWV se tiene,

$$
\Delta P W V=-k \cdot \frac{2.2779}{f(\lambda, H)} \cdot \Delta P_{s}
$$

El factor de corrección por gravedad $f$ varía muy poco para el rango de latitudes y altitudes a las que se encuentran las distintas estaciones. Por ejemplo, para una latitud de $36^{\circ}$ varía entre 0.9992 al nivel del mar y 0.9989 a $1 \mathrm{Km}$ de altitud, o para 44ํㅜ de latitud varía entre 0.9999 al nivel del mar y 0.9996 a $1 \mathrm{Km}$ de altitud, por lo que se puede tomar un valor medio de 0.9995 igual para todas las estaciones. Sustituyendo este dato y el del valor medio de $1 / \kappa$ en la expresión anterior se tiene,

$$
\Delta P W V \approx-0.363 \cdot \Delta P_{s}
$$

Para el valor medio del PWV obtenido en este estudio para la Península, que como se verá en el Capítulo 3 es de $18.1 \mathrm{~mm}$ (equivalente a $113.7 \mathrm{~mm}$ de ZWD), se tiene,

$$
\frac{\Delta P W V}{P W V}(\%) \approx-2 \cdot \Delta P_{s}
$$

Combinando la incertidumbre en $T_{m}(1.34)$ y $P_{s}(1.39)$ para este valor medio del ZWD queda,

$$
\Delta P W V \approx 0.065 \cdot \Delta T_{m}-0.363 \cdot \Delta P_{s}
$$

De la expresión anterior se concluye que el PWV es menos sensible a los errores en la temperatura que a los de la presión, del orden de cinco veces menos. Una incertidumbre de 5 oK en la temperatura media de la atmósfera produce una incertidumbre en el PWV de $0.33 \mathrm{~mm}$, aproximadamente un 1.8\%. Mientras que una incertidumbre en la presión de sólo $1 \mathrm{hPa}$ produce básicamente la misma incertidumbre en el PWV (0.36 mm, aproximadamente un $2 \%$ ). Otros autores han llegado a resultados semejantes (Hagemann et al., 2003).

Desgraciadamente los receptores GPS y las estaciones meteorológicas no se encuentran en la misma ubicación en todos los emplazamientos, ello implica un error en las medidas de temperatura y presión asociado principalmente a la diferencia de altitud entre los emplazamientos. La altitud de las estaciones meteorológicas es conocida con una precisión mejor de una decena de metros en el peor de los casos, por lo que el error asociado con la incertidumbre en la altitud al reducir la temperatura de la estación meteorológica al nivel de la estación GPS se puede considerar menor de $0.1 \stackrel{\circ}{\circ}$, que se correspondería con una diferencia en la altitud de quince metros (en una atmósfera estándar el gradiente vertical de temperatura es aproximadamente de $6.5{ }^{\circ} \mathrm{C} / \mathrm{Km}$ ). Esta diferencia produce una variación totalmente insignificante en el PWV según se ha visto anteriormente. Sin embargo, en el caso de la presión se tiene que una diferencia de ocho metros en la altitud al nivel del suelo supone aproximadamente una diferencia en la presión de $1 \mathrm{hPa}$, que según se ha visto produce una diferencia del $2 \%$ en el PWV. Por ello, es muy recomendable disponer de datos precisos de presión en el mismo emplazamiento del GPS. 
En el cálculo del PWV con medidas de GPS están involucradas distintas fuentes de error, unas son independientes del propio valor del PWV y otras son proporcionales al mismo. Según Bevis et al. (1992 y 1994), para regiones no áridas el paso de ZWD a PWV introduce unos errores menores del $5 \%$ en casi todas las condiciones; y este error se debe principalmente al error en la estimación de la temperatura media atmosférica. El resto de las fuentes de error están relacionadas con la precisión con la que el retraso húmedo puede ser calculado. Este autor concluye que el PWV se puede calcular con un rmse menor de $2 \mathrm{~mm}$, imputable en su mayoría a las incertidumbres en el cálculo del ZWD.

La transformación de ZWD en PWV supone que el retraso es debido sólo al vapor de agua y no al agua líquida o la nieve, lo que es considerado una buena aproximación por la comunidad geodésica. Pero argumentos teóricos apuntan a que las nubes densas y espesas pueden causar un retraso tan grande como $7.5 \mathrm{~mm}$, por lo que en tales condiciones se estaría sobrestimando el PWV en aproximadamente $1 \mathrm{~mm}$. Sin embargo, el retraso causado por las gotas de lluvia si puede ser ignorado (Elgered, 1993). No obstante, la calidad de los datos de PWV obtenidos de las redes de GPS ha sido probada por varios autores (Elgered et al., 1997; Emardson et al., 1998; Ohtani y Naito, 2000; Dai et al., 2002; Bokoye et al., 2003; Li et al., 2003; Santangelo et al., 2003; Wang et al., 2007; Wang y Zhang, 2008; Heise et al., 2009; Morland, 2009; Schneider et al., 2009; Campmany et al., 2010) por comparación con los datos proporcionados por otros instrumentos y técnicas (sondeos, radiómetros de microondas, fotómetros solares, MODIS, modelos de predicción,...), estableciendo todos ellos el error entre 1 y $3 \mathrm{~mm}$. 


\section{Capítulo 2}

\section{ESTACIONES Y DATOS}

El presente estudio se ha realizado en base a los datos de los años 2002 al 2008, ambos inclusive, de las estaciones de radiosondeo de los Servicios Meteorológicos, fotométricas de la red AERONET, y de receptores GPS de EUREF, situadas en la Península lbérica. El motivo de empezar en el año 2002 se debe a que hay un mayor número de estaciones fotométricas y de receptores de GPS operando desde esa fecha. Aunque la antigüedad de la estaciones de radiosondeos es bastante mayor, se pretende caracterizar el PWV con una resolución espacial y temporal mayor que la proporcionada por estas estaciones. Las series de datos de los distintos emplazamientos deben corresponder al mismo periodo de tiempo para que los resultados obtenidos sean comparables entre sí.

No todas las estaciones disponen de datos para todo el periodo de estudio. Por ello, no se han usado con el mismo propósito. Las que disponen de las series completas se han utilizado para obtener los valores medios y el ciclo anual del PWV sobre la Península Ibérica. Además, los datos GPS se usaron también para describir el ciclo diurno y la variabilidad intra-día. Por otra parte, las estaciones con series cortas se han utilizado solamente en la comparación entre técnicas, para casos de estudio, y para determinar hasta que punto los resultados obtenidos en los emplazamientos con series largas son representativos de zonas más amplias.

A continuación se relacionan las estaciones disponibles de cada una de las técnicas, así como el proceso de obtención de los datos y el control de calidad al que han sido sometidos.

\subsection{Estaciones de Radiosondeo}

En la Península Ibérica hay ocho estaciones de radiosondeo (Tabla 2.1): Coruña, Santander, Madrid (Barajas), Zaragoza, y Murcia, operadas por la Agencia Estatal de Meteorología (AEMET); Gibraltar, perteneciente al MetOffice inglés; Barcelona, del Servicio Meteorológico de Cataluña; y Lisboa, del Instituto de Meteorología de Portugal.

La Figura 2.1 muestra la distribución geográfica de estas estaciones. La mayoría de ellas se localizan a lo largo del litoral, y sólo dos están situadas en el interior bastante alejadas de la costa (Madrid y Zaragoza). 
El programa estándar de lanzamientos de sondeos consiste en dos al día, a las 00 y 12 UTC. En algunas estaciones, y por periodos muy cortos de tiempo, se lanzan sondeo a horas intermedias (principalmente a las 06 o 18 UTC) para estudios particulares. El porcentaje de estos sondeos extras es sumamente bajo, por lo que se puede considerar que de cada estación, salvo fallo en el lanzamiento, se dispone sólo de dos datos al día, excepto de Lisboa que desde el mes de diciembre de 2003 sólo realiza un lanzamiento al día (a las 12 UTC).

\begin{tabular}{lccr}
\hline \multicolumn{1}{c}{ Estación } & Latitud & Longitud & Altitud \\
\hline Barcelona & $41^{\circ} 37^{\prime} \mathrm{N}$ & $2^{\circ} 12^{\prime} \mathrm{E}$ & 98 \\
Coruña & $43^{\circ} 22^{\prime} \mathrm{N}$ & $8^{\circ} 25^{\prime} \mathrm{W}$ & 58 \\
Gibraltar & $3^{\circ} 09^{\prime} \mathrm{N}$ & $5^{\circ} 21^{\prime} \mathrm{W}$ & 3 \\
Lisboa & $38^{\circ} 46^{\prime} \mathrm{N}$ & $9^{\circ} 08^{\prime} \mathrm{W}$ & 104 \\
Madrid & $40^{\circ} 28^{\prime} \mathrm{N}$ & $3^{\circ} 35^{\prime} \mathrm{W}$ & 631 \\
Murcia & $38^{\circ} 00^{\prime} \mathrm{N}$ & $1^{\circ} 10^{\prime} \mathrm{W}$ & 61 \\
Santander & $43^{\circ} 29^{\prime} \mathrm{N}$ & $3^{\circ} 48^{\prime} \mathrm{W}$ & 52 \\
Zaragoza & $41^{\circ} 40^{\prime} \mathrm{N}$ & $1^{\circ} 00^{\prime} \mathrm{W}$ & 263 \\
\hline Tabla 2 1-Coordenadas de las estaciones de radiosondeo
\end{tabular}

Los datos de los sondeos se han descargado de la página Web de la Universidad de Wyoming (http://weather.uwyo.edu/upperair/sounding.html). Todas las estaciones disponen de datos para todo el periodo de estudio, salvo Barcelona que empezó a funcionar en enero del 2008, y de Zaragoza que presenta una interrupción de la serie que abarca todo el año 2005.

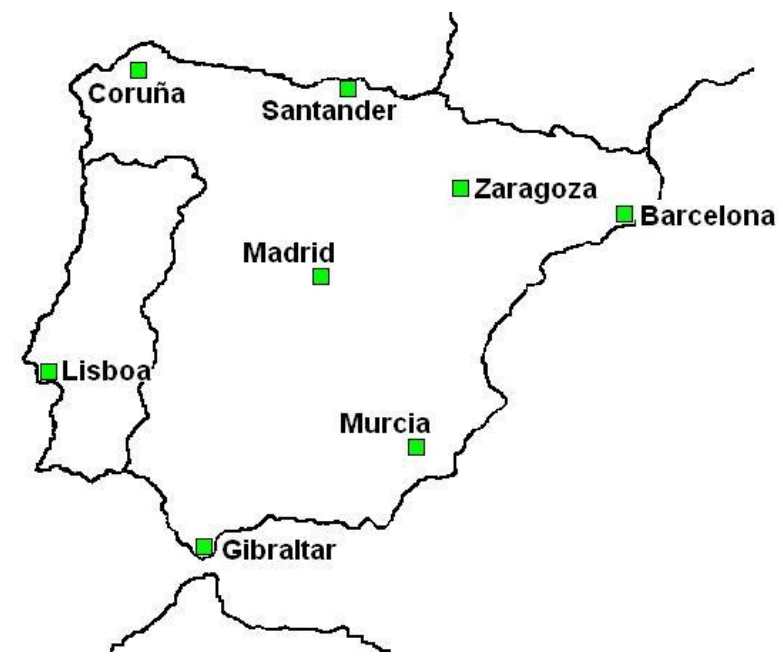

Figura 2.1 - Mapa de estaciones de radiosondeo.

Los datos originales, tal y como se han descargado, consisten en un fichero por estación y mes que contiene la información detallada de cada sondeo. Un ejemplo de este tipo de fichero se puede ver en la Figura 2.2. 
08221 LEMD Madrid Observations at $00 Z 01$ Jan 2000

PRES HGHT TEMP DWPT RELH MIXR DRCT SKNT THTA THTE THTV

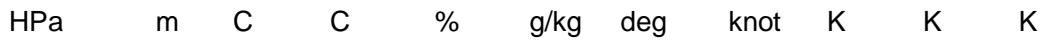

$\begin{array}{lllllllllll}1000.0 & 226 & & & & & & & & & \\ 952.0 & 633 & 4.2 & -3.8 & 56 & 3.05 & 10 & 2 & 281.3 & 290.1 & 281.8 \\ 945.0 & 693 & 6.2 & -3.8 & 49 & 3.07 & 10 & 2 & 283.9 & 292.9 & 284.4 \\ 925.0 & 869 & 5.8 & -6.2 & 42 & 2.61 & 10 & 4 & 285.2 & 293.0 & 285.7\end{array}$

\begin{tabular}{|c|c|c|c|c|c|c|c|c|c|}
\hline 100.0 & 16120 & -64.5 & -94.5 & 1 & 0.00 & 0 & 29 & 402.8 & 402.8 \\
\hline 70.8 & 18250 & -65.9 & 94.9 & 1 & 0.00 & 5 & 16 & 441.6 & 441.6 \\
\hline 70.0 & 18320 & -65.9 & -94.9 & 1 & 0.00 & 350 & 16 & 443.1 & 443.1 \\
\hline
\end{tabular}

Station information and sounding indices

Station identifier: LEMD

Station number: 8221

Observation time: 000101/0000

Station latitude: 40.50

Station longitude: -3.58

Station elevation: 633.0

Showalter index: 10.54

Lifted index: 15.29

Precipitable water [mm] for entire sounding: 9.10

08221 LEMD Madrid Observations at 00Z 01 Jan 2000

Figura 2.2 - Ejemplo de fichero original de datos de radiosondeos.

Estos ficheros contienen los siguientes datos para cada sondeo:

* De cada nivel sondeado: la presión $(\mathrm{hPa})$, la altitud $(\mathrm{m})$, la temperatura $\left({ }^{\circ} \mathrm{C}\right)$, el punto de rocío $\left({ }^{\circ} \mathrm{C}\right)$, la humedad relativa (\%), la proporción de mezcla $(\mathrm{gr} / \mathrm{Kgr})$, la dirección del viento $\left({ }^{\circ} \mathrm{dec}\right)$, la velocidad del viento (nudos), la temperatura potencial $\left({ }^{\circ} \mathrm{K}\right)$, la temperatura potencial equivalente $\left({ }^{\circ} \mathrm{K}\right)$, y la temperatura potencial virtual $\left({ }^{\circ} \mathrm{K}\right)$.

* Un resumen con: datos generales de la estación (coordenadas), índices del análisis de estabilidad (Showalter, Lifted, Total de Totales, Cape,...), y finalmente el PWV en mm.

Para el tratamiento de estos datos se ha desarrollado un programa (ver Anexo III) que transforma y fusiona todos los ficheros mensuales de una estación, resultando un único fichero resumen como el que se muestra en Figura 2.3. 
Fecha ; Hora; PWV'; PWV²; TempSup; TempMed; Nivel_Ini; Nivel_Final; № Niveles 01/01/00; 00:00; 9.10; 9.11; 4.2; 271.33; 633; 18320; 57 01/01/00; 12:00; 7.65; 7.68; 6.0; 269.66; 633; 26766; 37 $02 / 01 / 00 ; 00: 00 ; 6.90 ; 6.92 ; 2.0 ; 271.31 ; 633 ; 24767 ; 36$

$30 / 12 / 08 ; 12: 00 ; 17.33 ; 17.29 ; 10.0 ; 273.29 ; 633 ; 34940 ; 128$

$31 / 12 / 08 ; 00: 00 ; 12.93 ; 12.89 ; 6.6 ; 271.72 ; 633 ; 29122 ; 125$

$31 / 12 / 08 ; 12: 00 ; 14.83 ; 4.82 ; 9.2 ; 269.35 ; 633 ; 32463 ; 110$

Figura 2.3 - Ejemplo de fichero trasformado de datos de radiosondeo.

Estos ficheros resumen constan de un registro para cada sondeo con la siguiente información: la fecha, la hora, el PWV ${ }^{1}(\mathrm{~mm})$ del fichero original, el $\mathrm{PWV}^{2}(\mathrm{~mm})$ calculado por integración a partir de los datos de la proporción de mezcla de cada nivel, la temperatura $\left({ }^{\circ} \mathrm{C}\right)$ al nivel de la estación, la temperatura media ( $\left({ }^{\circ}\right)$ ponderada por el contenido de vapor de agua definida por Davis et al. (1985), la altitud o nivel inicial del primer dato (metros), la altitud máxima alcanzada por el sondeo (metros), y el número de niveles sondeados en la vertical.

Además del fichero resumen, el programa genera también un fichero para cada sondeo con un registro por cada nivel sondeado con los siguientes datos: la presión, la altitud, la temperatura, el punto de rocío, la humedad relativa, la razón de mezcla, la tensión de vapor y la humedad absoluta. Estos ficheros se han utilizado para calcular la distribución vertical del vapor de agua.

Aunque en los ficheros originales figura el dato de PWV, este se ha vuelto a calcular partiendo de las medidas de cada nivel sondeado como una medida de control de calidad para detectar datos erróneos por lecturas falsas a algún nivel. El cálculo se ha realizado según el procedimiento que se detalla a continuación:

1) Para cada capa sondeada se ha obtenido la tensión de vapor e $(\mathrm{hPa})$ de los datos de presión $p(\mathrm{hPa})$ y razón de mezcla $m$ (gr/gr) según la expresión,

$$
e=p \cdot m /(m+0.622)
$$

2) De la tensión de vapor e y la temperatura $T\left({ }^{\circ} \mathrm{K}\right)$ se ha calculado la humedad absoluta $a$ $\left(\mathrm{gr} / \mathrm{m}^{3}\right)$ según,

$$
a=216.9 \cdot e / \mathrm{T}
$$

3) El PWV se obtiene por integración de la humedad absoluta $a$ de cada capa. Al disponer de niveles discretos, la integración se ha realizado como el sumatorio de los productos de la humedad absoluta media de cada capa por la altura de la misma. 


$$
P W V=\sum_{i, j} \frac{\left(a_{i}+a_{j}\right)}{2} \times\left(z_{i}-z_{j}\right)
$$

Los datos de los sondeos descargados son datos brutos, por lo que se han sometido a un control de calidad propio en el que se han considerado como válidos aquellos que cumplían las siguientes condiciones:

* Que se hubieran sondeado al menos quince niveles de altitud (o presión).

* Que el primer nivel sondeado correspondiese a la altitud de la estación.

* Que la diferencia entre el dato de PWV del fichero original y el calculado según la expresión (2.3) fuese menor a $1 \mathrm{~mm}$.

* Que la temperatura del primer nivel sondeado (nivel de la estación) estuviera en consonancia con la temperatura de la estación meteorológica próxima.

* Que la altitud máxima alcanzada por el sondeo fuera al menos de $9 \mathrm{Km}$, salvo en las estaciones de Lisboa, Santander, y Zaragoza donde este límite se ha bajado a $7 \mathrm{Km}$, porque en otro caso el número de sondeos válidos disminuía drásticamente.

* Que la temperatura media ponderada por el contenido de vapor de agua no presentara valores extremos anormales.

* Que el dato de PWV no presentara un valor extremo aislados fuera del rango normal de variación del contenido de vapor de agua.

\subsection{Estaciones Fotométricas}

Las estaciones de fotómetros solares ubicadas en la Península pertenecientes a AERONET (Figura 2.4) están relacionadas en la Tabla 2.2. La mayoría de ellas disponen de series de datos muy cortas o presentan numerosas lagunas de varios meses de duración, lo que las hace inapropiadas para un estudio de caracterización del PWV.

\begin{tabular}{lccrc}
\hline \multicolumn{1}{c}{ Estación } & Latitud & Longitud & Altitud & 19 Dato \\
\hline Barcelona & $4^{\circ} 23^{\prime} \mathrm{N}$ & $2^{\circ} 07^{\prime} \mathrm{E}$ & 125 & $16 / 12 / 2004$ \\
Burjassot (Valencia) & $39^{\circ} 30^{\prime} \mathrm{N}$ & $0^{\circ} 25^{\prime} \mathrm{W}$ & 30 & $16 / 04 / 2007$ \\
Cabo Roca (Portugal) & $38^{\circ} 47^{\prime} \mathrm{N}$ & $9^{\circ} 30^{\prime} \mathrm{W}$ & 140 & $10 / 12 / 2003$ \\
Cáceres & $39^{\circ} 29^{\prime} \mathrm{N}$ & $6^{\circ} 21^{\prime} \mathrm{W}$ & 397 & $25 / 07 / 2005$ \\
El Arenosillo (Huelva) & $37^{\circ} 06^{\prime} \mathrm{N}$ & $6^{\circ} 44^{\prime} \mathrm{W}$ & 0 & $16 / 02 / 2000$ \\
Evora (Portugal) & $38^{\circ} 34^{\prime} \mathrm{N}$ & $7^{\circ} 55^{\prime} \mathrm{W}$ & 293 & $03 / 07 / 2003$ \\
Granada & $37^{\circ} 10^{\prime} \mathrm{N}$ & $3^{\circ} 36^{\prime} \mathrm{W}$ & 680 & $29 / 12 / 2004$ \\
Palencia & $4^{\circ} 59^{\prime} \mathrm{N}$ & $4^{\circ} 31^{\prime} \mathrm{W}$ & 750 & $23 / 01 / 2003$ \\
\hline
\end{tabular}

Tabla 2.2 - Estaciones fotométricas de AERONET en la Península.

Las medidas de PWV de los fotómetros solares se han obtenidos de la página Web de AERONET (http://aeronet.gsfc.nasa.gov/). En ella están disponibles los datos procesados con 
dos versiones del algoritmo utilizado por AERONET. Para este estudio se han seleccionado los datos correspondientes a la Versión 2, que supone una mejora con respecto a la anterior (Smirnov, 2004). Aunque esta versión se puso operativa en el año 2005, las medidas de los años anteriores han sido reprocesadas con la nueva versión.

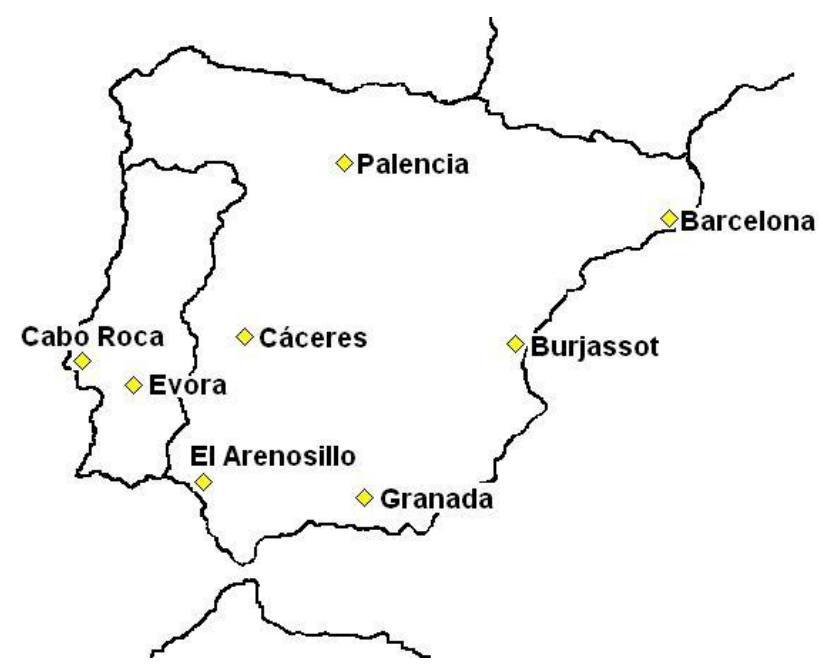

Figura 2.4 - Mapa de estaciones fotométricas de AERONET.

Los datos de AERONET tienen tres niveles de calidad. El nivel 1.0 se corresponde con las medidas procesadas sin pasar ningún control de calidad. En el nivel 1.5 los datos han sido sometidos a un proceso de cloud-screening (Smirnov, 2000). Para alcanzar el nivel 2.0 el instrumento tiene que ser sometido a una segunda calibración al final del periodo, normalmente un año, para eliminar el efecto de la degradación de los filtros con el tiempo. Los coeficientes de calibración del instrumento se recalculan por interpolación entre los de la calibración inicial y final asumiendo una degradación lineal de los filtros. Con estos nuevos coeficientes de calibración se reprocesan las medidas para obtener los datos definitivos del nivel 2.0.

En este trabajo se han utilizado los datos del nivel 1.5. Aunque los del nivel 2.0 tienen una mayor calidad, las series presentan grandes lagunas disponiéndose de pocos datos. Ello es debido en muchos casos a que no se conoce la forma espectral de los filtros usados con anterioridad al año 2005, lo que es necesario para que los datos reprocesados con la versión V2 puedan acceder al nivel de calidad 2.0.

La secuencia automática estándar de medida de los instrumentos de AERONET consiste en mediciones a masas ópticas fijas por la mañana y por la tarde entre las masas ópticas 7 y 2 , inicialmente a intervalos de 0.5 hasta masa óptica 4 y luego cada 0.2 , es la denominada secuencia Langley, y a intervalos de quince minutos en las horas centrales del día entre las masas ópticas 2 de la mañana y 2 de la tarde. Con ello, la frecuencia media es de una medida cada diez a quince minutos, siempre y cuando la nubosidad no oculte el Sol. 
Los datos originales, tal y como se han descargado, consisten en un único fichero por estación que abarca todo el periodo de estudio. Estos ficheros constan de una cabecera con datos generales y un registro por cada observación, que además del PWV (en centímetros) contiene: el AOD para cada uno de los canales del fotómetro Cimel, la variación del triplete de medidas que conforman cada observación, los exponentes de Angstrom, la fecha y hora, etc. La Figura 2.5 muestra un ejemplo de estos ficheros.

Level 1.5. Real Time Cloud Screened data. The following data are automatically cloud cleared but may not have final calibration applied. These data are not Quality Assured. Version 2 Direct Sun Algorithm. Location=Palencia,long=4.516,lat=41.989,elev=750,Nmeas=5,Pl=Victoria_E_Cachorro_Revilla,Email=chiqui @goa.uva.es. AOD Level 1.5, All Points,UNITS can be found at,..http:/aeronet.gsfc.nasa.gov/data_menu.html Date(dd-mm-yy),Time(hh:mm:ss),Julian_Day,AOT_1640,AOT_1020,AOT_870,AOT_675,AOT_667,AOT_555, AOT_551,AOT_532,AOT_531,AOT_500,AOT_490,AOT_443,AOT_440,AOT_412,AOT_380,AOT_340,Water (cm),\%TripletVar_1640,\%TripletVar_102,\%TripletVar_870,\%TripletVar_675,\%TripletVar_667,\%TripletVar_55 5,\%TripletVar_551,\%TripletVar_532,\%TripletVar_531,\%TripletVar_500,\%TripletVar_490,\%TripletVar_443,\%T ripletVar_440,\%TripletVar_412,\%TripletVar_380,\%TripletVar_340,\%WaterError,440-870Angstrom,380-500An gstrom,440-675Angstrom,500-870Angstrom,340-440Angstrom,440-675Angstrom(Polar),Last_Processing_Da te,Solar_Zenith_Angle

23:01:2003,14:45:39,23.615035,N/A,0.037723,0.040350,0.043507,N/A,N/A,N/A,N/A,N/A,N/A,N/A,N/A,0.0718 $30, N / A, N / A, N / A, 0.651471, N / A, 0.712281,0.553418,0.895895, N / A, N / A, N / A, N / A, N / A, N / A, N / A, N / A, 1.397918, N / A$ ,N/A,N/A,N/A,0.879163,N/A,1.167920,0.297513,N/A,1.167920,23/01/2003,68.937840

23:01:2003,15:37:58,23.651366,N/A,0.033205,0.033595,0.035646,N/A,N/A,N/A,N/A,N/A,N/A,N/A,N/A,0.0554 16,N/A,N/A,N/A,0.611446,N/A,0.160608,0.169571,0.136254,N/A,N/A,N/A,N/A,N/A,N/A,N/A,N/A,0.062862,N/A ,N/A,N/A,N/A,0.764489,N/A,1.027799,0.234098,N/A,1.027799,23/01/2003,75.155757

30:12:2008,13:51:23,365.577350,N/A,0.026856,0.038114,0.048864,N/A,N/A,N/A,N/A,N/A,0.081842,N/A,N/A, $0.094107, N / A, 0.118074,0.124960,1.912874, N / A, 0.187039,0.273357,0.307903, N / A, N / A, N / A, N / A, N / A, 0.40427$ $0, N / A, N / A, 0.421879, N / A, 0.659834,0.679831, N / A, 1.375449,1.356793,1.564553,1.383775,1.127252, N / A, 30 / 12$ $/ 2008,68.349789$

Figura 2.5 - Ejemplo de fichero original con datos fotométricos de una estación de AERONET.

Al igual que con los sondeos, para el tratamiento de los datos de los fotómetros se ha desarrollado un programa que extrae exclusivamente el dato de PWV de los ficheros originales (ver Anexo III). Los ficheros transformados sólo contienen la fecha, la hora, y el dato de PWV (Figura 2.6).

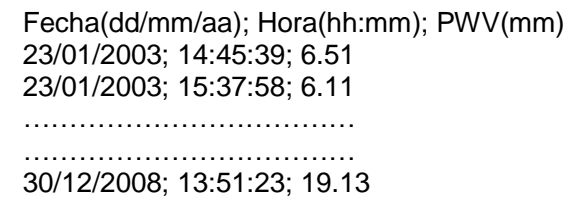

Figura 2.6 - Ejemplo de fichero transformado. 
Estos datos no han sido sometidos a ningún control de calidad adicional al propio realizado por AERONET. Sólo a la vista de la representación gráfica de los mismos se han eliminado algunos valores extremos aislados que no guardaban correlación con el resto de las medidas.

\subsection{Estaciones GPS}

En los últimos años ha proliferado la instalación de receptores GPS por parte de distintos organismos, como el Instituto Geográfico Nacional (IGN), Comunidades Autónomas, Universidades, etc. Para este estudio se han utilizado los datos de aquellas estaciones que pertenecen a EUREF, red asociada al IGS que es una federación de agencias e instituciones que conforman un fondo común de recursos y estaciones permanentes para generar productos de alta precisión, siendo la comunidad civil internacional de productos GPS de más alta precisión (Beutler et al., 1999).

En la Tabla 2.3 están relacionadas las estaciones referidas (Figura 2.7). Prácticamente la mitad de estas estaciones disponen de datos de ZTD desde el 5 de agosto del 2001, y son estas las que se han utilizado para el estudio de caracterización climatológica. Posteriormente, a partir del año 2005 la red de estaciones se ha ido ampliando hasta duplicar su tamaño. Algunas de ellas han tenido que ser desechadas al no disponerse de datos meteorológicos en las proximidades para poder transformar los valores del ZTD en PWV.

\begin{tabular}{|c|c|c|c|c|c|c|c|c|c|}
\hline Estación & Lat. & Long. & Alt. & 10 Dato & Estación & Lat. & Long. & Alt. & 10 Dato \\
\hline Alicante & $38^{\circ} 20^{\prime}$ & $0^{\circ} 29^{\prime} \mathrm{W}$ & 10 & 05/08/01 & Logroño & $42^{\circ} 27^{\prime}$ & $2^{\circ} 30^{\prime} \mathrm{W}$ & 452 & $13 / 11 / 05$ \\
\hline Albacete & $38^{\circ} 59^{\prime}$ & $1^{\circ} 51^{\prime} \mathrm{W}$ & 700 & 09/09/07 & Roquetes & $40^{\circ} 49^{\prime}$ & $0^{\circ} 30^{\prime} \mathrm{E}$ & 58 & 05/08/01 \\
\hline Almería & $36^{\circ} 51^{\prime}$ & $2^{\circ} 28^{\prime} W$ & 77 & 05/08/01 & Salamanca & $40^{\circ} 57^{\prime}$ & $5^{\circ} 30^{\prime} \mathrm{W}$ & 800 & $12 / 11 / 06$ \\
\hline Burriana & $39^{\circ} 54^{\prime}$ & $0^{\circ} 05^{\prime} \mathrm{W}$ & 22 & $21 / 10 / 07$ & S.Fernando & $36^{\circ} 28^{\prime}$ & $6^{\circ} 12^{\prime} \mathrm{W}$ & 40 & 05/08/01 \\
\hline Cáceres & $39^{\circ} 29^{\prime}$ & $6^{\circ} 21^{\prime} \mathrm{W}$ & 384 & 02/09/01 & Santander & $43^{\circ} 28^{\prime}$ & $3^{\circ} 48^{\prime} \mathrm{W}$ & 48 & 05/08/01 \\
\hline Cascais & $38^{\circ} 42^{\prime}$ & $9^{\circ} 25^{\prime} \mathrm{W}$ & 27 & 05/08/01 & Sonseca & $39^{\circ} 41^{\prime}$ & $3^{\circ} 58^{\prime} \mathrm{W}$ & 755 & 09/09/07 \\
\hline Córdoba & $37^{\circ} 55^{\prime}$ & $4^{\circ} 43^{\prime} \mathrm{W}$ & 162 & $27 / 02 / 05$ & Valencia & $39^{\circ} 29^{\prime}$ & $0^{\circ} 20^{\prime} \mathrm{W}$ & 28 & 05/08/01 \\
\hline Coruña & $43^{\circ} 22^{\prime}$ & $8^{\circ} 24^{\prime} \mathrm{W}$ & 12 & 05/08/01 & Vigo & $42^{\circ} 11^{\prime}$ & $8^{\circ} 49^{\prime} \mathrm{W}$ & 33 & $13 / 11 / 05$ \\
\hline Creus & $42^{\circ} 19^{\prime}$ & $3^{\circ} 19^{\prime} \mathrm{E}$ & 84 & 05/08/01 & Villafranca & $40^{\circ} 27^{\prime}$ & $3^{\circ} 57^{\prime} \mathrm{W}$ & 596 & 05/08/01 \\
\hline Huelva & $37^{\circ} 12^{\prime}$ & $6^{\circ} 55^{\prime} \mathrm{W}$ & 29 & 09/09/07 & Yebes & $40^{\circ} 31^{\prime}$ & $3^{\circ} 05^{\prime} \mathrm{W}$ & 921 & 05/08/01 \\
\hline León & $42^{\circ} 35^{\prime}$ & $5^{\circ} 39^{\prime} \mathrm{W}$ & 915 & 09/09/07 & Zaragoza & $41^{\circ} 38^{\prime}$ & $0^{\circ} 53^{\prime} \mathrm{W}$ & 246 & $25 / 06 / 06$ \\
\hline Málaga & $36^{\circ} 44^{\prime}$ & $4^{\circ} 24^{\prime} \mathrm{W}$ & 71 & $13 / 11 / 05$ & & & & & \\
\hline
\end{tabular}

Tabla 2.3 - Estaciones de receptores GPS pertenecientes a EUREF en la Península Ibérica.

Dentro de EUREF existen varios centros locales de análisis (LAC) que generan los datos de ZTD como un subproducto a partir de las mediciones de los receptores GPS. EUREF también genera los ZTD promedios de los generados por cada uno de los LAC. Estos últimos datos son utilizados para validar la calidad de los generados por cada LAC. Para este estudio se han 
seleccionado los generados por el IGN, porque es el único LAC que procesa los datos de todas las estaciones de la Península. Los datos de ZTD se han descargado de la página Web de EUREF (http://epncb.oma.be/ ; ftp://epncb.oma.be/pub/product/).

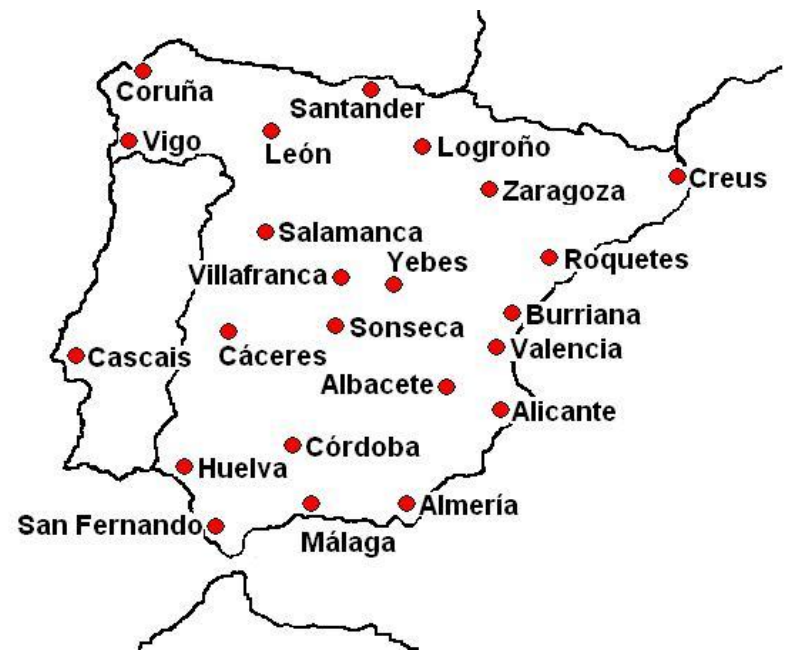

Figura 2.7 - Mapa de los emplazamientos con receptores de GPS.

Los LACs procesan las medidas de los receptores GPS sobre una base semanal, generando un fichero en formato SINEX para cada día de la semana con los datos del ZTD de todas las estaciones que procesan. En el caso del IGN los ficheros se denominan 'IGEssssd.tro. $z$ ', donde 'ssss' es el número de semana GPS y ' $d$ ' el día de la semana. Las semanas GPS comienzan a las 00:00 UTC de la noche del sábado al domingo, y empezaron a numerarse desde la semana que se inició la noche del sábado 5 al domingo 6 de enero de 1980. Estos ficheros contienen un bloque con información sobre el procesado de los datos, otro con las coordenadas de las estaciones, y un último bloque que comienza con el identificador '+TROP/SOLUTION' que contiene los datos del ZTD. En este último bloque cada registro está precedido por el indicativo de la estación (cuatro letras), seguido de la fecha y hora de la observación en formato 'aa:ddd:sssss', donde 'aa' son las dos últimas cifras del año, 'ddd' el día juliano, y 'sssss' los segundos transcurridos desde el inicio del día, y finalmente el ZTD y su desviación estándar en milímetros. La frecuencia de los datos es horaria coincidiendo con las horas y media. Un ejemplo de este tipo de ficheros se puede ver en la Figura 2.8.

Para el procesamiento de las señales GPS el IGN utiliza el programa Bernese GPS Software con las funciones de mapeo de Niell y las órbitas precisas de los satélites proporcionadas por el IGS. Durante el periodo de tiempo que abarca el estudio ha habido varios cambios en este procesamiento, pero el más significativo fue el paso de una corrección relativa de las variaciones del centro de fase de las antenas de los receptores a una corrección absoluta a partir de la semana GPS 1400 (5/11/2006). Las implicaciones de esta modificación se verán con detalle en el Capítulo 8. 


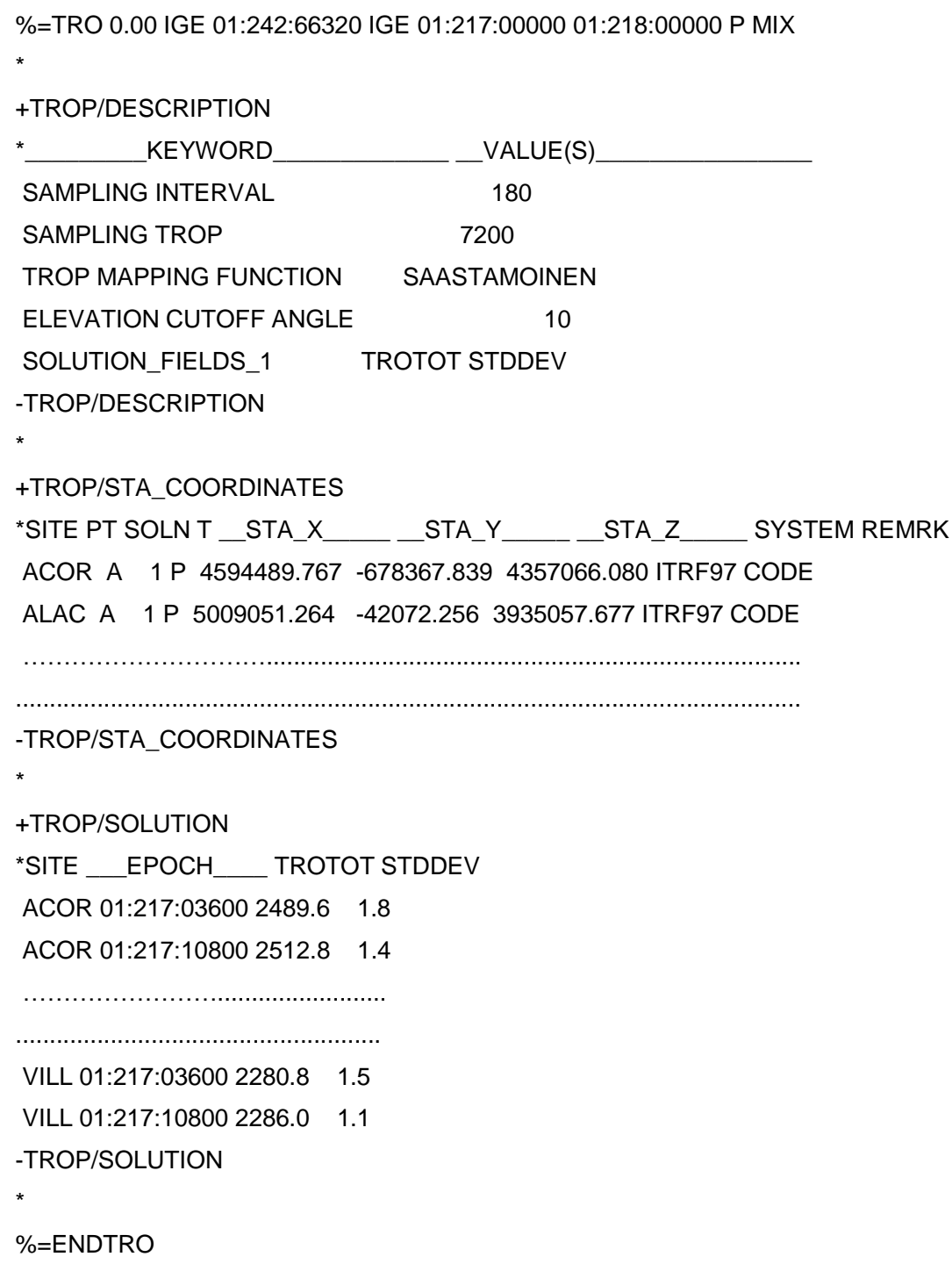

Figura 2.8 - Ejemplo de fichero original del IGN con datos de ZTD en formato SINEX.

Los ficheros originales del IGN se han procesado mediante un programa informático (Anexo III) que genera un único fichero para cada estación con los datos del ZTD para todo el periodo de estudio (Figura 2.9). Estos ficheros contienen un único registro por observación con la fecha, la hora, y el dato del ZTD.

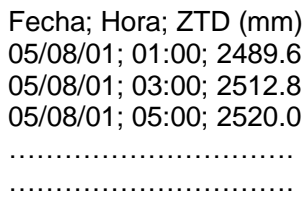

Figura 2.9 - Ejemplo de fichero transformado de datos ZTD 
Como se ha visto en el capítulo anterior, para calcular el PWV a partir de las medidas del ZTD se necesita conocer la presión y la temperatura al nivel de la estación. Excepto en el caso de la estación de Cascais que tiene instalados sensores meteorológicos propios, para el resto de estaciones los datos meteorológicos se han obtenido de la red de estaciones sinópticas de AEMET, principalmente de las emplazadas en aeropuertos por poseer una instrumentación más precisa para la medida de la presión, cuyo error se ha visto en el capítulo anterior que afecta más a la precisión final del PWV. Así, a cada estación GPS se le ha asignado una estación meteorológica (Tabla 2.4). No obstante, hay que remarcar que en el caso de las estaciones de Villafranca, San Fernando, Sonseca y Yebes, la estación meteorológica se encuentra a una distancia del orden de $25 \mathrm{Km}$ en línea recta, con el agravante en las dos últimas de una diferencia de altitud de 240 y 340 m respectivamente. Aún peor es el caso de la estación de Creus, donde la distancia aumenta hasta los $50 \mathrm{Km}$, encontrándose además la estación GPS en la costa y la meteorológica en el interior.

Los datos meteorológicos están organizados en un fichero por estación, donde cada registro contiene los siguientes datos para cada día: la presión a las 00, 07, 12 y 18 UTC, y la temperatura horaria. La Figura 2.10 muestra un ejemplo de estos ficheros.

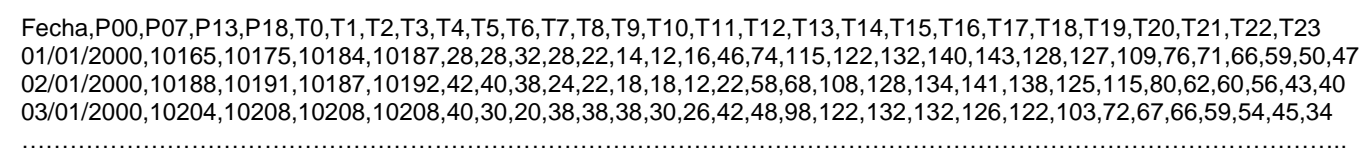

Figura 2.10 - Ejemplo de fichero de datos meteorológicos. Las presiones están expresadas en décimas de hPa y las temperaturas en décimas de grado.

Para cada estación GPS se ha fusionado el fichero transformado con los datos del ZTD con el de los datos meteorológicos (Figura 2.11), asignando a cada dato de ZTD los valores de la presión y la temperatura calculados por interpolación entre las dos observaciones meteorológicas más próximas en el tiempo a la hora de la observación del dato de ZTD. En el caso de la temperatura se interpoló linealmente. Sin embargo, para la presión la interpolación se hizo teniendo en cuenta la marea barométrica, la cual presenta sobre la Península un ciclo semidiurno de una amplitud de unos $0.5 \mathrm{mb}$ (Ray y Ponte, 2003) con picos sobre las 10 y 22 UTC y valles sobre las 4 y 16 UTC. Se procedió de esta manera a fin de evitar introducir un ciclo diurno artificial en el PWV al disponer de sólo cuatro datos de presión al día. Como se ha visto en el capítulo anterior, el PWV es muy sensible a las incertidumbres en la presión, un error de $0.5 \mathrm{mb}$ produce un error del 1\% en el PWV (Hagemann et al., 2003), y como se verá en el Capítulo 5, la amplitud del ciclo diurno del PWV es muy pequeña, por lo que si se interpola linealmente se estaría transfiriendo el ciclo diurno de la presión al del PWV en un porcentaje significativo. En caso de no disponer de datos meteorológicos para un día se han descartado los datos de ZTD de ese día. 


\begin{tabular}{|c|c|c|c|c|c|c|c|c|c|}
\hline \multicolumn{5}{|c|}{ Estación GPS } & \multicolumn{5}{|c|}{ Estación AEMET } \\
\hline Nombre & Indicat. & Lat. & Long. & Alt. & Nombre & Indicat. & Lat. & Long. & Alt. \\
\hline Alicante & ALAC & 38.34 & 0.48 & 60 & Alicante & 8025 & 38.37 & 0.49 & 132 \\
\hline Albacete & ALBA & 38.98 & 1.86 & 752 & Albacete-Los Llanos & 8175 & 38.95 & 1.86 & 756 \\
\hline Almería & ALME & 36.83 & 2.46 & 127 & Almería (Aero.) & 63250 & 36.84 & 2.39 & 71 \\
\hline Borriana & BORR & 39.91 & 0.08 & 73 & Castellón-Almazora & $8500 \mathrm{~A}$ & 39.95 & 0.02 & 85 \\
\hline Cáceres & CACE & 39.48 & 6.34 & 438 & Cáceres & $3469 A$ & 39.47 & 6.34 & 459 \\
\hline Cascais & CASC & 38.69 & 9.42 & 77 & Cascais & CASC & 38.69 & 9.42 & 77 \\
\hline Coruña & ACOR & 43.36 & 8.40 & 67 & Coruña & 1387 & 43.37 & 8.42 & 122 \\
\hline Córdoba & COBA & 37.92 & 4.72 & 213 & Córdoba (Aero.) & 5402 & 37.84 & 4.85 & 143 \\
\hline Creus & CREU & 42.32 & -3.32 & 133 & Girona (Aero.) & 0367 & 41.90 & -2.76 & 179 \\
\hline Huelva & HUEL & 37.20 & 6.92 & 82 & Huelva & 4642E & 37.28 & 6.91 & 73 \\
\hline León & LEON & 42.59 & 5.65 & 970 & León-Virgen del C. & 2661 & 42.59 & 5.65 & 970 \\
\hline Málaga & MALA & 36.73 & 4.39 & 120 & Málaga (Aero.) & $6155 A$ & 36.67 & 4.49 & 55 \\
\hline Logroño & RIOJ & 42.46 & 2.50 & 503 & Logroño-Agoncillo & 9170 & 42.45 & 2.33 & 414 \\
\hline Roquetes & EBRE & 40.82 & -0.49 & 108 & Tortosa & $9981 \mathrm{~A}$ & 40.82 & -0.49 & 100 \\
\hline Salamanca & SALA & 40.95 & 5.50 & 855 & Salamanca-Matacan & 2867 & 40.95 & 5.50 & 849 \\
\hline S.Fernando & SFER & 36.46 & 6.21 & 86 & Jerez (Aero.) & 5960 & 36.75 & 6.06 & 74 \\
\hline Santander & CANT & 43.47 & 3.80 & 99 & Santander & 1111 & 43.49 & 3.80 & 110 \\
\hline Sonseca & SONS & 39.68 & 3.96 & 809 & Toledo-Buenavista & $3260 \mathrm{~B}$ & 39.89 & 4.05 & 569 \\
\hline Valencia & VALE & 39.48 & 0.34 & 78 & Valencia-Manises & $8414 \mathrm{~A}$ & 39.49 & 0.47 & 112 \\
\hline Vigo & VIGO & 42.18 & 8.81 & 88 & Vigo-Peinador & 1495 & 42.22 & 8.63 & 311 \\
\hline Villafranca & VILL & 40.44 & 3.95 & 648 & Madrid-Barajas & 3129 & 40.45 & 3.54 & 633 \\
\hline Yebes & YEBE & 40.53 & 3.09 & 973 & Madrid-Barajas & 3129 & 40.45 & 3.54 & 633 \\
\hline Zaragoza & ZARA & 41.63 & 0.88 & 296 & Zaragoza (Aero.) & 9434 & 41.66 & 1.01 & 308 \\
\hline
\end{tabular}

Tabla 2.4 - Estaciones meteorológicas de referencia para cada estación GPS. Los indicativos de las estaciones son los propios utilizados por EUREF y AEMET en cada caso. La latitud y la longitud están expresadas en grados y las longitudes negativas son este. Las altitudes están referidas al elipsoide. 'Aero' quiere decir aeropuerto.

Cuando la estación meteorológica y el receptor de GPS no están ubicados en el mismo emplazamiento se hace necesario al menos corregir los datos meteorológicos por la diferencia de altitud entre ambas estaciones. En el caso de la temperatura esto se ha realizado considerando una atmósfera estándar con un gradiente vertical de temperatura constante de $6.5^{\circ} \mathrm{C} / \mathrm{Km}$, según la expresión,

$$
T_{G P S}=T_{m e t}-6.5 \cdot\left(A l t_{G P S}-A l t_{m e t}\right)
$$

donde 'GPS' y 'met' hacen referencia al nivel de la estación GPS o meteorológica respectivamente.

Una vez obtenida la temperatura al nivel del receptor GPS, la presión se ha corregido utilizando la expresión (2.5), que relaciona la diferencia de presión entre dos niveles de altitud a temperaturas conocidas expresadas en grados kelvin. 


$$
\log \frac{P_{G P S}}{P_{m e t}}=\frac{\left(A l t_{m e t}-A l t_{G P S}\right) \cdot 0.01484}{\left(T_{G P S}+T_{m e t}\right) / 2}
$$

Los ficheros fusionados con los datos meteorológico y de ZTD proporcionan los datos de entrada al programa que calcula el PWV según el procedimiento descrito en la metodología, (ver subrutina en Anexo III).

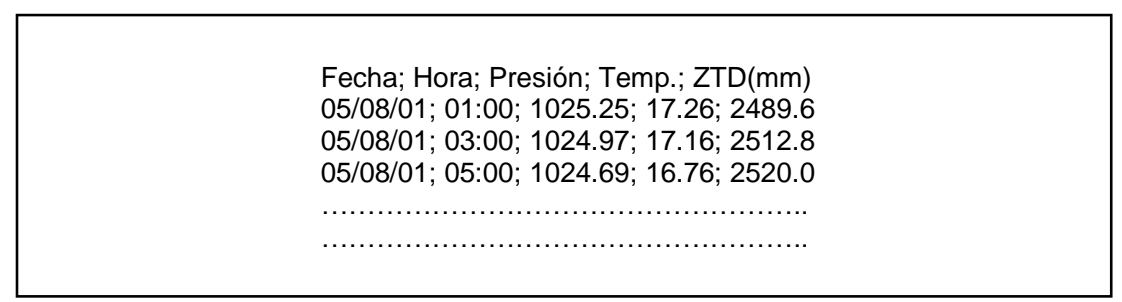

Figura 2.11 - Ejemplo de fichero compuesto de datos meteorológicos y de ZTD.

Finalmente, una vez obtenidos los datos de PWV se han eliminado todos aquellos inferiores a cero. Estos valores negativos no tienen sentido físico, y son debidos a imprecisiones o medidas erróneas del ZTD, la presión, o la temperatura.

Además de los datos procesados por el IGN, el IGS genera desde noviembre del 2006 datos de ZTD con una frecuencia de cinco minutos para cuatro estaciones españolas (Roquetes, San Fernando, Villafranca, y Yebes). Estos datos están disponibles en la página Web del IGS (ftp://igs.ensg.ign.fr/pub/igs/products/troposphere/ ; http://igscb.jpl.nasa.gov/), y se han utilizado para el análisis en detalle de casos de estudio por su alta resolución temporal (Capítulo 9). 


\section{Capítulo 3}

\section{ANÁLISIS ESTADÍSTICO}

En este capítulo se presentan en forma de tablas y gráficos individualizados por estación los valores de un conjunto de estadísticos usados para caracterizar las series de datos del PWV. También, en el último apartado del capítulo se verá la distribución vertical media del vapor de agua en la atmósfera obtenida de los sondeos.

Este análisis sólo se ha realizado para las estaciones con datos durante todo el periodo de estudio, es decir del 2002 al 2008. La Organización Meteorológica Mundial (OMM) establece que la climatología de cualquier variable meteorológica se debe calcular en base a un periodo de referencia de treinta años. Es por ello, que en este estudio no hablamos de Climatología sino de caracterización o análisis estadístico, pues sólo se dispone de siete años de datos. Aún así, y como se verá en el próximo capítulo, se considera que los resultados aquí presentados pueden representar con suficiente validez el comportamiento del PWV sobre la Península Ibérica.

\subsection{Estaciones y Metodología}

Todas las estaciones de radiosondeos, excepto Barcelona, cumplen el requisito de disponer de datos para todo el periodo de estudio (2002/2008), aunque la estación de Zaragoza presenta una laguna de datos que comprende todo el año 2005. Respecto a las estaciones de GPS, a pesar de ser las más numerosas, solamente once de ellas disponen de datos desde el año 2002. Su número se ha incrementado considerablemente en los últimos años, pero aún no se disponen de series de datos suficientemente largas para obtener resultados representativos. De las estaciones fotométricas, sólo la de El Arenosillo dispone de datos desde 2002. Por ello se ha incluido también en este análisis la estación de Palencia para disponer de más estaciones de este tipo, aunque empezó a funcionar en enero del 2003.

La Figura 3.1 muestra la distribución geográfica de las estaciones analizadas. Como se puede observar ésta no es homogénea, existiendo una mayor densidad de estaciones en las zonas costeras que en el interior, especialmente en la costa Mediterránea, quedando grandes zonas sin cubrir, como el interior de Galicia, Portugal, el valle del Guadalquivir, del Tajo, etc. Este ha sido también el motivo para incluir en el análisis las estaciones de Zaragoza y Palencia. 


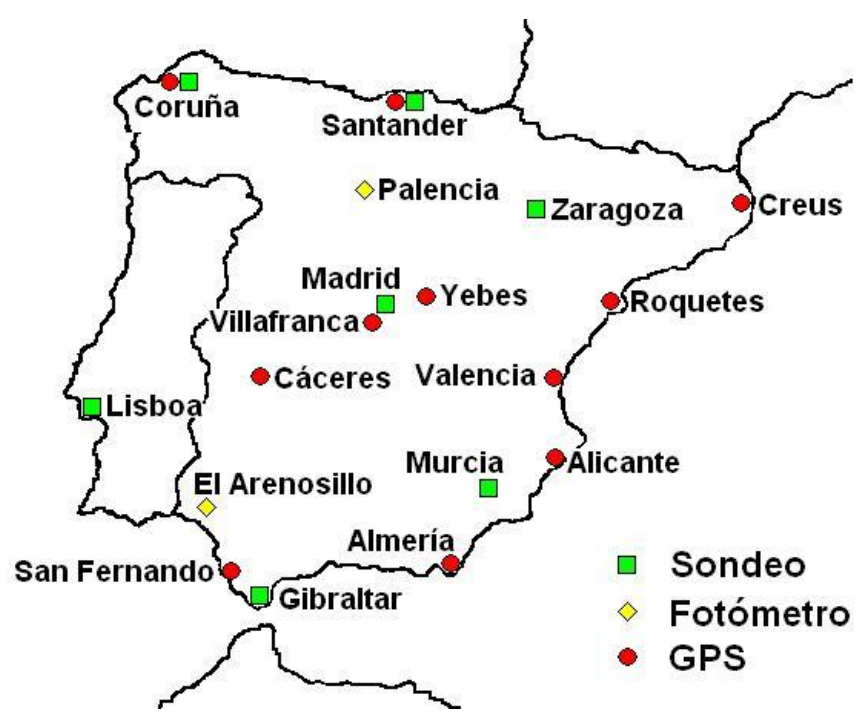

Figura 3.1 - Distribución geográfica de las estaciones analizadas.

El análisis estadístico se ha realizado de acuerdo al siguiente procedimiento:

(Nota: el término media mensual o anual hace referencia al valor medio de un mes o año concreto respectivamente, y el término promedio mensual o anual al valor medio de varias medias mensuales o anuales correspondientes a de distintos años.)

1ㅇ Se han obtenido las estadísticas para el conjunto de forma global de todas las medidas que habían superado el correspondiente control de calidad. Los estadísticos calculados han sido: el número de medidas, la media aritmética, la desviación estándar de las medidas (std), la mediana, la moda (clase modal), los percentiles 5 y 95, el valor máximo y mínimo absoluto, y los coeficientes de asimetría y curtosis de la distribución. Para el cálculo de la moda se han agrupado las medidas en intervalos de $2.5 \mathrm{~mm}$ (de 0 a 2.5; de 2.5 a 5 ; de 5 a $7.5 ; \ldots$ ). Con los percentiles 5 y 95 se puede representar de una manera más fiable el orden de magnitud de los valores mínimos y máximos del PWV respectivamente, puesto que los valores mínimos y máximos absolutos pueden no ser representativos al corresponderse con situaciones anómalas de muy infrecuente ocurrencia, o a errores en las medidas que no han sido detectados en el control de calidad de las mismas.

2 - Se han agrupado las medidas por mes del año, y se ha calculado para cada uno de ellos los mismos estadísticos que en el punto anterior, obteniendo de esta manera la evolución media anual de los mismos.

30 Se han obtenido las series de las medias diarias, calculando para cada día la media aritmética de todas las medidas disponibles en el día, independientemente del número de ellas. 
4 Con las series de las medias diarias se ha procedido igual que se hizo en el punto primero y segundo con las de las medidas puntuales, calculando unas estadísticas del conjunto global de datos y otras de estos agrupados por mes del año.

$5^{-}$Se han agrupado las medias diarias por mes y año y se ha calculado para cada mes/año: la media mensual, la desviación típica de los promedios diarios, el valor máximo y mínimo de las medias diarias, y el número de días con dato.

60 Las medias mensuales de todos los estadísticos obtenidos en el punto anterior se han promediado para todos los meses de un año y para todos los años de un mismo mes. En este promedio se han descartado los meses con un número de días con dato válido inferior a la mitad de los días nominales del mes, para que estos, que pueden ser no significativos, no pesen demasiado en las medias al no disponer de series de datos muy largas. En el caso de los fotómetros este límite se ha tenido que bajar a siete días de datos para no descartar demasiados meses, porque hay muchos días sin datos por la presencia de nubosidad.

$7^{\circ}$ Partiendo de las medias mensuales del conjunto de los siete años de datos obtenidas en el apartado $5^{\circ}$ se ha calculado para cada mes del año, el promedio mensual, la desviación típica de las medias mensuales, la mediana, y el máximo y el mínimo de las medias mensuales. En el Capítulo 4 se estudiará en detalle el ciclo anual del PWV en base a estos promedios.

$8^{\circ}$ Las medias anuales de cada uno de los siete años de datos obtenidas en el apartado $6^{\circ}$ se han promediado para calcular el promedio global anual.

9o Por último, los valores promedios mensuales y anuales de cada una de las estaciones se han promediado para obtener unos valores promedios globales para la Península lbérica.

A la hora de interpretar los resultados hay que resaltar que las medidas de los GPS recogen bastante fielmente la evolución del PWV durante todo el día, pues para la gran mayoría de los días se dispone de veinticuatro datos de frecuencia horaria. Sin embargo, no se puede decir lo mismo para las medidas de los sondeos y de los fotómetros solares. En el caso de los sondeos sólo hay dos datos al día (00 y 12 UTC), salvo para algunos pocos días en los que se dispone de alguno más a horas intermedias, o el caso contrario, cuando sólo se dispone de un dato porque algún sondeo resultó fallido, o en la estación de Lisboa que desde el año 2004 sólo se lanza el sondeo de las 12 UTC. En estos últimos casos el dato diario coincide con el del único sondeo disponible. No obstante, como se verá en el Capítulo 5, el efecto del ciclo diurno del PWV no introduce ningún sesgo significativo, al ser este de pequeña amplitud y estar bastante compensado entre las horas de los dos lanzamientos de los sondeos. En el caso de los 
fotómetros no se dispone del mismo número de medidas para todos los días sino que éstas varían en función de las condiciones meteorológicas. Los datos de los fotómetros pueden presentar un sesgo por dos motivos:

a) Porque los fotómetros sólo operan durante el día y no recogen el efecto del ciclo diurno del PWV. El PWV es mayor durante el día que durante la noche (ver Capítulo 5).

b) Porque los fotómetros sólo proporcionan medidas válidas en ausencia de nubosidad. En término medio el PWV es menor en condiciones de cielo despejado que con cielos nubosos (ver Capítulo 8).

También hay que tener en cuenta que se contabilizaron sólo aquellos sondeos que superaron en su ascensión los $9 \mathrm{Km}$ de altitud, excepto en las estaciones de Lisboa, Santander y Zaragoza donde se tuvo que bajar este límite a los $7 \mathrm{Km}$ como ya se ha explicado. Como se verá más adelante en este capítulo cuando se estudie la distribución vertical media del vapor de agua en la atmósfera, por encima de los $9 \mathrm{Km}$ de altitud la humedad absoluta es despreciable y la contribución media de la capa comprendida entre los 7 y $9 \mathrm{Km}$ es de 0.15 $\mathrm{Kgr} / \mathrm{m}^{3}$, lo que supone una contribución de unos $0.30 \mathrm{~mm}$ de PWV, aproximadamente un $2 \%$ del contenido total medio.

\subsection{Estadísticos por estación}

El procedimiento descrito en el punto anterior se ha repetido para cada estación, presentándose a continuación los resultados obtenidos en forma de tablas y gráficas de forma individualizada, donde todos los datos están expresados en milímetros de PWV.

Para cada estación se presentan los resultados organizados según los siguientes apartados:

a) Tabla con las estadísticas del conjunto global de todas las medidas para el período de estudio. Esta tabla contiene: el número total de medidas, la media aritmética, la mediana, la clase modal, la desviación típica, el valor máximo y mínimo de las medidas, los percentiles cinco y noventa y cinco, y los coeficiente de asimetría y curtosis de la distribución de las medidas.

b) Tabla con las estadísticas de las medidas por mes del año. Contiene los mismos estadísticos que se han nombrado en el apartado a) pero agrupados por mes del año.

c) Tabla con las estadísticas del conjunto global de las medias diarias de las medidas. Tabla equivalente a la del apartado a) pero con las medias diarias. 
d) Tabla con las estadísticas por mes del año de las medias diarias de las medidas. Tabla equivalente a la del apartado b) pero con las medias diarias.

e) Tablas con estadísticas por mes y año de las medias diarias. Se presentan cinco tablas con los siguientes contenidos: e1) media mensual, calculada como la media de las medias diarias; e2) valor máximo de la media diaria; e3) valor mínimo de la media diaria; e4) desviación estándar de las medias diarias; e5) número de días con dato válido. La última fila de las tablas anteriores representa el promedioa para todos los años de los valores mensuales para cada mes del año, y la última columna la media de todos los meses de cada año.

f) Tabla de estadísticos en base a las medias mensuales del PWV de los siete años. Para cada mes se presenta el promedio, la mediana, la desviación típica, el máximo, y el mínimo, de las siete medias mensuales disponibles, así como la media del número total de días con dato válido.

g) Gráfica de la evolución temporal del dato medio diario durante el periodo de estudio.

h) Histograma de frecuencias de la distribución de los datos medios diarios agrupados en intervalos de $2.5 \mathrm{~mm}$ de longitud.

i) Gráfica de las medias mensuales para cada uno de los años.

j) Gráfica del ciclo medio anual del PWV. Además del valor promedio mensual de los siete años, se representa también el valor promedio \pm la desviación típica de las medias mensuales, y el valor máximo y mínimo de las medias mensuales.

En la presentación de los resultados de cada estación, los contenidos de los apartados etiquetados con a), b), c)..., se corresponden con los descritos anteriormente para cada letra. 


\subsubsection{MADRID (aeropuerto de Barajas). Estación de radiosondeo.}

El análisis estadístico se ha realizado en base a los sondeos que han superado los $9000 \mathrm{~m}$ de altitud.

a) Estadísticas globales del conjunto de los sondeos de Madrid (Barajas):

\begin{tabular}{|c|c|c|c|c|c|c|c|c|c|c|}
\hline $\begin{array}{c}\mathbf{N}^{0} \\
\text { Sondeos }\end{array}$ & Media & STD & Mediana & $\begin{array}{c}\text { Clase } \\
\text { Modal }\end{array}$ & $\begin{array}{c}\text { Percentil } \\
\mathbf{5}\end{array}$ & $\begin{array}{c}\text { Percentil } \\
\mathbf{9 5}\end{array}$ & Máximo & Mínimo & $\begin{array}{c}\text { Coef. } \\
\text { Asimetría }\end{array}$ & Curtosis \\
\hline 4204 & 14.46 & 6.00 & 13.91 & $12.5-15$ & 5.46 & 25.16 & 35.19 & 0.90 & 0.39 & -0.18 \\
\hline
\end{tabular}

b) Estadísticas por mes del conjunto de los sondeos de Madrid (Barajas):

\begin{tabular}{|c|c|c|c|c|c|c|c|c|c|c|c|c|}
\hline Estadístico \ Mes & 1 & 2 & 3 & 4 & 5 & 6 & 7 & 8 & 9 & 10 & 11 & 12 \\
\hline Media & 9.81 & 9.92 & 10.56 & 12.06 & 15.25 & 18.63 & 17.61 & 18.30 & 18.49 & 16.96 & 12.43 & 10.47 \\
\hline STD & 4.29 & 4.35 & 4.17 & 3.96 & 4.95 & 4.96 & 4.94 & 4.75 & 6.14 & 5.94 & 5.00 & 4.45 \\
\hline Mediana & 9.26 & 9.25 & 10.82 & 12.02 & 14.91 & 18.68 & 17.11 & 18.29 & 18.15 & 16.03 & 12.08 & 10.02 \\
\hline Máximo & 22.47 & 22.80 & 22.22 & 26.55 & 30.59 & 32.34 & 33.11 & 34.42 & 35.19 & 34.69 & 30.03 & 24.46 \\
\hline Mínimo & 2.15 & 0.90 & 2.14 & 3.04 & 5.19 & 5.16 & 5.83 & 6.75 & 5.23 & 4.39 & 1.88 & 2.11 \\
\hline Percentil 5 & 3.50 & 3.96 & 3.32 & 6.05 & 7.54 & 10.93 & 10.76 & 10.67 & 8.90 & 8.89 & 5.13 & 3.54 \\
\hline Percentil 95 & 18.44 & 18.11 & 17.30 & 18.68 & 23.31 & 26.63 & 26.70 & 26.12 & 29.54 & 27.43 & 21.29 & 18.39 \\
\hline Coef. Asimetría & 0.61 & 0.51 & -0.04 & 0.24 & 0.32 & 0.06 & 0.55 & 0.17 & 0.26 & 0.46 & 0.53 & 0.45 \\
\hline Curtosis & 0.09 & -0.35 & -0.56 & -0.23 & -0.15 & -0.28 & 0.05 & 0.02 & -0.49 & -0.30 & 0.29 & -0.06 \\
\hline No Sondeos & 320 & 266 & 341 & 368 & 369 & 379 & 368 & 391 & 362 & 372 & 338 & 330 \\
\hline
\end{tabular}

c) Estadísticas globales de las medias diarias de los sondeos de Madrid (Barajas):

\begin{tabular}{|c|c|c|c|c|c|c|c|c|c|c|}
\hline $\mathrm{N}^{0}$ Días & Media & STD & Mediana & Moda & \begin{tabular}{|c|} 
Percentil \\
5 \\
\end{tabular} & \begin{tabular}{|c|} 
Percentil \\
95 \\
\end{tabular} & Máximo & Mínimo & \begin{tabular}{|c} 
Coef. \\
Asimetría
\end{tabular} & Curtosis \\
\hline 2300 & 14.45 & 5.75 & 14.05 & $12.5-15$ & 5.68 & 24.52 & 34.69 & 0.90 & 0.35 & -0.19 \\
\hline
\end{tabular}

d) Resumen por mes de las medias diarias de los sondeos de Madrid (Barajas):

\begin{tabular}{|c|c|c|c|c|c|c|c|c|c|c|c|c|}
\hline Estadístico \Mes & 1 & 2 & 3 & 4 & 5 & 6 & 7 & 8 & 9 & 10 & 11 & 12 \\
\hline Media & 9.78 & 9.93 & 10.61 & 12.04 & 15.19 & 18.68 & 17.73 & 18.33 & 18.37 & 17.13 & 12.58 & 10.46 \\
\hline STD & 4.01 & 4.15 & 3.87 & 3.70 & 4.64 & 4.56 & 4.56 & 4.46 & 5.64 & 5.75 & 4.78 & 4.12 \\
\hline Mediana & 9.26 & 9.22 & 10.90 & 12.11 & 15.04 & 18.61 & 17.24 & 18.44 & 18.30 & 16.23 & 12.00 & 10.18 \\
\hline Máximo & 21.23 & 19.58 & 20.60 & 26.55 & 29.65 & 32.34 & 33.11 & 32.27 & 32.90 & 34.69 & 30.03 & 22.31 \\
\hline Mínimo & 2.15 & 0.90 & 2.24 & 3.78 & 5.84 & 5.82 & 9.36 & 7.20 & 5.86 & 4.92 & 2.30 & 2.14 \\
\hline Percentil 5 & 3.67 & 4.22 & 4.06 & 6.45 & 8.13 & 12.08 & 11.73 & 11.01 & 9.46 & 8.92 & 5.99 & 3.42 \\
\hline Percentil 95 & 16.95 & 17.96 & 15.77 & 17.79 & 22.87 & 25.75 & 26.13 & 25.83 & 27.68 & 26.59 & 20.37 & 17.12 \\
\hline Coef. Asimetría & 0.49 & 0.42 & -0.22 & 0.17 & 0.39 & -0.03 & 0.64 & 0.10 & 0.15 & 0.48 & 0.52 & 0.31 \\
\hline Curtosis & -0.15 & -0.54 & -0.57 & 0.09 & -0.02 & -0.09 & 0.13 & 0.03 & -0.56 & -0.21 & 0.54 & -0.15 \\
\hline No Días & 178 & 152 & 190 & 204 & 200 & 203 & 205 & 208 & 195 & 202 & 184 & 179 \\
\hline
\end{tabular}

e1) Media de las medias diarias por mes y año de los sondeos de Madrid (Barajas):

\begin{tabular}{|c|c|c|c|c|c|c|c|c|c|c|c|c|c|}
\hline Año \Mes & 1 & 2 & 3 & 4 & 5 & 6 & 7 & 8 & 9 & 10 & 11 & 12 & Media \\
\hline 2002 & 10.72 & 9.16 & 10.71 & 10.73 & 13.18 & 17.15 & 17.93 & 17.63 & 17.76 & 16.07 & 14.24 & -- & 14.12 \\
\hline 2003 & --- & --- & 11.77 & 12.77 & 14.41 & 19.25 & 15.78 & 19.63 & 17.07 & 16.88 & 14.06 & 10.96 & 15.26 \\
\hline 2004 & 10.51 & 9.46 & 11.69 & 10.81 & 15.36 & 18.39 & 17.55 & 18.78 & 17.30 & 15.60 & 10.19 & 10.79 & 13.87 \\
\hline 2005 & 6.18 & 6.93 & 9.50 & 10.77 & 13.31 & 19.77 & 17.55 & 17.46 & 16.78 & 17.20 & 13.01 & 10.21 & 13.22 \\
\hline 2006 & 9.30 & 8.28 & 11.43 & 12.87 & 15.75 & 19.08 & 20.27 & 16.63 & 20.88 & 20.93 & 17.03 & 10.58 & 15.25 \\
\hline 2007 & 10.68 & 13.18 & 9.75 & 14.40 & 16.85 & 17.76 & 17.19 & 19.63 & 20.16 & 16.17 & 8.59 & 9.28 & 14.47 \\
\hline 2008 & 11.53 & 12.08 & 9.95 & 12.12 & 17.27 & 19.39 & 17.95 & 18.73 & 18.78 & 17.82 & 10.36 & 10.15 & 14.68 \\
\hline Media & 9.82 & 9.85 & 10.68 & 12.07 & 15.16 & 18.69 & 17.75 & 18.35 & 18.39 & 17.24 & 12.50 & 10.33 & 14.41 \\
\hline
\end{tabular}


e2) Máximo de las medias diarias por mes y año de los sondeos de Madrid (Barajas):

\begin{tabular}{|c|c|c|c|c|c|c|c|c|c|c|c|c|c|}
\hline Año \Mes & $\mathbf{1}$ & $\mathbf{2}$ & $\mathbf{3}$ & $\mathbf{4}$ & $\mathbf{5}$ & $\mathbf{6}$ & $\mathbf{7}$ & $\mathbf{8}$ & $\mathbf{9}$ & $\mathbf{1 0}$ & $\mathbf{1 1}$ & $\mathbf{1 2}$ & Media \\
\hline $\mathbf{2 0 0 2}$ & 21.23 & 14.82 & 15.35 & 15.88 & 19.56 & 22.98 & 25.83 & 25.01 & 29.12 & 27.66 & 30.03 & --- & $\mathbf{2 2 . 5 0}$ \\
$\mathbf{2 0 0 3}$ & -- & --- & 19.98 & 18.45 & 20.45 & 24.74 & 22.17 & 25.73 & 23.98 & 29.75 & 21.29 & 16.04 & $\mathbf{2 2 . 2 6}$ \\
$\mathbf{2 0 0 4}$ & 18.44 & 18.11 & 17.06 & 16.64 & 22.35 & 26.72 & 26.73 & 25.88 & 30.76 & 31.61 & 20.28 & 16.09 & $\mathbf{2 2 . 5 6}$ \\
$\mathbf{2 0 0 5}$ & 14.33 & 13.22 & 17.76 & 18.02 & 29.65 & 28.90 & 33.11 & 29.41 & 27.22 & 29.31 & 20.20 & 20.10 & $\mathbf{2 3 . 4 4}$ \\
$\mathbf{2 0 0 6}$ & 13.97 & 14.24 & 20.60 & 19.15 & 23.77 & 26.27 & 30.18 & 27.27 & 31.25 & 34.69 & 25.11 & 22.31 & $\mathbf{2 4 . 0 7}$ \\
$\mathbf{2 0 0 7}$ & 18.46 & 19.58 & 15.24 & 19.26 & 28.60 & 29.04 & 26.19 & 32.27 & 29.40 & 33.35 & 20.82 & 14.38 & $\mathbf{2 3 . 8 8}$ \\
$\mathbf{2 0 0 8}$ & 19.37 & 19.46 & 14.84 & 26.55 & 23.65 & 32.34 & 29.31 & 28.11 & 32.90 & 26.58 & 15.06 & 20.76 & $\mathbf{2 4 . 0 8}$ \\
\hline Media & $\mathbf{1 7 . 6 3}$ & $\mathbf{1 6 . 5 7}$ & $\mathbf{1 7 . 2 6}$ & $\mathbf{1 9 . 1 4}$ & $\mathbf{2 4 . 0 0}$ & $\mathbf{2 7 . 2 8}$ & $\mathbf{2 7 . 6 5}$ & $\mathbf{2 7 . 6 7}$ & $\mathbf{2 9 . 2 3}$ & $\mathbf{3 0 . 4 2}$ & $\mathbf{2 1 . 8 3}$ & $\mathbf{1 8 . 2 8}$ & $\mathbf{2 3 . 2 5}$ \\
\hline
\end{tabular}

e3) Mínimo de las medias diarias por mes y año de los sondeos de Madrid (Barajas):

\begin{tabular}{|c|l|l|l|l|l|r|r|r|r|r|r|c|c|}
\hline Año \Mes & $\mathbf{1}$ & $\mathbf{2}$ & $\mathbf{3}$ & $\mathbf{4}$ & $\mathbf{5}$ & \multicolumn{1}{|c|}{$\mathbf{6}$} & \multicolumn{1}{|c|}{$\mathbf{1}$} & \multicolumn{1}{|c}{$\mathbf{8}$} & $\mathbf{9}$ & \multicolumn{1}{|c}{$\mathbf{1 0}$} & $\mathbf{1 1}$ & $\mathbf{1 2}$ & Media \\
\hline $\mathbf{2 0 0 2}$ & 7.16 & 3.97 & 5.32 & 6.59 & 6.50 & 12.47 & 10.60 & 12.38 & 7.71 & 8.90 & 8.47 & --- & $\mathbf{8 . 1 9}$ \\
$\mathbf{2 0 0 3}$ & -- & --- & 5.24 & 4.23 & 7.32 & 12.62 & 9.72 & 12.66 & 8.89 & 6.62 & 7.58 & 7.00 & $\mathbf{8 . 1 9}$ \\
$\mathbf{2 0 0 4}$ & 3.16 & 2.69 & 2.50 & 5.97 & 6.93 & 5.82 & 10.19 & 10.14 & 8.02 & 8.30 & 3.48 & 4.54 & $\mathbf{5 . 9 8}$ \\
$\mathbf{2 0 0 5}$ & 2.15 & 0.90 & 2.24 & 4.90 & 5.84 & 11.32 & 9.36 & 7.20 & 5.86 & 4.92 & 6.23 & 2.69 & $\mathbf{5 . 3 0}$ \\
$\mathbf{2 0 0 6}$ & 3.63 & 3.04 & 2.76 & 5.98 & 6.50 & 7.96 & 14.37 & 7.78 & 12.53 & 11.83 & 6.61 & 3.38 & $\mathbf{7 . 2 0}$ \\
$\mathbf{2 0 0 7}$ & 4.44 & 4.96 & 3.42 & 6.58 & 9.84 & 9.26 & 11.04 & 12.60 & 10.46 & 7.10 & 2.30 & 2.14 & $\mathbf{7 . 0 1}$ \\
$\mathbf{2 0 0 8}$ & 6.26 & 4.62 & 4.27 & 3.78 & 6.98 & 12.34 & 11.72 & 7.98 & 10.79 & 8.89 & 5.68 & 2.37 & $\mathbf{7 . 1 4}$ \\
\hline Media & $\mathbf{4 . 4 7}$ & $\mathbf{3 . 3 6}$ & $\mathbf{3 . 6 8}$ & $\mathbf{5 . 4 3}$ & $\mathbf{7 . 1 3}$ & $\mathbf{1 0 . 2 6}$ & $\mathbf{1 1 . 0 0}$ & $\mathbf{1 0 . 1 1}$ & $\mathbf{9 . 1 8}$ & $\mathbf{8 . 0 8}$ & $\mathbf{5 . 7 6}$ & $\mathbf{3 . 6 9}$ & $\mathbf{7 . 0 0}$ \\
\hline
\end{tabular}

e4) Desviación estándar de las medias diarias de cada mes y año de los sondeos de Madrid:

\begin{tabular}{|c|l|l|l|l|l|l|l|l|l|l|l|l|l|}
\hline Año \Mes & $\mathbf{1}$ & $\mathbf{2}$ & $\mathbf{3}$ & $\mathbf{4}$ & $\mathbf{5}$ & $\mathbf{6}$ & $\mathbf{7}$ & $\mathbf{8}$ & $\mathbf{9}$ & $\mathbf{1 0}$ & $\mathbf{1 1}$ & $\mathbf{1 2}$ & Media \\
\hline $\mathbf{2 0 0 2}$ & 4.02 & 2.98 & 2.71 & 2.06 & 3.25 & 2.79 & 3.59 & 2.94 & 5.55 & 4.54 & 3.86 & --- & $\mathbf{3 . 4 8}$ \\
$\mathbf{2 0 0 3}$ & -- & --- & 4.12 & 4.24 & 3.66 & 3.36 & 3.30 & 3.22 & 4.82 & 5.25 & 3.40 & 2.78 & $\mathbf{3 . 8 1}$ \\
$\mathbf{2 0 0 4}$ & 4.51 & 4.07 & 3.79 & 3.07 & 4.18 & 4.86 & 4.26 & 4.19 & 5.71 & 4.76 & 4.38 & 3.02 & $\mathbf{4 . 2 3}$ \\
$\mathbf{2 0 0 5}$ & 2.86 & 2.72 & 4.78 & 3.70 & 5.49 & 5.34 & 5.29 & 5.82 & 5.17 & 6.53 & 4.20 & 4.59 & $\mathbf{4 . 7 1}$ \\
$\mathbf{2 0 0 6}$ & 2.86 & 2.88 & 4.39 & 3.30 & 5.23 & 5.54 & 4.87 & 4.13 & 5.56 & 4.70 & 5.14 & 4.64 & $\mathbf{4 . 4 4}$ \\
$\mathbf{2 0 0 7}$ & 3.48 & 3.61 & 3.11 & 2.76 & 5.16 & 4.65 & 4.40 & 4.62 & 5.39 & 6.39 & 3.60 & 3.72 & $\mathbf{4 . 2 4}$ \\
$\mathbf{2 0 0 8}$ & 3.51 & 4.31 & 3.17 & 4.51 & 3.47 & 4.15 & 4.74 & 4.73 & 5.79 & 6.09 & 2.77 & 5.03 & $\mathbf{4 . 3 6}$ \\
\hline Media & $\mathbf{3 . 5 4}$ & $\mathbf{3 . 4 3}$ & $\mathbf{3 . 7 3}$ & $\mathbf{3 . 3 8}$ & $\mathbf{4 . 3 5}$ & $\mathbf{4 . 3 8}$ & $\mathbf{4 . 3 5}$ & $\mathbf{4 . 2 3}$ & $\mathbf{5 . 4 3}$ & $\mathbf{5 . 4 7}$ & $\mathbf{3 . 9 1}$ & $\mathbf{3 . 9 6}$ & $\mathbf{4 . 1 8}$ \\
\hline
\end{tabular}

e5) Número de días con dato válido por mes y año de los sondeos de Madrid (Barajas):

\begin{tabular}{|c|c|c|c|c|c|c|c|c|c|c|c|c|c|}
\hline Año \Mes & 1 & 2 & 3 & 4 & 5 & 6 & 7 & 8 & 9 & 10 & 11 & 12 & Tota \\
\hline 2002 & 29 & 21 & 29 & 30 & 31 & 30 & 30 & 31 & 30 & 29 & 29 & 9 & 328 \\
\hline 2003 & 0 & 0 & 17 & 29 & 26 & 29 & 31 & 31 & 28 & 31 & 30 & 29 & 281 \\
\hline 2004 & 31 & 28 & 29 & 30 & 31 & 30 & 30 & 24 & 30 & 30 & 17 & 29 & 339 \\
\hline 2005 & 31 & 27 & 29 & 30 & 26 & 27 & 29 & 31 & 24 & 27 & 22 & 25 & 328 \\
\hline 2006 & 30 & 22 & 28 & 26 & 26 & 30 & 30 & 31 & 25 & 24 & 27 & 25 & 324 \\
\hline 2007 & 27 & 27 & 27 & 29 & 29 & 27 & 30 & 30 & 28 & 31 & 29 & 31 & 345 \\
\hline 2008 & 30 & 27 & 31 & 30 & 31 & 30 & 25 & 30 & 30 & 30 & 30 & 31 & 355 \\
\hline Total & 178 & 152 & 190 & 204 & 200 & 203 & 205 & 208 & 195 & 202 & 184 & 170 & 2291 \\
\hline
\end{tabular}

f) Resumen por mes de las medias mensuales de cada año de los sondeos de Madrid:

\begin{tabular}{|c|c|c|c|c|c|c|c|c|c|c|c|c|}
\hline Mes & 1 & 2 & 3 & 4 & 5 & 6 & 7 & 8 & 9 & 10 & 11 & 12 \\
\hline Media & 9.82 & 9.85 & 10.68 & 12.07 & 15.16 & 18.69 & 17.75 & 18.35 & 18.39 & 17.24 & 12.50 & 10.33 \\
\hline STD & 1.76 & 2.15 & 0.89 & 1.29 & 1.49 & 0.88 & 1.24 & 1.06 & 1.49 & 1.66 & 2.71 & 0.55 \\
\hline Mediana & 10.59 & 9.31 & 10.71 & 12.12 & 15.36 & 19.08 & 17.55 & 18.73 & 17.76 & 16.88 & 13.01 & 10.39 \\
\hline Máximo & 11.53 & 13.18 & 11.77 & 14.40 & 17.27 & 19.77 & 20.27 & 19.63 & 20.88 & 20.93 & 17.03 & 10.96 \\
\hline Mínimo & 6.18 & 6.93 & 9.50 & 10.73 & 13.18 & 17.15 & 15.78 & 16.63 & 16.78 & 15.60 & 8.59 & 9.28 \\
\hline $\mathrm{N}^{0}$ Días & 178 & 152 & 190 & 204 & 200 & 203 & 205 & 208 & 195 & 202 & 184 & 170 \\
\hline
\end{tabular}




\section{Gráficas de la estación de Madrid (Barajas)}

g) Evolución temporal de las medias diarias.

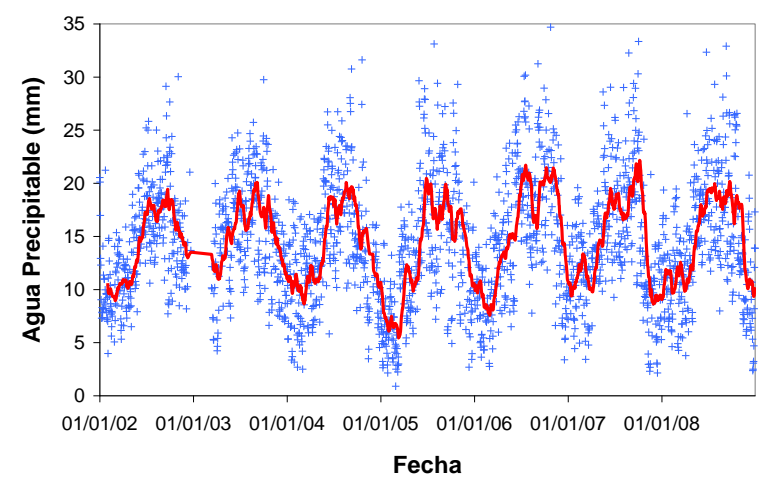

La línea roja representa la media móvil mensual.

i) Valores medios mensuales de las medias diarias para cada mes y año.

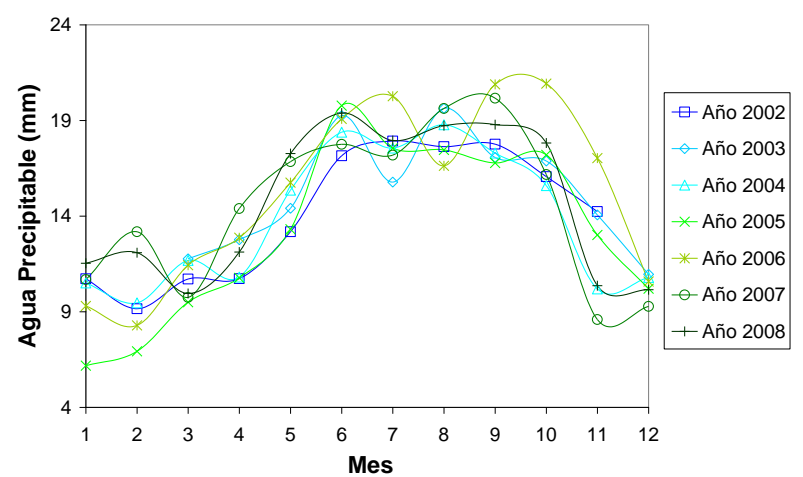

h) Histograma de las medias diarias.

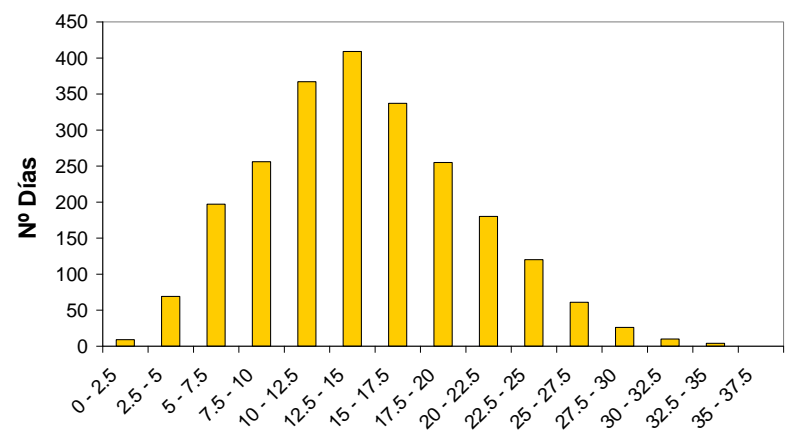

Agua Precipitable $(\mathrm{mm})$

La distribución presenta un desplazamiento hacia la derecha (coef. de asimetría positivo), y un ligero achatamiento (curtosis negativa) respecto de la distribución normal.

j) Ciclo promedio anual.

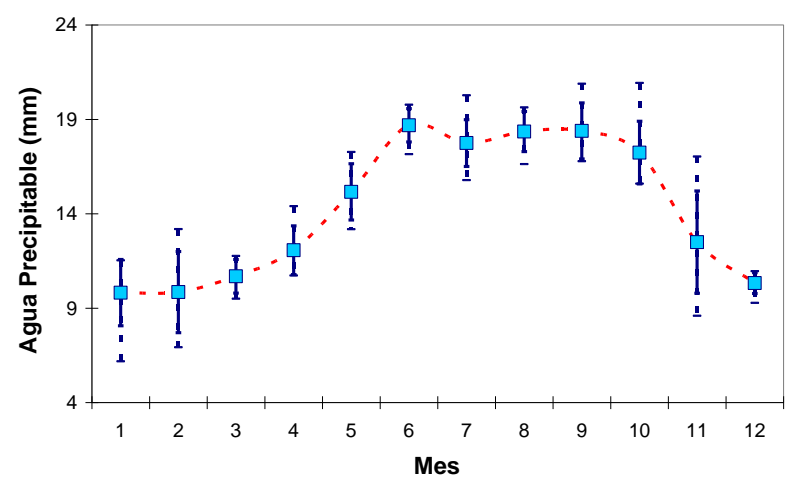

Valor promedio de las medias mensuales de cada año (cuadrados). Valor promedio más/menos la desviación típica de las medias mensuales (barras sólidas). Valor máximo y mínimo absoluto de las medias mensuales (líneas de trazos). 


\subsubsection{CORUÑA (aeropuerto). Estación de radiosondeo.}

El análisis estadístico se ha realizado en base a los sondeos que han superado los $9000 \mathrm{~m}$ de altitud.

a) Estadísticas globales del conjunto de los sondeos de Coruña:

\begin{tabular}{|c|c|c|c|c|c|c|c|c|c|c|}
\hline $\begin{array}{c}\mathbf{N}^{0} \\
\text { Sondeos }\end{array}$ & Media & STD & Mediana & $\begin{array}{c}\text { Clase } \\
\text { Modal }\end{array}$ & $\begin{array}{c}\text { Percentil } \\
\mathbf{5}\end{array}$ & $\begin{array}{c}\text { Percentil } \\
\mathbf{9 5}\end{array}$ & Máximo & Mínimo & $\begin{array}{c}\text { Coef. } \\
\text { Asimetría }\end{array}$ & Curtosis \\
\hline 4265 & 18.65 & 7.07 & 17.97 & $17.5-20$ & 8.21 & 31.20 & 45.79 & 2.72 & 0.43 & -0.12 \\
\hline
\end{tabular}

b) Estadísticas por mes del conjunto de los sondeos de Coruña:

\begin{tabular}{|c|c|c|c|c|c|c|c|c|c|c|c|c|}
\hline Estadístico \ Mes & 1 & 2 & 3 & 4 & 5 & 6 & 7 & 8 & 9 & 10 & 11 & 12 \\
\hline Media & 15.00 & 12.88 & 14.80 & 14.89 & 18.31 & 22.35 & 24.19 & 24.26 & 22.47 & 21.46 & 17.30 & 15.08 \\
\hline STD & 5.66 & 5.23 & 5.69 & 4.40 & 4.97 & 6.04 & 6.11 & 6.09 & 6.47 & 6.85 & 6.04 & 6.28 \\
\hline Mediana & 14.02 & 11.91 & 14.69 & 14.54 & 17.56 & 22.54 & 23.32 & 23.23 & 22.14 & 21.37 & 16.54 & 14.11 \\
\hline Máximo & 41.29 & 28.94 & 31.97 & 28.65 & 34.56 & 37.59 & 44.94 & 45.79 & 39.56 & 40.85 & 36.57 & 33.96 \\
\hline Mínimo & 4.09 & 4.15 & 2.74 & 4.08 & 7.70 & 5.20 & 8.44 & 11.60 & 8.70 & 8.21 & 3.37 & 2.72 \\
\hline Percentil 5 & 7.44 & 6.36 & 5.73 & 8.37 & 11.40 & 12.86 & 16.11 & 16.26 & 12.39 & 10.66 & 9.04 & 5.43 \\
\hline Percentil 95 & 26.08 & 23.24 & 24.94 & 22.30 & 27.77 & 31.95 & 35.71 & 35.20 & 33.06 & 33.26 & 29.13 & 26.23 \\
\hline Coef. Asimetría & 0.81 & 0.89 & 0.27 & 0.29 & 0.56 & 0.04 & 0.60 & 0.68 & 0.27 & 0.26 & 0.64 & 0.49 \\
\hline Curtosis & 0.88 & 0.37 & -0.18 & -0.26 & 0.01 & -0.51 & 0.09 & 0.34 & -0.59 & -0.53 & 0.14 & -0.03 \\
\hline $\mathrm{N}^{0}$ Sondeos & 355 & 320 & 363 & 350 & 374 & 346 & 360 & 379 & 354 & 354 & 341 & 369 \\
\hline
\end{tabular}

c) Estadísticas globales de las medias diarias de los sondeos de Coruña:

\begin{tabular}{|c|c|c|c|c|c|c|c|c|c|c|}
\hline N$^{\circ}$ Días & Media & STD & Mediana & Moda & $\begin{array}{c}\text { Percentil } \\
\mathbf{5}\end{array}$ & $\begin{array}{c}\text { Percentil } \\
\mathbf{9 5}\end{array}$ & Máximo & Mínimo & $\begin{array}{c}\text { Coef. } \\
\text { Asimetría }\end{array}$ & Curtosis \\
\hline 2367 & 18.50 & 6.65 & 17.99 & $15-17.5$ & 8.35 & 30.27 & 41.29 & 2.72 & 0.30 & -0.29 \\
\hline
\end{tabular}

d) Resumen por mes de las medias diarias de los sondeos de Coruña:

\begin{tabular}{|c|c|c|c|c|c|c|c|c|c|c|c|c|}
\hline Estadístico \Mes & 1 & 2 & 3 & 4 & 5 & 6 & 7 & 8 & 9 & 10 & 11 & 12 \\
\hline Media & 15.00 & 12.89 & 14.50 & 14.72 & 18.22 & 22.04 & 23.89 & 23.94 & 22.40 & 21.36 & 17.15 & 15.11 \\
\hline STD & 5.45 & 4.97 & 5.42 & 4.10 & 4.44 & 5.65 & 5.40 & 5.44 & 5.88 & 6.20 & 5.52 & 5.82 \\
\hline Mediana & 14.33 & 12.04 & 14.49 & 14.53 & 17.73 & 22.46 & 23.18 & 23.28 & 21.89 & 21.90 & 16.34 & 14.74 \\
\hline Máximo & 41.29 & 27.26 & 29.72 & 25.47 & 31.48 & 35.29 & 38.26 & 39.65 & 35.92 & 36.76 & 34.34 & 32.84 \\
\hline Mínimo & 4.09 & 4.15 & 2.74 & 5.14 & 7.70 & 8.78 & 13.00 & 11.71 & 11.24 & 8.21 & 3.90 & 2.72 \\
\hline Percentil 5 & 7.53 & 6.62 & 5.27 & 8.17 & 11.66 & 12.29 & 16.32 & 15.69 & 13.00 & 12.02 & 9.48 & 5.91 \\
\hline Percentil 95 & 24.12 & 22.44 & 23.11 & 21.30 & 26.33 & 31.05 & 33.85 & 33.77 & 31.93 & 31.74 & 27.12 & 25.65 \\
\hline Coef. Asimetría & 0.94 & 0.81 & 0.08 & 0.09 & 0.34 & 0.02 & 0.51 & 0.38 & 0.16 & 0.07 & 0.56 & 0.36 \\
\hline Curtosis & 2.01 & 0.25 & -0.36 & -0.43 & -0.11 & -0.47 & -0.24 & -0.41 & -0.81 & -0.59 & 0.17 & 0.03 \\
\hline $\mathrm{N}^{0}$ Días & 200 & 179 & 203 & 192 & 202 & 199 & 197 & 211 & 196 & 196 & 189 & 203 \\
\hline
\end{tabular}

e1) Media de las medias diarias por mes y año de los sondeos de Coruña:

\begin{tabular}{|c|c|c|c|c|c|c|c|c|c|c|c|c|c|}
\hline Año \Mes & $\mathbf{1}$ & $\mathbf{2}$ & $\mathbf{3}$ & $\mathbf{4}$ & $\mathbf{5}$ & $\mathbf{6}$ & $\mathbf{7}$ & $\mathbf{8}$ & $\mathbf{9}$ & $\mathbf{1 0}$ & $\mathbf{1 1}$ & $\mathbf{1 2}$ & Media \\
\hline $\mathbf{2 0 0 2}$ & 15.67 & 14.24 & 12.39 & 12.70 & 17.69 & 20.20 & 23.59 & 23.41 & 24.08 & 22.58 & 18.21 & 17.77 & $\mathbf{1 8 . 5 4}$ \\
$\mathbf{2 0 0 3}$ & 14.01 & 13.59 & 14.60 & 16.00 & 17.70 & 23.18 & 23.62 & 26.18 & 22.66 & 19.80 & 18.89 & 16.94 & $\mathbf{1 8 . 9 3}$ \\
$\mathbf{2 0 0 4}$ & 17.38 & 10.24 & 14.29 & 13.05 & 17.70 & 22.27 & 23.75 & 24.25 & 23.29 & 20.90 & 14.07 & 13.65 & $\mathbf{1 7 . 9 0}$ \\
$\mathbf{2 0 0 5}$ & 14.12 & 10.06 & 13.56 & 15.90 & 16.67 & 22.48 & 23.01 & 22.67 & 21.02 & 22.66 & 17.18 & 14.08 & $\mathbf{1 7 . 7 8}$ \\
$\mathbf{2 0 0 6}$ & 11.97 & 10.13 & 16.91 & 14.76 & 16.95 & 22.58 & 25.60 & 22.93 & 24.18 & 25.26 & 21.60 & 15.61 & $\mathbf{1 9 . 0 4}$ \\
$\mathbf{2 0 0 7}$ & 15.50 & 16.04 & 14.80 & 15.86 & 20.14 & 22.12 & 23.73 & 23.77 & 18.96 & 18.99 & 12.72 & 13.93 & $\mathbf{1 8 . 0 5}$ \\
$\mathbf{2 0 0 8}$ & 16.41 & 15.70 & 14.93 & 15.11 & 20.27 & 21.35 & 23.87 & 24.40 & 22.74 & 20.14 & 16.49 & 13.84 & $\mathbf{1 8 . 7 7}$ \\
\hline Media & $\mathbf{1 5 . 0 1}$ & $\mathbf{1 2 . 8 6}$ & $\mathbf{1 4 . 5 0}$ & $\mathbf{1 4 . 7 7}$ & $\mathbf{1 8 . 1 6}$ & $\mathbf{2 2 . 0 2}$ & $\mathbf{2 3 . 8 8}$ & $\mathbf{2 3 . 9 4}$ & $\mathbf{2 2 . 4 2}$ & $\mathbf{2 1 . 4 7}$ & $\mathbf{1 7 . 0 2}$ & $\mathbf{1 5 . 1 2}$ & $\mathbf{1 8 . 4 3}$ \\
\hline
\end{tabular}


e2) Máximo de las medias diarias por mes y año de los sondeos de Coruña:

\begin{tabular}{|c|c|c|c|c|c|c|c|c|c|c|c|c|c|}
\hline Año \Mes & $\mathbf{1}$ & $\mathbf{2}$ & $\mathbf{3}$ & $\mathbf{4}$ & $\mathbf{5}$ & $\mathbf{6}$ & $\mathbf{7}$ & $\mathbf{8}$ & $\mathbf{9}$ & $\mathbf{1 0}$ & $\mathbf{1 1}$ & $\mathbf{1 2}$ & Media \\
\hline $\mathbf{2 0 0 2}$ & 22.85 & 27.17 & 23.51 & 20.23 & 25.55 & 29.06 & 36.82 & 31.37 & 32.83 & 31.58 & 33.44 & 32.84 & $\mathbf{2 8 . 9 4}$ \\
$\mathbf{2 0 0 3}$ & 29.00 & 22.06 & 23.17 & 25.47 & 29.01 & 35.02 & 35.78 & 35.13 & 32.74 & 30.11 & 30.96 & 31.81 & $\mathbf{3 0 . 0 2}$ \\
$\mathbf{2 0 0 4}$ & 41.29 & 19.17 & 22.56 & 24.42 & 28.77 & 35.29 & 31.64 & 33.80 & 33.07 & 31.38 & 22.48 & 21.98 & $\mathbf{2 8 . 8 2}$ \\
$\mathbf{2 0 0 5}$ & 26.10 & 16.20 & 26.64 & 21.46 & 22.35 & 34.61 & 38.26 & 39.65 & 35.28 & 33.76 & 34.34 & 25.93 & $\mathbf{2 9 . 5 5}$ \\
$\mathbf{2 0 0 6}$ & 22.36 & 22.40 & 28.75 & 22.22 & 26.18 & 34.56 & 38.00 & 34.42 & 33.02 & 36.76 & 29.24 & 29.65 & $\mathbf{2 9 . 8 0}$ \\
$\mathbf{2 0 0 7}$ & 23.26 & 27.26 & 29.72 & 22.95 & 31.48 & 29.66 & 37.02 & 36.03 & 29.22 & 34.16 & 21.08 & 24.71 & $\mathbf{2 8 . 8 8}$ \\
$\mathbf{2 0 0 8}$ & 28.84 & 27.00 & 24.07 & 23.84 & 27.74 & 32.72 & 35.01 & 35.99 & 35.92 & 33.27 & 28.54 & 28.52 & $\mathbf{3 0 . 1 2}$ \\
\hline Media & $\mathbf{2 7 . 6 7}$ & $\mathbf{2 3 . 0 4}$ & $\mathbf{2 5 . 4 9}$ & $\mathbf{2 2 . 9 4}$ & $\mathbf{2 7 . 3 0}$ & $\mathbf{3 2 . 9 9}$ & $\mathbf{3 6 . 0 8}$ & $\mathbf{3 5 . 2 0}$ & $\mathbf{3 3 . 1 5}$ & $\mathbf{3 3 . 0 0}$ & $\mathbf{2 8 . 5 8}$ & $\mathbf{2 7 . 9 2}$ & $\mathbf{2 9 . 4 5}$ \\
\hline
\end{tabular}

e3) Mínimo de las medias diarias por mes y año de los sondeos de Coruña:

\begin{tabular}{|c|c|c|c|c|c|c|c|c|c|c|c|c|c|}
\hline Año \Mes & 1 & 2 & 3 & 4 & 5 & 6 & 7 & 8 & 9 & 10 & 11 & 12 & Media \\
\hline 2002 & 9.12 & 6.04 & 6.70 & 6.22 & 11.33 & 9.93 & 15.69 & 11.71 & 11.24 & 11.32 & 11.90 & 9.30 & 10.04 \\
\hline 2003 & 6.37 & 4.82 & 3.83 & 6.72 & 9.82 & 12.26 & 14.60 & 19.84 & 14.70 & 12.41 & 10.24 & 11.02 & 10.55 \\
\hline 2004 & 4.09 & 4.15 & 2.74 & 8.62 & 7.70 & 11.23 & 15.30 & 14.33 & 11.28 & 8.21 & 8.16 & 7.42 & 8.60 \\
\hline 2005 & 5.72 & 6.78 & 4.25 & 7.82 & 10.18 & 12.29 & 13.00 & 15.21 & 11.88 & 8.40 & 9.53 & 2.72 & 8.98 \\
\hline 2006 & 6.57 & 5.20 & 8.57 & 5.48 & 9.12 & 10.35 & 16.80 & 13.92 & 16.43 & 12.32 & 10.66 & 5.62 & 10.09 \\
\hline 2007 & 7.53 & 10.09 & 3.41 & 10.86 & 10.08 & 14.04 & 17.05 & 14.35 & 12.18 & 9.35 & 3.90 & 3.22 & 9.67 \\
\hline 2008 & 10.12 & 7.98 & 4.67 & 5.14 & 13.26 & 8.78 & 15.82 & 15.70 & 11.41 & 11.44 & 9.90 & 4.30 & 9.88 \\
\hline Media & 7.07 & 6.44 & 4.88 & 7.27 & 10.21 & 11.27 & 15.47 & 15.01 & 12.73 & 10.49 & 9.18 & 6.23 & 9.69 \\
\hline
\end{tabular}

e4) Desviación estándar de las medias diarias de cada mes y año de los sondeos de Coruña:

\begin{tabular}{|c|l|l|l|l|l|l|l|l|l|l|l|l|c|}
\hline Año IMes & $\mathbf{1}$ & $\mathbf{2}$ & $\mathbf{3}$ & $\mathbf{4}$ & $\mathbf{5}$ & $\mathbf{6}$ & $\mathbf{7}$ & $\mathbf{8}$ & $\mathbf{9}$ & $\mathbf{1 0}$ & $\mathbf{1 1}$ & $\mathbf{1 2}$ & Media \\
\hline $\mathbf{2 0 0 2}$ & 3.55 & 4.82 & 4.20 & 2.83 & 3.71 & 4.70 & 5.33 & 5.08 & 6.39 & 5.18 & 5.42 & 5.35 & $\mathbf{4 . 7 1}$ \\
$\mathbf{2 0 0 3}$ & 5.20 & 4.49 & 5.42 & 5.06 & 5.12 & 4.60 & 5.38 & 3.45 & 5.10 & 4.11 & 4.72 & 4.78 & $\mathbf{4 . 7 9}$ \\
$\mathbf{2 0 0 4}$ & 8.19 & 3.40 & 5.24 & 3.66 & 4.81 & 6.60 & 4.11 & 5.54 & 6.05 & 5.92 & 3.89 & 3.63 & $\mathbf{5 . 0 9}$ \\
$\mathbf{2 0 0 5}$ & 5.22 & 2.29 & 6.63 & 4.24 & 3.29 & 5.75 & 6.36 & 5.82 & 5.27 & 6.38 & 5.03 & 6.10 & $\mathbf{5 . 2 0}$ \\
$\mathbf{2 0 0 6}$ & 3.43 & 3.64 & 4.54 & 3.33 & 4.19 & 6.95 & 5.02 & 5.25 & 4.48 & 6.48 & 5.60 & 6.83 & $\mathbf{4 . 9 8}$ \\
$\mathbf{2 0 0 7}$ & 4.64 & 4.44 & 5.83 & 3.18 & 4.65 & 4.20 & 5.46 & 6.19 & 4.16 & 6.56 & 4.22 & 5.93 & $\mathbf{4 . 9 5}$ \\
$\mathbf{2 0 0 8}$ & 4.57 & 5.94 & 4.69 & 4.70 & 3.33 & 5.78 & 5.49 & 5.54 & 7.17 & 6.12 & 3.99 & 6.26 & $\mathbf{5 . 3 0}$ \\
\hline Media & $\mathbf{4 . 9 7}$ & $\mathbf{4 . 1 5}$ & $\mathbf{5 . 2 2}$ & $\mathbf{3 . 8 5}$ & $\mathbf{4 . 1 6}$ & $\mathbf{5 . 5 1}$ & $\mathbf{5 . 3 1}$ & $\mathbf{5 . 2 7}$ & $\mathbf{5 . 5 2}$ & $\mathbf{5 . 8 2}$ & $\mathbf{4 . 7 0}$ & $\mathbf{5 . 5 6}$ & $\mathbf{5 . 0 0}$ \\
\hline
\end{tabular}

e5) Número de días con dato válido por mes y año de los sondeos de Coruña:

\begin{tabular}{|c|c|c|c|c|c|c|c|c|c|c|c|c|c|}
\hline Año \Mes & 1 & 2 & 3 & 4 & 5 & 6 & 7 & 8 & 9 & 10 & 11 & 12 & Total \\
\hline 2002 & 28 & 24 & 30 & 28 & 31 & 27 & 30 & 30 & 28 & 29 & 29 & 31 & 345 \\
\hline 2003 & 28 & 26 & 31 & 26 & 31 & 29 & 26 & 30 & 27 & 27 & 26 & 29 & 336 \\
\hline 2004 & 29 & 28 & 28 & 28 & 29 & 25 & 29 & 30 & 27 & 27 & 19 & 31 & 330 \\
\hline 2005 & 28 & 22 & 27 & 21 & 26 & 29 & 30 & 30 & 29 & 28 & 28 & 29 & 327 \\
\hline 2006 & 30 & 26 & 29 & 30 & 25 & 29 & 30 & 30 & 27 & 24 & 29 & 24 & 333 \\
\hline 2007 & 28 & 26 & 30 & 29 & 30 & 30 & 22 & 31 & 28 & 31 & 29 & 28 & 342 \\
\hline 2008 & 29 & 27 & 28 & 30 & 30 & 30 & 30 & 30 & 30 & 30 & 29 & 31 & 354 \\
\hline Total & 200 & 179 & 203 & 192 & 202 & 199 & 197 & 211 & 196 & 196 & 189 & 203 & 2367 \\
\hline
\end{tabular}

f) Resumen por mes de las medias mensuales de cada año de los sondeos de Coruña:

\begin{tabular}{|c|c|c|c|c|c|c|c|c|c|c|c|c|}
\hline Mes & 1 & 2 & 3 & 4 & 5 & 6 & 7 & 8 & 9 & 10 & 11 & 12 \\
\hline Media & 15.01 & 12.86 & 14.50 & 14.77 & 18.16 & 22.02 & 23.88 & 23.94 & 22.42 & 21.47 & 17.02 & 15.12 \\
\hline STD & 1.66 & 2.47 & 1.28 & 1.27 & 1.35 & 0.90 & 0.75 & 1.09 & 1.72 & 2.00 & 2.76 & 1.55 \\
\hline Mediana & 15.50 & 13.59 & 14.60 & 15.11 & 17.70 & 22.27 & 23.73 & 23.77 & 22.74 & 20.90 & 17.18 & 14.08 \\
\hline Máximo & 17.38 & 16.04 & 16.91 & 16.00 & 20.27 & 23.18 & 25.60 & 26.18 & 24.18 & 25.26 & 21.60 & 17.77 \\
\hline Mínimo & 11.97 & 10.06 & 12.39 & 12.70 & 16.67 & 20.20 & 23.01 & 22.67 & 18.96 & 18.99 & 12.72 & 13.65 \\
\hline No Días & 200 & 179 & 203 & 192 & 202 & 199 & 197 & 211 & 196 & 196 & 189 & 203 \\
\hline
\end{tabular}




\section{Gráficas de la estación de Coruña}

g) Evolución temporal de las medias diarias.

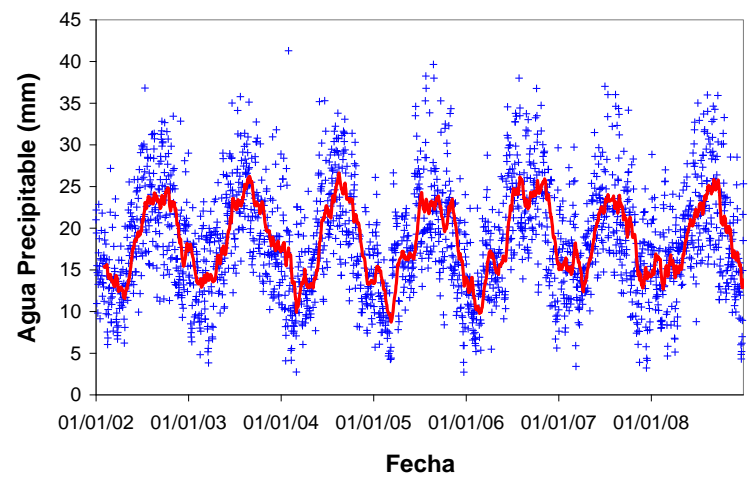

La línea roja representa la media móvil mensual. h) Histograma de las medias diarias.

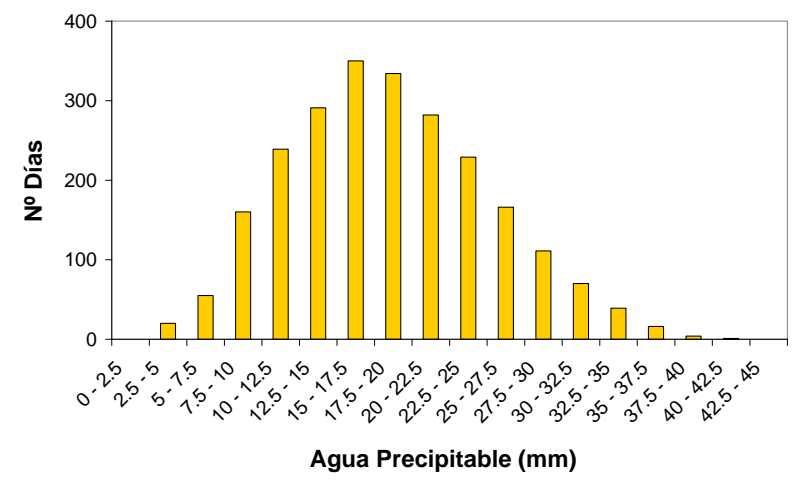

La distribución presenta un desplazamiento hacia la derecha (coef. de asimetría positivo), y un ligero achatamiento (curtosis negativa) respecto de la distribución normal.

j) Ciclo promedio anual.

para cada mes y año.
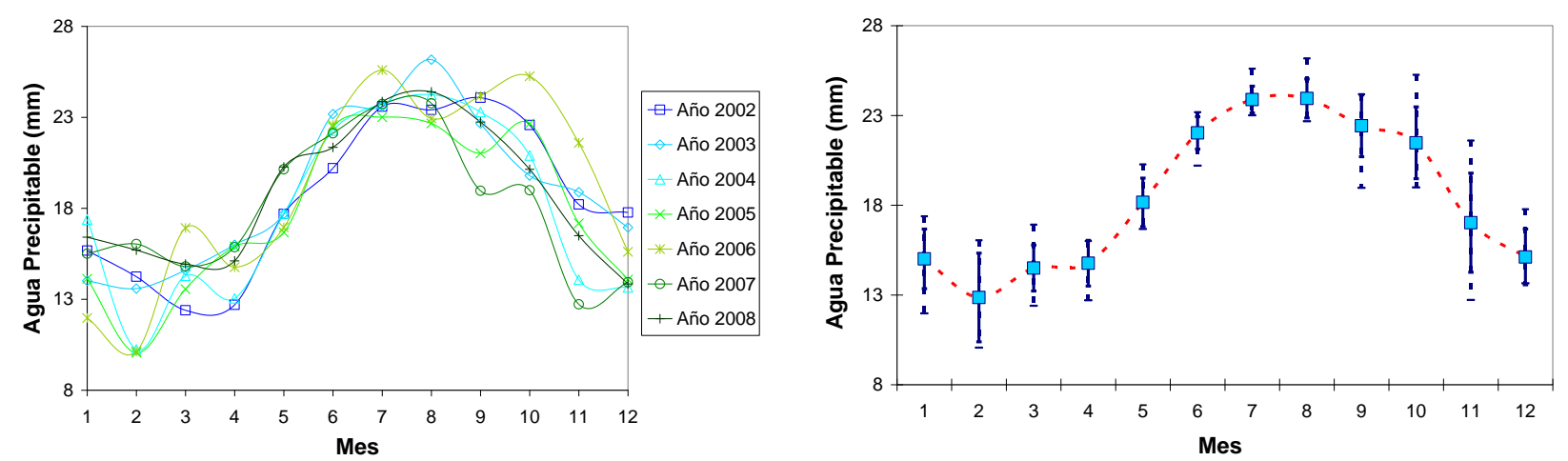

Valor promedio de las medias mensuales de cada año (cuadrados). Valor promedio más/menos la desviación típica de las medias mensuales (barras sólidas). Valor máximo y mínimo absoluto de las medias mensuales (líneas de trazos). 


\subsubsection{GIBRALTAR (aeropuerto). Estación de radiosondeo.}

El análisis estadístico se ha realizado en base a los sondeos que han superado los $9000 \mathrm{~m}$ de altitud.

a) Estadísticas globales del conjunto de los sondeos de Gibraltar:

\begin{tabular}{|c|c|c|c|c|c|c|c|c|c|c|}
\hline $\begin{array}{c}\mathrm{N}^{0} \\
\text { Sondeos } \\
\end{array}$ & Media & STD & Mediana & $\begin{array}{l}\text { Clase } \\
\text { Modal }\end{array}$ & $\begin{array}{c}\text { Percentil } \\
5 \\
\end{array}$ & $\begin{array}{c}\text { Percentil } \\
95 \\
\end{array}$ & Máximo & Mínimo & $\begin{array}{c}\text { Coef. } \\
\text { Asimetría }\end{array}$ & Curtosis \\
\hline 5046 & 20.42 & 7.41 & 19.78 & $17.5-20$ & 9.36 & 33.75 & 48.80 & 3.15 & 0.41 & -0.11 \\
\hline
\end{tabular}

b) Estadísticas por mes del conjunto de los sondeos de Gibraltar:

\begin{tabular}{|c|c|c|c|c|c|c|c|c|c|c|c|c|}
\hline Estadístico \ Mes & 1 & 2 & 3 & 4 & 5 & 6 & 7 & 8 & 9 & 10 & 11 & 12 \\
\hline Media & 14.21 & 15.57 & 15.89 & 17.26 & 19.80 & 23.66 & 22.99 & 25.85 & 27.36 & 25.58 & 19.10 & 16.85 \\
\hline STD & 5.10 & 5.49 & 5.35 & 5.24 & 5.58 & 5.50 & 6.26 & 6.55 & 6.71 & 7.52 & 6.40 & 5.54 \\
\hline Mediana & 13.64 & 15.12 & 15.81 & 16.92 & 19.61 & 23.49 & 22.48 & 25.58 & 27.40 & 26.11 & 18.63 & 16.41 \\
\hline Máximo & 31.49 & 30.60 & 37.49 & 35.06 & 36.81 & 40.04 & 43.00 & 44.40 & 44.28 & 48.80 & 38.47 & 35.60 \\
\hline Mínimo & 3.15 & 3.31 & 3.50 & 5.57 & 6.10 & 10.34 & 8.37 & 10.94 & 8.81 & 6.49 & 4.89 & 5.49 \\
\hline Percentil 5 & 6.54 & 6.67 & 6.99 & 9.55 & 11.07 & 14.96 & 14.09 & 15.93 & 17.02 & 13.71 & 9.10 & 8.19 \\
\hline Percentil 95 & 23.39 & 25.63 & 23.80 & 26.39 & 29.20 & 32.61 & 34.18 & 37.50 & 38.81 & 37.87 & 31.17 & 26.11 \\
\hline Coef. Asimetría & 0.49 & 0.31 & 0.26 & 0.48 & 0.18 & 0.15 & 0.37 & 0.32 & 0.19 & 0.06 & 0.46 & 0.50 \\
\hline Curtosis & 0.12 & -0.15 & 0.41 & 0.04 & -0.24 & -0.41 & -0.18 & -0.25 & -0.38 & -0.31 & 0.28 & 0.19 \\
\hline No Sondeos & 420 & 379 & 418 & 411 & 434 & 413 & 446 & 434 & 417 & 435 & 405 & 434 \\
\hline
\end{tabular}

c) Estadísticas globales de las medias diarias de los sondeos de Gibraltar:

\begin{tabular}{|c|c|c|c|c|c|c|c|c|c|c|}
\hline $\mathrm{N}^{0}$ Días & Media & STD & Mediana & Moda & \begin{tabular}{|c|} 
Percentil \\
5 \\
\end{tabular} & \begin{tabular}{|c|} 
Percentil \\
95 \\
\end{tabular} & Máximo & Mínimo & \begin{tabular}{|c|} 
Coef. \\
Asimetría \\
\end{tabular} & Curtosis \\
\hline 2531 & 20.37 & 7.02 & 20.37 & $17.5-20$ & 9.87 & 33.19 & 43.90 & 3.64 & 0.39 & -0.17 \\
\hline
\end{tabular}

d) Resumen por mes de las medias diarias de los sondeos de Gibraltar:

\begin{tabular}{|c|c|c|c|c|c|c|c|c|c|c|c|c|}
\hline Estadístico \Mes & 1 & 2 & 3 & 4 & 5 & 6 & 7 & 8 & 9 & 10 & 11 & 12 \\
\hline Media & 14.19 & 15.60 & 15.86 & 17.22 & 19.78 & 23.63 & 23.10 & 25.82 & 27.30 & 25.60 & 19.05 & 16.93 \\
\hline STD & 4.70 & 5.06 & 4.91 & 4.70 & 5.10 & 5.03 & 5.84 & 6.00 & 6.07 & 6.85 & 6.16 & 5.04 \\
\hline Mediana & 13.73 & 15.33 & 15.86 & 16.89 & 19.72 & 23.64 & 22.90 & 25.52 & 26.92 & 25.88 & 18.83 & 16.97 \\
\hline Máximo & 27.46 & 30.15 & 35.82 & 32.81 & 35.64 & 37.41 & 38.67 & 41.88 & 43.90 & 42.92 & 37.04 & 34.67 \\
\hline Mínimo & 3.64 & 4.97 & 5.54 & 6.72 & 7.41 & 13.22 & 11.06 & 13.04 & 14.92 & 9.41 & 5.72 & 5.49 \\
\hline Percentil 5 & 7.60 & 7.46 & 7.79 & 9.90 & 11.69 & 15.77 & 14.34 & 16.76 & 17.76 & 14.75 & 9.58 & 9.39 \\
\hline Percentil 95 & 22.33 & 24.21 & 23.05 & 25.18 & 28.48 & 31.86 & 33.64 & 36.10 & 37.31 & 36.42 & 30.84 & 24.20 \\
\hline Coef. Asimetría & 0.36 & 0.24 & 0.37 & 0.33 & 0.17 & 0.17 & 0.39 & 0.34 & 0.25 & -0.05 & 0.49 & 0.36 \\
\hline Curtosis & -0.20 & -0.18 & 0.69 & -0.02 & -0.15 & -0.53 & -0.35 & -0.31 & -0.37 & -0.53 & 0.35 & 0.10 \\
\hline No Días & 216 & 194 & 213 & 209 & 214 & 210 & 217 & 217 & 206 & 217 & 202 & 216 \\
\hline
\end{tabular}

e1) Media de las medias diarias por mes y año de los sondeos de Gibraltar:

\begin{tabular}{|c|c|c|c|c|c|c|c|c|c|c|c|c|c|}
\hline Año \Mes & $\mathbf{1}$ & $\mathbf{2}$ & $\mathbf{3}$ & $\mathbf{4}$ & $\mathbf{5}$ & $\mathbf{6}$ & $\mathbf{7}$ & $\mathbf{8}$ & $\mathbf{9}$ & $\mathbf{1 0}$ & $\mathbf{1 1}$ & $\mathbf{1 2}$ & Media \\
\hline $\mathbf{2 0 0 2}$ & 15.74 & 13.23 & 16.26 & 16.59 & 16.90 & 23.10 & 22.45 & 23.28 & 27.09 & 24.26 & 20.42 & 19.06 & $\mathbf{1 9 . 8 7}$ \\
$\mathbf{2 0 0 3}$ & 13.30 & 15.32 & 18.73 & 18.33 & 19.51 & 24.51 & 22.34 & 27.36 & 25.05 & 27.42 & 20.85 & 17.30 & $\mathbf{2 0 . 8 4}$ \\
$\mathbf{2 0 0 4}$ & 15.88 & 16.94 & 15.80 & 15.57 & 21.05 & 23.64 & 24.98 & 28.62 & 25.72 & 24.05 & 18.40 & 15.84 & $\mathbf{2 0 . 5 4}$ \\
$\mathbf{2 0 0 5}$ & 10.51 & 11.30 & 18.01 & 15.66 & 19.06 & 23.33 & 23.06 & 24.73 & 23.42 & 25.33 & 16.49 & 17.95 & $\mathbf{1 9 . 0 7}$ \\
$\mathbf{2 0 0 6}$ & 14.57 & 14.55 & 14.60 & 18.06 & 22.97 & 25.21 & 23.69 & 25.48 & 30.48 & 28.21 & 22.87 & 16.81 & $\mathbf{2 1 . 4 6}$ \\
$\mathbf{2 0 0 7}$ & 12.86 & 17.66 & 13.22 & 19.77 & 18.16 & 23.23 & 21.75 & 26.50 & 29.54 & 24.74 & 18.18 & 15.93 & $\mathbf{2 0 . 1 3}$ \\
$\mathbf{2 0 0 8}$ & 16.55 & 19.89 & 14.38 & 16.64 & 20.96 & 22.43 & 23.46 & 24.78 & 30.19 & 25.17 & 15.94 & 15.60 & $\mathbf{2 0 . 5 0}$ \\
\hline Media & $\mathbf{1 4 . 2 0}$ & $\mathbf{1 5 . 5 6}$ & $\mathbf{1 5 . 8 6}$ & $\mathbf{1 7 . 2 3}$ & $\mathbf{1 9 . 8 0}$ & $\mathbf{2 3 . 6 3}$ & $\mathbf{2 3 . 1 0}$ & $\mathbf{2 5 . 8 2}$ & $\mathbf{2 7 . 3 6}$ & $\mathbf{2 5 . 6 0}$ & $\mathbf{1 9 . 0 2}$ & $\mathbf{1 6 . 9 3}$ & $\mathbf{2 0 . 3 4}$ \\
\hline
\end{tabular}


e2) Máximo de las medias diarias por mes y año de los sondeos de Gibraltar:

\begin{tabular}{|c|c|c|c|c|c|c|c|c|c|c|c|c|c|}
\hline Año \Mes & $\mathbf{1}$ & $\mathbf{2}$ & $\mathbf{3}$ & $\mathbf{4}$ & $\mathbf{5}$ & $\mathbf{6}$ & $\mathbf{7}$ & $\mathbf{8}$ & $\mathbf{9}$ & $\mathbf{1 0}$ & $\mathbf{1 1}$ & $\mathbf{1 2}$ & Media \\
\hline $\mathbf{2 0 0 2}$ & 26.06 & 24.01 & 23.06 & 25.24 & 32.62 & 32.30 & 29.46 & 33.44 & 42.74 & 39.97 & 32.56 & 34.67 & $\mathbf{3 1 . 3 4}$ \\
$\mathbf{2 0 0 3}$ & 25.78 & 24.48 & 35.82 & 24.02 & 27.13 & 33.23 & 36.51 & 41.88 & 36.56 & 38.84 & 28.18 & 24.33 & $\mathbf{3 1 . 4 0}$ \\
$\mathbf{2 0 0 4}$ & 27.46 & 28.44 & 23.05 & 23.67 & 26.89 & 31.32 & 38.67 & 40.47 & 37.38 & 40.80 & 33.94 & 28.69 & $\mathbf{3 1 . 7 3}$ \\
$\mathbf{2 0 0 5}$ & 14.86 & 24.94 & 28.22 & 23.49 & 32.22 & 30.10 & 33.61 & 39.65 & 33.60 & 38.85 & 28.48 & 27.81 & $\mathbf{2 9 . 6 5}$ \\
$\mathbf{2 0 0 6}$ & 23.10 & 23.46 & 25.34 & 27.17 & 35.64 & 35.48 & 36.20 & 40.59 & 36.50 & 42.92 & 37.04 & 25.73 & $\mathbf{3 2 . 4 3}$ \\
$\mathbf{2 0 0 7}$ & 21.78 & 24.24 & 27.95 & 29.78 & 27.52 & 37.41 & 30.83 & 40.34 & 38.04 & 34.89 & 30.81 & 26.30 & $\mathbf{3 0 . 8 2}$ \\
$\mathbf{2 0 0 8}$ & 23.58 & 30.15 & 24.10 & 32.81 & 28.94 & 36.23 & 33.77 & 38.86 & 43.90 & 35.08 & 23.60 & 25.08 & $\mathbf{3 1 . 3 4}$ \\
\hline Media & $\mathbf{2 3 . 2 3}$ & $\mathbf{2 5 . 6 7}$ & $\mathbf{2 6 . 7 9}$ & $\mathbf{2 6 . 6 0}$ & $\mathbf{3 0 . 1 4}$ & $\mathbf{3 3 . 7 2}$ & $\mathbf{3 4 . 1 5}$ & $\mathbf{3 9 . 3 2}$ & $\mathbf{3 8 . 3 9}$ & $\mathbf{3 8 . 7 6}$ & $\mathbf{3 0 . 6 6}$ & $\mathbf{2 7 . 5 2}$ & $\mathbf{3 1 . 2 5}$ \\
\hline
\end{tabular}

e3) Mínimo de las medias diarias por mes y año de los sondeos de Gibraltar:

\begin{tabular}{|c|c|c|c|c|c|c|c|c|c|c|c|c|c|}
\hline Año \Mes & 1 & 2 & 3 & 4 & 5 & 6 & 7 & 8 & 9 & 10 & 11 & 12 & Media \\
\hline 2002 & 7.98 & 4.97 & 8.16 & 10.26 & 8.12 & 15.38 & 16.42 & 17.28 & 16.64 & 10.98 & 7.23 & 9.27 & 11.06 \\
\hline 2003 & 5.24 & 5.96 & 10.15 & 6.72 & 12.24 & 13.70 & 12.62 & 17.38 & 17.51 & 9.41 & 11.32 & 9.68 & 10.99 \\
\hline 2004 & 5.65 & 8.04 & 8.66 & 8.30 & 13.92 & 16.14 & 12.38 & 16.66 & 19.23 & 13.96 & 5.72 & 5.49 & 11.18 \\
\hline 2005 & 3.64 & 5.50 & 7.48 & 7.64 & 7.41 & 13.80 & 13.56 & 13.60 & 14.92 & 14.78 & 7.62 & 9.75 & 9.98 \\
\hline 2006 & 5.76 & 9.92 & 6.32 & 9.82 & 11.03 & 13.22 & 11.06 & 16.64 & 24.02 & 15.27 & 10.20 & 8.16 & 11.79 \\
\hline 2007 & 5.70 & 9.90 & 5.54 & 12.57 & 10.18 & 13.76 & 13.60 & 15.03 & 17.23 & 11.29 & 11.98 & 9.70 & 11.37 \\
\hline 2008 & 9.93 & 13.52 & 5.84 & 8.38 & 10.23 & 16.73 & 11.88 & 13.04 & 15.86 & 9.93 & 7.93 & 7.50 & 10.90 \\
\hline Media & 6.27 & 8.26 & 7.45 & 9.10 & 10.45 & 14.68 & 13.07 & 15.66 & 17.92 & 12.23 & 8.86 & 8.51 & 11.04 \\
\hline
\end{tabular}

e4) Desviación estándar de las medias diarias de cada mes y año de los sondeos de Gibraltar:

\begin{tabular}{|c|l|l|l|l|l|l|l|l|l|l|l|l|l|}
\hline Año IMes & $\mathbf{1}$ & $\mathbf{2}$ & $\mathbf{3}$ & $\mathbf{4}$ & $\mathbf{5}$ & $\mathbf{6}$ & $\mathbf{7}$ & $\mathbf{8}$ & $\mathbf{9}$ & $\mathbf{1 0}$ & $\mathbf{1 1}$ & $\mathbf{1 2}$ & Media \\
\hline $\mathbf{2 0 0 2}$ & 4.64 & 5.11 & 3.58 & 3.92 & 5.14 & 4.05 & 3.81 & 4.14 & 5.87 & 7.50 & 6.75 & 6.11 & $\mathbf{5 . 0 5}$ \\
$\mathbf{2 0 0 3}$ & 5.54 & 4.41 & 5.10 & 4.44 & 3.35 & 5.68 & 5.47 & 5.66 & 5.40 & 6.47 & 4.07 & 4.17 & $\mathbf{4 . 9 8}$ \\
$\mathbf{2 0 0 4}$ & 5.19 & 5.13 & 3.98 & 4.17 & 3.30 & 4.35 & 7.30 & 6.07 & 4.96 & 7.04 & 7.27 & 5.35 & $\mathbf{5 . 3 4}$ \\
$\mathbf{2 0 0 5}$ & 2.79 & 4.18 & 5.10 & 4.07 & 5.99 & 4.61 & 5.52 & 6.07 & 4.71 & 6.55 & 5.36 & 4.58 & $\mathbf{4 . 9 6}$ \\
$\mathbf{2 0 0 6}$ & 3.78 & 2.85 & 4.33 & 4.50 & 6.10 & 6.15 & 6.93 & 5.46 & 3.73 & 6.72 & 7.87 & 4.31 & $\mathbf{5 . 2 3}$ \\
$\mathbf{2 0 0 7}$ & 3.88 & 3.58 & 4.70 & 4.67 & 4.63 & 5.38 & 4.56 & 7.37 & 4.62 & 6.11 & 3.66 & 4.57 & $\mathbf{4 . 8 1}$ \\
$\mathbf{2 0 0 8}$ & 3.39 & 4.33 & 4.80 & 5.44 & 3.96 & 4.07 & 5.90 & 5.08 & 8.04 & 6.29 & 3.65 & 4.92 & $\mathbf{4 . 9 9}$ \\
\hline Media & $\mathbf{4 . 1 7}$ & $\mathbf{4 . 2 3}$ & $\mathbf{4 . 5 1}$ & $\mathbf{4 . 4 6}$ & $\mathbf{4 . 6 4}$ & $\mathbf{4 . 9 0}$ & $\mathbf{5 . 6 4}$ & $\mathbf{5 . 6 9}$ & $\mathbf{5 . 3 3}$ & $\mathbf{6 . 6 7}$ & $\mathbf{5 . 5 2}$ & $\mathbf{4 . 8 6}$ & $\mathbf{5 . 0 5}$ \\
\hline
\end{tabular}

e5) Número de días con dato válido por mes y año de los sondeos de Gibraltar:

\begin{tabular}{|c|c|c|c|c|c|c|c|c|c|c|c|c|c|}
\hline Año \Mes & 1 & 2 & 3 & 4 & 5 & 6 & 7 & 8 & 9 & 10 & 11 & 12 & Tota \\
\hline 2002 & 30 & 26 & 31 & 30 & 31 & 30 & 31 & 31 & 30 & 31 & 30 & 31 & 362 \\
\hline 2003 & 31 & 27 & 31 & 30 & 31 & 30 & 31 & 31 & 30 & 31 & 30 & 30 & 363 \\
\hline 2004 & 31 & 29 & 30 & 30 & 31 & 30 & 31 & 31 & 30 & 31 & 22 & 31 & 357 \\
\hline 2005 & 31 & 28 & 30 & 30 & 31 & 30 & 31 & 31 & 30 & 31 & 30 & 31 & 364 \\
\hline 2006 & 31 & 28 & 30 & 30 & 29 & 30 & 31 & 31 & 26 & 31 & 30 & 31 & 358 \\
\hline 2007 & 31 & 27 & 30 & 29 & 30 & 30 & 31 & 31 & 30 & 31 & 30 & 31 & 361 \\
\hline 2008 & 31 & 29 & 31 & 30 & 31 & 30 & 31 & 31 & 30 & 31 & 30 & 31 & 366 \\
\hline Total & 216 & 194 & 213 & 209 & 214 & 210 & 217 & 217 & 206 & 217 & 202 & 216 & 2531 \\
\hline
\end{tabular}

f) Resumen por mes de las medias mensuales de cada año de los sondeos de Gibraltar:

\begin{tabular}{|c|c|c|c|c|c|c|c|c|c|c|c|c|}
\hline Mes & 1 & 2 & 3 & 4 & 5 & 6 & 7 & 8 & 9 & 10 & 11 & 12 \\
\hline Media & 14.20 & 15.56 & 15.86 & 17.23 & 19.80 & 23.63 & 23.10 & 25.82 & 27.36 & 25.60 & 19.02 & 16.93 \\
\hline STD & 1.97 & 2.67 & 1.84 & 1.43 & 1.88 & 0.87 & 0.99 & 1.67 & 2.57 & 1.48 & 2.30 & 1.18 \\
\hline Mediana & 14.57 & 15.32 & 15.80 & 16.64 & 19.51 & 23.33 & 23.06 & 25.48 & 27.09 & 25.17 & 18.40 & 16.81 \\
\hline Máximo & 16.55 & 19.89 & 18.73 & 19.77 & 22.97 & 25.21 & 24.98 & 28.62 & 30.48 & 28.21 & 22.87 & 19.06 \\
\hline Mínimo & 10.51 & 11.30 & 13.22 & 15.57 & 16.90 & 22.43 & 21.75 & 23.28 & 23.42 & 24.05 & 15.94 & 15.60 \\
\hline $\mathrm{N}^{0}$ Días & 216 & 194 & 213 & 209 & 214 & 210 & 217 & 217 & 206 & 217 & 202 & 216 \\
\hline
\end{tabular}




\section{Gráficas de la estación de Gibraltar}

g) Evolución temporal de las medias diarias.

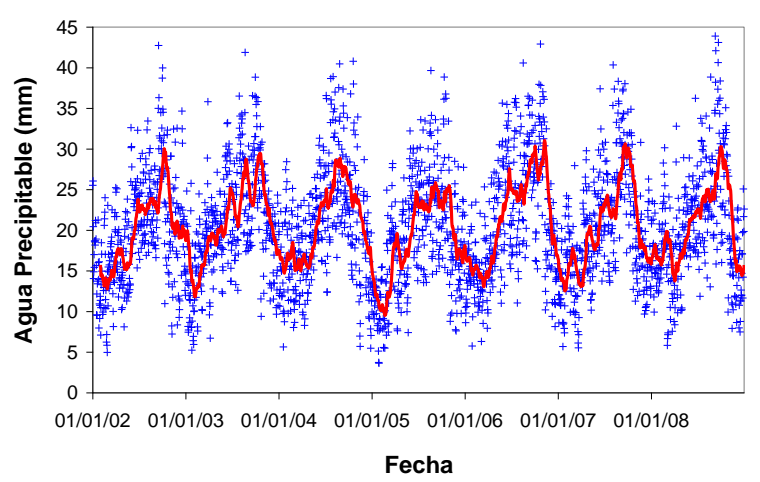

La línea roja representa la media móvil mensual.

i) Valores medios mensuales de las medias diarias para cada mes y año.

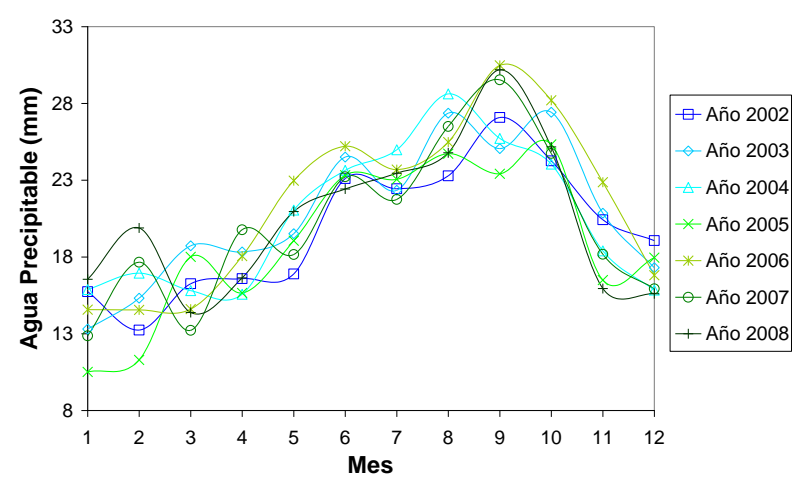

h) Histograma de las medias diarias.

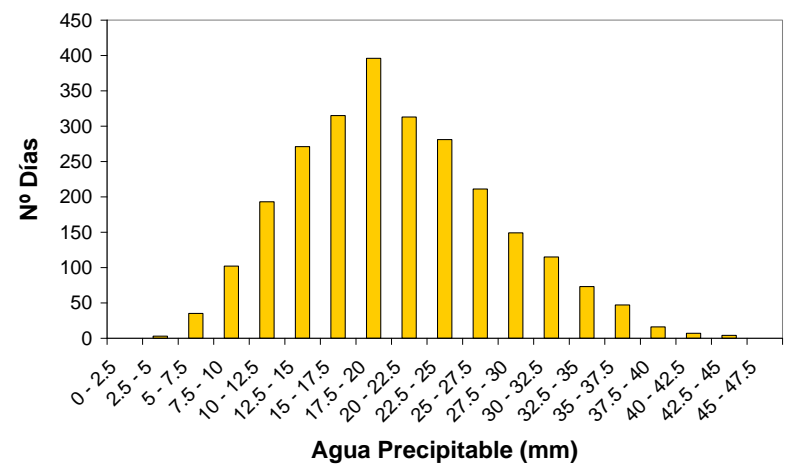

La distribución presenta un desplazamiento hacia la derecha (coef. de asimetría positivo), y un ligero achatamiento (curtosis negativa) respecto de la distribución normal.

j) Ciclo promedio anual.

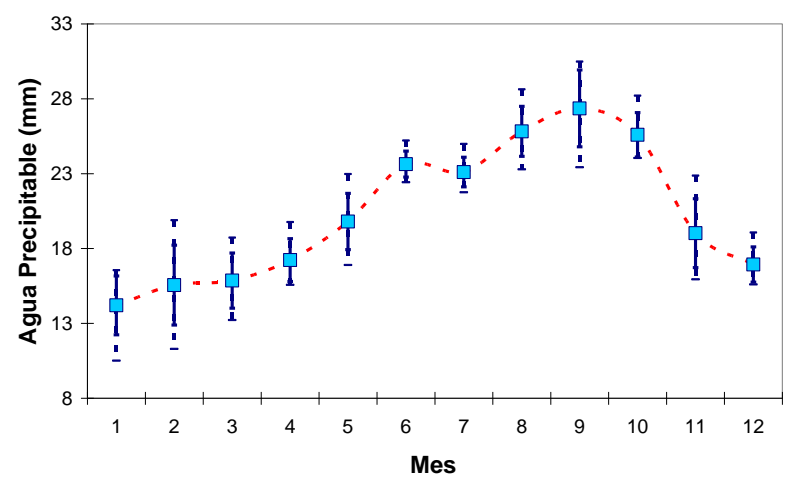

Valor promedio de las medias mensuales de cada año (cuadrados). Valor promedio más/menos la desviación típica de las medias mensuales (barras sólidas). Valor máximo y mínimo absoluto de las medias mensuales (líneas de trazos). 


\subsubsection{LISBOA (aeropuerto). Estación de radiosondeo.}

El análisis estadístico se ha realizado en base a los sondeos que han superado los $7000 \mathrm{~m}$ de altitud.

a) Estadísticas globales del conjunto de los sondeos de Lisboa:

\begin{tabular}{|c|c|c|c|c|c|c|c|c|c|c|}
\hline $\begin{array}{c}\mathbf{N}^{0} \\
\text { Sondeos }\end{array}$ & Media & STD & Mediana & $\begin{array}{c}\text { Clase } \\
\text { Modal }\end{array}$ & $\begin{array}{c}\text { Percentil } \\
\mathbf{5}\end{array}$ & $\begin{array}{c}\text { Percentil } \\
\mathbf{9 5}\end{array}$ & Máximo & Mínimo & $\begin{array}{c}\text { Coef. } \\
\text { Asimetría }\end{array}$ & Curtosis \\
\hline 2659 & 17.40 & 6.55 & 16.71 & $15-17.5$ & 8.00 & 29.43 & 40.43 & 2.63 & 0.52 & 0.03 \\
\hline
\end{tabular}

b) Estadísticas por mes del conjunto de los sondeos de Lisboa:

\begin{tabular}{|c|c|c|c|c|c|c|c|c|c|c|c|c|}
\hline Estadístico \Mes & 1 & 2 & 3 & 4 & 5 & 6 & 7 & 8 & 9 & 10 & 11 & 12 \\
\hline Media & 13.80 & 13.47 & 13.73 & 14.50 & 16.78 & 19.40 & 19.41 & 20.64 & 22.44 & 20.49 & 17.21 & 14.48 \\
\hline STD & 5.72 & 5.22 & 5.08 & 4.45 & 4.70 & 5.33 & 5.47 & 5.87 & 6.98 & 7.05 & 6.72 & 5.59 \\
\hline Mediana & 12.48 & 12.87 & 13.41 & 13.73 & 16.19 & 18.77 & 18.80 & 20.34 & 22.50 & 20.38 & 16.34 & 14.09 \\
\hline Máximo & 31.33 & 27.14 & 30.14 & 28.97 & 34.22 & 36.65 & 35.05 & 39.33 & 38.75 & 40.43 & 39.78 & 35.78 \\
\hline Mínimo & 4.34 & 2.82 & 2.63 & 5.39 & 5.53 & 7.99 & 8.51 & 6.50 & 7.61 & 5.85 & 2.98 & 3.97 \\
\hline Percentil 5 & 5.98 & 5.65 & 4.91 & 8.33 & 10.36 & 11.63 & 11.99 & 11.17 & 11.33 & 10.29 & 7.12 & 6.35 \\
\hline Percentil 95 & 25.87 & 22.87 & 22.84 & 22.85 & 25.35 & 28.96 & 30.03 & 30.98 & 33.51 & 32.46 & 28.71 & 23.86 \\
\hline Coef. Asimetría & 0.86 & 0.46 & 0.48 & 0.62 & 0.64 & 0.61 & 0.57 & 0.27 & 0.10 & 0.37 & 0.50 & 0.53 \\
\hline Curtosis & 0.40 & -0.26 & 0.80 & 0.13 & 0.59 & 0.51 & -0.05 & 0.00 & -0.70 & -0.42 & 0.01 & 0.24 \\
\hline $\mathrm{N}^{\circ}$ Sondeos & 194 & 198 & 195 & 186 & 215 & 233 & 218 & 243 & 223 & 263 & 249 & 242 \\
\hline
\end{tabular}

c) Estadísticas globales de las medias diarias de los sondeos de Lisboa:

\begin{tabular}{|c|c|c|c|c|c|c|c|c|c|c|}
\hline N$^{\circ}$ Días & Media & STD & Mediana & Moda & $\begin{array}{c}\text { Percentil } \\
\mathbf{5}\end{array}$ & $\begin{array}{c}\text { Percentil } \\
\mathbf{9 5}\end{array}$ & Máximo & Mínimo & $\begin{array}{c}\text { Coef. } \\
\text { Asimetría }\end{array}$ & Curtosis \\
\hline 2238 & 17.21 & 6.43 & 16.58 & $12.5-17.5$ & 7.90 & 28.80 & 40.43 & 2.63 & 0.50 & 0.07 \\
\hline
\end{tabular}

d) Resumen por mes de las medias diarias de los sondeos de Lisboa:

\begin{tabular}{|c|c|c|c|c|c|c|c|c|c|c|c|c|}
\hline Estadístico \Mes & 1 & 2 & 3 & 4 & 5 & 6 & 7 & 8 & 9 & 10 & 11 & 12 \\
\hline Media & 13.56 & 13.57 & 13.71 & 14.66 & 16.74 & 19.54 & 19.34 & 20.53 & 21.59 & 20.39 & 16.71 & 14.15 \\
\hline STD & 5.58 & 5.19 & 5.21 & 4.42 & 4.55 & 5.27 & 5.36 & 5.85 & 6.81 & 7.07 & 6.64 & 5.42 \\
\hline Mediana & 12.51 & 12.92 & 13.58 & 13.87 & 16.12 & 19.17 & 18.82 & 20.00 & 20.88 & 20.62 & 16.16 & 14.03 \\
\hline Máximo & 31.33 & 27.14 & 30.14 & 28.97 & 32.47 & 36.65 & 34.88 & 39.33 & 38.46 & 40.43 & 36.23 & 34.43 \\
\hline Mínimo & 4.34 & 2.82 & 2.63 & 5.39 & 5.53 & 7.99 & 8.51 & 6.50 & 7.61 & 5.85 & 4.31 & 3.97 \\
\hline Percentil 5 & 5.92 & 5.79 & 4.55 & 9.18 & 10.40 & 12.30 & 11.78 & 11.32 & 11.05 & 9.94 & 6.88 & 6.35 \\
\hline Percentil 95 & 24.78 & 22.90 & 22.90 & 22.49 & 24.70 & 28.69 & 29.97 & 31.01 & 32.65 & 32.61 & 28.18 & 22.94 \\
\hline Coef. Asimetría & 0.77 & 0.46 & 0.47 & 0.63 & 0.56 & 0.65 & 0.48 & 0.35 & 0.16 & 0.34 & 0.54 & 0.46 \\
\hline Curtosis & 0.32 & -0.17 & 0.81 & 0.13 & 0.40 & 0.75 & -0.13 & 0.14 & -0.71 & -0.42 & 0.07 & -0.01 \\
\hline $\mathrm{N}^{0}$ Días & 169 & 178 & 166 & 162 & 177 & 204 & 185 & 211 & 186 & 212 & 187 & 201 \\
\hline
\end{tabular}

e1) Media de las medias diarias por mes y año de los sondeos de Lisboa:

\begin{tabular}{|c|c|c|c|c|c|c|c|c|c|c|c|c|c|}
\hline Año \Mes & $\mathbf{1}$ & $\mathbf{2}$ & $\mathbf{3}$ & $\mathbf{4}$ & $\mathbf{5}$ & $\mathbf{6}$ & $\mathbf{7}$ & $\mathbf{8}$ & $\mathbf{9}$ & $\mathbf{1 0}$ & $\mathbf{1 1}$ & $\mathbf{1 2}$ & Media \\
\hline $\mathbf{2 0 0 2}$ & 15.07 & 11.76 & 13.63 & 13.18 & 16.50 & 18.45 & 18.65 & 20.85 & 26.15 & 23.22 & 18.33 & 17.26 & $\mathbf{1 7 . 7 5}$ \\
$\mathbf{2 0 0 3}$ & --- & 14.32 & --- & --- & --- & 20.02 & 18.41 & 22.21 & 20.05 & 18.91 & 19.54 & 13.66 & $\mathbf{1 8 . 3 9}$ \\
$\mathbf{2 0 0 4}$ & 16.45 & 13.17 & 12.47 & 13.33 & 16.71 & 19.73 & 18.01 & 22.93 & 18.84 & 17.40 & 14.64 & 13.47 & $\mathbf{1 6 . 4 3}$ \\
$\mathbf{2 0 0 5}$ & 9.85 & 8.80 & 13.82 & 14.54 & 15.27 & 19.16 & --- & 19.81 & 17.01 & 20.55 & 15.61 & 13.18 & $\mathbf{1 5 . 2 4}$ \\
$\mathbf{2 0 0 6}$ & 11.35 & 12.43 & 16.25 & 16.00 & --- & 22.52 & 22.81 & 18.55 & 22.63 & 26.14 & 21.10 & 14.26 & $\mathbf{1 8 . 5 5}$ \\
$\mathbf{2 0 0 7}$ & 12.68 & 16.21 & 11.56 & 15.13 & 17.70 & 19.83 & 18.15 & 18.06 & --- & 17.89 & 13.38 & 12.59 & $\mathbf{1 5 . 7 4}$ \\
$\mathbf{2 0 0 8}$ & 16.32 & 17.33 & 13.56 & --- & 19.48 & 17.12 & 21.49 & 21.42 & 23.21 & 18.46 & 12.88 & 14.54 & $\mathbf{1 7 . 8 0}$ \\
\hline Media & $\mathbf{1 3 . 6 2}$ & $\mathbf{1 3 . 4 3}$ & $\mathbf{1 3 . 5 5}$ & $\mathbf{1 4 . 4 4}$ & $\mathbf{1 7 . 1 3}$ & $\mathbf{1 9 . 5 5}$ & $\mathbf{1 9 . 5 9}$ & $\mathbf{2 0 . 5 5}$ & $\mathbf{2 1 . 3 1}$ & $\mathbf{2 0 . 3 7}$ & $\mathbf{1 6 . 5 0}$ & $\mathbf{1 4 . 1 4}$ & $\mathbf{1 7 . 1 3}$ \\
\hline
\end{tabular}


e2) Máximo de las medias diarias por mes y año de los sondeos de Lisboa:

\begin{tabular}{|c|c|c|c|c|c|c|c|c|c|c|c|c|c|}
\hline Año \Mes & $\mathbf{1}$ & $\mathbf{2}$ & $\mathbf{3}$ & $\mathbf{4}$ & $\mathbf{5}$ & $\mathbf{6}$ & $\mathbf{7}$ & $\mathbf{8}$ & $\mathbf{9}$ & $\mathbf{1 0}$ & $\mathbf{1 1}$ & $\mathbf{1 2}$ & Media \\
\hline $\mathbf{2 0 0 2}$ & 25.31 & 22.00 & 19.08 & 19.98 & 23.90 & 23.82 & 25.77 & 33.46 & 38.46 & 36.68 & 34.94 & 34.43 & $\mathbf{2 8 . 1 5}$ \\
$\mathbf{2 0 0 3}$ & --- & 25.19 & -- & --- & --- & 34.80 & 27.64 & 32.57 & 33.67 & 30.92 & 27.44 & 18.76 & $\mathbf{2 8 . 8 7}$ \\
$\mathbf{2 0 0 4}$ & 30.16 & 24.40 & 17.77 & 23.28 & 24.65 & 32.80 & 30.05 & 39.33 & 33.59 & 37.87 & 25.80 & 21.87 & $\mathbf{2 8 . 4 6}$ \\
$\mathbf{2 0 0 5}$ & 23.02 & 15.51 & 28.72 & 23.81 & 27.36 & 28.72 & --- & 35.29 & 28.68 & 37.89 & 28.77 & 23.13 & $\mathbf{2 7 . 3 5}$ \\
$\mathbf{2 0 0 6}$ & 21.49 & 22.67 & 30.14 & 25.24 & --- & 35.21 & 31.44 & 29.47 & 37.39 & 40.43 & 36.23 & 27.02 & $\mathbf{3 0 . 6 1}$ \\
$\mathbf{2 0 0 7}$ & 23.14 & 27.14 & 22.93 & 26.89 & 26.50 & 36.65 & 33.15 & 34.24 & --- & 28.31 & 30.16 & 23.88 & $\mathbf{2 8 . 4 5}$ \\
$\mathbf{2 0 0 8}$ & 31.33 & 26.92 & 29.05 & --- & 32.47 & 26.59 & 34.88 & 31.03 & 36.38 & 28.89 & 21.08 & 26.65 & $\mathbf{2 9 . 5 7}$ \\
\hline Media & $\mathbf{2 5 . 7 4}$ & $\mathbf{2 3 . 4 0}$ & $\mathbf{2 4 . 6 2}$ & $\mathbf{2 3 . 8 4}$ & $\mathbf{2 6 . 9 8}$ & $\mathbf{3 1 . 2 3}$ & $\mathbf{3 0 . 4 9}$ & $\mathbf{3 3 . 6 3}$ & $\mathbf{3 4 . 7 0}$ & $\mathbf{3 4 . 4 3}$ & $\mathbf{2 9 . 2 0}$ & $\mathbf{2 5 . 1 1}$ & $\mathbf{2 8 . 7 8}$ \\
\hline
\end{tabular}

e3) Mínimo de las medias diarias por mes y año de los sondeos de Lisboa:

\begin{tabular}{|c|c|c|c|c|c|c|c|c|c|c|c|c|c|}
\hline Año \Mes & 1 & 2 & 3 & 4 & 5 & 6 & 7 & 8 & 9 & 10 & 11 & 12 & Media \\
\hline 2002 & 9.69 & 6.57 & 8.12 & 8.28 & 8.15 & 12.80 & 11.32 & 10.09 & 15.27 & 13.84 & 4.96 & 7.30 & 9.70 \\
\hline 2003 & --- & 6.32 & --- & --- & --- & 9.46 & 9.29 & 13.01 & 10.18 & 10.27 & 12.04 & 5.73 & 9.54 \\
\hline 2004 & 4.90 & 4.69 & 3.79 & 9.29 & 9.35 & 12.61 & 8.51 & 9.07 & 8.43 & 9.54 & 6.98 & 6.35 & 7.79 \\
\hline 2005 & 4.36 & 2.82 & 3.75 & 5.39 & 7.47 & 11.50 & --- & 8.34 & 7.61 & 5.85 & 4.31 & 4.21 & 5.96 \\
\hline 2006 & 4.34 & 3.96 & 4.19 & 10.27 & --- & 12.98 & 15.86 & 9.32 & 12.10 & 12.35 & 7.17 & 6.01 & 8.96 \\
\hline 2007 & 5.04 & 8.48 & 2.63 & 7.43 & 10.65 & 8.92 & 13.41 & 6.50 & --- & 8.03 & 6.17 & 3.97 & 7.38 \\
\hline 2008 & 8.53 & 9.07 & 4.25 & --- & 10.33 & 7.99 & 11.61 & 11.13 & 10.98 & 8.85 & 6.27 & 6.59 & 8.69 \\
\hline Media & 6.14 & 5.99 & 4.46 & 8.13 & 9.19 & 10.89 & 11.67 & 9.64 & 10.76 & 9.82 & 6.84 & 5.74 & 8.29 \\
\hline
\end{tabular}

e4) Desviación estándar de las medias diarias de cada mes y año de los sondeos de Lisboa:

\begin{tabular}{|c|l|l|l|l|l|l|l|l|l|l|l|l|c|}
\hline Año IMes & $\mathbf{1}$ & $\mathbf{2}$ & $\mathbf{3}$ & $\mathbf{4}$ & $\mathbf{5}$ & $\mathbf{6}$ & $\mathbf{7}$ & $\mathbf{8}$ & $\mathbf{9}$ & $\mathbf{1 0}$ & $\mathbf{1 1}$ & $\mathbf{1 2}$ & Media \\
\hline $\mathbf{2 0 0 2}$ & 4.80 & 4.33 & 3.09 & 3.23 & 3.75 & 3.41 & 3.82 & 4.38 & 6.07 & 5.82 & 6.02 & 5.34 & $\mathbf{4 . 5 1}$ \\
$\mathbf{2 0 0 3}$ & --- & 4.43 & -- & --- & --- & 5.02 & 4.98 & 4.83 & 6.19 & 4.44 & 4.15 & 3.60 & $\mathbf{4 . 7 0}$ \\
$\mathbf{2 0 0 4}$ & 7.07 & 3.64 & 3.54 & 3.75 & 4.25 & 5.52 & 5.73 & 6.29 & 5.84 & 6.36 & 5.83 & 3.91 & $\mathbf{5 . 1 4}$ \\
$\mathbf{2 0 0 5}$ & 4.40 & 3.39 & 6.48 & 4.85 & 4.32 & 3.89 & --- & 6.21 & 5.14 & 8.81 & 6.47 & 5.22 & $\mathbf{5 . 3 8}$ \\
$\mathbf{2 0 0 6}$ & 3.41 & 5.23 & 5.49 & 4.32 & --- & 5.75 & 4.26 & 5.33 & 6.32 & 5.94 & 7.74 & 6.33 & $\mathbf{5 . 4 7}$ \\
$\mathbf{2 0 0 7}$ & 4.20 & 5.06 & 4.84 & 4.66 & 4.44 & 6.57 & 4.13 & 6.68 & -- & 6.39 & 6.26 & 5.47 & $\mathbf{5 . 3 3}$ \\
$\mathbf{2 0 0 8}$ & 5.27 & 5.01 & 5.29 & --- & 4.41 & 4.43 & 6.10 & 5.13 & 6.39 & 6.55 & 4.05 & 6.12 & $\mathbf{5 . 3 4}$ \\
\hline Media & $\mathbf{4 . 8 6}$ & $\mathbf{4 . 4 4}$ & $\mathbf{4 . 7 9}$ & $\mathbf{4 . 1 6}$ & $\mathbf{4 . 2 3}$ & $\mathbf{4 . 9 4}$ & $\mathbf{4 . 8 4}$ & $\mathbf{5 . 5 5}$ & $\mathbf{5 . 9 9}$ & $\mathbf{6 . 3 3}$ & $\mathbf{5 . 7 9}$ & $\mathbf{5 . 1 4}$ & $\mathbf{5 . 1 3}$ \\
\hline
\end{tabular}

e5) Número de días con dato válido por mes y año de los sondeos de Lisboa:

\begin{tabular}{|c|c|c|c|c|c|c|c|c|c|c|c|c|c|}
\hline Año \Mes & 1 & 2 & 3 & 4 & 5 & 6 & 7 & 8 & 9 & 10 & 11 & 12 & Total \\
\hline 2002 & 30 & 26 & 31 & 30 & 31 & 30 & 31 & 31 & 30 & 31 & 29 & 31 & 361 \\
\hline 2003 & 3 & 26 & 2 & 14 & 15 & 28 & 27 & 31 & 29 & 31 & 30 & 28 & 264 \\
\hline 2004 & 22 & 27 & 18 & 21 & 29 & 27 & 29 & 29 & 30 & 29 & 15 & 28 & 304 \\
\hline 2005 & 29 & 21 & 28 & 30 & 30 & 30 & 15 & 30 & 29 & 28 & 29 & 31 & 330 \\
\hline 2006 & 30 & 25 & 29 & 30 & 12 & 30 & 29 & 30 & 25 & 31 & 29 & 27 & 327 \\
\hline 2007 & 31 & 28 & 27 & 27 & 30 & 29 & 28 & 31 & 13 & 31 & 28 & 30 & 333 \\
\hline 2008 & 24 & 25 & 31 & 10 & 30 & 30 & 26 & 29 & 30 & 31 & 27 & 26 & 319 \\
\hline Total & 166 & 178 & 164 & 138 & 150 & 204 & 170 & 211 & 173 & 212 & 187 & 201 & 2154 \\
\hline
\end{tabular}

f) Resumen por mes de las medias mensuales de cada año de los sondeos de Lisboa:

\begin{tabular}{|c|c|c|c|c|c|c|c|c|c|c|c|c|}
\hline Mes & 1 & 2 & 3 & 4 & 5 & 6 & 7 & 8 & 9 & 10 & 11 & 12 \\
\hline Media & 13.62 & 13.43 & 13.55 & 14.44 & 17.13 & 19.55 & 19.59 & 20.55 & 21.31 & 20.37 & 16.50 & 14.14 \\
\hline STD & 2.51 & 2.65 & 1.44 & 1.07 & 1.40 & 1.53 & 1.86 & 1.69 & 3.03 & 2.98 & 2.95 & 1.41 \\
\hline Mediana & 13.88 & 13.17 & 13.60 & 14.54 & 16.71 & 19.73 & 18.53 & 20.85 & 21.34 & 18.91 & 15.61 & 13.66 \\
\hline Máximo & 16.45 & 17.33 & 16.25 & 16.00 & 19.48 & 22.52 & 22.81 & 22.93 & 26.15 & 26.14 & 21.10 & 17.26 \\
\hline Mínimo & 9.85 & 8.80 & 11.56 & 13.18 & 15.27 & 17.12 & 18.01 & 18.06 & 17.01 & 17.40 & 12.88 & 12.59 \\
\hline $\mathrm{N}^{0}$ Días & 166 & 178 & 164 & 138 & 150 & 204 & 170 & 211 & 173 & 212 & 187 & 201 \\
\hline
\end{tabular}




\section{Gráficas de la estación de radiosondeos Lisboa}

g) Evolución temporal de las medias diarias.

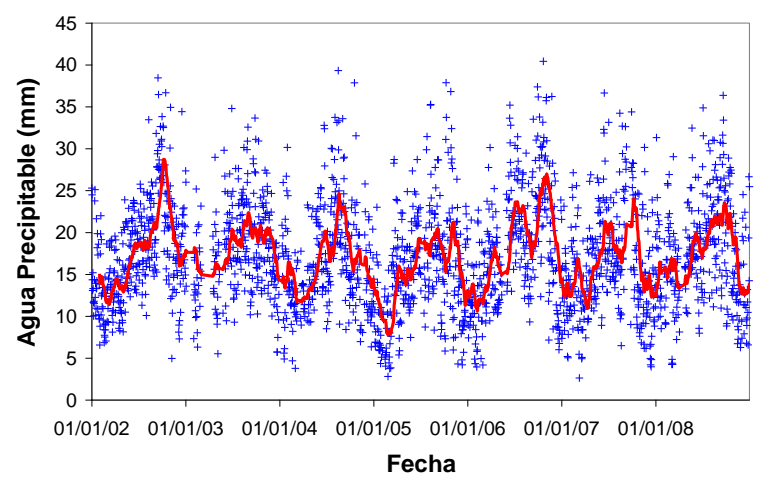

La línea roja representa la media móvil mensual. h) Histograma de las medias diarias.

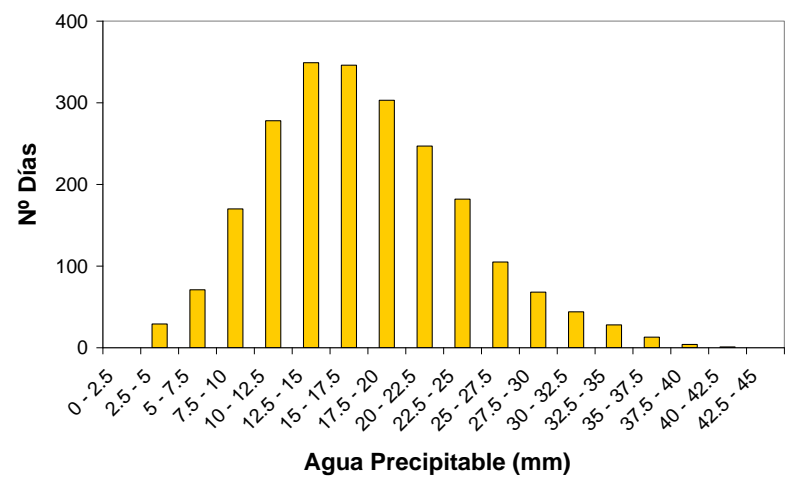

La distribución presenta un desplazamiento hacia la derecha (coef. de asimetría positivo). La distribución es prácticamente mesocúrtica (curtosis nula).

j) Ciclo promedio anual.

para cada mes y año.
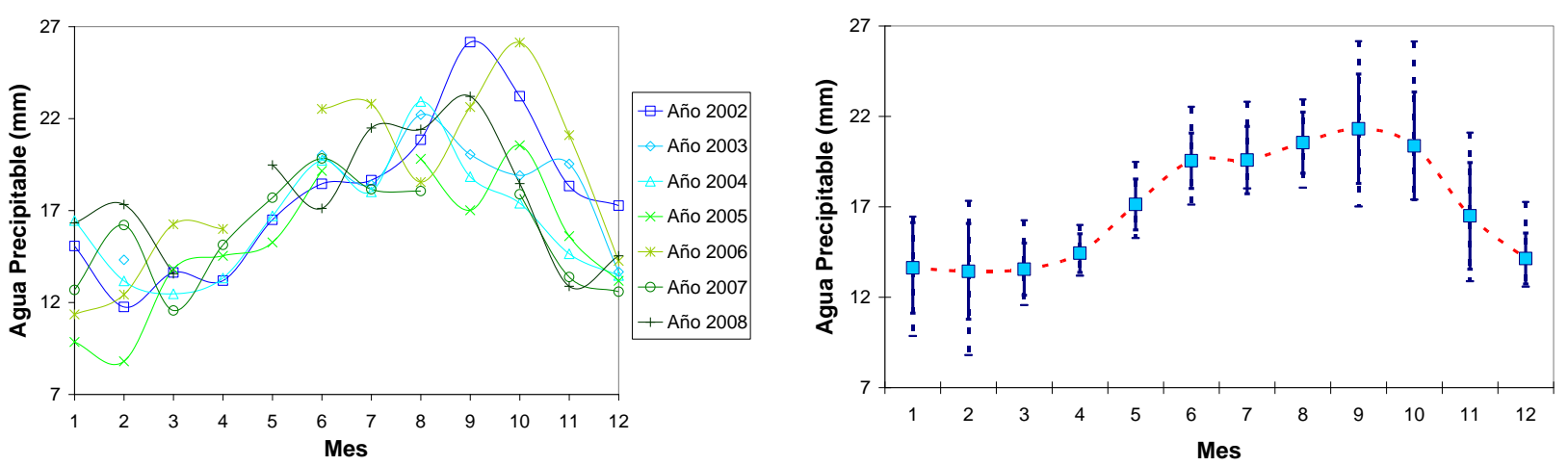

Valor promedio de las medias mensuales de cada año (cuadrados). Valor promedio más/menos la desviación típica de las medias mensuales (barras sólidas). Valor máximo y mínimo absoluto de las medias mensuales (líneas de trazos).

El número de sondeos es inferior al del resto de las estaciones porque desde diciembre del 2003 se redujo el número de lanzamientos a uno diario (12 UTC). Esto hace que esta estación pueda presentar un ligero sesgo positivo porque, como se verá en el capítulo del ciclo diurno, el PWV es mayor durante el día que durante la noche. 


\subsubsection{MURCIA (Observatorio Meteorológico). Estación de radiosondeo.}

El análisis estadístico se ha realizado en base a los sondeos que han superado los $9000 \mathrm{~m}$ de altitud.

a) Estadísticas globales del conjunto de los sondeos de Murcia:

\begin{tabular}{|c|c|c|c|c|c|c|c|c|c|c|}
\hline $\begin{array}{c}\mathbf{N}^{0} \\
\text { Sondeos }\end{array}$ & Media & STD & Mediana & $\begin{array}{c}\text { Clase } \\
\text { Modal }\end{array}$ & $\begin{array}{c}\text { Percentil } \\
\mathbf{5}\end{array}$ & $\begin{array}{c}\text { Percentil } \\
\mathbf{9 5}\end{array}$ & Máximo & Mínimo & $\begin{array}{c}\text { Coef. } \\
\text { Asimetría }\end{array}$ & Curtosis \\
\hline 4477 & 19.21 & 7.72 & 18.60 & $17.5-20$ & 7.74 & 32.81 & 46.48 & 2.46 & 0.33 & -0.44 \\
\hline
\end{tabular}

b) Estadísticas por mes del conjunto de los sondeos de Murcia:

\begin{tabular}{|c|c|c|c|c|c|c|c|c|c|c|c|c|}
\hline Estadístico | Mes & 1 & 2 & 3 & 4 & 5 & 6 & 7 & 8 & 9 & 10 & 11 & 12 \\
\hline Media & 11.94 & 12.71 & 13.63 & 16.19 & 19.71 & 24.01 & 25.54 & 27.27 & 26.83 & 22.67 & 16.13 & 13.99 \\
\hline STD & 4.72 & 4.72 & 4.47 & 4.46 & 5.16 & 4.85 & 5.26 & 6.34 & 6.57 & 6.32 & 6.14 & 4.72 \\
\hline Mediana & 11.56 & 12.31 & 13.29 & 16.27 & 19.62 & 24.01 & 25.52 & 27.12 & 26.48 & 23.30 & 15.41 & 13.47 \\
\hline Máximo & 31.28 & 26.16 & 26.08 & 29.63 & 32.93 & 34.89 & 41.63 & 46.48 & 41.62 & 42.11 & 37.96 & 31.32 \\
\hline Mínimo & 2.46 & 2.73 & 2.59 & 4.20 & 5.48 & 10.61 & 13.57 & 10.28 & 5.54 & 7.72 & 2.90 & 4.11 \\
\hline Percentil 5 & 4.79 & 5.83 & 5.83 & 8.62 & 11.37 & 16.17 & 17.25 & 17.80 & 16.51 & 12.28 & 6.99 & 7.23 \\
\hline Percentil 95 & 19.93 & 21.08 & 20.39 & 23.56 & 28.07 & 31.84 & 34.58 & 37.25 & 38.08 & 32.76 & 27.40 & 22.20 \\
\hline Coef. Asimetría & 0.54 & 0.35 & -0.07 & 0.02 & 0.07 & -0.14 & 0.24 & 0.04 & -0.07 & 0.03 & 0.72 & 0.48 \\
\hline Curtosis & 0.42 & -0.45 & -0.28 & 0.00 & -0.20 & -0.35 & -0.18 & -0.05 & -0.24 & -0.51 & 0.86 & -0.06 \\
\hline $\mathrm{N}^{0}$ Sondeos & 372 & 349 & 387 & 379 & 339 & 386 & 355 & 375 & 372 & 394 & 367 & 402 \\
\hline
\end{tabular}

c) Estadísticas globales de las medias diarias de los sondeos de Murcia:

\begin{tabular}{|c|c|c|c|c|c|c|c|c|c|c|}
\hline $\mathrm{N}^{0}$ Días & Media & STD & Mediana & Moda & \begin{tabular}{|c|} 
Percentil \\
5 \\
\end{tabular} & \begin{tabular}{|c|} 
Percentil \\
95 \\
\end{tabular} & Máximo & Mínimo & \begin{tabular}{|c} 
Coef. \\
Asimetría
\end{tabular} & Curtosis \\
\hline 2410 & 19.11 & 7.44 & 18.53 & $12.5-15$ & 7.97 & 32.02 & 45.13 & 2.90 & 0.30 & -0.52 \\
\hline
\end{tabular}

d) Resumen por mes de las medias diarias de los sondeos de Murcia:

\begin{tabular}{|c|c|c|c|c|c|c|c|c|c|c|c|c|}
\hline Estadístico \Mes & 1 & 2 & 3 & 4 & 5 & 6 & 7 & 8 & 9 & 10 & 11 & 12 \\
\hline Media & 11.91 & 12.74 & 13.62 & 16.20 & 19.41 & 23.99 & 25.38 & 27.32 & 26.31 & 22.49 & 15.91 & 13.94 \\
\hline STD & 4.35 & 4.44 & 4.11 & 4.12 & 4.83 & 4.42 & 4.72 & 5.79 & 6.23 & 5.90 & 5.84 & 4.37 \\
\hline Mediana & 11.87 & 12.17 & 13.17 & 16.37 & 19.23 & 24.01 & 25.27 & 27.44 & 25.52 & 22.86 & 15.00 & 13.60 \\
\hline Máximo & 28.16 & 25.08 & 22.96 & 29.23 & 30.71 & 34.52 & 36.89 & 45.13 & 40.53 & 38.59 & 36.84 & 29.07 \\
\hline Mínimo & 3.06 & 3.80 & 3.34 & 4.74 & 5.58 & 11.78 & 14.04 & 10.28 & 5.54 & 8.02 & 2.90 & 4.11 \\
\hline Percentil 5 & 5.66 & 6.28 & 6.28 & 9.48 & 12.08 & 17.03 & 17.67 & 18.55 & 17.44 & 12.79 & 7.56 & 7.46 \\
\hline Percentil 95 & 19.48 & 20.99 & 19.91 & 22.72 & 27.40 & 30.72 & 33.62 & 36.48 & 36.47 & 31.54 & 25.68 & 21.64 \\
\hline Coef. Asimetría & 0.52 & 0.37 & -0.15 & 0.06 & -0.01 & -0.23 & 0.14 & -0.07 & -0.12 & -0.02 & 0.73 & 0.47 \\
\hline Curtosis & 0.47 & -0.42 & -0.34 & 0.18 & -0.39 & -0.37 & -0.32 & 0.33 & 0.07 & -0.57 & 1.10 & 0.16 \\
\hline No Días & 209 & 191 & 208 & 202 & 176 & 207 & 201 & 205 & 198 & 213 & 191 & 209 \\
\hline
\end{tabular}

e1) Media de las medias diarias por mes y año de los sondeos de Murcia:

\begin{tabular}{|c|r|r|c|c|c|c|c|c|c|c|c|c|c|}
\hline Año \Mes & \multicolumn{1}{|c|}{$\mathbf{1}$} & \multicolumn{1}{|c|}{$\mathbf{2}$} & $\mathbf{3}$ & $\mathbf{4}$ & $\mathbf{5}$ & $\mathbf{6}$ & $\mathbf{7}$ & $\mathbf{8}$ & $\mathbf{9}$ & $\mathbf{1 0}$ & $\mathbf{1 1}$ & $\mathbf{1 2}$ & Media \\
\hline $\mathbf{2 0 0 2}$ & 13.43 & 10.60 & 14.16 & 16.03 & 15.99 & 20.43 & 24.17 & 27.55 & 24.89 & 21.13 & 16.24 & 15.34 & $\mathbf{1 8 . 3 3}$ \\
$\mathbf{2 0 0 3}$ & 10.68 & 12.81 & 14.91 & 16.53 & 20.31 & 25.30 & 25.69 & 27.17 & 25.78 & 21.44 & 18.18 & 12.97 & $\mathbf{1 9 . 3 1}$ \\
$\mathbf{2 0 0 4}$ & 10.97 & 12.09 & 13.47 & 14.73 & 20.04 & 24.68 & 26.32 & 27.84 & 28.16 & 20.38 & 12.10 & 14.34 & $\mathbf{1 8 . 7 6}$ \\
$\mathbf{2 0 0 5}$ & 8.41 & 9.69 & 13.61 & 13.37 & 17.58 & 24.17 & 23.84 & 22.64 & 19.63 & 21.79 & 13.47 & 13.72 & $\mathbf{1 6 . 8 3}$ \\
$\mathbf{2 0 0 6}$ & 13.68 & 13.06 & 13.59 & 19.27 & -- & 25.52 & 26.94 & 28.57 & 29.92 & 24.33 & 21.70 & 14.98 & $\mathbf{2 1 . 0 5}$ \\
$\mathbf{2 0 0 7}$ & 12.26 & 15.42 & 12.19 & 18.33 & -- & 24.01 & 23.24 & 29.19 & 28.78 & 22.98 & 14.15 & 13.09 & $\mathbf{1 9 . 4 2}$ \\
$\mathbf{2 0 0 8}$ & 14.01 & 15.48 & 13.27 & 14.78 & 21.15 & 23.91 & 27.07 & 27.95 & 27.37 & 25.34 & 13.96 & 13.02 & $\mathbf{1 9 . 7 8}$ \\
\hline Media & $\mathbf{1 1 . 9 2}$ & $\mathbf{1 2 . 7 4}$ & $\mathbf{1 3 . 6 0}$ & $\mathbf{1 6 . 1 5}$ & $\mathbf{1 9 . 0 1}$ & $\mathbf{2 4 . 0 0}$ & $\mathbf{2 5 . 3 3}$ & $\mathbf{2 7 . 2 7}$ & $\mathbf{2 6 . 3 6}$ & $\mathbf{2 2 . 4 9}$ & $\mathbf{1 5 . 6 9}$ & $\mathbf{1 3 . 9 2}$ & $\mathbf{1 9 . 0 7}$ \\
\hline
\end{tabular}


e2) Máximo de las medias diarias por mes y año de los sondeos de Murcia:

\begin{tabular}{|c|c|c|c|c|c|c|c|c|c|c|c|c|c|}
\hline Año \Mes & $\mathbf{1}$ & $\mathbf{2}$ & $\mathbf{3}$ & $\mathbf{4}$ & $\mathbf{5}$ & $\mathbf{6}$ & $\mathbf{7}$ & $\mathbf{8}$ & $\mathbf{9}$ & $\mathbf{1 0}$ & $\mathbf{1 1}$ & $\mathbf{1 2}$ & Media \\
\hline $\mathbf{2 0 0 2}$ & 28.16 & 16.39 & 18.58 & 24.70 & 25.28 & 28.24 & 34.99 & 34.85 & 35.34 & 38.59 & 26.84 & 29.07 & $\mathbf{2 8 . 4 2}$ \\
$\mathbf{2 0 0 3}$ & 21.41 & 21.35 & 21.80 & 23.71 & 27.35 & 31.92 & 35.90 & 37.08 & 40.02 & 30.64 & 25.98 & 17.86 & $\mathbf{2 7 . 9 2}$ \\
$\mathbf{2 0 0 4}$ & 16.92 & 21.48 & 20.74 & 22.14 & 30.71 & 30.29 & 36.89 & 36.74 & 38.22 & 30.74 & 24.52 & 24.36 & $\mathbf{2 7 . 8 1}$ \\
$\mathbf{2 0 0 5}$ & 16.35 & 14.27 & 21.58 & 18.87 & 28.84 & 32.28 & 31.37 & 39.96 & 29.51 & 31.41 & 21.70 & 19.14 & $\mathbf{2 5 . 4 4}$ \\
$\mathbf{2 0 0 6}$ & 19.78 & 23.88 & 22.96 & 29.23 & --- & 31.87 & 36.64 & 40.72 & 40.53 & 32.92 & 36.84 & 24.12 & $\mathbf{3 0 . 8 6}$ \\
$\mathbf{2 0 0 7}$ & 22.95 & 21.88 & 20.68 & 24.01 & --- & 30.52 & 35.34 & 45.13 & 39.14 & 32.10 & 27.55 & 21.13 & $\mathbf{2 9 . 1 3}$ \\
$\mathbf{2 0 0 8}$ & 20.42 & 25.08 & 21.65 & 28.27 & 29.70 & 34.52 & 34.11 & 37.60 & 35.40 & 37.74 & 26.04 & 21.74 & $\mathbf{2 9 . 3 6}$ \\
\hline Media & $\mathbf{2 0 . 8 6}$ & $\mathbf{2 0 . 6 2}$ & $\mathbf{2 1 . 1 4}$ & $\mathbf{2 4 . 4 2}$ & $\mathbf{2 8 . 3 8}$ & $\mathbf{3 1 . 3 8}$ & $\mathbf{3 5 . 0 3}$ & $\mathbf{3 8 . 8 7}$ & $\mathbf{3 6 . 8 8}$ & $\mathbf{3 3 . 4 5}$ & $\mathbf{2 7 . 0 7}$ & $\mathbf{2 2 . 4 9}$ & $\mathbf{2 8 . 4 2}$ \\
\hline
\end{tabular}

e3) Mínimo de las medias diarias por mes y año de los sondeos de Murcia:

\begin{tabular}{|c|c|c|c|c|c|c|c|c|c|c|c|c|c|}
\hline Año \Mes & 1 & 2 & 3 & 4 & 5 & 6 & 7 & 8 & 9 & 10 & 11 & 12 & Media \\
\hline 2002 & 7.98 & 3.80 & 9.69 & 8.09 & 5.58 & 12.35 & 16.77 & 20.04 & 17.43 & 12.62 & 8.93 & 8.43 & 10.98 \\
\hline 2003 & 4.44 & 4.54 & 7.91 & 8.18 & 10.68 & 15.56 & 16.84 & 17.98 & 14.03 & 8.02 & 10.20 & 5.72 & 10.34 \\
\hline 2004 & 5.30 & 3.92 & 3.34 & 9.43 & 12.74 & 19.34 & 14.04 & 21.63 & 17.52 & 11.24 & 4.18 & 6.16 & 10.74 \\
\hline 2005 & 3.06 & 4.04 & 5.26 & 4.74 & 9.81 & 13.14 & 15.55 & 11.77 & 5.54 & 11.78 & 7.31 & 8.15 & 8.35 \\
\hline 2006 & 7.30 & 6.38 & 7.25 & 10.80 & --- & 11.78 & 19.45 & 18.05 & 19.48 & 10.12 & 11.23 & 7.31 & 11.74 \\
\hline 2007 & 5.76 & 8.60 & 4.71 & 12.07 & -- & 14.35 & 15.78 & 10.28 & 18.05 & 11.74 & 2.90 & 4.11 & 9.85 \\
\hline 2008 & 5.79 & 8.32 & 3.43 & 7.71 & 15.92 & 17.25 & 15.24 & 20.66 & 10.57 & 11.70 & 7.12 & 6.66 & 10.86 \\
\hline Media & 5.66 & 5.66 & 5.94 & 8.72 & 10.95 & 14.82 & 16.24 & 17.20 & 14.66 & 11.03 & 7.41 & 6.65 & 10.41 \\
\hline
\end{tabular}

e4) Desviación estándar de las medias diarias por mes y año de los sondeos de Murcia:

\begin{tabular}{|c|l|l|l|l|l|l|l|l|l|l|l|l|c|}
\hline Año \Mes & $\mathbf{1}$ & $\mathbf{2}$ & $\mathbf{3}$ & $\mathbf{4}$ & $\mathbf{5}$ & $\mathbf{6}$ & $\mathbf{7}$ & $\mathbf{8}$ & $\mathbf{9}$ & $\mathbf{1 0}$ & $\mathbf{1 1}$ & $\mathbf{1 2}$ & Media \\
\hline $\mathbf{2 0 0 2}$ & 4.66 & 2.69 & 2.10 & 3.71 & 4.25 & 3.82 & 4.00 & 3.93 & 4.01 & 6.44 & 4.44 & 4.73 & $\mathbf{4 . 0 6}$ \\
$\mathbf{2 0 0 3}$ & 3.95 & 3.91 & 4.10 & 3.75 & 3.62 & 4.02 & 5.10 & 5.11 & 5.71 & 5.28 & 4.51 & 3.50 & $\mathbf{4 . 3 8}$ \\
$\mathbf{2 0 0 4}$ & 3.20 & 5.17 & 4.58 & 3.28 & 4.79 & 3.44 & 4.33 & 3.80 & 5.69 & 5.96 & 5.79 & 4.85 & $\mathbf{4 . 5 7}$ \\
$\mathbf{2 0 0 5}$ & 3.51 & 3.10 & 4.90 & 3.70 & 5.06 & 4.43 & 4.27 & 6.96 & 4.97 & 5.19 & 4.30 & 3.02 & $\mathbf{4 . 4 5}$ \\
$\mathbf{2 0 0 6}$ & 3.79 & 4.32 & 3.19 & 3.62 & --- & 5.24 & 5.03 & 5.53 & 5.51 & 5.02 & 6.80 & 4.65 & $\mathbf{4 . 7 9}$ \\
$\mathbf{2 0 0 7}$ & 4.17 & 3.56 & 4.08 & 3.11 & --- & 4.00 & 4.25 & 7.40 & 5.49 & 4.72 & 5.10 & 3.86 & $\mathbf{4 . 5 2}$ \\
$\mathbf{2 0 0 8}$ & 3.97 & 4.37 & 4.71 & 4.24 & 3.16 & 3.75 & 4.29 & 4.88 & 6.12 & 6.72 & 4.15 & 4.91 & $\mathbf{4 . 6 1}$ \\
\hline Media & $\mathbf{3 . 8 9}$ & $\mathbf{3 . 8 7}$ & $\mathbf{3 . 9 5}$ & $\mathbf{3 . 6 3}$ & $\mathbf{4 . 1 8}$ & $\mathbf{4 . 1 0}$ & $\mathbf{4 . 4 7}$ & $\mathbf{5 . 3 7}$ & $\mathbf{5 . 3 5}$ & $\mathbf{5 . 6 2}$ & $\mathbf{5 . 0 1}$ & $\mathbf{4 . 2 2}$ & $\mathbf{4 . 4 8}$ \\
\hline
\end{tabular}

e5) Número de días con dato válido por mes y año de los sondeos de Murcia:

\begin{tabular}{|c|c|c|c|c|c|c|c|c|c|c|c|c|c|}
\hline Año \ Mes & 1 & 2 & 3 & 4 & 5 & 6 & 7 & 8 & 9 & 10 & 11 & 12 & Tota \\
\hline 2002 & 30 & 27 & 31 & 28 & 31 & 30 & 30 & 31 & 30 & 31 & 30 & 31 & 360 \\
\hline 2003 & 31 & 28 & 31 & 30 & 31 & 30 & 30 & 30 & 29 & 31 & 30 & 30 & 361 \\
\hline 2004 & 28 & 25 & 29 & 30 & 31 & 30 & 29 & 30 & 29 & 30 & 16 & 31 & 338 \\
\hline 2005 & 30 & 28 & 29 & 29 & 31 & 30 & 28 & 27 & 28 & 29 & 30 & 29 & 348 \\
\hline 2006 & 30 & 28 & 30 & 30 & 15 & 28 & 30 & 31 & 26 & 31 & 28 & 30 & 337 \\
\hline 2007 & 31 & 27 & 29 & 30 & 7 & 30 & 25 & 27 & 28 & 31 & 27 & 30 & 322 \\
\hline 2008 & 29 & 28 & 29 & 25 & 30 & 29 & 29 & 29 & 28 & 30 & 30 & 28 & 344 \\
\hline Total & 209 & 191 & 208 & 202 & 154 & 207 & 201 & 205 & 198 & 213 & 191 & 209 & 2388 \\
\hline
\end{tabular}

f) Resumen por mes de las medias mensuales de cada año de los sondeos de Murcia:

\begin{tabular}{|c|c|c|c|c|c|c|c|c|c|c|c|c|}
\hline Mes & 1 & 2 & 3 & 4 & 5 & 6 & 7 & 8 & 9 & 10 & 11 & 12 \\
\hline Media & 11.92 & 12.74 & 13.60 & 16.15 & 19.01 & 24.00 & 25.33 & 27.27 & 26.36 & 22.49 & 15.69 & 13.92 \\
\hline STD & 1.87 & 2.04 & 0.77 & 1.94 & 1.92 & 1.57 & 1.45 & 1.99 & 3.18 & 1.68 & 3.06 & 0.91 \\
\hline Mediana & 12.26 & 12.81 & 13.59 & 16.03 & 20.04 & 24.17 & 25.69 & 27.84 & 27.37 & 21.79 & 14.15 & 13.72 \\
\hline Máximo & 14.01 & 15.48 & 14.91 & 19.27 & 21.15 & 25.52 & 27.07 & 29.19 & 29.92 & 25.34 & 21.70 & 15.34 \\
\hline Mínimo & 8.41 & 9.69 & 12.19 & 13.37 & 15.99 & 20.43 & 23.24 & 22.64 & 19.63 & 20.38 & 12.10 & 12.97 \\
\hline $\mathrm{N}^{0}$ Días & 209 & 191 & 208 & 202 & 154 & 207 & 201 & 205 & 198 & 213 & 191 & 209 \\
\hline
\end{tabular}




\section{Gráficas de la estación de Murcia}

g) Evolución temporal de las medias diarias.

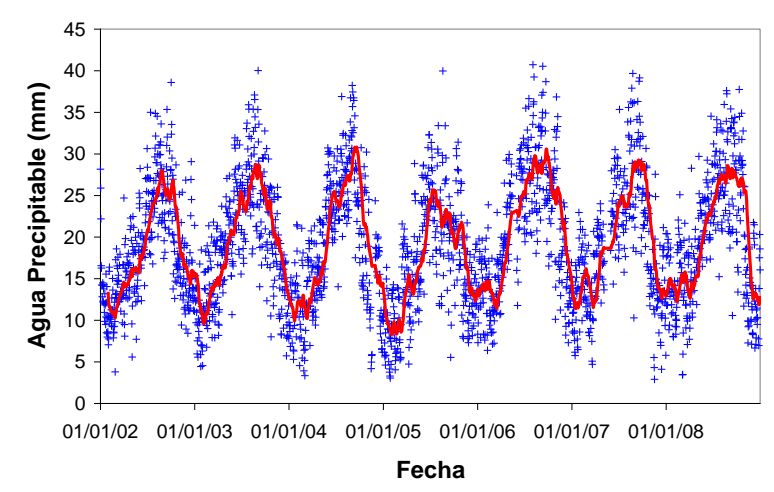

La línea roja representa la media móvil mensual. h) Histograma de las medias diarias.

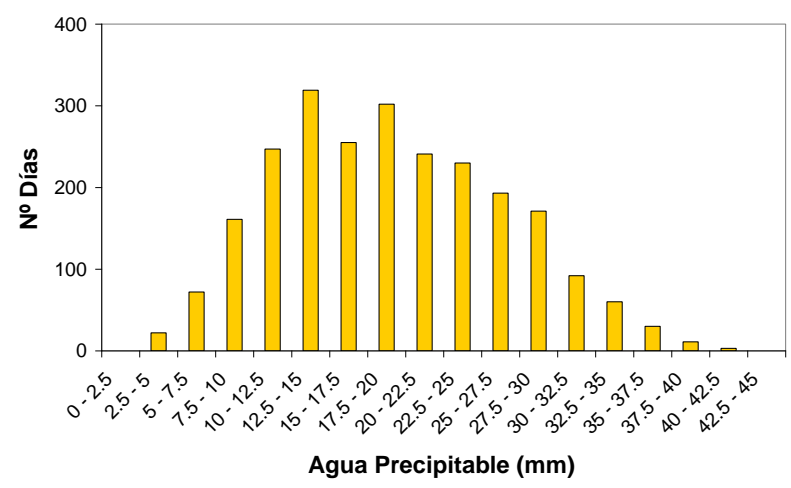

La distribución presenta un desplazamiento hacia la derecha (coef. de asimetría positivo), y un ligero achatamiento (curtosis negativa) respecto de la distribución normal.

j) Ciclo promedio anual.

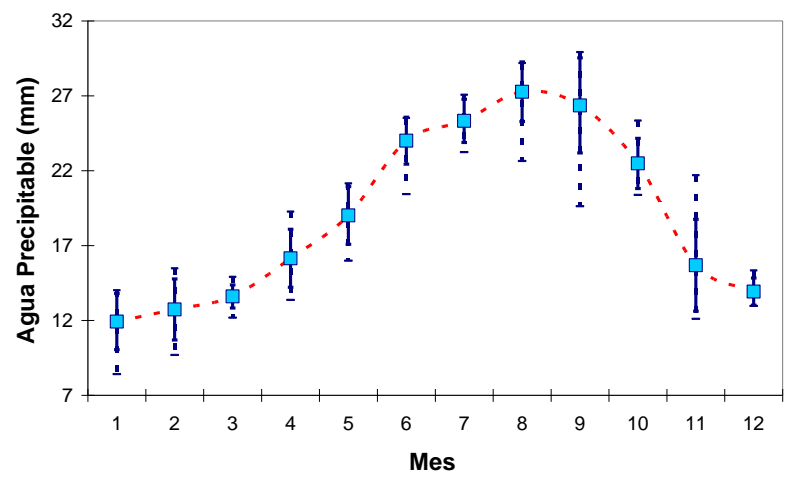

Valor promedio de las medias mensuales de cada año (cuadrados). Valor promedio más/menos la desviación típica de las medias mensuales (barras sólidas). Valor máximo y mínimo absoluto de las medias mensuales (líneas de trazos). 


\subsubsection{SANTANDER (aeropuerto). Estación de radiosondeo.}

El análisis estadístico se ha realizado en base a los sondeos que han superado los $7000 \mathrm{~m}$ de altitud.

a) Estadísticas globales del conjunto de los sondeos de Santander:

\begin{tabular}{|c|c|c|c|c|c|c|c|c|c|c|}
\hline $\begin{array}{c}\mathbf{N}^{\mathbf{0}} \\
\text { Sondeos }\end{array}$ & Media & STD & Mediana & $\begin{array}{c}\text { Clase } \\
\text { Modal }\end{array}$ & $\begin{array}{c}\text { Percentil } \\
\mathbf{5}\end{array}$ & $\begin{array}{c}\text { Percentil } \\
\mathbf{9 5}\end{array}$ & Máximo & Mínimo & $\begin{array}{c}\text { Coef. } \\
\text { Asimetría }\end{array}$ & Curtosis \\
\hline 4105 & 18.99 & 7.61 & 18.24 & $12.5-15$ & 7.98 & 32.51 & 46.49 & 2.87 & 0.45 & -0.30 \\
\hline
\end{tabular}

b) Estadísticas por mes del conjunto de los sondeos de Santander:

\begin{tabular}{|c|c|c|c|c|c|c|c|c|c|c|c|c|}
\hline Estadístico \Mes & 1 & 2 & 3 & 4 & 5 & 6 & 7 & 8 & 9 & 10 & 11 & 12 \\
\hline Media & 13.11 & 12.26 & 13.79 & 15.55 & 18.93 & 24.57 & 25.67 & 26.28 & 23.41 & 20.76 & 16.44 & 13.76 \\
\hline STD & 5.21 & 4.49 & 4.78 & 4.24 & 5.80 & 6.55 & 6.44 & 6.05 & 6.79 & 6.44 & 5.45 & 5.16 \\
\hline Mediana & 12.47 & 11.70 & 13.46 & 15.10 & 18.43 & 24.23 & 25.07 & 26.32 & 22.85 & 20.55 & 16.15 & 13.51 \\
\hline Máximo & 33.66 & 26.49 & 28.35 & 29.05 & 42.78 & 40.85 & 43.69 & 42.74 & 46.49 & 38.91 & 37.22 & 29.45 \\
\hline Mínimo & 3.90 & 2.87 & 3.55 & 5.32 & 6.19 & 9.12 & 8.72 & 10.32 & 8.91 & 6.03 & 3.96 & 3.40 \\
\hline Percentil 5 & 5.97 & 5.78 & 6.24 & 8.95 & 10.77 & 14.15 & 15.80 & 17.09 & 12.30 & 10.34 & 8.34 & 6.23 \\
\hline Percentil 95 & 22.25 & 20.99 & 21.23 & 22.69 & 29.18 & 35.61 & 38.00 & 37.16 & 33.94 & 31.61 & 25.86 & 23.82 \\
\hline Coef. Asimetría & 0.77 & 0.63 & 0.20 & 0.23 & 0.55 & 0.06 & 0.33 & 0.22 & 0.22 & 0.16 & 0.46 & 0.59 \\
\hline Curtosis & 0.55 & 0.31 & -0.46 & -0.45 & 0.29 & -0.64 & -0.19 & -0.09 & -0.26 & -0.38 & 0.38 & 0.11 \\
\hline $\mathrm{N}^{\circ}$ Sondeos & 323 & 301 & 331 & 308 & 368 & 360 & 361 & 375 & 335 & 378 & 336 & 329 \\
\hline
\end{tabular}

c) Estadísticas globales de las medias diarias de los sondeos de Santander:

\begin{tabular}{|c|c|c|c|c|c|c|c|c|c|c|}
\hline N$^{\circ}$ Días & Media & STD & Mediana & Moda & $\begin{array}{c}\text { Percentil } \\
\mathbf{5}\end{array}$ & $\begin{array}{c}\text { Percentil } \\
\mathbf{9 5}\end{array}$ & Máximo & Mínimo & $\begin{array}{c}\text { Coef. } \\
\text { Asimetría }\end{array}$ & Curtosis \\
\hline 2338 & 18.77 & 7.20 & 18.01 & $15-17.5$ & 8.34 & 31.29 & 41.96 & 3.40 & 0.37 & -0.50 \\
\hline
\end{tabular}

d) Resumen por mes de las medias diarias de los sondeos de Santander:

\begin{tabular}{|c|c|c|c|c|c|c|c|c|c|c|c|c|}
\hline Estadístico \Mes & 1 & 2 & 3 & 4 & 5 & 6 & 7 & 8 & 9 & 10 & 11 & 12 \\
\hline Media & 13.04 & 12.09 & 13.79 & 15.49 & 18.70 & 24.32 & 25.66 & 26.06 & 23.12 & 20.53 & 16.21 & 13.58 \\
\hline STD & 4.66 & 3.98 & 4.41 & 3.89 & 5.43 & 6.13 & 5.50 & 5.20 & 6.21 & 5.91 & 5.11 & 4.81 \\
\hline Mediana & 12.32 & 11.67 & 13.68 & 15.50 & 18.39 & 24.18 & 25.21 & 26.78 & 22.54 & 20.55 & 15.64 & 13.38 \\
\hline Máximo & 24.83 & 25.06 & 25.94 & 26.56 & 36.56 & 38.07 & 41.96 & 41.28 & 40.99 & 36.25 & 37.22 & 28.60 \\
\hline Mínimo & 4.99 & 3.97 & 4.23 & 5.32 & 7.40 & 9.12 & 14.59 & 12.69 & 8.91 & 7.14 & 4.10 & 3.40 \\
\hline Percentil 5 & 6.54 & 5.76 & 6.45 & 9.69 & 10.96 & 13.90 & 17.59 & 17.41 & 13.49 & 10.88 & 8.89 & 6.22 \\
\hline Percentil 95 & 21.58 & 19.00 & 20.37 & 21.33 & 27.75 & 34.32 & 35.42 & 34.00 & 32.71 & 30.38 & 25.37 & 23.02 \\
\hline Coef. Asimetría & 0.46 & 0.52 & 0.07 & 0.20 & 0.55 & -0.08 & 0.30 & 0.01 & 0.02 & 0.08 & 0.56 & 0.55 \\
\hline Curtosis & -0.47 & 0.45 & -0.53 & -0.19 & 0.01 & -0.51 & -0.49 & 0.08 & -0.56 & -0.48 & 0.76 & 0.31 \\
\hline $\mathrm{N}^{0}$ Días & 185 & 172 & 193 & 174 & 208 & 203 & 203 & 209 & 193 & 210 & 196 & 192 \\
\hline
\end{tabular}

e1) Media de las medias diarias por mes y año de los sondeos de Santander:

\begin{tabular}{|c|c|c|c|c|c|c|c|c|c|c|c|c|c|}
\hline Año \Mes & $\mathbf{1}$ & $\mathbf{2}$ & $\mathbf{3}$ & $\mathbf{4}$ & $\mathbf{5}$ & $\mathbf{6}$ & $\mathbf{7}$ & $\mathbf{8}$ & $\mathbf{9}$ & $\mathbf{1 0}$ & $\mathbf{1 1}$ & $\mathbf{1 2}$ & Media \\
\hline $\mathbf{2 0 0 2}$ & 12.54 & 12.92 & 13.87 & 13.48 & 18.03 & 23.24 & 24.13 & 26.20 & 21.69 & 21.32 & 17.07 & 16.50 & $\mathbf{1 8 . 4 2}$ \\
$\mathbf{2 0 0 3}$ & 12.77 & 13.00 & 14.18 & 14.91 & 17.78 & 25.78 & 25.32 & 28.23 & 24.19 & 20.35 & 17.92 & 14.49 & $\mathbf{1 9 . 0 8}$ \\
$\mathbf{2 0 0 4}$ & 15.27 & 10.60 & 13.37 & 13.30 & 17.22 & 23.29 & 24.07 & 25.20 & 23.38 & 17.68 & 13.66 & 13.04 & $\mathbf{1 7 . 5 1}$ \\
$\mathbf{2 0 0 5}$ & 11.09 & 9.65 & 10.61 & --- & 15.67 & 22.99 & 23.33 & 24.29 & 21.29 & 18.50 & 14.15 & 10.83 & $\mathbf{1 6 . 5 8}$ \\
$\mathbf{2 0 0 6}$ & 11.41 & 10.31 & 15.98 & 16.50 & 20.30 & 26.67 & 32.97 & 26.21 & 27.57 & 24.72 & 19.95 & 13.35 & $\mathbf{2 0 . 5 0}$ \\
$\mathbf{2 0 0 7}$ & 13.48 & 13.19 & 12.99 & 19.02 & 20.86 & 23.54 & 24.86 & 25.53 & 20.94 & 20.98 & 13.87 & 13.13 & $\mathbf{1 8 . 5 3}$ \\
$\mathbf{2 0 0 8}$ & 15.46 & 13.97 & 14.96 & 16.02 & 21.12 & 24.64 & 25.11 & 26.49 & 23.18 & 20.03 & 16.23 & 13.82 & $\mathbf{1 9 . 2 5}$ \\
\hline Media & $\mathbf{1 3 . 1 5}$ & $\mathbf{1 1 . 9 5}$ & $\mathbf{1 3 . 7 1}$ & $\mathbf{1 5 . 5 4}$ & $\mathbf{1 8 . 7 1}$ & $\mathbf{2 4 . 3 1}$ & $\mathbf{2 5 . 6 8}$ & $\mathbf{2 6 . 0 2}$ & $\mathbf{2 3 . 1 8}$ & $\mathbf{2 0 . 5 1}$ & $\mathbf{1 6 . 1 2}$ & $\mathbf{1 3 . 6 0}$ & $\mathbf{1 8 . 5 5}$ \\
\hline
\end{tabular}


e2) Máximo de las medias diarias por mes y año de los sondeos de Santander:

\begin{tabular}{|c|c|c|c|c|c|c|c|c|c|c|c|c|c|}
\hline Año \Mes & $\mathbf{1}$ & $\mathbf{2}$ & $\mathbf{3}$ & $\mathbf{4}$ & $\mathbf{5}$ & $\mathbf{6}$ & $\mathbf{7}$ & $\mathbf{8}$ & $\mathbf{9}$ & $\mathbf{1 0}$ & $\mathbf{1 1}$ & $\mathbf{1 2}$ & Media \\
\hline $\mathbf{2 0 0 2}$ & 20.90 & 19.38 & 19.85 & 18.57 & 26.28 & 30.32 & 36.47 & 32.80 & 30.14 & 33.89 & 37.22 & 28.60 & $\mathbf{2 7 . 8 7}$ \\
$\mathbf{2 0 0 3}$ & 21.16 & 18.72 & 24.98 & 20.46 & 30.54 & 35.78 & 35.64 & 39.64 & 33.06 & 32.15 & 26.55 & 27.84 & $\mathbf{2 8 . 8 8}$ \\
$\mathbf{2 0 0 4}$ & 24.20 & 17.08 & 24.30 & 23.61 & 27.10 & 33.72 & 32.02 & 34.86 & 35.04 & 26.33 & 21.40 & 17.80 & $\mathbf{2 6 . 4 6}$ \\
$\mathbf{2 0 0 5}$ & 18.66 & 18.48 & 19.88 & --- & 30.97 & 38.07 & 32.10 & 36.20 & 32.39 & 30.50 & 23.33 & 17.20 & $\mathbf{2 7 . 0 7}$ \\
$\mathbf{2 0 0 6}$ & 22.04 & 18.54 & 25.94 & 20.72 & 36.56 & 35.62 & 41.96 & 41.15 & 40.99 & 31.96 & 27.43 & 24.29 & $\mathbf{3 0 . 6 0}$ \\
$\mathbf{2 0 0 7}$ & 24.63 & 19.09 & 21.69 & 26.56 & 32.72 & 34.11 & 32.91 & 36.68 & 33.53 & 36.25 & 25.22 & 22.93 & $\mathbf{2 8 . 8 6}$ \\
$\mathbf{2 0 0 8}$ & 24.83 & 25.06 & 21.95 & 26.01 & 34.60 & 35.72 & 36.31 & 41.28 & 34.00 & 30.47 & 23.58 & 25.17 & $\mathbf{2 9 . 9 2}$ \\
\hline Media & $\mathbf{2 2 . 3 5}$ & $\mathbf{1 9 . 4 8}$ & $\mathbf{2 2 . 6 6}$ & $\mathbf{2 2 . 6 6}$ & $\mathbf{3 1 . 2 5}$ & $\mathbf{3 4 . 7 6}$ & $\mathbf{3 5 . 3 4}$ & $\mathbf{3 7 . 5 2}$ & $\mathbf{3 4 . 1 6}$ & $\mathbf{3 1 . 6 5}$ & $\mathbf{2 6 . 3 9}$ & $\mathbf{2 3 . 4 0}$ & $\mathbf{2 8 . 5 2}$ \\
\hline
\end{tabular}

e3) Mínimo de las medias diarias por mes y año de los sondeos de Santander:

\begin{tabular}{|c|c|c|c|c|c|c|c|c|c|c|c|c|c|}
\hline Año \Mes & 1 & 2 & 3 & 4 & 5 & 6 & 7 & 8 & 9 & 10 & 11 & 12 & Media \\
\hline 2002 & 6.32 & 9.07 & 6.30 & 8.32 & 10.65 & 14.16 & 15.84 & 17.39 & 9.60 & 8.35 & 9.00 & 8.82 & 10.32 \\
\hline 2003 & 6.32 & 4.78 & 6.30 & 8.46 & 9.84 & 18.30 & 15.68 & 17.20 & 16.35 & 7.14 & 11.77 & 7.26 & 10.78 \\
\hline 2004 & 5.16 & 4.39 & 4.73 & 8.67 & 8.45 & 10.52 & 16.31 & 14.90 & 9.23 & 9.23 & 6.25 & 6.70 & 8.71 \\
\hline 2005 & 4.99 & 5.08 & 4.23 & --- & 7.40 & 9.12 & 16.24 & 13.17 & 11.06 & 8.50 & 6.34 & 3.40 & 8.14 \\
\hline 2006 & 5.15 & 6.11 & 9.04 & 8.84 & 11.27 & 10.95 & 24.87 & 13.53 & 19.74 & 15.82 & 6.96 & 5.22 & 11.46 \\
\hline 2007 & 6.74 & 3.97 & 4.84 & 13.35 & 10.45 & 18.20 & 18.12 & 12.69 & 8.91 & 7.98 & 4.10 & 4.90 & 9.52 \\
\hline 2008 & 6.11 & 4.21 & 8.46 & 5.32 & 12.85 & 11.18 & 14.59 & 16.95 & 15.84 & 9.88 & 9.95 & 5.84 & 10.10 \\
\hline Media & 5.83 & 5.37 & 6.27 & 8.83 & 10.13 & 13.20 & 17.38 & 15.12 & 12.96 & 9.56 & 7.77 & 6.02 & 9.86 \\
\hline
\end{tabular}

e4) Desviación estándar de las medias diarias de cada mes y año de los sondeos de Santander:

\begin{tabular}{|c|l|l|l|l|l|l|l|l|l|l|l|l|c|}
\hline Año \Mes & $\mathbf{1}$ & $\mathbf{2}$ & $\mathbf{3}$ & $\mathbf{4}$ & $\mathbf{5}$ & $\mathbf{6}$ & $\mathbf{7}$ & $\mathbf{8}$ & $\mathbf{9}$ & $\mathbf{1 0}$ & $\mathbf{1 1}$ & $\mathbf{1 2}$ & Media \\
\hline $\mathbf{2 0 0 2}$ & 4.17 & 2.45 & 3.83 & 3.03 & 4.04 & 4.40 & 5.17 & 4.01 & 6.50 & 5.72 & 6.40 & 4.88 & $\mathbf{4 . 5 5}$ \\
$\mathbf{2 0 0 3}$ & 4.12 & 3.86 & 4.79 & 3.29 & 4.62 & 4.67 & 4.56 & 4.38 & 4.66 & 5.72 & 3.86 & 4.81 & $\mathbf{4 . 4 5}$ \\
$\mathbf{2 0 0 4}$ & 5.23 & 2.90 & 4.74 & 3.35 & 5.76 & 6.24 & 4.32 & 5.22 & 6.91 & 4.43 & 3.39 & 2.80 & $\mathbf{4 . 6 1}$ \\
$\mathbf{2 0 0 5}$ & 3.70 & 3.28 & 4.19 & --- & 4.55 & 7.64 & 4.69 & 5.16 & 5.63 & 4.94 & 4.31 & 3.76 & $\mathbf{4 . 7 1}$ \\
$\mathbf{2 0 0 6}$ & 3.69 & 2.84 & 4.09 & 3.09 & 5.42 & 7.61 & 3.68 & 5.42 & 5.52 & 4.19 & 5.37 & 5.04 & $\mathbf{4 . 6 6}$ \\
$\mathbf{2 0 0 7}$ & 4.69 & 3.09 & 3.66 & 3.42 & 6.08 & 4.05 & 3.72 & 6.22 & 5.74 & 7.12 & 4.76 & 5.17 & $\mathbf{4 . 8 1}$ \\
$\mathbf{2 0 0 8}$ & 5.05 & 6.06 & 3.50 & 4.55 & 4.79 & 6.34 & 5.71 & 4.88 & 5.67 & 6.01 & 3.14 & 4.86 & $\mathbf{5 . 0 5}$ \\
\hline Media & $\mathbf{4 . 3 8}$ & $\mathbf{3 . 5 0}$ & $\mathbf{4 . 1 1}$ & $\mathbf{3 . 4 6}$ & $\mathbf{5 . 0 4}$ & $\mathbf{5 . 8 5}$ & $\mathbf{4 . 5 5}$ & $\mathbf{5 . 0 4}$ & $\mathbf{5 . 8 1}$ & $\mathbf{5 . 4 5}$ & $\mathbf{4 . 4 6}$ & $\mathbf{4 . 4 7}$ & $\mathbf{4 . 6 9}$ \\
\hline
\end{tabular}

e5) Número de días con dato válido por mes y año de los sondeos de Santander:

\begin{tabular}{|c|c|c|c|c|c|c|c|c|c|c|c|c|c|}
\hline Año | Mes & 1 & 2 & 3 & 4 & 5 & 6 & 7 & 8 & 9 & 10 & 11 & 12 & Total \\
\hline 2002 & 30 & 26 & 28 & 27 & 31 & 30 & 29 & 31 & 27 & 30 & 27 & 28 & 344 \\
\hline 2003 & 25 & 26 & 28 & 29 & 29 & 29 & 31 & 31 & 27 & 30 & 29 & 26 & 340 \\
\hline 2004 & 29 & 24 & 27 & 26 & 30 & 27 & 29 & 28 & 28 & 29 & 21 & 28 & 326 \\
\hline 2005 & 28 & 17 & 24 & 13 & 30 & 28 & 28 & 28 & 28 & 31 & 30 & 29 & 314 \\
\hline 2006 & 29 & 26 & 30 & 30 & 28 & 29 & 28 & 29 & 26 & 31 & 30 & 24 & 340 \\
\hline 2007 & 24 & 28 & 29 & 20 & 30 & 30 & 28 & 31 & 29 & 29 & 30 & 28 & 336 \\
\hline 2008 & 20 & 25 & 27 & 29 & 30 & 30 & 30 & 31 & 28 & 30 & 29 & 29 & 338 \\
\hline Total & 185 & 172 & 193 & 161 & 208 & 203 & 203 & 209 & 193 & 210 & 196 & 192 & 2325 \\
\hline
\end{tabular}

f) Resumen por mes de las medias mensuales de cada año de los sondeos de Santander:

\begin{tabular}{|c|c|c|c|c|c|c|c|c|c|c|c|c|}
\hline Mes & 1 & 2 & 3 & 4 & 5 & 6 & 7 & 8 & 9 & 10 & 11 & 12 \\
\hline Media & 13.15 & 11.95 & 13.71 & 15.54 & 18.71 & 24.31 & 25.68 & 26.02 & 23.18 & 20.51 & 16.12 & 13.60 \\
\hline STD & 1.59 & 1.58 & 1.57 & 1.95 & 1.92 & 1.33 & 3.04 & 1.14 & 2.11 & 2.10 & 2.20 & 1.58 \\
\hline Mediana & 12.77 & 12.92 & 13.87 & 15.47 & 18.03 & 23.54 & 24.86 & 26.20 & 23.18 & 20.35 & 16.23 & 13.35 \\
\hline Máximo & 15.46 & 13.97 & 15.98 & 19.02 & 21.12 & 26.67 & 32.97 & 28.23 & 27.57 & 24.72 & 19.95 & 16.50 \\
\hline Mínimo & 11.09 & 9.65 & 10.61 & 13.30 & 15.67 & 22.99 & 23.33 & 24.29 & 20.94 & 17.68 & 13.66 & 10.83 \\
\hline No Días & 185 & 172 & 193 & 161 & 208 & 203 & 203 & 209 & 193 & 210 & 196 & 192 \\
\hline
\end{tabular}




\section{Gráficas de la estación de Santander}

g) Evolución temporal de las medias diarias.

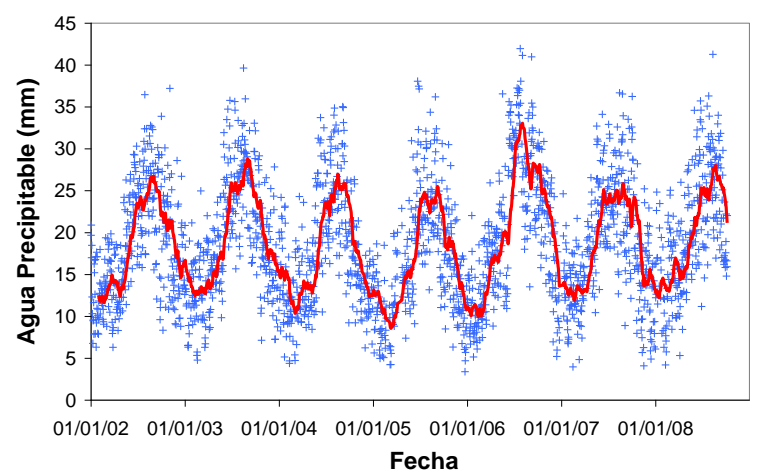

La línea roja representa la media móvil mensual. h) Histograma de las medias diarias.

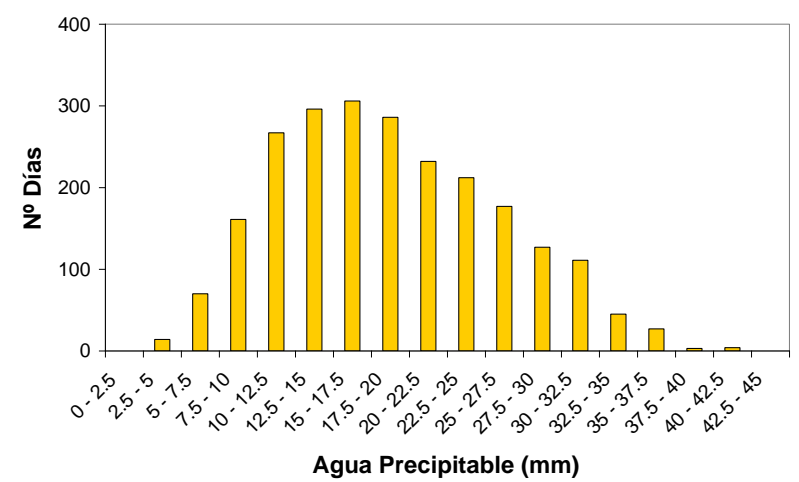

La distribución presenta un desplazamiento hacia la derecha (coef. de asimetría positivo), y un ligero achatamiento (curtosis negativa) respecto de la distribución normal.

j) Ciclo promedio anual. para cada mes y año.
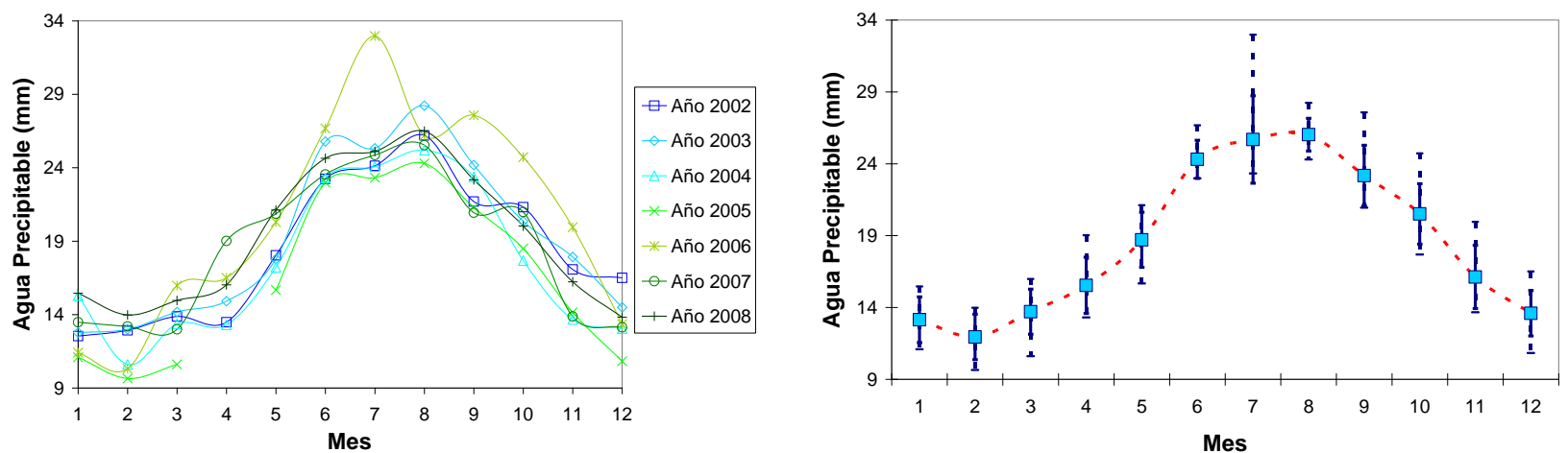

Valor promedio de las medias mensuales de cada año (cuadrados). Valor promedio más/menos la desviación típica de las medias mensuales (barras sólidas). Valor máximo y mínimo absoluto de las medias mensuales (líneas de trazos). 


\subsubsection{ZARAGOZA (aeropuerto). Estación de radiosondeo.}

El análisis estadístico se ha realizado en base a los sondeos que han superado los $7000 \mathrm{~m}$ de altitud.

a) Estadísticas globales del conjunto de los sondeos de Zaragoza:

\begin{tabular}{|c|c|c|c|c|c|c|c|c|c|c|}
\hline $\begin{array}{c}\mathbf{N}^{0} \\
\text { Sondeos }\end{array}$ & Media & STD & Mediana & $\begin{array}{c}\text { Clase } \\
\text { Modal }\end{array}$ & $\begin{array}{c}\text { Percentil } \\
\mathbf{5}\end{array}$ & $\begin{array}{c}\text { Percentil } \\
\mathbf{9 5}\end{array}$ & Máximo & Mínimo & $\begin{array}{c}\text { Coef. } \\
\text { Asimetría }\end{array}$ & Curtosis \\
\hline 3095 & 16.97 & 7.25 & 16.04 & $15-17.5$ & 6.55 & 30.02 & 42.58 & 2.54 & 0.45 & -0.44 \\
\hline
\end{tabular}

b) Estadísticas por mes del conjunto de los sondeos de Zaragoza:

\begin{tabular}{|c|c|c|c|c|c|c|c|c|c|c|c|c|}
\hline Estadístico \ Mes & 1 & 2 & 3 & 4 & 5 & 6 & 7 & 8 & 9 & 10 & 11 & 12 \\
\hline Media & 12.20 & 11.29 & 12.71 & 14.69 & 17.64 & 22.97 & 23.65 & 24.10 & 22.55 & 19.52 & 14.57 & 12.24 \\
\hline STD & 4.59 & 4.29 & 4.64 & 4.69 & 5.29 & 6.44 & 6.33 & 5.42 & 7.44 & 6.35 & 5.63 & 5.06 \\
\hline Mediana & 11.56 & 10.80 & 12.57 & 14.75 & 17.23 & 23.92 & 23.47 & 24.42 & 23.52 & 18.93 & 13.79 & 11.73 \\
\hline Máximo & 24.65 & 26.05 & 25.66 & 26.48 & 30.60 & 39.06 & 42.58 & 35.80 & 38.50 & 35.15 & 32.37 & 27.37 \\
\hline Mínimo & 3.31 & 2.54 & 2.84 & 5.38 & 6.26 & 6.98 & 10.20 & 12.57 & 5.79 & 6.47 & 2.61 & 2.97 \\
\hline Percentil 5 & 5.31 & 4.97 & 5.20 & 7.81 & 9.92 & 12.09 & 13.46 & 14.63 & 9.43 & 9.63 & 6.04 & 4.86 \\
\hline Percentil 95 & 20.53 & 19.82 & 20.84 & 22.83 & 27.24 & 32.24 & 34.80 & 32.70 & 32.82 & 31.48 & 24.81 & 21.87 \\
\hline Coef. Asimetría & 0.36 & 0.60 & 0.20 & 0.16 & 0.23 & -0.31 & 0.22 & -0.06 & -0.27 & 0.32 & 0.50 & 0.63 \\
\hline Curtosis & -0.60 & 0.18 & -0.42 & -0.74 & -0.55 & -0.46 & -0.19 & -0.66 & -0.82 & -0.22 & 0.04 & 0.09 \\
\hline No Sondeos & 299 & 254 & 273 & 297 & 273 & 270 & 250 & 227 & 186 & 217 & 265 & 284 \\
\hline
\end{tabular}

c) Estadísticas globales de las medias diarias de los sondeos de Zaragoza:

\begin{tabular}{|c|c|c|c|c|c|c|c|c|c|c|}
\hline $\mathrm{N}^{0}$ Días & Media & STD & Mediana & Moda & \begin{tabular}{|c|} 
Percentil \\
5 \\
\end{tabular} & \begin{tabular}{|c|} 
Percentil \\
95 \\
\end{tabular} & Máximo & Mínimo & \begin{tabular}{|c} 
Coef. \\
Asimetría
\end{tabular} & Curtosis \\
\hline 1771 & 17.07 & 7.04 & 16.11 & $15-17.5$ & 7.02 & 29.56 & 42.58 & 2.54 & 0.40 & -0.51 \\
\hline
\end{tabular}

d) Resumen por mes de las medias diarias de los sondeos de Zaragoza:

\begin{tabular}{|c|c|c|c|c|c|c|c|c|c|c|c|c|}
\hline Estadístico \Mes & 1 & 2 & 3 & 4 & 5 & 6 & 7 & 8 & 9 & 10 & 11 & 12 \\
\hline Media & 12.25 & 11.25 & 12.78 & 14.63 & 17.81 & 22.90 & 23.52 & 23.99 & 22.60 & 19.81 & 14.38 & 12.26 \\
\hline STD & 4.28 & 4.19 & 4.22 & 4.46 & 4.94 & 6.06 & 5.86 & 5.05 & 7.20 & 6.15 & 5.21 & 4.83 \\
\hline Mediana & 11.66 & 10.72 & 13.05 & 14.90 & 17.37 & 23.86 & 23.77 & 24.25 & 24.12 & 18.98 & 13.84 & 12.01 \\
\hline Máximo & 22.54 & 26.05 & 24.08 & 25.79 & 30.30 & 39.06 & 42.58 & 34.76 & 37.22 & 34.59 & 29.70 & 26.57 \\
\hline Mínimo & 3.50 & 2.54 & 3.56 & 5.79 & 7.32 & 8.07 & 11.00 & 13.01 & 6.55 & 7.58 & 2.78 & 2.97 \\
\hline Percentil 5 & 5.81 & 5.12 & 5.27 & 7.85 & 10.77 & 11.92 & 13.41 & 15.09 & 9.99 & 9.80 & 5.99 & 4.83 \\
\hline Percentil 95 & 20.06 & 19.45 & 19.70 & 22.02 & 25.92 & 30.95 & 33.27 & 31.58 & 32.13 & 30.64 & 23.47 & 20.54 \\
\hline Coef. Asimetría & 0.33 & 0.65 & 0.03 & 0.13 & 0.29 & -0.39 & 0.17 & -0.19 & -0.33 & 0.25 & 0.33 & 0.45 \\
\hline Curtosis & -0.58 & 0.56 & -0.29 & -0.70 & -0.60 & -0.41 & 0.22 & -0.61 & -0.86 & -0.44 & -0.08 & -0.17 \\
\hline $\mathrm{N}^{\circ}$ Días & 168 & 142 & 152 & 169 & 155 & 154 & 145 & 138 & 113 & 127 & 147 & 161 \\
\hline
\end{tabular}

e1) Media de las medias diarias por mes y año de los sondeos de Zaragoza:

\begin{tabular}{|c|c|c|c|c|c|c|c|c|c|c|c|c|c|}
\hline Año \Mes & $\mathbf{1}$ & $\mathbf{2}$ & $\mathbf{3}$ & $\mathbf{4}$ & $\mathbf{5}$ & $\mathbf{6}$ & $\mathbf{7}$ & $\mathbf{8}$ & $\mathbf{9}$ & $\mathbf{1 0}$ & $\mathbf{1 1}$ & $\mathbf{1 2}$ & Media \\
\hline $\mathbf{2 0 0 2}$ & 12.51 & 11.54 & 13.65 & 12.62 & 17.47 & 22.59 & 23.13 & 25.08 & 20.27 & 19.04 & 14.61 & 14.55 & $\mathbf{1 7 . 2 6}$ \\
$\mathbf{2 0 0 3}$ & 12.21 & 10.43 & 12.86 & 15.44 & 17.27 & 25.73 & 22.93 & 24.33 & 22.02 & 18.77 & 14.69 & 12.02 & $\mathbf{1 7 . 3 9}$ \\
$\mathbf{2 0 0 4}$ & 11.57 & 9.39 & 10.79 & 12.54 & 15.73 & 21.36 & 22.46 & 24.27 & 24.04 & -- & --- & -- & $\mathbf{1 6 . 9 0}$ \\
$\mathbf{2 0 0 5}$ & --- & --- & --- & --- & --- & --- & --- & -- & --- & -- & -- & --- & --- \\
$\mathbf{2 0 0 6}$ & 11.09 & 9.30 & 14.08 & 15.59 & 19.58 & 23.26 & 28.91 & 21.71 & 27.36 & 24.74 & 19.43 & 12.16 & $\mathbf{1 8 . 9 3}$ \\
$\mathbf{2 0 0 7}$ & 12.79 & 13.42 & --- & 18.09 & 18.04 & --- & 20.20 & 23.88 & -- & 17.54 & 10.46 & 11.50 & $\mathbf{1 6 . 2 1}$ \\
$\mathbf{2 0 0 8}$ & 13.22 & 13.80 & 12.23 & 13.78 & 19.89 & 20.75 & --- & --- & 22.03 & --- & 12.72 & 12.15 & $\mathbf{1 5 . 6 2}$ \\
\hline Media & $\mathbf{1 2 . 2 3}$ & $\mathbf{1 1 . 3 1}$ & $\mathbf{1 2 . 7 2}$ & $\mathbf{1 4 . 6 8}$ & $\mathbf{1 7 . 9 9}$ & $\mathbf{2 2 . 7 4}$ & $\mathbf{2 3 . 5 3}$ & $\mathbf{2 3 . 8 5}$ & $\mathbf{2 3 . 1 4}$ & $\mathbf{2 0 . 0 2}$ & $\mathbf{1 4 . 3 8}$ & $\mathbf{1 2 . 4 8}$ & $\mathbf{1 7 . 0 5}$ \\
\hline
\end{tabular}


e2) Máximo de las medias diarias por mes y año de los sondeos de Zaragoza:

\begin{tabular}{|c|c|c|c|c|c|c|c|c|c|c|c|c|c|}
\hline Año \Mes & $\mathbf{1}$ & $\mathbf{2}$ & $\mathbf{3}$ & $\mathbf{4}$ & $\mathbf{5}$ & $\mathbf{6}$ & $\mathbf{7}$ & $\mathbf{8}$ & $\mathbf{9}$ & $\mathbf{1 0}$ & $\mathbf{1 1}$ & $\mathbf{1 2}$ & Máximo \\
\hline $\mathbf{2 0 0 2}$ & 21.59 & 19.97 & 20.00 & 18.75 & 26.54 & 31.60 & 35.23 & 30.87 & 30.70 & 30.68 & 26.22 & 25.58 & $\mathbf{2 6 . 4 8}$ \\
$\mathbf{2 0 0 3}$ & 20.21 & 20.06 & 22.14 & 23.38 & 24.04 & 32.18 & 31.52 & 33.42 & 34.90 & 29.75 & 21.68 & 20.34 & $\mathbf{2 6 . 1 4}$ \\
$\mathbf{2 0 0 4}$ & 22.24 & 16.43 & 16.93 & 24.61 & 25.42 & 28.73 & 33.35 & 33.62 & 33.42 & -- & -- & --- & $\mathbf{2 6 . 0 8}$ \\
$\mathbf{2 0 0 5}$ & --- & --- & --- & --- & --- & --- & --- & -- & -- & --- & -- & -- & --- \\
$\mathbf{2 0 0 6}$ & 19.10 & 16.00 & 24.08 & 23.14 & 30.30 & 34.09 & 42.58 & 32.26 & 37.22 & 34.59 & 29.70 & 26.57 & $\mathbf{2 9 . 1 4}$ \\
$\mathbf{2 0 0 7}$ & 20.13 & 18.41 & --- & 25.79 & 29.16 & -- & 28.50 & 33.41 & --- & 32.18 & 23.62 & 23.54 & $\mathbf{2 6 . 0 8}$ \\
$\mathbf{2 0 0 8}$ & 22.54 & 26.05 & 18.16 & 21.60 & 28.47 & 29.19 & --- & --- & 31.81 & --- & 20.12 & 22.53 & $\mathbf{2 4 . 5 0}$ \\
\hline Media & $\mathbf{2 0 . 9 7}$ & $\mathbf{1 9 . 4 9}$ & $\mathbf{2 0 . 2 6}$ & $\mathbf{2 2 . 8 8}$ & $\mathbf{2 7 . 3 2}$ & $\mathbf{3 1 . 1 6}$ & $\mathbf{3 4 . 2 4}$ & $\mathbf{3 2 . 7 2}$ & $\mathbf{3 3 . 6 1}$ & $\mathbf{3 1 . 8 0}$ & $\mathbf{2 4 . 2 7}$ & $\mathbf{2 3 . 7 1}$ & $\mathbf{2 6 . 4 0}$ \\
\hline
\end{tabular}

e3) Mínimo de las medias diarias por mes y año de los sondeos de Zaragoza:

\begin{tabular}{|c|l|l|l|l|c|c|c|c|c|c|c|c|c|}
\hline Año \Mes & $\mathbf{1}$ & $\mathbf{2}$ & $\mathbf{3}$ & $\mathbf{4}$ & $\mathbf{5}$ & $\mathbf{6}$ & $\mathbf{7}$ & $\mathbf{8}$ & $\mathbf{9}$ & $\mathbf{1 0}$ & $\mathbf{1 1}$ & $\mathbf{1 2}$ & Mínimo \\
\hline $\mathbf{2 0 0 2}$ & 7.72 & 6.80 & 8.60 & 8.65 & 8.52 & 12.60 & 11.82 & 13.01 & 6.55 & 7.58 & 9.79 & 9.26 & $\mathbf{9 . 2 4}$ \\
$\mathbf{2 0 0 3}$ & 5.41 & 2.54 & 3.56 & 5.82 & 10.60 & 13.13 & 15.92 & 14.26 & 7.90 & 8.28 & 8.55 & 4.83 & $\mathbf{8 . 4 0}$ \\
$\mathbf{2 0 0 4}$ & 4.78 & 4.89 & 3.93 & 5.99 & 8.50 & 9.64 & 11.06 & 13.42 & 10.01 & -- & --- & --- & $\mathbf{8 . 0 2}$ \\
$\mathbf{2 0 0 5}$ & -- & --- & -- & -- & -- & --- & -- & -- & -- & -- & -- & -- & -- \\
$\mathbf{2 0 0 6}$ & 4.81 & 4.04 & 6.38 & 5.79 & 7.32 & 8.07 & 18.87 & 13.49 & 13.14 & 16.70 & 9.18 & 6.18 & $\mathbf{9 . 5 0}$ \\
$\mathbf{2 0 0 7}$ & 3.50 & 4.54 & --- & 11.30 & 11.32 & -- & 11.00 & 15.15 & -- & 9.72 & 2.78 & 2.97 & $\mathbf{8 . 0 3}$ \\
$\mathbf{2 0 0 8}$ & 5.52 & 7.30 & 5.67 & 7.48 & 11.12 & 12.18 & --- & --- & 12.84 & -- & 4.85 & 4.15 & $\mathbf{7 . 9 0}$ \\
\hline Mínimo & $\mathbf{5 . 2 9}$ & $\mathbf{5 . 0 2}$ & $\mathbf{5 . 6 3}$ & $\mathbf{7 . 5 1}$ & $\mathbf{9 . 5 6}$ & $\mathbf{1 1 . 1 2}$ & $\mathbf{1 3 . 7 3}$ & $\mathbf{1 3 . 8 7}$ & $\mathbf{1 0 . 0 9}$ & $\mathbf{1 0 . 5 7}$ & $\mathbf{7 . 0 3}$ & $\mathbf{5 . 4 8}$ & $\mathbf{8 . 5 2}$ \\
\hline
\end{tabular}

e4) Desviación estándar de las medias diarias de cada mes y año de los sondeos de Zaragoza:

\begin{tabular}{|c|l|l|l|l|l|l|l|l|l|l|l|l|l|}
\hline Año \Mes & $\mathbf{1}$ & $\mathbf{2}$ & $\mathbf{3}$ & $\mathbf{4}$ & $\mathbf{5}$ & $\mathbf{6}$ & $\mathbf{7}$ & $\mathbf{8}$ & $\mathbf{9}$ & $\mathbf{1 0}$ & $\mathbf{1 1}$ & $\mathbf{1 2}$ & Media \\
\hline $\mathbf{2 0 0 2}$ & 4.02 & 3.08 & 3.07 & 2.56 & 4.17 & 5.01 & 5.46 & 4.50 & 6.97 & 5.38 & 3.82 & 4.34 & $\mathbf{4 . 3 7}$ \\
$\mathbf{2 0 0 3}$ & 4.23 & 4.31 & 5.24 & 4.74 & 4.13 & 4.49 & 3.77 & 4.17 & 6.64 & 5.55 & 4.02 & 4.08 & $\mathbf{4 . 6 1}$ \\
$\mathbf{2 0 0 4}$ & 4.76 & 3.40 & 4.08 & 4.29 & 4.08 & 5.50 & 6.12 & 5.72 & 7.94 & -- & --- & -- & $\mathbf{5 . 1 0}$ \\
$\mathbf{2 0 0 5}$ & --- & --- & --- & --- & -- & --- & -- & -- & -- & -- & -- & -- & -- \\
$\mathbf{2 0 0 6}$ & 3.72 & 2.68 & 4.11 & 4.32 & 5.72 & 7.77 & 5.45 & 4.89 & 5.92 & 5.62 & 4.97 & 4.87 & $\mathbf{5 . 0 0}$ \\
$\mathbf{2 0 0 7}$ & 3.99 & 3.97 & -- & 3.39 & 5.31 & -- & 4.84 & 5.13 & -- & 5.99 & 4.40 & 4.77 & $\mathbf{4 . 6 4}$ \\
$\mathbf{2 0 0 8}$ & 4.53 & 4.89 & 3.62 & 4.40 & 5.24 & 5.14 & --- & --- & 6.28 & --- & 4.21 & 5.00 & $\mathbf{4 . 8 1}$ \\
\hline Media & $\mathbf{4 . 2 1}$ & $\mathbf{3 . 7 2}$ & $\mathbf{4 . 0 2}$ & $\mathbf{3 . 9 5}$ & $\mathbf{4 . 7 7}$ & $\mathbf{5 . 5 8}$ & $\mathbf{5 . 1 3}$ & $\mathbf{4 . 8 8}$ & $\mathbf{6 . 7 5}$ & $\mathbf{5 . 6 3}$ & $\mathbf{4 . 2 9}$ & $\mathbf{4 . 6 1}$ & $\mathbf{4 . 7 6}$ \\
\hline
\end{tabular}

e5) Número de días con dato válido por mes y año de los sondeos de Zaragoza:

\begin{tabular}{|c|c|c|c|c|c|c|c|c|c|c|c|c|c|}
\hline Año \Mes & 1 & 2 & 3 & 4 & 5 & 6 & 7 & 8 & 9 & 10 & 11 & 12 & Tota \\
\hline 2002 & 30 & 27 & 28 & 30 & 30 & 30 & 29 & 25 & 29 & 31 & 30 & 31 & 350 \\
\hline 2003 & 17 & 23 & 30 & 30 & 31 & 30 & 31 & 31 & 30 & 31 & 30 & 28 & 342 \\
\hline 2004 & 29 & 24 & 29 & 30 & 29 & 30 & 31 & 27 & 16 & 0 & 0 & 0 & 245 \\
\hline 2005 & 0 & 0 & 0 & 0 & 0 & 0 & 0 & 0 & 0 & 0 & 0 & 11 & 11 \\
\hline 2006 & 30 & 25 & 30 & 30 & 28 & 30 & 26 & 28 & 17 & 30 & 29 & 31 & 334 \\
\hline 2007 & 31 & 15 & 8 & 26 & 21 & 13 & 25 & 22 & 2 & 24 & 29 & 29 & 245 \\
\hline 2008 & 31 & 28 & 27 & 23 & 16 & 21 & 3 & 5 & 19 & 11 & 29 & 31 & 244 \\
\hline Total & 168 & 142 & 144 & 169 & 155 & 141 & 142 & 133 & 111 & 116 & 147 & 150 & 1718 \\
\hline
\end{tabular}

f) Resumen por mes de las medias mensuales de cada año de los sondeos de Zaragoza:

\begin{tabular}{|c|c|c|c|c|c|c|c|c|c|c|c|c|}
\hline Mes & 1 & 2 & 3 & 4 & 5 & 6 & 7 & 8 & 9 & 10 & 11 & 12 \\
\hline Media & 12.23 & 11.31 & 12.72 & 14.68 & 17.99 & 22.74 & 23.53 & 23.85 & 23.14 & 20.02 & 14.38 & 12.48 \\
\hline STD & 0.72 & 1.79 & 1.16 & 1.94 & 1.42 & 1.74 & 2.89 & 1.14 & 2.42 & 2.78 & 2.96 & 1.06 \\
\hline Mediana & 12.36 & 10.98 & 12.86 & 14.61 & 17.75 & 22.59 & 22.93 & 24.27 & 22.03 & 18.90 & 14.61 & 12.15 \\
\hline Máximo & 13.22 & 13.80 & 14.08 & 18.09 & 19.89 & 25.73 & 28.91 & 25.08 & 27.36 & 24.74 & 19.43 & 14.55 \\
\hline Mínimo & 11.09 & 9.30 & 10.79 & 12.54 & 15.73 & 20.75 & 20.20 & 21.71 & 20.27 & 17.54 & 10.46 & 11.50 \\
\hline $\mathrm{N}^{0}$ Días & 168 & 142 & 144 & 169 & 155 & 141 & 142 & 133 & 111 & 116 & 147 & 150 \\
\hline
\end{tabular}




\section{Gráficas de la estación de Zaragoza}

g) Evolución temporal de las medias diarias.

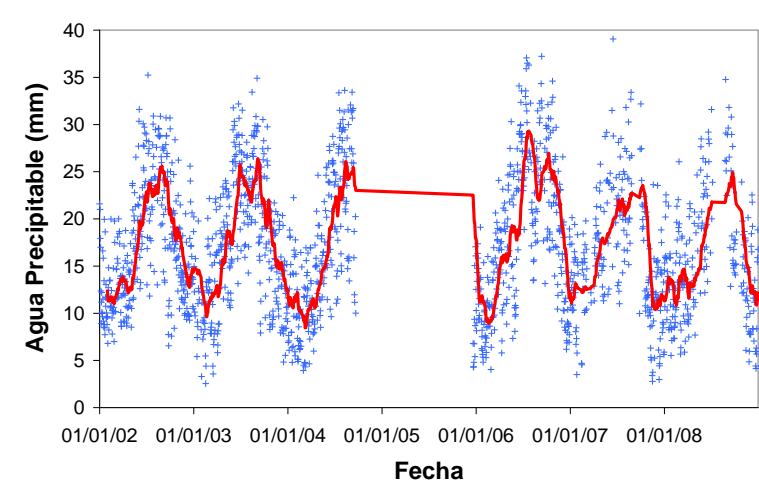

La línea roja representa la media móvil mensual. h) Histograma de las medias diarias.

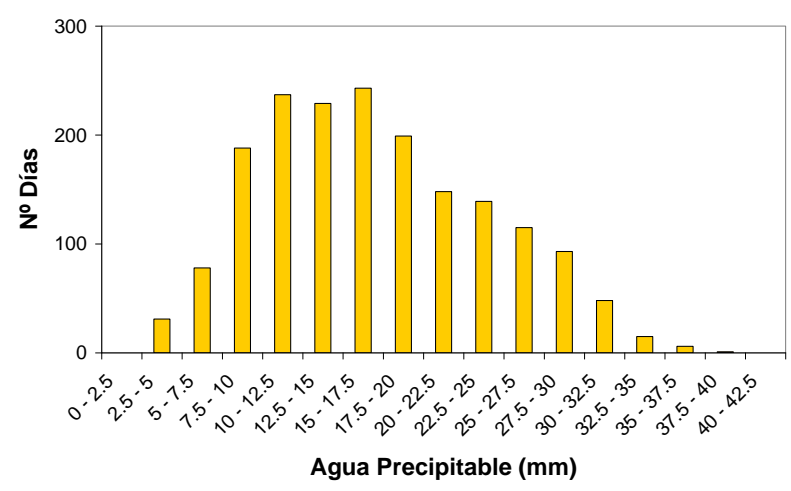

La distribución presenta un desplazamiento hacia la derecha (coef. de asimetría positivo), y un ligero achatamiento (curtosis negativa) respecto de la distribución normal.

j) Ciclo promedio anual.

i) Valores medios mensuales de las medias diarias para cada mes y año.
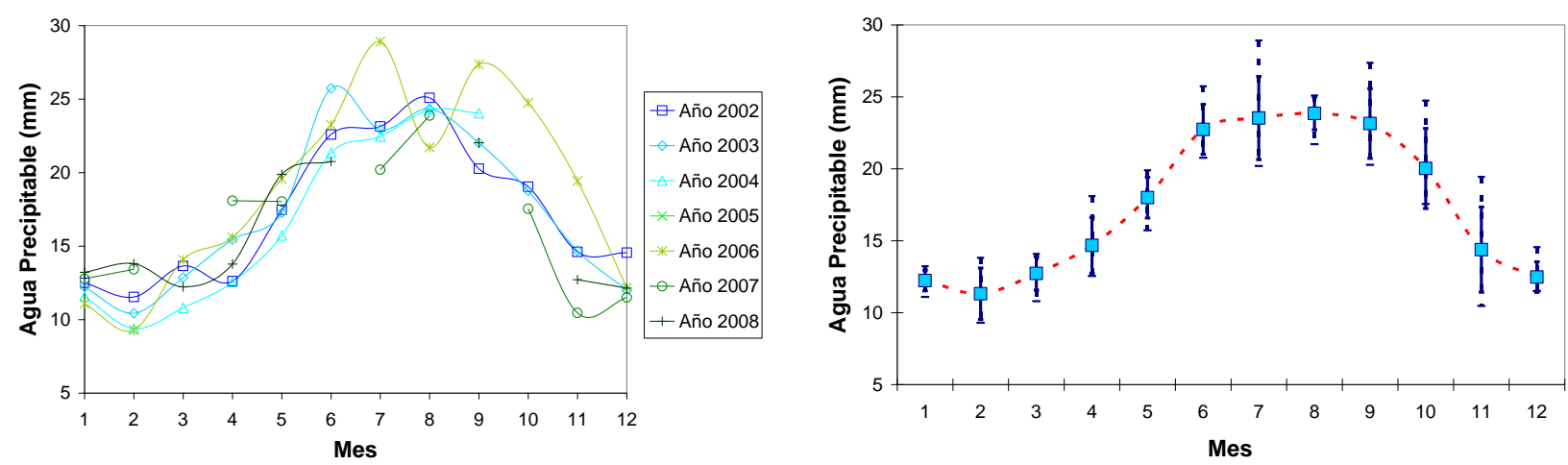

Valor promedio de las medias mensuales de cada año (cuadrados). Valor promedio más/menos la desviación típica de las medias mensuales (barras sólidas). Valor máximo y mínimo absoluto de las medias mensuales (líneas de trazos).

Hay que resaltar que durante el año 2005 no se dispone de datos de esta estación. 


\subsubsection{EL ARENOSILLO (Huelva, INTA). Estación fotométrica.}

El análisis estadístico se ha realizado en base a los datos del nivel de calidad 1.5 de la versión 2 del algoritmo de procesamiento de AERONET.

a) Estadísticas globales del conjunto de las medidas del fotómetro de El Arenosillo:

\begin{tabular}{|c|c|c|c|c|c|c|c|c|c|c|}
\hline $\begin{array}{c}\mathbf{N}^{0} \\
\text { Medidas }\end{array}$ & Media & STD & Mediana & $\begin{array}{c}\text { Clase } \\
\text { Modal }\end{array}$ & $\begin{array}{c}\text { Percentil } \\
\mathbf{5}\end{array}$ & $\begin{array}{c}\text { Percentil } \\
\mathbf{9 5}\end{array}$ & Máximo & Mínimo & $\begin{array}{c}\text { Coef. } \\
\text { Asimetría }\end{array}$ & Curtosis \\
\hline 61521 & 17.67 & 6.82 & 17.07 & $12.5-15$ & 7.54 & 29.49 & 45.56 & 1.73 & 0.38 & -0.24 \\
\hline
\end{tabular}

b) Estadísticas por mes del conjunto de las medidas del fotómetro de El Arenosillo:

\begin{tabular}{|c|c|c|c|c|c|c|c|c|c|c|c|c|}
\hline Estadístico \Mes & 1 & 2 & 3 & 4 & 5 & 6 & 7 & 8 & 9 & 10 & 11 & 12 \\
\hline Media & 10.99 & 11.36 & 11.81 & 13.76 & 17.64 & 21.77 & 20.13 & 21.87 & 22.52 & 19.21 & 14.32 & 12.32 \\
\hline STD & 3.28 & 3.91 & 4.55 & 4.45 & 4.80 & 6.14 & 6.09 & 5.76 & 5.89 & 5.29 & 5.29 & 3.87 \\
\hline Mediana & 10.86 & 11.19 & 11.82 & 13.46 & 17.14 & 20.97 & 19.51 & 22.08 & 23.11 & 18.46 & 13.39 & 11.91 \\
\hline Máximo & 23.92 & 24.20 & 25.08 & 28.06 & 37.09 & 41.94 & 45.56 & 39.03 & 41.73 & 40.13 & 35.71 & 25.87 \\
\hline Mínimo & 3.17 & 2.46 & 1.73 & 4.10 & 6.83 & 6.47 & 5.95 & 5.61 & 5.47 & 6.10 & 2.57 & 4.46 \\
\hline Percentil 5 & 6.01 & 5.10 & 4.49 & 6.94 & 10.67 & 12.44 & 11.33 & 12.28 & 13.05 & 11.33 & 6.65 & 6.72 \\
\hline Percentil 95 & 16.77 & 18.76 & 19.46 & 22.20 & 26.96 & 34.56 & 31.00 & 31.48 & 32.13 & 28.17 & 24.12 & 19.15 \\
\hline Coef. Asimetría & 0.34 & 0.32 & 0.06 & 0.46 & 0.49 & 0.61 & 0.42 & -0.03 & -0.12 & 0.36 & 0.59 & 0.50 \\
\hline Curtosis & 0.12 & -0.05 & -0.68 & 0.09 & -0.14 & 0.57 & -0.17 & 0.01 & -0.24 & -0.08 & 0.06 & -0.18 \\
\hline $\mathrm{N}^{0}$ Medidas & 3914 & 4027 & 4007 & 3981 & 4100 & 7516 & 8639 & 8149 & 6072 & 4055 & 3334 & 3727 \\
\hline
\end{tabular}

c) Estadísticas globales de las medias diarias de las medidas del fotómetro de El Arenosillo:

\begin{tabular}{|c|c|c|c|c|c|c|c|c|c|c|}
\hline N$^{\circ}$ Días & Media & STD & Mediana & Moda & $\begin{array}{c}\text { Percentil } \\
\mathbf{5}\end{array}$ & $\begin{array}{c}\text { Percentil } \\
\mathbf{9 5}\end{array}$ & Máximo & Mínimo & $\begin{array}{c}\text { Coef. } \\
\text { Asimetría }\end{array}$ & Curtosis \\
\hline 2101 & 17.79 & 6.65 & 17.06 & $12.5-15$ & 7.99 & 29.68 & 45.28 & 2.24 & 0.47 & -0.11 \\
\hline
\end{tabular}

d) Resumen por mes de las medias diarias de las medidas del fotómetro de El Arenosillo:

\begin{tabular}{|c|c|c|c|c|c|c|c|c|c|c|c|c|}
\hline Estadístico \Mes & 1 & 2 & 3 & 4 & 5 & 6 & 7 & 8 & 9 & 10 & 11 & 12 \\
\hline Media & 11.87 & 12.73 & 12.97 & 14.96 & 18.42 & 22.10 & 20.62 & 22.19 & 23.93 & 20.95 & 16.01 & 13.66 \\
\hline STD & 3.66 & 4.00 & 4.25 & 4.21 & 4.83 & 5.89 & 6.15 & 5.63 & 5.90 & 5.71 & 5.69 & 4.51 \\
\hline Mediana & 11.89 & 12.38 & 13.07 & 14.54 & 17.85 & 21.83 & 19.78 & 21.93 & 24.30 & 21.31 & 15.17 & 13.25 \\
\hline Máximo & 21.82 & 22.57 & 23.48 & 25.63 & 35.96 & 38.01 & 45.28 & 37.15 & 38.26 & 39.30 & 33.86 & 25.39 \\
\hline Mínimo & 3.96 & 3.53 & 2.24 & 5.16 & 6.83 & 7.79 & 9.76 & 8.02 & 8.37 & 8.39 & 3.11 & 5.05 \\
\hline Percentil 5 & 6.68 & 6.22 & 5.39 & 8.39 & 11.96 & 12.98 & 12.05 & 13.45 & 13.82 & 11.89 & 7.56 & 7.26 \\
\hline Percentil 95 & 18.37 & 20.28 & 19.38 & 22.46 & 26.99 & 34.60 & 31.56 & 32.70 & 32.81 & 29.90 & 25.19 & 21.98 \\
\hline Coef. Asimetría & 0.31 & 0.29 & -0.12 & 0.32 & 0.72 & 0.44 & 0.65 & 0.11 & -0.22 & 0.35 & 0.44 & 0.48 \\
\hline Curtosis & -0.12 & -0.08 & -0.53 & -0.05 & 0.74 & 0.34 & 0.58 & -0.15 & -0.35 & 0.21 & -0.04 & -0.38 \\
\hline $\mathrm{N}^{0}$ Días & 177 & 165 & 168 & 166 & 154 & 199 & 195 & 202 & 197 & 162 & 150 & 166 \\
\hline
\end{tabular}

e1) Media de las medias diarias por mes y año de las medidas del fotómetro de El Arenosillo:

\begin{tabular}{|c|c|c|c|c|c|c|c|c|c|c|c|c|c|}
\hline Año \Mes & $\mathbf{1}$ & $\mathbf{2}$ & $\mathbf{3}$ & $\mathbf{4}$ & $\mathbf{5}$ & $\mathbf{6}$ & $\mathbf{7}$ & $\mathbf{8}$ & $\mathbf{9}$ & $\mathbf{1 0}$ & $\mathbf{1 1}$ & $\mathbf{1 2}$ & Media \\
\hline $\mathbf{2 0 0 2}$ & 12.97 & 11.95 & 14.22 & 14.09 & 15.92 & 18.91 & 19.70 & 21.70 & 28.59 & 21.51 & 17.36 & 15.63 & $\mathbf{1 7 . 7 1}$ \\
$\mathbf{2 0 0 3}$ & 10.62 & 12.18 & 14.43 & 14.77 & 19.82 & 21.24 & 18.28 & 23.01 & 19.23 & 19.82 & 17.12 & 12.44 & $\mathbf{1 6 . 9 1}$ \\
$\mathbf{2 0 0 4}$ & 12.85 & 12.79 & 12.80 & 12.70 & 21.27 & 29.17 & 25.91 & 28.28 & 26.52 & 23.16 & 16.78 & 15.61 & $\mathbf{1 9 . 8 2}$ \\
$\mathbf{2 0 0 5}$ & 10.60 & 10.32 & 15.39 & 16.39 & 19.88 & 24.73 & 22.95 & 23.34 & 21.59 & 22.57 & 15.53 & 15.14 & $\mathbf{1 8 . 2 0}$ \\
$\mathbf{2 0 0 6}$ & 11.81 & 13.08 & 13.12 & 16.19 & --- & 22.29 & 18.46 & 21.16 & 23.39 & 20.89 & 16.95 & 12.39 & $\mathbf{1 7 . 2 5}$ \\
$\mathbf{2 0 0 7}$ & 10.89 & 13.41 & 10.65 & 17.31 & 16.52 & 20.28 & 19.78 & 20.20 & 26.04 & 19.12 & 12.76 & 11.55 & $\mathbf{1 6 . 5 4}$ \\
$\mathbf{2 0 0 8}$ & 13.42 & 15.70 & 12.21 & 12.45 & 17.74 & 17.30 & 18.54 & 18.04 & 23.40 & 19.14 & -- & 13.25 & $\mathbf{1 6 . 4 7}$ \\
\hline Media & $\mathbf{1 1 . 8 8}$ & $\mathbf{1 2 . 7 8}$ & $\mathbf{1 3 . 1 0}$ & $\mathbf{1 4 . 8 4}$ & $\mathbf{1 8 . 2 7}$ & $\mathbf{2 1 . 9 9}$ & $\mathbf{2 0 . 6 5}$ & $\mathbf{2 2 . 2 5}$ & $\mathbf{2 4 . 1 1}$ & $\mathbf{2 0 . 8 9}$ & $\mathbf{1 6 . 0 8}$ & $\mathbf{1 3 . 7 2}$ & $\mathbf{1 7 . 5 4}$ \\
\hline
\end{tabular}


e2) Máximo de las medias diarias por mes y año de las medidas del fotómetro de El Arenosillo:

\begin{tabular}{|c|c|c|c|c|c|c|c|c|c|c|c|c|c|}
\hline Año \Mes & $\mathbf{1}$ & $\mathbf{2}$ & $\mathbf{3}$ & $\mathbf{4}$ & $\mathbf{5}$ & $\mathbf{6}$ & $\mathbf{7}$ & $\mathbf{8}$ & $\mathbf{9}$ & $\mathbf{1 0}$ & $\mathbf{1 1}$ & $\mathbf{1 2}$ & Media \\
\hline $\mathbf{2 0 0 2}$ & 19.36 & 21.34 & --- & 20.40 & 25.16 & 25.84 & --- & 34.82 & 37.08 & 34.11 & 33.86 & 24.60 & $\mathbf{2 7 . 6 6}$ \\
$\mathbf{2 0 0 3}$ & 21.82 & 20.56 & 19.66 & 21.79 & --- & 27.56 & 28.24 & 27.05 & 26.52 & 29.20 & 22.39 & 22.69 & $\mathbf{2 4 . 3 2}$ \\
$\mathbf{2 0 0 4}$ & 20.78 & 22.12 & 18.67 & 21.16 & 29.68 & 38.01 & 38.34 & 37.15 & 38.26 & 36.57 & 29.96 & 22.92 & $\mathbf{2 9 . 4 7}$ \\
$\mathbf{2 0 0 5}$ & 18.93 & 14.76 & 23.48 & 25.02 & 35.96 & 35.82 & 45.28 & 33.54 & 32.88 & 39.30 & 24.03 & 24.27 & $\mathbf{2 9 . 4 4}$ \\
$\mathbf{2 0 0 6}$ & 18.20 & 20.26 & 19.39 & 20.14 & --- & 31.22 & 27.73 & 32.91 & 30.56 & 29.68 & 30.90 & 25.39 & $\mathbf{2 6 . 0 3}$ \\
$\mathbf{2 0 0 7}$ & 17.13 & 20.69 & 17.50 & 25.63 & 24.34 & 36.77 & 33.28 & 28.97 & 32.84 & 26.91 & 18.62 & 19.86 & $\mathbf{2 5 . 2 1}$ \\
$\mathbf{2 0 0 8}$ & 20.40 & 22.57 & 20.82 & 18.00 & 26.59 & 23.28 & 29.75 & 27.11 & 36.48 & 27.35 & --- & 24.13 & $\mathbf{2 5 . 1 3}$ \\
\hline Media & $\mathbf{1 9 . 5 2}$ & $\mathbf{2 0 . 3 3}$ & $\mathbf{1 9 . 9 2}$ & $\mathbf{2 1 . 7 3}$ & $\mathbf{2 8 . 3 5}$ & $\mathbf{3 1 . 2 1}$ & $\mathbf{3 3 . 7 7}$ & $\mathbf{3 1 . 6 5}$ & $\mathbf{3 3 . 5 2}$ & $\mathbf{3 1 . 8 7}$ & $\mathbf{2 6 . 6 3}$ & $\mathbf{2 3 . 4 1}$ & $\mathbf{2 6 . 7 5}$ \\
\hline
\end{tabular}

e3) Mínimo de las medias diarias por mes y año de las medidas del fotómetro de El Arenosillo:

\begin{tabular}{|c|c|c|c|c|c|c|c|c|c|c|c|c|c|}
\hline Año \Mes & 1 & 2 & 3 & 4 & 5 & 6 & 7 & 8 & 9 & 10 & 11 & 12 & Media \\
\hline 2002 & 7.00 & 5.01 & --- & 8.43 & 6.83 & 7.99 & --- & 11.63 & 16.24 & 12.53 & 3.11 & 7.19 & 8.60 \\
\hline 2003 & 4.55 & 6.15 & 6.98 & 6.53 & --- & 9.85 & 10.84 & 16.11 & 8.82 & 8.39 & 10.02 & 5.90 & 8.56 \\
\hline 2004 & 5.01 & 6.48 & 2.24 & 8.37 & 11.75 & 20.48 & 14.91 & 19.74 & 16.64 & 14.54 & 6.18 & 7.46 & 11.15 \\
\hline 2005 & 3.98 & 3.53 & 5.13 & 6.80 & 9.48 & 18.09 & 12.13 & 10.21 & 10.56 & 11.88 & 6.49 & 6.30 & 8.72 \\
\hline 2006 & 3.96 & 6.12 & 5.80 & 12.84 & --- & 7.79 & 12.41 & 13.11 & 12.81 & 14.54 & 6.26 & 7.05 & 9.34 \\
\hline 2007 & 7.31 & 7.89 & 4.93 & 10.22 & 11.82 & 11.68 & 10.15 & 12.10 & 13.02 & 8.99 & 7.64 & 5.05 & 9.23 \\
\hline 2008 & 8.03 & 9.90 & 4.25 & 5.16 & 9.53 & 11.95 & 9.76 & 8.02 & 8.37 & 9.64 & --- & 6.84 & 8.31 \\
\hline Media & 5.69 & 6.44 & 4.89 & 8.34 & 9.88 & 12.55 & 11.70 & 12.99 & 12.35 & 11.50 & 6.62 & 6.54 & 9.13 \\
\hline
\end{tabular}

e4) Desviación estándar de las medias diarias de cada mes y año del fotómetro de El Arenosillo:

\begin{tabular}{|c|l|l|l|l|l|l|l|l|l|l|l|l|c|}
\hline Año \Mes & $\mathbf{1}$ & $\mathbf{2}$ & $\mathbf{3}$ & $\mathbf{4}$ & $\mathbf{5}$ & $\mathbf{6}$ & $\mathbf{7}$ & $\mathbf{8}$ & $\mathbf{9}$ & $\mathbf{1 0}$ & $\mathbf{1 1}$ & $\mathbf{1 2}$ & Media \\
\hline $\mathbf{2 0 0 2}$ & 3.16 & 4.60 & -- & 2.57 & 3.82 & 4.15 & -- & 4.72 & 5.04 & 5.57 & 6.32 & 4.90 & $\mathbf{4 . 4 8}$ \\
$\mathbf{2 0 0 3}$ & 4.89 & 3.52 & 3.27 & 4.20 & -- & 4.51 & 4.09 & 2.97 & 4.16 & 5.40 & 3.61 & 3.64 & $\mathbf{4 . 0 2}$ \\
$\mathbf{2 0 0 4}$ & 4.10 & 3.36 & 4.08 & 3.16 & 5.10 & 5.05 & 5.99 & 4.28 & 4.28 & 4.62 & 6.36 & 4.08 & $\mathbf{4 . 5 4}$ \\
$\mathbf{2 0 0 5}$ & 3.35 & 3.66 & 5.49 & 4.70 & 6.31 & 4.76 & 7.40 & 5.94 & 5.47 & 7.10 & 5.50 & 4.54 & $\mathbf{5 . 3 5}$ \\
$\mathbf{2 0 0 6}$ & 3.06 & 3.79 & 4.16 & 2.15 & --- & 5.36 & 3.83 & 4.96 & 4.34 & 4.14 & 7.16 & 3.83 & $\mathbf{4 . 2 5}$ \\
$\mathbf{2 0 0 7}$ & 2.46 & 2.99 & 3.14 & 4.86 & 2.82 & 4.75 & 5.51 & 4.57 & 5.00 & 5.40 & 2.94 & 3.67 & $\mathbf{4 . 0 1}$ \\
$\mathbf{2 0 0 8}$ & 3.34 & 3.63 & 4.24 & 3.28 & 3.72 & 2.99 & 5.99 & 5.04 & 7.29 & 5.77 & --- & 4.98 & $\mathbf{4 . 5 7}$ \\
\hline Media & $\mathbf{3 . 4 8}$ & $\mathbf{3 . 6 5}$ & $\mathbf{4 . 0 6}$ & $\mathbf{3 . 5 6}$ & $\mathbf{4 . 3 5}$ & $\mathbf{4 . 5 1}$ & $\mathbf{5 . 4 7}$ & $\mathbf{4 . 6 4}$ & $\mathbf{5 . 0 8}$ & $\mathbf{5 . 4 3}$ & $\mathbf{5 . 3 2}$ & $\mathbf{4 . 2 3}$ & $\mathbf{4 . 4 6}$ \\
\hline
\end{tabular}

e5) Número de días con dato válido por mes y año del fotómetro de El Arenosillo:

\begin{tabular}{|c|c|c|c|c|c|c|c|c|c|c|c|c|c|}
\hline Año | Mes & 1 & 2 & 3 & 4 & 5 & 6 & 7 & 8 & 9 & 10 & 11 & 12 & Total \\
\hline 2002 & 23 & 26 & 10 & 20 & 26 & 26 & 12 & 30 & 20 & 24 & 26 & 22 & 265 \\
\hline 2003 & 20 & 21 & 24 & 25 & 12 & 30 & 30 & 24 & 28 & 22 & 24 & 24 & 284 \\
\hline 2004 & 23 & 25 & 27 & 19 & 28 & 30 & 31 & 30 & 30 & 23 & 28 & 31 & 325 \\
\hline 2005 & 29 & 25 & 19 & 30 & 30 & 30 & 31 & 27 & 30 & 26 & 27 & 15 & 319 \\
\hline 2006 & 26 & 24 & 28 & 19 & 0 & 28 & 30 & 30 & 30 & 23 & 18 & 28 & 284 \\
\hline 2007 & 28 & 21 & 30 & 27 & 29 & 26 & 30 & 30 & 30 & 29 & 27 & 25 & 332 \\
\hline 2008 & 28 & 23 & 30 & 26 & 29 & 29 & 31 & 31 & 29 & 15 & 0 & 21 & 292 \\
\hline Total & 177 & 165 & 158 & 166 & 142 & 199 & 183 & 202 & 197 & 162 & 150 & 166 & 2067 \\
\hline
\end{tabular}

f) Resumen por mes de las medias mensuales de cada año del fotómetro de El Arenosillo:

\begin{tabular}{|c|c|c|c|c|c|c|c|c|c|c|c|c|}
\hline Mes & 1 & 2 & 3 & 4 & 5 & 6 & 7 & 8 & 9 & 10 & 11 & 12 \\
\hline Media & 11.88 & 12.78 & 13.10 & 14.84 & 18.27 & 21.99 & 20.65 & 22.25 & 24.11 & 20.89 & 16.08 & 13.72 \\
\hline STD & 1.11 & 1.52 & 1.52 & 1.74 & 2.02 & 3.66 & 2.85 & 2.96 & 2.95 & 1.50 & 1.60 & 1.59 \\
\hline Mediana & 11.81 & 12.79 & 12.96 & 14.77 & 17.74 & 21.24 & 19.16 & 21.70 & 23.40 & 20.89 & 16.87 & 13.25 \\
\hline Máximo & 13.42 & 15.70 & 15.39 & 17.31 & 21.27 & 29.17 & 25.91 & 28.28 & 28.59 & 23.16 & 17.36 & 15.63 \\
\hline Mínimo & 10.60 & 10.32 & 10.65 & 12.45 & 15.92 & 17.30 & 18.28 & 18.04 & 19.23 & 19.12 & 12.76 & 11.55 \\
\hline No Días & 177 & 165 & 158 & 166 & 142 & 199 & 183 & 202 & 197 & 162 & 150 & 166 \\
\hline
\end{tabular}




\section{Gráficas de la estación de Huelva (El Arenosillo)}

g) Evolución temporal de las medias diarias.

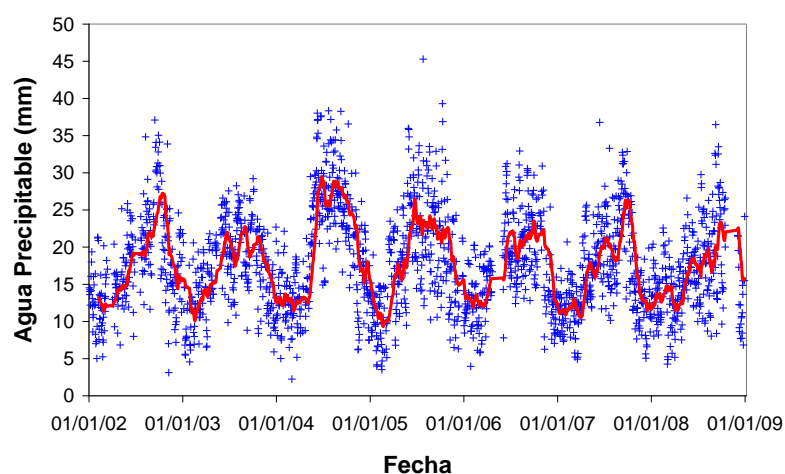

La línea roja representa la media móvil mensual. h) Histograma de las medias diarias.

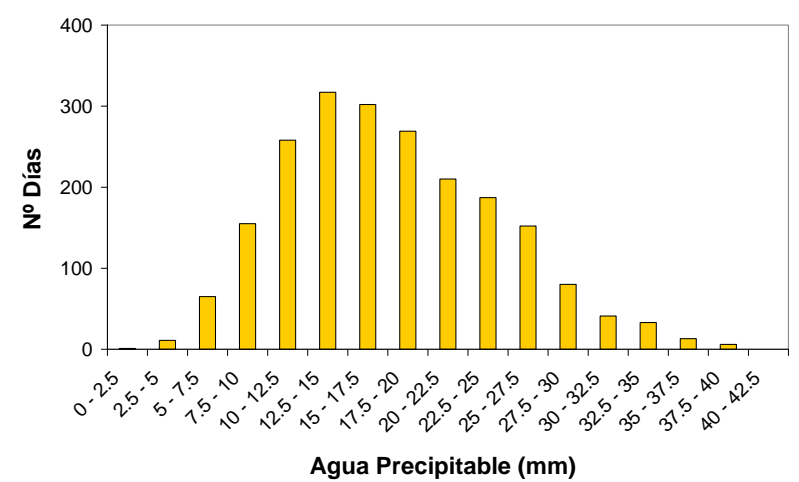

La distribución presenta un desplazamiento hacia la derecha (coef. de asimetría positivo), y un ligero achatamiento (curtosis negativa) respecto de la distribución normal.

j) Ciclo promedio anual. para cada mes y año.
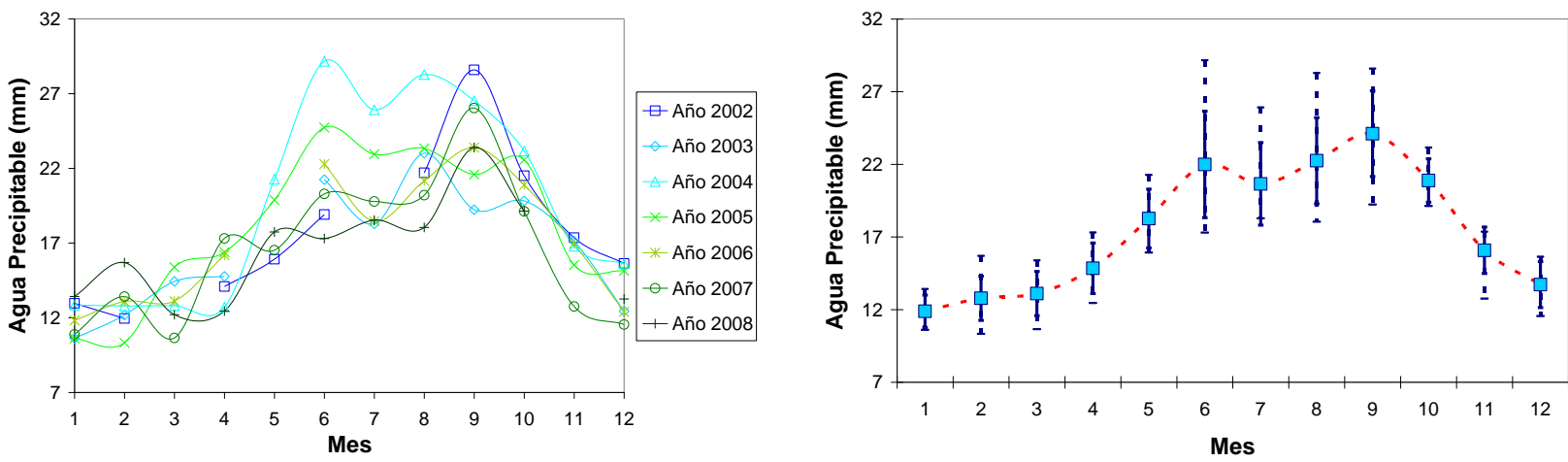

Valor promedio de las medias mensuales de cada año (cuadrados). Valor promedio más/menos la desviación típica de las medias mensuales (barras sólidas). Valor máximo y mínimo absoluto de las medias mensuales (líneas de trazos). 


\subsubsection{PALENCIA (E.T.S.I.A., Universidad de Valladolid). Estación fotométrica.}

El análisis estadístico se ha realizado en base a los datos del nivel de calidad 1.5 de la versión 2 del algoritmo de procesamiento de AERONET.

a) Estadísticas globales del conjunto de las medidas del fotómetro de Palencia:

\begin{tabular}{|c|c|c|c|c|c|c|c|c|c|c|}
\hline $\begin{array}{c}\mathbf{N}^{0} \\
\text { Medidas }\end{array}$ & Media & STD & Mediana & $\begin{array}{c}\text { Clase } \\
\text { Modal }\end{array}$ & $\begin{array}{c}\text { Percentil } \\
\mathbf{5}\end{array}$ & $\begin{array}{c}\text { Percentil } \\
\mathbf{9 5}\end{array}$ & Máximo & Mínimo & $\begin{array}{c}\text { Coef. } \\
\text { Asimetría }\end{array}$ & Curtosis \\
\hline 40356 & 12.20 & 5.31 & 11.95 & $10-12.5$ & 4.17 & 21.76 & 35.40 & 1.15 & 0.45 & 0.00 \\
\hline
\end{tabular}

b) Estadísticas por mes del conjunto de las medidas del fotómetro de Palencia:

\begin{tabular}{|c|c|c|c|c|c|c|c|c|c|c|c|c|}
\hline Estadístico | Mes & 1 & 2 & 3 & 4 & 5 & 6 & 7 & 8 & 9 & 10 & 11 & 12 \\
\hline Media & 6.58 & 6.33 & 6.76 & 9.19 & 11.68 & 14.57 & 15.46 & 15.67 & 13.92 & 12.73 & 9.24 & 6.38 \\
\hline STD & 2.54 & 2.63 & 2.91 & 2.95 & 3.43 & 4.54 & 4.44 & 4.77 & 4.32 & 5.17 & 3.96 & 3.16 \\
\hline Mediana & 5.97 & 5.73 & 6.52 & 8.95 & 11.41 & 14.23 & 14.80 & 15.08 & 13.72 & 11.89 & 8.72 & 5.86 \\
\hline Máximo & 15.77 & 17.24 & 16.68 & 22.06 & 23.37 & 28.34 & 34.10 & 34.23 & 35.40 & 28.27 & 22.82 & 20.01 \\
\hline Mínimo & 2.50 & 1.41 & 1.15 & 3.01 & 4.06 & 3.20 & 5.42 & 4.67 & 4.29 & 4.27 & 1.47 & 1.37 \\
\hline Percentil 5 & 3.28 & 2.90 & 2.34 & 4.52 & 6.55 & 7.70 & 9.41 & 8.90 & 6.97 & 5.56 & 2.78 & 2.20 \\
\hline Percentil 95 & 11.68 & 11.18 & 11.81 & 14.61 & 17.93 & 22.21 & 24.21 & 24.13 & 21.95 & 24.33 & 17.44 & 11.93 \\
\hline Coef. Asimetría & 0.77 & 0.84 & 0.24 & 0.38 & 0.60 & 0.17 & 0.87 & 0.42 & 0.43 & 0.88 & 0.52 & 0.61 \\
\hline Curtosis & -0.09 & 0.45 & -0.63 & -0.12 & 0.46 & -0.39 & 0.90 & -0.14 & 0.39 & 0.40 & 0.17 & -0.04 \\
\hline $\mathrm{N}^{0}$ Medidas & 1108 & 2451 & 2528 & 2782 & 3520 & 4770 & 6259 & 5128 & 5199 & 2989 & 2007 & 1615 \\
\hline
\end{tabular}

c) Estadísticas globales de las medias diarias de las medidas del fotómetro de Palencia:

\begin{tabular}{|c|c|c|c|c|c|c|c|c|c|c|}
\hline $\mathrm{N}^{0}$ Días & Media & STD & Mediana & Moda & \begin{tabular}{|c|} 
Percentil \\
5 \\
\end{tabular} & \begin{tabular}{|c|} 
Percentil \\
95 \\
\end{tabular} & Máximo & Mínimo & \begin{tabular}{|c} 
Coef. \\
Asimetría
\end{tabular} & Curtosis \\
\hline 1565 & 12.15 & 5.27 & 11.61 & $10-12.5$ & 4.60 & 21.85 & 35.36 & 1.51 & 0.56 & 0.16 \\
\hline
\end{tabular}

d) Resumen por mes de las medias diarias de las medidas del fotómetro de Palencia:

\begin{tabular}{|c|c|c|c|c|c|c|c|c|c|c|c|c|}
\hline Estadístico \ Mes & 1 & 2 & 3 & 4 & 5 & 6 & 7 & 8 & 9 & 10 & 11 & 12 \\
\hline Media & 7.45 & 7.27 & 7.40 & 9.77 & 12.48 & 15.40 & 16.06 & 16.39 & 15.16 & 13.79 & 10.34 & 8.00 \\
\hline STD & 2.81 & 2.84 & 2.86 & 2.88 & 3.56 & 4.13 & 4.30 & 4.74 & 4.94 & 5.02 & 4.17 & 3.67 \\
\hline Mediana & 6.98 & 7.00 & 7.01 & 9.40 & 11.93 & 15.18 & 15.19 & 15.81 & 14.62 & 12.81 & 9.49 & 7.76 \\
\hline Máximo & 15.77 & 17.24 & 16.68 & 17.49 & 21.58 & 26.14 & 30.17 & 33.34 & 35.36 & 27.76 & 22.61 & 20.01 \\
\hline Mínimo & 2.91 & 1.81 & 1.51 & 3.84 & 5.84 & 5.58 & 7.11 & 5.98 & 5.71 & 4.99 & 1.76 & 1.55 \\
\hline Percentil 5 & 3.78 & 3.26 & 2.88 & 5.75 & 7.51 & 9.07 & 10.64 & 9.71 & 7.71 & 6.59 & 4.24 & 2.76 \\
\hline Percentil 95 & 12.17 & 12.26 & 12.23 & 14.92 & 20.41 & 21.84 & 24.61 & 23.98 & 23.88 & 24.49 & 18.43 & 14.06 \\
\hline Coef. Asimetría & 0.63 & 0.72 & 0.39 & 0.34 & 0.69 & 0.15 & 0.90 & 0.42 & 0.65 & 0.73 & 0.57 & 0.63 \\
\hline Curtosis & -0.22 & 0.47 & 0.13 & -0.43 & 0.15 & -0.23 & 0.85 & 0.11 & 1.04 & 0.20 & 0.00 & 0.55 \\
\hline $\mathbf{N}^{0}$ Días & 81 & 126 & 113 & 126 & 157 & 146 & 158 & 147 & 152 & 140 & 121 & 98 \\
\hline
\end{tabular}

e1) Media de las medias diarias por mes y año de las medidas del fotómetro de Palencia:

\begin{tabular}{|c|c|c|c|c|c|c|c|c|c|c|c|c|c|}
\hline Año | Mes & 1 & 2 & 3 & 4 & 5 & 6 & 7 & 8 & 9 & 10 & 11 & 12 & Media \\
\hline 2002 & --- & --- & -- & -- & -- & -- & --- & --- & --- & --- & --- & --- & --- \\
\hline 2003 & 7.97 & 8.06 & --- & 9.04 & 12.85 & 16.70 & 15.65 & 17.80 & 14.19 & 12.80 & 11.48 & --- & 12.65 \\
\hline 2004 & --- & 7.39 & 7.62 & 10.14 & 13.80 & 17.27 & 16.84 & 17.20 & 15.78 & 12.73 & 8.76 & 8.87 & 12.40 \\
\hline 2005 & 6.55 & 6.14 & 7.73 & 9.55 & 11.17 & 14.36 & 13.55 & 13.77 & 12.03 & 12.35 & 8.42 & 7.29 & 10.24 \\
\hline 2006 & 6.56 & 5.62 & 7.15 & 10.20 & 10.97 & --- & --- & 15.50 & 17.33 & 16.62 & 14.31 & 8.68 & 11.30 \\
\hline 2007 & 9.32 & 9.85 & 7.23 & 11.15 & 13.39 & 13.96 & 14.18 & 15.68 & 14.17 & 10.65 & 7.26 & 6.50 & 11.11 \\
\hline 2008 & 7.70 & 7.30 & 7.12 & 8.23 & 12.34 & 14.74 & 19.86 & 19.74 & 18.28 & 18.40 & 12.74 & 8.96 & 12.95 \\
\hline Media & 7.62 & 7.40 & 7.37 & 9.72 & 12.42 & 15.41 & 16.02 & 16.61 & 15.30 & 13.92 & 10.50 & 8.06 & 11.78 \\
\hline
\end{tabular}


e2) Máximo de las medias diarias por mes y año de las medidas del fotómetro de Palencia:

\begin{tabular}{|c|c|c|c|c|c|c|c|c|c|c|c|c|c|}
\hline Año \Mes & $\mathbf{1}$ & $\mathbf{2}$ & $\mathbf{3}$ & $\mathbf{4}$ & $\mathbf{5}$ & $\mathbf{6}$ & $\mathbf{7}$ & $\mathbf{8}$ & $\mathbf{9}$ & $\mathbf{1 0}$ & $\mathbf{1 1}$ & $\mathbf{1 2}$ & Media \\
\hline $\mathbf{2 0 0 2}$ & --- & --- & --- & -- & --- & --- & -- & -- & -- & --- & -- & -- & -- \\
$\mathbf{2 0 0 3}$ & 14.23 & 11.77 & -- & 15.92 & 20.35 & 22.39 & 23.09 & 22.35 & 19.77 & 19.04 & 14.72 & -- & $\mathbf{1 8 . 3 6}$ \\
$\mathbf{2 0 0 4}$ & --- & 14.08 & 12.90 & 15.23 & 21.58 & 26.14 & 21.94 & 26.52 & 26.09 & 19.78 & 14.53 & 12.27 & $\mathbf{1 9 . 1 9}$ \\
$\mathbf{2 0 0 5}$ & 11.91 & 11.67 & 16.68 & 17.49 & 17.37 & 21.57 & 21.10 & 23.05 & 17.08 & 21.93 & 15.95 & 14.48 & $\mathbf{1 7 . 5 2}$ \\
$\mathbf{2 0 0 6}$ & 10.55 & 9.25 & 12.56 & 15.04 & 15.58 & --- & --- & 22.32 & 23.90 & 22.76 & 22.61 & 20.01 & $\mathbf{1 7 . 4 6}$ \\
$\mathbf{2 0 0 7}$ & 15.77 & 17.24 & 12.25 & 14.08 & 21.38 & 21.95 & 23.44 & 24.90 & 23.86 & 16.83 & 11.61 & 16.15 & $\mathbf{1 8 . 2 9}$ \\
$\mathbf{2 0 0 8}$ & 12.17 & 13.82 & 11.42 & 15.56 & 17.73 & 21.86 & 30.17 & 33.34 & 35.36 & 27.76 & 18.98 & 18.87 & $\mathbf{2 1 . 4 2}$ \\
\hline Media & $\mathbf{1 2 . 9 3}$ & $\mathbf{1 2 . 9 7}$ & $\mathbf{1 3 . 1 6}$ & $\mathbf{1 5 . 5 5}$ & $\mathbf{1 9 . 0 0}$ & $\mathbf{2 2 . 7 8}$ & $\mathbf{2 3 . 9 5}$ & $\mathbf{2 5 . 4 1}$ & $\mathbf{2 4 . 3 4}$ & $\mathbf{2 1 . 3 5}$ & $\mathbf{1 6 . 4 0}$ & $\mathbf{1 6 . 3 6}$ & $\mathbf{1 8 . 7 1}$ \\
\hline
\end{tabular}

e3) Mínimo de las medias diarias por mes y año de las medidas del fotómetro de Palencia:

\begin{tabular}{|c|l|l|l|l|l|l|r|r|r|r|r|r|c|}
\hline Año \Mes & $\mathbf{1}$ & $\mathbf{2}$ & $\mathbf{3}$ & $\mathbf{4}$ & $\mathbf{5}$ & $\mathbf{6}$ & \multicolumn{1}{|c|}{$\mathbf{7}$} & $\mathbf{8}$ & $\mathbf{9}$ & $\mathbf{1 0}$ & $\mathbf{1 1}$ & $\mathbf{1 2}$ & Media \\
\hline $\mathbf{2 0 0 2}$ & --- & --- & --- & --- & --- & --- & -- & -- & -- & --- & -- & --- & -- \\
$\mathbf{2 0 0 3}$ & 5.17 & 2.80 & --- & 4.55 & 9.03 & 10.26 & 9.85 & 10.85 & 7.32 & 6.49 & 6.73 & -- & $\mathbf{7 . 3 1}$ \\
$\mathbf{2 0 0 4}$ & --- & 3.02 & 3.18 & 6.31 & 7.34 & 8.90 & 12.36 & 10.00 & 7.29 & 8.57 & 5.30 & 4.66 & $\mathbf{6 . 9 9}$ \\
$\mathbf{2 0 0 5}$ & 3.78 & 1.81 & 1.51 & 5.73 & 5.84 & 5.58 & 7.11 & 5.98 & 5.71 & 5.30 & 3.28 & 1.55 & $\mathbf{4 . 4 3}$ \\
$\mathbf{2 0 0 6}$ & 2.91 & 2.70 & 4.76 & 6.48 & 6.24 & --- & --- & 9.28 & 8.50 & 10.88 & 7.15 & 4.95 & $\mathbf{6 . 3 9}$ \\
$\mathbf{2 0 0 7}$ & 5.09 & 4.31 & 3.57 & 6.86 & 7.80 & 9.89 & 10.73 & 9.07 & 7.37 & 4.99 & 1.76 & 2.37 & $\mathbf{6 . 1 5}$ \\
$\mathbf{2 0 0 8}$ & 3.47 & 3.92 & 3.10 & 3.84 & 6.91 & 5.59 & 10.51 & 10.14 & 12.40 & 7.33 & 6.74 & 2.65 & $\mathbf{6 . 3 8}$ \\
\hline Media & $\mathbf{4 . 0 8}$ & $\mathbf{3 . 0 9}$ & $\mathbf{3 . 2 2}$ & $\mathbf{5 . 6 3}$ & $\mathbf{7 . 1 9}$ & $\mathbf{8 . 0 4}$ & $\mathbf{1 0 . 1 1}$ & $\mathbf{9 . 2 2}$ & $\mathbf{8 . 1 0}$ & $\mathbf{7 . 2 6}$ & $\mathbf{5 . 1 6}$ & $\mathbf{3 . 2 4}$ & $\mathbf{6 . 2 7}$ \\
\hline
\end{tabular}

e4) Desviación estándar de las medias diarias de cada mes y año del fotómetro de Palencia:

\begin{tabular}{|c|l|l|l|l|l|l|l|l|l|l|l|l|l|}
\hline Año \Mes & $\mathbf{1}$ & $\mathbf{2}$ & $\mathbf{3}$ & $\mathbf{4}$ & $\mathbf{5}$ & $\mathbf{6}$ & $\mathbf{7}$ & $\mathbf{8}$ & $\mathbf{9}$ & $\mathbf{1 0}$ & $\mathbf{1 1}$ & $\mathbf{1 2}$ & Media \\
\hline $\mathbf{2 0 0 2}$ & --- & --- & --- & --- & --- & --- & -- & -- & --- & --- & -- & --- & --- \\
$\mathbf{2 0 0 3}$ & 3.10 & 2.63 & -- & 3.50 & 2.91 & 2.90 & 2.77 & 3.38 & 3.74 & 3.52 & 2.29 & -- & $\mathbf{3 . 0 8}$ \\
$\mathbf{2 0 0 4}$ & -- & 2.70 & 2.64 & 2.48 & 4.41 & 4.97 & 3.08 & 4.16 & 5.10 & 2.81 & 2.23 & 2.33 & $\mathbf{3 . 3 5}$ \\
$\mathbf{2 0 0 5}$ & 2.36 & 2.02 & 4.08 & 3.10 & 3.01 & 4.39 & 3.30 & 3.92 & 3.59 & 4.38 & 2.98 & 3.47 & $\mathbf{3 . 3 8}$ \\
$\mathbf{2 0 0 6}$ & 2.42 & 1.99 & 2.36 & 2.47 & 2.86 & --- & --- & 3.38 & 3.95 & 3.54 & 4.36 & 3.67 & $\mathbf{3 . 1 0}$ \\
$\mathbf{2 0 0 7}$ & 2.98 & 3.02 & 2.16 & 1.84 & 4.17 & 2.70 & 2.50 & 4.63 & 4.49 & 3.68 & 2.64 & 3.67 & $\mathbf{3 . 2 1}$ \\
$\mathbf{2 0 0 8}$ & 2.50 & 2.57 & 1.95 & 2.90 & 2.37 & 3.99 & 5.71 & 5.40 & 5.73 & 6.18 & 3.56 & 4.27 & $\mathbf{3 . 9 3}$ \\
\hline Media & $\mathbf{2 . 6 7}$ & $\mathbf{2 . 4 9}$ & $\mathbf{2 . 6 4}$ & $\mathbf{2 . 7 1}$ & $\mathbf{3 . 2 9}$ & $\mathbf{3 . 7 9}$ & $\mathbf{3 . 4 7}$ & $\mathbf{4 . 1 5}$ & $\mathbf{4 . 4 3}$ & $\mathbf{4 . 0 2}$ & $\mathbf{3 . 0 1}$ & $\mathbf{3 . 4 8}$ & $\mathbf{3 . 3 4}$ \\
\hline
\end{tabular}

e5) Número de días con dato válido por mes y año de las medidas del fotómetro de Palencia:

\begin{tabular}{|c|c|c|c|c|c|c|c|c|c|c|c|c|c|}
\hline Año \Mes & 1 & 2 & 3 & 4 & 5 & 6 & 7 & 8 & 9 & 10 & 11 & 12 & Tota \\
\hline 2002 & 0 & 0 & 0 & 0 & 0 & 0 & 0 & 0 & 0 & 0 & 0 & 0 & 0 \\
\hline 2003 & 9 & 12 & 0 & 15 & 29 & 28 & 31 & 7 & 19 & 24 & 10 & 0 & 184 \\
\hline 2004 & 6 & 26 & 23 & 24 & 28 & 30 & 31 & 30 & 30 & 24 & 19 & 18 & 289 \\
\hline 2005 & 17 & 26 & 29 & 24 & 28 & 30 & 31 & 30 & 29 & 24 & 21 & 26 & 315 \\
\hline 2006 & 18 & 22 & 14 & 16 & 21 & 0 & 3 & 24 & 26 & 16 & 23 & 18 & 201 \\
\hline 2007 & 12 & 20 & 20 & 25 & 27 & 29 & 31 & 30 & 28 & 26 & 27 & 18 & 293 \\
\hline 2008 & 19 & 20 & 27 & 22 & 24 & 29 & 31 & 26 & 20 & 26 & 21 & 18 & 283 \\
\hline Total & 81 & 126 & 113 & 126 & 157 & 146 & 158 & 147 & 152 & 140 & 121 & 98 & 1556 \\
\hline
\end{tabular}

f) Resumen por mes de las medias mensuales de cada año del fotómetro de Palencia:

\begin{tabular}{|c|c|c|c|c|c|c|c|c|c|c|c|c|}
\hline Mes & 1 & 2 & 3 & 4 & 5 & 6 & 7 & 8 & 9 & 10 & 11 & 12 \\
\hline Media & 7.62 & 7.40 & 7.37 & 9.72 & 12.42 & 15.41 & 16.02 & 16.61 & 15.30 & 13.92 & 10.50 & 8.06 \\
\hline STD & 1.03 & 1.37 & 0.26 & 0.93 & 1.06 & 1.32 & 2.24 & 1.90 & 2.10 & 2.68 & 2.53 & 0.99 \\
\hline Mediana & 7.70 & 7.35 & 7.23 & 9.84 & 12.59 & 14.74 & 15.65 & 16.44 & 14.99 & 12.76 & 10.12 & 8.68 \\
\hline Máximo & 9.32 & 9.85 & 7.73 & 11.15 & 13.80 & 17.27 & 19.86 & 19.74 & 18.28 & 18.40 & 14.31 & 8.96 \\
\hline Mínimo & 6.55 & 5.62 & 7.12 & 8.23 & 10.97 & 13.96 & 13.55 & 13.77 & 12.03 & 10.65 & 7.26 & 6.50 \\
\hline $\mathrm{N}^{0}$ Días & 75 & 126 & 113 & 126 & 157 & 146 & 155 & 147 & 152 & 140 & 121 & 98 \\
\hline
\end{tabular}




\section{Gráficas de la estación de Palencia}

g) Evolución temporal de las medias diarias.

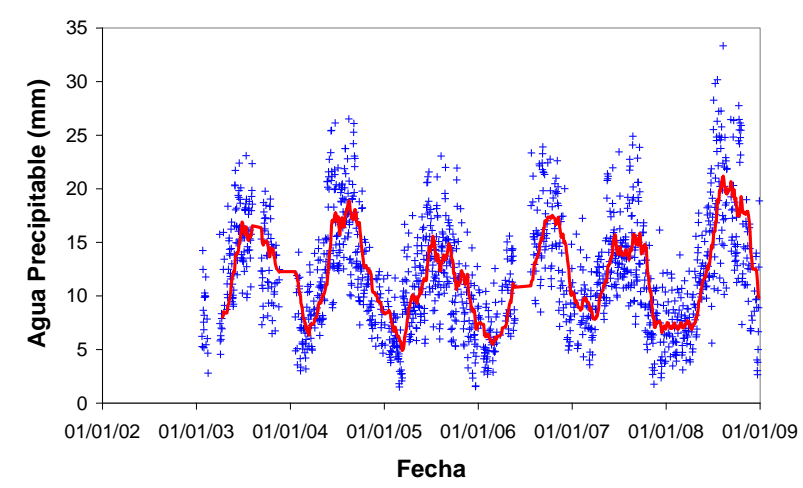

La línea roja representa la media móvil mensual. h) Histograma de las medias diarias.

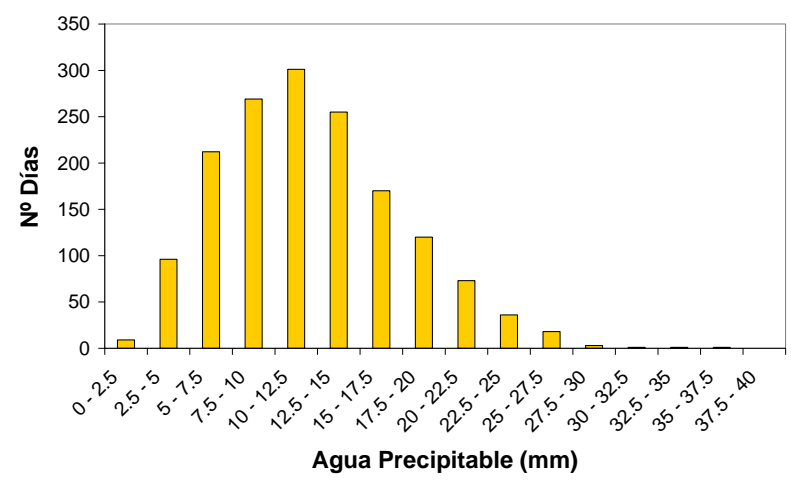

La distribución presenta un desplazamiento hacia la derecha (coef. de asimetría positivo), y los datos están más concentrados en la zona central que lo que correspondería a una distribución normal (distribución leptocúrtica).

j) Ciclo promedio anual.

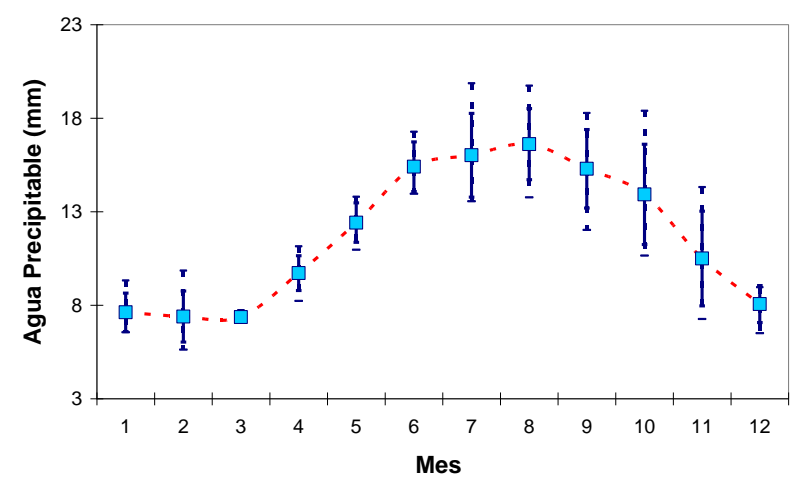

Valor promedio de las medias mensuales de cada año (cuadrados). Valor promedio más/menos la desviación típica de las medias mensuales (barras sólidas). Valor máximo y mínimo absoluto de las medias mensuales (líneas de trazos).

La estación de Palencia empezó a funcionar en enero 2003. 


\subsubsection{CORUÑA (puerto). Estación GPS.}

El análisis estadístico se ha realizado en base a los datos de ZTD generados por el centro de análisis IGN de EUREF.

a) Estadísticas globales del conjunto de las medidas del GPS de Coruña:

\begin{tabular}{|c|c|c|c|c|c|c|c|c|c|c|}
\hline $\begin{array}{c}\mathbf{N}^{0} \\
\text { Medidas }\end{array}$ & Media & STD & Mediana & $\begin{array}{c}\text { Clase } \\
\text { Modal }\end{array}$ & $\begin{array}{c}\text { Percentil } \\
\mathbf{5}\end{array}$ & $\begin{array}{c}\text { Percentil } \\
\mathbf{9 5}\end{array}$ & Máximo & Mínimo & $\begin{array}{c}\text { Coef. } \\
\text { Asimetría }\end{array}$ & Curtosis \\
\hline 54287 & 20.12 & 7.72 & 19.36 & $15-17.5$ & 8.62 & 34.14 & 52.54 & 1.56 & 0.43 & -0.14 \\
\hline
\end{tabular}

b) Estadísticas por mes del conjunto de las medidas del GPS de Coruña:

\begin{tabular}{|c|c|c|c|c|c|c|c|c|c|c|c|c|}
\hline Estadístico \Mes & 1 & 2 & 3 & 4 & 5 & 6 & 7 & 8 & 9 & 10 & 11 & 12 \\
\hline Media & 15.62 & 13.71 & 16.45 & 16.62 & 20.30 & 24.67 & 26.81 & 26.16 & 24.59 & 23.37 & 17.98 & 15.92 \\
\hline STD & 5.55 & 5.21 & 6.17 & 5.16 & 5.17 & 7.03 & 6.50 & 6.52 & 7.41 & 7.92 & 6.10 & 6.72 \\
\hline Mediana & 14.91 & 12.74 & 16.43 & 15.99 & 19.73 & 24.60 & 26.15 & 25.35 & 23.74 & 23.45 & 17.28 & 15.57 \\
\hline Máximo & 36.86 & 37.42 & 37.47 & 37.31 & 44.04 & 45.84 & 52.54 & 50.35 & 44.47 & 44.74 & 40.25 & 40.76 \\
\hline Mínimo & 2.28 & 2.05 & 2.26 & 2.58 & 7.96 & 6.28 & 7.11 & 11.04 & 8.52 & 4.57 & 2.26 & 1.56 \\
\hline Percentil 5 & 7.79 & 6.68 & 6.82 & 9.02 & 12.99 & 13.80 & 17.41 & 16.53 & 13.58 & 10.76 & 9.20 & 4.90 \\
\hline Percentil 95 & 26.06 & 23.93 & 26.76 & 26.18 & 30.03 & 36.48 & 38.33 & 38.09 & 37.44 & 36.29 & 28.68 & 27.32 \\
\hline Coef. Asimetría & 0.63 & 0.70 & 0.20 & 0.53 & 0.68 & 0.12 & 0.49 & 0.52 & 0.28 & 0.09 & 0.53 & 0.28 \\
\hline Curtosis & 0.15 & 0.00 & -0.40 & 0.23 & 0.51 & -0.54 & -0.01 & 0.06 & -0.75 & -0.71 & 0.29 & -0.16 \\
\hline $\mathrm{N}^{0}$ Medidas & 4742 & 3996 & 4373 & 5022 & 5164 & 4303 & 4548 & 4524 & 4210 & 4088 & 4557 & 4760 \\
\hline
\end{tabular}

c) Estadísticas globales de las medias diarias del GPS de Coruña:

\begin{tabular}{|c|c|c|c|c|c|c|c|c|c|c|}
\hline No Días & Media & STD & Mediana & Moda & $\begin{array}{c}\text { Percentil } \\
\mathbf{5}\end{array}$ & $\begin{array}{c}\text { Percentil } \\
\mathbf{9 5}\end{array}$ & Máximo & Mínimo & $\begin{array}{c}\text { Coef. } \\
\text { Asimetría }\end{array}$ & Curtosis \\
\hline 2283 & 20.14 & 7.14 & 19.51 & $17.5-20$ & 9.14 & 32.62 & 44.34 & 3.02 & 0.32 & -0.26 \\
\hline
\end{tabular}

d) Resumen por mes de las medias diarias del GPS de Coruña:

\begin{tabular}{|c|c|c|c|c|c|c|c|c|c|c|c|c|}
\hline Estadístico \Mes & 1 & 2 & 3 & 4 & 5 & 6 & 7 & 8 & 9 & 10 & 11 & 12 \\
\hline Media & 15.66 & 13.72 & 16.41 & 16.63 & 20.31 & 24.69 & 26.85 & 26.18 & 24.59 & 23.37 & 17.99 & 16.00 \\
\hline STD & 4.98 & 4.67 & 5.56 & 4.49 & 4.40 & 6.29 & 5.62 & 5.61 & 6.70 & 6.96 & 5.48 & 6.10 \\
\hline Mediana & 15.25 & 12.82 & 16.30 & 16.15 & 19.86 & 24.80 & 26.38 & 25.70 & 24.13 & 24.22 & 17.67 & 16.42 \\
\hline Máximo & 32.04 & 27.72 & 29.93 & 29.31 & 38.17 & 39.09 & 44.34 & 43.26 & 38.39 & 41.10 & 34.66 & 29.81 \\
\hline Mínimo & 5.67 & 5.94 & 4.81 & 5.71 & 11.66 & 9.96 & 14.93 & 13.72 & 11.54 & 7.93 & 3.80 & 3.02 \\
\hline Percentil 5 & 8.32 & 7.12 & 6.84 & 9.33 & 14.05 & 14.44 & 18.81 & 17.92 & 14.61 & 11.12 & 9.83 & 5.15 \\
\hline Percentil 95 & 24.91 & 22.73 & 25.08 & 24.54 & 28.56 & 35.02 & 36.61 & 36.09 & 36.37 & 33.89 & 27.49 & 26.70 \\
\hline Coef. Asimetría & 0.66 & 0.57 & 0.00 & 0.32 & 0.76 & -0.06 & 0.51 & 0.27 & 0.15 & -0.11 & 0.41 & -0.06 \\
\hline Curtosis & 0.54 & -0.23 & -0.68 & -0.07 & 1.11 & -0.64 & 0.16 & -0.32 & -0.81 & -0.53 & 0.31 & -0.48 \\
\hline $\mathrm{N}^{0}$ Días & 202 & 167 & 184 & 210 & 216 & 180 & 193 & 190 & 178 & 172 & 190 & 201 \\
\hline
\end{tabular}

e1) Media de las medias diarias por mes y año del GPS de Coruña:

\begin{tabular}{|c|c|c|c|c|c|c|c|c|c|c|c|c|c|}
\hline Año \Mes & $\mathbf{1}$ & $\mathbf{2}$ & $\mathbf{3}$ & $\mathbf{4}$ & $\mathbf{5}$ & $\mathbf{6}$ & $\mathbf{7}$ & $\mathbf{8}$ & $\mathbf{9}$ & $\mathbf{1 0}$ & $\mathbf{1 1}$ & $\mathbf{1 2}$ & Media \\
\hline $\mathbf{2 0 0 2}$ & 16.91 & 15.05 & 13.98 & 14.58 & 19.90 & --- & -- & 27.77 & 27.87 & 26.48 & 19.73 & 20.71 & $\mathbf{2 0 . 3 0}$ \\
$\mathbf{2 0 0 3}$ & 15.03 & 16.35 & 18.39 & 19.68 & 21.02 & 28.79 & 28.90 & -- & -- & -- & 20.26 & 18.17 & $\mathbf{2 0 . 7 3}$ \\
$\mathbf{2 0 0 4}$ & 16.75 & 11.97 & 16.12 & 15.45 & 20.73 & 24.56 & 27.71 & 28.72 & 26.89 & 24.17 & 16.76 & 16.51 & $\mathbf{2 0 . 5 3}$ \\
$\mathbf{2 0 0 5}$ & 16.25 & 12.20 & 16.36 & 18.95 & 19.58 & 26.03 & 26.80 & 25.65 & 24.44 & 24.17 & 19.89 & 15.91 & $\mathbf{2 0 . 5 2}$ \\
$\mathbf{2 0 0 6}$ & 14.51 & 12.26 & 19.55 & 16.90 & 20.35 & 24.91 & 29.73 & 25.08 & 27.17 & 27.74 & 21.90 & 15.22 & $\mathbf{2 1 . 2 8}$ \\
$\mathbf{2 0 0 7}$ & 15.33 & -- & --- & 16.27 & 19.90 & 22.48 & 24.81 & 23.89 & 19.08 & 18.70 & 12.81 & 13.05 & $\mathbf{1 8 . 6 3}$ \\
$\mathbf{2 0 0 8}$ & 15.39 & 14.57 & 13.97 & 14.58 & 20.70 & 20.97 & 23.81 & 25.00 & 22.04 & 20.17 & 15.99 & 13.40 & $\mathbf{1 8 . 3 8}$ \\
\hline Media & $\mathbf{1 5 . 7 4}$ & $\mathbf{1 3 . 7 3}$ & $\mathbf{1 6 . 4 0}$ & $\mathbf{1 6 . 6 3}$ & $\mathbf{2 0 . 3 1}$ & $\mathbf{2 4 . 6 2}$ & $\mathbf{2 6 . 9 6}$ & $\mathbf{2 6 . 0 2}$ & $\mathbf{2 4 . 5 8}$ & $\mathbf{2 3 . 5 7}$ & $\mathbf{1 8 . 1 9}$ & $\mathbf{1 6 . 1 4}$ & $\mathbf{2 0 . 0 5}$ \\
\hline
\end{tabular}


e2) Máximo de las medias diarias por mes y año del GPS de Coruña:

\begin{tabular}{|c|c|c|c|c|c|c|c|c|c|c|c|c|c|}
\hline Año \Mes & $\mathbf{1}$ & $\mathbf{2}$ & $\mathbf{3}$ & $\mathbf{4}$ & $\mathbf{5}$ & $\mathbf{6}$ & $\mathbf{7}$ & $\mathbf{8}$ & $\mathbf{9}$ & $\mathbf{1 0}$ & $\mathbf{1 1}$ & $\mathbf{1 2}$ & Media \\
\hline $\mathbf{2 0 0 2}$ & 25.73 & 23.34 & 25.09 & 22.89 & 28.42 & --- & -- & 38.11 & 38.29 & 35.33 & 34.66 & 28.73 & $\mathbf{3 0 . 0 6}$ \\
$\mathbf{2 0 0 3}$ & 32.04 & 25.82 & 28.86 & 27.87 & 32.53 & 37.95 & 44.34 & -- & -- & -- & 32.98 & 26.64 & $\mathbf{3 2 . 1 1}$ \\
$\mathbf{2 0 0 4}$ & 29.91 & 21.05 & 25.34 & 24.63 & 38.17 & 36.55 & 36.75 & 37.42 & 38.39 & 34.95 & 25.74 & 23.70 & $\mathbf{3 1 . 0 5}$ \\
$\mathbf{2 0 0 5}$ & 26.88 & 20.41 & 29.93 & 29.31 & 25.42 & 39.09 & 42.86 & 38.39 & 37.02 & 39.76 & 33.55 & 27.74 & $\mathbf{3 2 . 5 3}$ \\
$\mathbf{2 0 0 6}$ & 25.24 & 27.72 & 27.41 & 21.74 & 31.33 & 35.45 & 39.66 & 37.31 & 36.49 & 41.10 & 32.11 & 29.81 & $\mathbf{3 2 . 1 1}$ \\
$\mathbf{2 0 0 7}$ & 24.86 & -- & --- & 22.41 & 29.39 & 31.89 & 36.73 & 43.26 & 28.84 & 32.58 & 22.19 & 24.50 & $\mathbf{2 9 . 6 7}$ \\
$\mathbf{2 0 0 8}$ & 28.28 & 25.28 & 23.42 & 23.32 & 26.35 & 30.61 & 33.99 & 38.33 & 33.29 & 31.09 & 25.18 & 25.94 & $\mathbf{2 8 . 7 6}$ \\
\hline Media & $\mathbf{2 7 . 5 6}$ & $\mathbf{2 3 . 9 4}$ & $\mathbf{2 6 . 6 8}$ & $\mathbf{2 4 . 6 0}$ & $\mathbf{3 0 . 2 3}$ & $\mathbf{3 5 . 2 6}$ & $\mathbf{3 9 . 0 6}$ & $\mathbf{3 8 . 8 0}$ & $\mathbf{3 5 . 3 9}$ & $\mathbf{3 5 . 8 0}$ & $\mathbf{2 9 . 4 9}$ & $\mathbf{2 6 . 7 2}$ & $\mathbf{3 0 . 9 0}$ \\
\hline
\end{tabular}

e3) Mínimo de las medias diarias por mes y año del GPS de Coruña:

\begin{tabular}{|c|c|c|c|c|c|c|c|c|c|c|c|c|c|}
\hline Año | Mes & 1 & 2 & 3 & 4 & 5 & 6 & 7 & 8 & 9 & 10 & 11 & 12 & Media \\
\hline 2002 & 10.49 & 6.37 & 6.55 & 9.18 & 13.27 & -- & -- & 19.01 & 11.94 & 15.20 & 13.31 & 10.50 & 11.58 \\
\hline 2003 & 5.67 & 7.10 & 7.30 & 8.21 & 13.49 & 19.87 & 20.00 & --- & --- & --- & 12.89 & 13.14 & 11.96 \\
\hline 2004 & 6.91 & 5.94 & 5.62 & 10.50 & 12.87 & 10.73 & 17.33 & 19.28 & 15.19 & 16.12 & 9.97 & 9.22 & 11.64 \\
\hline 2005 & 8.82 & 7.10 & 5.56 & 10.40 & 12.44 & 15.95 & 15.93 & 13.72 & 15.18 & 7.93 & 9.66 & 4.74 & 10.62 \\
\hline 2006 & 8.54 & 6.81 & 10.82 & 8.47 & 11.73 & 10.27 & 19.89 & 15.54 & 19.65 & 14.19 & 10.13 & 4.78 & 11.74 \\
\hline 2007 & 6.89 & --- & -- & 11.38 & 11.66 & 14.34 & 18.26 & 15.32 & 11.67 & 8.82 & 3.80 & 3.28 & 10.54 \\
\hline 2008 & 9.02 & 6.71 & 4.81 & 5.71 & 15.29 & 9.96 & 14.93 & 16.46 & 11.54 & 11.03 & 10.02 & 3.02 & 9.88 \\
\hline Media & 8.05 & 6.67 & 6.78 & 9.12 & 12.96 & 13.52 & 17.72 & 16.56 & 14.20 & 12.22 & 9.97 & 6.95 & 11.14 \\
\hline
\end{tabular}

e4) Desviación estándar de las medias diarias de cada mes y año del GPS de Coruña:

\begin{tabular}{|c|l|l|l|l|l|l|l|l|l|l|l|l|c|}
\hline Año IMes & $\mathbf{1}$ & $\mathbf{2}$ & $\mathbf{3}$ & $\mathbf{4}$ & $\mathbf{5}$ & $\mathbf{6}$ & $\mathbf{7}$ & $\mathbf{8}$ & $\mathbf{9}$ & $\mathbf{1 0}$ & $\mathbf{1 1}$ & $\mathbf{1 2}$ & Media \\
\hline $\mathbf{2 0 0 2}$ & 3.31 & 4.13 & 4.40 & 2.76 & 3.94 & -- & -- & 4.81 & 7.56 & 5.43 & 4.41 & 4.77 & $\mathbf{4 . 5 5}$ \\
$\mathbf{2 0 0 3}$ & 5.87 & 4.73 & 6.00 & 5.83 & 4.84 & 4.86 & 5.95 & -- & -- & -- & 5.16 & 2.99 & $\mathbf{5 . 1 4}$ \\
$\mathbf{2 0 0 4}$ & 8.05 & 3.66 & 5.07 & 3.55 & 5.75 & 7.03 & 4.61 & 5.05 & 7.02 & 4.95 & 4.21 & 3.80 & $\mathbf{5 . 2 3}$ \\
$\mathbf{2 0 0 5}$ & 5.03 & 2.98 & 6.71 & 4.68 & 3.29 & 5.98 & 6.56 & 5.38 & 5.02 & 7.81 & 5.01 & 6.07 & $\mathbf{5 . 3 8}$ \\
$\mathbf{2 0 0 6}$ & 3.65 & 4.33 & 4.36 & 3.56 & 5.16 & 7.00 & 4.54 & 5.58 & 4.26 & 6.17 & 5.38 & 7.21 & $\mathbf{5 . 1 0}$ \\
$\mathbf{2 0 0 7}$ & 4.74 & --- & --- & 2.96 & 4.13 & 4.32 & 4.39 & 6.03 & 4.53 & 6.20 & 4.35 & 5.84 & $\mathbf{4 . 7 5}$ \\
$\mathbf{2 0 0 8}$ & 4.12 & 5.81 & 3.83 & 4.36 & 2.74 & 5.32 & 5.00 & 5.11 & 6.34 & 5.80 & 3.73 & 6.10 & $\mathbf{4 . 8 6}$ \\
\hline Media & $\mathbf{4 . 9 7}$ & $\mathbf{4 . 2 7}$ & $\mathbf{5 . 0 6}$ & $\mathbf{3 . 9 6}$ & $\mathbf{4 . 2 6}$ & $\mathbf{5 . 7 5}$ & $\mathbf{5 . 1 7}$ & $\mathbf{5 . 3 3}$ & $\mathbf{5 . 7 9}$ & $\mathbf{6 . 0 6}$ & $\mathbf{4 . 6 1}$ & $\mathbf{5 . 2 6}$ & $\mathbf{5 . 0 0}$ \\
\hline
\end{tabular}

e5) Número de días con dato válido por mes y año del GPS de Coruña:

\begin{tabular}{|c|c|c|c|c|c|c|c|c|c|c|c|c|c|}
\hline Año \Mes & 1 & 2 & 3 & 4 & 5 & 6 & 7 & 8 & 9 & 10 & 11 & 12 & Total \\
\hline 2002 & 31 & 28 & 31 & 30 & 31 & 4 & 8 & 31 & 29 & 21 & 25 & 31 & 300 \\
\hline 2003 & 31 & 27 & 31 & 30 & 31 & 30 & 30 & 8 & 0 & 0 & 15 & 16 & 249 \\
\hline 2004 & 16 & 28 & 31 & 30 & 30 & 30 & 31 & 29 & 30 & 29 & 30 & 31 & 345 \\
\hline 2005 & 31 & 28 & 30 & 30 & 31 & 30 & 31 & 31 & 30 & 30 & 30 & 31 & 363 \\
\hline 2006 & 31 & 28 & 31 & 30 & 31 & 30 & 31 & 30 & 30 & 30 & 30 & 31 & 363 \\
\hline 2007 & 31 & 0 & 0 & 30 & 31 & 30 & 31 & 31 & 29 & 31 & 30 & 31 & 305 \\
\hline 2008 & 31 & 28 & 30 & 30 & 31 & 26 & 31 & 30 & 30 & 31 & 30 & 30 & 358 \\
\hline Total & 202 & 167 & 184 & 210 & 216 & 176 & 185 & 182 & 178 & 172 & 190 & 201 & 2263 \\
\hline
\end{tabular}

f) Resumen por mes de las medias mensuales de cada año del GPS de Coruña:

\begin{tabular}{|c|c|c|c|c|c|c|c|c|c|c|c|c|}
\hline Mes & 1 & 2 & 3 & 4 & 5 & 6 & 7 & 8 & 9 & 10 & 11 & 12 \\
\hline Media & 15.74 & 13.73 & 16.40 & 16.63 & 20.31 & 24.62 & 26.96 & 26.02 & 24.58 & 23.57 & 18.19 & 16.14 \\
\hline STD & 0.84 & 1.68 & 2.07 & 1.88 & 0.49 & 2.49 & 2.10 & 1.68 & 3.15 & 3.21 & 2.91 & 2.48 \\
\hline Mediana & 15.39 & 13.42 & 16.24 & 16.27 & 20.35 & 24.74 & 27.25 & 25.37 & 25.66 & 24.17 & 19.73 & 15.91 \\
\hline Máximo & 16.91 & 16.35 & 19.55 & 19.68 & 21.02 & 28.79 & 29.73 & 28.72 & 27.87 & 27.74 & 21.90 & 20.71 \\
\hline Mínimo & 14.51 & 11.97 & 13.97 & 14.58 & 19.58 & 20.97 & 23.81 & 23.89 & 19.08 & 18.70 & 12.81 & 13.05 \\
\hline No Días & 202 & 167 & 184 & 210 & 216 & 176 & 185 & 182 & 178 & 172 & 190 & 201 \\
\hline
\end{tabular}




\section{Gráficas de la estación de Coruña}

g) Evolución temporal de las medias diarias.

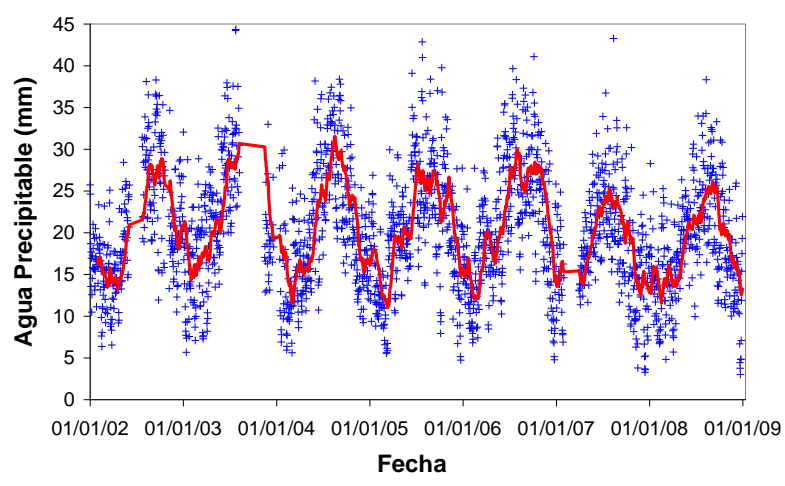

La línea roja representa la media móvil mensual. h) Histograma de las medias diarias.

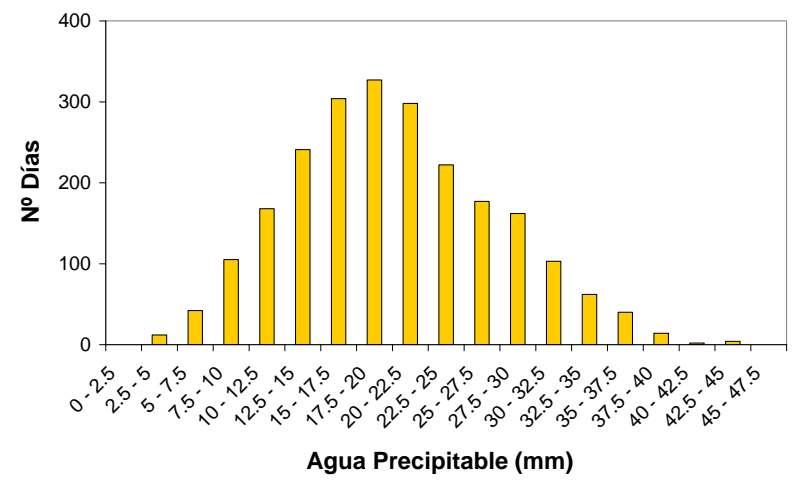

La distribución presenta un desplazamiento hacia la derecha (coef. de asimetría positivo), y un ligero achatamiento (curtosis negativa) respecto de la distribución normal.

j) Ciclo promedio anual.

para cada mes y año.
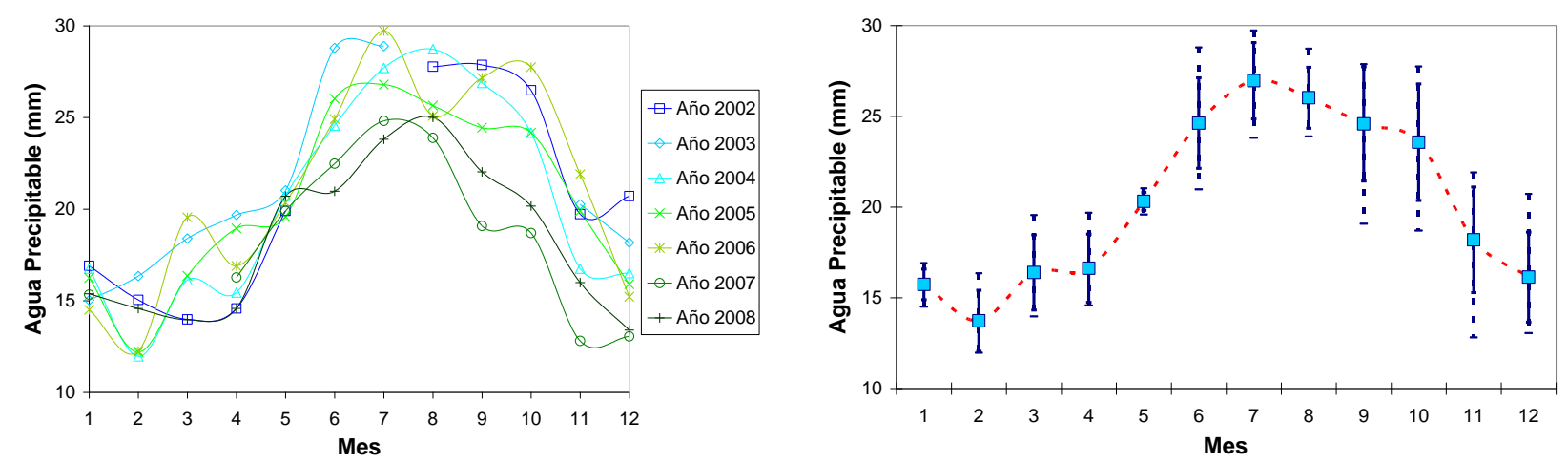

Valor promedio de las medias mensuales de cada año (cuadrados). Valor promedio más/menos la desviación típica de las medias mensuales (barras sólidas). Valor máximo y mínimo absoluto de las medias mensuales (líneas de trazos). 


\subsubsection{ALICANTE (puerto). Estación GPS.}

El análisis estadístico se ha realizado en base a los datos de ZTD generados por el centro de análisis IGN de EUREF.

a) Estadísticas globales del conjunto de las medidas del GPS de Alicante:

\begin{tabular}{|c|c|c|c|c|c|c|c|c|c|c|}
\hline $\begin{array}{c}\mathrm{N}^{0} \\
\text { Medidas }\end{array}$ & Media & STD & Mediana & $\begin{array}{l}\text { Clase } \\
\text { Modal }\end{array}$ & $\begin{array}{c}\text { Percentil } \\
5 \\
\end{array}$ & $\begin{array}{c}\text { Percentil } \\
95 \\
\end{array}$ & Máximo & Mínimo & \begin{tabular}{|c|}
$\begin{array}{c}\text { Coef. } \\
\text { Asimetría }\end{array}$ \\
\end{tabular} & Curtosis \\
\hline 56628 & 21.06 & 8.73 & 20.213 & $15-17.5$ & 8.04 & 36.20 & 50.35 & 0.35 & 0.28 & -0.67 \\
\hline
\end{tabular}

b) Estadísticas por mes del conjunto de las medidas del GPS de Alicante:

\begin{tabular}{|c|c|c|c|c|c|c|c|c|c|c|c|c|}
\hline Estadístico | Mes & 1 & 2 & 3 & 4 & 5 & 6 & 7 & 8 & 9 & 10 & 11 & 12 \\
\hline Media & 12.67 & 13.47 & 15.06 & 17.39 & 21.41 & 26.71 & 29.04 & 31.02 & 29.97 & 25.27 & 17.57 & 14.77 \\
\hline STD & 4.91 & 4.90 & 5.08 & 4.74 & 5.35 & 5.13 & 5.48 & 6.18 & 6.69 & 6.78 & 6.41 & 5.23 \\
\hline Mediana & 12.35 & 13.19 & 14.99 & 17.51 & 21.42 & 26.72 & 28.94 & 31.48 & 30.24 & 25.68 & 16.92 & 14.30 \\
\hline Máximo & 33.77 & 28.32 & 29.57 & 31.25 & 38.43 & 42.37 & 47.81 & 50.35 & 47.90 & 45.69 & 42.60 & 34.65 \\
\hline Mínimo & 1.47 & 0.89 & 0.35 & 4.39 & 6.80 & 11.49 & 9.77 & 7.73 & 10.99 & 7.67 & 2.09 & 3.02 \\
\hline Percentil 5 & 5.22 & 6.07 & 6.75 & 9.35 & 13.05 & 18.29 & 20.00 & 20.67 & 18.42 & 13.95 & 8.02 & 7.11 \\
\hline Percentil 95 & 21.16 & 22.17 & 23.38 & 24.88 & 30.23 & 35.07 & 38.00 & 40.61 & 40.62 & 35.70 & 28.66 & 23.52 \\
\hline Coef. Asimetría & 0.42 & 0.32 & 0.02 & -0.03 & 0.07 & -0.06 & 0.03 & -0.19 & -0.15 & -0.10 & 0.49 & 0.49 \\
\hline Curtosis & -0.07 & -0.25 & -0.47 & -0.30 & -0.44 & -0.37 & -0.12 & -0.32 & -0.37 & -0.48 & 0.32 & 0.14 \\
\hline $\mathrm{N}^{0}$ Medidas & 5070 & 4695 & 4975 & 4319 & 4294 & 3781 & 4817 & 4820 & 4975 & 4774 & 4950 & 5158 \\
\hline
\end{tabular}

c) Estadísticas globales de las medias diarias del GPS de Alicante:

\begin{tabular}{|c|c|c|c|c|c|c|c|c|c|c|}
\hline $\mathrm{N}^{0}$ Días & Media & STD & Mediana & Moda & \begin{tabular}{|c|} 
Percentil \\
5 \\
\end{tabular} & \begin{tabular}{|c|} 
Percentil \\
95 \\
\end{tabular} & Máximo & Mínimo & \begin{tabular}{|c} 
Coef. \\
Asimetría
\end{tabular} & Curtosis \\
\hline 2387 & 21.07 & 8.33 & 20.24 & $12.5-15$ & 8.57 & 35.49 & 44.99 & 3.00 & 0.26 & -0.78 \\
\hline
\end{tabular}

d) Resumen por mes de las medias diarias del GPS de Alicante:

\begin{tabular}{|c|c|c|c|c|c|c|c|c|c|c|c|c|}
\hline Estadístico \Mes & 1 & 2 & 3 & 4 & 5 & 6 & 7 & 8 & 9 & 10 & 11 & 12 \\
\hline Media & 12.66 & 13.47 & 15.04 & 17.39 & 21.42 & 26.67 & 29.04 & 31.03 & 29.98 & 25.31 & 17.55 & 14.77 \\
\hline STD & 4.34 & 4.43 & 4.53 & 4.10 & 4.80 & 4.50 & 4.70 & 5.33 & 6.03 & 6.02 & 5.83 & 4.61 \\
\hline Mediana & 12.49 & 13.37 & 14.80 & 17.85 & 21.40 & 26.57 & 29.10 & 31.52 & 30.20 & 25.49 & 16.96 & 14.38 \\
\hline Máximo & 27.84 & 25.02 & 26.47 & 26.75 & 32.90 & 36.59 & 39.59 & 42.38 & 44.99 & 42.38 & 37.55 & 31.54 \\
\hline Mínimo & 3.74 & 3.00 & 3.84 & 7.52 & 10.47 & 16.98 & 14.47 & 15.43 & 13.89 & 9.40 & 3.17 & 5.48 \\
\hline Percentil 5 & 6.02 & 6.74 & 7.46 & 9.70 & 13.64 & 19.66 & 21.77 & 22.16 & 19.82 & 14.42 & 9.25 & 7.78 \\
\hline Percentil 95 & 20.25 & 22.06 & 22.52 & 23.98 & 29.32 & 34.15 & 36.85 & 39.10 & 38.60 & 33.49 & 27.36 & 21.58 \\
\hline Coef. Asimetría & 0.40 & 0.34 & -0.04 & -0.20 & 0.06 & 0.05 & -0.03 & -0.27 & -0.16 & -0.22 & 0.52 & 0.53 \\
\hline Curtosis & 0.18 & -0.20 & -0.35 & -0.39 & -0.50 & -0.68 & -0.27 & -0.49 & -0.46 & -0.45 & 0.52 & 0.46 \\
\hline No Días & 215 & 198 & 209 & 180 & 181 & 161 & 201 & 203 & 210 & 205 & 209 & 215 \\
\hline
\end{tabular}

e1) Media de las medias diarias por mes y año del GPS de Alicante:

\begin{tabular}{|c|c|c|c|c|c|c|c|c|c|c|c|c|c|}
\hline Año \Mes & $\mathbf{1}$ & $\mathbf{2}$ & $\mathbf{3}$ & $\mathbf{4}$ & $\mathbf{5}$ & $\mathbf{6}$ & $\mathbf{7}$ & $\mathbf{8}$ & $\mathbf{9}$ & $\mathbf{1 0}$ & $\mathbf{1 1}$ & $\mathbf{1 2}$ & Media \\
\hline $\mathbf{2 0 0 2}$ & 13.58 & 10.36 & 16.13 & 18.14 & 19.14 & 24.49 & 28.62 & 33.05 & 30.94 & 23.07 & 18.14 & 17.38 & $\mathbf{2 1 . 0 8}$ \\
$\mathbf{2 0 0 3}$ & 11.66 & 13.98 & 15.66 & 17.94 & 22.83 & 27.86 & 29.40 & 29.41 & 31.29 & 26.28 & 21.06 & 15.05 & $\mathbf{2 1 . 8 7}$ \\
$\mathbf{2 0 0 4}$ & 13.36 & 14.37 & 16.70 & 17.11 & 22.80 & --- & 30.86 & 32.65 & 32.52 & 26.16 & 17.09 & 16.53 & $\mathbf{2 1 . 8 3}$ \\
$\mathbf{2 0 0 5}$ & 10.66 & 11.81 & 16.90 & 17.16 & 21.29 & $\mathbf{2 9 . 0 9}$ & 30.06 & 30.92 & 26.48 & 26.56 & 16.42 & 14.49 & $\mathbf{2 0 . 9 9}$ \\
$\mathbf{2 0 0 6}$ & 14.52 & 13.74 & 15.11 & -- & -- & -- & 28.77 & 31.46 & 30.42 & 26.15 & 21.24 & 14.73 & $\mathbf{2 1 . 7 9}$ \\
$\mathbf{2 0 0 7}$ & 12.03 & 14.57 & 12.30 & 19.17 & 19.57 & 25.66 & 26.47 & 29.79 & 29.11 & 23.75 & 14.49 & 12.61 & $\mathbf{1 9 . 9 6}$ \\
$\mathbf{2 0 0 8}$ & 12.90 & 15.36 & 12.81 & 14.84 & 23.04 & 25.15 & 28.95 & 29.78 & 29.09 & 25.56 & 14.36 & 12.65 & $\mathbf{2 0 . 3 7}$ \\
\hline Media & $\mathbf{1 2 . 6 7}$ & $\mathbf{1 3 . 4 5}$ & $\mathbf{1 5 . 0 9}$ & $\mathbf{1 7 . 3 9}$ & $\mathbf{2 1 . 4 4}$ & $\mathbf{2 6 . 4 5}$ & $\mathbf{2 9 . 0 2}$ & $\mathbf{3 1 . 0 1}$ & $\mathbf{2 9 . 9 8}$ & $\mathbf{2 5 . 3 6}$ & $\mathbf{1 7 . 5 4}$ & $\mathbf{1 4 . 7 8}$ & $\mathbf{2 1 . 1 3}$ \\
\hline
\end{tabular}


e2) Máximo de las medias diarias por mes y año del GPS de Alicante:

\begin{tabular}{|c|c|c|c|c|c|c|c|c|c|c|c|c|c|}
\hline Año \Mes & $\mathbf{1}$ & $\mathbf{2}$ & $\mathbf{3}$ & $\mathbf{4}$ & $\mathbf{5}$ & $\mathbf{6}$ & $\mathbf{7}$ & $\mathbf{8}$ & $\mathbf{9}$ & $\mathbf{1 0}$ & $\mathbf{1 1}$ & $\mathbf{1 2}$ & Media \\
\hline $\mathbf{2 0 0 2}$ & 27.84 & 17.12 & 20.69 & 25.13 & 29.24 & 35.97 & 38.20 & 42.03 & 43.39 & 42.38 & 27.86 & 31.54 & $\mathbf{3 1 . 7 8}$ \\
$\mathbf{2 0 0 3}$ & 23.75 & 22.62 & 24.24 & 24.48 & 29.62 & 34.34 & 39.59 & 39.12 & 44.99 & 34.21 & 28.46 & 20.53 & $\mathbf{3 0 . 5 0}$ \\
$\mathbf{2 0 0 4}$ & 22.78 & 24.98 & 23.99 & 23.98 & 32.47 & & 37.61 & 40.91 & 41.67 & 36.07 & 31.25 & 22.61 & $\mathbf{3 0 . 7 6}$ \\
$\mathbf{2 0 0 5}$ & 18.54 & 17.58 & 26.47 & 26.75 & 32.90 & 36.59 & 38.40 & 40.23 & 33.90 & 36.28 & 25.11 & 21.76 & $\mathbf{2 9 . 5 4}$ \\
$\mathbf{2 0 0 6}$ & 20.69 & 22.78 & 22.70 & -- & --- & -- & 36.85 & 39.49 & 40.67 & 32.78 & 37.55 & 23.24 & $\mathbf{3 0 . 7 5}$ \\
$\mathbf{2 0 0 7}$ & 23.77 & 21.95 & 20.93 & 23.90 & 29.32 & 33.42 & 34.03 & 42.38 & 37.87 & 33.49 & 27.59 & 21.19 & $\mathbf{2 9 . 1 5}$ \\
$\mathbf{2 0 0 8}$ & 20.26 & 25.02 & 18.12 & 26.13 & 31.22 & 31.13 & 35.86 & 38.94 & 37.99 & 36.36 & 26.89 & 20.62 & $\mathbf{2 9 . 0 5}$ \\
\hline Media & $\mathbf{2 2 . 5 2}$ & $\mathbf{2 1 . 7 2}$ & $\mathbf{2 2 . 4 5}$ & $\mathbf{2 5 . 0 6}$ & $\mathbf{3 0 . 8 0}$ & $\mathbf{3 4 . 2 9}$ & $\mathbf{3 7 . 2 2}$ & $\mathbf{4 0 . 4 4}$ & $\mathbf{4 0 . 0 7}$ & $\mathbf{3 5 . 9 4}$ & $\mathbf{2 9 . 2 4}$ & $\mathbf{2 3 . 0 7}$ & $\mathbf{3 0 . 2 2}$ \\
\hline
\end{tabular}

e3) Mínimo de las medias diarias por mes y año del GPS de Alicante:

\begin{tabular}{|c|c|c|c|c|c|c|c|c|c|c|c|c|c|}
\hline Año \Mes & 1 & 2 & 3 & 4 & 5 & 6 & 7 & 8 & 9 & 10 & 11 & 12 & Media \\
\hline 2002 & 5.44 & 4.48 & 11.59 & 11.53 & 10.47 & 16.98 & 21.92 & 24.41 & 20.77 & 12.99 & 10.34 & 8.15 & 13.26 \\
\hline 2003 & 3.97 & 4.99 & 8.04 & 8.58 & 14.55 & 18.67 & 18.95 & 17.72 & 19.10 & 9.40 & 12.37 & 6.96 & 11.94 \\
\hline 2004 & 4.70 & 6.28 & 5.52 & 10.22 & 15.19 & & 14.47 & 25.84 & 21.15 & 13.67 & 7.68 & 7.14 & 11.99 \\
\hline 2005 & 3.82 & 5.79 & 6.48 & 8.23 & 13.37 & 16.99 & 19.36 & 20.91 & 13.89 & 17.11 & 7.99 & 9.75 & 11.97 \\
\hline 2006 & 7.72 & 7.51 & 8.01 & --- & --- & --- & 21.77 & 23.56 & 19.99 & 13.82 & 11.52 & 8.29 & 13.58 \\
\hline 2007 & 3.74 & 3.00 & 5.25 & 12.17 & 11.10 & 19.73 & 19.36 & 20.79 & 16.76 & 11.59 & 3.17 & 5.48 & 11.01 \\
\hline 2008 & 6.34 & 8.35 & 3.84 & 7.52 & 12.86 & 17.53 & 20.60 & 15.43 & 18.32 & 12.71 & 7.75 & 6.65 & 11.49 \\
\hline Media & 5.10 & 5.77 & 6.96 & 9.71 & 12.92 & 17.98 & 19.49 & 21.24 & 18.57 & 13.04 & 8.69 & 7.49 & 12.18 \\
\hline
\end{tabular}

e4) Desviación estándar de las medias diarias de cada mes y año del GPS de Alicante:

\begin{tabular}{|c|l|l|l|l|l|l|l|l|l|l|l|l|c|}
\hline Año IMes & $\mathbf{1}$ & $\mathbf{2}$ & $\mathbf{3}$ & $\mathbf{4}$ & $\mathbf{5}$ & $\mathbf{6}$ & $\mathbf{7}$ & $\mathbf{8}$ & $\mathbf{9}$ & $\mathbf{1 0}$ & $\mathbf{1 1}$ & $\mathbf{1 2}$ & Media \\
\hline $\mathbf{2 0 0 2}$ & 4.79 & 3.10 & 2.21 & 3.66 & 4.79 & 4.66 & 4.16 & 4.29 & 5.38 & 6.87 & 4.23 & 5.61 & $\mathbf{4 . 4 8}$ \\
$\mathbf{2 0 0 3}$ & 4.56 & 4.00 & 4.44 & 4.15 & 3.50 & 4.21 & 5.48 & 5.80 & 6.62 & 5.66 & 4.52 & 3.63 & $\mathbf{4 . 7 1}$ \\
$\mathbf{2 0 0 4}$ & 4.36 & 5.40 & 5.14 & 3.40 & 4.68 & & 4.89 & 3.95 & 5.33 & 6.30 & 6.20 & 4.95 & $\mathbf{4 . 9 6}$ \\
$\mathbf{2 0 0 5}$ & 3.69 & 3.58 & 5.57 & 4.62 & 5.47 & 4.38 & 4.87 & 6.40 & 5.05 & 5.82 & 4.69 & 3.16 & $\mathbf{4 . 7 7}$ \\
$\mathbf{2 0 0 6}$ & 3.73 & 3.46 & 3.61 & -- & -- & -- & 4.94 & 4.42 & 6.55 & 4.83 & 6.97 & 3.76 & $\mathbf{4 . 7 0}$ \\
$\mathbf{2 0 0 7}$ & 4.21 & 4.10 & 3.86 & 3.11 & 4.42 & 3.82 & 3.69 & 5.46 & 5.18 & 5.33 & 5.21 & 4.03 & $\mathbf{4 . 3 7}$ \\
$\mathbf{2 0 0 8}$ & 3.63 & 4.67 & 3.88 & 4.13 & 4.04 & 3.55 & 3.44 & 5.78 & 5.90 & 6.26 & 3.94 & 4.56 & $\mathbf{4 . 4 8}$ \\
\hline Media & $\mathbf{4 . 1 4}$ & $\mathbf{4 . 0 5}$ & $\mathbf{4 . 1 0}$ & $\mathbf{3 . 8 4}$ & $\mathbf{4 . 4 8}$ & $\mathbf{4 . 1 2}$ & $\mathbf{4 . 5 0}$ & $\mathbf{5 . 1 6}$ & $\mathbf{5 . 7 2}$ & $\mathbf{5 . 8 7}$ & $\mathbf{5 . 1 1}$ & $\mathbf{4 . 2 4}$ & $\mathbf{4 . 6 4}$ \\
\hline
\end{tabular}

e5) Número de días con dato válido por mes y año del GPS de Alicante:

\begin{tabular}{|c|c|c|c|c|c|c|c|c|c|c|c|c|c|}
\hline Año \Mes & 1 & 2 & 3 & 4 & 5 & 6 & 7 & 8 & 9 & 10 & 11 & 12 & Tota \\
\hline 2002 & 31 & 28 & 31 & 30 & 30 & 30 & 31 & 31 & 30 & 31 & 30 & 30 & 363 \\
\hline 2003 & 31 & 28 & 30 & 30 & 31 & 30 & 30 & 31 & 30 & 31 & 30 & 31 & 363 \\
\hline 2004 & 31 & 29 & 26 & 30 & 31 & 13 & 31 & 31 & 30 & 22 & 30 & 31 & 335 \\
\hline 2005 & 31 & 28 & 30 & 30 & 31 & 30 & 31 & 20 & 30 & 28 & 29 & 31 & 349 \\
\hline 2006 & 30 & 28 & 30 & 0 & 0 & 0 & 16 & 31 & 30 & 31 & 30 & 31 & 257 \\
\hline 2007 & 31 & 28 & 31 & 30 & 31 & 29 & 31 & 31 & 30 & 31 & 30 & 31 & 364 \\
\hline 2008 & 30 & 29 & 31 & 30 & 27 & 29 & 31 & 28 & 30 & 31 & 30 & 30 & 356 \\
\hline Total & 215 & 198 & 209 & 180 & 181 & 148 & 201 & 203 & 210 & 205 & 209 & 215 & 2374 \\
\hline
\end{tabular}

f) Resumen por mes de las medias mensuales de cada año del GPS de Alicante:

\begin{tabular}{|c|c|c|c|c|c|c|c|c|c|c|c|c|}
\hline Mes & 1 & 2 & 3 & 4 & 5 & 6 & 7 & 8 & 9 & 10 & 11 & 12 \\
\hline Media & 12.67 & 13.45 & 15.09 & 17.39 & 21.44 & 26.45 & 29.02 & 31.01 & 29.98 & 25.36 & 17.54 & 14.78 \\
\hline STD & 1.21 & 1.62 & 1.70 & 1.33 & 1.59 & 1.74 & 1.27 & 1.34 & 1.81 & 1.28 & 2.60 & 1.66 \\
\hline Mediana & 12.90 & 13.98 & 15.66 & 17.55 & 22.04 & 25.66 & 28.95 & 30.92 & 30.42 & 26.15 & 17.09 & 14.73 \\
\hline Máximo & 14.52 & 15.36 & 16.90 & 19.17 & 23.04 & 29.09 & 30.86 & 33.05 & 32.52 & 26.56 & 21.24 & 17.38 \\
\hline Mínimo & 10.66 & 10.36 & 12.30 & 14.84 & 19.14 & 24.49 & 26.47 & 29.41 & 26.48 & 23.07 & 14.36 & 12.61 \\
\hline $\mathrm{N}^{0}$ Días & 215 & 198 & 209 & 180 & 181 & 148 & 201 & 203 & 210 & 205 & 209 & 215 \\
\hline
\end{tabular}




\section{Gráficas de la estación de Alicante}

g) Evolución temporal de las medias diarias.

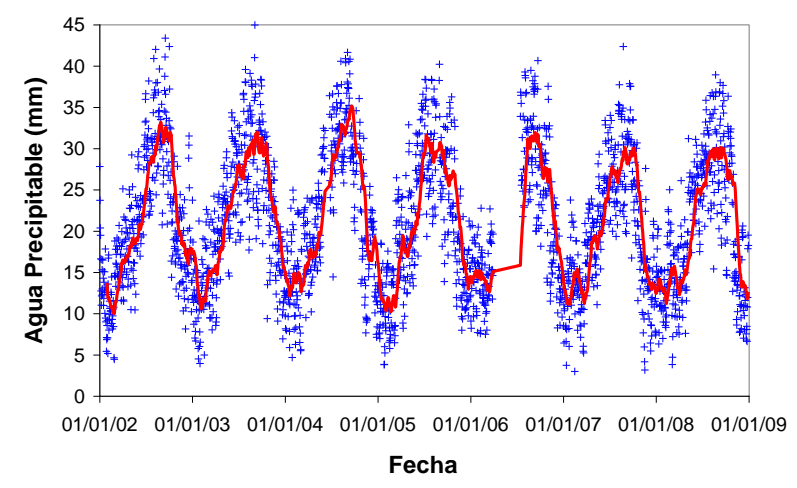

La línea roja representa la media móvil mensual. h) Histograma de las medias diarias.

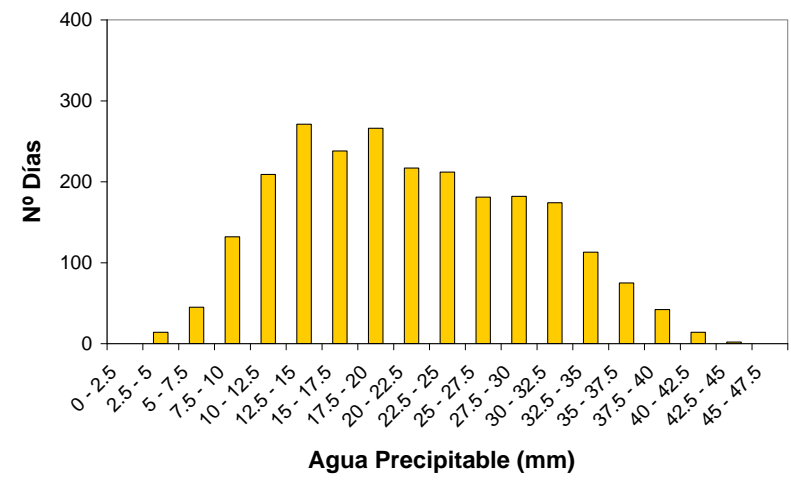

La distribución presenta un desplazamiento hacia la derecha (coef. de asimetría positivo), y un ligero achatamiento (curtosis negativa) respecto de la distribución normal.

j) Ciclo promedio anual.

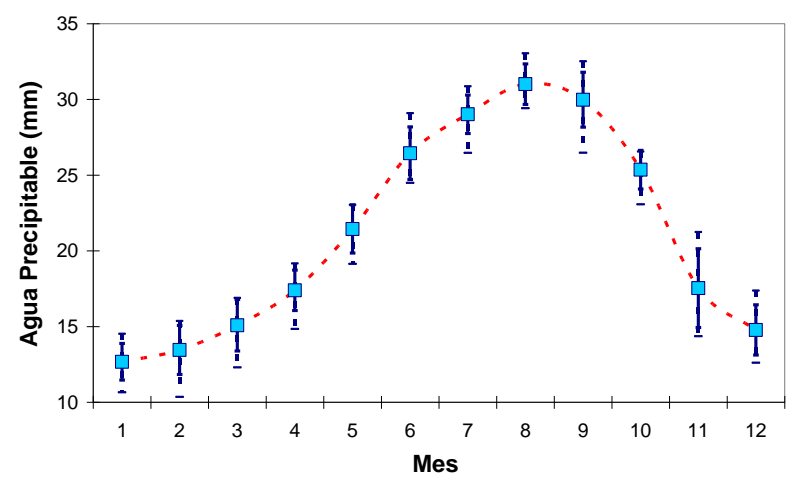

Valor promedio de las medias mensuales de cada año (cuadrados). Valor promedio más/menos la desviación típica de las medias mensuales (barras sólidas). Valor máximo y mínimo absoluto de las medias mensuales (líneas de trazos). 


\subsubsection{ALMERÍA (Observatorio geofísico). Estación GPS.}

El análisis estadístico se ha realizado en base a los datos de ZTD generados por el centro de análisis IGN de EUREF.

a) Estadísticas globales del conjunto de las medidas del GPS de Almería:

\begin{tabular}{|c|c|c|c|c|c|c|c|c|c|c|}
\hline $\begin{array}{c}\mathbf{N}^{\circ} \\
\text { Medidas }\end{array}$ & Media & STD & Mediana & $\begin{array}{c}\text { Clase } \\
\text { Modal }\end{array}$ & $\begin{array}{c}\text { Percentil } \\
\mathbf{5}\end{array}$ & $\begin{array}{c}\text { Percentil } \\
\mathbf{9 5}\end{array}$ & Máximo & Mínimo & $\begin{array}{c}\text { Coef. } \\
\text { Asimetría }\end{array}$ & Curtosis \\
\hline 59539 & 20.43 & 7.80 & 19.69 & $17.5-20$ & 8.70 & 33.92 & 48.60 & 1.25 & 0.32 & -0.46 \\
\hline
\end{tabular}

b) Estadísticas por mes del conjunto de las medidas del GPS de Almería:

\begin{tabular}{|c|c|c|c|c|c|c|c|c|c|c|c|c|}
\hline Estadístico \Mes & 1 & 2 & 3 & 4 & 5 & 6 & 7 & 8 & 9 & 10 & 11 & 12 \\
\hline Media & 13.03 & 13.96 & 14.97 & 17.03 & 20.86 & 24.97 & 25.94 & 27.92 & 28.00 & 24.42 & 17.40 & 14.66 \\
\hline STD & 4.54 & 4.65 & 5.14 & 4.73 & 5.71 & 5.50 & 6.03 & 6.38 & 6.05 & 6.62 & 6.00 & 4.83 \\
\hline Mediana & 12.61 & 13.65 & 14.97 & 17.09 & 20.21 & 24.99 & 25.92 & 27.51 & 28.13 & 24.33 & 16.76 & 14.42 \\
\hline Máximo & 36.86 & 28.37 & 34.70 & 32.65 & 40.13 & 42.60 & 45.96 & 48.60 & 47.80 & 42.81 & 39.24 & 33.63 \\
\hline Mínimo & 1.67 & 2.29 & 1.25 & 4.56 & 6.21 & 5.58 & 7.74 & 8.90 & 9.99 & 7.14 & 3.86 & 1.99 \\
\hline Percentil 5 & 5.88 & 7.00 & 6.42 & 9.36 & 12.23 & 15.79 & 16.39 & 18.30 & 17.89 & 13.69 & 8.69 & 7.54 \\
\hline Percentil 95 & 20.97 & 22.17 & 23.51 & 24.85 & 30.66 & 33.81 & 35.70 & 39.11 & 37.59 & 35.55 & 28.20 & 22.28 \\
\hline Coef. Asimetría & 0.44 & 0.32 & 0.11 & 0.12 & 0.30 & -0.17 & 0.09 & 0.26 & -0.01 & 0.07 & 0.57 & 0.46 \\
\hline Curtosis & 0.29 & -0.29 & -0.04 & -0.29 & -0.40 & 0.11 & -0.18 & -0.15 & -0.33 & -0.45 & 0.19 & 0.39 \\
\hline $\mathrm{N}^{0}$ Medidas & 4441 & 4471 & 5010 & 5013 & 5208 & 5026 & 5184 & 5073 & 5023 & 5108 & 4944 & 5038 \\
\hline
\end{tabular}

c) Estadísticas globales de las medias diarias del GPS de Almería:

\begin{tabular}{|c|c|c|c|c|c|c|c|c|c|c|}
\hline N$^{\circ}$ Días & Media & STD & Mediana & Moda & $\begin{array}{c}\text { Percentil } \\
\mathbf{5}\end{array}$ & $\begin{array}{c}\text { Percentil } \\
\mathbf{9 5}\end{array}$ & Máximo & Mínimo & $\begin{array}{c}\text { Coef. } \\
\text { Asimetría }\end{array}$ & Curtosis \\
\hline 2490 & 20.42 & 7.32 & 19.72 & $17.5-20$ & 9.48 & 33.00 & 45.72 & 4.13 & 0.27 & -0.58 \\
\hline
\end{tabular}

d) Resumen por mes de las medias diarias del GPS de Almería:

\begin{tabular}{|c|c|c|c|c|c|c|c|c|c|c|c|c|}
\hline Estadístico \Mes & 1 & 2 & 3 & 4 & 5 & 6 & 7 & 8 & 9 & 10 & 11 & 12 \\
\hline Media & 13.01 & 13.95 & 14.97 & 17.03 & 20.86 & 24.95 & 25.94 & 27.90 & 28.01 & 24.40 & 17.40 & 14.72 \\
\hline STD & 3.97 & 4.17 & 4.68 & 4.00 & 5.12 & 4.81 & 5.14 & 5.33 & 5.26 & 5.85 & 5.44 & 4.37 \\
\hline Mediana & 12.62 & 13.62 & 14.95 & 16.91 & 20.13 & 25.17 & 26.06 & 27.43 & 28.15 & 24.39 & 16.34 & 14.59 \\
\hline Máximo & 27.14 & 25.60 & 31.49 & 26.54 & 37.43 & 36.51 & 40.09 & 45.72 & 39.95 & 40.05 & 36.52 & 31.54 \\
\hline Mínimo & 5.18 & 5.80 & 4.13 & 7.48 & 9.45 & 8.11 & 12.15 & 17.94 & 16.29 & 10.63 & 7.03 & 6.33 \\
\hline Percentil 5 & 6.37 & 7.42 & 6.96 & 10.52 & 13.63 & 17.01 & 18.11 & 20.19 & 19.01 & 14.91 & 9.70 & 8.37 \\
\hline Percentil 95 & 19.80 & 21.92 & 22.80 & 23.53 & 29.76 & 32.90 & 34.42 & 36.90 & 36.13 & 34.00 & 27.14 & 20.67 \\
\hline Coef. Asimetría & 0.35 & 0.36 & 0.15 & -0.03 & 0.45 & -0.23 & 0.07 & 0.44 & -0.06 & 0.01 & 0.66 & 0.60 \\
\hline Curtosis & 0.06 & -0.20 & 0.21 & -0.46 & -0.30 & 0.13 & -0.22 & -0.17 & -0.52 & -0.34 & 0.45 & 1.15 \\
\hline $\mathrm{N}^{0}$ Días & 187 & 188 & 209 & 210 & 217 & 210 & 216 & 212 & 210 & 214 & 206 & 211 \\
\hline
\end{tabular}

e1) Media de las medias diarias por mes y año del GPS de Almería:

\begin{tabular}{|c|c|c|c|c|c|c|c|c|c|c|c|c|c|}
\hline Año \Mes & $\mathbf{1}$ & $\mathbf{2}$ & $\mathbf{3}$ & $\mathbf{4}$ & $\mathbf{5}$ & $\mathbf{6}$ & $\mathbf{7}$ & $\mathbf{8}$ & $\mathbf{9}$ & $\mathbf{1 0}$ & $\mathbf{1 1}$ & $\mathbf{1 2}$ & Media \\
\hline $\mathbf{2 0 0 2}$ & 14.02 & 11.58 & 15.90 & 17.26 & 17.64 & 24.82 & 26.18 & 29.04 & 28.44 & 22.34 & 18.89 & 16.81 & $\mathbf{2 0 . 2 4}$ \\
$\mathbf{2 0 0 3}$ & 11.89 & 14.81 & 16.75 & 17.40 & 21.86 & 25.71 & 24.70 & 27.20 & 27.53 & 26.76 & 20.45 & 15.79 & $\mathbf{2 0 . 9 0}$ \\
$\mathbf{2 0 0 4}$ & 14.13 & 15.63 & 16.96 & 15.86 & 22.63 & 27.07 & 29.87 & 30.07 & 29.55 & 23.93 & 17.41 & 15.60 & $\mathbf{2 1 . 5 6}$ \\
$\mathbf{2 0 0 5}$ & 10.03 & 11.84 & 17.54 & 16.65 & 19.67 & 26.39 & 26.69 & 27.94 & 25.03 & 24.72 & 16.33 & 15.82 & $\mathbf{1 9 . 8 9}$ \\
$\mathbf{2 0 0 6}$ & 15.12 & 14.28 & 13.97 & 19.26 & 25.61 & 24.77 & 25.46 & 26.76 & 28.12 & 25.48 & 19.59 & 13.69 & $\mathbf{2 1 . 0 1}$ \\
$\mathbf{2 0 0 7}$ & -- & 13.72 & 11.52 & 18.24 & 18.28 & 23.62 & 22.85 & 27.29 & 28.19 & 23.24 & 15.18 & 12.91 & $\mathbf{1 9 . 5 5}$ \\
$\mathbf{2 0 0 8}$ & 13.26 & 15.60 & 12.50 & 14.54 & 20.36 & 22.30 & 25.79 & 26.82 & 29.26 & 24.33 & 14.13 & 12.22 & $\mathbf{1 9 . 2 6}$ \\
\hline Media & $\mathbf{1 3 . 0 8}$ & $\mathbf{1 3 . 9 2}$ & $\mathbf{1 5 . 0 2}$ & $\mathbf{1 7 . 0 3}$ & $\mathbf{2 0 . 8 6}$ & $\mathbf{2 4 . 9 5}$ & $\mathbf{2 5 . 9 3}$ & $\mathbf{2 7 . 8 7}$ & $\mathbf{2 8 . 0 1}$ & $\mathbf{2 4 . 4 0}$ & $\mathbf{1 7 . 4 3}$ & $\mathbf{1 4 . 6 9}$ & $\mathbf{2 0 . 3 4}$ \\
\hline
\end{tabular}


e2) Máximo de las medias diarias por mes y año del GPS de Almería:

\begin{tabular}{|c|c|c|c|c|c|c|c|c|c|c|c|c|c|}
\hline Año \Mes & $\mathbf{1}$ & $\mathbf{2}$ & $\mathbf{3}$ & $\mathbf{4}$ & $\mathbf{5}$ & $\mathbf{6}$ & $\mathbf{7}$ & $\mathbf{8}$ & $\mathbf{9}$ & $\mathbf{1 0}$ & $\mathbf{1 1}$ & $\mathbf{1 2}$ & Media \\
\hline $\mathbf{2 0 0 2}$ & 27.14 & 18.90 & 20.83 & 23.12 & 30.26 & 34.05 & 33.74 & 39.41 & 39.65 & 40.05 & 28.20 & 31.54 & $\mathbf{3 0 . 5 7}$ \\
$\mathbf{2 0 0 3}$ & 20.85 & 21.91 & 31.49 & 23.24 & 27.16 & 34.83 & 35.84 & 39.94 & 38.98 & 37.50 & 28.73 & 20.42 & $\mathbf{3 0 . 0 7}$ \\
$\mathbf{2 0 0 4}$ & 21.23 & 25.60 & 24.90 & 24.52 & 31.36 & 34.23 & 40.09 & 45.72 & 38.62 & 35.05 & 27.62 & 22.24 & $\mathbf{3 0 . 9 3}$ \\
$\mathbf{2 0 0 5}$ & 17.54 & 18.97 & 27.15 & 23.88 & 33.39 & 36.51 & 37.66 & 40.64 & 30.51 & 38.46 & 24.44 & 22.89 & $\mathbf{2 9 . 3 4}$ \\
$\mathbf{2 0 0 6}$ & 21.55 & 23.72 & 23.15 & 26.54 & 37.43 & 33.90 & 34.43 & 36.62 & 39.95 & 32.85 & 36.52 & 20.78 & $\mathbf{3 0 . 6 2}$ \\
$\mathbf{2 0 0 7}$ & -- & 18.57 & 18.70 & 26.28 & 29.36 & 32.91 & 30.31 & 39.15 & 35.49 & 33.07 & 28.07 & 20.26 & $\mathbf{2 8 . 3 8}$ \\
$\mathbf{2 0 0 8}$ & 19.95 & 24.34 & 19.25 & 25.54 & 30.73 & 29.16 & 35.23 & 38.66 & 39.11 & 32.47 & 24.84 & 21.42 & $\mathbf{2 8 . 3 9}$ \\
\hline Media & $\mathbf{2 1 . 3 8}$ & $\mathbf{2 1 . 7 2}$ & $\mathbf{2 3 . 6 4}$ & $\mathbf{2 4 . 7 3}$ & $\mathbf{3 1 . 3 8}$ & $\mathbf{3 3 . 6 6}$ & $\mathbf{3 5 . 3 3}$ & $\mathbf{4 0 . 0 2}$ & $\mathbf{3 7 . 4 7}$ & $\mathbf{3 5 . 6 4}$ & $\mathbf{2 8 . 3 5}$ & $\mathbf{2 2 . 7 9}$ & $\mathbf{2 9 . 7 6}$ \\
\hline
\end{tabular}

e3) Mínimo de las medias diarias por mes y año del GPS de Almería:

\begin{tabular}{|c|c|c|c|c|c|c|c|c|c|c|c|c|c|}
\hline Año \Mes & 1 & 2 & 3 & 4 & 5 & 6 & 7 & 8 & 9 & 10 & 11 & 12 & Media \\
\hline 2002 & 6.59 & 5.80 & 11.55 & 9.28 & 9.45 & 16.87 & 18.57 & 20.00 & 16.29 & 12.13 & 11.29 & 9.07 & 12.24 \\
\hline 2003 & 5.91 & 7.56 & 8.96 & 7.80 & 13.07 & 14.54 & 17.53 & 18.39 & 20.15 & 15.46 & 12.35 & 9.37 & 12.59 \\
\hline 2004 & 6.48 & 7.33 & 5.29 & 9.23 & 14.66 & 18.16 & 16.20 & 17.94 & 21.04 & 15.34 & 9.30 & 6.78 & 12.31 \\
\hline 2005 & 5.18 & 6.15 & 6.39 & 10.61 & 11.25 & 17.16 & 18.45 & 19.03 & 16.29 & 15.68 & 7.23 & 9.62 & 11.92 \\
\hline 2006 & 9.15 & 7.74 & 5.69 & 10.02 & 17.27 & 8.11 & 16.85 & 19.30 & 18.87 & 17.89 & 7.03 & 6.84 & 12.06 \\
\hline 2007 & -- & 10.28 & 4.39 & 11.92 & 12.40 & 16.75 & 12.15 & 18.30 & 20.80 & 10.99 & 8.65 & 7.83 & 12.22 \\
\hline 2008 & 9.50 & 6.29 & 4.13 & 7.48 & 15.06 & 14.80 & 16.52 & 20.46 & 17.36 & 10.63 & 9.31 & 6.33 & 11.49 \\
\hline Media & 7.14 & 7.31 & 6.63 & 9.48 & 13.31 & 15.20 & 16.61 & 19.06 & 18.69 & 14.02 & 9.31 & 7.98 & 12.12 \\
\hline
\end{tabular}

e4) Desviación estándar de las medias diarias de cada mes y año del GPS de Almería:

\begin{tabular}{|c|l|l|l|l|l|l|l|l|l|l|l|l|c|}
\hline Año \Mes & $\mathbf{1}$ & $\mathbf{2}$ & $\mathbf{3}$ & $\mathbf{4}$ & $\mathbf{5}$ & $\mathbf{6}$ & $\mathbf{7}$ & $\mathbf{8}$ & $\mathbf{9}$ & $\mathbf{1 0}$ & $\mathbf{1 1}$ & $\mathbf{1 2}$ & Media \\
\hline $\mathbf{2 0 0 2}$ & 4.24 & 3.20 & 2.34 & 3.21 & 4.46 & 4.09 & 3.90 & 4.68 & 5.24 & 7.79 & 4.35 & 5.70 & $\mathbf{4 . 4 3}$ \\
$\mathbf{2 0 0 3}$ & 3.86 & 3.41 & 4.89 & 4.13 & 3.45 & 5.03 & 4.91 & 5.32 & 5.08 & 5.25 & 4.07 & 3.38 & $\mathbf{4 . 4 0}$ \\
$\mathbf{2 0 0 4}$ & 4.11 & 4.75 & 4.75 & 3.89 & 4.72 & 4.19 & 5.54 & 5.98 & 4.96 & 5.95 & 5.60 & 4.54 & $\mathbf{4 . 9 1}$ \\
$\mathbf{2 0 0 5}$ & 3.08 & 3.60 & 5.09 & 3.42 & 5.96 & 4.58 & 4.94 & 5.68 & 4.32 & 5.86 & 4.14 & 3.09 & $\mathbf{4 . 4 8}$ \\
$\mathbf{2 0 0 6}$ & 2.98 & 3.48 & 3.58 & 3.72 & 4.88 & 6.16 & 4.32 & 4.75 & 5.98 & 4.51 & 8.11 & 3.49 & $\mathbf{4 . 6 6}$ \\
$\mathbf{2 0 0 7}$ & -- & 2.60 & 3.53 & 3.43 & 4.00 & 3.67 & 4.59 & 5.31 & 3.98 & 4.56 & 3.94 & 3.03 & $\mathbf{3 . 8 8}$ \\
$\mathbf{2 0 0 8}$ & 2.89 & 4.97 & 4.19 & 4.23 & 2.96 & 3.74 & 4.86 & 4.43 & 5.66 & 5.20 & 3.57 & 4.37 & $\mathbf{4 . 2 5}$ \\
\hline Media & $\mathbf{3 . 5 3}$ & $\mathbf{3 . 7 1}$ & $\mathbf{4 . 0 5}$ & $\mathbf{3 . 7 2}$ & $\mathbf{4 . 3 5}$ & $\mathbf{4 . 5 0}$ & $\mathbf{4 . 7 2}$ & $\mathbf{5 . 1 6}$ & $\mathbf{5 . 0 3}$ & $\mathbf{5 . 5 9}$ & $\mathbf{4 . 8 3}$ & $\mathbf{3 . 9 4}$ & $\mathbf{4 . 4 3}$ \\
\hline
\end{tabular}

e5) Número de días con dato válido por mes y año del GPS de Almería:

\begin{tabular}{|c|c|c|c|c|c|c|c|c|c|c|c|c|c|}
\hline Año \Mes & 1 & 2 & 3 & 4 & 5 & 6 & 7 & 8 & 9 & 10 & 11 & 12 & Total \\
\hline 2002 & 31 & 28 & 31 & 30 & 31 & 30 & 31 & 31 & 30 & 31 & 30 & 31 & 365 \\
\hline 2003 & 31 & 28 & 30 & 30 & 31 & 30 & 31 & 31 & 30 & 31 & 30 & 31 & 364 \\
\hline 2004 & 31 & 29 & 26 & 30 & 31 & 30 & 31 & 31 & 30 & 31 & 30 & 31 & 361 \\
\hline 2005 & 31 & 28 & 30 & 30 & 31 & 30 & 31 & 31 & 30 & 30 & 29 & 31 & 362 \\
\hline 2006 & 30 & 28 & 31 & 30 & 31 & 30 & 31 & 27 & 30 & 31 & 27 & 25 & 351 \\
\hline 2007 & 2 & 18 & 31 & 30 & 31 & 30 & 31 & 31 & 30 & 31 & 30 & 31 & 326 \\
\hline 2008 & 31 & 29 & 30 & 30 & 31 & 30 & 30 & 30 & 30 & 29 & 30 & 31 & 361 \\
\hline Total & 185 & 188 & 209 & 210 & 217 & 210 & 216 & 212 & 210 & 214 & 206 & 211 & 2488 \\
\hline
\end{tabular}

f) Resumen por mes de las medias mensuales de cada año del GPS de Almería:

\begin{tabular}{|c|c|c|c|c|c|c|c|c|c|c|c|c|}
\hline Mes & 1 & 2 & 3 & 4 & 5 & 6 & 7 & 8 & 9 & 10 & 11 & 12 \\
\hline Media & 13.08 & 13.92 & 15.02 & 17.03 & 20.86 & 24.95 & 25.93 & 27.87 & 28.01 & 24.40 & 17.43 & 14.69 \\
\hline STD & 1.68 & 1.53 & 2.19 & 1.43 & 2.55 & 1.51 & 1.98 & 1.15 & 1.38 & 1.34 & 2.17 & 1.61 \\
\hline Mediana & 13.64 & 14.28 & 15.90 & 17.26 & 20.36 & 24.82 & 25.79 & 27.29 & 28.19 & 24.33 & 17.41 & 15.60 \\
\hline Máximo & 15.12 & 15.63 & 17.54 & 19.26 & 25.61 & 27.07 & 29.87 & 30.07 & 29.55 & 26.76 & 20.45 & 16.81 \\
\hline Mínimo & 10.03 & 11.58 & 11.52 & 14.54 & 17.64 & 22.30 & 22.85 & 26.76 & 25.03 & 22.34 & 14.13 & 12.22 \\
\hline $\mathrm{N}^{0}$ Días & 185 & 188 & 209 & 210 & 217 & 210 & 216 & 212 & 210 & 214 & 206 & 211 \\
\hline
\end{tabular}




\section{Gráficas de la estación de Almería}

g) Evolución temporal de las medias diarias.

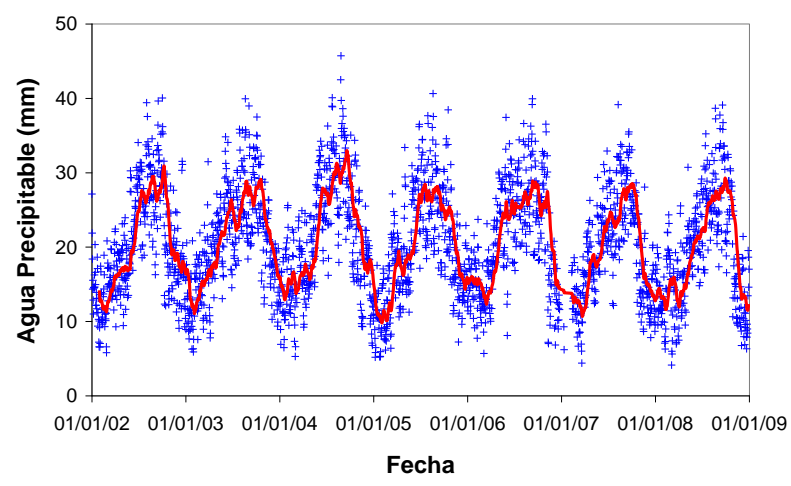

La línea roja representa la media móvil mensual. h) Histograma de las medias diarias.

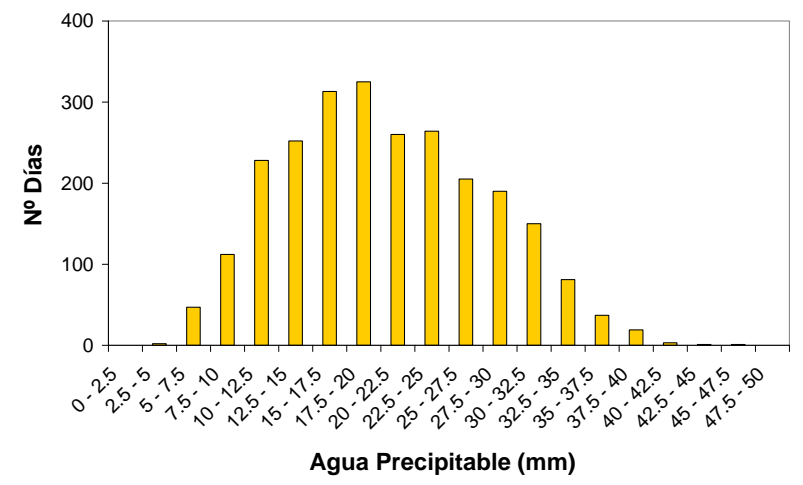

La distribución presenta un desplazamiento hacia la derecha (coef. de asimetría positivo), y un ligero achatamiento (curtosis negativa) respecto de la distribución normal.

j) Ciclo promedio anual.

para cada mes y año.
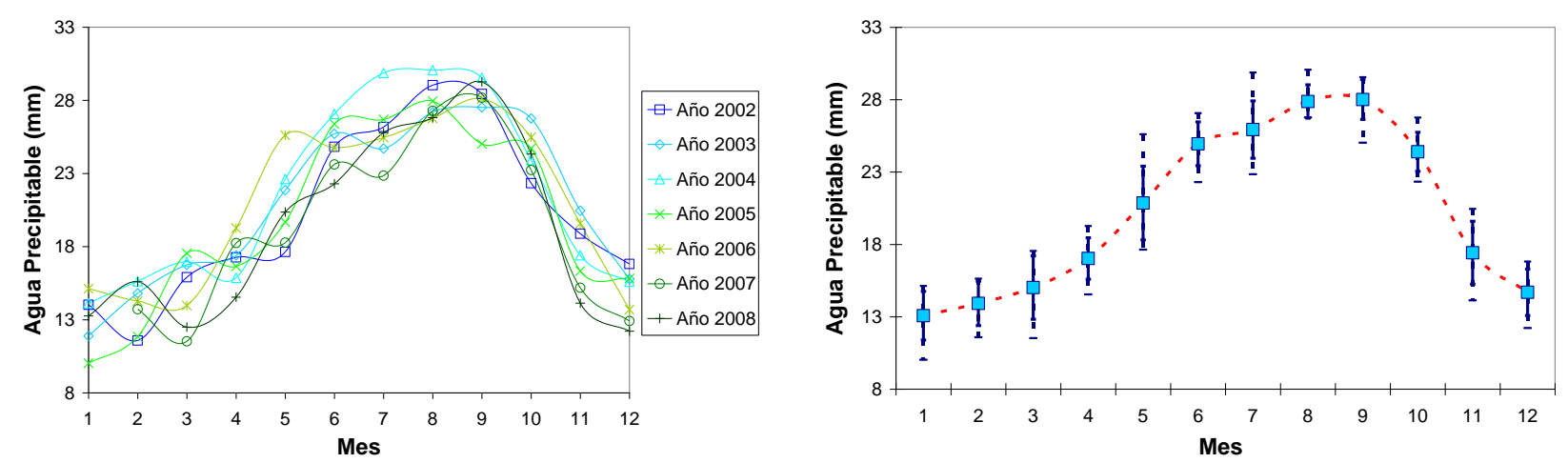

Valor promedio de las medias mensuales de cada año (cuadrados). Valor promedio más/menos la desviación típica de las medias mensuales (barras sólidas). Valor máximo y mínimo absoluto de las medias mensuales (líneas de trazos). 


\subsubsection{CÁCERES (Escuela Politécnica). Estación GPS.}

El análisis estadístico se ha realizado en base a los datos de ZTD generados por el centro de análisis IGN de EUREF.

a) Estadísticas globales del conjunto de las medidas del GPS de Cáceres:

\begin{tabular}{|c|c|c|c|c|c|c|c|c|c|c|}
\hline $\begin{array}{c}\mathbf{N}^{0} \\
\text { Medidas }\end{array}$ & Media & STD & Mediana & $\begin{array}{c}\text { Clase } \\
\text { Modal }\end{array}$ & $\begin{array}{c}\text { Percentil } \\
\mathbf{5}\end{array}$ & $\begin{array}{c}\text { Percentil } \\
\mathbf{9 5}\end{array}$ & Máximo & Mínimo & $\begin{array}{c}\text { Coef. } \\
\text { Asimetría }\end{array}$ & Curtosis \\
\hline 58454 & 16.26 & 6.83 & 15.67 & $12.5-15$ & 6.03 & 28.50 & 47.52 & 0.66 & 0.41 & -0.21 \\
\hline
\end{tabular}

b) Estadísticas por mes del conjunto de las medidas del GPS de Cáceres:

\begin{tabular}{|c|c|c|c|c|c|c|c|c|c|c|c|c|}
\hline Estadístico | Mes & 1 & 2 & 3 & 4 & 5 & 6 & 7 & 8 & 9 & 10 & 11 & 12 \\
\hline Media & 11.29 & 11.72 & 12.81 & 14.46 & 17.24 & 20.77 & 19.10 & 20.86 & 21.20 & 19.98 & 14.54 & 12.21 \\
\hline STD & 5.08 & 4.81 & 5.25 & 4.55 & 5.55 & 5.91 & 5.54 & 6.21 & 6.19 & 7.11 & 6.64 & 5.45 \\
\hline Mediana & 10.56 & 11.43 & 12.78 & 14.23 & 16.71 & 20.27 & 18.87 & 20.32 & 21.22 & 19.78 & 13.42 & 11.68 \\
\hline Máximo & 30.28 & 27.18 & 29.38 & 31.82 & 37.50 & 39.96 & 40.79 & 47.52 & 38.53 & 42.03 & 39.65 & 35.56 \\
\hline Mínimo & 0.68 & 1.28 & 0.68 & 3.04 & 5.56 & 6.69 & 5.50 & 5.67 & 4.78 & 3.48 & 0.66 & 0.93 \\
\hline Percentil 5 & 4.55 & 4.82 & 4.20 & 7.42 & 9.05 & 11.72 & 11.00 & 11.59 & 10.71 & 8.19 & 5.44 & 4.35 \\
\hline Percentil 95 & 21.62 & 20.52 & 21.55 & 22.14 & 27.29 & 30.81 & 29.09 & 31.85 & 31.47 & 32.39 & 26.27 & 21.90 \\
\hline Coef. Asimetría & 0.91 & 0.42 & 0.15 & 0.31 & 0.53 & 0.21 & 0.31 & 0.45 & 0.00 & 0.22 & 0.56 & 0.49 \\
\hline Curtosis & 0.80 & -0.30 & -0.49 & -0.04 & 0.12 & -0.63 & -0.35 & 0.02 & -0.42 & -0.25 & -0.19 & -0.14 \\
\hline $\mathrm{N}^{0}$ Medidas & 5068 & 4656 & 5135 & 4799 & 5055 & 5011 & 5142 & 4336 & 4216 & 4998 & 4976 & 5062 \\
\hline
\end{tabular}

c) Estadísticas globales de las medias diarias del GPS de Cáceres:

\begin{tabular}{|c|c|c|c|c|c|c|c|c|c|c|}
\hline $\mathrm{N}^{0}$ Días & Media & STD & Mediana & Moda & \begin{tabular}{|c|} 
Percentil \\
10 \\
\end{tabular} & \begin{tabular}{|c|} 
Percentil \\
90 \\
\end{tabular} & Máximo & Mínimo & \begin{tabular}{|c} 
Coef. \\
Asimetría
\end{tabular} & Curtosis \\
\hline 2452 & 16.26 & 6.34 & 15.87 & $12.5-15$ & 6.45 & 27.45 & 38.43 & 1.29 & 0.32 & -0.32 \\
\hline
\end{tabular}

d) Resumen por mes de las medias diarias del GPS de Cáceres:

\begin{tabular}{|c|c|c|c|c|c|c|c|c|c|c|c|c|}
\hline Estadístico \Mes & 1 & 2 & 3 & 4 & 5 & 6 & 7 & 8 & 9 & 10 & 11 & 12 \\
\hline Media & 11.29 & 11.75 & 12.76 & 14.46 & 17.25 & 20.77 & 19.09 & 20.85 & 21.20 & 19.98 & 14.54 & 12.38 \\
\hline STD & 4.59 & 4.22 & 4.72 & 3.94 & 4.97 & 5.34 & 4.80 & 5.47 & 5.56 & 6.45 & 6.12 & 5.10 \\
\hline Mediana & 10.72 & 11.67 & 12.77 & 14.59 & 16.90 & 20.32 & 18.94 & 20.52 & 21.23 & 20.21 & 13.89 & 12.12 \\
\hline Máximo & 26.73 & 24.13 & 26.16 & 25.99 & 34.30 & 34.55 & 32.14 & 38.43 & 32.67 & 37.72 & 33.52 & 31.28 \\
\hline Mínimo & 2.36 & 4.25 & 2.35 & 5.26 & 7.82 & 9.56 & 9.35 & 9.39 & 6.93 & 5.47 & 1.29 & 2.11 \\
\hline Percentil 5 & 5.16 & 5.39 & 4.38 & 7.60 & 10.17 & 12.64 & 11.83 & 12.21 & 11.43 & 8.91 & 5.95 & 4.38 \\
\hline Percentil 95 & 19.53 & 19.37 & 20.17 & 20.91 & 26.30 & 29.57 & 27.81 & 30.70 & 30.07 & 30.26 & 24.23 & 20.09 \\
\hline Coef. Asimetría & 0.84 & 0.37 & -0.03 & 0.08 & 0.63 & 0.20 & 0.25 & 0.30 & -0.20 & 0.01 & 0.47 & 0.40 \\
\hline Curtosis & 0.69 & -0.31 & -0.47 & -0.07 & 0.48 & -0.73 & -0.43 & -0.31 & -0.43 & -0.31 & -0.24 & 0.18 \\
\hline $\mathrm{N}^{\circ}$ Días & 213 & 195 & 216 & 200 & 211 & 209 & 215 & 182 & 178 & 210 & 208 & 215 \\
\hline
\end{tabular}

e1) Media de las medias diarias por mes y año del GPS de Cáceres:

\begin{tabular}{|c|r|r|r|c|c|c|c|c|c|c|c|c|c|}
\hline Año \Mes & \multicolumn{1}{|c|}{$\mathbf{1}$} & \multicolumn{1}{|c|}{$\mathbf{2}$} & \multicolumn{1}{|c|}{$\mathbf{3}$} & $\mathbf{4}$ & $\mathbf{5}$ & $\mathbf{6}$ & $\mathbf{7}$ & $\mathbf{8}$ & $\mathbf{9}$ & $\mathbf{1 0}$ & $\mathbf{1 1}$ & $\mathbf{1 2}$ & Media \\
\hline $\mathbf{2 0 0 2}$ & 13.16 & 10.26 & 13.40 & 13.83 & 16.30 & 19.98 & 19.35 & 21.00 & -- & 21.43 & 17.24 & 16.42 & $\mathbf{1 6 . 5 8}$ \\
$\mathbf{2 0 0 3}$ & 10.42 & 12.90 & 14.53 & 15.69 & 16.38 & 22.70 & 18.21 & 25.30 & 21.07 & 19.91 & 17.84 & 14.18 & $\mathbf{1 7 . 4 3}$ \\
$\mathbf{2 0 0 4}$ & 14.64 & 13.05 & 13.51 & 12.51 & 19.19 & 22.82 & 20.28 & 23.87 & 20.65 & 20.92 & 13.78 & 12.87 & $\mathbf{1 7 . 3 4}$ \\
$\mathbf{2 0 0 5}$ & 8.46 & 8.83 & 14.18 & 14.79 & 18.04 & 22.91 & 19.74 & 20.01 & 18.10 & 20.61 & 15.25 & 12.93 & $\mathbf{1 6 . 1 5}$ \\
$\mathbf{2 0 0 6}$ & 11.37 & 11.33 & 14.48 & 15.79 & 17.91 & 21.65 & 22.08 & 18.92 & 23.05 & 23.61 & 18.67 & 10.53 & $\mathbf{1 7 . 4 5}$ \\
$\mathbf{2 0 0 7}$ & 9.68 & 13.24 & 9.29 & 14.77 & 15.76 & 18.09 & 16.48 & 17.27 & 22.11 & 15.90 & 8.75 & 9.42 & $\mathbf{1 4 . 2 3}$ \\
$\mathbf{2 0 0 8}$ & 11.54 & 12.62 & 9.94 & 13.21 & 17.54 & 17.10 & 17.71 & --- & 20.08 & 17.57 & 9.92 & 10.58 & $\mathbf{1 4 . 3 5}$ \\
\hline Media & $\mathbf{1 1 . 3 2}$ & $\mathbf{1 1 . 7 5}$ & $\mathbf{1 2 . 7 6}$ & $\mathbf{1 4 . 3 7}$ & $\mathbf{1 7 . 3 0}$ & $\mathbf{2 0 . 7 5}$ & $\mathbf{1 9 . 1 2}$ & $\mathbf{2 1 . 0 6}$ & $\mathbf{2 0 . 8 4}$ & $\mathbf{2 0 . 0 0}$ & $\mathbf{1 4 . 4 9}$ & $\mathbf{1 2 . 4 2}$ & $\mathbf{1 6 . 2 2}$ \\
\hline
\end{tabular}


e2) Máximo de las medias diarias por mes y año del GPS de Cáceres:

\begin{tabular}{|c|c|c|c|c|c|c|c|c|c|c|c|c|c|}
\hline Año \Mes & $\mathbf{1}$ & $\mathbf{2}$ & $\mathbf{3}$ & $\mathbf{4}$ & $\mathbf{5}$ & $\mathbf{6}$ & $\mathbf{7}$ & $\mathbf{8}$ & $\mathbf{9}$ & $\mathbf{1 0}$ & $\mathbf{1 1}$ & $\mathbf{1 2}$ & Media \\
\hline $\mathbf{2 0 0 2}$ & 26.73 & 18.12 & 20.17 & 19.80 & 25.56 & 27.27 & 25.09 & 29.35 & -- & 35.80 & 27.43 & 31.28 & $\mathbf{2 6 . 0 5}$ \\
$\mathbf{2 0 0 3}$ & 25.67 & 19.83 & 21.58 & 25.99 & 26.77 & 29.77 & 23.55 & 31.21 & 32.67 & 28.43 & 23.74 & 19.44 & $\mathbf{2 5 . 7 2}$ \\
$\mathbf{2 0 0 4}$ & 25.37 & 24.13 & 20.06 & 17.45 & 26.41 & 32.36 & 29.55 & 38.43 & 30.05 & 37.72 & 24.09 & 20.76 & $\mathbf{2 7 . 2 0}$ \\
$\mathbf{2 0 0 5}$ & 19.62 & 14.38 & 26.16 & 21.94 & 34.30 & 33.21 & 29.85 & 33.09 & 26.62 & 33.72 & 24.72 & 21.29 & $\mathbf{2 6 . 5 8}$ \\
$\mathbf{2 0 0 6}$ & 16.41 & 20.36 & 22.46 & 22.32 & 29.08 & 30.02 & 32.14 & 25.70 & 31.75 & 33.45 & 33.52 & 24.53 & $\mathbf{2 6 . 8 1}$ \\
$\mathbf{2 0 0 7}$ & 15.86 & 23.10 & 16.37 & 21.99 & 26.01 & 34.55 & 27.26 & 30.93 & 32.21 & 32.26 & 22.75 & 15.70 & $\mathbf{2 4 . 9 2}$ \\
$\mathbf{2 0 0 8}$ & 20.47 & 21.46 & 18.03 & 20.91 & 24.18 & 24.60 & 27.27 & --- & 30.34 & 26.95 & 17.06 & 19.59 & $\mathbf{2 2 . 8 1}$ \\
\hline Media & $\mathbf{2 1 . 4 5}$ & $\mathbf{2 0 . 2 0}$ & $\mathbf{2 0 . 6 9}$ & $\mathbf{2 1 . 4 9}$ & $\mathbf{2 7 . 4 7}$ & $\mathbf{3 0 . 2 5}$ & $\mathbf{2 7 . 8 2}$ & $\mathbf{3 1 . 4 5}$ & $\mathbf{3 0 . 6 1}$ & $\mathbf{3 2 . 6 2}$ & $\mathbf{2 4 . 7 6}$ & $\mathbf{2 1 . 8 0}$ & $\mathbf{2 5 . 7 3}$ \\
\hline
\end{tabular}

e3) Mínimo de las medias diarias por mes y año del GPS de Cáceres:

\begin{tabular}{|c|c|c|c|c|c|c|c|c|c|c|c|c|c|}
\hline Año \Mes & 1 & 2 & 3 & 4 & 5 & 6 & 7 & 8 & 9 & 10 & 11 & 12 & Media \\
\hline 2002 & 6.54 & 5.37 & 6.90 & 8.09 & 8.08 & 12.12 & 10.78 & 12.06 & -- & 10.97 & 6.17 & 7.10 & 8.56 \\
\hline 2003 & 2.36 & 4.27 & 5.50 & 5.71 & 9.16 & 13.95 & 12.60 & 15.50 & 10.65 & 8.73 & 10.37 & 7.19 & 8.83 \\
\hline 2004 & 5.49 & 6.99 & 3.21 & 6.88 & 11.19 & 12.45 & 11.04 & 14.64 & 13.53 & 11.82 & 6.00 & 6.41 & 9.14 \\
\hline 2005 & 3.77 & 4.25 & 3.40 & 7.56 & 9.00 & 16.12 & 11.10 & 12.58 & 8.36 & 5.47 & 6.95 & 5.22 & 7.82 \\
\hline 2006 & 6.18 & 5.04 & 4.40 & 9.72 & 8.07 & 9.78 & 13.89 & 12.01 & 14.07 & 10.47 & 5.43 & 4.25 & 8.61 \\
\hline 2007 & 4.66 & 6.72 & 2.35 & 8.89 & 8.12 & 9.56 & 11.49 & 9.39 & 8.80 & 7.07 & 1.29 & 2.11 & 6.70 \\
\hline 2008 & 6.19 & 5.31 & 2.51 & 5.26 & 7.82 & 11.79 & 9.35 & -- & 6.93 & 6.88 & 4.69 & 3.70 & 6.40 \\
\hline Media & 5.03 & 5.42 & 4.04 & 7.44 & 8.78 & 12.25 & 11.46 & 12.70 & 10.39 & 8.77 & 5.84 & 5.14 & 8.01 \\
\hline
\end{tabular}

e4) Desviación estándar de las medias diarias de cada mes y año del GPS de Cáceres:

\begin{tabular}{|c|l|l|l|l|l|l|l|l|l|l|l|l|c|}
\hline Año \Mes & $\mathbf{1}$ & $\mathbf{2}$ & $\mathbf{3}$ & $\mathbf{4}$ & $\mathbf{5}$ & $\mathbf{6}$ & $\mathbf{7}$ & $\mathbf{8}$ & $\mathbf{9}$ & $\mathbf{1 0}$ & $\mathbf{1 1}$ & $\mathbf{1 2}$ & Media \\
\hline $\mathbf{2 0 0 2}$ & 4.70 & 3.89 & 3.19 & 3.12 & 4.06 & 3.68 & 3.37 & 4.41 & --- & 6.06 & 4.44 & 5.70 & $\mathbf{4 . 2 4}$ \\
$\mathbf{2 0 0 3}$ & 6.01 & 4.16 & 4.19 & 5.32 & 4.27 & 4.95 & 3.13 & 4.04 & 5.41 & 4.68 & 3.82 & 3.26 & $\mathbf{4 . 4 4}$ \\
$\mathbf{2 0 0 4}$ & 4.89 & 3.88 & 4.01 & 2.93 & 4.73 & 5.52 & 4.75 & 5.48 & 4.45 & 5.13 & 5.36 & 3.41 & $\mathbf{4 . 5 5}$ \\
$\mathbf{2 0 0 5}$ & 3.59 & 2.72 & 6.21 & 4.03 & 6.64 & 4.56 & 5.40 & 5.03 & 5.58 & 7.93 & 5.19 & 4.48 & $\mathbf{5 . 1 1}$ \\
$\mathbf{2 0 0 6}$ & 2.45 & 3.96 & 4.53 & 2.92 & 5.71 & 5.74 & 4.77 & 3.69 & 5.18 & 5.47 & 7.38 & 5.16 & $\mathbf{4 . 7 5}$ \\
$\mathbf{2 0 0 7}$ & 2.85 & 3.63 & 3.39 & 3.04 & 4.38 & 5.80 & 4.39 & 5.18 & 5.42 & 6.26 & 4.17 & 4.12 & $\mathbf{4 . 3 9}$ \\
$\mathbf{2 0 0 8}$ & 3.69 & 4.88 & 3.64 & 4.19 & 3.34 & 2.98 & 5.20 & --- & 5.61 & 6.33 & 2.92 & 5.41 & $\mathbf{4 . 3 8}$ \\
\hline Media & $\mathbf{4 . 0 3}$ & $\mathbf{3 . 8 8}$ & $\mathbf{4 . 1 7}$ & $\mathbf{3 . 6 5}$ & $\mathbf{4 . 7 3}$ & $\mathbf{4 . 7 5}$ & $\mathbf{4 . 4 3}$ & $\mathbf{4 . 6 4}$ & $\mathbf{5 . 2 8}$ & $\mathbf{5 . 9 8}$ & $\mathbf{4 . 7 6}$ & $\mathbf{4 . 5 1}$ & $\mathbf{4 . 5 5}$ \\
\hline
\end{tabular}

e5) Número de días con dato válido por mes y año del GPS de Cáceres:

\begin{tabular}{|c|c|c|c|c|c|c|c|c|c|c|c|c|c|}
\hline Año \ Mes & 1 & 2 & 3 & 4 & 5 & 6 & 7 & 8 & 9 & 10 & 11 & 12 & Tota \\
\hline 2002 & 30 & 28 & 31 & 30 & 31 & 30 & 31 & 16 & 6 & 31 & 30 & 29 & 323 \\
\hline 2003 & 30 & 28 & 31 & 30 & 31 & 30 & 31 & 31 & 30 & 31 & 30 & 31 & 364 \\
\hline 2004 & 29 & 29 & 31 & 20 & 25 & 30 & 31 & 30 & 30 & 31 & 30 & 31 & 347 \\
\hline 2005 & 31 & 28 & 30 & 30 & 31 & 30 & 31 & 31 & 22 & 24 & 30 & 31 & 349 \\
\hline 2006 & 31 & 27 & 31 & 30 & 31 & 30 & 29 & 31 & 30 & 31 & 30 & 31 & 362 \\
\hline 2007 & 31 & 28 & 31 & 30 & 31 & 30 & 31 & 31 & 30 & 31 & 30 & 31 & 365 \\
\hline 2008 & 31 & 27 & 31 & 30 & 31 & 29 & 31 & 12 & 30 & 31 & 28 & 31 & 342 \\
\hline Total & 213 & 195 & 216 & 200 & 211 & 209 & 215 & 170 & 172 & 210 & 208 & 215 & 2434 \\
\hline
\end{tabular}

f) Resumen por mes de las medias mensuales de cada año del GPS de Cáceres:

\begin{tabular}{|c|c|c|c|c|c|c|c|c|c|c|c|c|}
\hline Mes & 1 & 2 & 3 & 4 & 5 & 6 & 7 & 8 & 9 & 10 & 11 & 12 \\
\hline Media & 11.32 & 11.75 & 12.76 & 14.37 & 17.30 & 20.75 & 19.12 & 21.06 & 20.84 & 20.00 & 14.49 & 12.42 \\
\hline STD & 1.93 & 1.56 & 2.04 & 1.15 & 1.12 & 2.22 & 1.70 & 2.77 & 1.57 & 2.36 & 3.61 & 2.25 \\
\hline Mediana & 11.37 & 12.62 & 13.51 & 14.77 & 17.54 & 21.65 & 19.35 & 20.51 & 20.86 & 20.61 & 15.25 & 12.87 \\
\hline Máximo & 14.64 & 13.24 & 14.53 & 15.79 & 19.19 & 22.91 & 22.08 & 25.30 & 23.05 & 23.61 & 18.67 & 16.42 \\
\hline Mínimo & 8.46 & 8.83 & 9.29 & 12.51 & 15.76 & 17.10 & 16.48 & 17.27 & 18.10 & 15.90 & 8.75 & 9.42 \\
\hline $\mathrm{N}^{0}$ Días & 213 & 195 & 216 & 200 & 211 & 209 & 215 & 170 & 172 & 210 & 208 & 215 \\
\hline
\end{tabular}




\section{Gráficas de la estación de Cáceres}

g) Evolución temporal de las medias diarias.

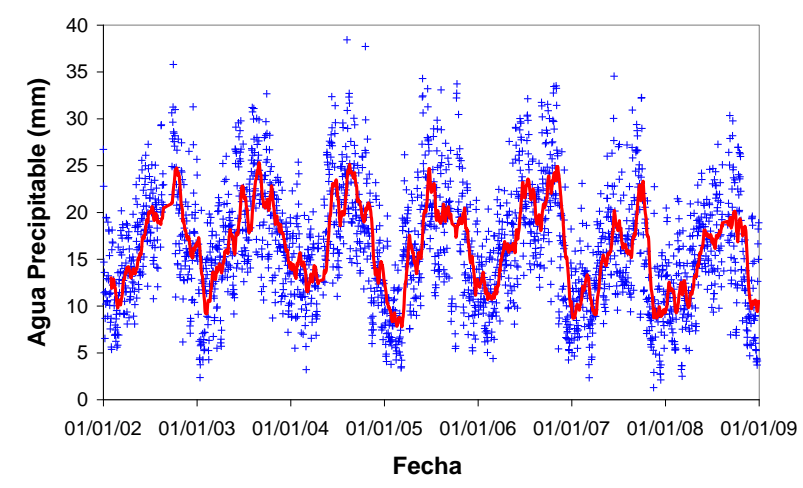

La línea roja representa la media móvil mensual. h) Histograma de las medias diarias.

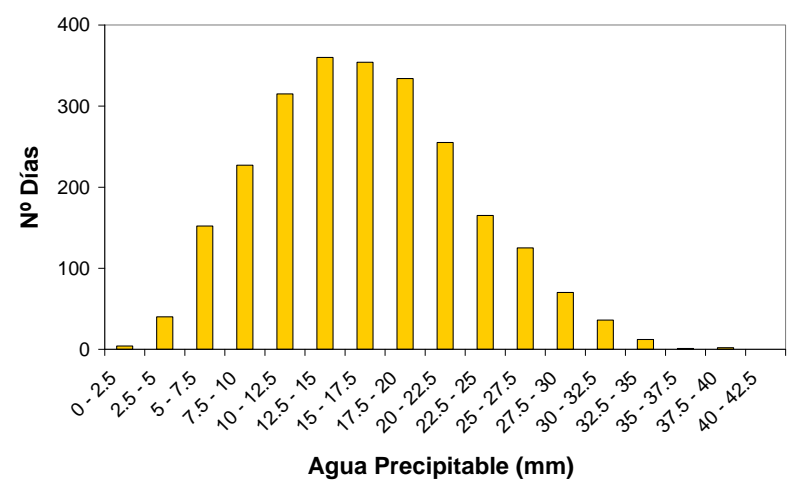

La distribución presenta un desplazamiento hacia la derecha (coef. de asimetría positivo), y un ligero achatamiento (curtosis negativa) respecto de la distribución normal.

j) Ciclo promedio anual.

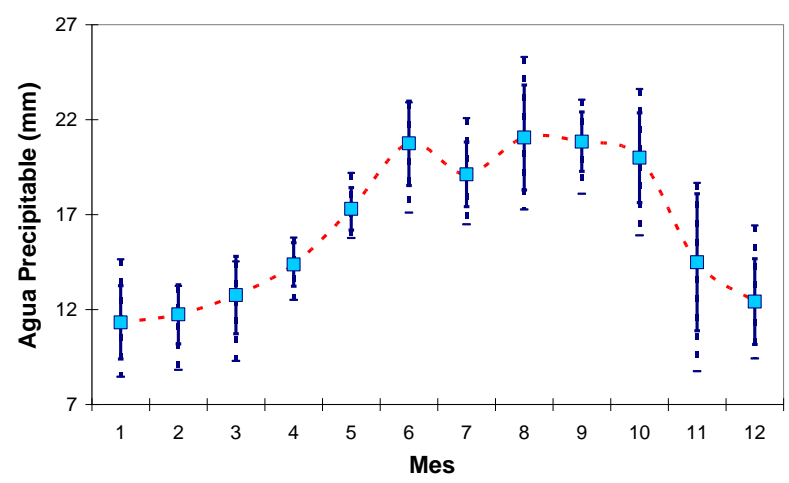

Valor promedio de las medias mensuales de cada año (cuadrados). Valor promedio más/menos la desviación típica de las medias mensuales (barras sólidas). Valor máximo y mínimo absoluto de las medias mensuales (líneas de trazos). 


\subsubsection{SANTANDER (Escuela Ingenieros). Estación GPS.}

El análisis estadístico se ha realizado en base a los datos de ZTD generados por el centro de análisis IGN de EUREF.

a) Estadísticas globales del conjunto de las medidas del GPS de Santander:

\begin{tabular}{|c|c|c|c|c|c|c|c|c|c|c|}
\hline $\begin{array}{c}\mathbf{N}^{0} \\
\text { Medidas }\end{array}$ & Media & STD & Mediana & $\begin{array}{c}\text { Clase } \\
\text { Modal }\end{array}$ & $\begin{array}{c}\text { Percentil } \\
\mathbf{5}\end{array}$ & $\begin{array}{c}\text { Percentil } \\
\mathbf{9 5}\end{array}$ & Máximo & Mínimo & $\begin{array}{c}\text { Coef. } \\
\text { Asimetría }\end{array}$ & Curtosis \\
\hline 58550 & 20.13 & 8.06 & 19.26 & $15-17.5$ & 8.19 & 34.56 & 58.04 & 1.01 & 0.37 & -0.41 \\
\hline
\end{tabular}

b) Estadísticas por mes del conjunto de las medidas del GPS de Santander:

\begin{tabular}{|c|c|c|c|c|c|c|c|c|c|c|c|c|}
\hline Estadístico \Mes & 1 & 2 & 3 & 4 & 5 & 6 & 7 & 8 & 9 & 10 & 11 & 12 \\
\hline Media & 14.28 & 13.08 & 14.66 & 16.99 & 21.04 & 26.70 & 27.92 & 28.14 & 25.22 & 22.69 & 17.24 & 14.35 \\
\hline STD & 5.26 & 4.63 & 5.28 & 4.64 & 5.47 & 6.71 & 6.07 & 6.18 & 7.59 & 6.78 & 5.61 & 5.56 \\
\hline Mediana & 13.89 & 12.41 & 14.51 & 16.72 & 20.47 & 27.30 & 27.72 & 28.10 & 25.25 & 22.59 & 16.71 & 14.25 \\
\hline Máximo & 32.51 & 28.60 & 34.41 & 33.36 & 40.40 & 44.40 & 50.99 & 58.04 & 48.20 & 42.63 & 46.69 & 36.31 \\
\hline Mínimo & 1.68 & 1.01 & 2.46 & 4.75 & 8.61 & 7.61 & 13.09 & 11.89 & 4.74 & 5.95 & 2.51 & 2.12 \\
\hline Percentil 5 & 6.44 & 6.09 & 6.35 & 9.79 & 12.97 & 15.28 & 18.55 & 18.37 & 13.45 & 11.71 & 9.12 & 5.59 \\
\hline Percentil 95 & 24.16 & 21.01 & 23.60 & 24.73 & 30.32 & 36.99 & 38.16 & 38.47 & 37.90 & 33.68 & 26.76 & 24.25 \\
\hline Coef. Asimetría & 0.43 & 0.43 & 0.21 & 0.16 & 0.41 & -0.23 & 0.19 & 0.23 & 0.13 & 0.05 & 0.44 & 0.31 \\
\hline Curtosis & -0.21 & -0.10 & -0.36 & -0.27 & -0.24 & -0.48 & -0.49 & -0.10 & -0.65 & -0.57 & 0.68 & 0.00 \\
\hline $\mathrm{N}^{0}$ Medidas & 5082 & 4656 & 5167 & 5016 & 5207 & 5040 & 5111 & 4755 & 4388 & 4421 & 4638 & 5069 \\
\hline
\end{tabular}

c) Estadísticas globales de las medias diarias del GPS de Santander:

\begin{tabular}{|c|c|c|c|c|c|c|c|c|c|c|}
\hline No Días & Media & STD & Mediana & Moda & $\begin{array}{c}\text { Percentil } \\
\mathbf{5}\end{array}$ & $\begin{array}{c}\text { Percentil } \\
\mathbf{9 5}\end{array}$ & Máximo & Mínimo & $\begin{array}{c}\text { Coef. } \\
\text { Asimetría }\end{array}$ & Curtosis \\
\hline 2448 & 20.15 & 7.60 & 19.30 & $15-17.5$ & 9.01 & 33.37 & 42.15 & 3.14 & 0.33 & -0.53 \\
\hline
\end{tabular}

d) Resumen por mes de las medias diarias del GPS de Santander:

\begin{tabular}{|c|c|c|c|c|c|c|c|c|c|c|c|c|}
\hline Estadístico \Mes & 1 & 2 & 3 & 4 & 5 & 6 & 7 & 8 & 9 & 10 & 11 & 12 \\
\hline Media & 14.28 & 13.08 & 14.66 & 16.99 & 21.04 & 26.70 & 27.92 & 28.14 & 25.25 & 22.71 & 17.23 & 14.41 \\
\hline STD & 4.58 & 4.00 & 4.74 & 4.06 & 4.85 & 6.07 & 5.32 & 5.34 & 7.02 & 6.00 & 4.93 & 5.03 \\
\hline Mediana & 14.15 & 12.70 & 14.97 & 16.86 & 20.47 & 27.74 & 27.75 & 28.04 & 25.23 & 23.28 & 16.67 & 14.42 \\
\hline Máximo & 28.23 & 24.05 & 27.34 & 30.16 & 35.90 & 39.73 & 40.71 & 41.44 & 42.15 & 37.04 & 32.24 & 28.20 \\
\hline Mínimo & 4.85 & 3.69 & 4.14 & 5.61 & 12.13 & 10.10 & 14.34 & 14.98 & 10.75 & 7.94 & 3.90 & 3.14 \\
\hline Percentil 5 & 7.69 & 6.60 & 7.18 & 10.18 & 13.95 & 16.36 & 19.47 & 19.70 & 14.10 & 13.21 & 10.44 & 5.80 \\
\hline Percentil 95 & 22.47 & 19.89 & 22.63 & 23.76 & 29.27 & 35.79 & 37.64 & 37.16 & 37.24 & 32.78 & 25.44 & 23.03 \\
\hline Coef. Asimetría & 0.36 & 0.26 & 0.06 & 0.12 & 0.39 & -0.39 & 0.11 & 0.04 & 0.10 & -0.06 & 0.23 & 0.03 \\
\hline Curtosis & -0.27 & -0.16 & -0.42 & -0.09 & -0.36 & -0.39 & -0.58 & -0.31 & -0.67 & -0.46 & 0.19 & -0.33 \\
\hline $\mathrm{N}^{0}$ Días & 212 & 194 & 216 & 209 & 217 & 210 & 214 & 199 & 185 & 185 & 194 & 213 \\
\hline
\end{tabular}

e1) Media de las medias diarias por mes y año del GPS de Santander:

\begin{tabular}{|c|c|c|c|c|c|c|c|c|c|c|c|c|c|}
\hline Año \Mes & $\mathbf{1}$ & $\mathbf{2}$ & $\mathbf{3}$ & $\mathbf{4}$ & $\mathbf{5}$ & $\mathbf{6}$ & $\mathbf{7}$ & $\mathbf{8}$ & $\mathbf{9}$ & $\mathbf{1 0}$ & $\mathbf{1 1}$ & $\mathbf{1 2}$ & Media \\
\hline $\mathbf{2 0 0 2}$ & 14.07 & 14.49 & 14.51 & 15.21 & 20.13 & 26.66 & 26.96 & 29.58 & 24.13 & 23.44 & 19.46 & 17.86 & $\mathbf{2 0 . 5 4}$ \\
$\mathbf{2 0 0 3}$ & 13.94 & 13.69 & 14.60 & 17.78 & 20.38 & 29.37 & 28.67 & 32.05 & -- & -- & 18.64 & 15.29 & $\mathbf{2 0 . 4 4}$ \\
$\mathbf{2 0 0 4}$ & 16.78 & 11.34 & 14.48 & 14.88 & 20.65 & 27.12 & 28.86 & 29.82 & 28.54 & 22.62 & 16.52 & 16.21 & $\mathbf{2 0 . 6 5}$ \\
$\mathbf{2 0 0 5}$ & 13.91 & 11.98 & 14.11 & 19.18 & 21.25 & 27.22 & 27.31 & 27.50 & 25.14 & 23.89 & 17.49 & 13.69 & $\mathbf{2 0 . 2 2}$ \\
$\mathbf{2 0 0 6}$ & 13.60 & 11.99 & 17.12 & 17.79 & 21.84 & 27.72 & 33.37 & 26.73 & 29.34 & 26.11 & 19.20 & 12.54 & $\mathbf{2 1 . 4 5}$ \\
$\mathbf{2 0 0 7}$ & 14.15 & 15.16 & 13.58 & 18.82 & 21.53 & 24.04 & 25.20 & 26.33 & 21.30 & 19.91 & 13.42 & 12.17 & $\mathbf{1 8 . 8 0}$ \\
$\mathbf{2 0 0 8}$ & 13.49 & 13.23 & 14.23 & 15.28 & 21.51 & 24.75 & 25.17 & 26.58 & 22.28 & 20.35 & 16.56 & 13.32 & $\mathbf{1 8 . 9 0}$ \\
\hline Media & $\mathbf{1 4 . 2 8}$ & $\mathbf{1 3 . 1 2}$ & $\mathbf{1 4 . 6 6}$ & $\mathbf{1 6 . 9 9}$ & $\mathbf{2 1 . 0 4}$ & $\mathbf{2 6 . 7 0}$ & $\mathbf{2 7 . 9 3}$ & $\mathbf{2 8 . 3 7}$ & $\mathbf{2 5 . 1 1}$ & $\mathbf{2 2 . 7 2}$ & $\mathbf{1 7 . 3 3}$ & $\mathbf{1 4 . 4 4}$ & $\mathbf{2 0 . 1 4}$ \\
\hline
\end{tabular}


e2) Máximo de las medias diarias por mes y año del GPS de Santander:

\begin{tabular}{|c|c|c|c|c|c|c|c|c|c|c|c|c|c|}
\hline Año \Mes & $\mathbf{1}$ & $\mathbf{2}$ & $\mathbf{3}$ & $\mathbf{4}$ & $\mathbf{5}$ & $\mathbf{6}$ & $\mathbf{7}$ & $\mathbf{8}$ & $\mathbf{9}$ & $\mathbf{1 0}$ & $\mathbf{1 1}$ & $\mathbf{1 2}$ & Media \\
\hline $\mathbf{2 0 0 2}$ & 23.08 & 21.40 & 24.85 & 22.58 & 27.82 & 33.66 & 37.62 & 37.13 & 37.84 & 36.87 & 32.24 & 28.20 & $\mathbf{3 0 . 2 7}$ \\
$\mathbf{2 0 0 3}$ & 24.21 & 18.63 & 24.52 & 25.55 & 32.47 & 37.43 & 37.76 & 41.44 & -- & -- & 27.87 & 23.68 & $\mathbf{2 9 . 3 6}$ \\
$\mathbf{2 0 0 4}$ & 28.23 & 16.48 & 23.47 & 21.65 & 33.43 & 38.88 & 38.80 & 40.49 & 42.15 & 35.97 & 26.20 & 23.85 & $\mathbf{3 0 . 8 0}$ \\
$\mathbf{2 0 0 5}$ & 21.83 & 20.86 & 27.34 & 30.16 & 35.90 & 39.73 & 38.00 & 39.71 & 31.58 & 33.33 & 25.61 & 24.25 & $\mathbf{3 0 . 6 9}$ \\
$\mathbf{2 0 0 6}$ & 20.57 & 23.90 & 25.79 & 21.89 & 29.25 & 37.10 & 40.71 & 36.68 & 40.66 & 33.71 & 27.83 & 23.10 & $\mathbf{3 0 . 1 0}$ \\
$\mathbf{2 0 0 7}$ & 22.74 & 21.87 & 25.53 & 26.92 & 31.32 & 33.20 & 34.43 & 35.17 & 31.87 & 37.04 & 21.41 & 21.32 & $\mathbf{2 8 . 5 7}$ \\
$\mathbf{2 0 0 8}$ & 25.96 & 24.05 & 23.19 & 22.46 & 28.40 & 34.15 & 33.70 & 39.78 & 34.30 & 30.70 & 21.91 & 23.63 & $\mathbf{2 8 . 5 2}$ \\
\hline Media & $\mathbf{2 3 . 8 0}$ & $\mathbf{2 1 . 0 3}$ & $\mathbf{2 4 . 9 6}$ & $\mathbf{2 4 . 4 6}$ & $\mathbf{3 1 . 2 3}$ & $\mathbf{3 6 . 3 1}$ & $\mathbf{3 7 . 2 9}$ & $\mathbf{3 8 . 6 3}$ & $\mathbf{3 6 . 4 0}$ & $\mathbf{3 4 . 6 0}$ & $\mathbf{2 6 . 1 5}$ & $\mathbf{2 4 . 0 0}$ & $\mathbf{2 9 . 7 6}$ \\
\hline
\end{tabular}

e3) Mínimo de las medias diarias por mes y año del GPS de Santander:

\begin{tabular}{|c|c|c|c|c|c|c|c|c|c|c|c|c|c|}
\hline Año \Mes & 1 & 2 & 3 & 4 & 5 & 6 & 7 & 8 & 9 & 10 & 11 & 12 & Media \\
\hline 2002 & 7.35 & 3.69 & 7.26 & 10.02 & 13.35 & 18.85 & 17.96 & 22.00 & 12.06 & 11.10 & 13.31 & 11.01 & 12.33 \\
\hline 2003 & 6.39 & 5.52 & 4.73 & 9.33 & 12.41 & 20.60 & 19.63 & 19.97 & --- & --- & 11.01 & 8.83 & 11.84 \\
\hline 2004 & 8.38 & 5.38 & 6.19 & 9.89 & 12.46 & 16.13 & 19.96 & 19.70 & 15.32 & 13.81 & 9.99 & 10.95 & 12.35 \\
\hline 2005 & 7.86 & 5.55 & 5.94 & 11.27 & 13.96 & 10.10 & 19.63 & 14.98 & 12.99 & 14.17 & 10.48 & 5.06 & 11.00 \\
\hline 2006 & 4.85 & 7.59 & 9.81 & 9.22 & 12.96 & 11.57 & 28.04 & 18.24 & 21.16 & 18.88 & 6.44 & 4.74 & 12.79 \\
\hline 2007 & 5.96 & 5.64 & 4.14 & 12.56 & 13.26 & 19.00 & 18.86 & 15.07 & 12.83 & 7.94 & 3.90 & 4.08 & 10.27 \\
\hline 2008 & 5.42 & 5.63 & 8.06 & 5.61 & 12.13 & 13.55 & 14.34 & 17.97 & 14.01 & 10.32 & 10.19 & 3.14 & 10.03 \\
\hline Media & 6.60 & 5.57 & 6.59 & 9.70 & 12.93 & 15.69 & 19.77 & 18.28 & 14.51 & 12.70 & 9.33 & 6.83 & 11.50 \\
\hline
\end{tabular}

e4) Desviación estándar de las medias diarias de cada mes y año del GPS de Santander:

\begin{tabular}{|c|l|l|l|l|l|l|l|l|l|l|l|l|c|}
\hline Año \Mes & $\mathbf{1}$ & $\mathbf{2}$ & $\mathbf{3}$ & $\mathbf{4}$ & $\mathbf{5}$ & $\mathbf{6}$ & $\mathbf{7}$ & $\mathbf{8}$ & $\mathbf{9}$ & $\mathbf{1 0}$ & $\mathbf{1 1}$ & $\mathbf{1 2}$ & Media \\
\hline $\mathbf{2 0 0 2}$ & 4.13 & 3.52 & 3.87 & 2.88 & 3.89 & 4.54 & 5.46 & 3.90 & 7.60 & 5.96 & 5.28 & 4.61 & $\mathbf{4 . 6 4}$ \\
$\mathbf{2 0 0 3}$ & 4.38 & 3.97 & 5.86 & 4.19 & 4.71 & 4.13 & 4.32 & 5.58 & -- & -- & 4.52 & 3.35 & $\mathbf{4 . 5 0}$ \\
$\mathbf{2 0 0 4}$ & 5.39 & 2.86 & 4.76 & 2.78 & 5.91 & 6.65 & 5.35 & 5.10 & 7.84 & 5.26 & 4.21 & 3.34 & $\mathbf{4 . 9 6}$ \\
$\mathbf{2 0 0 5}$ & 3.96 & 3.24 & 5.37 & 4.48 & 4.69 & 7.34 & 4.75 & 5.87 & 6.03 & 5.11 & 4.24 & 5.22 & $\mathbf{5 . 0 2}$ \\
$\mathbf{2 0 0 6}$ & 4.19 & 3.39 & 4.07 & 3.49 & 4.62 & 7.38 & 3.41 & 4.40 & 5.37 & 4.13 & 5.40 & 5.20 & $\mathbf{4 . 5 9}$ \\
$\mathbf{2 0 0 7}$ & 4.11 & 3.11 & 4.46 & 3.43 & 5.51 & 3.56 & 3.34 & 5.87 & 5.22 & 7.07 & 4.30 & 5.09 & $\mathbf{4 . 5 9}$ \\
$\mathbf{2 0 0 8}$ & 4.81 & 5.58 & 3.54 & 4.21 & 4.03 & 5.93 & 5.29 & 4.29 & 5.94 & 5.70 & 3.31 & 5.09 & $\mathbf{4 . 8 1}$ \\
\hline Media & $\mathbf{4 . 4 2}$ & $\mathbf{3 . 6 7}$ & $\mathbf{4 . 5 6}$ & $\mathbf{3 . 6 4}$ & $\mathbf{4 . 7 7}$ & $\mathbf{5 . 6 5}$ & $\mathbf{4 . 5 6}$ & $\mathbf{5 . 0 0}$ & $\mathbf{6 . 3 4}$ & $\mathbf{5 . 5 4}$ & $\mathbf{4 . 4 7}$ & $\mathbf{4 . 5 6}$ & $\mathbf{4 . 7 3}$ \\
\hline
\end{tabular}

e5) Número de días con dato válido por mes y año del GPS de Santander:

\begin{tabular}{|c|c|c|c|c|c|c|c|c|c|c|c|c|c|}
\hline Año \Mes & 1 & 2 & 3 & 4 & 5 & 6 & 7 & 8 & 9 & 10 & 11 & 12 & Total \\
\hline 2002 & 31 & 27 & 31 & 30 & 31 & 30 & 31 & 31 & 29 & 31 & 30 & 30 & 362 \\
\hline 2003 & 30 & 28 & 31 & 29 & 31 & 30 & 30 & 17 & 6 & 0 & 15 & 28 & 275 \\
\hline 2004 & 31 & 29 & 31 & 30 & 31 & 30 & 29 & 31 & 30 & 31 & 30 & 31 & 364 \\
\hline 2005 & 31 & 28 & 30 & 30 & 31 & 30 & 31 & 29 & 30 & 30 & 30 & 31 & 361 \\
\hline 2006 & 31 & 28 & 31 & 30 & 31 & 30 & 31 & 31 & 30 & 31 & 30 & 31 & 365 \\
\hline 2007 & 27 & 25 & 31 & 30 & 31 & 30 & 31 & 31 & 30 & 31 & 30 & 31 & 358 \\
\hline 2008 & 31 & 29 & 31 & 30 & 31 & 30 & 31 & 29 & 30 & 31 & 29 & 31 & 363 \\
\hline Total & 212 & 194 & 216 & 209 & 217 & 210 & 214 & 199 & 179 & 185 & 194 & 213 & 2442 \\
\hline
\end{tabular}

f) Resumen por mes de las medias mensuales de cada año del GPS de Santander:

\begin{tabular}{|c|c|c|c|c|c|c|c|c|c|c|c|c|}
\hline Mes & 1 & 2 & 3 & 4 & 5 & 6 & 7 & 8 & 9 & 10 & 11 & 12 \\
\hline Media & 14.28 & 13.12 & 14.66 & 16.99 & 21.04 & 26.70 & 27.93 & 28.37 & 25.11 & 22.72 & 17.33 & 14.44 \\
\hline STD & 1.05 & 1.32 & 1.05 & 1.69 & 0.60 & 1.67 & 2.60 & 2.00 & 2.98 & 2.12 & 1.94 & 1.93 \\
\hline Mediana & 13.94 & 13.23 & 14.48 & 17.78 & 21.25 & 27.12 & 27.31 & 27.50 & 24.61 & 23.03 & 17.49 & 13.69 \\
\hline Máximo & 16.78 & 15.16 & 17.12 & 19.18 & 21.84 & 29.37 & 33.37 & 32.05 & 29.34 & 26.11 & 19.46 & 17.86 \\
\hline Mínimo & 13.49 & 11.34 & 13.58 & 14.88 & 20.13 & 24.04 & 25.17 & 26.33 & 21.30 & 19.91 & 13.42 & 12.17 \\
\hline $\mathrm{N}^{0}$ Días & 212 & 194 & 216 & 209 & 217 & 210 & 214 & 199 & 179 & 185 & 194 & 213 \\
\hline
\end{tabular}




\section{Gráficas de la estación de Santander}

g) Evolución temporal de las medias diarias.

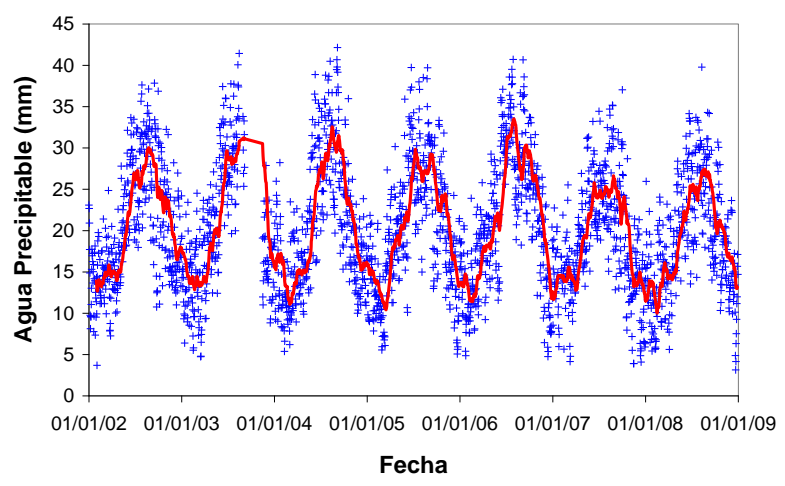

La línea roja representa la media móvil mensual. h) Histograma de las medias diarias.

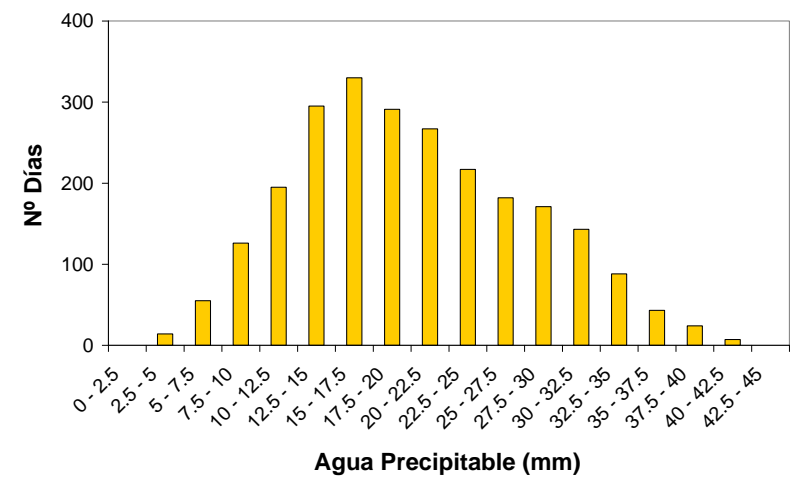

La distribución presenta un desplazamiento hacia la derecha (coef. de asimetría positivo), y un ligero achatamiento (curtosis negativa) respecto de la distribución normal.

j) Ciclo promedio anual.

para cada mes y año.
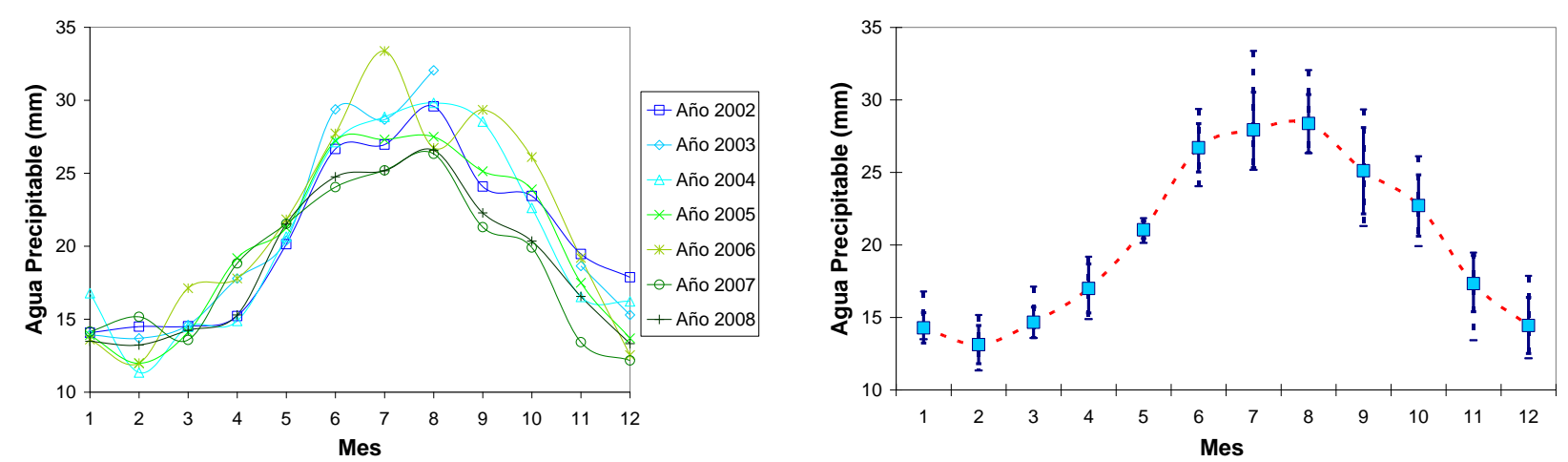

Valor promedio de las medias mensuales de cada año (cuadrados). Valor promedio más/menos la desviación típica de las medias mensuales (barras sólidas). Valor máximo y mínimo absoluto de las medias mensuales (líneas de trazos). 


\subsubsection{CREUS (Faro). Estación GPS.}

El análisis estadístico se ha realizado en base a los datos de ZTD generados por el centro de análisis IGN de EUREF.

a) Estadísticas globales del conjunto de las medidas del GPS del faro de Creus:

\begin{tabular}{|c|c|c|c|c|c|c|c|c|c|c|}
\hline $\begin{array}{c}\mathrm{N}^{0} \\
\text { Medidas }\end{array}$ & Media & STD & Mediana & $\begin{array}{l}\text { Clase } \\
\text { Modal }\end{array}$ & $\begin{array}{c}\text { Percentil } \\
5 \\
\end{array}$ & \begin{tabular}{|c|} 
Percentil \\
95 \\
\end{tabular} & Máximo & Mínimo & $\begin{array}{c}\text { Coef. } \\
\text { Asimetría }\end{array}$ & Curtosis \\
\hline 55481 & 20.05 & 8.74 & 19.18 & $17.5-20$ & 7.35 & 35.56 & 51.13 & 0.47 & 0.35 & -0.62 \\
\hline
\end{tabular}

b) Estadísticas por mes del conjunto de las medidas del GPS del faro de Creus:

\begin{tabular}{|c|c|c|c|c|c|c|c|c|c|c|c|c|}
\hline Estadístico \Mes & 1 & 2 & 3 & 4 & 5 & 6 & 7 & 8 & 9 & 10 & 11 & 12 \\
\hline Media & 12.35 & 11.89 & 13.87 & 16.90 & 21.39 & 26.77 & 28.60 & 29.51 & 26.23 & 23.78 & 16.27 & 13.72 \\
\hline STD & 5.09 & 4.55 & 5.41 & 4.62 & 5.43 & 6.59 & 6.06 & 6.37 & 8.64 & 7.14 & 6.13 & 5.27 \\
\hline Mediana & 11.89 & 11.14 & 13.61 & 16.97 & 21.37 & 26.96 & 28.97 & 29.61 & 26.67 & 23.63 & 15.27 & 13.13 \\
\hline Máximo & 27.27 & 29.12 & 30.46 & 33.30 & 39.49 & 45.73 & 48.93 & 51.13 & 50.15 & 45.74 & 37.51 & 36.50 \\
\hline Mínimo & 0.47 & 0.92 & 0.55 & 4.23 & 4.97 & 7.62 & 9.13 & 8.74 & 1.29 & 4.86 & 0.96 & 3.53 \\
\hline Percentil 5 & 4.85 & 5.67 & 6.14 & 9.16 & 12.62 & 16.01 & 18.04 & 18.77 & 12.88 & 11.89 & 7.29 & 6.27 \\
\hline Percentil 95 & 21.54 & 20.61 & 23.13 & 24.43 & 30.37 & 37.31 & 37.98 & 39.62 & 39.66 & 35.92 & 27.54 & 22.93 \\
\hline Coef. Asimetría & 0.36 & 0.61 & 0.29 & 0.09 & 0.19 & -0.05 & -0.28 & -0.07 & -0.02 & 0.05 & 0.42 & 0.45 \\
\hline Curtosis & -0.44 & 0.09 & -0.64 & -0.12 & -0.11 & -0.36 & 0.04 & -0.30 & -0.99 & -0.38 & -0.46 & -0.42 \\
\hline $\mathrm{N}^{0}$ Medidas & 4971 & 4132 & 4655 & 4542 & 4939 & 4798 & 4704 & 3988 & 4396 & 4986 & 4552 & 4818 \\
\hline
\end{tabular}

c) Estadísticas globales de las medias diarias del GPS del faro de Creus:

\begin{tabular}{|c|c|c|c|c|c|c|c|c|c|c|}
\hline $\mathrm{N}^{0}$ Días & Media & STD & Mediana & Moda & \begin{tabular}{|c|} 
Percentil \\
5 \\
\end{tabular} & \begin{tabular}{|c|} 
Percentil \\
95 \\
\end{tabular} & Máximo & Mínimo & \begin{tabular}{|c} 
Coef. \\
Asimetría
\end{tabular} & Curtosis \\
\hline 2328 & 20.04 & 8.31 & 19.20 & $12.5-15$ & 7.94 & 34.67 & 43.67 & 2.57 & 0.31 & -0.73 \\
\hline
\end{tabular}

d) Resumen por mes de las medias diarias del GPS del faro de Creus:

\begin{tabular}{|c|c|c|c|c|c|c|c|c|c|c|c|c|}
\hline Estadístico \Mes & 1 & 2 & 3 & 4 & 5 & 6 & 7 & 8 & 9 & 10 & 11 & 12 \\
\hline Media & 12.34 & 11.88 & 13.84 & 16.87 & 21.36 & 26.77 & 28.60 & 29.55 & 26.27 & 23.77 & 16.30 & 13.72 \\
\hline STD & 4.58 & 4.02 & 4.92 & 4.07 & 4.70 & 5.87 & 5.08 & 5.53 & 8.04 & 6.40 & 5.54 & 4.63 \\
\hline Mediana & 12.28 & 11.32 & 14.09 & 17.25 & 21.37 & 27.05 & 28.79 & 29.62 & 26.84 & 23.77 & 15.02 & 13.42 \\
\hline Máximo & 24.29 & 23.52 & 26.71 & 28.78 & 35.31 & 40.38 & 40.46 & 43.67 & 42.54 & 43.48 & 30.69 & 26.28 \\
\hline Mínimo & 3.30 & 2.57 & 3.57 & 6.81 & 11.38 & 10.46 & 12.75 & 15.25 & 9.33 & 8.09 & 4.37 & 5.11 \\
\hline Percentil 5 & 5.64 & 6.42 & 6.72 & 9.52 & 14.12 & 17.78 & 19.76 & 20.78 & 13.75 & 13.06 & 8.41 & 7.11 \\
\hline Percentil 95 & 20.55 & 19.58 & 22.13 & 23.21 & 29.29 & 36.18 & 36.66 & 37.47 & 38.27 & 34.02 & 26.74 & 21.61 \\
\hline Coef. Asimetría & 0.35 & 0.59 & 0.26 & -0.02 & 0.23 & -0.16 & -0.41 & -0.06 & -0.10 & 0.05 & 0.41 & 0.33 \\
\hline Curtosis & -0.41 & 0.04 & -0.74 & -0.07 & -0.14 & -0.40 & 0.38 & -0.37 & -1.06 & -0.22 & -0.54 & -0.58 \\
\hline No Días & 209 & 174 & 195 & 191 & 208 & 200 & 196 & 168 & 186 & 208 & 191 & 202 \\
\hline
\end{tabular}

e1) Media de las medias diarias por mes y año del GPS del faro de Creus:

\begin{tabular}{|c|r|c|c|c|c|c|c|c|c|c|c|c|c|}
\hline Año \Mes & \multicolumn{1}{|c|}{$\mathbf{1}$} & $\mathbf{2}$ & $\mathbf{3}$ & $\mathbf{4}$ & $\mathbf{5}$ & $\mathbf{6}$ & $\mathbf{7}$ & $\mathbf{8}$ & $\mathbf{9}$ & $\mathbf{1 0}$ & $\mathbf{1 1}$ & $\mathbf{1 2}$ & Media \\
\hline $\mathbf{2 0 0 2}$ & 11.45 & 11.73 & 13.34 & 16.38 & 20.11 & 25.68 & 29.31 & 30.74 & 23.88 & 20.68 & 16.28 & 15.48 & $\mathbf{1 9 . 5 9}$ \\
$\mathbf{2 0 0 3}$ & 9.92 & 11.71 & 11.93 & 15.51 & 21.19 & 28.73 & 29.73 & 29.41 & 26.19 & 23.11 & 19.37 & 15.58 & $\mathbf{2 0 . 2 0}$ \\
$\mathbf{2 0 0 4}$ & 14.04 & 11.07 & 14.55 & 17.40 & 21.01 & 27.99 & 28.86 & 32.49 & 29.40 & 24.76 & 15.89 & 15.83 & $\mathbf{2 1 . 1 1}$ \\
$\mathbf{2 0 0 5}$ & 10.43 & 10.82 & 14.27 & 17.73 & 21.20 & 28.90 & 29.89 & 28.68 & 27.15 & 27.91 & 17.10 & 11.89 & $\mathbf{2 0 . 5 0}$ \\
$\mathbf{2 0 0 6}$ & 14.77 & 12.45 & 16.67 & 18.08 & 22.25 & 25.37 & 31.61 & -- & 31.26 & 26.36 & 17.85 & 12.40 & $\mathbf{2 0 . 8 2}$ \\
$\mathbf{2 0 0 7}$ & 12.47 & 11.62 & 12.62 & 17.90 & 21.04 & 26.49 & 26.10 & 27.89 & 22.19 & 20.32 & 12.60 & 11.71 & $\mathbf{1 8 . 5 8}$ \\
$\mathbf{2 0 0 8}$ & 13.14 & 13.42 & 12.90 & 15.02 & 22.83 & 24.23 & 25.06 & 28.70 & 23.87 & 23.30 & 15.10 & 12.80 & $\mathbf{1 9 . 1 9}$ \\
\hline Media & $\mathbf{1 2 . 3 2}$ & $\mathbf{1 1 . 8 3}$ & $\mathbf{1 3 . 7 5}$ & $\mathbf{1 6 . 8 6}$ & $\mathbf{2 1 . 3 7}$ & $\mathbf{2 6 . 7 7}$ & $\mathbf{2 8 . 6 5}$ & $\mathbf{2 9 . 6 5}$ & $\mathbf{2 6 . 2 7}$ & $\mathbf{2 3 . 7 8}$ & $\mathbf{1 6 . 3 1}$ & $\mathbf{1 3 . 6 7}$ & $\mathbf{2 0 . 0 0}$ \\
\hline
\end{tabular}


e2) Máximo de las medias diarias por mes y año del GPS del faro de Creus:

\begin{tabular}{|c|c|c|c|c|c|c|c|c|c|c|c|c|c|}
\hline Año \Mes & $\mathbf{1}$ & $\mathbf{2}$ & $\mathbf{3}$ & $\mathbf{4}$ & $\mathbf{5}$ & $\mathbf{6}$ & $\mathbf{7}$ & $\mathbf{8}$ & $\mathbf{9}$ & $\mathbf{1 0}$ & $\mathbf{1 1}$ & $\mathbf{1 2}$ & Media \\
\hline $\mathbf{2 0 0 2}$ & 20.73 & 17.52 & 21.24 & 24.50 & 28.81 & 32.32 & 37.77 & 40.81 & 37.13 & 33.89 & 26.44 & 24.18 & $\mathbf{2 8 . 7 8}$ \\
$\mathbf{2 0 0 3}$ & 18.17 & 19.73 & 22.10 & 22.48 & 26.68 & 35.43 & 36.33 & 37.17 & 38.93 & 33.46 & 30.69 & 24.72 & $\mathbf{2 8 . 8 2}$ \\
$\mathbf{2 0 0 4}$ & 24.29 & 18.36 & 24.18 & 28.78 & 35.31 & 40.38 & 37.49 & 43.67 & 39.21 & 36.18 & 26.58 & 26.28 & $\mathbf{3 1 . 7 3}$ \\
$\mathbf{2 0 0 5}$ & 17.80 & 22.87 & 26.71 & 24.70 & 34.39 & 39.59 & 38.32 & 38.82 & 38.28 & 43.48 & 27.61 & 18.95 & $\mathbf{3 0 . 9 6}$ \\
$\mathbf{2 0 0 6}$ & 23.92 & 22.49 & 22.54 & 23.23 & 32.35 & 36.22 & 40.46 & -- & 42.54 & 33.16 & 23.57 & 21.64 & $\mathbf{2 9 . 2 8}$ \\
$\mathbf{2 0 0 7}$ & 19.06 & 16.92 & 16.35 & 27.15 & 32.07 & 34.24 & 33.55 & 42.02 & 36.92 & 35.87 & 27.87 & 21.02 & $\mathbf{2 8 . 5 9}$ \\
$\mathbf{2 0 0 8}$ & 22.34 & 23.52 & 18.04 & 22.31 & 32.93 & 34.26 & 36.60 & 38.25 & 35.31 & 36.09 & 27.56 & 20.92 & $\mathbf{2 9 . 0 1}$ \\
\hline Media & $\mathbf{2 0 . 9 0}$ & $\mathbf{2 0 . 2 0}$ & $\mathbf{2 1 . 5 9}$ & $\mathbf{2 4 . 7 4}$ & $\mathbf{3 1 . 7 9}$ & $\mathbf{3 6 . 0 6}$ & $\mathbf{3 7 . 2 2}$ & $\mathbf{4 0 . 1 2}$ & $\mathbf{3 8 . 3 3}$ & $\mathbf{3 6 . 0 2}$ & $\mathbf{2 7 . 1 9}$ & $\mathbf{2 2 . 5 3}$ & $\mathbf{2 9 . 6 0}$ \\
\hline
\end{tabular}

e3) Mínimo de las medias diarias por mes y año del GPS del faro de Creus:

\begin{tabular}{|c|c|c|c|c|c|c|c|c|c|c|c|c|c|}
\hline Año \Mes & 1 & 2 & 3 & 4 & 5 & 6 & 7 & 8 & 9 & 10 & 11 & 12 & Media \\
\hline 2002 & 4.36 & 5.47 & 6.07 & 9.07 & 12.55 & 18.94 & 19.26 & 20.81 & 9.33 & 11.14 & 7.78 & 9.25 & 11.17 \\
\hline 2003 & 3.30 & 4.89 & 3.57 & 6.81 & 12.19 & 18.46 & 23.97 & 22.13 & 14.06 & 9.90 & 9.58 & 7.80 & 11.39 \\
\hline 2004 & 6.94 & 6.45 & 6.56 & 10.27 & 14.11 & 16.38 & 18.25 & 21.15 & 12.26 & 16.46 & 8.46 & 6.89 & 12.02 \\
\hline 2005 & 5.42 & 5.86 & 7.20 & 12.59 & 12.49 & 15.84 & 20.44 & 17.00 & 11.64 & 17.84 & 9.47 & 6.25 & 11.84 \\
\hline 2006 & 7.96 & 7.60 & 7.14 & 8.16 & 11.38 & 10.46 & 25.93 & --- & 16.75 & 19.54 & 9.34 & 6.36 & 11.87 \\
\hline 2007 & 4.89 & 2.57 & 6.72 & 12.64 & 13.16 & 17.94 & 17.51 & 15.25 & 10.19 & 8.09 & 4.37 & 5.11 & 9.87 \\
\hline 2008 & 4.34 & 7.27 & 5.84 & 7.90 & 13.11 & 13.19 & 12.75 & 19.83 & 12.33 & 12.27 & 6.33 & 5.18 & 10.03 \\
\hline Media & 5.32 & 5.73 & 6.16 & 9.63 & 12.71 & 15.89 & 19.73 & 19.36 & 12.37 & 13.61 & 7.90 & 6.69 & 11.17 \\
\hline
\end{tabular}

e4) Desviación estándar de las medias diarias de cada mes y año del GPS del faro de Creus:

\begin{tabular}{|c|l|l|l|l|l|l|l|l|l|l|l|l|c|}
\hline Año IMes & $\mathbf{1}$ & $\mathbf{2}$ & $\mathbf{3}$ & $\mathbf{4}$ & $\mathbf{5}$ & $\mathbf{6}$ & $\mathbf{7}$ & $\mathbf{8}$ & $\mathbf{9}$ & $\mathbf{1 0}$ & $\mathbf{1 1}$ & $\mathbf{1 2}$ & Media \\
\hline $\mathbf{2 0 0 2}$ & 3.96 & 3.36 & 3.91 & 4.03 & 3.83 & 4.27 & 4.01 & 4.70 & 7.69 & 4.71 & 4.61 & 3.79 & $\mathbf{4 . 4 1}$ \\
$\mathbf{2 0 0 3}$ & 4.24 & 4.15 & 5.16 & 4.44 & 3.75 & 4.69 & 3.14 & 4.52 & 7.77 & 6.48 & 5.43 & 5.09 & $\mathbf{4 . 9 1}$ \\
$\mathbf{2 0 0 4}$ & 5.12 & 3.14 & 5.65 & 4.47 & 4.97 & 6.99 & 5.18 & 5.32 & 8.04 & 4.91 & 4.76 & 5.09 & $\mathbf{5 . 3 0}$ \\
$\mathbf{2 0 0 5}$ & 3.29 & 4.17 & 6.05 & 3.23 & 5.18 & 6.61 & 5.08 & 5.80 & 6.81 & 6.40 & 6.31 & 3.52 & $\mathbf{5 . 2 0}$ \\
$\mathbf{2 0 0 6}$ & 4.32 & 3.46 & 4.32 & 3.74 & 5.02 & 7.53 & 3.74 & - & 7.00 & 4.14 & 3.83 & 4.25 & $\mathbf{4 . 6 7}$ \\
$\mathbf{2 0 0 7}$ & 3.79 & 3.89 & 2.93 & 3.47 & 4.60 & 3.68 & 4.06 & 5.49 & 7.18 & 7.39 & 5.62 & 4.34 & $\mathbf{4 . 7 0}$ \\
$\mathbf{2 0 0 8}$ & 4.81 & 4.92 & 3.44 & 3.84 & 4.78 & 4.45 & 6.45 & 4.82 & 7.40 & 6.19 & 4.66 & 3.64 & $\mathbf{4 . 9 5}$ \\
\hline Media & $\mathbf{4 . 2 2}$ & $\mathbf{3 . 8 7}$ & $\mathbf{4 . 4 9}$ & $\mathbf{3 . 8 9}$ & $\mathbf{4 . 5 9}$ & $\mathbf{5 . 4 6}$ & $\mathbf{4 . 5 2}$ & $\mathbf{5 . 1 1}$ & $\mathbf{7 . 4 1}$ & $\mathbf{5 . 7 4}$ & $\mathbf{5 . 0 3}$ & $\mathbf{4 . 2 5}$ & $\mathbf{4 . 8 8}$ \\
\hline
\end{tabular}

e5) Número de días con dato válido por mes y año del GPS del faro de Creus:

\begin{tabular}{|c|c|c|c|c|c|c|c|c|c|c|c|c|c|}
\hline Año \ Mes & 1 & 2 & 3 & 4 & 5 & 6 & 7 & 8 & 9 & 10 & 11 & 12 & Tota \\
\hline 2002 & 27 & 27 & 30 & 29 & 30 & 30 & 31 & 28 & 26 & 30 & 29 & 30 & 347 \\
\hline 2003 & 30 & 24 & 28 & 23 & 29 & 26 & 24 & 19 & 25 & 30 & 30 & 29 & 317 \\
\hline 2004 & 29 & 25 & 30 & 29 & 30 & 29 & 31 & 31 & 27 & 29 & 20 & 31 & 341 \\
\hline 2005 & 30 & 26 & 29 & 25 & 30 & 30 & 31 & 29 & 25 & 30 & 30 & 31 & 346 \\
\hline 2006 & 31 & 28 & 30 & 28 & 31 & 27 & 23 & 2 & 28 & 29 & 23 & 22 & 302 \\
\hline 2007 & 31 & 15 & 18 & 28 & 31 & 30 & 31 & 29 & 30 & 29 & 29 & 30 & 331 \\
\hline 2008 & 31 & 29 & 30 & 29 & 27 & 28 & 25 & 30 & 25 & 31 & 30 & 29 & 344 \\
\hline Total & 209 & 174 & 195 & 191 & 208 & 200 & 196 & 166 & 186 & 208 & 191 & 202 & 2326 \\
\hline
\end{tabular}

f) Resumen por mes de las medias mensuales de cada año del GPS del faro de Creus:

\begin{tabular}{|c|c|c|c|c|c|c|c|c|c|c|c|c|}
\hline Mes & 1 & 2 & 3 & 4 & 5 & 6 & 7 & 8 & 9 & 10 & 11 & 12 \\
\hline Media & 12.32 & 11.83 & 13.75 & 16.86 & 21.37 & 26.77 & 28.65 & 29.65 & 26.27 & 23.78 & 16.31 & 13.67 \\
\hline STD & 1.68 & 0.81 & 1.46 & 1.14 & 0.83 & 1.67 & 2.12 & 1.54 & 3.01 & 2.59 & 1.99 & 1.73 \\
\hline Mediana & 12.47 & 11.71 & 13.34 & 17.40 & 21.19 & 26.49 & 29.31 & 29.05 & 26.19 & 23.30 & 16.28 & 12.80 \\
\hline Máximo & 14.77 & 13.42 & 16.67 & 18.08 & 22.83 & 28.90 & 31.61 & 32.49 & 31.26 & 27.91 & 19.37 & 15.83 \\
\hline Mínimo & 9.92 & 10.82 & 11.93 & 15.02 & 20.11 & 24.23 & 25.06 & 27.89 & 22.19 & 20.32 & 12.60 & 11.71 \\
\hline $\mathrm{N}^{0}$ Días & 209 & 174 & 195 & 191 & 208 & 200 & 196 & 166 & 186 & 208 & 191 & 202 \\
\hline
\end{tabular}




\section{Gráficas de la estación de Creus}

g) Evolución temporal de las medias diarias.

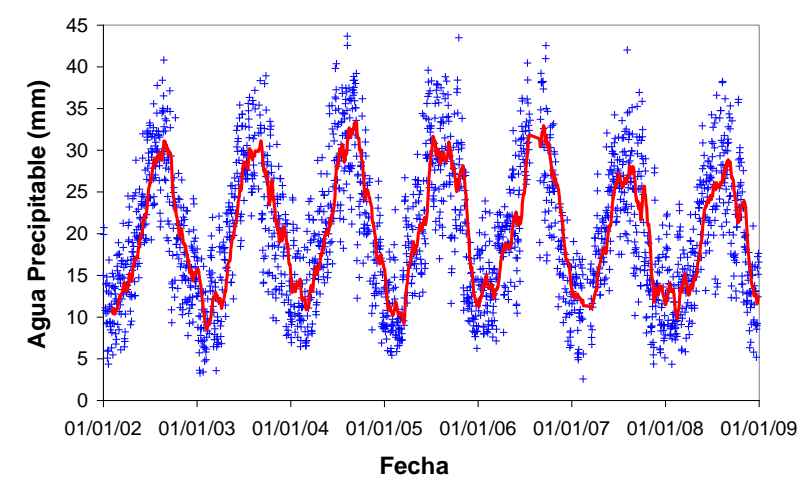

La línea roja representa la media móvil mensual. h) Histograma de las medias diarias.

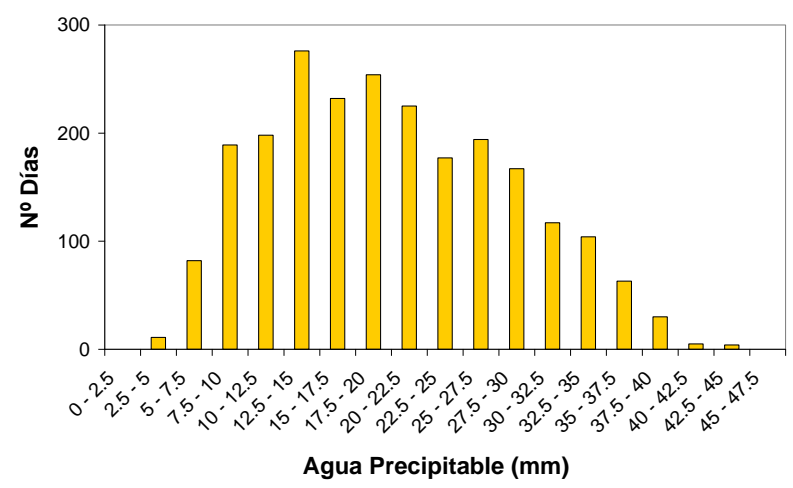

La distribución presenta un desplazamiento hacia la derecha (coef. de asimetría positivo), y un ligero achatamiento (curtosis negativa) respecto de la distribución normal.

j) Ciclo promedio anual.

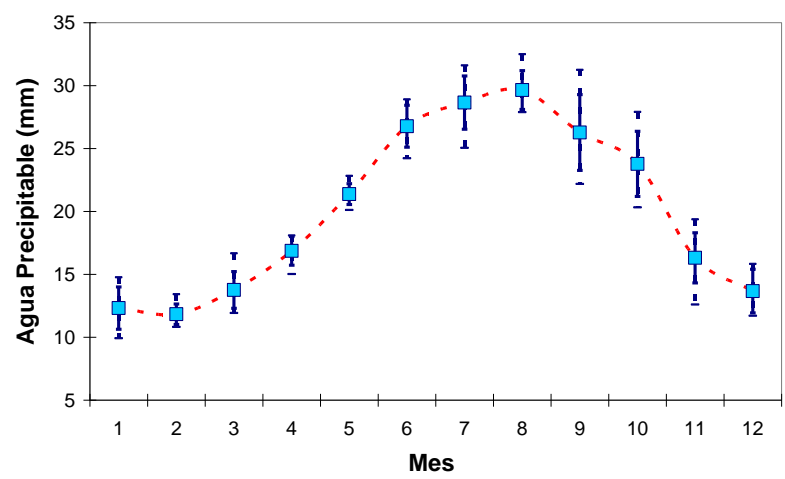

Valor promedio de las medias mensuales de cada año (cuadrados). Valor promedio más/menos la desviación típica de las medias mensuales (barras sólidas). Valor máximo y mínimo absoluto de las medias mensuales (líneas de trazos). 


\subsubsection{ROQUETES (Observatorio del Ebre). Estación GPS.}

El análisis estadístico se ha realizado en base a los datos de ZTD generados por el centro de análisis IGN de EUREF.

a) Estadísticas globales del conjunto de las medidas del GPS de Roquetes:

\begin{tabular}{|c|c|c|c|c|c|c|c|c|c|c|}
\hline $\begin{array}{c}\mathbf{N}^{\mathbf{0}} \\
\text { Medidas }\end{array}$ & Media & STD & Mediana & $\begin{array}{c}\text { Clase } \\
\text { Modal }\end{array}$ & $\begin{array}{c}\text { Percentil } \\
\mathbf{5}\end{array}$ & $\begin{array}{c}\text { Percentil } \\
\mathbf{9 5}\end{array}$ & Máximo & Mínimo & $\begin{array}{c}\text { Coef. } \\
\text { Asimetría }\end{array}$ & Curtosis \\
\hline 54701 & 21.08 & 9.32 & 20.01 & $12.5-15$ & 7.61 & 37.65 & 54.20 & 1.30 & 0.35 & -0.67 \\
\hline
\end{tabular}

b) Estadísticas por mes del conjunto de las medidas del GPS de Roquetes:

\begin{tabular}{|c|c|c|c|c|c|c|c|c|c|c|c|c|}
\hline Estadístico \Mes & 1 & 2 & 3 & 4 & 5 & 6 & 7 & 8 & 9 & 10 & 11 & 12 \\
\hline Media & 12.66 & 12.62 & 14.57 & 17.54 & 22.08 & 27.63 & 30.98 & 30.39 & 28.40 & 24.37 & 16.33 & 13.98 \\
\hline STD & 4.99 & 4.82 & 5.21 & 4.99 & 5.78 & 6.68 & 6.53 & 7.77 & 8.78 & 7.18 & 6.20 & 5.44 \\
\hline Mediana & 12.03 & 11.96 & 14.73 & 17.68 & 22.42 & 27.96 & 31.56 & 30.90 & 28.77 & 24.24 & 15.60 & 13.41 \\
\hline Máximo & 29.36 & 26.56 & 29.26 & 32.65 & 37.72 & 47.91 & 49.47 & 54.20 & 52.03 & 45.43 & 37.96 & 35.57 \\
\hline Mínimo & 2.12 & 1.30 & 1.77 & 3.38 & 4.55 & 8.38 & 7.29 & 8.12 & 3.71 & 6.09 & 1.88 & 3.13 \\
\hline Percentil 5 & 4.89 & 5.62 & 6.00 & 9.37 & 11.90 & 15.96 & 19.16 & 17.18 & 13.47 & 13.32 & 7.40 & 6.22 \\
\hline Percentil 95 & 21.53 & 21.88 & 23.00 & 25.64 & 30.88 & 38.11 & 40.41 & 42.22 & 41.23 & 36.27 & 27.44 & 23.10 \\
\hline Coef. Asimetría & 0.37 & 0.50 & -0.03 & -0.05 & -0.21 & -0.18 & -0.49 & -0.20 & -0.24 & 0.09 & 0.35 & 0.47 \\
\hline Curtosis & -0.44 & -0.21 & -0.69 & -0.48 & -0.37 & -0.32 & 0.25 & -0.55 & -0.77 & -0.65 & -0.27 & -0.22 \\
\hline $\mathrm{N}^{0}$ Medidas & 4662 & 4313 & 4104 & 4313 & 4734 & 4464 & 4954 & 4731 & 4056 & 4968 & 4734 & 4668 \\
\hline
\end{tabular}

c) Estadísticas globales de las medias diarias del GPS de Roquetes:

\begin{tabular}{|c|c|c|c|c|c|c|c|c|c|c|}
\hline N$^{\circ}$ Días & Media & STD & Mediana & Moda & $\begin{array}{c}\text { Percentil } \\
\mathbf{5}\end{array}$ & $\begin{array}{c}\text { Percentil } \\
\mathbf{9 5}\end{array}$ & Máximo & Mínimo & $\begin{array}{c}\text { Coef. } \\
\text { Asimetría }\end{array}$ & Curtosis \\
\hline 2285 & 21.08 & 8.90 & 19.99 & $15-17.5$ & 8.12 & 37.01 & 44.11 & 2.21 & 0.32 & -0.77 \\
\hline
\end{tabular}

d) Resumen por mes de las medias diarias del GPS de Roquetes:

\begin{tabular}{|c|c|c|c|c|c|c|c|c|c|c|c|c|}
\hline Estadístico \Mes & 1 & 2 & 3 & 4 & 5 & 6 & 7 & 8 & 9 & 10 & 11 & 12 \\
\hline Media & 12.65 & 12.62 & 14.57 & 17.54 & 22.08 & 27.63 & 30.97 & 30.43 & 28.34 & 24.37 & 16.36 & 13.96 \\
\hline STD & 4.38 & 4.32 & 4.75 & 4.31 & 5.15 & 5.98 & 5.45 & 6.89 & 8.34 & 6.51 & 5.67 & 4.86 \\
\hline Mediana & 12.19 & 11.93 & 14.86 & 17.75 & 22.34 & 27.79 & 31.64 & 30.90 & 28.67 & 24.51 & 15.52 & 13.86 \\
\hline Máximo & 22.98 & 24.99 & 24.21 & 26.88 & 35.19 & 41.08 & 42.97 & 44.11 & 43.13 & 38.35 & 31.30 & 28.91 \\
\hline Mínimo & 3.82 & 2.21 & 4.09 & 7.01 & 7.95 & 12.03 & 15.29 & 12.42 & 8.88 & 9.68 & 2.49 & 3.80 \\
\hline Percentil 5 & 5.97 & 6.54 & 6.74 & 10.31 & 13.07 & 17.46 & 20.78 & 18.27 & 14.28 & 14.30 & 8.10 & 6.96 \\
\hline Percentil 95 & 20.48 & 20.84 & 21.90 & 24.35 & 29.90 & 36.19 & 38.65 & 40.53 & 40.36 & 35.47 & 25.76 & 21.52 \\
\hline Coef. Asimetría & 0.22 & 0.52 & -0.14 & -0.19 & -0.25 & -0.23 & -0.63 & -0.26 & -0.27 & 0.07 & 0.24 & 0.35 \\
\hline Curtosis & -0.59 & -0.10 & -0.66 & -0.40 & -0.26 & -0.51 & 0.25 & -0.67 & -0.87 & -0.75 & -0.34 & -0.23 \\
\hline $\mathrm{N}^{0}$ Días & 195 & 180 & 171 & 180 & 198 & 186 & 207 & 198 & 170 & 207 & 198 & 195 \\
\hline
\end{tabular}

e1) Media de las medias diarias por mes y año del GPS de Roquetes:

\begin{tabular}{|c|c|c|c|c|c|c|c|c|c|c|c|c|c|}
\hline Año \Mes & \multicolumn{1}{|c|}{} & $\mathbf{2}$ & $\mathbf{3}$ & $\mathbf{4}$ & $\mathbf{5}$ & $\mathbf{6}$ & $\mathbf{7}$ & $\mathbf{8}$ & $\mathbf{9}$ & $\mathbf{1 0}$ & $\mathbf{1 1}$ & $\mathbf{1 2}$ & Media \\
\hline $\mathbf{2 0 0 2}$ & 13.49 & 11.65 & 16.67 & 17.58 & 20.55 & 25.37 & 30.93 & 31.82 & 28.06 & 22.22 & 17.07 & 16.69 & $\mathbf{2 1 . 0 1}$ \\
$\mathbf{2 0 0 3}$ & 11.34 & 13.23 & 14.94 & 18.12 & 22.63 & 29.94 & 32.74 & 30.75 & 28.78 & 23.18 & 19.75 & 13.94 & $\mathbf{2 1 . 6 1}$ \\
$\mathbf{2 0 0 4}$ & 13.70 & 12.48 & 15.07 & 16.73 & 20.66 & 30.03 & 30.73 & 34.85 & 32.12 & 24.40 & 14.44 & 16.24 & $\mathbf{2 1 . 7 9}$ \\
$\mathbf{2 0 0 5}$ & 9.95 & 10.63 & --- & 17.78 & 22.75 & 29.88 & 31.84 & 29.85 & -- & 26.75 & 16.61 & 12.02 & $\mathbf{2 0 . 8 1}$ \\
$\mathbf{2 0 0 6}$ & 13.98 & 12.02 & 16.05 & 18.28 & 23.88 & 27.81 & 32.89 & 25.29 & 30.52 & 27.59 & 20.60 & 12.62 & $\mathbf{2 1 . 7 9}$ \\
$\mathbf{2 0 0 7}$ & 12.63 & 13.70 & 12.64 & 18.56 & 20.69 & 26.63 & 27.88 & 28.43 & 26.67 & 21.79 & 11.85 & 12.90 & $\mathbf{1 9 . 5 3}$ \\
$\mathbf{2 0 0 8}$ & 12.46 & 15.15 & 12.37 & 15.21 & 23.69 & 25.28 & 30.23 & 32.38 & 25.72 & 24.64 & 13.59 & 13.15 & $\mathbf{2 0 . 3 2}$ \\
\hline Media & $\mathbf{1 2 . 5 1}$ & $\mathbf{1 2 . 6 9}$ & $\mathbf{1 4 . 6 2}$ & $\mathbf{1 7 . 4 7}$ & $\mathbf{2 2 . 1 2}$ & $\mathbf{2 7 . 8 5}$ & $\mathbf{3 1 . 0 3}$ & $\mathbf{3 0 . 4 8}$ & $\mathbf{2 8 . 6 4}$ & $\mathbf{2 4 . 3 7}$ & $\mathbf{1 6 . 2 7}$ & $\mathbf{1 3 . 9 4}$ & $\mathbf{2 0 . 9 8}$ \\
\hline
\end{tabular}


e2) Máximo de las medias diarias por mes y año del GPS de Roquetes:

\begin{tabular}{|c|c|c|c|c|c|c|c|c|c|c|c|c|c|}
\hline Año \Mes & $\mathbf{1}$ & $\mathbf{2}$ & $\mathbf{3}$ & $\mathbf{4}$ & $\mathbf{5}$ & $\mathbf{6}$ & $\mathbf{7}$ & $\mathbf{8}$ & $\mathbf{9}$ & $\mathbf{1 0}$ & $\mathbf{1 1}$ & $\mathbf{1 2}$ & Máximo \\
\hline $\mathbf{2 0 0 2}$ & 22.98 & 19.38 & 20.46 & 25.39 & 29.27 & 34.08 & 40.39 & 39.82 & 43.13 & 37.11 & 25.74 & 28.91 & $\mathbf{3 0 . 5 6}$ \\
$\mathbf{2 0 0 3}$ & 21.93 & 23.21 & 24.21 & 26.83 & 29.32 & 38.62 & 42.97 & 43.70 & 41.64 & 35.52 & 28.95 & 22.01 & $\mathbf{3 1 . 5 8}$ \\
$\mathbf{2 0 0 4}$ & 21.14 & 22.14 & 23.45 & 26.88 & 30.82 & 41.08 & 39.71 & 44.11 & 41.06 & 38.35 & 26.76 & 24.55 & $\mathbf{3 1 . 6 7}$ \\
$\mathbf{2 0 0 5}$ & 15.76 & 20.71 & --- & 26.07 & 35.19 & 39.99 & 38.93 & 41.44 & -- & 37.58 & 24.49 & 20.14 & $\mathbf{3 0 . 0 3}$ \\
$\mathbf{2 0 0 6}$ & 20.60 & 17.95 & 23.91 & 24.34 & 31.11 & 37.04 & 41.04 & 35.08 & 41.91 & 35.84 & 31.30 & 21.67 & $\mathbf{3 0 . 1 5}$ \\
$\mathbf{2 0 0 7}$ & 20.47 & 19.88 & 19.10 & 26.08 & 33.01 & 34.92 & 36.43 & 39.01 & 39.69 & 37.55 & 25.70 & 20.60 & $\mathbf{2 9 . 3 7}$ \\
$\mathbf{2 0 0 8}$ & 21.78 & 24.99 & 17.41 & 24.63 & 29.98 & 33.91 & 38.61 & 40.51 & 39.09 & 38.14 & 23.65 & 22.26 & $\mathbf{2 9 . 5 8}$ \\
\hline Media & $\mathbf{2 0 . 6 7}$ & $\mathbf{2 1 . 1 8}$ & $\mathbf{2 1 . 4 2}$ & $\mathbf{2 5 . 7 5}$ & $\mathbf{3 1 . 2 4}$ & $\mathbf{3 7 . 0 9}$ & $\mathbf{3 9 . 7 3}$ & $\mathbf{4 0 . 5 2}$ & $\mathbf{4 1 . 0 9}$ & $\mathbf{3 7 . 1 6}$ & $\mathbf{2 6 . 6 6}$ & $\mathbf{2 2 . 8 8}$ & $\mathbf{3 0 . 4 2}$ \\
\hline
\end{tabular}

e3) Mínimo de las medias diarias por mes y año del GPS de Roquetes:

\begin{tabular}{|c|c|c|c|c|c|c|c|c|c|c|c|c|c|}
\hline Año \Mes & 1 & 2 & 3 & 4 & 5 & 6 & 7 & 8 & 9 & 10 & 11 & 12 & Media \\
\hline 2002 & 8.68 & 5.82 & 12.12 & 11.57 & 10.08 & 16.88 & 18.49 & 20.67 & 8.88 & 12.00 & 8.89 & 8.80 & 11.91 \\
\hline 2003 & 4.02 & 4.96 & 4.09 & 7.01 & 14.45 & 16.64 & 22.27 & 15.78 & 13.69 & 9.68 & 10.98 & 6.45 & 10.84 \\
\hline 2004 & 5.66 & 6.88 & 5.18 & 10.24 & 9.67 & 17.66 & 15.29 & 20.20 & 12.03 & 15.80 & 5.79 & 7.84 & 11.02 \\
\hline 2005 & 4.39 & 4.93 & -- & 10.31 & 12.55 & 19.53 & 21.95 & 17.25 & -- & 12.99 & 9.03 & 6.09 & 11.90 \\
\hline 2006 & 6.31 & 5.75 & 7.08 & 8.19 & 7.95 & 12.03 & 24.31 & 14.72 & 16.55 & 18.48 & 11.18 & 5.99 & 11.55 \\
\hline 2007 & 3.82 & 2.21 & 6.30 & 14.39 & 10.44 & 14.72 & 15.67 & 15.89 & 13.06 & 12.05 & 2.49 & 4.82 & 9.66 \\
\hline 2008 & 5.04 & 9.06 & 4.25 & 7.61 & 13.61 & 12.54 & 15.87 & 12.42 & 15.21 & 12.25 & 6.40 & 3.80 & 9.84 \\
\hline Media & 5.42 & 5.66 & 6.50 & 9.90 & 11.25 & 15.71 & 19.12 & 16.70 & 13.24 & 13.32 & 7.82 & 6.26 & 10.96 \\
\hline
\end{tabular}

e4) Desviación estándar de las medias diarias de cada mes y año del GPS de Roquetes:

\begin{tabular}{|c|l|l|l|l|l|l|l|l|l|l|l|l|c|}
\hline Año \Mes & $\mathbf{1}$ & $\mathbf{2}$ & $\mathbf{3}$ & $\mathbf{4}$ & $\mathbf{5}$ & $\mathbf{6}$ & $\mathbf{7}$ & $\mathbf{8}$ & $\mathbf{9}$ & $\mathbf{1 0}$ & $\mathbf{1 1}$ & $\mathbf{1 2}$ & Media \\
\hline $\mathbf{2 0 0 2}$ & 4.23 & 3.30 & 2.28 & 3.69 & 4.76 & 4.61 & 4.75 & 5.25 & 8.96 & 6.07 & 4.18 & 5.07 & $\mathbf{4 . 7 6}$ \\
$\mathbf{2 0 0 3}$ & 4.74 & 4.62 & 5.88 & 5.17 & 4.23 & 6.57 & 4.79 & 6.98 & 8.11 & 6.49 & 5.29 & 4.47 & $\mathbf{5 . 6 1}$ \\
$\mathbf{2 0 0 4}$ & 4.87 & 4.39 & 5.47 & 3.99 & 5.03 & 5.96 & 6.53 & 6.17 & 8.64 & 6.23 & 4.33 & 4.52 & $\mathbf{5 . 5 1}$ \\
$\mathbf{2 0 0 5}$ & 3.11 & 3.84 & --- & 4.18 & 6.09 & 5.06 & 4.46 & 8.78 & -- & 6.34 & 5.20 & 3.64 & $\mathbf{5 . 0 7}$ \\
$\mathbf{2 0 0 6}$ & 4.12 & 3.11 & 4.51 & 4.34 & 4.55 & 6.90 & 4.53 & 4.62 & 7.47 & 4.86 & 5.10 & 4.40 & $\mathbf{4 . 8 8}$ \\
$\mathbf{2 0 0 7}$ & 3.66 & 4.21 & 3.48 & 3.16 & 5.45 & 4.97 & 5.40 & 6.21 & 6.32 & 6.27 & 5.10 & 4.46 & $\mathbf{4 . 8 9}$ \\
$\mathbf{2 0 0 8}$ & 4.07 & 4.94 & 3.65 & 4.73 & 4.30 & 5.38 & 5.58 & 5.53 & 7.88 & 6.83 & 4.23 & 5.13 & $\mathbf{5 . 1 9}$ \\
\hline Media & $\mathbf{4 . 1 2}$ & $\mathbf{4 . 0 6}$ & $\mathbf{4 . 2 1}$ & $\mathbf{4 . 1 8}$ & $\mathbf{4 . 9 2}$ & $\mathbf{5 . 6 4}$ & $\mathbf{5 . 1 5}$ & $\mathbf{6 . 2 2}$ & $\mathbf{7 . 9 0}$ & $\mathbf{6 . 1 6}$ & $\mathbf{4 . 7 8}$ & $\mathbf{4 . 5 3}$ & $\mathbf{5 . 1 3}$ \\
\hline
\end{tabular}

e5) Número de días con dato válido por mes y año del GPS de Roquetes:

\begin{tabular}{|c|c|c|c|c|c|c|c|c|c|c|c|c|c|}
\hline Año \Mes & 1 & 2 & 3 & 4 & 5 & 6 & 7 & 8 & 9 & 10 & 11 & 12 & Total \\
\hline 2002 & 31 & 28 & 30 & 30 & 31 & 30 & 31 & 29 & 29 & 31 & 29 & 31 & 360 \\
\hline 2003 & 30 & 24 & 27 & 26 & 25 & 19 & 31 & 28 & 25 & 30 & 30 & 27 & 322 \\
\hline 2004 & 30 & 29 & 30 & 28 & 29 & 30 & 31 & 27 & 27 & 28 & 24 & 27 & 340 \\
\hline 2005 & 19 & 27 & 5 & 25 & 28 & 21 & 30 & 25 & 10 & 30 & 27 & 31 & 278 \\
\hline 2006 & 29 & 28 & 30 & 28 & 30 & 26 & 23 & 30 & 26 & 29 & 30 & 30 & 339 \\
\hline 2007 & 31 & 16 & 18 & 24 & 29 & 30 & 30 & 29 & 28 & 28 & 28 & 22 & 313 \\
\hline 2008 & 25 & 28 & 31 & 19 & 26 & 30 & 31 & 30 & 25 & 31 & 30 & 27 & 333 \\
\hline Total & 195 & 180 & 166 & 180 & 198 & 186 & 207 & 198 & 160 & 207 & 198 & 195 & 2270 \\
\hline
\end{tabular}

f) Resumen por mes de las medias mensuales de cada año del GPS de Roquetes:

\begin{tabular}{|c|c|c|c|c|c|c|c|c|c|c|c|c|}
\hline Mes & 1 & 2 & 3 & 4 & 5 & 6 & 7 & 8 & 9 & 10 & 11 & 12 \\
\hline Media & 12.51 & 12.69 & 14.62 & 17.47 & 22.12 & 27.85 & 31.03 & 30.48 & 28.64 & 24.37 & 16.27 & 13.94 \\
\hline STD & 1.33 & 1.37 & 1.61 & 1.07 & 1.36 & 1.98 & 1.59 & 2.83 & 2.17 & 2.03 & 2.97 & 1.69 \\
\hline Mediana & 12.63 & 12.48 & 15.01 & 17.78 & 22.63 & 27.81 & 30.93 & 30.75 & 28.42 & 24.40 & 16.61 & 13.15 \\
\hline Máximo & 13.98 & 15.15 & 16.67 & 18.56 & 23.88 & 30.03 & 32.89 & 34.85 & 32.12 & 27.59 & 20.60 & 16.69 \\
\hline Mínimo & 9.95 & 10.63 & 12.37 & 15.21 & 20.55 & 25.28 & 27.88 & 25.29 & 25.72 & 21.79 & 11.85 & 12.02 \\
\hline $\mathrm{N}^{0}$ Días & 195 & 180 & 166 & 180 & 198 & 186 & 207 & 198 & 160 & 207 & 198 & 195 \\
\hline
\end{tabular}




\section{Gráficas de la estación de Roquetes}

g) Evolución temporal de las medias diarias.

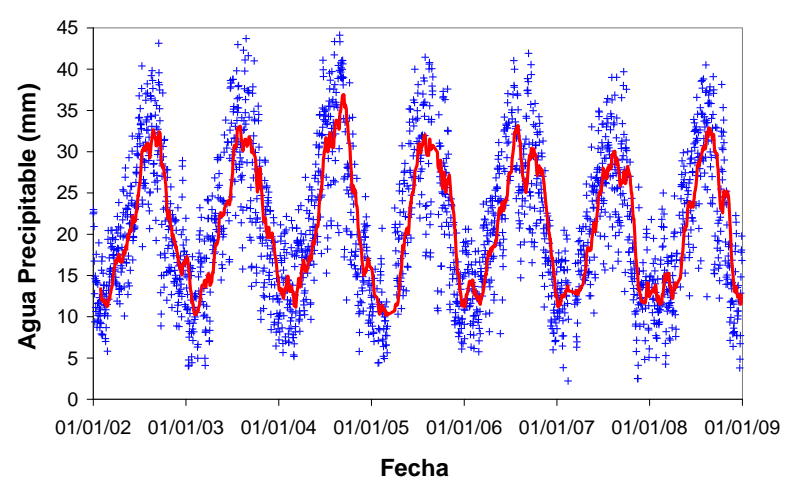

La línea roja representa la media móvil mensual. h) Histograma de las medias diarias.

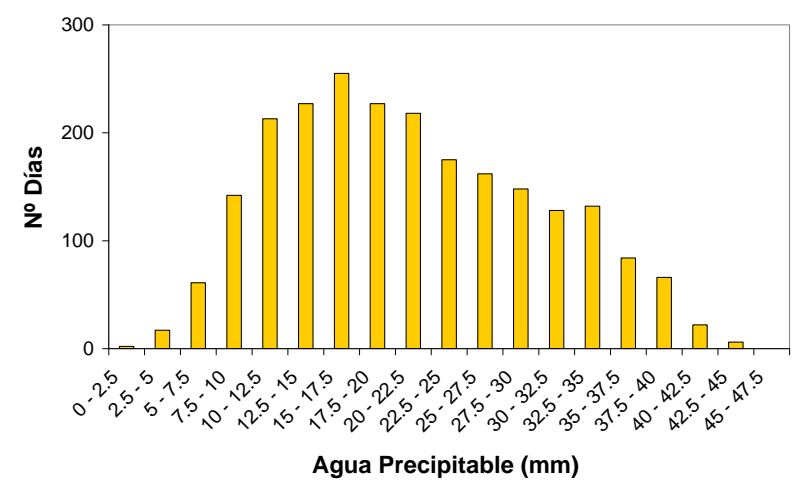

La distribución presenta un desplazamiento hacia la derecha (coef. de asimetría positivo), y un ligero achatamiento (curtosis negativa) respecto de la distribución normal.

j) Ciclo promedio anual.

para cada mes y año.
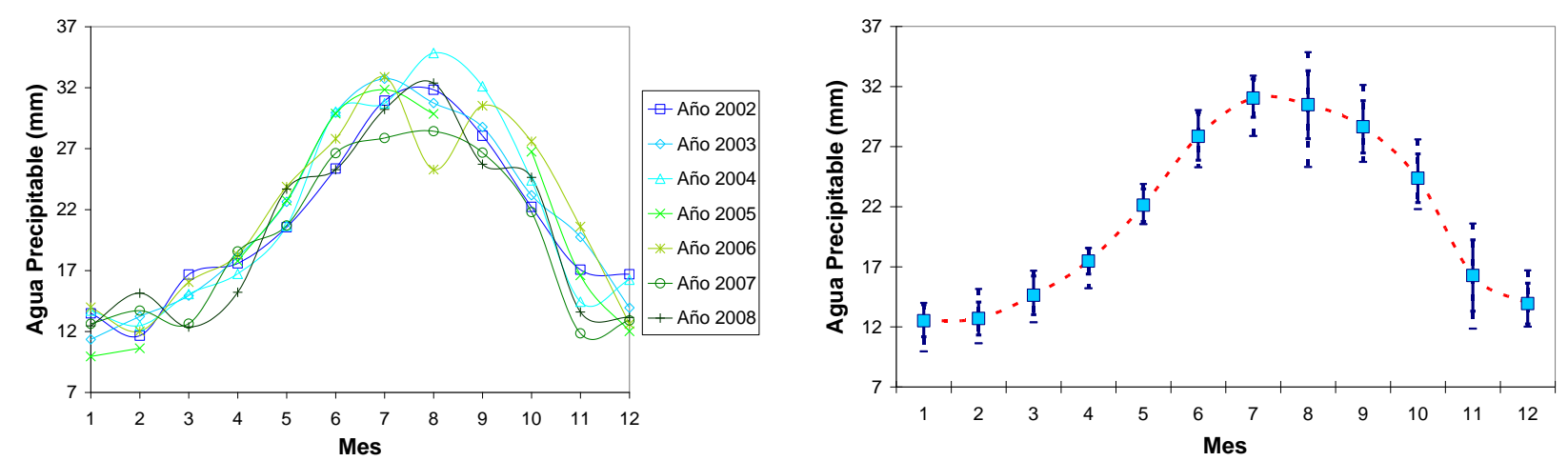

Valor promedio de las medias mensuales de cada año (cuadrados). Valor promedio más/menos la desviación típica de las medias mensuales (barras sólidas). Valor máximo y mínimo absoluto de las medias mensuales (líneas de trazos). 


\subsubsection{SAN FERNANDO (Observatorio de la Armada). Estación GPS.}

El análisis estadístico se ha realizado en base a los datos de ZTD generados por el centro de análisis IGN de EUREF.

a) Estadísticas globales del conjunto de las medidas del GPS de San Fernando:

\begin{tabular}{|c|c|c|c|c|c|c|c|c|c|c|}
\hline $\begin{array}{c}\mathrm{N}^{0} \\
\text { Medidas }\end{array}$ & Media & STD & Mediana & $\begin{array}{l}\text { Clase } \\
\text { Modal }\end{array}$ & \begin{tabular}{|c} 
Percentil \\
5 \\
\end{tabular} & \begin{tabular}{|c|} 
Percentil \\
95 \\
\end{tabular} & Máximo & Mínimo & $\begin{array}{c}\text { Coef. } \\
\text { Asimetría }\end{array}$ & Curtosis \\
\hline 57648 & 19.03 & 7.28 & 18.53 & $15-17.5$ & 8.08 & 32.146 & 48.89 & 0.52 & 0.41 & -0.05 \\
\hline
\end{tabular}

b) Estadísticas por mes del conjunto de las medidas del GPS de San Fernando:

\begin{tabular}{|c|c|c|c|c|c|c|c|c|c|c|c|c|}
\hline Estadístico | Mes & 1 & 2 & 3 & 4 & 5 & 6 & 7 & 8 & 9 & 10 & 11 & 12 \\
\hline Media & 13.10 & 14.71 & 15.10 & 16.34 & 18.84 & 22.69 & 21.04 & 23.57 & 25.50 & 24.18 & 17.37 & 15.50 \\
\hline STD & 5.52 & 5.28 & 5.70 & 5.46 & 5.62 & 5.81 & 5.66 & 6.12 & 6.53 & 7.64 & 6.90 & 5.76 \\
\hline Mediana & 12.15 & 14.55 & 14.88 & 16.03 & 18.57 & 22.17 & 20.53 & 23.14 & 25.15 & 23.56 & 16.60 & 14.87 \\
\hline Máximo & 35.41 & 31.47 & 35.46 & 36.93 & 38.94 & 43.56 & 42.22 & 45.45 & 48.89 & 48.78 & 41.51 & 36.15 \\
\hline Mínimo & 0.58 & 1.82 & 0.52 & 2.87 & 4.82 & 7.19 & 7.27 & 6.70 & 7.65 & 5.37 & 2.49 & 3.08 \\
\hline Percentil 5 & 5.39 & 6.42 & 6.01 & 7.35 & 9.98 & 13.91 & 12.91 & 14.17 & 15.12 & 12.68 & 7.44 & 7.33 \\
\hline Percentil 95 & 23.81 & 23.85 & 24.42 & 25.63 & 28.56 & 32.93 & 31.65 & 34.28 & 36.17 & 37.74 & 30.62 & 25.77 \\
\hline Coef. Asimetría & 0.70 & 0.22 & 0.23 & 0.33 & 0.24 & 0.26 & 0.58 & 0.33 & 0.22 & 0.27 & 0.63 & 0.58 \\
\hline Curtosis & 0.33 & -0.24 & -0.18 & 0.28 & -0.39 & -0.33 & 0.30 & 0.23 & -0.10 & -0.45 & 0.21 & 0.10 \\
\hline $\mathrm{N}^{0}$ Medidas & 5073 & 4232 & 4717 & 4785 & 4883 & 4785 & 5093 & 4760 & 4790 & 4989 & 4446 & 5095 \\
\hline
\end{tabular}

c) Estadísticas globales de las medias diarias del GPS de San Fernando:

\begin{tabular}{|c|c|c|c|c|c|c|c|c|c|c|}
\hline $\mathrm{N}^{0}$ Días & Media & STD & Mediana & Moda & \begin{tabular}{|c|} 
Percentil \\
5 \\
\end{tabular} & \begin{tabular}{|c|} 
Percentil \\
95 \\
\end{tabular} & Máximo & Mínimo & \begin{tabular}{|c} 
Coef. \\
Asimetría
\end{tabular} & Curtosis \\
\hline 2434 & 19.03 & 6.75 & 19.03 & $17.5-20$ & 8.61 & 30.73 & 43.37 & 2.69 & 0.34 & -0.14 \\
\hline
\end{tabular}

d) Resumen por mes de las medias diarias del GPS de San Fernando:

\begin{tabular}{|c|c|c|c|c|c|c|c|c|c|c|c|c|}
\hline Estadístico \Mes & 1 & 2 & 3 & 4 & 5 & 6 & 7 & 8 & 9 & 10 & 11 & 12 \\
\hline Media & 13.11 & 14.71 & 15.12 & 16.34 & 18.83 & 22.74 & 21.07 & 23.61 & 25.52 & 24.17 & 17.32 & 15.49 \\
\hline STD & 4.94 & 4.76 & 4.93 & 4.90 & 5.06 & 5.19 & 5.00 & 5.13 & 5.86 & 6.91 & 6.29 & 5.14 \\
\hline Mediana & 12.43 & 14.64 & 15.19 & 16.11 & 18.42 & 22.20 & 20.40 & 23.36 & 25.52 & 23.72 & 16.40 & 15.25 \\
\hline Máximo & 25.48 & 28.48 & 28.69 & 31.30 & 33.83 & 37.26 & 38.48 & 38.78 & 43.37 & 41.62 & 38.54 & 32.33 \\
\hline Mínimo & 3.61 & 3.62 & 2.69 & 4.87 & 7.81 & 9.25 & 10.85 & 9.15 & 12.00 & 9.55 & 5.39 & 6.50 \\
\hline Percentil 5 & 6.16 & 7.45 & 7.38 & 8.36 & 11.28 & 14.58 & 13.71 & 15.48 & 15.94 & 13.90 & 7.73 & 8.02 \\
\hline Percentil 95 & 22.49 & 22.71 & 22.69 & 24.32 & 27.48 & 30.97 & 30.41 & 33.02 & 34.75 & 36.78 & 29.15 & 24.18 \\
\hline Coef. Asimetría & 0.53 & 0.11 & -0.08 & 0.22 & 0.23 & 0.22 & 0.65 & 0.16 & 0.15 & 0.20 & 0.57 & 0.45 \\
\hline Curtosis & -0.32 & -0.18 & -0.56 & 0.17 & -0.32 & -0.45 & 0.60 & 0.04 & -0.30 & -0.50 & 0.24 & -0.12 \\
\hline No Días & 214 & 178 & 203 & 201 & 205 & 203 & 213 & 202 & 203 & 209 & 188 & 215 \\
\hline
\end{tabular}

e1) Media de las medias diarias por mes y año del GPS de San Fernando:

\begin{tabular}{|c|c|c|c|c|c|c|c|c|c|c|c|c|c|}
\hline Año \Mes & \multicolumn{1}{|c|}{} & $\mathbf{2}$ & $\mathbf{3}$ & $\mathbf{4}$ & $\mathbf{5}$ & $\mathbf{6}$ & $\mathbf{7}$ & $\mathbf{8}$ & $\mathbf{9}$ & $\mathbf{1 0}$ & $\mathbf{1 1}$ & $\mathbf{1 2}$ & Media \\
\hline $\mathbf{2 0 0 2}$ & 14.52 & --- & 15.69 & 15.30 & 16.04 & 21.88 & 19.86 & 22.91 & 28.16 & 23.52 & 20.09 & 18.01 & $\mathbf{1 9 . 6 3}$ \\
$\mathbf{2 0 0 3}$ & 12.27 & 15.04 & 17.41 & 17.56 & 18.23 & 24.48 & 21.14 & 25.46 & 23.67 & 26.31 & -- & 16.26 & $\mathbf{1 9 . 8 0}$ \\
$\mathbf{2 0 0 4}$ & 16.03 & 15.22 & 15.24 & 14.72 & 20.71 & 23.81 & 22.99 & 27.02 & 24.28 & 24.03 & 16.54 & 14.83 & $\mathbf{1 9 . 6 2}$ \\
$\mathbf{2 0 0 5}$ & 9.32 & 10.72 & 17.37 & 15.10 & 19.31 & 23.08 & 22.58 & 22.87 & 22.44 & 23.77 & 16.40 & 18.00 & $\mathbf{1 8 . 4 2}$ \\
$\mathbf{2 0 0 6}$ & 14.47 & 15.00 & 15.37 & 18.33 & 21.33 & 25.30 & 21.58 & 23.32 & 26.70 & 26.74 & 20.79 & 13.54 & $\mathbf{2 0 . 2 0}$ \\
$\mathbf{2 0 0 7}$ & 10.81 & 16.65 & 11.67 & 18.11 & 17.28 & 21.48 & 18.99 & 22.42 & 25.49 & 20.64 & 15.37 & 13.34 & $\mathbf{1 7 . 6 9}$ \\
$\mathbf{2 0 0 8}$ & 14.09 & 16.17 & 13.21 & 14.84 & 19.15 & 18.76 & 20.22 & 20.89 & 27.93 & 23.92 & 13.90 & 14.33 & $\mathbf{1 8 . 1 3}$ \\
\hline Media & $\mathbf{1 3 . 0 7}$ & $\mathbf{1 4 . 8 0}$ & $\mathbf{1 5 . 1 4}$ & $\mathbf{1 6 . 2 8}$ & $\mathbf{1 8 . 8 7}$ & $\mathbf{2 2 . 6 8}$ & $\mathbf{2 1 . 0 5}$ & $\mathbf{2 3 . 5 6}$ & $\mathbf{2 5 . 5 2}$ & $\mathbf{2 4 . 1 3}$ & $\mathbf{1 7 . 1 8}$ & $\mathbf{1 5 . 4 7}$ & $\mathbf{1 9 . 0 7}$ \\
\hline
\end{tabular}


e2) Máximo de las medias diarias por mes y año del GPS de San Fernando:

\begin{tabular}{|c|c|c|c|c|c|c|c|c|c|c|c|c|c|}
\hline Año \Mes & $\mathbf{1}$ & $\mathbf{2}$ & $\mathbf{3}$ & $\mathbf{4}$ & $\mathbf{5}$ & $\mathbf{6}$ & $\mathbf{7}$ & $\mathbf{8}$ & $\mathbf{9}$ & $\mathbf{1 0}$ & $\mathbf{1 1}$ & $\mathbf{1 2}$ & Media \\
\hline $\mathbf{2 0 0 2}$ & 25.27 & --- & 23.27 & 22.23 & 27.13 & 30.33 & 26.41 & 28.49 & 38.45 & 40.81 & 32.62 & 32.33 & $\mathbf{2 9 . 7 6}$ \\
$\mathbf{2 0 0 3}$ & 24.44 & 21.65 & 28.69 & 24.32 & 29.49 & 30.02 & 30.67 & 36.46 & 43.37 & 37.35 & -- & 25.35 & $\mathbf{3 0 . 1 6}$ \\
$\mathbf{2 0 0 4}$ & 25.48 & 24.87 & 22.40 & 22.98 & 27.44 & 32.95 & 38.48 & 38.78 & 33.51 & 41.62 & 29.17 & 22.34 & $\mathbf{3 0 . 0 0}$ \\
$\mathbf{2 0 0 5}$ & 12.65 & 22.71 & 24.20 & 21.25 & 33.83 & 30.81 & 37.46 & 33.65 & 30.66 & 37.38 & 23.84 & 27.83 & $\mathbf{2 8 . 0 2}$ \\
$\mathbf{2 0 0 6}$ & 23.97 & 20.72 & 23.56 & 29.39 & 29.57 & 34.99 & 34.09 & 33.23 & 35.86 & 38.23 & 38.54 & 24.86 & $\mathbf{3 0 . 5 8}$ \\
$\mathbf{2 0 0 7}$ & 18.70 & 28.48 & 19.83 & 27.54 & 25.62 & 37.26 & 25.43 & 35.48 & 34.77 & 29.27 & 32.56 & 23.41 & $\mathbf{2 8 . 2 0}$ \\
$\mathbf{2 0 0 8}$ & 22.25 & 26.48 & 21.76 & 31.30 & 25.56 & 24.02 & 31.24 & 27.88 & 40.30 & 32.58 & 19.30 & 23.05 & $\mathbf{2 7 . 1 4}$ \\
\hline Media & $\mathbf{2 1 . 8 2}$ & $\mathbf{2 4 . 1 5}$ & $\mathbf{2 3 . 3 9}$ & $\mathbf{2 5 . 5 7}$ & $\mathbf{2 8 . 3 8}$ & $\mathbf{3 1 . 4 8}$ & $\mathbf{3 1 . 9 7}$ & $\mathbf{3 3 . 4 2}$ & $\mathbf{3 6 . 7 0}$ & $\mathbf{3 6 . 7 5}$ & $\mathbf{2 9 . 3 4}$ & $\mathbf{2 5 . 6 0}$ & $\mathbf{2 9 . 1 2}$ \\
\hline
\end{tabular}

e3) Mínimo de las medias diarias por mes y año del GPS de San Fernando:

\begin{tabular}{|c|c|c|c|c|c|c|c|c|c|c|c|c|c|}
\hline Año \Mes & 1 & 2 & 3 & 4 & 5 & 6 & 7 & 8 & 9 & 10 & 11 & 12 & Media \\
\hline 2002 & 6.15 & --- & 8.92 & 8.36 & 7.81 & 15.22 & 13.57 & 15.18 & 15.51 & 10.19 & 6.87 & 6.50 & 10.39 \\
\hline 2003 & 4.05 & 6.24 & 9.24 & 6.01 & 10.81 & 14.32 & 14.01 & 18.54 & 13.74 & 9.55 & --- & 8.72 & 10.48 \\
\hline 2004 & 4.97 & 8.62 & 4.89 & 6.67 & 13.20 & 16.37 & 10.85 & 19.51 & 17.65 & 13.97 & 5.39 & 6.60 & 10.72 \\
\hline 2005 & 3.61 & 3.62 & 5.79 & 6.24 & 8.86 & 15.91 & 12.37 & 14.69 & 14.01 & 13.95 & 7.79 & 9.64 & 9.71 \\
\hline 2006 & 9.17 & 8.65 & 8.14 & 12.85 & 9.15 & 9.25 & 12.81 & 16.34 & 14.92 & 16.28 & 5.53 & 6.58 & 10.81 \\
\hline 2007 & 4.62 & 9.86 & 5.25 & 11.93 & 10.12 & 12.86 & 12.88 & 14.19 & 15.99 & 10.12 & 7.69 & 6.75 & 10.19 \\
\hline 2008 & 6.17 & 8.47 & 2.69 & 4.87 & 9.57 & 12.89 & 11.82 & 9.15 & 12.00 & 9.93 & 6.77 & 7.17 & 8.46 \\
\hline Media & 5.53 & 7.58 & 6.42 & 8.13 & 9.93 & 13.83 & 12.62 & 15.37 & 14.83 & 12.00 & 6.67 & 7.42 & 10.11 \\
\hline
\end{tabular}

e4) Desviación estándar de las medias diarias de cada mes y año del GPS de San Fernando:

\begin{tabular}{|c|l|l|l|l|l|l|l|l|l|l|l|l|c|}
\hline Año \Mes & $\mathbf{1}$ & $\mathbf{2}$ & $\mathbf{3}$ & $\mathbf{4}$ & $\mathbf{5}$ & $\mathbf{6}$ & $\mathbf{7}$ & $\mathbf{8}$ & $\mathbf{9}$ & $\mathbf{1 0}$ & $\mathbf{1 1}$ & $\mathbf{1 2}$ & Media \\
\hline $\mathbf{2 0 0 2}$ & 4.93 & --- & 3.76 & 3.15 & 4.27 & 3.38 & 3.36 & 3.20 & 6.01 & 7.88 & 5.92 & 6.03 & $\mathbf{4 . 7 2}$ \\
$\mathbf{2 0 0 3}$ & 6.04 & 4.17 & 5.02 & 5.13 & 4.24 & 4.30 & 4.23 & 3.89 & 6.04 & 6.41 & -- & 4.43 & $\mathbf{4 . 9 0}$ \\
$\mathbf{2 0 0 4}$ & 5.62 & 4.52 & 4.31 & 4.47 & 4.00 & 4.71 & 6.60 & 4.91 & 3.80 & 6.81 & 6.40 & 4.01 & $\mathbf{5 . 0 1}$ \\
$\mathbf{2 0 0 5}$ & 2.33 & 4.63 & 4.99 & 3.98 & 5.95 & 4.21 & 5.30 & 5.63 & 4.62 & 7.17 & 4.57 & 4.82 & $\mathbf{4 . 8 5}$ \\
$\mathbf{2 0 0 6}$ & 3.59 & 3.32 & 4.55 & 3.99 & 5.77 & 6.55 & 4.90 & 4.27 & 4.73 & 6.51 & 8.47 & 4.27 & $\mathbf{5 . 0 8}$ \\
$\mathbf{2 0 0 7}$ & 3.38 & 4.22 & 4.17 & 4.32 & 4.33 & 6.00 & 3.66 & 5.79 & 5.11 & 5.61 & 4.91 & 4.68 & $\mathbf{4 . 6 8}$ \\
$\mathbf{2 0 0 8}$ & 3.89 & 4.65 & 4.55 & 6.85 & 4.08 & 3.21 & 4.76 & 4.44 & 7.42 & 6.08 & 3.71 & 5.13 & $\mathbf{4 . 9 0}$ \\
\hline Media & $\mathbf{4 . 2 5}$ & $\mathbf{4 . 2 5}$ & $\mathbf{4 . 4 8}$ & $\mathbf{4 . 5 6}$ & $\mathbf{4 . 6 6}$ & $\mathbf{4 . 6 2}$ & $\mathbf{4 . 6 9}$ & $\mathbf{4 . 5 9}$ & $\mathbf{5 . 3 9}$ & $\mathbf{6 . 6 4}$ & $\mathbf{5 . 6 6}$ & $\mathbf{4 . 7 7}$ & $\mathbf{4 . 8 8}$ \\
\hline
\end{tabular}

e5) Número de días con dato válido por mes y año del GPS de San Fernando:

\begin{tabular}{|c|c|c|c|c|c|c|c|c|c|c|c|c|c|}
\hline Año \Mes & 1 & 2 & 3 & 4 & 5 & 6 & 7 & 8 & 9 & 10 & 11 & 12 & Tota \\
\hline 2002 & 31 & 10 & 23 & 27 & 31 & 30 & 28 & 20 & 29 & 27 & 30 & 31 & 317 \\
\hline 2003 & 30 & 27 & 30 & 30 & 31 & 28 & 31 & 31 & 28 & 30 & 10 & 31 & 337 \\
\hline 2004 & 31 & 29 & 30 & 29 & 31 & 29 & 31 & 31 & 29 & 31 & 29 & 31 & 361 \\
\hline 2005 & 29 & 27 & 30 & 29 & 31 & 30 & 31 & 31 & 30 & 30 & 30 & 31 & 359 \\
\hline 2006 & 31 & 28 & 31 & 30 & 29 & 30 & 30 & 28 & 30 & 31 & 30 & 31 & 359 \\
\hline 2007 & 31 & 28 & 31 & 30 & 31 & 30 & 31 & 31 & 28 & 29 & 29 & 30 & 359 \\
\hline 2008 & 31 & 29 & 28 & 26 & 21 & 26 & 31 & 30 & 29 & 31 & 30 & 30 & 348 \\
\hline Total & 214 & 168 & 203 & 201 & 205 & 203 & 213 & 202 & 203 & 209 & 178 & 215 & 2414 \\
\hline
\end{tabular}

f) Resumen por mes de las medias mensuales de cada año del GPS de San Fernando:

\begin{tabular}{|c|c|c|c|c|c|c|c|c|c|c|c|c|}
\hline Mes & 1 & 2 & 3 & 4 & 5 & 6 & 7 & 8 & 9 & 10 & 11 & 12 \\
\hline Media & 13.07 & 14.80 & 15.14 & 16.28 & 18.87 & 22.68 & 21.05 & 23.56 & 25.52 & 24.13 & 17.18 & 15.47 \\
\hline STD & 2.19 & 1.92 & 1.94 & 1.51 & 1.72 & 2.03 & 1.35 & 1.89 & 2.02 & 1.86 & 2.47 & 1.83 \\
\hline Mediana & 14.09 & 15.13 & 15.37 & 15.30 & 19.15 & 23.08 & 21.14 & 22.91 & 25.49 & 23.92 & 16.47 & 14.83 \\
\hline Máximo & 16.03 & 16.65 & 17.41 & 18.33 & 21.33 & 25.30 & 22.99 & 27.02 & 28.16 & 26.74 & 20.79 & 18.01 \\
\hline Mínimo & 9.32 & 10.72 & 11.67 & 14.72 & 16.04 & 18.76 & 18.99 & 20.89 & 22.44 & 20.64 & 13.90 & 13.34 \\
\hline $\mathrm{N}^{0}$ Días & 214 & 168 & 203 & 201 & 205 & 203 & 213 & 202 & 203 & 209 & 178 & 215 \\
\hline
\end{tabular}




\section{Gráficas de la estación de San Fernando}

g) Evolución temporal de las medias diarias.

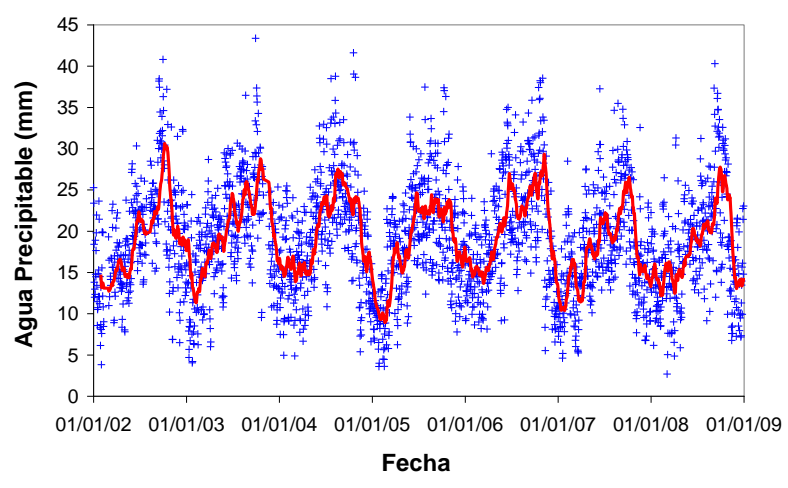

La línea roja representa la media móvil mensual.

i) Valores medios mensuales de las medias diarias para cada mes y año.
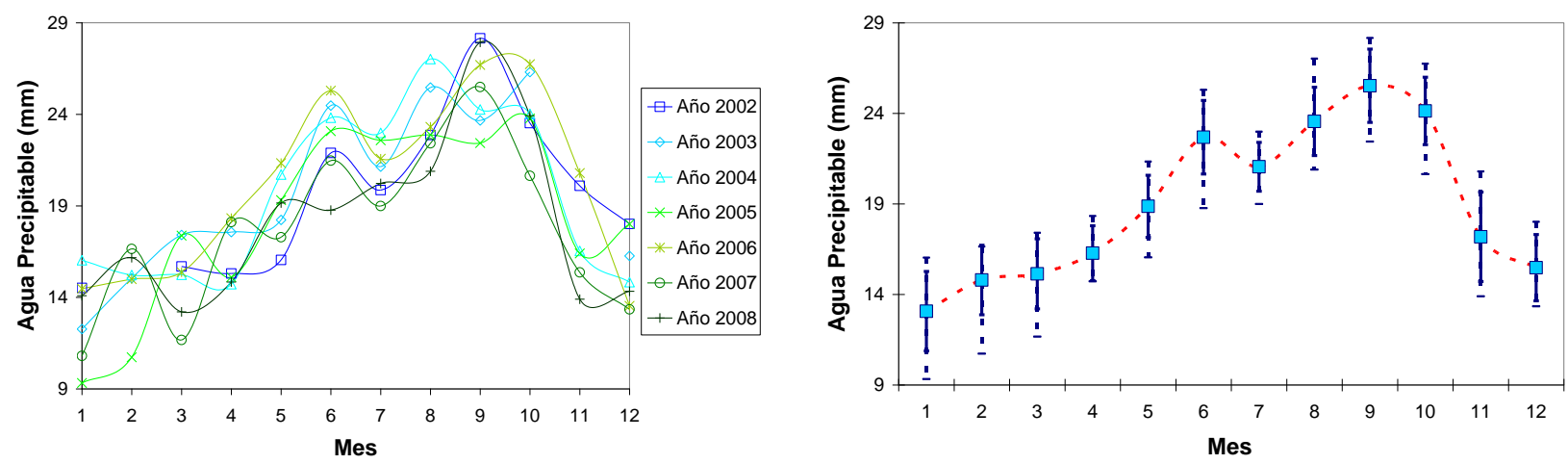

Valor promedio de las medias mensuales de cada año (cuadrados). Valor promedio más/menos la desviación típica de las medias mensuales (barras sólidas). Valor máximo y mínimo absoluto de las medias mensuales (líneas de trazos). 


\subsubsection{VALENCIA (Universidad Politécnica). Estación GPS.}

El análisis estadístico se ha realizado en base a los datos de ZTD generados por el centro de análisis IGN de EUREF.

a) Estadísticas globales del conjunto de las medidas del GPS de Valencia:

\begin{tabular}{|c|c|c|c|c|c|c|c|c|c|c|}
\hline $\begin{array}{c}\mathbf{N}^{0} \\
\text { Medidas }\end{array}$ & Media & STD & Mediana & $\begin{array}{c}\text { Clase } \\
\text { Modal }\end{array}$ & $\begin{array}{c}\text { Percentil } \\
\mathbf{5}\end{array}$ & $\begin{array}{c}\text { Percentil } \\
\mathbf{9 5}\end{array}$ & Máximo & Mínimo & $\begin{array}{c}\text { Coef. } \\
\text { Asimetría }\end{array}$ & Curtosis \\
\hline 50078 & 20.82 & 9.27 & 19.59 & $15-17.5$ & 7.60 & 37.38 & 51.99 & 0.45 & 0.39 & -0.61 \\
\hline
\end{tabular}

b) Estadísticas por mes del conjunto de las medidas del GPS de Valencia:

\begin{tabular}{|c|c|c|c|c|c|c|c|c|c|c|c|c|}
\hline Estadístico \Mes & 1 & 2 & 3 & 4 & 5 & 6 & 7 & 8 & 9 & 10 & 11 & 12 \\
\hline Media & 12.61 & 13.39 & 14.72 & 18.03 & 21.90 & 27.14 & 30.81 & 31.97 & 29.92 & 25.30 & 16.51 & 14.25 \\
\hline STD & 5.04 & 4.86 & 5.20 & 4.68 & 5.83 & 5.65 & 5.72 & 6.72 & 7.94 & 6.91 & 5.77 & 5.44 \\
\hline Mediana & 12.05 & 12.84 & 14.91 & 18.14 & 22.41 & 27.51 & 30.73 & 32.50 & 30.18 & 25.66 & 16.32 & 13.75 \\
\hline Máximo & 28.24 & 27.88 & 28.75 & 32.43 & 41.38 & 43.41 & 51.53 & 50.06 & 51.99 & 42.97 & 33.33 & 33.49 \\
\hline Mínimo & 0.45 & 0.60 & 2.18 & 4.19 & 7.28 & 10.28 & 11.65 & 7.18 & 8.63 & 6.54 & 0.90 & 2.10 \\
\hline Percentil 5 & 5.08 & 6.01 & 6.07 & 10.33 & 11.70 & 16.69 & 21.81 & 20.02 & 16.02 & 13.72 & 7.72 & 6.51 \\
\hline Percentil 95 & 21.51 & 22.00 & 22.88 & 25.75 & 30.73 & 35.87 & 40.59 & 41.94 & 42.18 & 36.12 & 26.92 & 23.43 \\
\hline Coef. Asimetría & 0.42 & 0.29 & -0.06 & 0.00 & -0.14 & -0.17 & 0.06 & -0.46 & -0.15 & -0.14 & 0.13 & 0.44 \\
\hline Curtosis & -0.33 & -0.35 & -0.64 & -0.23 & -0.49 & -0.30 & 0.13 & 0.12 & -0.53 & -0.61 & -0.28 & -0.16 \\
\hline $\mathrm{N}^{0}$ Medidas & 5125 & 4503 & 4331 & 4185 & 3354 & 2471 & 4081 & 4430 & 4207 & 4011 & 4302 & 5078 \\
\hline
\end{tabular}

c) Estadísticas globales de las medias diarias del GPS de Valencia:

\begin{tabular}{|c|c|c|c|c|c|c|c|c|c|c|}
\hline N$^{\circ}$ Días & Media & STD & Mediana & Moda & $\begin{array}{c}\text { Percentil } \\
\mathbf{5}\end{array}$ & $\begin{array}{c}\text { Percentil } \\
\mathbf{9 5}\end{array}$ & Máximo & Mínimo & $\begin{array}{c}\text { Coef. } \\
\text { Asimetría }\end{array}$ & Curtosis \\
\hline 2113 & 20.82 & 8.87 & 19.48 & $15-17.5$ & 8.20 & 36.46 & 45.72 & 2.39 & 0.38 & -0.69 \\
\hline
\end{tabular}

d) Resumen por mes de las medias diarias del GPS de Valencia:

\begin{tabular}{|c|c|c|c|c|c|c|c|c|c|c|c|c|}
\hline Estadístico \Mes & 1 & 2 & 3 & 4 & 5 & 6 & 7 & 8 & 9 & 10 & 11 & 12 \\
\hline Media & 12.60 & 13.34 & 14.72 & 18.01 & 21.95 & 27.17 & 30.80 & 31.94 & 29.88 & 25.32 & 16.48 & 14.32 \\
\hline STD & 4.42 & 4.33 & 4.72 & 4.04 & 5.29 & 5.08 & 4.83 & 5.92 & 7.39 & 6.15 & 5.17 & 4.89 \\
\hline Mediana & 12.33 & 12.93 & 14.79 & 18.14 & 22.32 & 27.60 & 30.74 & 32.64 & 30.40 & 25.42 & 16.25 & 13.52 \\
\hline Máximo & 26.23 & 24.17 & 25.61 & 26.53 & 36.10 & 38.86 & 44.37 & 42.92 & 45.72 & 38.22 & 28.65 & 31.05 \\
\hline Mínimo & 3.83 & 2.39 & 3.35 & 7.59 & 10.62 & 15.22 & 17.31 & 12.40 & 12.32 & 10.85 & 2.46 & 3.92 \\
\hline Percentil 5 & 5.62 & 7.18 & 6.19 & 10.86 & 12.84 & 18.14 & 23.47 & 21.81 & 17.54 & 15.06 & 8.50 & 7.51 \\
\hline Percentil 95 & 20.68 & 21.34 & 22.11 & 24.73 & 29.50 & 34.09 & 39.05 & 40.85 & 41.53 & 35.10 & 25.17 & 22.03 \\
\hline Coef. Asimetría & 0.37 & 0.34 & -0.12 & -0.22 & -0.20 & -0.21 & 0.13 & -0.57 & -0.13 & -0.19 & 0.03 & 0.43 \\
\hline Curtosis & -0.15 & -0.36 & -0.55 & -0.31 & -0.63 & -0.44 & 0.28 & 0.18 & -0.65 & -0.61 & -0.12 & 0.01 \\
\hline $\mathrm{N}^{0}$ Días & 216 & 191 & 182 & 176 & 146 & 105 & 171 & 186 & 178 & 168 & 181 & 213 \\
\hline
\end{tabular}

e1) Media de las medias diarias por mes y año del GPS de Valencia:

\begin{tabular}{|c|c|c|c|c|c|c|c|c|c|c|c|c|c|}
\hline Año \Mes & $\mathbf{1}$ & $\mathbf{2}$ & $\mathbf{3}$ & $\mathbf{4}$ & $\mathbf{5}$ & $\mathbf{6}$ & $\mathbf{7}$ & $\mathbf{8}$ & $\mathbf{9}$ & $\mathbf{1 0}$ & $\mathbf{1 1}$ & $\mathbf{1 2}$ & Media \\
\hline $\mathbf{2 0 0 2}$ & 14.05 & 11.09 & 16.82 & 18.54 & 19.80 & --- & 29.30 & 33.78 & --- & --- & 17.32 & 17.21 & $\mathbf{1 9 . 7 7}$ \\
$\mathbf{2 0 0 3}$ & 11.40 & 14.05 & 15.39 & 18.17 & -- & 31.00 & 32.12 & 30.09 & 31.27 & 25.89 & 20.71 & 14.96 & $\mathbf{2 2 . 2 8}$ \\
$\mathbf{2 0 0 4}$ & 13.50 & 13.64 & 16.46 & 16.94 & 22.98 & 27.49 & 33.28 & 33.66 & 32.99 & 24.54 & 17.19 & 16.73 & $\mathbf{2 2 . 4 5}$ \\
$\mathbf{2 0 0 5}$ & 10.48 & 11.84 & --- & --- & --- & --- & -- & 32.14 & 27.28 & 26.78 & 16.40 & 13.84 & $\mathbf{1 9 . 8 3}$ \\
$\mathbf{2 0 0 6}$ & 14.27 & 13.38 & 15.51 & 20.02 & 24.75 & 28.11 & 31.19 & 30.41 & 30.66 & -- & -- & 13.51 & $\mathbf{2 2 . 1 7}$ \\
$\mathbf{2 0 0 7}$ & 11.91 & 14.27 & 11.89 & 18.85 & 19.10 & 26.09 & 28.26 & --- & 28.96 & 23.12 & 12.63 & 12.13 & $\mathbf{1 8 . 8 4}$ \\
$\mathbf{2 0 0 8}$ & 12.53 & 14.75 & 12.48 & 15.44 & 22.96 & 25.01 & 30.01 & 31.65 & 27.96 & 25.46 & 13.89 & 12.23 & $\mathbf{2 0 . 3 6}$ \\
\hline Media & $\mathbf{1 2 . 5 9}$ & $\mathbf{1 3 . 2 9}$ & $\mathbf{1 4 . 7 6}$ & $\mathbf{1 7 . 9 9}$ & $\mathbf{2 1 . 9 2}$ & $\mathbf{2 7 . 5 4}$ & $\mathbf{3 0 . 7 0}$ & $\mathbf{3 1 . 9 5}$ & $\mathbf{2 9 . 8 5}$ & $\mathbf{2 5 . 1 6}$ & $\mathbf{1 6 . 3 6}$ & $\mathbf{1 4 . 3 7}$ & $\mathbf{2 0 . 8 1}$ \\
\hline
\end{tabular}


e2) Máximo de las medias diarias por mes y año del GPS de Valencia:

\begin{tabular}{|c|c|c|c|c|c|c|c|c|c|c|c|c|c|}
\hline Año \Mes & $\mathbf{1}$ & $\mathbf{2}$ & $\mathbf{3}$ & $\mathbf{4}$ & $\mathbf{5}$ & $\mathbf{6}$ & $\mathbf{7}$ & $\mathbf{8}$ & $\mathbf{9}$ & $\mathbf{1 0}$ & $\mathbf{1 1}$ & $\mathbf{1 2}$ & Media \\
\hline $\mathbf{2 0 0 2}$ & 26.23 & 17.36 & 20.94 & 26.53 & 29.09 & --- & 40.01 & 41.31 & --- & -- & 23.03 & 31.05 & $\mathbf{2 8 . 3 9}$ \\
$\mathbf{2 0 0 3}$ & 23.76 & 24.05 & 25.61 & 25.88 & --- & 38.86 & 43.59 & 42.92 & 45.72 & 35.21 & 28.31 & 21.59 & $\mathbf{3 2 . 3 2}$ \\
$\mathbf{2 0 0 4}$ & 22.05 & 24.17 & 23.07 & 24.37 & 31.26 & 27.74 & 39.03 & 42.43 & 45.01 & 38.22 & 28.65 & 24.49 & $\mathbf{3 0 . 8 7}$ \\
$\mathbf{2 0 0 5}$ & 18.51 & 18.09 & --- & --- & --- & --- & --- & 42.78 & 37.48 & 37.03 & 24.43 & 21.66 & $\mathbf{2 8 . 5 7}$ \\
$\mathbf{2 0 0 6}$ & 21.09 & 19.17 & 24.22 & 25.81 & 36.10 & 35.49 & 40.16 & 40.95 & 40.94 & -- & -- & 22.61 & $\mathbf{3 0 . 6 5}$ \\
$\mathbf{2 0 0 7}$ & 21.08 & 22.45 & 20.29 & 24.89 & 30.38 & 38.33 & 34.29 & -- & 39.32 & 34.16 & 24.05 & 20.98 & $\mathbf{2 8 . 2 0}$ \\
$\mathbf{2 0 0 8}$ & 20.01 & 22.99 & 19.43 & 24.92 & 30.82 & 32.52 & 35.19 & 38.09 & 39.04 & 37.13 & 23.88 & 23.08 & $\mathbf{2 8 . 9 3}$ \\
\hline Media & $\mathbf{2 1 . 8 2}$ & $\mathbf{2 1 . 1 8}$ & $\mathbf{2 2 . 2 6}$ & $\mathbf{2 5 . 4 0}$ & $\mathbf{3 1 . 5 3}$ & $\mathbf{3 4 . 5 9}$ & $\mathbf{3 8 . 7 1}$ & $\mathbf{4 1 . 4 1}$ & $\mathbf{4 1 . 2 5}$ & $\mathbf{3 6 . 3 5}$ & $\mathbf{2 5 . 3 9}$ & $\mathbf{2 3 . 6 4}$ & $\mathbf{2 9 . 7 1}$ \\
\hline
\end{tabular}

e3) Mínimo de las medias diarias por mes y año del GPS de Valencia:

\begin{tabular}{|c|l|l|l|c|c|c|c|c|c|c|c|c|c|}
\hline Año \Mes & $\mathbf{1}$ & $\mathbf{2}$ & $\mathbf{3}$ & $\mathbf{4}$ & $\mathbf{5}$ & $\mathbf{6}$ & $\mathbf{7}$ & $\mathbf{8}$ & $\mathbf{9}$ & $\mathbf{1 0}$ & $\mathbf{1 1}$ & $\mathbf{1 2}$ & Media \\
\hline $\mathbf{2 0 0 2}$ & 6.51 & 4.61 & 12.75 & 12.45 & 10.62 & --- & 17.31 & 21.57 & -- & -- & 9.74 & 8.63 & 11.58 \\
$\mathbf{2 0 0 3}$ & 3.94 & 5.70 & 5.62 & 7.59 & -- & 22.40 & 18.73 & 15.46 & 14.11 & 10.85 & 12.26 & 7.41 & $\mathbf{1 1 . 2 8}$ \\
$\mathbf{2 0 0 4}$ & 5.33 & 5.85 & 5.39 & 10.63 & 11.78 & 27.24 & 26.71 & 23.15 & 17.48 & 15.00 & 9.08 & 7.15 & $\mathbf{1 3 . 7 3}$ \\
$\mathbf{2 0 0 5}$ & 3.83 & 6.32 & --- & --- & --- & --- & --- & 16.52 & 13.97 & 15.35 & 8.50 & 7.76 & $\mathbf{1 0 . 3 2}$ \\
$\mathbf{2 0 0 6}$ & 6.58 & 6.88 & 7.89 & 14.23 & 11.63 & 15.22 & 21.53 & 20.49 & 17.71 & -- & -- & 8.05 & $\mathbf{1 3 . 0 2}$ \\
$\mathbf{2 0 0 7}$ & 5.71 & 2.39 & 5.37 & 12.10 & 12.59 & 16.35 & 21.05 & -- & 12.32 & 12.54 & 2.46 & 5.06 & $\mathbf{9 . 8 1}$ \\
$\mathbf{2 0 0 8}$ & 5.33 & 7.62 & 3.35 & 8.47 & 13.89 & 17.46 & 19.49 & 12.40 & 13.60 & 11.96 & 6.92 & 3.92 & $\mathbf{1 0 . 3 7}$ \\
\hline Media & $\mathbf{5 . 3 2}$ & $\mathbf{5 . 6 2}$ & $\mathbf{6 . 7 3}$ & $\mathbf{1 0 . 9 1}$ & $\mathbf{1 2 . 1 0}$ & $\mathbf{1 9 . 7 3}$ & $\mathbf{2 0 . 8 0}$ & $\mathbf{1 8 . 2 7}$ & $\mathbf{1 4 . 8 7}$ & $\mathbf{1 3 . 1 4}$ & $\mathbf{8 . 1 6}$ & $\mathbf{6 . 8 5}$ & $\mathbf{1 1 . 4 4}$ \\
\hline
\end{tabular}

e4) Desviación estándar de las medias diarias de cada mes y año del GPS de Valencia:

\begin{tabular}{|c|l|l|l|l|l|l|l|l|l|l|l|l|c|}
\hline Año \Mes & $\mathbf{1}$ & $\mathbf{2}$ & $\mathbf{3}$ & $\mathbf{4}$ & $\mathbf{5}$ & $\mathbf{6}$ & $\mathbf{7}$ & $\mathbf{8}$ & $\mathbf{9}$ & $\mathbf{1 0}$ & $\mathbf{1 1}$ & $\mathbf{1 2}$ & Media \\
\hline $\mathbf{2 0 0 2}$ & 4.89 & 3.28 & 2.16 & 3.62 & 4.80 & --- & 5.29 & 4.12 & --- & --- & 3.72 & 5.31 & $\mathbf{4 . 1 3}$ \\
$\mathbf{2 0 0 3}$ & 4.91 & 4.18 & 5.39 & 4.73 & -- & 4.15 & 5.62 & 6.97 & 8.51 & 5.67 & 4.70 & 4.05 & $\mathbf{5 . 3 5}$ \\
$\mathbf{2 0 0 4}$ & 4.66 & 4.87 & 5.47 & 3.73 & 5.17 & 0.25 & 3.45 & 4.86 & 8.08 & 6.50 & 4.88 & 5.08 & $\mathbf{4 . 7 5}$ \\
$\mathbf{2 0 0 5}$ & 3.49 & 3.79 & --- & -- & --- & --- & -- & 7.43 & 5.73 & 5.63 & 4.93 & 3.49 & $\mathbf{4 . 9 3}$ \\
$\mathbf{2 0 0 6}$ & 3.89 & 3.18 & 4.34 & 2.88 & 5.37 & 5.78 & 4.70 & 4.90 & 6.84 & -- & -- & 4.03 & $\mathbf{4 . 5 9}$ \\
$\mathbf{2 0 0 7}$ & 3.59 & 4.35 & 3.85 & 3.44 & 4.94 & 4.50 & 3.18 & --- & 5.87 & 5.80 & 4.97 & 4.35 & $\mathbf{4 . 4 4}$ \\
$\mathbf{2 0 0 8}$ & 3.90 & 4.92 & 4.00 & 3.93 & 4.19 & 3.88 & 3.92 & 5.99 & 7.04 & 6.95 & 3.93 & 5.16 & $\mathbf{4 . 8 2}$ \\
\hline Media & $\mathbf{4 . 1 9}$ & $\mathbf{4 . 0 8}$ & $\mathbf{4 . 2 0}$ & $\mathbf{3 . 7 2}$ & $\mathbf{4 . 8 9}$ & $\mathbf{3 . 7 1}$ & $\mathbf{4 . 3 6}$ & $\mathbf{5 . 7 1}$ & $\mathbf{7 . 0 1}$ & $\mathbf{6 . 1 1}$ & $\mathbf{4 . 5 2}$ & $\mathbf{4 . 5 0}$ & $\mathbf{4 . 7 2}$ \\
\hline
\end{tabular}

e5) Número de días con dato válido por mes y año del GPS de Valencia:

\begin{tabular}{|c|c|c|c|c|c|c|c|c|c|c|c|c|c|}
\hline Año \Mes & 1 & 2 & 3 & 4 & 5 & 6 & 7 & 8 & 9 & 10 & 11 & 12 & Total \\
\hline 2002 & 31 & 28 & 31 & 30 & 25 & 0 & 21 & 31 & 4 & 0 & 24 & 27 & 252 \\
\hline 2003 & 30 & 28 & 31 & 30 & 12 & 16 & 31 & 31 & 30 & 31 & 30 & 31 & 331 \\
\hline 2004 & 31 & 29 & 27 & 26 & 19 & 2 & 21 & 31 & 30 & 31 & 28 & 31 & 306 \\
\hline 2005 & 31 & 22 & 0 & 0 & 0 & 0 & 8 & 31 & 30 & 30 & 28 & 31 & 213 \\
\hline 2006 & 31 & 27 & 31 & 30 & 31 & 30 & 31 & 31 & 30 & 15 & 12 & 31 & 331 \\
\hline 2007 & 31 & 28 & 31 & 30 & 28 & 30 & 31 & 7 & 24 & 30 & 30 & 31 & 331 \\
\hline 2008 & 31 & 29 & 31 & 30 & 31 & 27 & 28 & 24 & 30 & 31 & 29 & 31 & 352 \\
\hline Total & 216 & 191 & 182 & 176 & 134 & 105 & 163 & 179 & 174 & 153 & 169 & 213 & 2055 \\
\hline
\end{tabular}

f) Resumen por mes de las medias mensuales de cada año del GPS de Valencia:

\begin{tabular}{|c|c|c|c|c|c|c|c|c|c|c|c|c|}
\hline Mes & 1 & 2 & 3 & 4 & 5 & 6 & 7 & 8 & 9 & 10 & 11 & 12 \\
\hline Media & 12.59 & 13.29 & 14.76 & 17.99 & 21.92 & 27.54 & 30.70 & 31.95 & 29.85 & 25.16 & 16.36 & 14.37 \\
\hline STD & 1.32 & 1.24 & 1.90 & 1.46 & 2.13 & 2.04 & 1.70 & 1.43 & 1.98 & 1.25 & 2.60 & 1.87 \\
\hline Mediana & 12.53 & 13.64 & 15.45 & 18.35 & 22.96 & 27.49 & 30.60 & 31.89 & 29.81 & 25.46 & 16.79 & 13.84 \\
\hline Máximo & 14.27 & 14.75 & 16.82 & 20.02 & 24.75 & 31.00 & 33.28 & 33.78 & 32.99 & 26.78 & 20.71 & 17.21 \\
\hline Mínimo & 10.48 & 11.09 & 11.89 & 15.44 & 19.10 & 25.01 & 28.26 & 30.09 & 27.28 & 23.12 & 12.63 & 12.13 \\
\hline $\mathrm{N}^{0}$ Días & 216 & 191 & 182 & 176 & 134 & 105 & 163 & 179 & 174 & 153 & 169 & 213 \\
\hline
\end{tabular}




\section{Gráficas de la estación de Valencia}

g) Evolución temporal de las medias diarias.

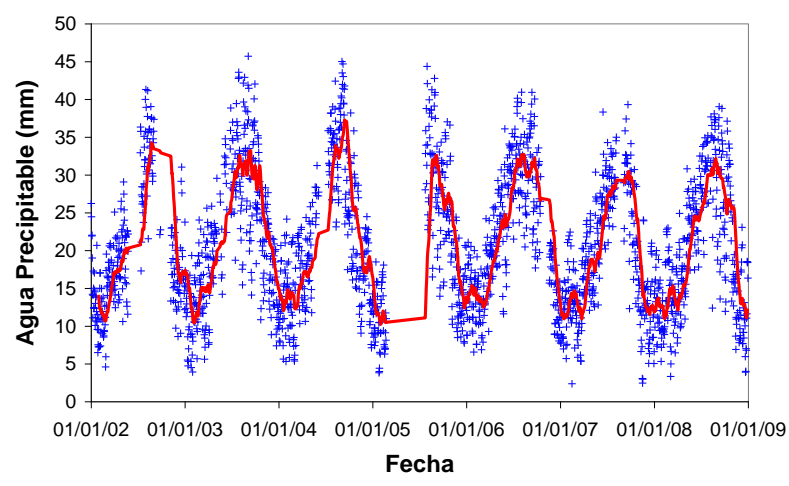

La línea roja representa la media móvil mensual. h) Histograma de las medias diarias.

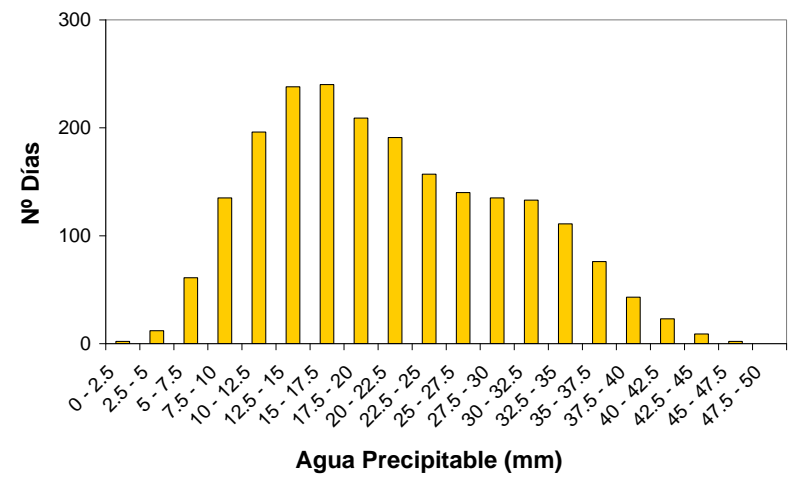

La distribución presenta un desplazamiento hacia la derecha (coef. de asimetría positivo), y un ligero achatamiento (curtosis negativa) respecto de la distribución normal.

j) Ciclo promedio anual.

para cada mes y año.
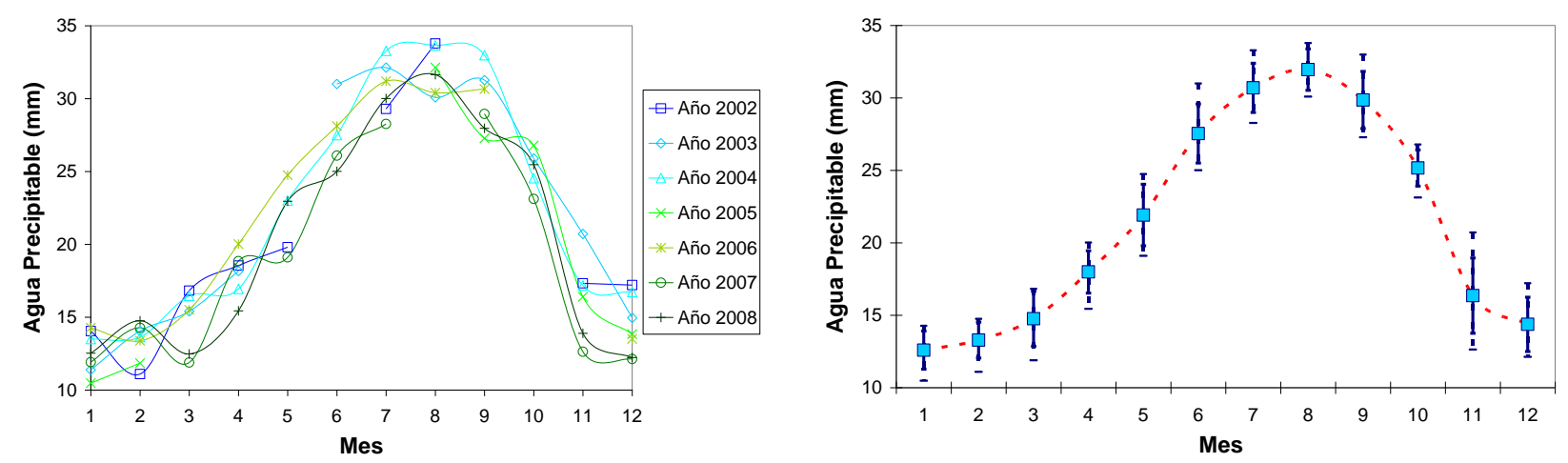

Valor promedio de las medias mensuales de cada año (cuadrados). Valor promedio más/menos la desviación típica de las medias mensuales (barras sólidas). Valor máximo y mínimo absoluto de las medias mensuales (líneas de trazos). 


\subsubsection{VILLAFRANCA DEL CASTILLO (Estación de la ESA). Estación GPS.}

El análisis estadístico se ha realizado en base a los datos de ZTD generados por el centro de análisis IGN de EUREF.

a) Estadísticas globales del conjunto de las medidas del GPS de Villafranca:

\begin{tabular}{|c|c|c|c|c|c|c|c|c|c|c|}
\hline $\begin{array}{c}\mathbf{N}^{0} \\
\text { Medidas }\end{array}$ & Media & STD & Mediana & $\begin{array}{c}\text { Clase } \\
\text { Modal }\end{array}$ & $\begin{array}{c}\text { Percentil } \\
\mathbf{5}\end{array}$ & $\begin{array}{c}\text { Percentil } \\
\mathbf{9 5}\end{array}$ & Máximo & Mínimo & $\begin{array}{c}\text { Coef. } \\
\text { Asimetría }\end{array}$ & Curtosis \\
\hline 57733 & 15.75 & 6.67 & 15.22 & $12.5-15$ & 5.84 & 27.61 & 40.67 & 0.88 & 0.36 & -0.39 \\
\hline
\end{tabular}

b) Estadísticas por mes del conjunto de las medidas del GPS de Villafranca:

\begin{tabular}{|c|c|c|c|c|c|c|c|c|c|c|c|c|}
\hline Estadístico \Mes & 1 & 2 & 3 & 4 & 5 & 6 & 7 & 8 & 9 & 10 & 11 & 12 \\
\hline Media & 10.37 & 10.65 & 11.73 & 13.52 & 17.51 & 21.07 & 19.74 & 20.80 & 20.56 & 18.65 & 13.04 & 11.38 \\
\hline STD & 4.46 & 4.19 & 4.74 & 4.14 & 5.15 & 5.53 & 5.06 & 5.55 & 6.48 & 6.37 & 5.32 & 4.86 \\
\hline Mediana & 9.63 & 10.29 & 11.64 & 13.34 & 17.27 & 21.02 & 19.61 & 20.65 & 20.64 & 18.21 & 12.29 & 10.83 \\
\hline Máximo & 26.01 & 24.31 & 26.48 & 28.22 & 35.89 & 36.36 & 36.71 & 40.67 & 38.84 & 39.21 & 33.62 & 33.40 \\
\hline Mínimo & 0.88 & 1.16 & 1.42 & 2.32 & 6.04 & 4.25 & 5.94 & 6.51 & 2.47 & 5.50 & 1.58 & 1.00 \\
\hline Percentil 5 & 4.27 & 4.36 & 4.25 & 6.97 & 9.38 & 12.10 & 11.98 & 12.05 & 9.56 & 8.82 & 5.28 & 4.32 \\
\hline Percentil 95 & 18.93 & 17.87 & 19.47 & 20.52 & 26.15 & 30.39 & 28.63 & 30.13 & 31.20 & 30.06 & 22.57 & 19.57 \\
\hline Coef. Asimetría & 0.70 & 0.27 & 0.20 & 0.20 & 0.32 & 0.03 & 0.23 & 0.19 & 0.02 & 0.28 & 0.49 & 0.54 \\
\hline Curtosis & 0.18 & -0.51 & -0.55 & -0.21 & -0.14 & -0.51 & -0.39 & -0.24 & -0.58 & -0.54 & -0.06 & 0.29 \\
\hline $\mathrm{N}^{0}$ Medidas & 5131 & 4517 & 5157 & 4459 & 4739 & 4857 & 4993 & 5138 & 4383 & 4882 & 4514 & 4963 \\
\hline
\end{tabular}

c) Estadísticas globales de las medias diarias del GPS de Villafranca:

\begin{tabular}{|c|c|c|c|c|c|c|c|c|c|c|}
\hline $\mathrm{N}^{0}$ Días & Media & STD & Mediana & Moda & \begin{tabular}{|c|} 
Percentil \\
5 \\
\end{tabular} & \begin{tabular}{|c|} 
Percentil \\
95 \\
\end{tabular} & Máximo & Mínimo & \begin{tabular}{|c} 
Coef. \\
Asimetría
\end{tabular} & Curtosis \\
\hline 2440 & 15.75 & 6.26 & 15.22 & $12.5-15$ & 6.35 & 26.56 & 34.75 & 1.72 & 0.30 & -0.48 \\
\hline
\end{tabular}

d) Resumen por mes de las medias diarias del GPS de Villafranca:

\begin{tabular}{|c|c|c|c|c|c|c|c|c|c|c|c|c|}
\hline Estadístico \Mes & 1 & 2 & 3 & 4 & 5 & 6 & 7 & 8 & 9 & 10 & 11 & 12 \\
\hline Media & 10.36 & 10.63 & 11.75 & 13.55 & 17.48 & 21.05 & 19.73 & 20.82 & 20.56 & 18.67 & 13.07 & 11.41 \\
\hline STD & 3.99 & 3.62 & 4.32 & 3.61 & 4.66 & 4.90 & 4.45 & 4.87 & 6.00 & 5.77 & 4.86 & 4.42 \\
\hline Mediana & 9.78 & 10.67 & 11.71 & 13.64 & 17.33 & 20.52 & 19.92 & 20.56 & 20.76 & 18.32 & 12.84 & 11.06 \\
\hline Máximo & 23.38 & 20.67 & 24.56 & 21.32 & 33.01 & 32.41 & 30.94 & 34.75 & 34.70 & 33.07 & 26.28 & 25.80 \\
\hline Mínimo & 2.53 & 2.22 & 2.99 & 4.63 & 7.66 & 9.13 & 11.33 & 8.82 & 7.80 & 7.24 & 2.65 & 1.72 \\
\hline Percentil 5 & 4.92 & 4.73 & 4.53 & 7.38 & 10.35 & 12.98 & 13.00 & 13.24 & 9.77 & 9.79 & 5.97 & 4.54 \\
\hline Percentil 95 & 17.78 & 16.68 & 18.98 & 19.92 & 24.99 & 29.21 & 28.11 & 28.41 & 29.71 & 28.37 & 21.26 & 18.60 \\
\hline Coef. Asimetría & 0.61 & 0.10 & 0.07 & 0.00 & 0.37 & -0.03 & 0.23 & 0.10 & -0.06 & 0.13 & 0.27 & 0.38 \\
\hline Curtosis & 0.09 & -0.52 & -0.57 & -0.42 & -0.02 & -0.45 & -0.46 & -0.46 & -0.62 & -0.70 & -0.43 & 0.28 \\
\hline No Días & 216 & 194 & 216 & 191 & 199 & 205 & 211 & 216 & 186 & 205 & 191 & 210 \\
\hline
\end{tabular}

e1) Media de las medias diarias por mes y año del GPS de Villafranca:

\begin{tabular}{|c|r|r|r|c|c|c|c|c|c|c|c|c|c|}
\hline Año \Mes & \multicolumn{1}{|c|}{$\mathbf{1}$} & \multicolumn{1}{|c|}{$\mathbf{2}$} & \multicolumn{1}{|c|}{$\mathbf{3}$} & $\mathbf{4}$ & $\mathbf{5}$ & $\mathbf{6}$ & $\mathbf{7}$ & $\mathbf{8}$ & $\mathbf{9}$ & $\mathbf{1 0}$ & $\mathbf{1 1}$ & $\mathbf{1 2}$ & Media \\
\hline $\mathbf{2 0 0 2}$ & 11.42 & 9.62 & 12.02 & 12.60 & 15.77 & 20.51 & 20.25 & 21.74 & 21.82 & 18.68 & 15.89 & 14.74 & $\mathbf{1 6 . 2 6}$ \\
$\mathbf{2 0 0 3}$ & 9.76 & 11.24 & 12.62 & 14.05 & 18.25 & 23.10 & 18.84 & 23.59 & 20.62 & 19.09 & 16.55 & 12.50 & $\mathbf{1 6 . 6 8}$ \\
$\mathbf{2 0 0 4}$ & 12.19 & 10.66 & 12.85 & 12.81 & 18.65 & 22.18 & 21.37 & 23.36 & 23.43 & 19.53 & 12.54 & 12.45 & $\mathbf{1 6 . 8 3}$ \\
$\mathbf{2 0 0 5}$ & 7.89 & 8.64 & 12.54 & 14.04 & 17.40 & 22.41 & 19.71 & 19.86 & 17.70 & 19.81 & 13.79 & 11.27 & $\mathbf{1 5 . 4 2}$ \\
$\mathbf{2 0 0 6}$ & 10.50 & 10.10 & 13.24 & 14.74 & 17.92 & 21.00 & 22.12 & 18.63 & 21.66 & 20.84 & -- & 9.41 & $\mathbf{1 6 . 3 8}$ \\
$\mathbf{2 0 0 7}$ & 9.75 & 12.42 & 9.51 & 14.57 & 16.91 & 18.65 & 17.61 & 19.06 & 20.54 & 15.67 & 8.40 & 9.37 & $\mathbf{1 4 . 3 7}$ \\
$\mathbf{2 0 0 8}$ & 10.97 & 11.63 & 9.53 & 12.47 & 17.40 & 19.19 & 18.34 & 19.44 & 19.04 & 17.75 & 10.03 & 9.90 & $\mathbf{1 4 . 6 4}$ \\
\hline Media & $\mathbf{1 0 . 3 6}$ & $\mathbf{1 0 . 6 2}$ & $\mathbf{1 1 . 7 6}$ & $\mathbf{1 3 . 6 1}$ & $\mathbf{1 7 . 4 7}$ & $\mathbf{2 1 . 0 1}$ & $\mathbf{1 9 . 7 5}$ & $\mathbf{2 0 . 8 1}$ & $\mathbf{2 0 . 6 9}$ & $\mathbf{1 8 . 7 7}$ & $\mathbf{1 2 . 8 6}$ & $\mathbf{1 1 . 3 8}$ & $\mathbf{1 5 . 8 0}$ \\
\hline
\end{tabular}


e2) Máximo de las medias diarias por mes y año del GPS de Villafranca:

\begin{tabular}{|c|c|c|c|c|c|c|c|c|c|c|c|c|c|}
\hline Año \Mes & $\mathbf{1}$ & $\mathbf{2}$ & $\mathbf{3}$ & $\mathbf{4}$ & $\mathbf{5}$ & $\mathbf{6}$ & $\mathbf{7}$ & $\mathbf{8}$ & $\mathbf{9}$ & $\mathbf{1 0}$ & $\mathbf{1 1}$ & $\mathbf{1 2}$ & Máximo \\
\hline $\mathbf{2 0 0 2}$ & 23.38 & 15.30 & 17.68 & 19.51 & 24.72 & 27.03 & 26.77 & 29.23 & 31.45 & 32.54 & 23.32 & 25.80 & $\mathbf{2 4 . 7 3}$ \\
$\mathbf{2 0 0 3}$ & 22.13 & 17.32 & 20.97 & 21.32 & 25.43 & 30.45 & 24.82 & 29.05 & 30.73 & 28.28 & 23.77 & 20.49 & $\mathbf{2 4 . 5 6}$ \\
$\mathbf{2 0 0 4}$ & 20.63 & 17.29 & 19.00 & 20.53 & 26.29 & 30.72 & 28.84 & 34.75 & 34.70 & 33.07 & 20.26 & 17.73 & $\mathbf{2 5 . 3 2}$ \\
$\mathbf{2 0 0 5}$ & 17.86 & 15.66 & 24.56 & 20.91 & 33.01 & 32.41 & 28.94 & 31.96 & 24.21 & 31.07 & 22.21 & 18.73 & $\mathbf{2 5 . 1 3}$ \\
$\mathbf{2 0 0 6}$ & 14.66 & 15.44 & 20.83 & 20.99 & 26.85 & 27.47 & 30.94 & 29.09 & 31.47 & 29.41 & -- & 21.27 & $\mathbf{2 4 . 4 0}$ \\
$\mathbf{2 0 0 7}$ & 17.18 & 20.67 & 14.59 & 21.25 & 24.98 & 32.40 & 25.86 & 29.83 & 29.54 & 29.38 & 23.32 & 15.45 & $\mathbf{2 3 . 7 0}$ \\
$\mathbf{2 0 0 8}$ & 19.02 & 18.64 & 16.94 & 20.06 & 24.41 & 26.28 & 25.92 & 28.07 & 33.12 & 26.30 & 15.60 & 19.38 & $\mathbf{2 2 . 8 1}$ \\
\hline Media & $\mathbf{1 9 . 2 7}$ & $\mathbf{1 7 . 1 9}$ & $\mathbf{1 9 . 2 2}$ & $\mathbf{2 0 . 6 5}$ & $\mathbf{2 6 . 5 3}$ & $\mathbf{2 9 . 5 4}$ & $\mathbf{2 7 . 4 4}$ & $\mathbf{3 0 . 2 8}$ & $\mathbf{3 0 . 7 5}$ & $\mathbf{3 0 . 0 1}$ & $\mathbf{2 1 . 4 1}$ & $\mathbf{1 9 . 8 4}$ & $\mathbf{2 4 . 3 8}$ \\
\hline
\end{tabular}

e3) Mínimo de las medias diarias por mes y año del GPS de Villafranca:

\begin{tabular}{|c|c|c|c|c|c|c|c|c|c|c|c|c|c|}
\hline Año \ Mes & 1 & 2 & 3 & 4 & 5 & 6 & 7 & 8 & 9 & 10 & 11 & 12 & Media \\
\hline 2002 & 5.96 & 4.74 & 6.97 & 6.92 & 8.65 & 13.99 & 12.14 & 15.46 & 9.00 & 10.70 & 9.19 & 7.99 & 9.31 \\
\hline 2003 & 2.53 & 2.22 & 5.54 & 5.44 & 10.52 & 14.86 & 12.70 & 16.28 & 9.30 & 8.34 & 9.60 & 6.98 & 8.69 \\
\hline 2004 & 5.11 & 3.37 & 3.56 & 7.29 & 10.05 & 9.13 & 13.45 & 13.21 & 11.51 & 11.01 & 5.53 & 5.91 & 8.26 \\
\hline 2005 & 3.23 & 3.12 & 3.83 & 7.09 & 8.81 & 12.98 & 11.37 & 12.11 & 7.80 & 7.24 & 7.58 & 4.31 & 7.46 \\
\hline 2006 & 4.86 & 3.68 & 4.32 & 8.26 & 8.73 & 9.97 & 15.29 & 10.95 & 14.07 & 9.80 & --- & 5.55 & 8.68 \\
\hline 2007 & 2.78 & 7.06 & 2.99 & 8.77 & 9.41 & 11.08 & 12.49 & 9.05 & 9.60 & 7.34 & 2.65 & 2.88 & 7.18 \\
\hline 2008 & 5.30 & 4.55 & 3.94 & 4.63 & 7.66 & 12.66 & 11.33 & 8.82 & 9.10 & 8.29 & 4.93 & 1.72 & 6.91 \\
\hline Media & 4.25 & 4.11 & 4.45 & 6.91 & 9.12 & 12.10 & 12.68 & 12.27 & 10.05 & 8.96 & 6.58 & 5.05 & 8.07 \\
\hline
\end{tabular}

e4) Desviación estándar de las medias diarias de cada mes y año del GPS de Villafranca:

\begin{tabular}{|c|l|l|l|l|l|l|l|l|l|l|l|l|l|}
\hline Año \Mes & $\mathbf{1}$ & $\mathbf{2}$ & $\mathbf{3}$ & $\mathbf{4}$ & $\mathbf{5}$ & $\mathbf{6}$ & $\mathbf{7}$ & $\mathbf{8}$ & $\mathbf{9}$ & $\mathbf{1 0}$ & $\mathbf{1 1}$ & $\mathbf{1 2}$ & Media \\
\hline $\mathbf{2 0 0 2}$ & 3.87 & 3.16 & 3.23 & 2.49 & 3.66 & 3.07 & 3.39 & 3.31 & 6.71 & 5.08 & 3.07 & 4.81 & $\mathbf{3 . 8 2}$ \\
$\mathbf{2 0 0 3}$ & 4.90 & 3.79 & 4.24 & 4.84 & 3.52 & 3.91 & 3.56 & 3.87 & 5.57 & 4.89 & 3.69 & 3.10 & $\mathbf{4 . 1 6}$ \\
$\mathbf{2 0 0 4}$ & 4.61 & 3.66 & 4.06 & 3.22 & 5.00 & 5.38 & 4.53 & 5.31 & 6.61 & 4.76 & 3.95 & 3.13 & $\mathbf{4 . 5 2}$ \\
$\mathbf{2 0 0 5}$ & 3.38 & 2.94 & 5.70 & 3.93 & 5.93 & 5.38 & 4.68 & 4.97 & 4.91 & 6.58 & 4.35 & 4.03 & $\mathbf{4 . 7 3}$ \\
$\mathbf{2 0 0 6}$ & 2.80 & 2.94 & 4.30 & 3.04 & 5.02 & 5.59 & 4.83 & 3.77 & 5.34 & 5.62 & -- & 3.66 & $\mathbf{4 . 2 7}$ \\
$\mathbf{2 0 0 7}$ & 2.91 & 2.81 & 3.16 & 2.82 & 4.89 & 4.94 & 3.81 & 5.12 & 5.67 & 5.92 & 4.00 & 3.82 & $\mathbf{4 . 1 6}$ \\
$\mathbf{2 0 0 8}$ & 3.48 & 4.27 & 3.20 & 3.99 & 3.38 & 3.47 & 4.35 & 4.64 & 5.80 & 5.82 & 2.66 & 5.04 & $\mathbf{4 . 1 8}$ \\
\hline Media & $\mathbf{3 . 7 1}$ & $\mathbf{3 . 3 7}$ & $\mathbf{3 . 9 8}$ & $\mathbf{3 . 4 8}$ & $\mathbf{4 . 4 8}$ & $\mathbf{4 . 5 3}$ & $\mathbf{4 . 1 6}$ & $\mathbf{4 . 4 3}$ & $\mathbf{5 . 8 0}$ & $\mathbf{5 . 5 3}$ & $\mathbf{3 . 6 2}$ & $\mathbf{3 . 9 4}$ & $\mathbf{4 . 2 6}$ \\
\hline
\end{tabular}

e5) Número de días con dato válido por mes y año del GPS de Villafranca:

\begin{tabular}{|c|c|c|c|c|c|c|c|c|c|c|c|c|c|}
\hline Año \Mes & 1 & 2 & 3 & 4 & 5 & 6 & 7 & 8 & 9 & 10 & 11 & 12 & Tota \\
\hline 2002 & 31 & 27 & 31 & 30 & 31 & 29 & 31 & 31 & 30 & 31 & 29 & 31 & 362 \\
\hline 2003 & 30 & 28 & 31 & 20 & 25 & 30 & 31 & 31 & 29 & 31 & 30 & 31 & 347 \\
\hline 2004 & 31 & 29 & 31 & 30 & 31 & 30 & 27 & 31 & 16 & 28 & 29 & 29 & 342 \\
\hline 2005 & 31 & 28 & 30 & 28 & 29 & 30 & 30 & 31 & 30 & 30 & 30 & 31 & 358 \\
\hline 2006 & 31 & 25 & 31 & 30 & 31 & 30 & 31 & 31 & 30 & 23 & 13 & 26 & 332 \\
\hline 2007 & 31 & 28 & 31 & 23 & 21 & 29 & 30 & 30 & 30 & 31 & 30 & 31 & 345 \\
\hline 2008 & 31 & 29 & 31 & 30 & 31 & 27 & 31 & 31 & 21 & 31 & 30 & 31 & 354 \\
\hline Total & 216 & 194 & 216 & 191 & 199 & 205 & 211 & 216 & 186 & 205 & 178 & 210 & 2427 \\
\hline
\end{tabular}

f) Resumen por mes de las medias mensuales de cada año del GPS de Villafranca:

\begin{tabular}{|c|c|c|c|c|c|c|c|c|c|c|c|c|}
\hline Mes & 1 & 2 & 3 & 4 & 5 & 6 & 7 & 8 & 9 & 10 & 11 & 12 \\
\hline Media & 10.36 & 10.62 & 11.76 & 13.61 & 17.47 & 21.01 & 19.75 & 20.81 & 20.69 & 18.77 & 12.86 & 11.38 \\
\hline STD & 1.29 & 1.19 & 1.46 & 0.89 & 0.88 & 1.55 & 1.51 & 1.92 & 1.75 & 1.54 & 2.94 & 1.85 \\
\hline Mediana & 10.50 & 10.66 & 12.54 & 14.04 & 17.40 & 21.00 & 19.71 & 19.86 & 20.62 & 19.09 & 13.16 & 11.27 \\
\hline Máximo & 12.19 & 12.42 & 13.24 & 14.74 & 18.65 & 23.10 & 22.12 & 23.59 & 23.43 & 20.84 & 16.55 & 14.74 \\
\hline Mínimo & 7.89 & 8.64 & 9.51 & 12.47 & 15.77 & 18.65 & 17.61 & 18.63 & 17.70 & 15.67 & 8.40 & 9.37 \\
\hline $\mathrm{N}^{0}$ Días & 216 & 194 & 216 & 191 & 199 & 205 & 211 & 216 & 186 & 205 & 178 & 210 \\
\hline
\end{tabular}




\section{Gráficas de la estación de Villafranca del Castillo}

g) Evolución temporal de las medias diarias.

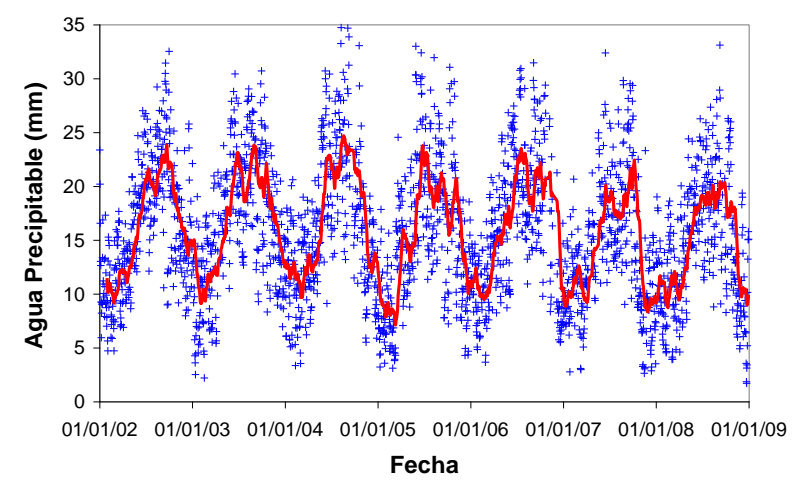

La línea roja representa la media móvil mensual. h) Histograma de las medias diarias.

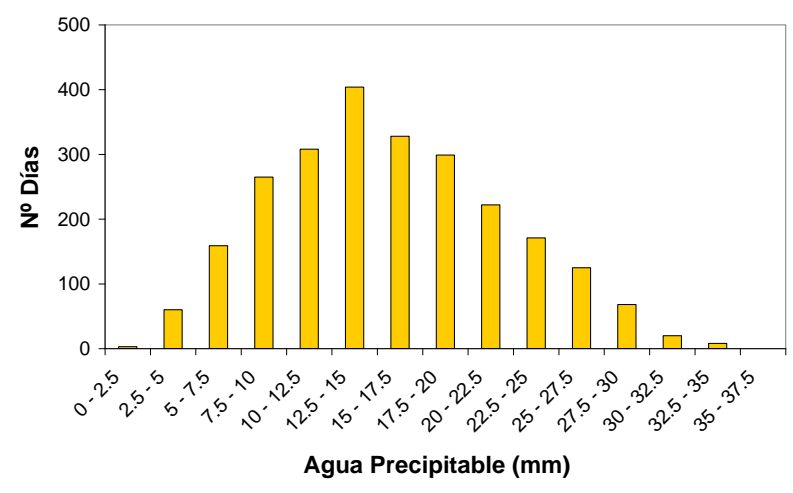

La distribución presenta un desplazamiento hacia la derecha (coef. de asimetría positivo), y un ligero achatamiento (curtosis negativa) respecto de la distribución normal.

j) Ciclo promedio anual.

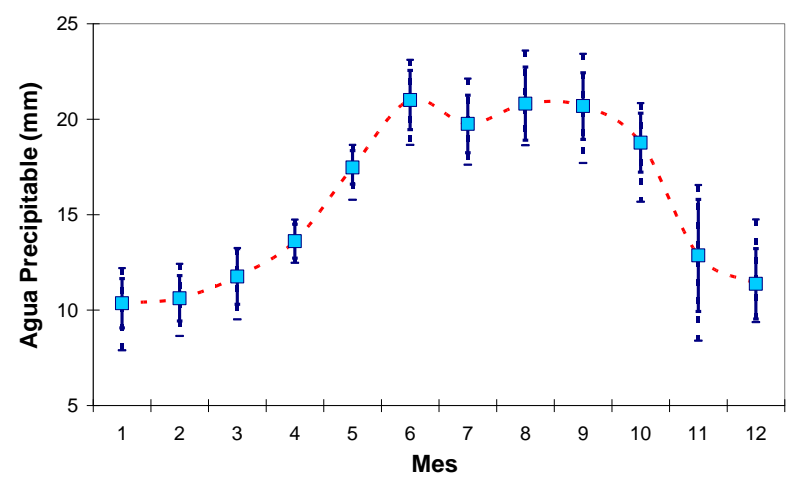

Valor promedio de las medias mensuales de cada año (cuadrados). Valor promedio más/menos la desviación típica de las medias mensuales (barras sólidas). Valor máximo y mínimo absoluto de las medias mensuales (líneas de trazos). 


\subsubsection{YEBES (Observatorio astronómico). Estación GPS.}

El análisis estadístico se ha realizado en base a los datos de ZTD generados por el centro de análisis IGN de EUREF.

a) Estadísticas globales del conjunto de las medidas del GPS de Yebes:

\begin{tabular}{|c|c|c|c|c|c|c|c|c|c|c|}
\hline $\begin{array}{c}\mathbf{N}^{0} \\
\text { Medidas }\end{array}$ & Media & STD & Mediana & $\begin{array}{c}\text { Clase } \\
\text { Modal }\end{array}$ & $\begin{array}{c}\text { Percentil } \\
\mathbf{5}\end{array}$ & $\begin{array}{c}\text { Percentil } \\
\mathbf{9 5}\end{array}$ & Máximo & Mínimo & $\begin{array}{c}\text { Coef. } \\
\text { Asimetría }\end{array}$ & Curtosis \\
\hline 58939 & 13.70 & 6.07 & 13.23 & $12.5-15$ & 4.61 & 24.46 & 36.14 & 0.18 & 0.33 & -0.45 \\
\hline
\end{tabular}

b) Estadísticas por mes del conjunto de las medidas del GPS de Yebes:

\begin{tabular}{|c|c|c|c|c|c|c|c|c|c|c|c|c|}
\hline Estadístico \Mes & 1 & 2 & 3 & 4 & 5 & 6 & 7 & 8 & 9 & 10 & 11 & 12 \\
\hline Media & 8.58 & 8.86 & 9.98 & 11.80 & 14.95 & 18.57 & 17.78 & 18.52 & 17.90 & 16.29 & 11.45 & 9.86 \\
\hline STD & 4.19 & 3.81 & 4.23 & 3.89 & 4.67 & 5.13 & 4.70 & 4.95 & 5.69 & 5.57 & 4.98 & 4.47 \\
\hline Mediana & 7.75 & 8.57 & 10.00 & 11.68 & 14.79 & 18.62 & 17.72 & 18.56 & 17.78 & 15.74 & 10.91 & 9.43 \\
\hline Máximo & 23.22 & 21.51 & 22.98 & 24.56 & 34.49 & 32.47 & 35.39 & 36.14 & 34.77 & 34.68 & 28.99 & 30.69 \\
\hline Mínimo & 0.24 & 0.31 & 0.18 & 1.51 & 4.11 & 4.17 & 4.44 & 5.06 & 4.06 & 0.89 & 0.40 & 0.37 \\
\hline Percentil 5 & 3.00 & 3.14 & 3.37 & 5.69 & 7.56 & 10.02 & 10.36 & 10.59 & 8.46 & 7.86 & 4.16 & 3.11 \\
\hline Percentil 95 & 16.78 & 15.58 & 16.87 & 18.37 & 22.70 & 26.87 & 25.82 & 26.64 & 27.38 & 25.96 & 20.52 & 17.73 \\
\hline Coef. Asimetría & 0.77 & 0.32 & 0.17 & 0.17 & 0.27 & -0.05 & 0.22 & 0.08 & 0.05 & 0.30 & 0.49 & 0.55 \\
\hline Curtosis & 0.17 & -0.47 & -0.60 & -0.36 & -0.19 & -0.59 & -0.28 & -0.31 & -0.59 & -0.56 & -0.04 & 0.32 \\
\hline $\mathrm{N}^{0}$ Medidas & 4908 & 4694 & 5104 & 4996 & 5181 & 4717 & 5014 & 4944 & 4658 & 4936 & 4922 & 4865 \\
\hline
\end{tabular}

c) Estadísticas globales de las medias diarias del GPS de Yebes:

\begin{tabular}{|c|c|c|c|c|c|c|c|c|c|c|}
\hline N$^{\circ}$ Días & Media & STD & Mediana & Moda & $\begin{array}{c}\text { Percentil } \\
\mathbf{5}\end{array}$ & $\begin{array}{c}\text { Percentil } \\
\mathbf{9 5}\end{array}$ & Máximo & Mínimo & $\begin{array}{c}\text { Coef. } \\
\text { Asimetría }\end{array}$ & Curtosis \\
\hline 2470 & 13.71 & 5.69 & 13.26 & $12.5-15$ & 5.03 & 23.75 & 31.75 & 1.08 & 0.27 & -0.54 \\
\hline
\end{tabular}

d) Resumen por mes de las medias diarias del GPS de Yebes:

\begin{tabular}{|c|c|c|c|c|c|c|c|c|c|c|c|c|}
\hline Estadístico \Mes & 1 & 2 & 3 & 4 & 5 & 6 & 7 & 8 & 9 & 10 & 11 & 12 \\
\hline Media & 8.59 & 8.86 & 9.97 & 11.80 & 14.97 & 18.57 & 17.78 & 18.52 & 17.90 & 16.32 & 11.46 & 9.92 \\
\hline STD & 3.71 & 3.30 & 3.83 & 3.36 & 4.23 & 4.60 & 4.11 & 4.32 & 5.24 & 4.98 & 4.56 & 4.05 \\
\hline Mediana & 7.99 & 8.75 & 10.15 & 12.06 & 15.09 & 18.36 & 17.77 & 18.76 & 17.58 & 16.00 & 11.33 & 9.85 \\
\hline Máximo & 20.45 & 17.67 & 20.60 & 20.42 & 27.36 & 28.89 & 27.55 & 31.75 & 28.86 & 28.65 & 25.74 & 22.71 \\
\hline Mínimo & 1.48 & 1.60 & 2.18 & 3.75 & 6.31 & 7.38 & 9.13 & 7.58 & 5.55 & 6.65 & 1.08 & 1.25 \\
\hline Percentil 5 & 3.66 & 3.67 & 3.67 & 6.32 & 8.36 & 11.19 & 11.46 & 11.40 & 8.92 & 8.29 & 4.77 & 3.32 \\
\hline Percentil 95 & 15.44 & 14.54 & 16.30 & 17.05 & 21.67 & 25.54 & 25.38 & 25.06 & 26.71 & 24.63 & 19.42 & 16.61 \\
\hline Coef. Asimetría & 0.66 & 0.15 & 0.04 & -0.06 & 0.25 & -0.08 & 0.20 & 0.00 & -0.04 & 0.11 & 0.37 & 0.39 \\
\hline Curtosis & 0.05 & -0.51 & -0.66 & -0.43 & -0.24 & -0.62 & -0.47 & -0.41 & -0.67 & -0.76 & -0.03 & 0.27 \\
\hline $\mathrm{N}^{0}$ Días & 206 & 196 & 213 & 209 & 217 & 199 & 209 & 207 & 195 & 207 & 207 & 205 \\
\hline
\end{tabular}

e1) Media de las medias diarias por mes y año del GPS de Yebes:

\begin{tabular}{|c|r|r|r|r|c|c|c|c|c|c|c|c|c|}
\hline Año \Mes & \multicolumn{1}{|c|}{$\mathbf{1}$} & \multicolumn{1}{|c|}{$\mathbf{2}$} & \multicolumn{1}{|c|}{$\mathbf{3}$} & $\mathbf{4}$ & \multicolumn{1}{|c|}{$\mathbf{5}$} & $\mathbf{6}$ & $\mathbf{7}$ & $\mathbf{8}$ & $\mathbf{9}$ & $\mathbf{1 0}$ & $\mathbf{1 1}$ & $\mathbf{1 2}$ & Media \\
\hline $\mathbf{2 0 0 2}$ & 9.45 & 8.04 & 10.24 & 11.00 & 13.85 & 18.72 & 18.13 & 19.50 & 20.52 & 15.57 & 13.38 & 12.71 & $\mathbf{1 4 . 2 6}$ \\
$\mathbf{2 0 0 3}$ & 8.66 & 9.44 & 10.28 & 12.68 & 14.84 & 20.81 & 17.34 & 20.60 & 18.02 & 16.78 & 14.10 & 10.58 & $\mathbf{1 4 . 5 1}$ \\
$\mathbf{2 0 0 4}$ & 10.00 & 8.63 & 11.08 & 10.98 & 15.88 & 19.32 & 19.11 & 20.79 & 17.92 & 16.40 & 10.44 & 10.85 & $\mathbf{1 4 . 2 8}$ \\
$\mathbf{2 0 0 5}$ & 6.39 & 7.18 & 10.64 & 12.10 & 14.61 & 19.81 & 17.40 & 17.40 & 15.74 & 17.00 & 11.46 & 8.61 & $\mathbf{1 3 . 2 0}$ \\
$\mathbf{2 0 0 6}$ & 8.28 & 8.24 & 10.85 & 12.10 & 15.60 & 17.52 & 19.29 & 16.00 & 19.25 & 19.32 & 14.80 & 9.20 & $\mathbf{1 4 . 2 0}$ \\
$\mathbf{2 0 0 7}$ & 8.09 & 10.53 & 8.08 & 12.88 & 14.37 & 16.50 & 16.35 & 16.91 & 17.88 & 13.44 & 7.03 & 8.46 & $\mathbf{1 2 . 5 4}$ \\
$\mathbf{2 0 0 8}$ & 9.24 & 9.93 & 8.56 & 10.90 & 15.68 & 16.95 & 16.48 & 18.57 & 17.12 & 15.98 & 8.75 & 8.47 & $\mathbf{1 3 . 0 5}$ \\
\hline Media & $\mathbf{8 . 5 9}$ & $\mathbf{8 . 8 5}$ & $\mathbf{9 . 9 6}$ & $\mathbf{1 1 . 8 1}$ & $\mathbf{1 4 . 9 7}$ & $\mathbf{1 8 . 5 2}$ & $\mathbf{1 7 . 7 3}$ & $\mathbf{1 8 . 5 4}$ & $\mathbf{1 8 . 0 6}$ & $\mathbf{1 6 . 3 6}$ & $\mathbf{1 1 . 4 2}$ & $\mathbf{9 . 8 4}$ & $\mathbf{1 3 . 7 2}$ \\
\hline
\end{tabular}


e2) Máximo de las medias diarias por mes y año del GPS de Yebes:

\begin{tabular}{|c|c|c|c|c|c|c|c|c|c|c|c|c|c|}
\hline Año \Mes & $\mathbf{1}$ & $\mathbf{2}$ & $\mathbf{3}$ & $\mathbf{4}$ & $\mathbf{5}$ & $\mathbf{6}$ & $\mathbf{7}$ & $\mathbf{8}$ & $\mathbf{9}$ & $\mathbf{1 0}$ & $\mathbf{1 1}$ & $\mathbf{1 2}$ & Media \\
\hline $\mathbf{2 0 0 2}$ & 20.45 & 13.53 & 14.69 & 17.08 & 21.64 & 24.64 & 24.51 & 26.62 & 27.08 & 23.12 & 18.52 & 22.71 & $\mathbf{2 1 . 2 2}$ \\
$\mathbf{2 0 0 3}$ & 19.56 & 15.83 & 18.82 & 19.85 & 23.03 & 27.06 & 23.44 & 25.06 & 27.20 & 24.71 & 20.47 & 17.44 & $\mathbf{2 1 . 8 7}$ \\
$\mathbf{2 0 0 4}$ & 17.56 & 15.42 & 16.55 & 18.36 & 22.72 & 28.16 & 27.55 & 31.75 & 28.86 & 28.65 & 17.79 & 14.95 & $\mathbf{2 2 . 3 6}$ \\
$\mathbf{2 0 0 5}$ & 15.54 & 14.53 & 20.60 & 20.42 & 27.36 & 28.32 & 25.42 & 26.04 & 22.54 & 26.78 & 18.32 & 16.04 & $\mathbf{2 1 . 8 3}$ \\
$\mathbf{2 0 0 6}$ & 13.54 & 13.00 & 17.98 & 18.16 & 24.10 & 25.58 & 27.42 & 25.51 & 28.20 & 26.17 & 25.74 & 19.68 & $\mathbf{2 2 . 0 9}$ \\
$\mathbf{2 0 0 7}$ & 15.36 & 17.67 & 13.00 & 16.72 & 25.37 & 28.89 & 22.46 & 25.05 & 26.59 & 24.31 & 21.33 & 13.58 & $\mathbf{2 0 . 8 6}$ \\
$\mathbf{2 0 0 8}$ & 16.62 & 16.51 & 15.65 & 18.20 & 22.02 & 22.79 & 23.21 & 25.95 & 27.33 & 23.22 & 13.82 & 17.26 & $\mathbf{2 0 . 2 2}$ \\
\hline Media & $\mathbf{1 6 . 9 5}$ & $\mathbf{1 5 . 2 1}$ & $\mathbf{1 6 . 7 6}$ & $\mathbf{1 8 . 4 0}$ & $\mathbf{2 3 . 7 5}$ & $\mathbf{2 6 . 4 9}$ & $\mathbf{2 4 . 8 6}$ & $\mathbf{2 6 . 5 7}$ & $\mathbf{2 6 . 8 3}$ & $\mathbf{2 5 . 2 8}$ & $\mathbf{1 9 . 4 3}$ & $\mathbf{1 7 . 3 8}$ & $\mathbf{2 1 . 4 9}$ \\
\hline
\end{tabular}

e3) Mínimo de las medias diarias por mes y año del GPS de Yebes:

\begin{tabular}{|c|c|c|c|c|c|c|c|c|c|c|c|c|c|}
\hline Año \Mes & 1 & 2 & 3 & 4 & 5 & 6 & 7 & 8 & 9 & 10 & 11 & 12 & Media \\
\hline 2002 & 4.42 & 3.47 & 5.49 & 6.66 & 7.29 & 12.67 & 9.13 & 13.76 & 8.99 & 8.67 & 8.62 & 6.88 & 8.00 \\
\hline 2003 & 1.48 & 1.60 & 3.44 & 3.75 & 7.95 & 13.66 & 11.37 & 13.12 & 7.90 & 7.04 & 6.98 & 5.56 & 6.99 \\
\hline 2004 & 3.85 & 2.90 & 2.94 & 5.62 & 8.05 & 7.38 & 10.18 & 10.45 & 10.04 & 8.71 & 3.42 & 4.58 & 6.51 \\
\hline 2005 & 2.22 & 2.32 & 2.81 & 5.14 & 6.31 & 11.57 & 10.76 & 8.99 & 5.55 & 6.78 & 5.52 & 2.71 & 5.89 \\
\hline 2006 & 3.64 & 1.98 & 3.34 & 6.77 & 6.33 & 7.69 & 12.79 & 7.58 & 12.19 & 10.21 & 5.66 & 4.38 & 6.88 \\
\hline 2007 & 2.27 & 4.37 & 2.18 & 7.73 & 8.04 & 9.20 & 11.65 & 7.94 & 8.26 & 6.65 & 1.08 & 2.44 & 5.98 \\
\hline 2008 & 3.73 & 3.47 & 3.62 & 3.89 & 7.37 & 9.52 & 10.00 & 12.85 & 8.28 & 7.67 & 4.15 & 1.25 & 6.32 \\
\hline Media & 3.09 & 2.87 & 3.40 & 5.65 & 7.33 & 10.24 & 10.84 & 10.67 & 8.74 & 7.96 & 5.06 & 3.97 & 6.65 \\
\hline
\end{tabular}

e4) Desviación estándar de las medias diarias de cada mes y año del GPS de Yebes:

\begin{tabular}{|c|l|l|l|l|l|l|l|l|l|l|l|l|c|}
\hline Año \Mes & $\mathbf{1}$ & $\mathbf{2}$ & $\mathbf{3}$ & $\mathbf{4}$ & $\mathbf{5}$ & $\mathbf{6}$ & $\mathbf{7}$ & $\mathbf{8}$ & $\mathbf{9}$ & $\mathbf{1 0}$ & $\mathbf{1 1}$ & $\mathbf{1 2}$ & Media \\
\hline $\mathbf{2 0 0 2}$ & 3.77 & 2.83 & 2.74 & 2.31 & 3.27 & 3.11 & 3.29 & 3.17 & 4.76 & 4.14 & 2.54 & 4.32 & $\mathbf{3 . 3 5}$ \\
$\mathbf{2 0 0 3}$ & 4.56 & 3.35 & 4.09 & 4.23 & 3.79 & 3.50 & 3.29 & 3.39 & 5.23 & 4.24 & 3.30 & 2.88 & $\mathbf{3 . 8 2}$ \\
$\mathbf{2 0 0 4}$ & 3.95 & 3.19 & 3.77 & 3.11 & 4.32 & 4.96 & 4.69 & 4.75 & 5.43 & 4.33 & 3.46 & 2.86 & $\mathbf{4 . 0 7}$ \\
$\mathbf{2 0 0 5}$ & 3.16 & 2.78 & 4.99 & 3.74 & 5.18 & 5.10 & 4.37 & 4.73 & 4.71 & 5.50 & 3.74 & 3.77 & $\mathbf{4 . 3 1}$ \\
$\mathbf{2 0 0 6}$ & 2.99 & 2.83 & 3.85 & 2.95 & 4.51 & 6.13 & 4.50 & 3.60 & 4.87 & 4.41 & 5.59 & 4.06 & $\mathbf{4 . 1 9}$ \\
$\mathbf{2 0 0 7}$ & 2.66 & 2.65 & 2.94 & 2.28 & 4.66 & 4.42 & 3.58 & 4.05 & 5.04 & 5.20 & 3.79 & 3.48 & $\mathbf{3 . 7 3}$ \\
$\mathbf{2 0 0 8}$ & 3.20 & 3.96 & 2.78 & 3.74 & 2.99 & 3.13 & 3.68 & 3.47 & 5.31 & 4.83 & 2.54 & 4.61 & $\mathbf{3 . 6 9}$ \\
\hline Media & $\mathbf{3 . 4 7}$ & $\mathbf{3 . 0 9}$ & $\mathbf{3 . 5 9}$ & $\mathbf{3 . 1 9}$ & $\mathbf{4 . 1 0}$ & $\mathbf{4 . 3 4}$ & $\mathbf{3 . 9 1}$ & $\mathbf{3 . 8 8}$ & $\mathbf{5 . 0 5}$ & $\mathbf{4 . 6 7}$ & $\mathbf{3 . 5 7}$ & $\mathbf{3 . 7 1}$ & $\mathbf{3 . 8 8}$ \\
\hline
\end{tabular}

e5) Número de días con dato válido por mes y año del GPS de Yebes:

\begin{tabular}{|c|c|c|c|c|c|c|c|c|c|c|c|c|c|}
\hline Año \Mes & 1 & 2 & 3 & 4 & 5 & 6 & 7 & 8 & 9 & 10 & 11 & 12 & Total \\
\hline 2002 & 31 & 27 & 30 & 30 & 31 & 30 & 31 & 28 & 18 & 30 & 30 & 31 & 347 \\
\hline 2003 & 31 & 28 & 31 & 30 & 31 & 30 & 31 & 31 & 29 & 25 & 30 & 31 & 358 \\
\hline 2004 & 30 & 28 & 31 & 30 & 31 & 30 & 31 & 31 & 30 & 31 & 30 & 31 & 364 \\
\hline 2005 & 31 & 28 & 30 & 30 & 31 & 30 & 31 & 31 & 30 & 30 & 29 & 26 & 357 \\
\hline 2006 & 23 & 28 & 31 & 30 & 31 & 19 & 31 & 31 & 28 & 29 & 30 & 31 & 342 \\
\hline 2007 & 31 & 28 & 30 & 29 & 31 & 30 & 23 & 31 & 30 & 31 & 29 & 26 & 349 \\
\hline 2008 & 29 & 29 & 30 & 30 & 31 & 30 & 31 & 24 & 30 & 31 & 29 & 29 & 353 \\
\hline Total & 206 & 196 & 213 & 209 & 217 & 199 & 209 & 207 & 195 & 207 & 207 & 205 & 2470 \\
\hline
\end{tabular}

f) Resumen por mes de las medias mensuales de cada año del GPS de Yebes:

\begin{tabular}{|c|c|c|c|c|c|c|c|c|c|c|c|c|}
\hline Mes & 1 & 2 & 3 & 4 & 5 & 6 & 7 & 8 & 9 & 10 & 11 & 12 \\
\hline Media & 8.59 & 8.85 & 9.96 & 11.81 & 14.97 & 18.52 & 17.73 & 18.54 & 18.06 & 16.36 & 11.42 & 9.84 \\
\hline STD & 1.09 & 1.08 & 1.08 & 0.78 & 0.71 & 1.47 & 1.08 & 1.72 & 1.40 & 1.63 & 2.67 & 1.49 \\
\hline Mediana & 8.66 & 8.63 & 10.28 & 12.10 & 14.84 & 18.72 & 17.40 & 18.57 & 17.92 & 16.40 & 11.46 & 9.20 \\
\hline Máximo & 10.00 & 10.53 & 11.08 & 12.88 & 15.88 & 20.81 & 19.29 & 20.79 & 20.52 & 19.32 & 14.80 & 12.71 \\
\hline Mínimo & 6.39 & 7.18 & 8.08 & 10.90 & 13.85 & 16.50 & 16.35 & 16.00 & 15.74 & 13.44 & 7.03 & 8.46 \\
\hline No Días & 206 & 196 & 213 & 209 & 217 & 199 & 209 & 207 & 195 & 207 & 207 & 205 \\
\hline
\end{tabular}




\section{Gráficas de la estación de Yebes}

g) Evolución temporal de las medias diarias.

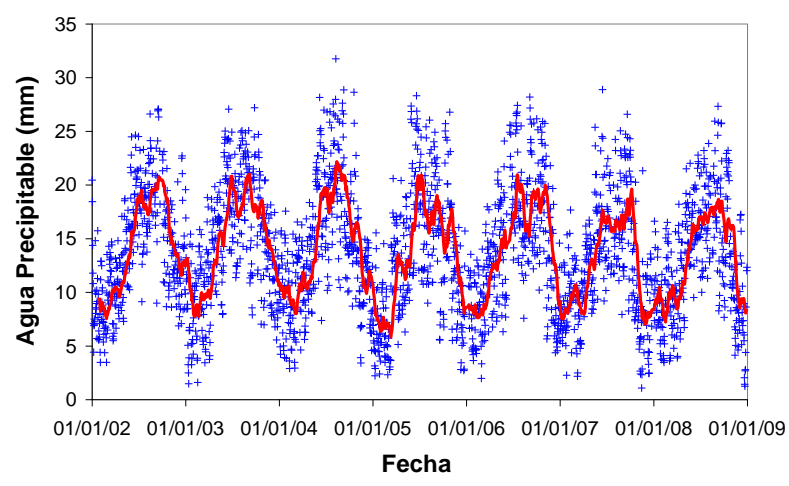

La línea roja representa la media móvil mensual.

i) Valores medios mensuales de las medias diarias para cada mes y año.

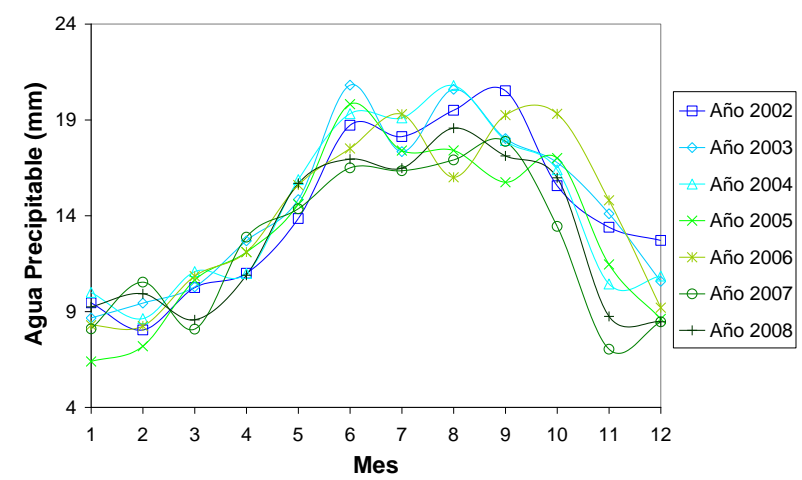

h) Histograma de las medias diarias.

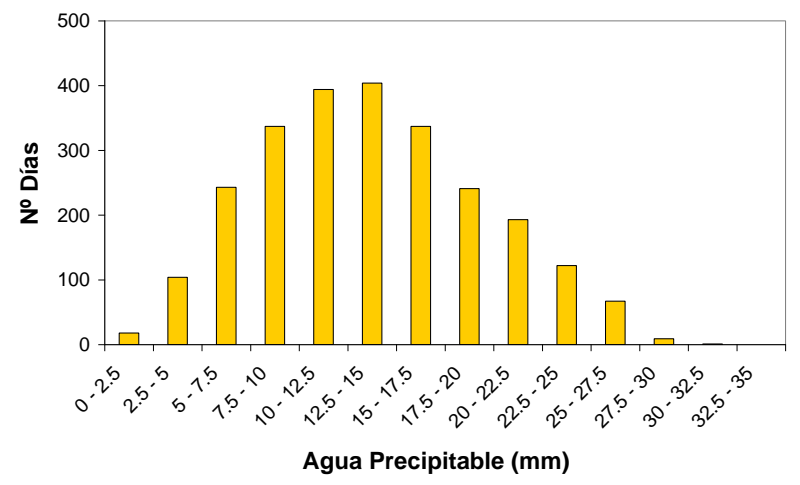

La distribución presenta un desplazamiento hacia la derecha (coef. de asimetría positivo), y un ligero achatamiento (curtosis negativa) respecto de la distribución normal.

j) Ciclo promedio anual.

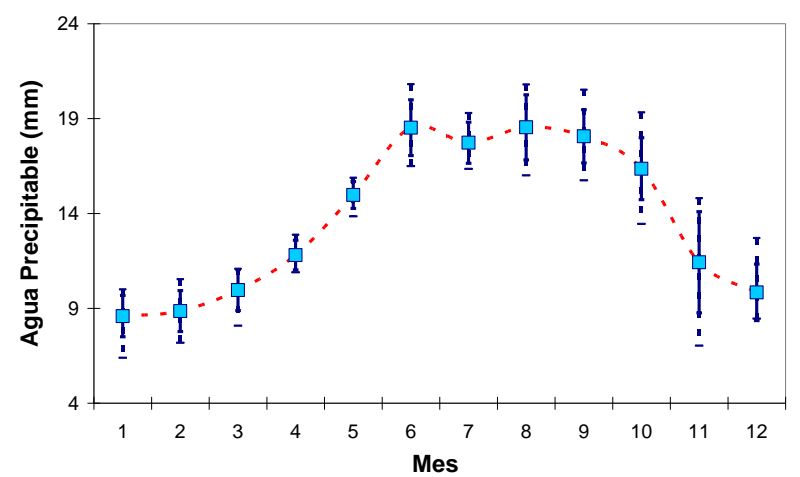

Valor promedio de las medias mensuales de cada año (cuadrados). Valor promedio más/menos la desviación típica de las medias mensuales (barras sólidas). Valor máximo y mínimo absoluto de las medias mensuales (líneas de trazos). 


\subsection{Discusión de resultados}

En este apartado se comentarán de forma resumida algunas de las características del comportamiento del PWV a la vista de los resultados presentados anteriormente. Un análisis más detallado se estudiará en los próximos capítulos. En concreto, el Capítulo 4 está íntegramente dedicado al estudio del ciclo anual, el Capítulo 5 al ciclo diurno, y el Capítulo 6 a la variabilidad diaria y horaria.

A la hora de valorar los resultados hay que tener en cuenta que los datos han sido adquiridos con tres tipos de instrumentación basadas en técnicas diferentes, cada una de ellas con sus ventajas e inconvenientes según se ha visto en el Capítulo 1. Este hecho puede implicar diferencias en las medidas, como queda de manifiesto cuando se comparan los resultados obtenidos para un mismo emplazamiento con instrumentaciones distintas, como es el caso de Coruña o Santander que disponen de estación de sondeo y de receptor de GPS. La comparativa entre las distintas técnicas de medida del PWV usadas en este estudio es tema de estudio de los Capítulos 7 y 8, pero se adelanta en este punto que las medidas de los GPS con anterioridad a noviembre del 2006 sobrestiman el PWV con respecto a las otras dos técnicas.

El número de medidas usadas para realizar el análisis estadístico anterior varía mucho en función de la técnica utilizada. De los sondeos son de los que se disponen menos datos, entre cuatro y cinco mil por estación, salvo en Zaragoza que baja a los tres mil y en Lisboa donde se quedan por debajo de este número. En el caso de los fotómetros y los GPS el número de medidas es un orden de magnitud mayor, con un promedio de unas cincuenta y cinco mil medidas por estación, aunque desigualmente distribuidas a lo largo del día en el caso de los fotómetros.

Partiendo de las estadísticas globales del conjunto de las medias diarias de cada estación (Tabla 3.1) se desprende que:

a) El número medio de días con dato es de 2288 de los 2556 posibles. Si excluimos las estaciones fotométricas, afectadas por las condiciones meteorológicas, y la estación de sondeo de Zaragoza, el número asciende a 2371 , que supone un $93 \%$ de los días.

b) El PWV es mayor en las estaciones ubicadas en la costa que en las del interior, y mayor en las de la costa mediterránea que en las de la atlántica. Para las estaciones del interior los valores oscilan entre unos 12 y $17 \mathrm{~mm}$, mientras que en las de costa lo hacen aproximadamente entre los 17 y los $21 \mathrm{~mm}$. Además, el PWV disminuye en término medio conforme aumenta la altitud de la estación. Ello puede influir en que la dispersión entre los valores medios del PWV en las estaciones del interior sea mayor que en las de la costa, las cuales se encuentran a altitudes más próximas. 
c) La std de las medias diarias del PWV oscila entre los 5 y $9 \mathrm{~mm}$, siendo menor en las estaciones del interior que en las costeras. En porcentaje respecto del valor medio del PWV la std oscila entre un 34 y un $43 \%$, registrándose generalmente los valores más bajos en las costas atlánticas.

d) La media y la mediana de la distribución difieren poco entre sí, entre 0.34 y $1.34 \mathrm{~mm}$ (aproximadamente un 2 a 6\%), siendo la media siempre mayor que la mediana. Ambos estadísticos se sitúan mayoritariamente a la derecha de la clase modal, o bien dentro del intervalo de esta. Es decir, la distribución de las medias diarias presenta una asimetría a derechas, con un coeficiente de asimetría entre 0.26 y 0.56 . A si mismo, para la mayoría de las estaciones la distribución resulta ser platicúrtica, menos apuntada que la distribución normal, con unos valores de la curtosis entre -0.78 y -0.11 , salvo para Palencia y Lisboa donde la curtosis es ligeramente positiva (distribución leptocúrtica o más apuntada que la normal). Las distribuciones con mayor valor negativo de la curtosis se corresponden con las de las estaciones de la costa mediterránea.

e) Los valores del Percentil 5 de la distribución oscilan entre 5 y $10 \mathrm{~mm}$, registrándose los más bajos en las estaciones del interior, con valores entre 5 y $7 \mathrm{~mm}$, y los más altos en las costas, con valores entre 8 y $10 \mathrm{~mm}$, sin que se observe distinción entre las costas atlánticas o la mediterránea.

f) Los valores mínimos absolutos de las medias diarias se sitúan sobre los 1 a $2 \mathrm{~mm}$ en las estaciones del interior y sobre los 2 a $4 \mathrm{~mm}$ en las costas. El mínimo valor registrado de todas las estaciones ha sido de $0.9 \mathrm{~mm}$ en la estación de sondeos de Madrid-Barajas.

g) Los valores del Percentil 95 de la distribución oscilan entre 22 y $37 \mathrm{~mm}$, registrándose los menores valores en las estaciones del interior, entre 22 y $30 \mathrm{~mm}$, y los mayores en la costa mediterránea, entre 33 y $37 \mathrm{~mm}$.

h) Los valores máximos absolutos de las medias diarias se sitúan sobre los 32 a $43 \mathrm{~mm}$ en las estaciones del interior y sobre los 40 a $46 \mathrm{~mm}$ en las costas. En las estaciones costeras estos valores son más uniformes que en las del interior. El máximo valor registrado ha sido de $45.72 \mathrm{~mm}$ en las estaciones GPS de Valencia y Almería.

i) El PWV promedio de las medias diarias de todas las estaciones para todo el periodo de estudio toma un valor de $18.19 \mathrm{~mm}$, con unos percentiles 5 y 95 de $7.73 \mathrm{~mm}$ y $30.62 \mathrm{~mm}$ respectivamente, un promedio de los máximos de $41.48 \mathrm{~mm}$, y un promedio de los mínimos de 2.49, un coeficiente de asimetría promedio de 0.35 (asimetría a derechas) y una curtosis promedia de -0.39 (distribución platicúrtica). 
A conclusiones similares se llega del análisis directo del conjunto global de las medidas en vez de con las medias diarias, con la salvedad de los valores máximos y mínimos absolutos. Al tratarse de medidas puntuales estos valores son más extremos que los de las medias diarias. El valor de la medida máxima registrada fue de $58.04 \mathrm{~mm}$ el 11 de agosto del 2003 en la estación GPS de Santander y el de la mínima fue de $0.18 \mathrm{~mm}$ el día 19 de marzo del 2003 en la estación GPS de Yebes. Sin embargo, estos valores extremos absolutos hay que tomarlos con más cautela porque pueden corresponderse con alguna medida errónea.

\begin{tabular}{|c|c|c|c|c|c|c|c|c|c|c|c|c|}
\hline Estación & Técnica I & Nº Días & Media & STD & Mediana & Moda & $\begin{array}{c}\text { Percentil } \\
5 \\
\end{array}$ & $\begin{array}{c}\text { Percentil } \\
95 \\
\end{array}$ & Máximo & Mínimo & $\begin{array}{c}\text { Coef. } \\
\text { Asimetría }\end{array}$ & Curtosis \\
\hline Alicante & GPS & 2387 & 21.07 & 8.33 & 20.24 & $12.5-15$ & 8.57 & 35.49 & 44.99 & 3.00 & 0.26 & -0.78 \\
\hline Almería & & 2490 & 20.42 & 7.32 & & & 9.48 & 33.00 & 45.72 & 4.13 & 0.27 & -0.58 \\
\hline Cáceres & GPS & 2452 & 16.26 & 634 & 15.87 & $12.5-15$ & 6.45 & 27.45 & 38.43 & 120 & 0.32 & -0.32 \\
\hline Coruña & Sond & 2367 & 18.50 & 6.65 & 17.99 & $15-17.5$ & 8.35 & 30.27 & & 2.12 & 0.30 & -0.29 \\
\hline Coruña & GPS & 2283 & 20.14 & 7.14 & 19.51 & $17.5-20$ & 9.14 & 32.62 & & 3.02 & 0.32 & -0.26 \\
\hline Creus & & 2328 & 20.04 & 8.31 & 19.20 & $12.5-15$ & 7.94 & 34.67 & 43.67 & 2.01 & 0.31 & -0.73 \\
\hline EI Arenosillo & Fotom & 2101 & 17.79 & 6.65 & 17.06 & $12.5-15$ & 7.99 & 29.68 & 45.28 & 2.24 & 0.47 & -0.11 \\
\hline Gibraltar & Sond & 2531 & 20.37 & 7.02 & 19.70 & $17.5-20$ & 9.87 & 33.19 & 43.90 & 3.64 & 0.39 & -0.17 \\
\hline Lisboa & Sond & 2238 & 17.21 & 6.43 & 16.58 & $12.5-17.5$ & 7.90 & 28.80 & 40.43 & 2.63 & 0.50 & 0.07 \\
\hline Madrid & Sond & 2300 & 14.45 & 5.75 & 14.05 & $12.5-15$ & 5.68 & 24.52 & 34.69 & 0.90 & 0.35 & -0.19 \\
\hline Murcia & Sond & 2410 & 19.11 & 7.44 & 18.53 & $12.5-15$ & 7.97 & 32.02 & 45.13 & 2.90 & 0.30 & -0.52 \\
\hline Palencia & Fotom & 1565 & 12.15 & 5.27 & 11.61 & $10-12.5$ & 4.60 & 21.85 & 35.36 & 1.51 & 0.56 & 0.16 \\
\hline Roquetes & GPS & 2285 & 21.08 & 8.90 & 19.99 & $15-17.5$ & 8.12 & 37.01 & 44.11 & 2.21 & 0.32 & -0.77 \\
\hline S. Fernando & GPS & 2434 & 19.03 & 6.75 & 18.69 & $17.5-20$ & 8.61 & 30.73 & 43.37 & 2.69 & 0.34 & -0.14 \\
\hline Santander & Sond & 2338 & 18.77 & 7.20 & 18.01 & $15-17.5$ & 8.34 & 31.29 & 41.96 & 3.40 & 0.37 & -0.50 \\
\hline Santander & GPS & 2448 & 20.15 & 7.60 & 19.30 & $15-17.5$ & 9.01 & 33.37 & 42.15 & 3.14 & 0.33 & -0.53 \\
\hline Valencia & GPS & 2113 & 20.82 & 8.87 & 19.48 & $15-17.5$ & 8.20 & 36.46 & 45.72 & 2.39 & 0.38 & -0.69 \\
\hline Villafranca & GPS & 2440 & 15.75 & 6.26 & 15.22 & $12.5-15$ & 6.35 & 26.56 & 34.75 & 1.72 & 0.30 & -0.48 \\
\hline Yebes & GPS & 2470 & 13.71 & 5.69 & 13.26 & $12.5-15$ & 5.03 & 23.78 & 31.75 & 1.08 & 0.27 & -0.54 \\
\hline Zaragoza & Sond & 1771 & 17.07 & 7.04 & 16.11 & $15-17.5$ & 7.02 & 29.56 & 42.58 & 2.54 & 0.40 & -0.51 \\
\hline
\end{tabular}

Tabla 3.1 - Estadísticas globales de las medias diarias del PWV por estación.

Aunque el ciclo anual del PWV se verá en profundidad en el capítulo siguiente, en este apartado se adelanta el comportamiento medio del mismo sobre la Península, obtenido en base a los promedios para cada mes del año de las medias diarias de cada estación. De acuerdo a los resultados (Figura 3.2), el PWV registra sus valores más bajos en los meses del invierno, experimenta un aumento durante los meses de marzo a junio, se mantiene entorno a sus valores máximos de julio a septiembre, y finalmente disminuye de octubre a diciembre de una forma más pronunciada que el ascenso de la primavera. La amplitud media de este ciclo es de unos $12 \mathrm{~mm}$, duplicando los valores del verano $(24-25 \mathrm{~mm})$ a los del invierno (12-13 $\mathrm{mm}$ ). Los valores máximos, mínimos, y de los percentiles 5 y 95 de las medias diarias presentan un comportamiento similar a lo largo del año, de hecho las gráficas son bastantes paralelas. La diferencia media entre la media y los percentiles 5 y 95 se sitúa sobre los $8 \mathrm{~mm}$ 
(aproximadamente un 47\%), siendo mayor en los meses del verano y otoño que en los del invierno y primavera. Por su parte los máximos se encuentran en promedio $14 \mathrm{~mm}$ (83\%) por encima de la media, mientras que los mínimos lo están $11 \mathrm{~mm}(65 \%)$ por debajo de la media.

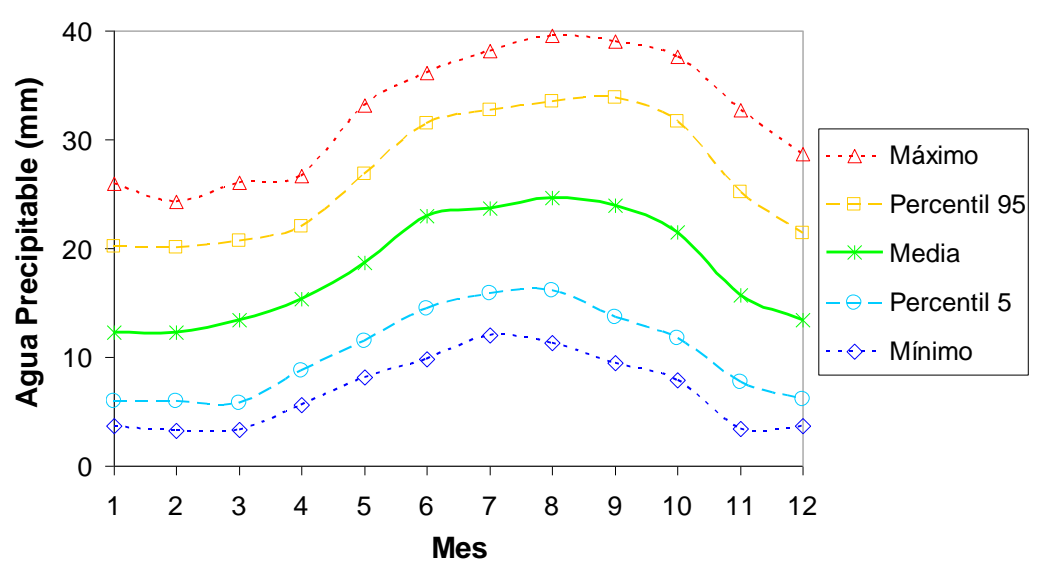

Figura 3.2 - Evolución anual media de todas las estaciones de los valores promedios de las medias diarias del PWV para cada mes.

La std oscila en todos los emplazamientos entorno a los $5 \mathrm{~mm}$ para la mayoría de los meses, siendo menor en el invierno y la primavera, y mayor en el verano y otoño, especialmente en este último. La máxima dispersión se ha registrado en la estación de Roquetes para el mes septiembre, superando los $8 \mathrm{~mm}$, mientras que la mínima se registró en Palencia para el mes de enero con $3 \mathrm{~mm}$.

La distribución de las medias diarias presenta un coeficiente medio de asimetría positivo para todos los meses, con valores más elevados en los meses de noviembre a febrero, es decir, en invierno, cuando el contenido de PWV es menor, hay una mayor concentración de datos a la izquierda de la media. Por su parte la curtosis resulta negativa para la mayoría de los meses, sólo de noviembre a enero resulta ligeramente positiva. En la Figura 3.3 se observa como el coeficiente de asimetría y la curtosis siguen una evolución paralela a lo largo del año. Conforme el coeficiente de asimetría toma valores mayores, la cola de la distribución se extiende más hacia los valores altos de PWV que hacia los bajos, es decir, los valores máximos de PWV se separan de la media más que los mínimos y la distribución es menos achatada, tomando la curtosis valores próximo a cero. Por el contrario, cuando el coeficiente de asimetría toma valores próximos a cero, es decir, los valores máximos y mínimos de la distribución se encuentran equidistantes de la media, la distribución se hace más achatada, tomando la curtosis los valores más bajos.

Por último, se analizarán los valores medios anuales del PWV para cada uno de los siete años de este estudio. En las estaciones de la costa mediterránea se han registrado todos los años valores medios anuales del PWV entre 19 y $22 \mathrm{~mm}$, mientras que en las de la costa atlántica lo han hecho entre 15 y $21 \mathrm{~mm}$, y en las del interior entre 11 y $18 \mathrm{~mm}$. Las diferencias entre los 
años con mayor y menor cantidad de PWV se sitúan entre los 2 a $4 \mathrm{~mm}$ para la mayoría de las estaciones, independientemente de su localización geográfica. En las estaciones GPS se observa que el año con mayor valor medio del PWV fue para todas ellas anterior al 2007, mientras que el de menor PWV fue siempre posterior al 2006. Este hecho está relacionado con el cambio en el procesamiento de las señales del GPS que tuvo lugar en noviembre del 2006 y que supuso una disminución en las cantidades del PWV estimadas por esta técnica (ver Capítulo 7).

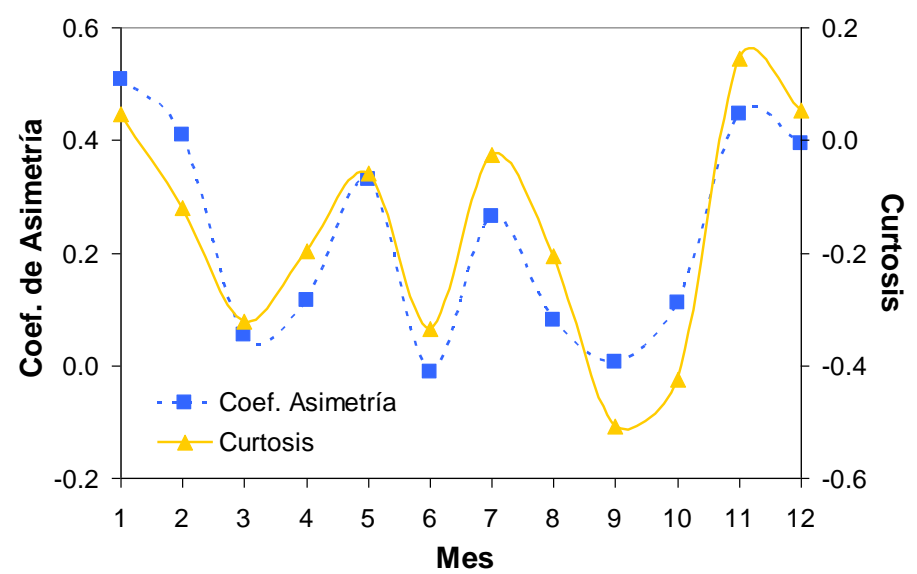

Figura 3.3 - Coeficientes promedios mensuales de asimetría y curtosis de las distribuciones de las medias diarias de PWV.

Los mayores valores de la media anual de los máximos mensuales de las medias diarias se registran en las zonas costeras, entre 28 y $32 \mathrm{~mm}$, y los menores en el interior con valores muy dispersos. Por su parte, la media de los mínimos varía entre 10 y 14 mm en las costas y los 6 y $9 \mathrm{~mm}$ en el interior.

\begin{tabular}{cccc}
\hline Año & Media & $\begin{array}{c}\text { Media } \\
\text { de los } \\
\text { máximos }\end{array}$ & $\begin{array}{c}\text { Media } \\
\text { de los }\end{array}$ \\
\hline $\mathbf{2 0 0 2}$ & 18.4 & 28.1 & 10.4 \\
$\mathbf{2 0 0 3}$ & 19.0 & 28.0 & 10.2 \\
$\mathbf{2 0 0 4}$ & 18.7 & 28.3 & 10.0 \\
$\mathbf{2 0 0 5}$ & 17.4 & 27.5 & 8.9 \\
$\mathbf{2 0 0 6}$ & 19.1 & 28.4 & 10.4 \\
$\mathbf{2 0 0 7}$ & 17.1 & 27.0 & 9.1 \\
$\mathbf{2 0 0 8}$ & 17.7 & 27.2 & 9.1 \\
\hline
\end{tabular}

Tabla 3.2 - Valores promedios anuales del PWV en la Península lbérica. La media de los máximos y de los mínimos se refiere a la media anual de los máximos y mínimos mensuales de las medias diarias.

La media de los promedios anuales de PWV de cada estación varía entre los $19.1 \mathrm{~mm}$ del año 2006 y los $17.1 \mathrm{~mm}$ del 2007, mientras que la media de los máximos mensuales lo hace entre los $27 \mathrm{~mm}$ del año 2007 y los $28.4 \mathrm{~mm}$ del 2006, y la de los mínimos entre los $8.9 \mathrm{~mm}$ del año 2005 y los $10.4 \mathrm{~mm}$ del 2002 y 2006 (Tabla 3.2). 


\subsection{Distribución vertical del vapor de agua}

En las secciones anteriores se ha caracterizado el contenido total de PWV sobre la Península. En este apartado se estudiará su distribución vertical a partir de los perfiles verticales suministrados por los sondeos, que es la única técnica de las utilizadas que aporta este tipo de información. Para este análisis se han utilizado nueve años de datos, del 2000 al 2008.

A la hora de promediar los perfiles verticales de humedad de los sondeos, el problema que se plantea es que estos no toman siempre las lecturas a los mismos niveles de altitud o de presión, por ello, primero se han reducido las lecturas a unos niveles estándar de presión o altitud, establecidos como de referencia. A este respecto se ha dividido la atmósfera en capas de altura variable, de $100 \mathrm{~m}$ durante los primeros $3 \mathrm{Km}$ de altitud, de $200 \mathrm{~m}$ entre los $3 \mathrm{Km}$ y los $9 \mathrm{Km}$ de altitud, de $500 \mathrm{~m}$ hasta los $14 \mathrm{Km}$, y de $1 \mathrm{Km}$ a partir de este nivel y hasta la máxima altitud alcanzada por el sondeo. Los niveles de referencia se han denominado por el valor de la altitud del punto medio de cada capa, es decir, el nivel de referencia $50 \mathrm{~m}$ comprenderá las lecturas tomadas en la capa que va desde los $0 \mathrm{~m}$ (nivel del mar) a los $100 \mathrm{~m}$ de altitud, y de igual manera con el resto de capas.

Para cada estación se han procesado de forma global todos los sondeos, asignando cada lectura a la capa de referencia correspondiente a su altitud. Se ha utilizado esta técnica en vez de recalcular las lecturas de los sondeos para ajustarlas mediante una interpolación a los niveles estándar predefinidos, porque esto implicaría presuponer un comportamiento lineal del PWV, lo que no tiene porque ajustarse a la realidad por la presencia de capas intermedias de carácter seco o húmedo. Posteriormente, las lecturas asignadas a cada capa se han promediado para obtener la distribución media vertical. De esta manera, para cada capa o nivel de referencia se ha determinado el valor medio de la presión, la temperatura, el punto de rocío, la humedad relativa, la razón de mezcla, la tensión de vapor y la humedad absoluta. Este mismo procedimiento también se ha realizado por mes, para estudiar así la variación anual de la distribución vertical. Esta última parte se verá en el próximo capítulo.

En la Figura 3.4 se ha representado la distribución vertical media obtenida para la humedad absoluta. En ella se observa cómo en las capas bajas (por debajo de $1 \mathrm{Km}$ ) la distribución del vapor de agua, representado por la humedad absoluta, es más heterogénea entre estaciones, registrándose los valores más altos en las estaciones costeras, donde el aporte de vapor desde la superficie es mayor. A partir de ese nivel el contenido de vapor de agua en la atmósfera tiende a homogeneizarse, y por encima de los $5 \mathrm{Km}$ es prácticamente el mismo en todas las estaciones. Ello es debido a que el vapor de agua se incorpora a la atmósfera desde la superficie terrestre, difundiéndose hacia las capas medias y altas por movimientos verticales de convección y turbulencia. A esos niveles es transportado en la horizontal por los intensos vientos, produciéndose una mezcla a gran escala. Por ello, en los niveles medios y altos el 
contenido de vapor de agua está muy determinado por la escala sinóptica, cuyo orden de magnitud (de $1000 \mathrm{Km}$ o más) cubre toda la Península, mientras que en las capas más bajas lo está a nivel de mesoescala, jugando un papel prioritario el tipo de superficie y la configuración geográfica de la zona.

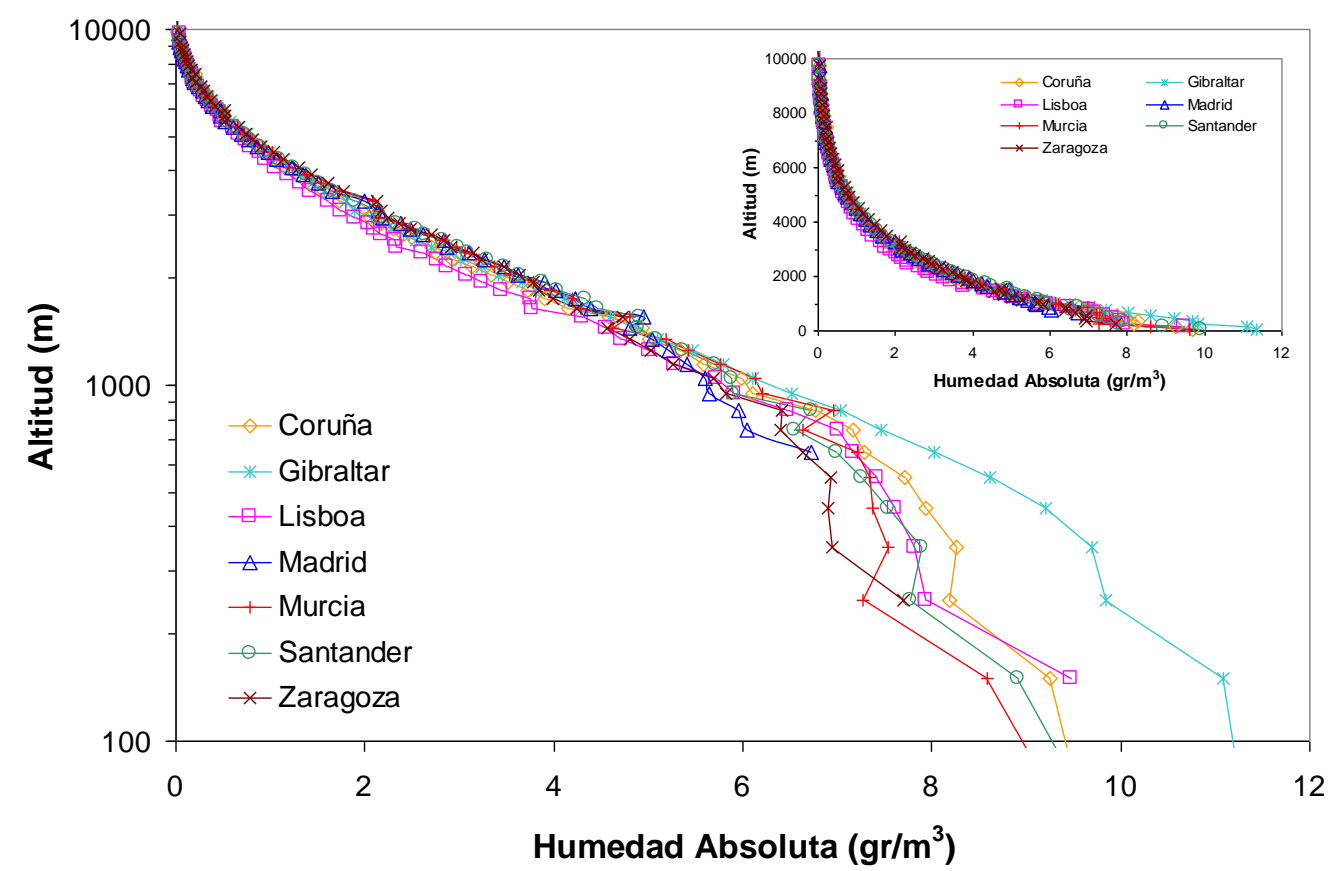

Figura 3.4 - Distribución media en la vertical de la humedad absoluta para cada estación de sondeo. La altitud se encuentra representada a escala logarítmica para resaltar las capas bajas donde las diferencias entre estaciones son mayores. La gráfica de cada estación se corta cuando se alcanza la superficie terrestre a la altitud de cada una. En la esquina superior derecha se ha representado la misma gráfica en escala lineal de altitud.

En término medio la humedad absoluta disminuye con la altitud, aunque su ritmo de decrecimiento también va disminuyendo con esta (Tabla 3.3), si bien en valores relativos oscila siempre entorno a un $40-50 \%$ por kilómetro a todos los niveles durante los primeros $10 \mathrm{Km}$. A partir de esta altitud la humedad absoluta se puede considerar despreciable, tomando unos valores medios de $0.01 \mathrm{gr} / \mathrm{cm}^{3}$ o menores para el resto de la columna atmosférica.

Otra característica que se observa en la gráfica anterior es la presencia de una estrecha capa ligeramente más seca hacia los $250 \mathrm{~m}$, excepto evidentemente en las estaciones que se encuentran por encima de esta altitud.

\begin{tabular}{|c|c|c|c|c|c|c|c|c|c|c|}
\hline & $\begin{array}{l}0-1 \\
\mathrm{Km}\end{array}$ & $\begin{array}{l}1-2 \\
\mathrm{Km}\end{array}$ & $\begin{array}{l}2-3 \\
\mathrm{Km}\end{array}$ & $\begin{array}{l}3-4 \\
\mathrm{Km}\end{array}$ & $\begin{array}{l}4-5 \\
\mathrm{Km}\end{array}$ & $\begin{array}{l}5-6 \\
\mathrm{Km}\end{array}$ & $\begin{array}{l}6-7 \\
\mathrm{Km}\end{array}$ & $\begin{array}{l}7-8 \\
\mathrm{Km}\end{array}$ & $\begin{array}{l}8-9 \\
\mathrm{Km}\end{array}$ & $\begin{array}{c}9-10 \\
\mathrm{Km}\end{array}$ \\
\hline $\begin{array}{c}\text { Razón Absoluta } \\
\left(\mathrm{gr} / \mathrm{m}^{3} \cdot \mathrm{Km}\right)\end{array}$ & 4.13 & 2.19 & 1.36 & 0.69 & 0.41 & 0.23 & 0.16 & 0.07 & 0.06 & 0.00 \\
\hline $\begin{array}{c}\text { Razón Relativa } \\
(\%)\end{array}$ & 53 & 47 & 49 & 42 & 42 & 40 & 50 & 41 & 67 & 12 \\
\hline
\end{tabular}

Tabla 3.3 - Razón media de la disminución de la humedad absoluta con la altitud en los primeros $10 \mathrm{Km}$ de atmósfera. Se ha representado tanto el valor absoluto de la disminución $\left(\mathrm{gr} / \mathrm{m}^{3} \cdot \mathrm{Km}\right)$, como la variación relativa (\%) respecto al valor medio de la humedad absoluta para cada kilómetro de altitud. 
Para cuantificar la contribución relativa de cada capa al total del PWV, se ha calculado el PWV de cada capa multiplicando la humedad absoluta media de la capa por su anchura. Posteriormente, se ha calculado para cada capa el PWV acumulado por encima de la capa hasta los $10 \mathrm{Km}$ (Figura 3.5), y por debajo hasta el nivel del suelo (Figura 3.6). En la primera figura se observa cómo la contribución absoluta al PWV total de las capas atmosféricas por encima de los $3 \mathrm{Km}$ es prácticamente la misma en todas las estaciones. Entre $3 \mathrm{Km}$ y $1 \mathrm{Km}$ empiezan a ser patentes las primeras diferencias, más apreciables en la estación de Lisboa. Por debajo de $1 \mathrm{Km}$, y especialmente de los $400 \mathrm{~m}$, las diferencias son más significativas. En términos relativos porcentuales respecto del total, la contribución de las capas superiores es prácticamente igual para todas las estaciones por encima de los $5 \mathrm{Km}$. Ello es debido a la diferencia de altitud entre las estaciones. Sin embargo, para las situadas a la misma altitud (nivel del mar), la contribución relativa de las capas superiores de cada nivel es prácticamente la misma para todas ellas, salvo para Gibraltar donde es ligeramente menor.

Estudiando las mismas gráficas, pero en niveles de altura respecto a la estación en lugar de en niveles de altitud respecto del nivel del mar, la dispersión entre estaciones se hace más patente por la diferencia de altitud entre ellas. Las situadas a mayor altitud se localizan en la zona izquierda de la gráfica, ya que para una misma altura estamos observando capas atmosféricas más altas donde la temperatura y el contenido de PWV es menor. Sin embargo, en términos relativos de porcentaje respecto del valor medio del PWV las gráficas de cada estación se superponen, indicando que el ritmo de disminución del PWV con la altura es prácticamente el mismo para todas las estaciones, y por tanto el contenido total de PWV está muy determinado por la contribución de las capas más bajas junto al suelo.

En el caso del PWV acumulado desde la superficie hasta cada altitud (Figura 3.6), se observa claramente que son las capas más bajas las que marcan la diferencia entre las gráficas, siguiendo posteriormente trayectorias paralelas, lo que pone una vez más de manifiesto que la contribución de las capas altas es la misma en todas las estaciones. Sólo en la estación de Lisboa se observa cómo la gráfica sufre un desplazamiento hacia la izquierda en las capas medias (entre los $2 \mathrm{Km}$ y $5 \mathrm{Km}$ ). Esto indicaría la presencia a esas altitudes de una capa relativamente más seca sobre esta estación que sobre las demás. En la gráfica superior izquierda se observa como la estación de Madrid se encuentra desplazada a la izquierda en el eje $X$ unos $4 \mathrm{~mm}$, que es aproximadamente la contribución media de la capa atmosférica entre el nivel del mar y los $600 \mathrm{~m}$ de altitud donde se localiza esta estación.

Para la media de todas las estaciones se ha obtenido que en los primeros $1500 \mathrm{~m}$ de altitud se localiza el $51 \%$ del total del PWV, y por debajo de los $5 \mathrm{Km}$ el $93 \%$. Mientras que este último valor es bastante constante para todas las estaciones, variando entre un 92 y $94 \%$, en el primero hay una mayor dispersión, variando entre el 35\% de Madrid y el 57\% de Gibraltar. 

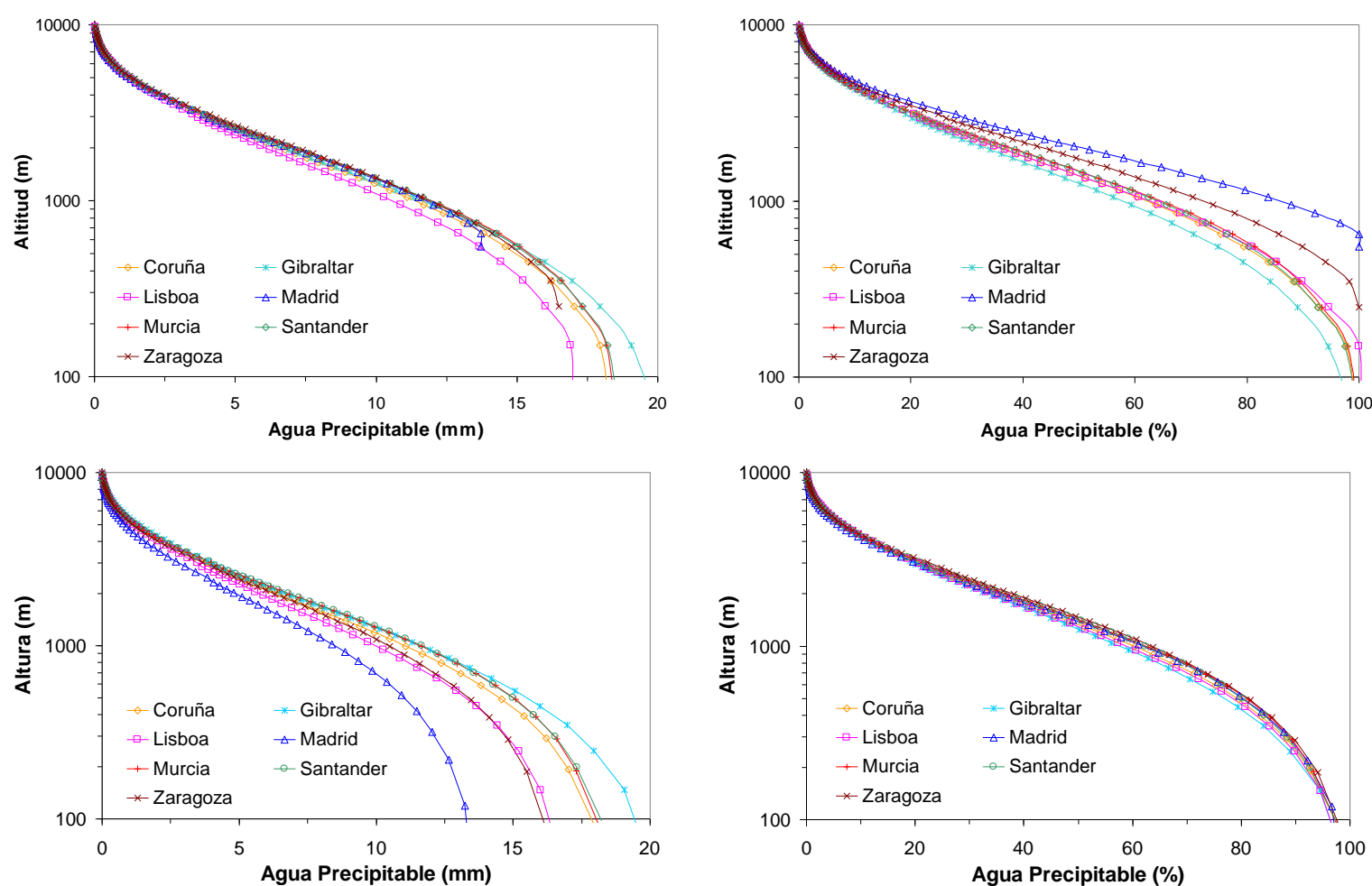

Figura 3.5 - Distribución vertical media del PWV acumulado desde cada nivel hasta los $10 \mathrm{Km}$ de altitud. Gráficas superiores: PWV acumulado por niveles de altitud en valor absoluto (izquierda) y en porcentaje (derecha). Gráficas inferiores: PWV acumulado por niveles de altura en valor absoluto (izquierda) y en porcentaje (derecha). La altitud y la altura están expresadas en escala logarítmica.
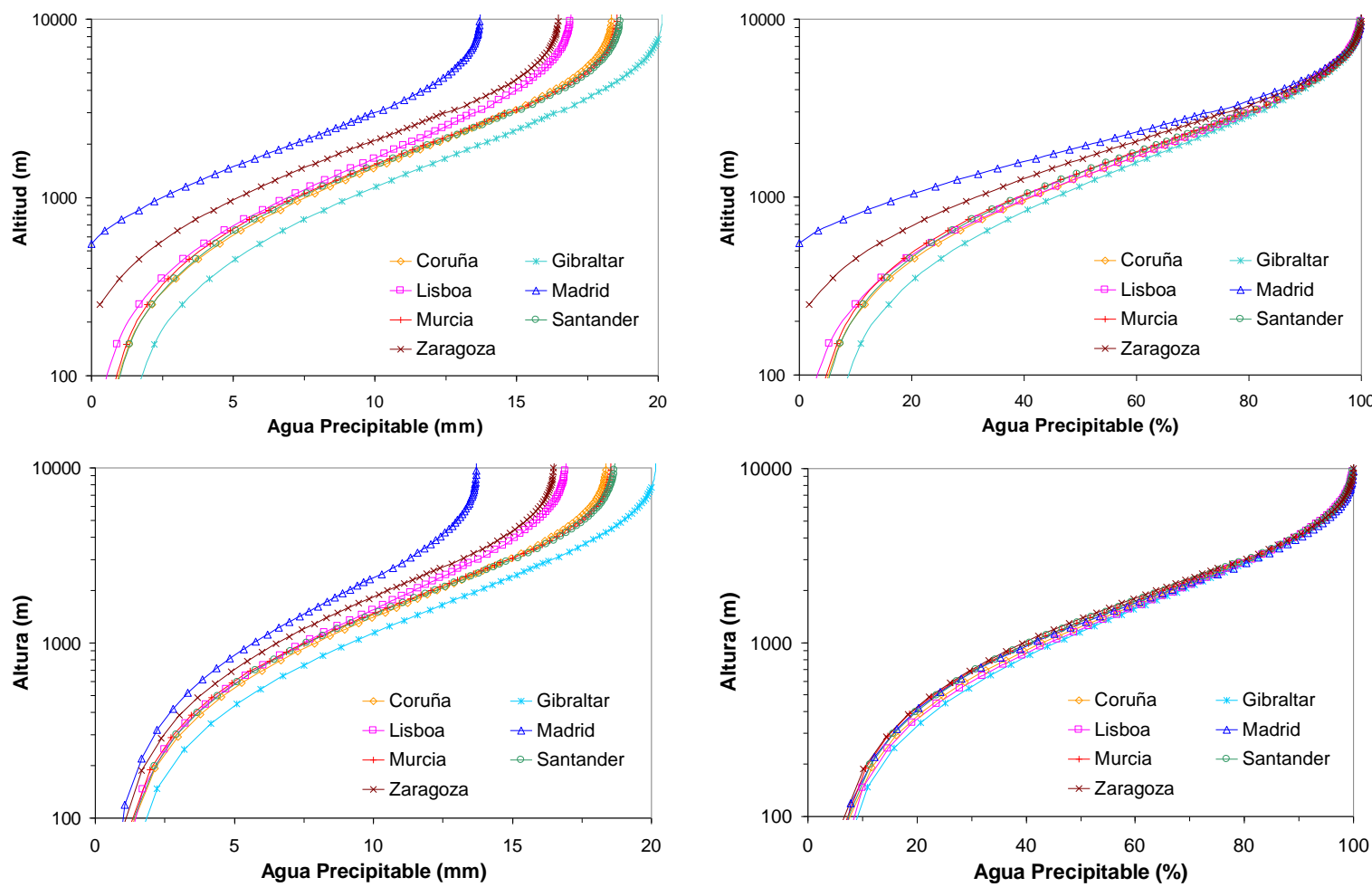

Figura 3.6 - Distribución vertical media del PWV acumulado desde la superficie hasta cada nivel de altitud. (Ver Figura 3.5 para más explicaciones). 
La contribución media de las capas situadas por encima de los $7 \mathrm{Km}$ de altitud es sólo de un $2 \%$ ( $0.3 \mathrm{~mm}$ en valor absoluto), mientras que la contribución de las capas situadas por encima de los $9 \mathrm{Km}$ es de $0.05 \mathrm{~mm}$, prácticamente un $0 \%$. En la Figura 3.6 se observa como para las capas altas las gráficas toman una trayectoria casi vertical, el PWV prácticamente no aumenta al computar la contribución de estas capas. Este hecho confirma que el criterio aplicado de haber alcanzado los $9 \mathrm{Km}$ de altitud para considerar un sondeo como válido es correcto. Pero hay que recordar aquí que en las estaciones de Santander, Zaragoza y Lisboa se han tomado como válidos los sondeos que han alcanzado sólo los $7 \mathrm{Km}$ de altitud. Como en estas estaciones el número de sondeos que han alcanzado una altitud entre los $7 \mathrm{Km}$ y los $9 \mathrm{Km}$ es algo menos de la mitad (aproximadamente un $40-45 \%$ del total de los computados) y la contribución media de las capas superiores a $7 \mathrm{Km}$ es de un $2 \%$, se estaría subestimando el PWV el un porcentaje inferior al $1 \%$. 
- 128 - 


\section{Capítulo 4}

\section{CICLO ANUAL}

En este capítulo se analizará en primer lugar la evolución anual del PWV sobre la Península, utilizando para ello los resultados obtenidos en el capítulo anterior. Como el número de emplazamientos con siete años de datos no es muy elevado para cubrir la compleja geografía de la Península, en el segundo apartado se estudiará el ciclo anual sólo con los datos del año 2008. De esta manera, el número de estaciones disponibles casi se duplica, y aunque el estudio no tenga ningún valor climatológico, si permite determinar mejor la homogeneidad del PWV sobre la Península, y así valorar la representatividad de los resultados obtenidos en el primer apartado. En un tercer apartado se examinará la evolución anual de la distribución vertical del vapor de agua con la ayuda de nueve años de datos de sondeos, del 2000 al 2008. Finalmente, para validar el carácter climatológico de los resultados obtenidos, se comparará el ciclo anual de las estaciones de radiosondeo de Coruña y Madrid con el obtenido con la serie de veinticinco años de datos, de 1984 a 2008, de las mismas estaciones.

\subsection{Ciclo anual medio del agua precipitable}

Las gráficas de la evolución temporal de las medias diarias del PWV muestran claramente como el PWV presenta un ciclo a lo largo del año (ver Capítulo 3). El ciclo anual medio para cada emplazamiento se obtuvo en el capítulo anterior. Estos ciclos están representados en la Figura 4.1, y sus valores se recogen en la Tabla 4.1.

De un primer análisis se concluye que el PWV experimenta un comportamiento muy similar para todas las estaciones, describiendo un ciclo anual con un mínimo en los meses del invierno, incrementando durante la primavera hasta alcanzar el valor máximo hacia finales del verano, y disminuyendo durante el otoño, de una manera más pronunciada que el ascenso de la primavera hasta volver a alcanzar el mínimo en invierno. Los ciclos de las estaciones del interior presentan una mayor separación vertical entre sí que los de las estaciones de las zonas costeras, debido principalmente a la diferencia de altitud a las que se encuentran las primeras. Se observa un comportamiento singular para las estaciones situadas en el cuadrante suroeste, que consiste en la presencia de un mínimo relativo en el mes de julio. Este fenómeno se verá con más detalle en el punto 4.4 del presente capítulo. 
En las estaciones ubicadas más al norte, tanto en la costa como en el interior, el mínimo valor del PWV se registra en febrero, mientras que en el resto lo hace en enero. Por su parte, el máximo de PWV se registra principalmente en el mes de agosto, retrasándose a septiembre para las estaciones más al sur.

\begin{tabular}{|c|c|c|c|c|c|c|c|c|c|c|c|c|c|c|c|}
\hline Esta & & ne & Feb & Mar & Abr & May & un & Jul & Ago & Sep & Oct & Nov & Dic & M-m & $\mathrm{M} / \mathrm{m}$ \\
\hline & & & & & & & & & & & & & 14.8 & 183 & 2.4 \\
\hline & & & 3.9 & & & & & & & & & & & 14.9 & 2.1 \\
\hline & & & & 12.8 & & & 20.7 & 19.1 & 21.1 & 20.8 & 20.0 & 14.5 & 12.4 & 9.7 & 1.9 \\
\hline & & 15.0 & 129 & 14.5 & 14.8 & 18.2 & 22.0 & 23.9 & 23.9 & 22.4 & 21.5 & 17.0 & 15.1 & 11.1 & 1.9 \\
\hline & & 15.7 & 13.7 & 16.4 & 16.6 & 20.3 & 24.6 & & 26.0 & & & 18.2 & 16.1 & 13.2 & 2.0 \\
\hline Creus & GPS & 12.3 & 11.8 & 13.8 & 16.9 & 21.4 & 26.8 & 28.7 & 29.7 & 26.3 & 23.8 & 16.3 & 13.7 & 17.8 & 2.5 \\
\hline El Are & Cimel & 11.9 & 12.8 & 13.1 & 14.8 & 18.3 & 22.0 & 20.7 & 22.2 & 24.1 & 20.9 & 16.1 & 13.7 & 12.2 & 2.0 \\
\hline & Sondeo & 14.2 & 15.6 & 15.9 & 17.2 & 19.8 & 23.6 & 23.1 & 25.8 & 27.4 & 25.6 & 19.0 & 16.9 & 13.2 & 1.9 \\
\hline & solineo & 13.6 & 10.4 & 10.0 & 14.4 & 17.1 & 19.5 & 19.6 & 20.5 & 21.3 & 20.4 & 16.5 & 14.1 & 7.9 & 1.6 \\
\hline Madrid & Sondeo & 9.8 & 9.8 & 10.7 & 12.1 & 15.2 & 18.7 & 17.7 & 18.4 & 18.4 & 17.2 & 12.5 & 10.3 & 8.9 & 1.9 \\
\hline & Sondeo & 11.9 & 12.7 & 13.6 & 16.1 & 19.0 & 24.0 & 25.3 & 27.3 & 26.4 & 22.5 & 15.7 & 13.9 & 15.4 & 2.3 \\
\hline Palencia & Cimel & 7.6 & 7.4 & 7.4 & 9.7 & 12.4 & 15.4 & 16.0 & 16.6 & 15.3 & 13.9 & 10.5 & 8.1 & 9.2 & 2.3 \\
\hline Roquetes & GPS & 12.5 & 12.7 & 14.6 & 17.5 & 22.1 & 27.8 & 31.0 & 30.5 & 28.6 & 24.4 & 16.3 & 13.9 & 18.5 & 2.5 \\
\hline & Sondeo & 13.1 & 11.9 & 13.7 & 15.5 & 18.7 & 24.3 & 25.7 & 26.0 & 23.2 & 20.5 & 16.1 & 13.6 & 14.1 & 2.2 \\
\hline Santander & GPS & 14.3 & 13.1 & 14.7 & 17.0 & 21.0 & 26.7 & 27.9 & 28.4 & 25.1 & 22.7 & 17.3 & 14.4 & 15.2 & 2.2 \\
\hline S. Fernando & GPS & 13.1 & 14.8 & 15.1 & 16.3 & 18.9 & 22.7 & 21.1 & 23.6 & 25.5 & 24.1 & 17.2 & 15.5 & 12.5 & 2.0 \\
\hline Valencia & GPS & 12.6 & 13.3 & 14.8 & 18.0 & 21.9 & 27.5 & 30.7 & 32.0 & 29.9 & 25.2 & 16.4 & 14.4 & 19.4 & 2.5 \\
\hline Villafranca & GPS & 10.4 & 10.6 & 11.8 & 13.6 & 17.5 & 21.0 & 19.8 & 20.9 & 20.5 & 19.1 & 12.9 & 11.4 & 10.7 & 2.0 \\
\hline Yebes & ST & 8.6 & 8.9 & 10.0 & 11.8 & 15.0 & 18.5 & 17.7 & 18.5 & 18.1 & 16.4 & 11.4 & 9.8 & 10.0 & 2.2 \\
\hline Zaragoza & Sondeo & 12.2 & 11.3 & 12.7 & 14.7 & 18.0 & 22.7 & 23.5 & 23.9 & 23.1 & 20.0 & 14.4 & 12.5 & 12.5 & 2.1 \\
\hline
\end{tabular}

Tabla 4.1 - Promedios mensuales del PWV (mm). En rojo se ha marcado el valor máximo y en azul el mínimo. Las dos últimas columnas representan respectivamente la diferencia y el cociente entre el máximo y el mínimo.

Los valores máximos oscilan entre los 16.6 y $32 \mathrm{~mm}$, registrándose los más bajos en las estaciones del interior, y siendo normalmente más bajos cuanto mayor es la altitud de la estación, mientras que los más altos se dan en las estaciones costeras, y especialmente en las de la costa mediterránea, destacando los $32 \mathrm{~mm}$ de Valencia, y los $31 \mathrm{~mm}$ de Roquetes y Alicante. Esto es debido a la mayor temperatura de las aguas del Mediterráneo y al régimen de brisas marinas, que favorecen un mayor aporte de humedad a la atmósfera.

Respecto a los valores mínimos, estos oscilan entre los 7.4 y los $14.3 \mathrm{~mm}$. Los más bajos aparecen en el interior peninsular, en las mismas estaciones que registraban los máximos más bajos, destacando Palencia con $7.4 \mathrm{~mm}$. Sin embargo, los mínimos más altos no se registran en la costa mediterránea, donde se registraban los máximos más altos, sino en la costa atlántica y en el área del estrecho, destacando Gibraltar con $14.2 \mathrm{~mm}$. Esto puede ser debido a 
que en esta zona los vientos dominantes en invierno (del oeste) presentan un carácter más húmedo que en el área mediterránea, donde soplan de tierra a mar.

Los valores máximos del verano son del orden del doble de los mínimos del invierno. La razón entre ambos valores varía entre 1.9 y 2.5 , excepto en Lisboa donde es 1.6. Los valores más altos de este cociente se registran en la costa mediterránea.

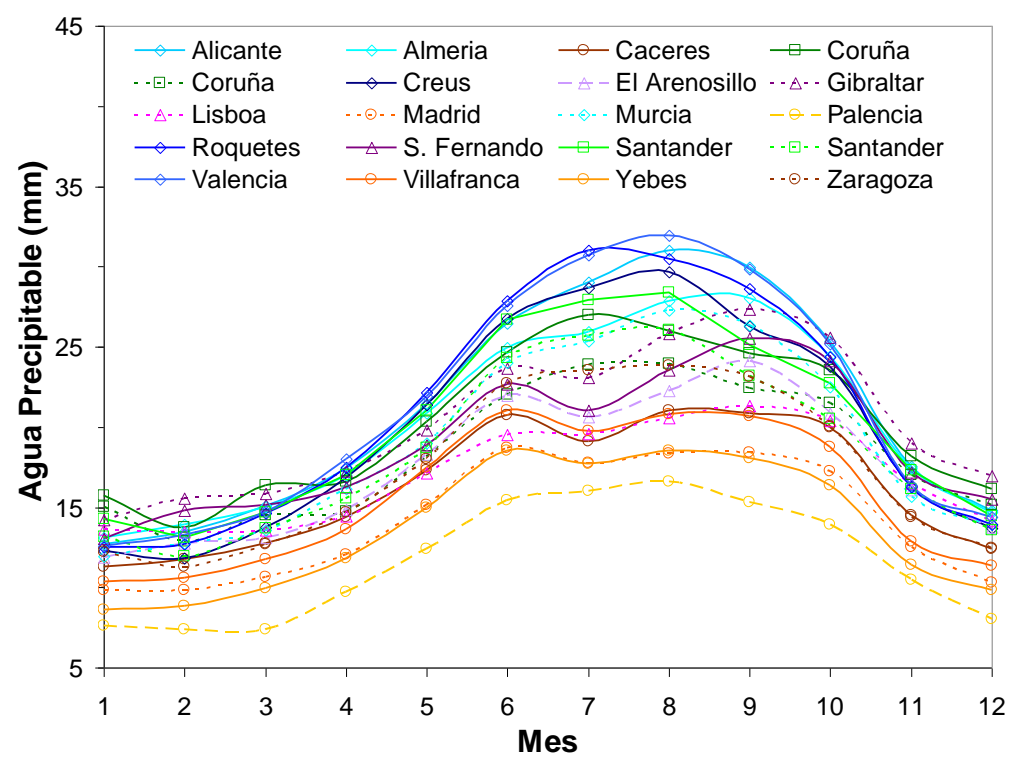

Figura 4.1 - Ciclo anual del PWV. Las líneas de puntos representan las estaciones de radiosondeo, las líneas de trazos las fotométricas, y las líneas continuas los receptores de GPS. Con cuadrados en tonos verdes están representadas las estaciones situadas en la costa cantábrica, con rombos en tonos azules las de la costa mediterránea, con triángulos en tonos violetas-morados las atlánticas, y con círculos en tonos marrones-naranjas las situadas en el interior.

La amplitud del ciclo anual, entendiendo como tal la diferencia entre el promedio mensual máximo y mínimo, es máxima para las estaciones de la costa este mediterránea, con valores en torno a los 18 a $19 \mathrm{~mm}$, y es mínima en las de la meseta interior, con valores entre los 8 y $10 \mathrm{~mm}$, aunque el menor valor se da en Lisboa con $7.9 \mathrm{~mm}$. La std de las medias mensuales para cada uno de los meses del año varía en media de todas las estaciones entre 1.4 y 2.6 $\mathrm{mm}$, no observándose ninguna tendencia en su distribución geográfica. Sin embargo, si se observa un ligero aumento de esta para los meses del otoño.

Gaffen et al. (1992) clasificaron los regímenes de humedad para todo el globo en cinco tipos: continental de latitudes medias y altas, oceánico de latitudes medias y altas, monzón de latitudes medias, tropical oceánico, y monzón tropical. Por la situación geográfica de la Península, en ella se podrían dar los regímenes continental y oceánico de latitudes medias y altas o una mezcla de ambos. De acuerdo a esta clasificación, el régimen continental se caracteriza por un pronunciado ciclo anual con un máximo al final del verano, de 3 a 10 veces mayor que el mínimo del invierno, y un bajo valor medio, entre 2 y $15 \mathrm{~mm}$. El régimen oceánico se caracteriza por un ciclo anual menos pronunciado, con un máximo en verano en fase con la 
temperatura, una razón entre máximo y mínimo de 1.5 a 3, y un valor medio entre 5 y $20 \mathrm{~mm}$. Los resultados obtenidos en este estudio, con un promedio anual del PWV en torno a los 18 mm y una razón entre el valor máximo y mínimo de los promedios mensuales de dos, indican que el régimen predominante sobre la Península es el oceánico de latitudes medias y altas.

Dentro de la Península, la zona mediterránea se caracteriza por un ciclo anual con un elevado valor medio del PWV y un amplio rango de variación, con el valor máximo más alto y un mínimo bajo, similar a la de la zona atlántica o cantábrica. En la zona interior se dan los valores más bajos tanto del valor medio como de la amplitud, sin embargo la razón entre el máximo y mínimo es ligeramente superior a la de la zona cantábrica o atlántica. Por su parte, en las zonas cantábrica y atlántica la media y la amplitud del ciclo toman valores intermedios entre los de las otras dos zonas, pero mientras que el mínimo toma un valor similar en ambas, el máximo y la amplitud es mayor en la cantábrica que en la atlántica.
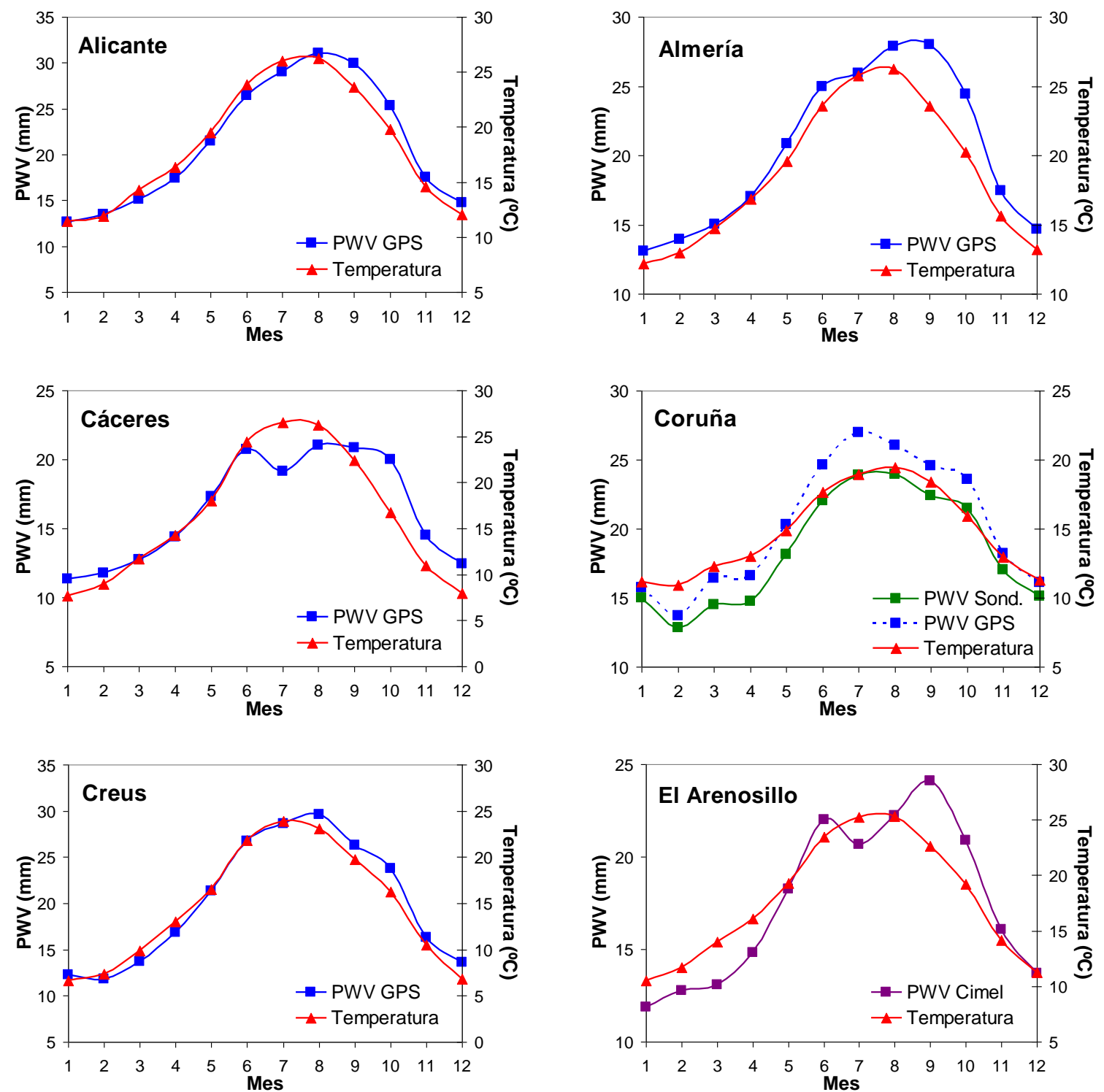

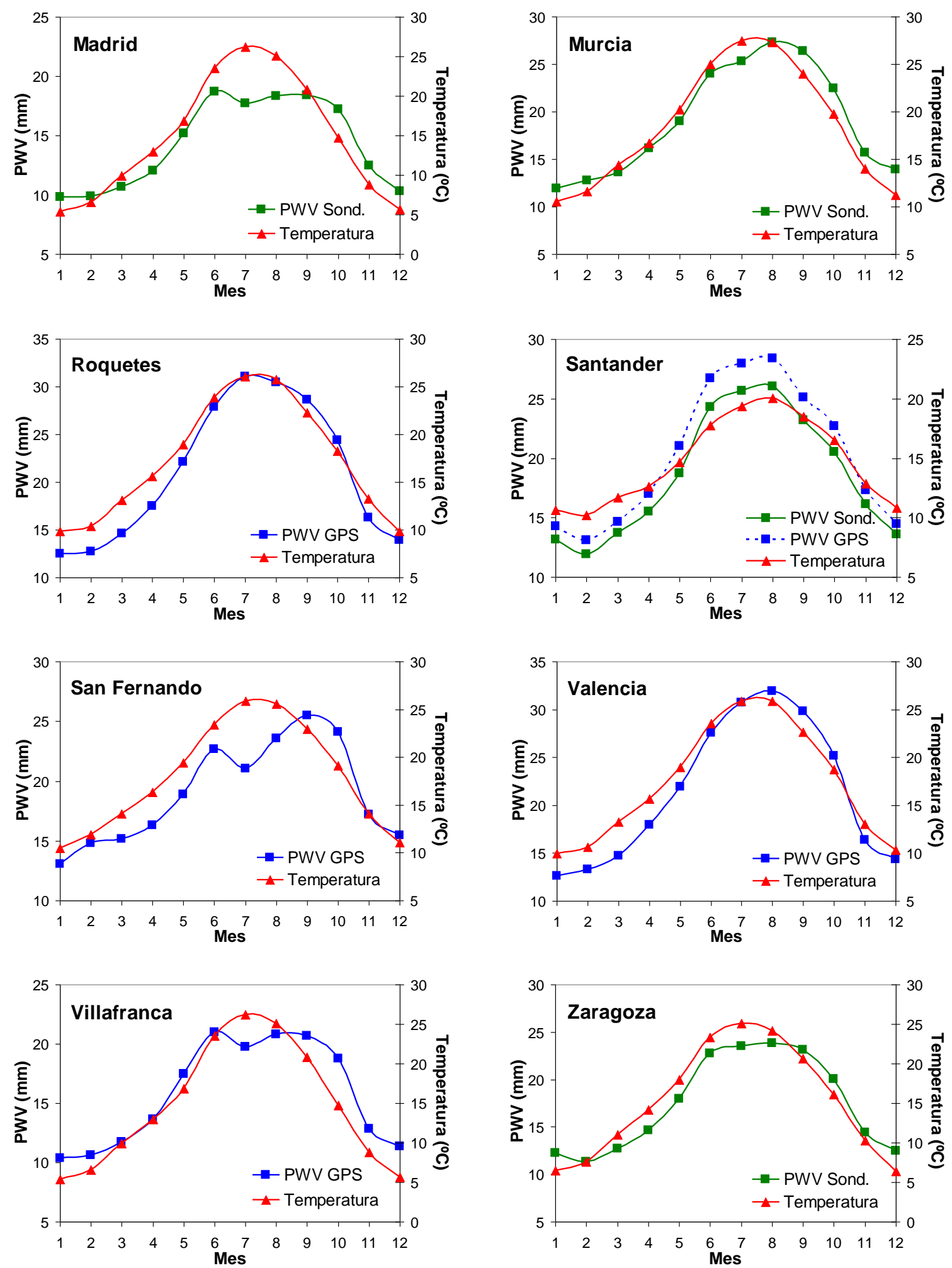

Figura 4.2 - Ciclo anual del PWV y de la temperatura (datos años 2002/08).

Con la excepción del mínimo relativo del mes de julio en algunas estaciones, el ciclo anual del PWV se ajusta bastante bien al de la temperatura (Figura 4.2). Sí se observa un pequeño desfase en la ocurrencia del máximo, alcanzándose el del PWV con posterioridad al de la temperatura. Este desfase es más patente en las estaciones de la costa mediterránea. 
Mientras la temperatura media mensual suele alcanzar su valor máximo en el mes de julio, el PWV lo hace en el mes de agosto. Ello se debe al mayor poder calorífico del agua, que hace que cuando al final del verano la tierra empieza a enfriarse las aguas de los mares aún se mantengan cálidas, aportando gran cantidad de vapor a la atmósfera.

En término medio, cuanto mayor es la temperatura mayor es el PWV. Pero esto es sólo cierto para cada emplazamiento de forma individual, cuando comparamos distintos emplazamientos entran en juego las características geográficas de las ubicaciones, como la proximidad a la costa, el régimen de vientos, la altitud,..., que juegan un papel determinante. En el interior peninsular los valores medios de la temperatura máxima son similares a los de la costa mediterránea, pero mayores que los de las costas cantábrica y atlántica. Sin embargo, el PWV máximo es el más bajo de todos. Es decir, en las estaciones del interior por mucho que en verano aumente la temperatura el PWV no aumenta en la misma proporción. Por el contrario, los valores mínimos si están más correlacionados, mientras menor es la temperatura menor es el PWV. Se puede concluir diciendo que el PWV es mayor cuanto mayor sea la temperatura siempre que haya una fuente inagotable de humedad.

Tampoco la amplitud del ciclo del PWV guarda una proporcionalidad directa con el de la temperatura, sino que depende del carácter continental o marítimo de la estación y de la latitud. La variación de temperatura entre el invierno y el verano es máxima en el interior peninsular, pero la del PWV es mínima, mientras que en las costas ocurre a la inversa.

\subsubsection{Análisis de armónicos de ciclo anual}

El ciclo anual de la anomalía del PWV (diferencia del PWV mensual respecto del anual) se ha descompuesto en armónicos simples. Así, el PWV del mes $m$ vendría dado por la expresión:

$$
P W V(m)=P W V_{0}+\sum_{n=1}^{4} S_{n}(m)+R
$$

siendo $S_{n}$,

$$
S_{n}(m)=A_{n} \cdot \sin \left(n \cdot m+\sigma_{n}\right)
$$

donde $\mathrm{PWV}_{0}$ es el valor medio anual, $\mathrm{R}$ el residuo, $\mathrm{S}_{\mathrm{n}, \mathrm{n}=1,2,3,4}$ denota los armónicos de periodo 12, 6, 4 y 3 meses respectivamente, $A_{n}$ la amplitud, y $\sigma_{n}$ el desfase. La Tabla 4.2 y la Figura 4.3 muestran el resultado del análisis de armónicos para cada estación.

El primer armónico (periodo 12 meses) es el dominante en todas las estaciones, con una amplitud media de $6.63 \mathrm{~mm}$ y un desfase de ocho meses (ocurrencia del máximo respecto del origen). Este armónico explica en término medio el $96 \%$ de la varianza, mientras que los otros tres armónicos explican menos del 1\%. Sólo en alguna estación en particular alguno de ellos es significante, siendo especialmente relevante la varianza explicada (4 a $5 \%$ ) por el segundo armónico (periodo 6 meses) en las estaciones próximas al estrecho de Gibraltar. 


\begin{tabular}{|c|c|c|c|c|c|c|c|c|c|c|c|c|c|}
\hline \multirow[b]{2}{*}{ Estación } & \multicolumn{3}{|c|}{$1^{\circ}$ Armónico } & \multicolumn{3}{|c|}{$2^{\circ}$ Armónico } & \multicolumn{3}{|c|}{$3^{\circ}$ Armónico } & \multicolumn{3}{|c|}{$4^{\circ}$ Armónico } & \multirow{2}{*}{$\begin{array}{l}\text { Var. } \\
\text { Total }\end{array}$} \\
\hline & Ampl. & Fase & Var. & Ampl. & Fase & Var. & Ampl. & Fase & Var. & Ampl. & Fase & Var. & \\
\hline Alicante & 9.16 & 7.73 & 95.4 & 1.33 & 2.54 & 1.9 & 0.55 & 0.95 & 0.3 & 0.41 & 0.14 & 0.2 & 97.8 \\
\hline Almería & 7.58 & 7.75 & 94.6 & 1.07 & 2.86 & 1.9 & 0.84 & 1.02 & 1.0 & 0.40 & 0.04 & 0.2 & 97.7 \\
\hline Cáceres & 5.08 & 7.68 & 91.6 & 0.62 & 3.69 & 1.4 & 0.93 & 1.11 & 2.7 & 0.00 & 0.00 & 0.0 & 95.7 \\
\hline Coruña Sond & 5.40 & 7.90 & 94.5 & 0.63 & 1.29 & 1.2 & 0.00 & 0.00 & 0.0 & 0.46 & 0.71 & 0.6 & 96.3 \\
\hline Coruña GPS & 6.17 & 7.74 & 94.6 & 0.53 & 1.06 & 0.0 & 0.00 & 0.00 & 0.7 & 0.68 & 0.63 & 1.0 & 96.2 \\
\hline Creus & 9.03 & 7.56 & 96.8 & 0.60 & 1.85 & 0.4 & 0.42 & 1.28 & 0.2 & 0.00 & 0.00 & 0.0 & 97.4 \\
\hline El Arenosillo & 5.65 & 7.83 & 91.6 & 0.70 & 3.52 & 1.4 & 1.07 & 1.02 & 2.9 & 0.73 & 2.89 & 1.4 & 97.3 \\
\hline Gibraltar & 5.93 & 8.10 & 89.9 & 1.19 & 3.36 & 3.6 & 0.97 & 1.10 & 2.2 & 0.59 & 2.95 & 0.8 & 96.5 \\
\hline Lisboa & 4.13 & 8.06 & 93.3 & 0.40 & 3.46 & 0.9 & 0.82 & 1.18 & 3.3 & 0.00 & 0.00 & 0.0 & 97.6 \\
\hline Madrid & 4.90 & 7.65 & 93.6 & 0.00 & 0.00 & 0.0 & 0.93 & 1.21 & 3.0 & 0.32 & 0.18 & 0.3 & 97.0 \\
\hline Murcia & 7.65 & 7.70 & 95.0 & 1.06 & 2.46 & 1.7 & 0.55 & 0.86 & 0.4 & 0.48 & 0.30 & 0.3 & 97.4 \\
\hline Palencia & 4.91 & 7.68 & 96.9 & 0.16 & 1.47 & 0.1 & 0.45 & 1.15 & 0.7 & 0.00 & 0.00 & 0.0 & 97.7 \\
\hline Roquetes & 9.68 & 7.53 & 96.3 & 1.06 & 1.99 & 1.1 & 0.54 & 1.25 & 0.3 & 0.59 & 0.56 & 0.3 & 97.9 \\
\hline Santander Sond & 6.99 & 7.58 & 95.9 & 0.85 & 1.33 & 1.3 & 0.00 & 0.00 & 0.0 & 0.33 & 0.55 & 0.2 & 97.4 \\
\hline Santander GPS & 7.73 & 7.54 & 96.1 & 0.83 & 1.29 & 1.0 & 0.48 & 1.35 & 0.3 & 0.00 & 0.00 & 0.0 & 97.4 \\
\hline S. Fernando & 5.37 & 8.00 & 85.4 & 1.28 & 3.45 & 4.8 & 1.24 & 1.14 & 4.1 & 0.72 & 2.97 & 1.4 & 95.6 \\
\hline Valencia & 9.83 & 7.60 & 95.3 & 1.45 & 2.26 & 2.0 & 0.50 & 0.80 & 0.2 & 0.50 & 0.55 & 0.2 & 97.7 \\
\hline Villafranca & 5.77 & 7.51 & 93.6 & 0.33 & 3.59 & 0.3 & 1.03 & 1.04 & 2.6 & 0.45 & 0.10 & 0.5 & 97.0 \\
\hline Yebes & 5.36 & 7.54 & 95.2 & 0.00 & 1.50 & 0.0 & 0.72 & 1.10 & 1.5 & 0.37 & 0.12 & 0.4 & 97.1 \\
\hline Zaragoza & 6.65 & 7.60 & 95.8 & 0.59 & 1.90 & 0.7 & 0.67 & 1.03 & 0.8 & 0.54 & 0.42 & 0.5 & 97.8 \\
\hline
\end{tabular}

Tabla 4.2 - Análisis de armónicos del ciclo anual de las anomalías del PWV. Para cada uno de los cuatro primeros armónicos con periodo 12, 6, 4 y 3 meses respectivamente se presenta la amplitud, la fase, y la varianza explicada, así como la varianza total explicada por el conjunto de los cuatro armónicos.
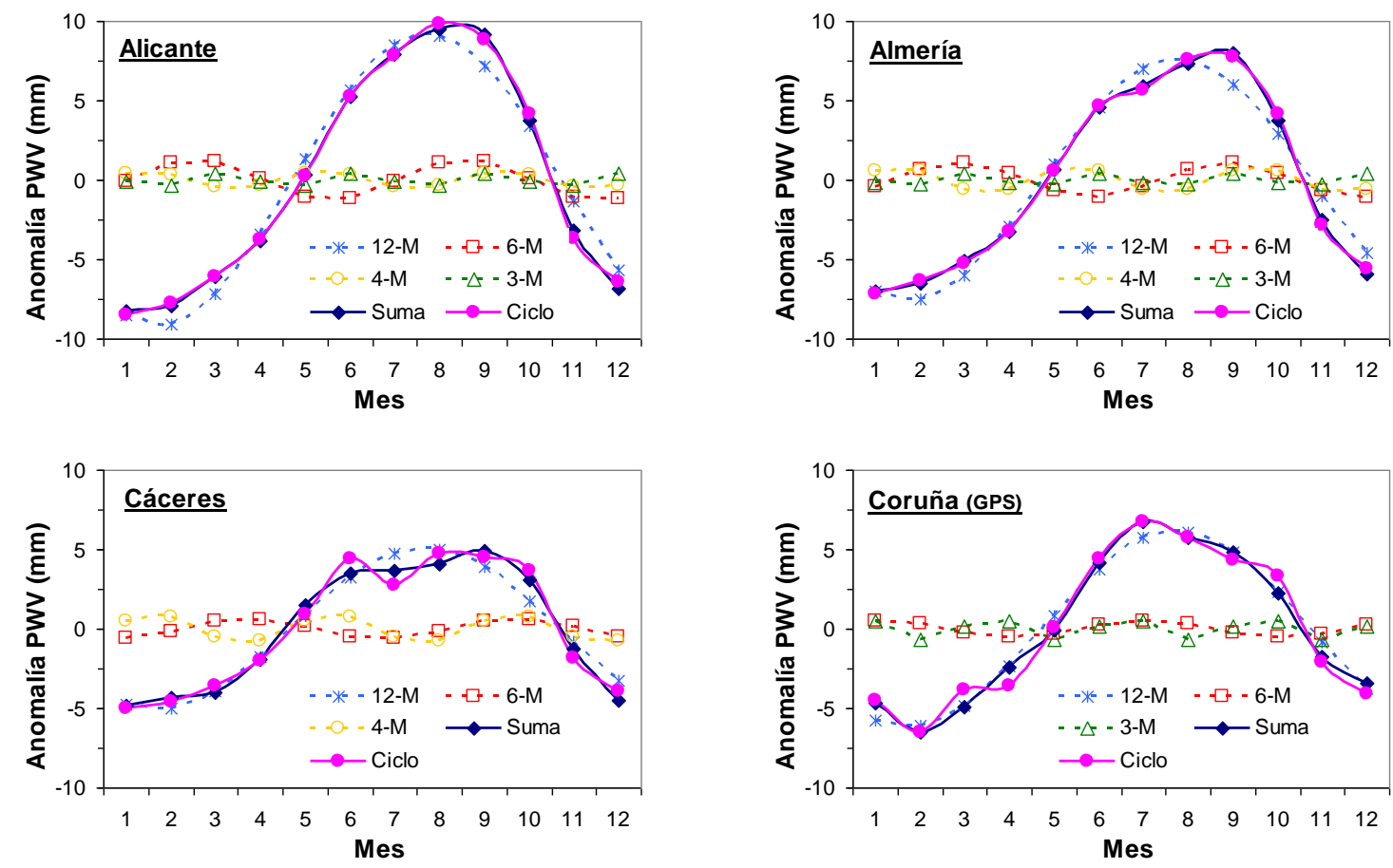

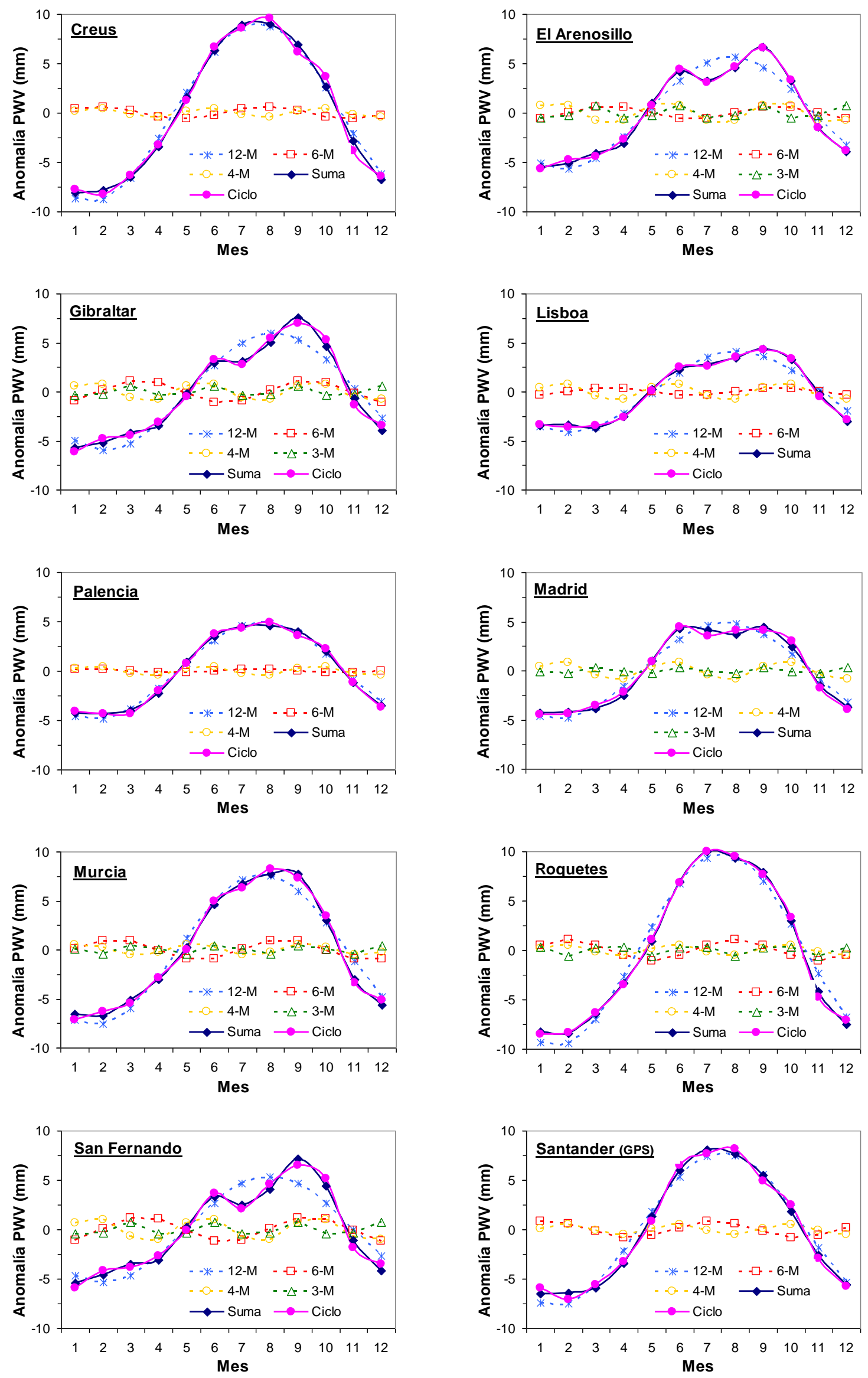

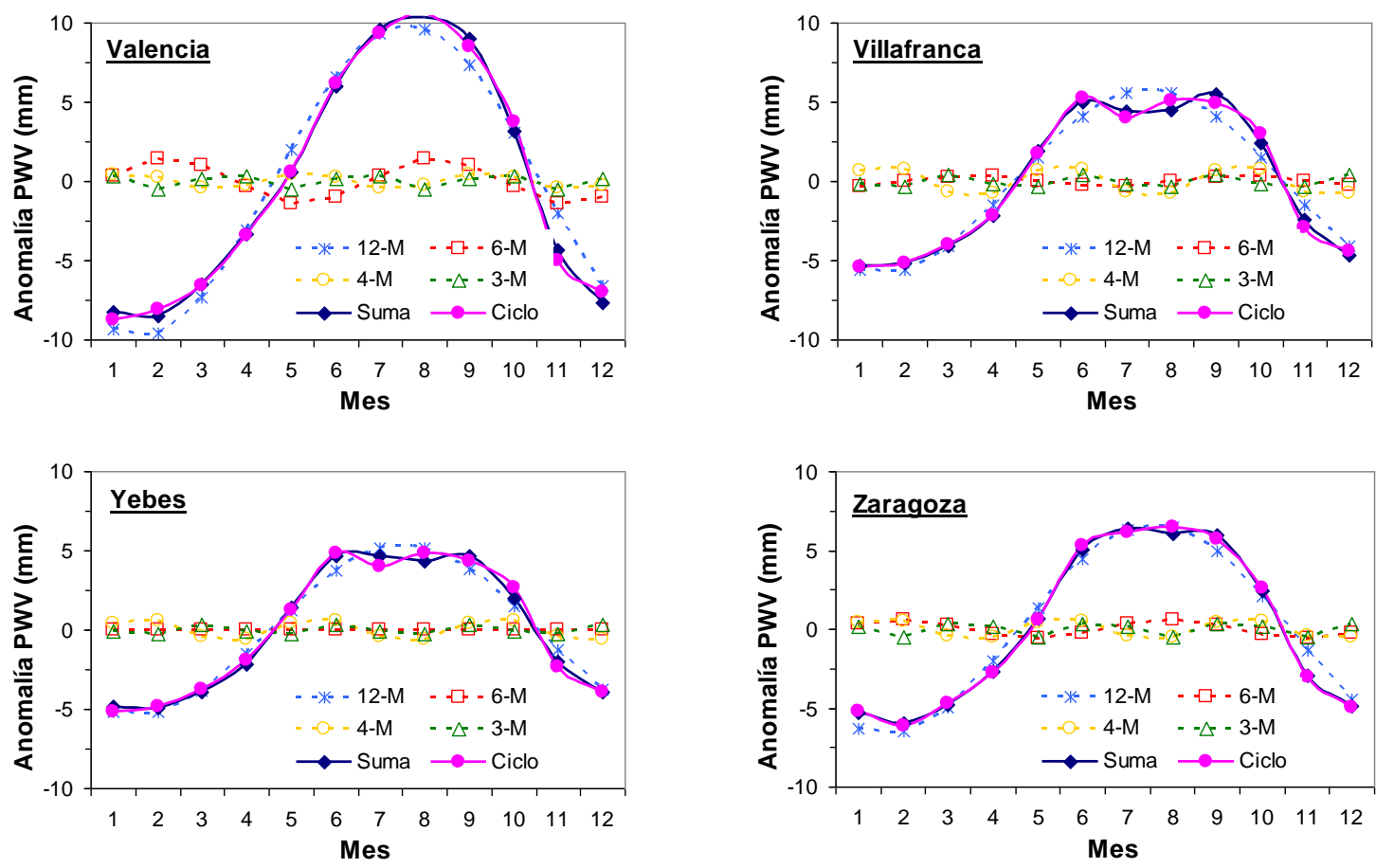

Figura 4.3 - Análisis de armónicos del ciclo anual del PWV. 'Suma' representa la suma de todos los armónicos (no representados los armónicos de amplitud cero), y ‘Ciclo’ el ciclo real medido.

\subsubsection{Comparativa entre técnicas del ciclo anual}

Aunque la comparativa entre técnicas se abordará en el Capítulo 7, en este punto se presenta una comparación del ciclo anual de las ubicaciones en las que existen estaciones con dos técnicas de medida. En la Figura 4.4 se puede observar como para un mismo emplazamiento la forma del ciclo anual obtenido con distintas técnicas es muy similar, con unos coeficientes de correlación altísimos, mayores de 0.99. Aunque la correlación es alta, se observa un desplazamiento vertical entre ambos ciclos, con unas bias entre 1.5 y $2 \mathrm{~mm}$. Los receptores GPS sobrevaloran siempre el PWV respecto de los sondeos, en torno a un $10 \%$. El motivo de esta sobreestimación de los GPS se verá con detalle en el Capítulo 8.

\begin{tabular}{lcrrrrrrrrrrrr}
\hline Estación & & Ene & Feb & Mar & Abr & May & Jun & Jul & Ago & Sep & Oct & Nov & Dic \\
\hline Coruña & $(\mathrm{mm})$ & 0.73 & 0.87 & 1.90 & 1.86 & 2.15 & 2.60 & 3.08 & 2.08 & 2.16 & 2.10 & 1.17 & 1.02 \\
& $\%$ & 4.8 & 6.8 & 13.1 & 12.6 & 11.9 & 11.8 & 12.9 & 8.7 & 9.6 & 9.8 & 6.9 & 6.8 \\
\hline \multirow{2}{*}{ Santander } & $(\mathrm{mm})$ & 1.13 & 1.18 & 0.95 & 1.46 & 2.34 & 2.40 & 2.25 & 2.35 & 1.94 & 2.21 & 1.21 & 0.85 \\
& $\%$ & 8.6 & 9.9 & 7.0 & 9.4 & 12.5 & 9.9 & 8.8 & 9.0 & 8.4 & 10.8 & 7.5 & 6.2 \\
\hline Madrid & $(\mathrm{mm})$ & 0.53 & 0.77 & 1.07 & 1.55 & 2.31 & 2.32 & 2.01 & 2.46 & 2.29 & 1.53 & 0.36 & 1.05 \\
& $\%$ & 5.3 & 7.8 & 10.0 & 12.8 & 15.2 & 12.4 & 11.3 & 13.4 & 12.5 & 8.9 & 2.9 & 10.2 \\
\hline
\end{tabular}

Tabla 4.3 - Evolución anual de la diferencia entre el PWV obtenido con los GPS y con los sondeos en los emplazamientos que disponen de ambas medidas. Las diferencias están expresadas en valores absolutos $(\mathrm{mm})$ y en porcentaje respecto del valor del sondeo.

Las diferencias entre los valores de ambos ciclos no son constantes sino proporcionales al PWV, las más pequeñas se registran en invierno y las mayores en verano (Tabla 4.3). 


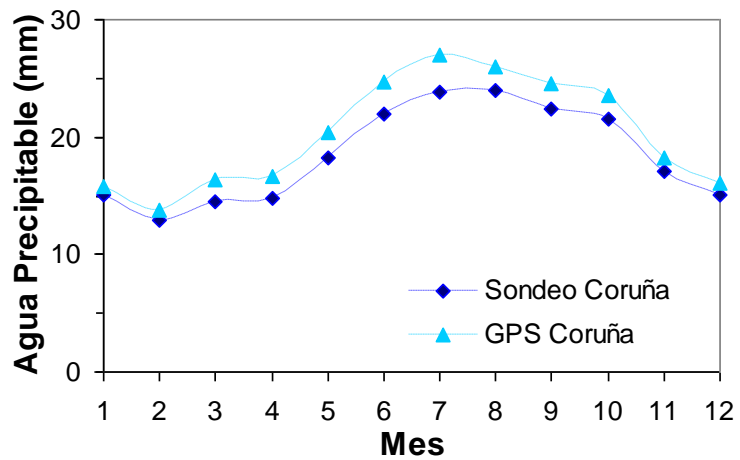

Coef. Correlación: 0.995

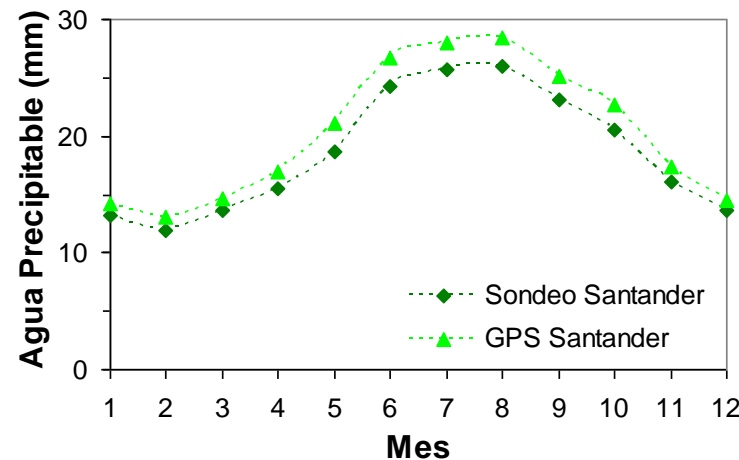

Coef. Correlación: 0.999

BIAS: 1.69 (9.0\%)

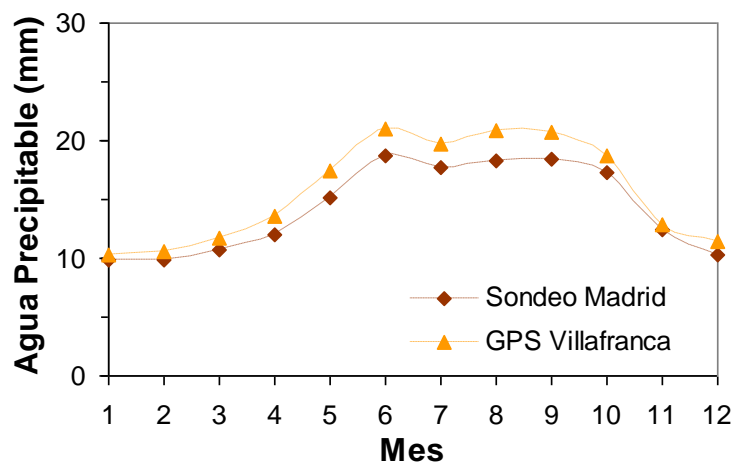

Coef. Correlación: 0.996

BIAS: $1.52(10.2 \%)$

Figura 4.4 - Comparativa del ciclo anual del PWV con distintas técnicas en emplazamientos próximos.

\subsection{Evolución anual del agua precipitable en 2008}

Las redes de medida del PWV utilizadas en este estudio han experimentado en los últimos años un importante incremento en el número de estaciones, especialmente la red del IGN de receptores de GPS, proporcionando así una mejor cobertura espacial. De muchas de estas nuevas estaciones apenas se dispone de poco más de un año de datos, por lo que de sus datos no se puede concluir ninguna característica del comportamiento del PWV en el largo plazo. Sin embargo, de la comparación de los datos de unas estaciones con otras se podría determinar si éstas presentan un comportamiento semejante o no, lo que podría ayudar a distinguir zonas con un comportamiento heterogéneo u homogéneo del PWV que permitiera extrapolar los resultados obtenidos en el apartado anterior a otras zonas. Esto es lo que se presenta en este apartado, donde se han comparado los valores medios mensuales del PWV del año 2008 de todas las estaciones disponibles.

La Figura 4.5 representa la evolución del PWV en el año 2008 para cada estación. Para una mejor visualización, las estaciones se han agrupado en cuatro grandes zonas: Cantábrico y valle del Ebro, costa este mediterránea, sur peninsular (Andalucía y Lisboa), e interior peninsular (meseta norte y sur). 
En general, las estaciones fotométricas presentan un comportamiento más dispar que el resto, como queda patente en los emplazamientos donde hay además otro tipo de instrumentación (Barcelona, Huelva o Cáceres). Las medidas del fotómetro quedan siempre por debajo, excepto para los meses de septiembre a diciembre en Cáceres, que coincide con una recalibración del equipo. Además, la magnitud de las diferencias difiere bastante de una estación a otra, lo que apunta a que las diferencias pueden no sólo ser debidas a un sesgo de la técnica, sino también a un problema de calibración de los fotómetros. Las bias toman un valor de $4 \mathrm{~mm}$ en Barcelona, de $2 \mathrm{~mm}$ en Huelva, y de $0.5 \mathrm{~mm}$ en Cáceres. En el Capítulo $7 \mathrm{se}$ estudiará con detalle la comparación entre técnicas, pero estos resultados ya muestran que las medidas de PWV de los fotómetros son más inciertas. En este caso las discrepancias son debidas a la técnica empleada, y no pueden atribuirse a que se trate de zonas con un comportamiento distinto del PWV. Por ello, estas estaciones no han sido consideradas en el resto del estudio. Por el contrario, los ciclos obtenidos del GPS y de los sondeos en aquellos emplazamientos provistos con ambas técnicas si se ajustan, el coeficiente de correlación es prácticamente uno, las bias no superan los $0.4 \mathrm{~mm}$ y la std los $0.6 \mathrm{~mm}$. La mejora en la estimación del PWV que supuso la aplicación de un modelo de calibración absoluto de las antenas a partir de noviembre del 2006, queda reflejado en los datos del año 2008 (Capítulo 8).
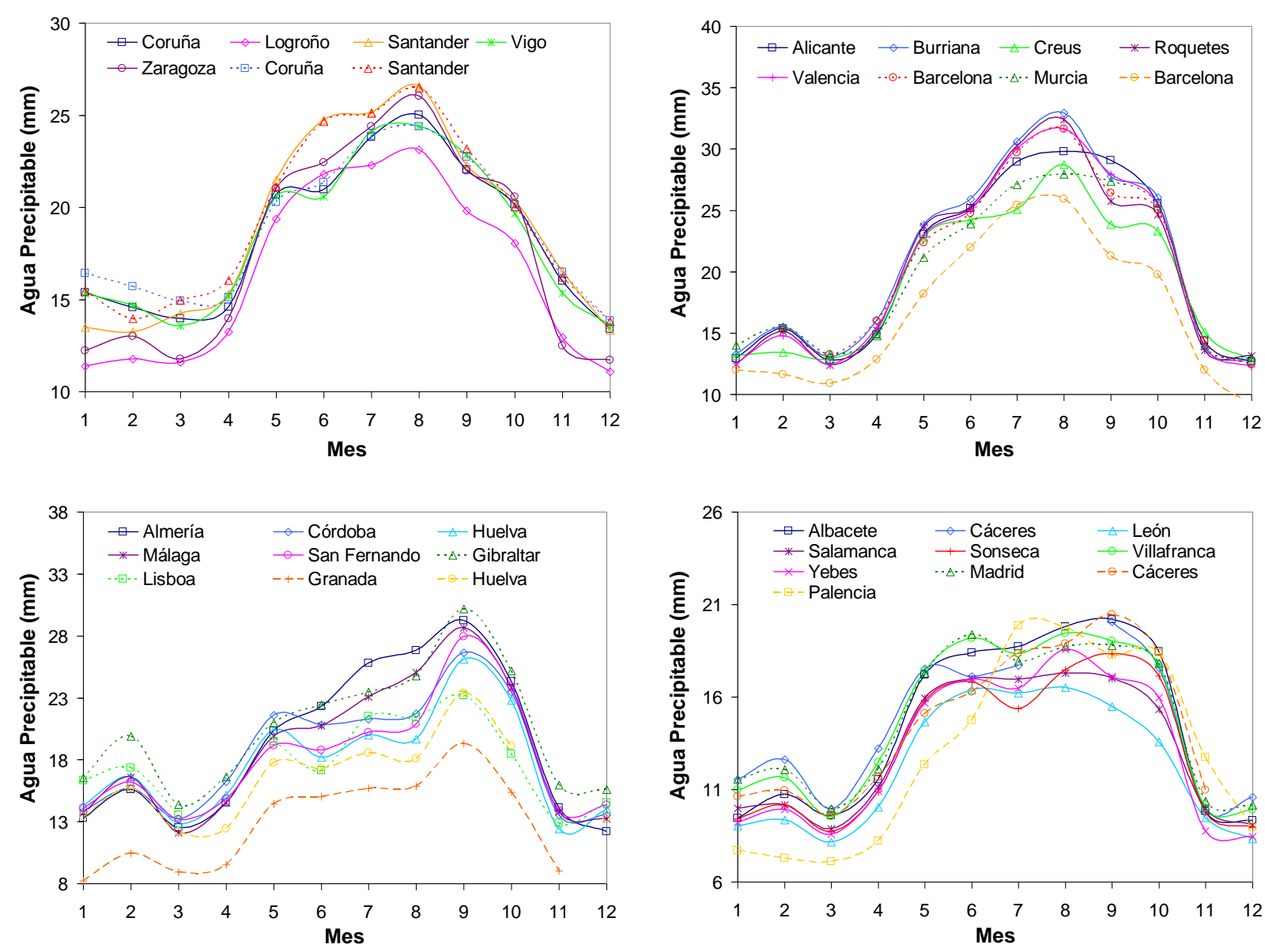

Figura 4.5 - Evolución del PWV durante el año 2008. Las estaciones de GPS están representadas en línea continua, las de sondeos en línea a puntos, y las fotométricas en línea a trazos. 
Las estaciones del cantábrico y del mediterráneo presentan un ciclo con la misma forma pero con mayor amplitud en las últimas. Los valores mínimos difieren poco, pero los máximos son más altos en el Mediterráneo. Logroño y Zaragoza, situadas en el valle del Ebro, tienen un comportamiento más parecido a las estaciones de la costa cantábrica que a las de la costa mediterránea o la meseta. Las estaciones del interior peninsular presentan un ciclo bastante homogéneo entre sí, a pesar de la heterogeneidad de la orografía. Solamente destacan por sus valores ligeramente más bajos las de la meseta norte (León y Salamanca). En la zona sur, a pesar de que la forma de los ciclos sigue el mismo patrón, se da una mayor separación vertical entre ellos, si bien es cierto que en esta zona se han incluido estaciones tanto de la vertiente atlántica como de la mediterránea y del valle del Guadalquivir. Son más semejantes entre sí los ciclos de las estaciones mediterráneas (Gibraltar, Málaga y Almería) por un lado y los de la atlántica (Huelva y San Fernando) y el valle del Guadalquivir (Córdoba) por otro. La std media de los ciclos anuales de las estaciones de cada una de la cuatro zonas se encuentra entre 0.9 y $1.4 \mathrm{~mm}$, registrándose normalmente valores mayores en los meses de junio a octubre (entre 1.1 y $2.1 \mathrm{~mm}$ ), mientras que de diciembre a mayo se reduce aproximadamente a la mitad (entre 0.5 y $1.1 \mathrm{~mm})$.

En base a estos resultados de las estaciones de radiosondeos y de receptores de GPS se podrían distinguir las siguientes zonas con un ciclo anual del PWV más semejante:

a) Atlántica; que comprendería la costa oeste de Portugal, representada por la estación de Lisboa.

b) Atlántico sur; zona del golfo de Cádiz (Huelva, San Fernando) y valle del Guadalquivir (Córdoba).

c) Cantábrico; costa atlántica desde Galicia al País Vasco (Vigo, Coruña y Santander).

d) Mediterráneo norte; costa desde Valencia al cabo Creus (Valencia, Burriana, Tortosa, Barcelona, Creus).

e) Mediterráneo centro; costa desde Valencia a Almería, representada por la estaciones de Alicante y Murcia.

f) Mediterráneo sur; costa desde el estrecho de Gibraltar a Almería (Gibraltar, Málaga y Almería).

g) Meseta norte; abarcaría básicamente la comunidad de Castilla y León (León y Salamanca).

h) Meseta sur; comunidades de Castilla La Mancha y Extremadura (Madrid, Sonseca, Cáceres, Albacete y Yebes).

i) Valle del Ebro; representado por las estaciones de Logroño y Zaragoza. 
Con esta clasificación la std media de los ciclos anuales de las estaciones de una misma zona no supera en ninguna de ellas $1 \mathrm{~mm}$. En porcentaje, esta dispersión varía entre el $2 \%$ del mediterráneo central y el $6 \%$ de la meseta sur.

\subsection{Evolución anual de la distribución vertical del vapor de agua}

Para estudiar la evolución a lo largo del año de la distribución vertical de la humedad absoluta y del PWV los sondeos de los nueve años de datos (2000/2008) de cada estación se han agrupando por meses, y se han promediado siguiendo el procedimiento explicado en el punto 3.4 del capítulo anterior.

Para resaltar los niveles bajos de la atmósfera, donde el contenido de vapor de agua es más importante, en todas las gráficas la altitud está expresada en escala logarítmica.
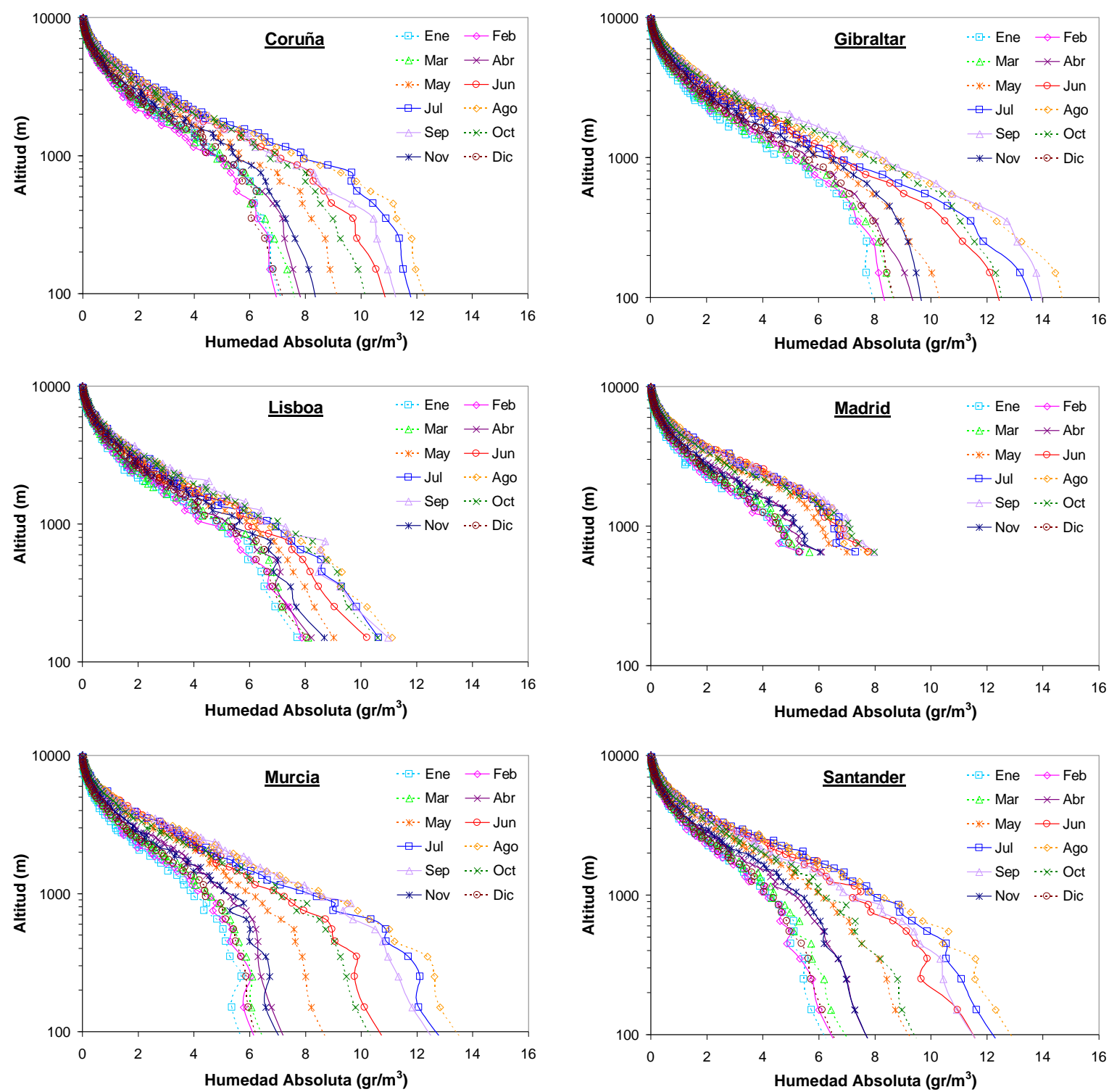


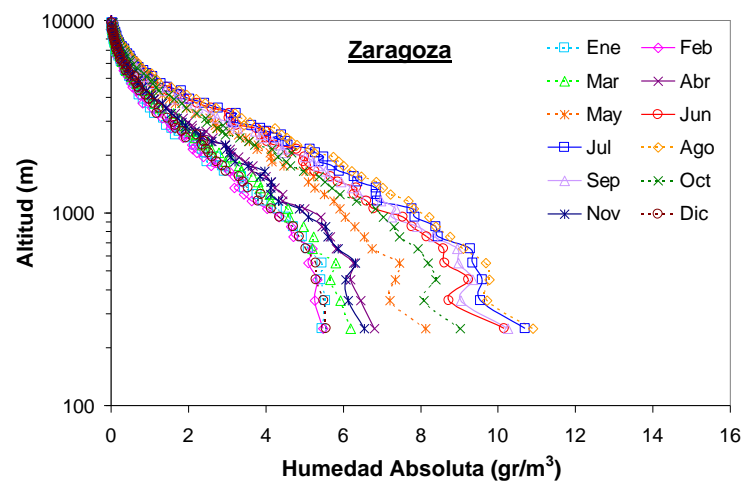

Figura 4.6 - Distribución vertical media mensual de la humedad absoluta. Para cada estación el perfil vertical comienza a su nivel de altitud.

En los perfiles verticales promedios (Figura 4.6), se observa que el comportamiento anual es muy similar para todas las estaciones. Prácticamente a todos los niveles la humedad absoluta crece desde los meses del invierno hasta finales del verano, donde alcanza el valor máximo, para a continuación disminuir durante el otoño hasta el final del invierno. Las diferencias entre meses se hacen menores conforme aumenta la altitud, tendiendo a converger a cero en las capas altas de la atmósfera.

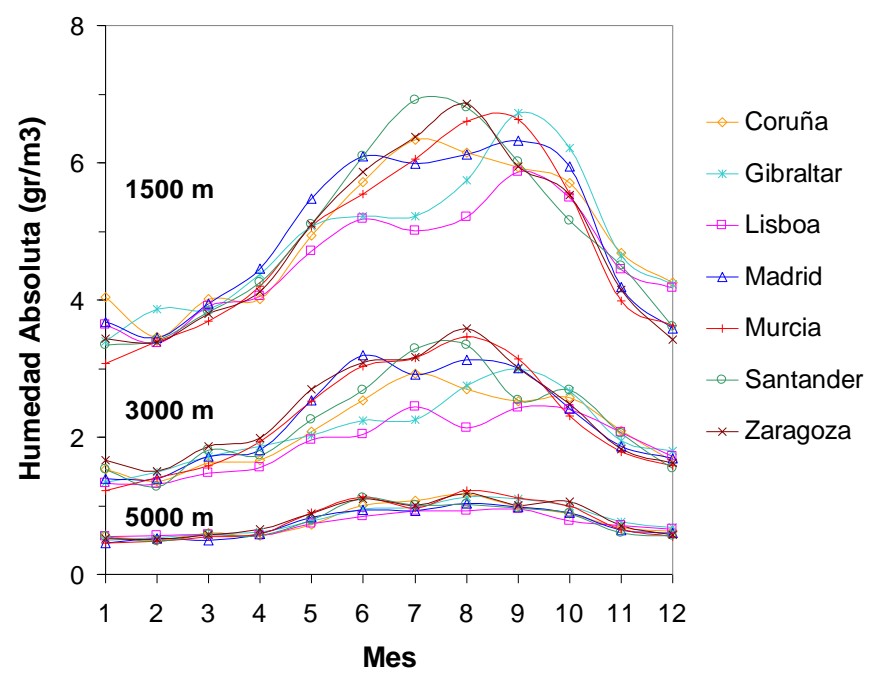

Figura 4.7 - Comparativa entre estaciones de la evolución anual de la humedad absoluta a tres niveles estándar de altitud: $1.5,3$, y $5 \mathrm{Km}$.

La figura 4.7 muestra la evolución anual de la humedad absoluta a tres niveles de altitud (1.5, 3, $5 \mathrm{Km}$ ). De noviembre a abril todas las estaciones presentan un comportamiento similar, mientras que de mayo a octubre las discrepancias son notables, aunque estas decrecen con la altitud. A $1.5 \mathrm{Km}$ la std de la humedad absoluta de todas las estaciones para cada mes varía desde los $0.1 \mathrm{gr} / \mathrm{m}^{3}$ de marzo a los $0.62 \mathrm{gr} / \mathrm{m}^{3}$ de julio. La máxima diferencia registrada fue de $1.9 \mathrm{gr} / \mathrm{m}^{3}$ entre Lisboa y Santander para el mes de julio. A los $3 \mathrm{Km}$ las discrepancias se hacen menores, la std varía entre los $0.08 \mathrm{gr} / \mathrm{m}^{3}$ de febrero y los $0.48 \mathrm{gr} / \mathrm{m}^{3}$ de agosto, siendo la máxima diferencia de $1.5 \mathrm{gr} / \mathrm{m}^{3}$ entre Zaragoza y Lisboa en agosto. Por último, a los $5 \mathrm{Km}$ la 
std toma valores inferiores a $0.1 \mathrm{gr} / \mathrm{m}^{3}$ para todos los meses, y la diferencia entre pares de estaciones es siempre menor de $0.3 \mathrm{gr} / \mathrm{m}^{3}$.

\begin{tabular}{|c|c|c|c|c|c|c|c|c|c|c|c|c|}
\hline \multirow[b]{2}{*}{ Estación } & \multicolumn{3}{|c|}{ Nivel de la estación } & \multicolumn{3}{|c|}{ Nivel $1.5 \mathrm{Km}$} & \multicolumn{3}{|c|}{ Nivel 3 Km } & \multicolumn{3}{|c|}{ Nivel 5 Km } \\
\hline & Máx & Mín & Ampl. & Máx & Mín & Ampl. & Máx & Mín & Ampl. & Máx & Mín & Ampl \\
\hline & & 1.06 & & & & & & & & & & 67 \\
\hline & & 8.44 & & & 3.40 & ? ? & 2.99 & 120 & & 13 & & .63 \\
\hline & & 7.72 & 3.39 & 5.86 & 3.37 & 2.4 & 2. & 1.31 & & 0.95 & 055 & 0.40 \\
\hline Madrid & 98 & 5.30 & 2.68 & 6.32 & 3.45 & 2.87 & 3.19 & 1.40 & 1.79 & 1.04 & 0.45 & 0.59 \\
\hline Murcia & 4.55 & 6.21 & 8.34 & 6.63 & 3.08 & 3.55 & 3.46 & 1.22 & 2.24 & 1.22 & 0.45 & 0.77 \\
\hline Santander & 13.74 & 7.02 & 6.72 & 6.91 & 3.34 & 3.57 & 3.34 & 1.28 & 2.06 & 1.02 & 0.48 & 0.64 \\
\hline Zaragoza & 0.90 & 5.45 & 5.45 & 6.86 & 3.38 & 3.48 & 3.59 & 1.51 & 2.08 & 1.18 & 0.51 & 0.67 \\
\hline
\end{tabular}

Tabla 4.4 - Valor máximo, mínimo y amplitud (máximo menos mínimo) de la humedad absoluta media mensual $\left(\mathrm{gr} / \mathrm{m}^{3}\right)$ a cuatro niveles de altitud: el de cada estación, a $1.5 \mathrm{Km}$, a $3 \mathrm{Km}$ y a $5 \mathrm{Km}$.

La amplitud del ciclo anual de la humedad absoluta depende de la altitud, en los niveles bajos es mayor que en los altos (Tabla 4.4). A $1.5 \mathrm{Km}$ la amplitud media es de $3.2 \mathrm{gr} / \mathrm{m}^{3}$, mientras que a $3 \mathrm{Km}$ es de $1.8 \mathrm{gr} / \mathrm{m}^{3}$, y a $5 \mathrm{Km}$ es de sólo $0.6 \mathrm{gr} / \mathrm{m}^{3}$, habiendo poca dispersión entre las estaciones en torno a estos valores. Sin embargo, al nivel de la superficie las diferencias pueden ser muy apreciables, debido sobre todo a la diferencia de altitud de las estaciones. Así, Madrid registra una amplitud de $2.68 \mathrm{gr} / \mathrm{m}^{3}$, mientras que Murcia llega a los $8.34 \mathrm{gr} / \mathrm{m}^{3}$. Las mayores diferencias se registran principalmente en los valores máximos. Mientras que estos oscilan entre los $7.98 \mathrm{gr} / \mathrm{m}^{3}$ de Madrid y los $14.92 \mathrm{gr} / \mathrm{m}^{3}$ de Gibraltar, los mínimos lo hacen entre los 5.30 y $8.44 \mathrm{gr} / \mathrm{m}^{3}$ en las mismas estaciones. A $1.5 \mathrm{Km}$ los valores máximos de la humedad absoluta oscilan entre 5.86 y $6.91 \mathrm{gr} / \mathrm{m}^{3}$ y los mínimos entre 3.08 y $3.46 \mathrm{gr} / \mathrm{m}^{3}$. Estos valores disminuyen con la altitud, así, a $3 \mathrm{Km}$ los máximos toman valores entre 2.44 y $3.59 \mathrm{gr} / \mathrm{m}^{3}$ y los mínimos entre 1.22 y $1.51 \mathrm{gr} / \mathrm{m}^{3}$, y a $5 \mathrm{Km}$ entre 0.95 y $1.22 \mathrm{gr} / \mathrm{m}^{3}$ y entre 0.45 y $0.55 \mathrm{gr} / \mathrm{m}^{3}$ respectivamente.

En el comportamiento estacional (Figura 4.8), se observa que por encima de $1 \mathrm{Km}$ de altitud las discrepancias entre estaciones sólo son significativas en el verano. Por debajo de este nivel las menores discrepancias se dan en otoño, si se excluye la estación de Gibraltar. En las capas más bajas estas apenas alcanzan $1 \mathrm{gr} / \mathrm{m}^{3}$ en el peor de los casos. La primavera y el invierno tienen un comportamiento muy similar, las gráficas de cada estación se encuentran en la misma posición relativa, aunque en invierno las discrepancias entre emplazamientos empiezan a una altitud más baja. En verano las diferencias son más notables y alcanzan capas más altas. Además, Lisboa y Murcia intercambian la posición relativa de sus perfiles respecto a la posición que tienen en invierno o primavera. Murcia pasa a ser la segunda estación con mayor distribución de humedad en los niveles bajos después de Gibraltar, y Lisboa pasa a ser la de menor. 

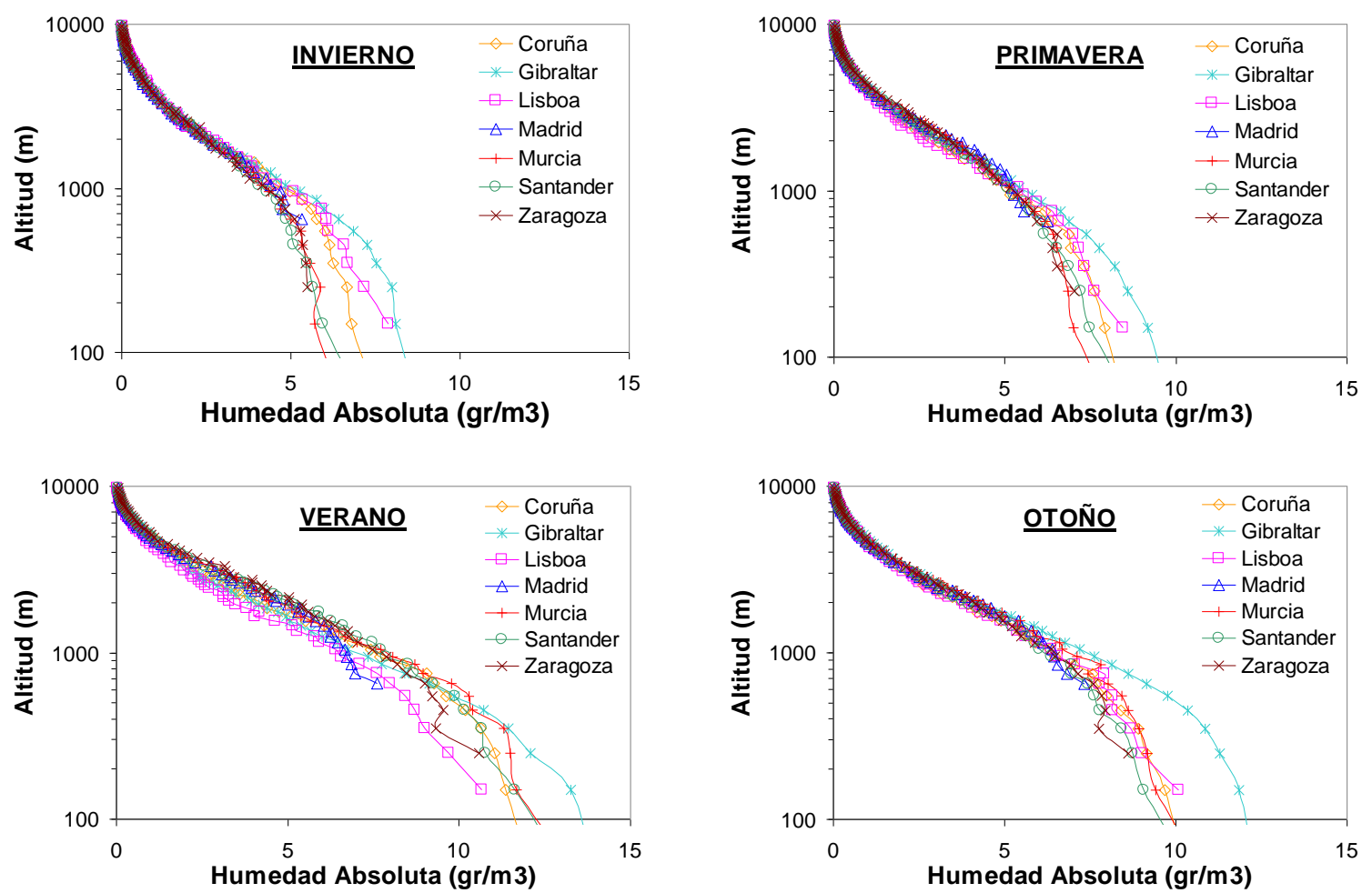

Figura 4.8 - Perfil vertical medio estacional de la humedad absoluta.

En la representación gráfica de los perfiles de las anomalías medias estacionales de la humedad absoluta respecto de su valor medio anual (Figura 4.9), se observan dos patrones de comportamiento, por un lado estarían Gibraltar y Lisboa, y por otro el resto de estaciones. En estas últimas, los cuatro perfiles estacionales guardan una buena simetría, sin embargo en las otras dos estaciones las gráficas del otoño y del verano se entrecruzan. El invierno es la estación que registra en todos los emplazamientos los menores valores de humedad absoluta a todos los niveles de altitud, aproximadamente un 20-30\% menos que la media anual en el primer $1 \mathrm{Km}$, y hasta un 40-50\% menos en las capas más altas. Por el contrario, el verano presenta los valores más altos, con unos intervalos de variación semejantes a los del invierno pero de signo positivo. El otoño y la primavera quedan entre las dos anteriores, pero la primavera con valores negativos de la anomalía y el otoño con valores positivos. Por debajo de $1 \mathrm{Km}$ las anomalías relativas no varían con la altitud, siendo los perfiles estacionales prácticamente verticales. Los mayores valores de las anomalías (positivos o negativos) se dan en las capas altas, pero en ellas la humedad absoluta es muy baja y cualquier pequeña variación implica un porcentaje de variación grande.

Las gráficas mensuales del PWV acumulado desde el nivel de la estación hasta cada nivel de altitud son similares para todos los meses en todos los emplazamientos (Figura 4.10). Desde el nivel de la estación y hasta los $5 \mathrm{Km}$ de altitud las trayectorias son divergentes. Por encima de este nivel se vuelven prácticamente paralelas al eje $\mathrm{Y}$, indicando que la contribución de esas capas al PWV total es prácticamente despreciable para todos los meses. En torno al $37 \%$ de la variabilidad mensual del PWV se produce en el primer kilómetro para las estaciones situadas al 
nivel del mar. Este porcentaje asciende al $50 \%$ al $1.5 \mathrm{Km}$, al $77 \%$ a los $3 \mathrm{Km}$, y al $92 \%$ a los 5 $\mathrm{Km}$. En las estaciones del interior estos porcentajes son tanto menor cuanto mayor es la altitud de la estación, pero en todos los casos a los $5 \mathrm{Km}$ el valor es ya superior al $90 \%$.
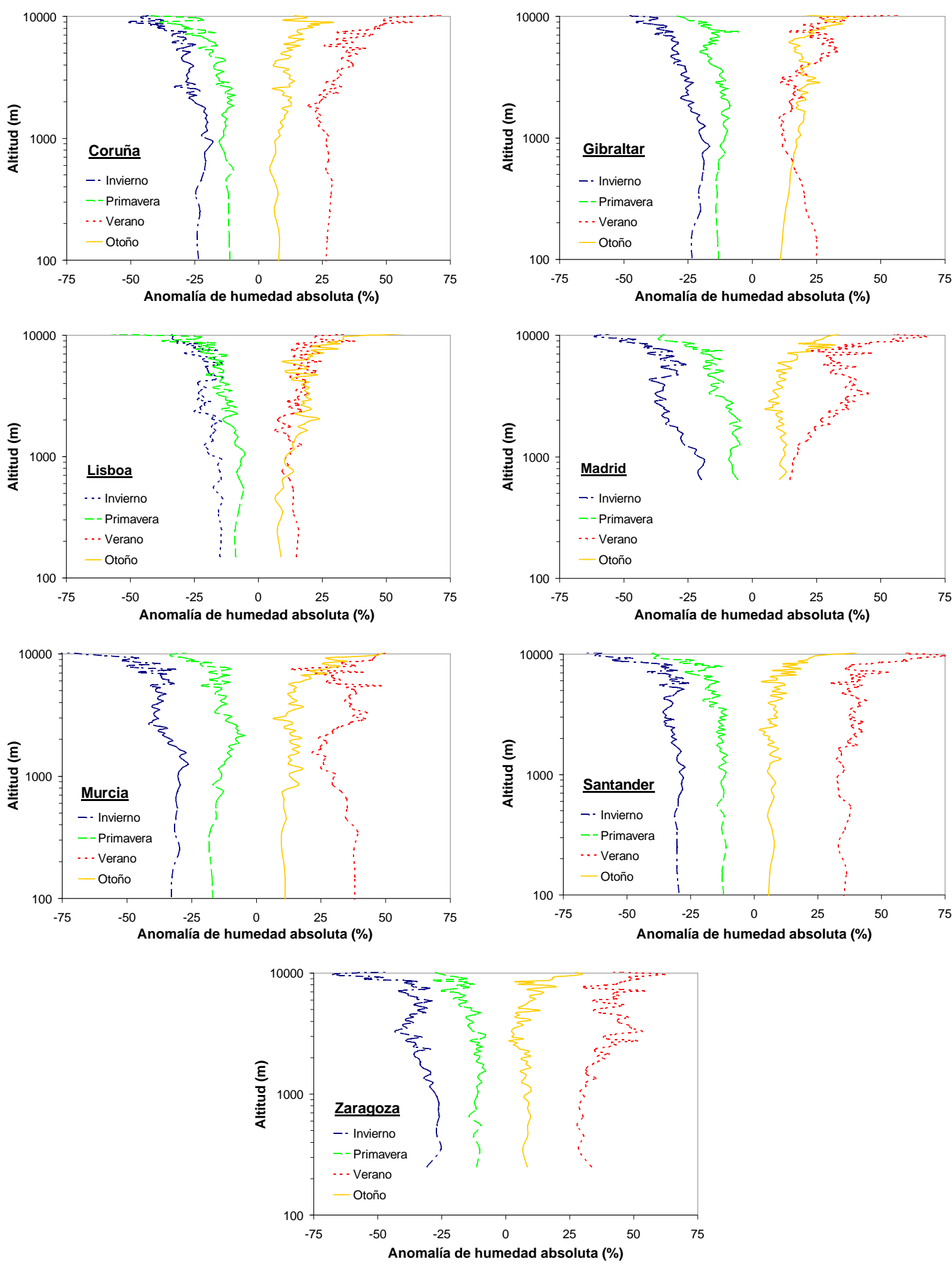

Figura 4.9 - Perfil vertical medio estacional de la anomalía de la humedad absoluta expresada en porcentaje respecto de su valor medio anual a cada nivel de altitud. 

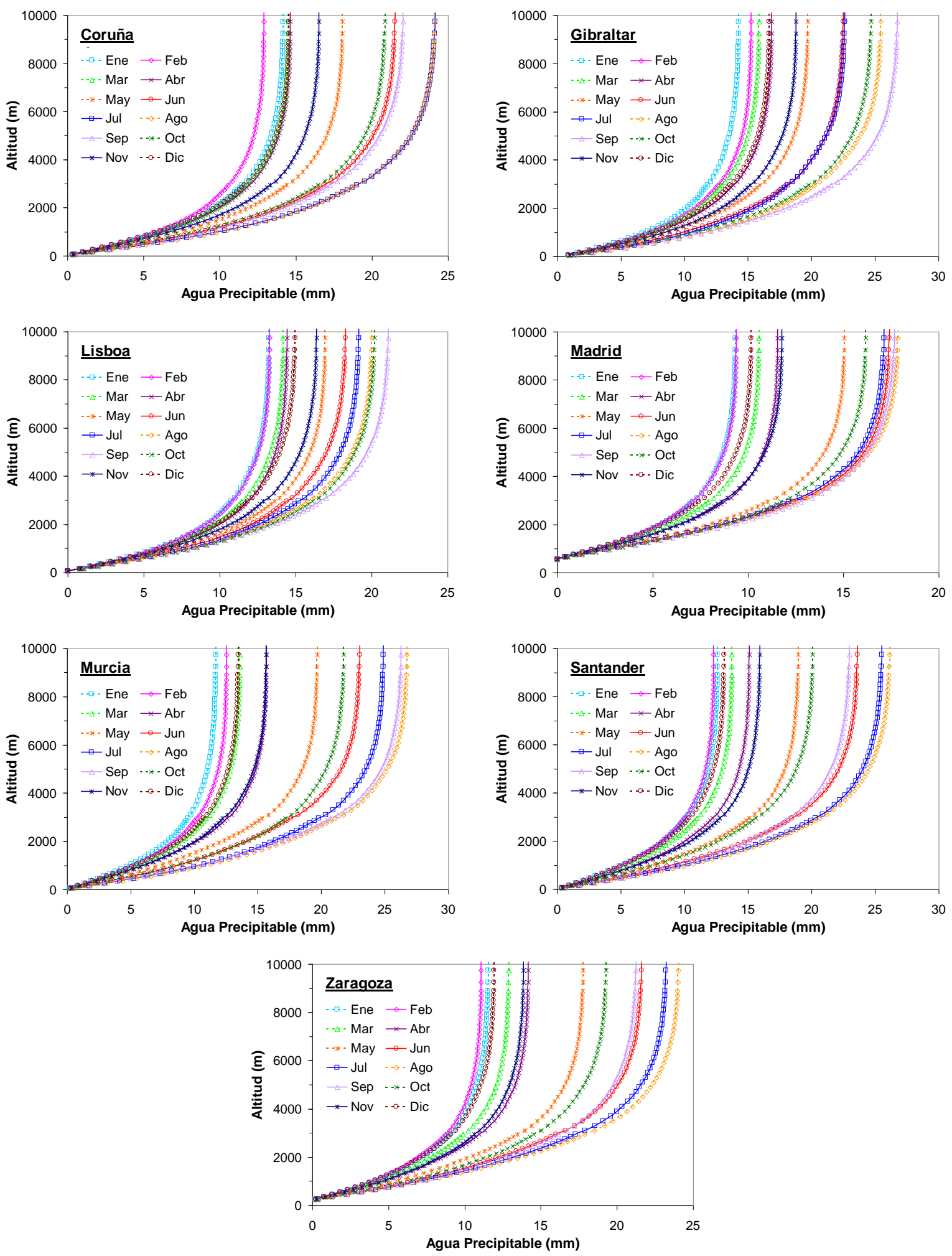

Figura 4.10 - Distribución vertical media mensual del PWV acumulado desde el nivel de la estación hasta cada nivel de altitud.

Las gráficas mensuales de los valores del PWV acumulado en términos de porcentaje sobre el valor medio de cada mes (no mostradas) prácticamente se superponen, con unas diferencias máximas entre meses de sólo el $5 \%$. Ello indica que todos los meses presentan el mismo comportamiento relativo del PWV acumulado. 


\subsection{Mínimo relativo del mes de julio}

Como se ha visto al principio de este capítulo, las estaciones situadas en el cuadrante suroccidental de la Península presentan un mínimo relativo del PWV en el mes de julio (Figura 4.11). Si bien este mínimo es poco profundo, el máximo descenso con respecto a junio es de sólo $1.6 \mathrm{~mm}$ (San Fernando y Cáceres), puede ser un característica significativa. Este mínimo relativo se hace menos pronunciado conforme aumenta la latitud de la estación. En las estaciones localizadas hacia el sureste (Almería y Murcia) no llega a aparecer este mínimo, pero sí se aprecia una disminución en el ritmo de crecimiento del PWV en julio con respecto a junio. Este mínimo se presenta en estaciones equipadas con distinta instrumentación, por lo que no puede ser un fenómeno achacable al método de medida, sino a la localización geográfica.

Las observaciones de los sondeos permiten profundizar más en las características de este mínimo. La distribución vertical de la variación de la humedad absoluta de los meses de junio a agosto respecto a los valores de julio en la estación de Gibraltar (Figura 4.12) muestra un incremento de la humedad absoluta en las capas junto al suelo de junio a agosto, como cabría de esperar por el mayor calentamiento de la superficie terrestre. Sin embargo, en las capas medias y medias bajas se aprecia una disminución en el mes de julio con respecto a junio. En concreto, entre 1 y $4 \mathrm{Km}$ de altitud la humedad absoluta es mayor en junio que en julio, dándose la máxima diferencia entre ambas a los $2 \mathrm{Km}$ de altitud con un valor de $0.7 \mathrm{gr} / \mathrm{m}^{3}$.

La disminución de la humedad en las capas por encima de $1 \mathrm{Km}$ del mes de julio compensa y sobrepasa el aumento que se produce en las capas bajas. Como resultado, el PWV total de julio disminuye respecto al de junio. Desde la superficie y hasta $1 \mathrm{Km}$ de altitud la diferencia entre el PWV acumulado en julio y en junio aumenta (Figura 4.13). A partir de $1 \mathrm{Km}$ la menor humedad absoluta en julio hace que se invierta esta tendencia, y a los $2.5 \mathrm{Km}$ es ya el PWV acumulado mayor en junio que en julio. Por encima de los $4 \mathrm{Km}$ las diferencias se estabilizan, indicando que la contribución de las capas superiores es la misma para ambos meses.

La explicación a este fenómeno podría encontrarse en la localización geográfica de la zona afectada, próxima a África y al desierto del Sahara. Cuatro situaciones sinópticas producen la intrusión de masas de aire sahariano sobre el sur de la Península lbérica (Escudero et al., 2005). Estas situaciones están relacionadas con el intenso calentamiento de la superficie del desierto, especialmente en verano, el cual produce un sistema de bajas presiones de origen término sobre el norte de África. La fuerte convección inyecta una gran cantidad de polvo sahariano a los niveles medios y altos de la atmósfera. A esos niveles, el polvo es transportado por los vientos allí reinantes hacia la Península. Un estudio de retro-trayectorias a diferentes niveles de altitud sobre el área de interés para el periodo 2000/2005 de Toledano et al. (2009), muestra una disminución por encima de los $1.5 \mathrm{Km}$ en la frecuencia de masas de origen 
sahariano y un incremento en las de origen atlántico para el mes de julio respecto a junio. En verano las masas de aire atlánticas son más frías, y por tanto la humedad absoluta es menor que la de las masas más cálidas del sur. Este resultado está en concordancia con las observaciones obtenidas de los sondeos.

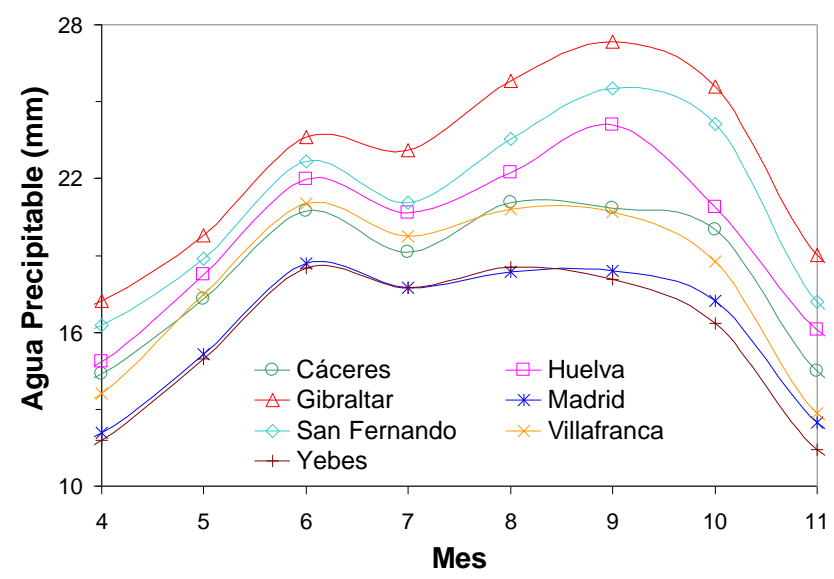

Figura 4.11 - Mínimo relativo de PWV en julio.

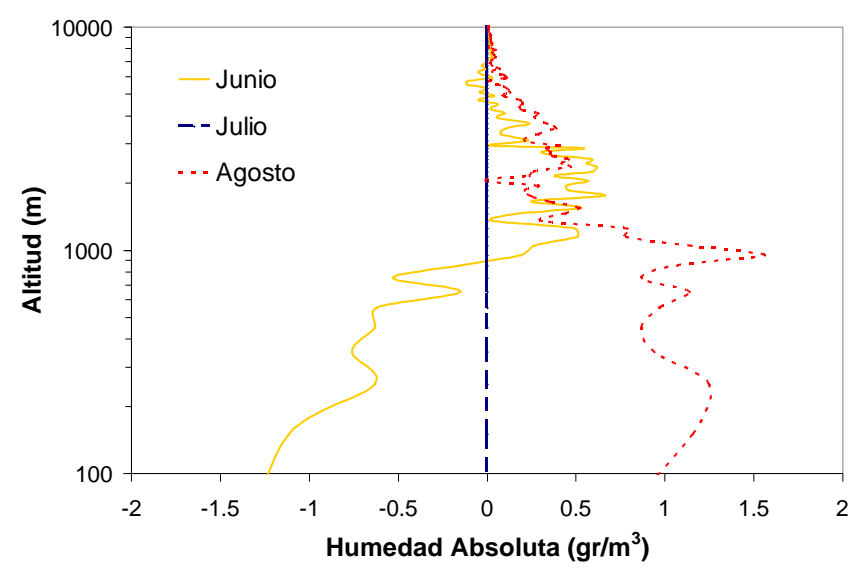

Figura 4.12 - Distribución vertical media de la variación de la humedad absoluta en los meses de junio a agosto respecto a los valores del mes de julio en la estación de Gibraltar.

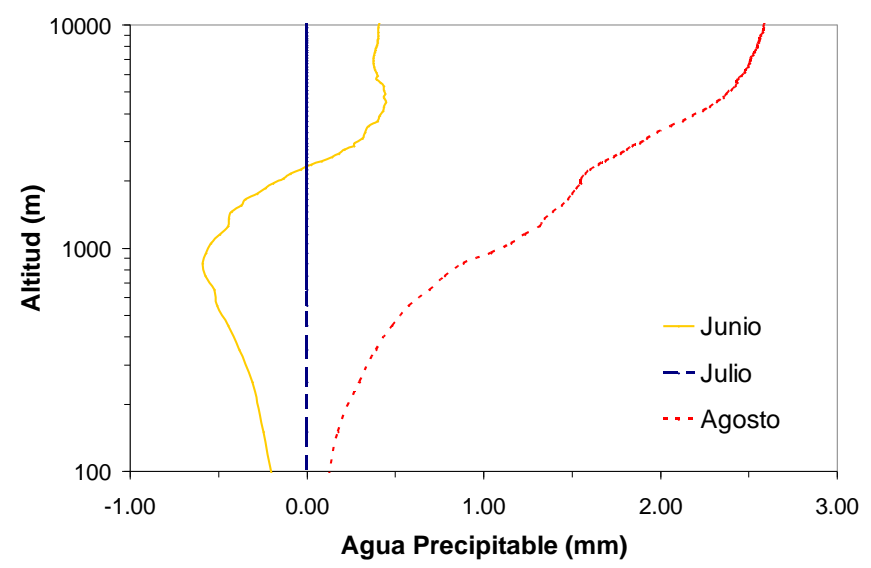

Figura 4.13 - Distribución vertical de la variación del PWV acumulado desde la superficie hasta cada nivel de altitud en los meses de junio a agosto respecto a los valores del mes de julio en Gibraltar. 
Las intrusiones de aire sahariano se caracterizan por un incremento en el espesor óptico de aerosoles y una disminución del exponente alfa de Angstrom. Valores típicos de las masas saharianas son: AOD (440nm) mayor de 0.25 , y exponente alfa inferior a uno, que indica predominio de partículas grandes (modo coarse) (Toledano et al., 2007). La evolución anual del AOD en la estación de AERONET de El Arenosillo presenta también un mínimo relativo en julio (Bennouna et al., 2011). Esto ayuda a confirmar la hipótesis de que el mínimo de PWV de julio se debe a una mayor frecuencia de intrusiones en niveles medio-bajos (1-4 Km) de masas más secas (contrastado por el sondeo), de origen atlántico (apoyado por el estudio de retrotrayectorias) y más frías y limpias (menor AOD y mayor alfa), frente a una mayor número de masa saharianas en junio.

\subsection{Comparativa con series de 25 años de sondeos}

Los resultados hasta aquí presentados no se pueden considerar con total validez climatológica al no ser las series suficientemente largas. Sin embargo, las estaciones de radiosondeo si disponen de series más largas, que no se han utilizado para que el periodo de estudio fuera el mismo en todos los emplazamientos y así los resultados pudieran ser intercomparables. No obstante, en estos emplazamientos de radiosondeos se pueden comparar los ciclos anuales del PWV obtenidos con las series largas con los presentados en el apartado 4.1, para valorar si estos últimos son representativos en el largo plazo, y por tanto pudieran tener validez para realizar una caracterización climatológica. En concreto, se ha realizado esta comparación en dos emplazamientos (Coruña, y Madrid) con veinticinco años de datos de cada una, del 1984 al 2008 (Figura 4.14).
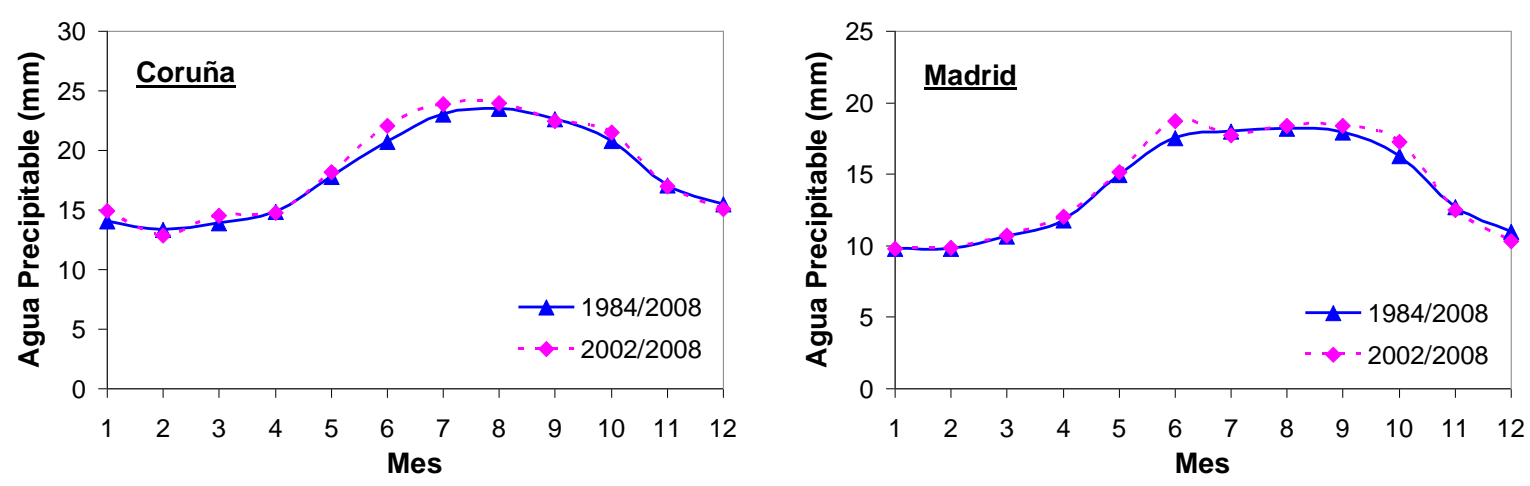

Figura 4.14 - Ciclo anual del PWV obtenido con 7 años (2002/2008) y 25 años (1984/2008) de datos en las estaciones de radiosondeo de Coruña y Madrid.

La std media de las medias mensuales utilizados para calcular el ciclo anual medio es ligeramente mayor en la serie de 25 años que en la de 7 , siendo de 1.87 y $1.56 \mathrm{~mm}$ respectivamente en Coruña, y de 1.90 y $1.43 \mathrm{~mm}$ en Madrid. La comparativa de los ciclos anuales del PWV obtenido con ambas series presenta un coeficiente de correlación $\left(\mathrm{R}^{2}\right)$ 
prácticamente de uno para los dos emplazamientos. En general la serie de 7 años presenta valores ligeramente mayores que la serie de 25 años (Tabla 4.5). La diferencia media es de $0.20 \mathrm{~mm}(1.03 \%)$ en Madrid y $0.33 \mathrm{~mm}(1.65 \%)$ en Coruña, siendo el error cuadrático medio (rmse) ligeramente superior a los $0.5 \mathrm{~mm}(\sim 3.5 \%)$. Este resultado está en concordancia con las mayores temperaturas superficies registradas en los últimos diez años.

\begin{tabular}{lcccccccc}
\hline Estación & $\begin{array}{c}\text { Media } \\
\text { Anual } \\
\mathbf{0 2 / 0 8}\end{array}$ & $\begin{array}{c}\text { Media } \\
\text { Anual } \\
\mathbf{8 4 / 0 8}\end{array}$ & BIAS & $\begin{array}{c}\text { BIAS } \\
\%\end{array}$ & RMSE & STD & MAE & $\begin{array}{c}\text { Coef. } \\
\mathbf{R}^{2}\end{array}$ \\
\hline Coruña & 18.43 & 18.10 & 0.33 & 1.65 & 0.64 & 0.54 & 0.54 & 0.98 \\
Madrid & 14.41 & 14.07 & 0.20 & 1.03 & 0.52 & 0.48 & 0.38 & 0.99 \\
\hline
\end{tabular}

Tabla 4.5 - Estadísticos de la comparativa de los ciclos anuales medios obtenidos con 7 y 25 años de datos de sondeos.

Las diferencias en valor absoluto de los promedios mensuales de ambas series se encuentran por debajo de $1 \mathrm{~mm}$ para todos los meses en los dos emplazamientos, salvo en el mes de junio cuando son ligeramente superiores, $1.28 \mathrm{~mm}$ en Coruña y $1.18 \mathrm{~mm}$ en Madrid, aproximadamente un $6 \%$ en valor relativo. La distribución de las diferencias, tanto en valor absoluto como relativo, es bastante dispar, con meses con diferencias despreciables y otros que destacan con diferencias en torno al milímetro (Figura 4.15).

La dispersión de las medias mensuales de los meses de junio de la serie de 7 años es significativamente más baja que la media. Esta concentración de valores altos del PWV en el mes de junio de los últimos años lleva a que la mayor discrepancia con la serie de 25 años se produzca en dicho mes. Es relevante el hecho de que en la serie de 25 años de Madrid el mínimo relativo del mes de julio, discutido en el apartado 4.4, ya no se aprecia, lo que apunta más bien a que éste era debido a unos valores más altos de lo normal en el mes de junio de los últimos años que a unos valores bajos en julio.
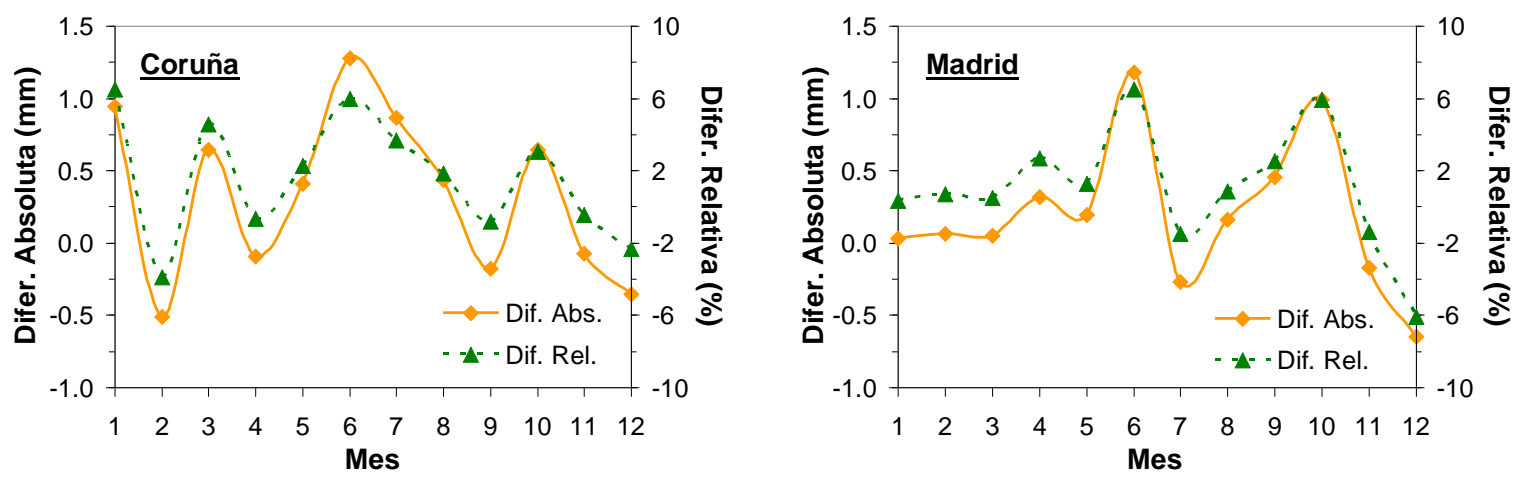

Figura 4.15 - Diferencias absolutas y relativas entre los valores medios mensuales del PWV de las series de 7 y 25 años.

Sólo con siete años de datos no se puede extraer una auténtica climatología, pero los errores medios del orden de $0.5 \mathrm{~mm}$ obtenidos en la comparación con los datos de 25 años respaldan 
el carácter climatológico de la caracterización del PWV sobre la Península Ibérica presentada en este estudio, aunque siempre hay que tener la oportuna precaución a la hora de interpretar los resultados. Así, puede haber características del corto plazo que en el largo plazo no sean significativas, o características del largo plazo que no tienen reflejo en el corto. 
- 152 - 


\section{Capítulo 5}

\section{CICLO DIURNO}

El conocimiento del ciclo diurno del contenido de vapor de agua en la atmósfera es escaso por la ausencia de datos con la suficiente resolución temporal. Mientras que los fotómetros solares sólo operan durante de día, y el número de sondeos diarios es insuficiente para describir la evolución del PWV a lo largo del día, la red de receptores de GPS si permite el estudio sistemático de esta evolución al suministrar datos durante todo el día con frecuencia horaria o incluso inferior. Algunos autores han comparado el ciclo diurno obtenido con receptores GPS y con radiómetros de microondas, y han sugerido que los datos proporcionados por los GPS son adecuados para estudiar las variaciones diurnas del PWV (Dai et al., 2002; Morland, 2009). El conocimiento del ciclo diurno del PWV puede ser aplicado para mejorar la modelización de la atenuación de la radiación solar por el vapor de agua (Jakobson et al., 2009), que se aplica por ejemplo en las correcciones de las imágenes de satélite, o para mejorar las parametrizaciones físicas de los modelos numéricos de predicción del tiempo, y con ello, afinar la predicción de la actividad convectiva.

En el primer apartado de este capítulo se presenta de manera descriptiva el ciclo diurno en media anual obtenido para las estaciones GPS con las series más largas de datos, esto es, las mismas once utilizadas en capítulos anteriores. En el segundo apartado se describen los ciclos diurnos medios para cada una de las cuatro estaciones climatológicas del año del mismo grupo de emplazamientos. Tanto el ciclo diurno medio anual como los estacionales fueron sometidos a un análisis de armónicos que se presenta en el punto tercero. Al igual que se hizo en el capítulo anterior con el ciclo anual, para valorar la representatividad geográfica de los resultados obtenidos, también se han comparado entre sí los ciclos diurnos obtenido exclusivamente con los datos del año 2008 para el conjunto de todas las estaciones GPS. Para finalizar, en el último punto del capítulo se intenta justificar de manera cualitativa la evolución diaria del PWV en base a los factores y/o elementos climáticos que provocan la condensación y la evaporación del vapor de agua atmosférico.

\subsection{Ciclo diurno anual}

Para obtener el ciclo diurno medio anual del PWV se ha procedido de la siguiente manera. En primer lugar se han calculado las anomalías horarias, restando de cada dato horario el valor 
medio del día. De esta manera, la contribución media al PWV total debida a la situación sinóptica reinante se elimina, permaneciendo únicamente la contribución de aquellos factores que experimentan una variación cíclica a lo largo del día (Jakobson et al., 2009). El ciclo diurno medio ha sido obtenido promediando para cada hora del día las anomalías de todos los días de los siete años de datos. En la Tabla 5.1 están representados los valores obtenidos. En ella, el tiempo está siempre expresado en horas de Tiempo Universal Coordinado (UTC) y no en hora local solar (LST), pero la máxima corrección a aplicar debido a la longitud geográfica de las estaciones se da en Coruña, y es de sólo treinta y cuatro minutos, que no resulta significativa a la hora de caracterizar el ciclo diurno, ya que la resolución temporal de los datos es de una hora.

\begin{tabular}{|c|c|c|c|c|c|c|c|c|c|c|c|}
\hline $\begin{array}{l}\text { HH:MM } \\
\text { UTC }\end{array}$ & Coruña & Alicante & Almería & Cáceres & Santander & Creus & Roquetes & $\begin{array}{c}\text { San } \\
\text { Fernando }\end{array}$ & Valencia & Villafranca & Yebes \\
\hline $00: 30$ & -0.30 & -0.20 & -0.28 & -0.21 & 0.00 & -0.22 & -0.26 & -0.20 & 0.18 & -0.05 & 0.07 \\
\hline 01:30 & -0.18 & -0.24 & -0.37 & -0.18 & 0.00 & -0.21 & -0.26 & -0.11 & 0.06 & -0.03 & 0.11 \\
\hline $02: 30$ & -0.13 & -0.39 & -0.51 & -0.24 & -0.02 & -0.26 & -0.37 & -0.12 & -0.13 & -0.03 & 0.07 \\
\hline 03:30 & -0.09 & -0.50 & -0.64 & -0.29 & -0.06 & -0.32 & -0.49 & -0.09 & -0.25 & -0.05 & 0.04 \\
\hline 04:30 & -0.09 & -0.57 & -0.68 & -0.33 & -0.09 & -0.37 & -0.56 & -0.11 & -0.32 & -0.08 & -0.01 \\
\hline $05: 30$ & -0.08 & -0.52 & -0.64 & -0.30 & -0.14 & -0.35 & -0.59 & -0.05 & -0.39 & -0.11 & -0.05 \\
\hline $06: 30$ & -0.09 & -0.41 & -0.57 & -0.24 & -0.17 & -0.29 & -0.58 & 0.07 & -0.42 & -0.14 & -0.11 \\
\hline $07: 30$ & -0.09 & -0.26 & -0.51 & -0.20 & -0.20 & -0.19 & -0.56 & 0.13 & -0.35 & -0.12 & -0.16 \\
\hline $08: 30$ & -0.09 & -0.13 & -0.39 & -0.13 & -0.28 & -0.16 & -0.53 & 0.20 & -0.29 & -0.11 & -0.19 \\
\hline $09: 30$ & -0.12 & -0.07 & -0.23 & -0.03 & -0.38 & -0.15 & -0.48 & 0.30 & -0.25 & -0.12 & -0.19 \\
\hline $10: 30$ & 0.00 & -0.05 & -0.07 & 0.08 & -0.45 & -0.19 & -0.33 & 0.36 & -0.32 & -0.12 & -0.16 \\
\hline $11: 30$ & 0.06 & -0.06 & 0.06 & 0.17 & -0.42 & -0.16 & -0.16 & 0.37 & -0.46 & -0.12 & -0.14 \\
\hline $12: 30$ & 0.13 & -0.05 & 0.15 & 0.19 & -0.40 & -0.10 & 0.07 & 0.34 & -0.55 & -0.12 & -0.14 \\
\hline $13: 30$ & 0.20 & -0.01 & 0.20 & 0.19 & -0.28 & 0.03 & 0.33 & 0.23 & -0.46 & -0.08 & -0.14 \\
\hline $14: 30$ & 0.33 & 0.12 & 0.28 & 0.25 & -0.07 & 0.22 & 0.56 & 0.12 & -0.34 & 0.03 & -0.10 \\
\hline $15: 30$ & 0.38 & 0.31 & 0.40 & 0.24 & 0.10 & 0.39 & 0.71 & -0.04 & -0.09 & 0.08 & -0.07 \\
\hline $16: 30$ & 0.34 & 0.44 & 0.49 & 0.22 & 0.29 & 0.53 & 0.76 & -0.21 & 0.18 & 0.18 & 0.01 \\
\hline $17: 30$ & 0.24 & 0.50 & 0.57 & 0.23 & 0.40 & 0.62 & 0.76 & -0.24 & 0.43 & 0.27 & 0.12 \\
\hline $18: 30$ & 0.12 & 0.51 & 0.65 & 0.22 & 0.48 & 0.56 & 0.69 & -0.22 & 0.63 & 0.27 & 0.20 \\
\hline $19: 30$ & 0.02 & 0.48 & 0.67 & 0.18 & 0.49 & 0.39 & 0.52 & -0.24 & 0.71 & 0.20 & 0.19 \\
\hline $20: 30$ & -0.07 & 0.49 & 0.65 & 0.14 & 0.48 & 0.29 & 0.42 & -0.19 & 0.78 & 0.15 & 0.20 \\
\hline $21: 30$ & -0.07 & 0.39 & 0.51 & 0.11 & 0.41 & 0.16 & 0.29 & -0.13 & 0.74 & 0.12 & 0.20 \\
\hline $22: 30$ & -0.16 & 0.22 & 0.27 & 0.02 & 0.27 & -0.02 & 0.11 & -0.10 & 0.57 & 0.04 & 0.17 \\
\hline $23: 30$ & -0.29 & 0.01 & -0.01 & -0.11 & 0.05 & -0.21 & -0.03 & -0.10 & 0.34 & -0.07 & 0.07 \\
\hline Máximo & 0.38 & 0.51 & 0.67 & 0.25 & 0.49 & 0.62 & 0.76 & 0.37 & 0.78 & 0.27 & 0.20 \\
\hline Mínimo & -0.30 & -0.57 & -0.68 & -0.33 & -0.45 & -0.37 & -0.59 & -0.24 & -0.55 & -0.14 & -0.19 \\
\hline Amp. & 0.68 & 1.07 & 1.35 & 0.58 & 0.94 & 0.99 & 1.35 & 0.62 & 1.33 & 0.41 & 0.39 \\
\hline Amp. (\%) & 3.4 & 5.1 & 6.7 & 3.5 & 4.6 & 4.9 & 6.4 & 3.2 & 6.2 & 2.6 & 2.8 \\
\hline
\end{tabular}

Tabla 5.1 - Anomalías medias respecto del valor medio del día del PWV para cada estación (en mm). Amp representa la amplitud del ciclo, definida como la diferencia entre el valor máximo y el mínimo. 
De los resultados de la Tabla 5.1 se extrae que el valor mínimo de PWV se alcanza durante la madrugada, aproximadamente a la misma hora para la mayoría de las estaciones (entre las 04:30 y las 05:30 UTC). Este mínimo es más pronunciado en las estaciones de la costa mediterránea. Por su parte, el valor máximo se alcanza mayoritariamente en la segunda mitad del día, siendo también en este caso más acusado en las estaciones de la costa mediterránea. Los valores máximos presenta una mayor dispersión en la hora a la que tienen lugar que los mínimos, variando desde las 11:30 UTC en San Fernando a las 20:30 UTC en Alicante o Valencia, aunque en la mayoría de las estaciones se alcanza entre las 17:30 y las 20:30 UTC, siendo sólo en las más occidentales (Coruña, Cáceres y San Fernando) donde tiene lugar antes de estas horas. En la Figura 5.1 se observa además como la forma de los ciclos en los diferentes emplazamientos es más uniforme durante la noche que durante el día, cuando las discrepancias aumentan de forma considerable. Todo esto sugiere que los mecanismos que producen las variaciones del PWV están más influenciados por efectos geográficos locales durante el día que durante la noche.

Las tres estaciones de la costa atlántica (Coruña, Santander y San Fernando) presentan un ciclo diurno con diferencias apreciables. Sin embargo, el ciclo de las situadas en la costa mediterránea es bastante más similar entre sí. Por su parte, el ciclo de las estaciones del interior está muy amortiguado, siendo más parecido al de Coruña.

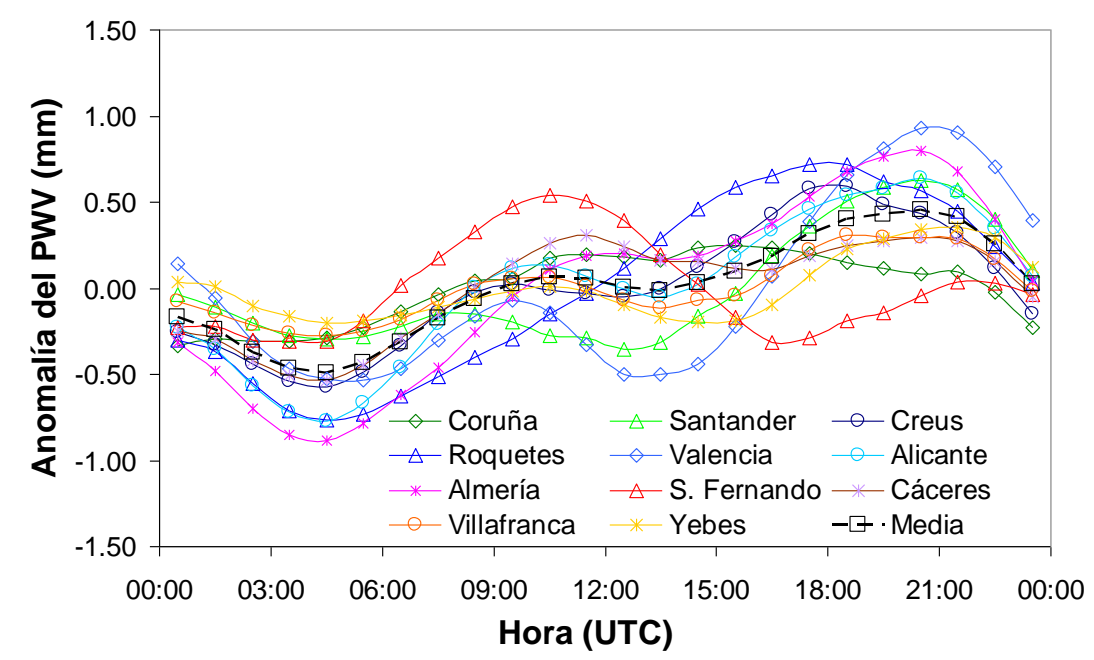

Figura 5.1 - Representación gráfica de los resultados de la Tabla 5.1. Los cuadrados negros indican la media aritmética de todas las estaciones.

La amplitud del ciclo diurno, entendiendo como tal la diferencia entre el valor máximo y mínimo de la anomalía, oscila entre $0.39 \mathrm{~mm}$ en Yebes y $1.35 \mathrm{~mm}$ en Almería y Roquetes. Los mayores valores se registran en las estaciones de la costa mediterránea, oscilando entre 0.99 y $1.35 \mathrm{~mm}$, mientras que los menores se registran en las estaciones del interior, variando entre 0.39 y $0.58 \mathrm{~mm}$. En términos relativos de porcentaje respecto del valor medio anual del PWV de cada emplazamiento, la amplitud del ciclo diurno varía desde un $2.6 \%$ en Villafranca hasta 
un $6.7 \%$ en Almería. También en este caso las mayores amplitudes tienen lugar en las estaciones de la costa mediterránea.

En el promedio de todos los emplazamientos (Tabla 5.2), el PWV disminuye durante la noche hasta alcanzar su mínimo valor sobre las 5:00 UTC, con una anomalía de $-0.29 \mathrm{~mm}$. Posteriormente, el PWV aumenta lentamente hasta que alcanza un valor máximo de $0.39 \mathrm{~mm}$ por encima del valor medio del día sobre las 18:30 UTC. A partir de ese momento disminuye de forma más pronunciada hasta volver a alcanzar su valor mínimo en la madrugada. La forma de este ciclo se asemeja a una sinusoide asimétrica, con la rama descendente más corta y pronunciada que la ascendente, siendo la altura del máximo ligeramente mayor que la profundidad del mínimo (Figura 5.1). La amplitud de este ciclo medio es de $0.66 \mathrm{~mm}$.

\begin{tabular}{ccccccccccccc}
\hline Hora & $\mathbf{0 0 : 3 0}$ & $\mathbf{0 1 : 3 0}$ & $\mathbf{0 2 : 3 0}$ & $\mathbf{0 3 : 3 0}$ & $\mathbf{0 4 : 3 0}$ & $\mathbf{0 5 : 3 0}$ & $\mathbf{0 6 : 3 0}$ & $\mathbf{0 7 : 3 0}$ & $\mathbf{0 8 : 3 0}$ & $\mathbf{0 9 : 3 0}$ & $\mathbf{1 0 : 3 0}$ & $\mathbf{1 1 : 3 0}$ \\
\hline $\begin{array}{c}\text { Anomalía } \\
(\mathrm{mm})\end{array}$ & -0.13 & -0.13 & -0.19 & -0.25 & -0.29 & -0.29 & -0.27 & -0.23 & -0.19 & -0.16 & -0.11 & -0.08 \\
\hline Hora & $\mathbf{1 2 : 3 0}$ & $\mathbf{1 3 : 3 0}$ & $\mathbf{1 4 : 3 0}$ & $\mathbf{1 5 : 3 0}$ & $\mathbf{1 6 : 3 0}$ & $\mathbf{1 7 : 3 0}$ & $\mathbf{1 8 : 3 0}$ & $\mathbf{1 9 : 3 0}$ & $\mathbf{2 0 : 3 0}$ & $\mathbf{2 1 : 3 0}$ & $\mathbf{2 2 : 3 0}$ & $\mathbf{2 3 : 3 0}$ \\
\hline $\begin{array}{c}\text { Anomalía } \\
(\mathrm{mm})\end{array}$ & -0.04 & 0.02 & 0.13 & 0.22 & 0.29 & 0.36 & 0.37 & 0.33 & 0.30 & 0.25 & 0.13 & -0.03 \\
\hline
\end{tabular}

Tabla 5.2 - Valores de la anomalía de ciclo diurno medio de todas las estaciones.

Este ciclo medio describe con más fidelidad el comportamiento de cada estación durante la noche, pero no así durante el día, cuando el ciclo diurno de cada estación está muy determinado por efectos locales.

\subsection{Ciclo diurno estacional}

Mediante un procedimiento similar al usado para obtener el ciclo diurno promedio anual se ha calculado el ciclo diurno para cada uno de los meses del año. Posteriormente, los ciclos diurnos estacionales se han obtenido agrupando y promediando los ciclos diurnos mensuales por estaciones climatológicas, considerando invierno los meses de diciembre a febrero, primavera de marzo a mayo, verano de junio a agosto, y otoño de septiembre a noviembre.

De la simple comparación visual de las gráficas de los ciclos diurnos (Fig. 5.2), se desprende que en término medio el ciclo diurno es claramente más pronunciado en verano que en cualquier otra estación. En la mayoría de los emplazamientos la máxima amplitud del ciclo tiene lugar en verano. Solamente en el los emplazamientos del interior peninsular es mayor la amplitud en otoño (Cáceres) o en primavera (Villafranca y Yebes). Por el contrario, la menor amplitud se registra en invierno y primavera. La amplitud del ciclo en primavera es mayor o sólo ligeramente menor que en invierno, excepto en Coruña donde es la mitad de la del invierno. Por su parte, la amplitud en otoño toma valores comprendidos entre los de la primavera y el verano, excepto en los emplazamientos del interior y en Santander. 


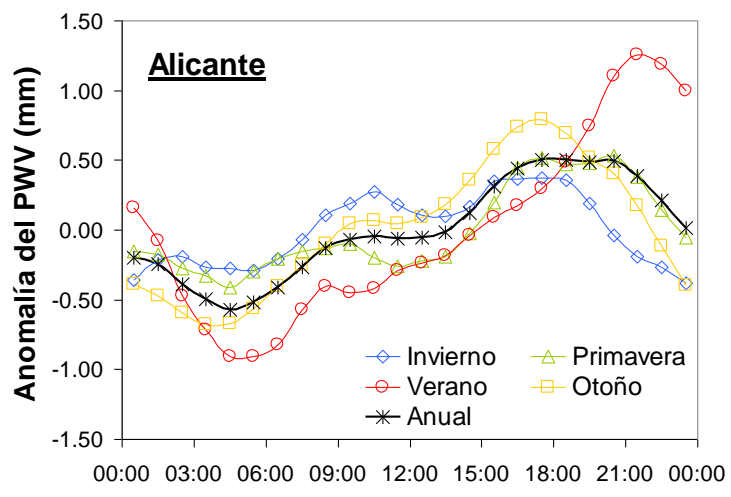

Hora (UTC)

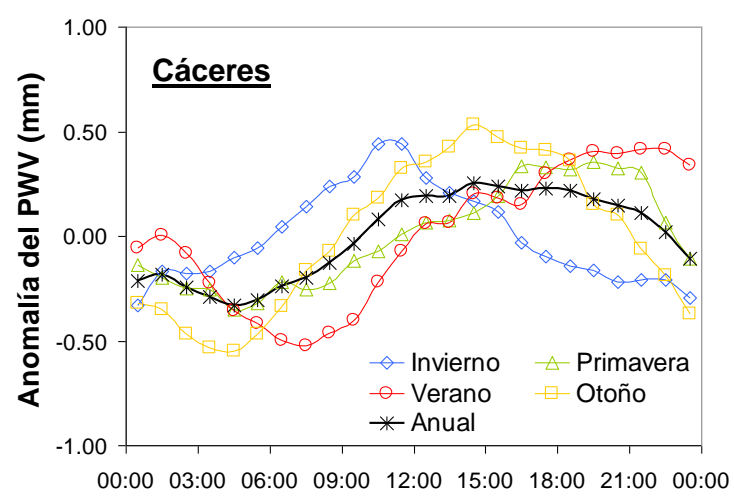

Hora (UTC)

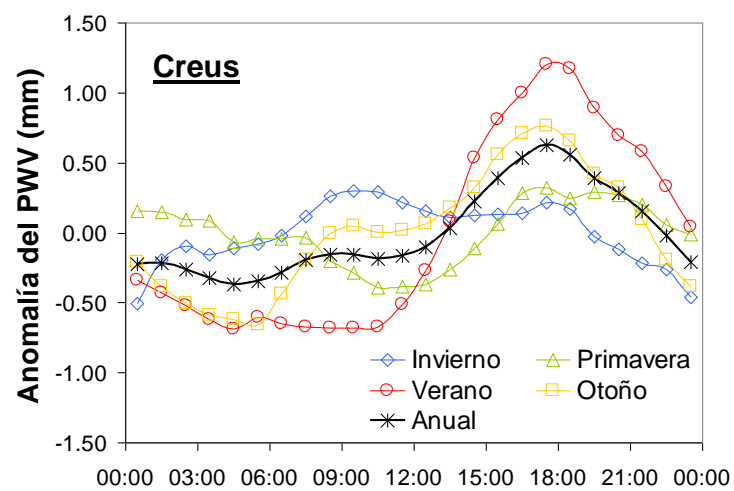

Hora (UTC)

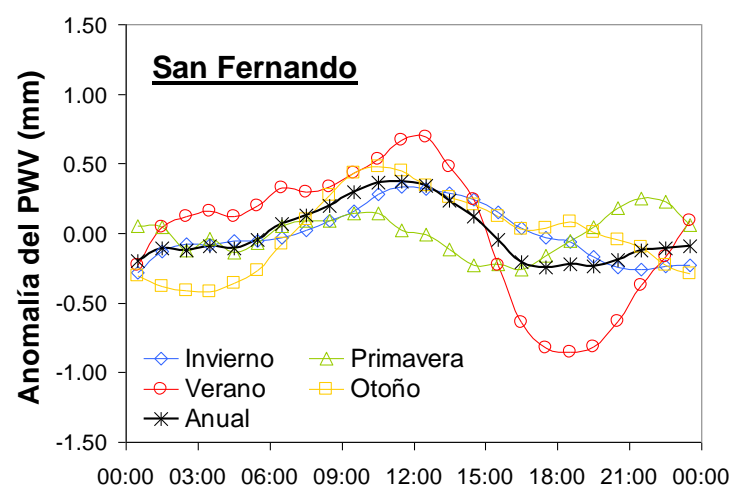

Hora (UTC)

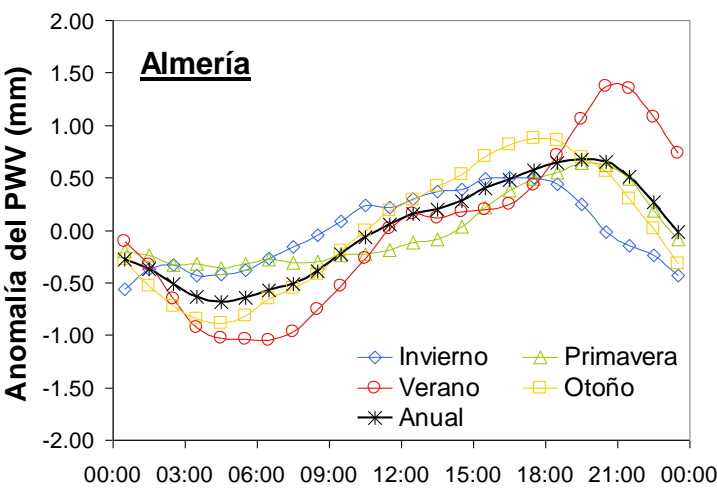

Hora (UTC)

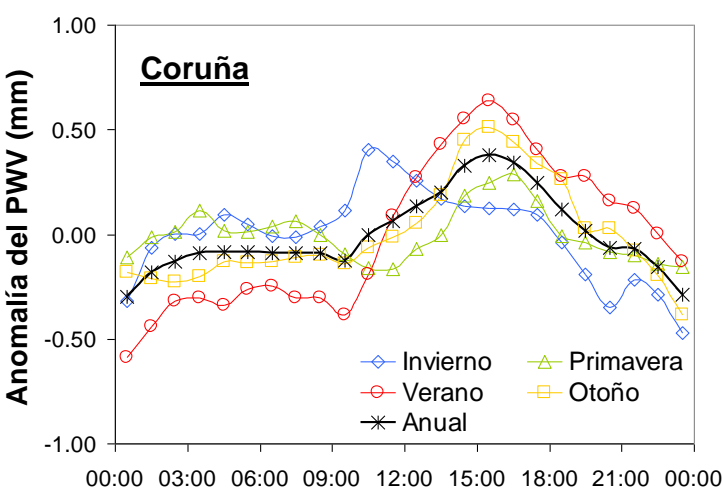

Hora (UTC)

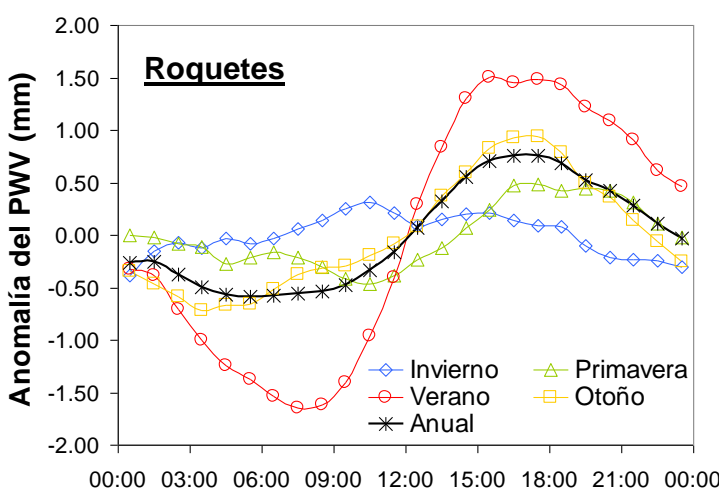

Hora (UTC)

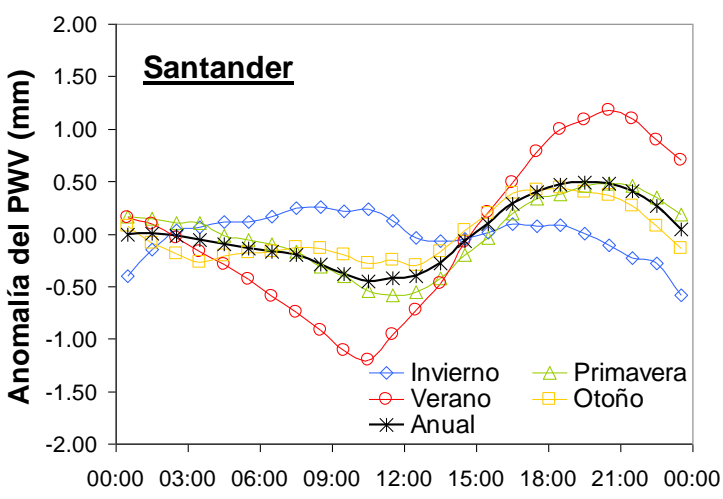

Hora (UTC) 

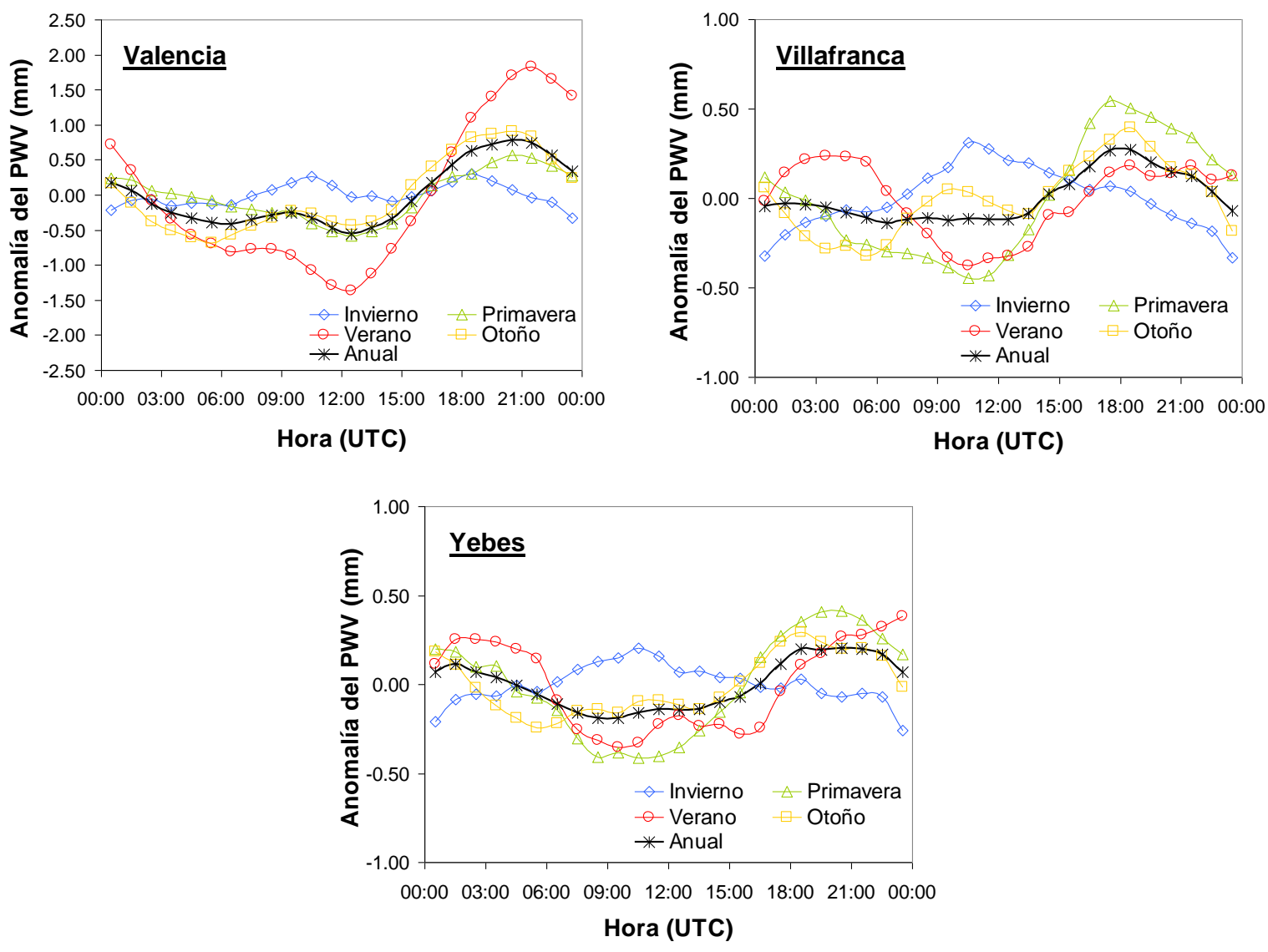

Figura 5.2 - Ciclos diurnos estacionales para cada estación GPS.

La amplitud del ciclo diurno oscila en verano entre los $0.62 \mathrm{~mm}$ de Villafranca y los $3.19 \mathrm{~mm}$ de Valencia, registrándose los valores más bajos en los emplazamientos del interior, y los más altos en los de la costa mediterránea y también en Santander; mientras que en invierno oscila entre los $0.46 \mathrm{~mm}$ de Yebes y los $1.07 \mathrm{~mm}$ de Almería; en primavera lo hace entre los $0.45 \mathrm{~mm}$ de Coruña y los $1.15 \mathrm{~mm}$ de Valencia, registrándose los menores valores en los emplazamientos más al oeste; y en otoño entre los $0.53 \mathrm{~mm}$ de Villafranca y los $1.77 \mathrm{~mm}$ de Almería, con los mayores valores localizados en los emplazamientos de la costa mediterránea.

Los valores máximo y mínimo de la anomalía en invierno son similares en todos los emplazamientos. Los máximos varían entre $0.20 \mathrm{~mm}$ en Yebes y $0.50 \mathrm{~mm}$ en Almería, mientras que los mínimos lo hacen entre $-0.26 \mathrm{~mm}$ en Yebes y $-0.58 \mathrm{~mm}$ en Santander. Por el contrario, en verano hay una mayor dispersión, los máximos varían entre $0.24 \mathrm{~mm}$ en Villafranca y 1.83 mm en Valencia, y los mínimos entre -0.35 mm en Yebes y -1.65 mm en Roquetes (Tabla 5.3).

Respecto a la forma del ciclo, en invierno es bastante similar en todos los emplazamientos, a pesar de las distintas localizaciones geográficas. La dispersión aumenta en primavera, y aún más en otoño. En verano, los efectos locales se hacen sentir fuertemente, haciendo que la forma del ciclo sea muy diferente de un emplazamiento a otro. Al menos se observan dos patrones claramente diferenciados en todos los emplazamientos, el del invierno y el del verano. 
En algunos emplazamientos la primavera y el otoño presentan un ciclo intermedio entre el invierno y el verano, como en las ubicadas en las costa mediterránea, mientras que en otras es similar al del invierno, como en San Fernando, o al del verano, como en Coruña.

\begin{tabular}{l|ccc|ccc|ccc|ccc}
\hline & \multicolumn{3}{|c|}{ INVIERNO } & \multicolumn{3}{c|}{ PRIMAVERA } & \multicolumn{3}{c|}{ VERANO } & \multicolumn{3}{c}{ OTOÑo } \\
Estación & Máx & Mín & Ampl. & Máx & Mín & Ampl. & Máx & Mín & Ampl. & Máx & Mín & Ampl. \\
\hline Alicante & 0.37 & -0.38 & 0.76 & 0.54 & -0.41 & 0.95 & 1.26 & -0.91 & 2.16 & 0.79 & -0.68 & 1.47 \\
Almería & 0.50 & -0.57 & 1.07 & 0.64 & -0.35 & 1.00 & 1.37 & -1.05 & 2.41 & 0.88 & -0.89 & 1.77 \\
Cáceres & 0.44 & -0.33 & 0.77 & 0.35 & -0.35 & 0.70 & 0.42 & -0.53 & 0.94 & 0.53 & -0.55 & 1.08 \\
Coruña & 0.40 & -0.47 & 0.88 & 0.29 & -0.16 & 0.45 & 0.64 & -0.59 & 1.23 & 0.51 & -0.38 & 0.89 \\
Creus & 0.30 & -0.51 & 0.81 & 0.32 & -0.39 & 0.71 & 1.20 & -0.68 & 1.89 & 0.76 & -0.30 & 1.06 \\
Roquetes & 0.31 & -0.38 & 0.69 & 0.48 & -0.46 & 0.95 & 1.51 & -1.65 & 3.16 & 0.94 & -0.72 & 1.66 \\
S. Fernando & 0.33 & -0.28 & 0.61 & 0.25 & -0.26 & 0.51 & 0.69 & -0.85 & 1.55 & 0.48 & -0.42 & 0.90 \\
Santander & 0.26 & -0.58 & 0.84 & 0.48 & -0.58 & 1.06 & 1.18 & -1.20 & 2.38 & 0.44 & -0.30 & 0.74 \\
Valencia & 0.30 & -0.33 & 0.63 & 0.57 & -0.58 & 1.15 & 1.83 & -1.37 & 3.19 & 0.91 & -0.68 & 1.59 \\
Villafranca & 0.31 & -0.33 & 0.64 & 0.54 & -0.45 & 0.99 & 0.24 & -0.38 & 0.62 & 0.39 & -0.32 & 0.72 \\
Yebes & 0.20 & -0.26 & 0.46 & 0.41 & -0.41 & 0.83 & 0.38 & -0.35 & 0.74 & 0.29 & -0.24 & 0.53 \\
\hline
\end{tabular}

Tabla 5.3 - Valores máximos, mínimos y amplitud de las anomalías de los ciclos diurnos estacionales.

Para apreciar mejor las diferencias entre los ciclos diurnos estacionales de los distintos emplazamientos, se han agrupándolos estos no por emplazamiento sino por estación del año (Figura 5.3). En estas figuras se observa claramente como las discrepancias entre emplazamientos son menores en invierno y mayores en verano.
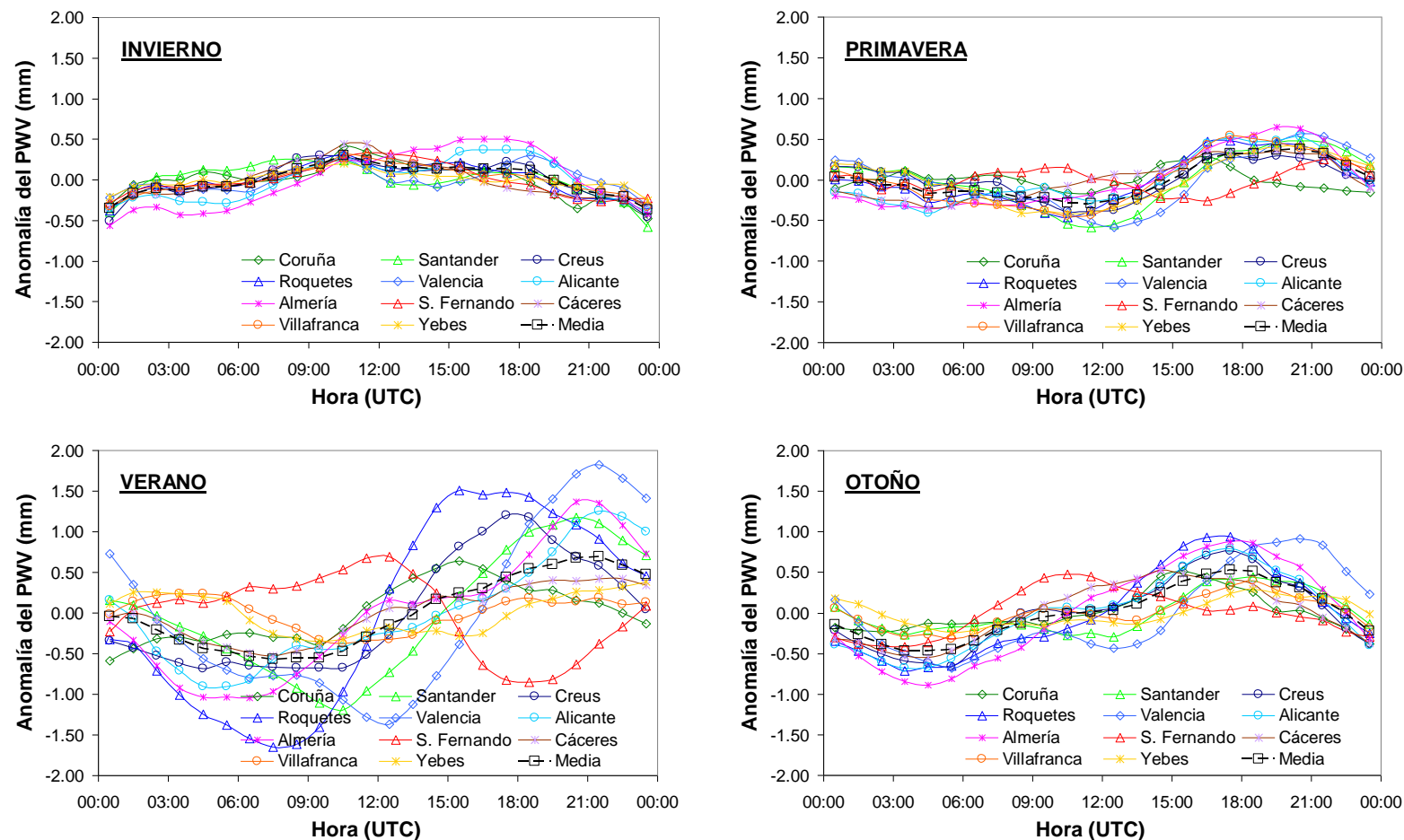

Figura 5.3 - Ciclos diurnos estacionales agrupados por estación climatológica. 
Al igual que ocurría con los ciclos diurnos anuales, se observa como también los estacionales son más similares durante la noche que durante el día, si bien en el verano la dispersión es también muy importante durante la noche.

Los ciclos diurnos estacionales promedios de todos los emplazamientos se muestran en la Figura 5.4. El verano se caracteriza por la mayor amplitud de la onda $(1.26 \mathrm{~mm})$, describiendo una curva con un mínimo amplio que abarca desde las 6:30 UTC a las 9:30 UTC, y un máximo más pronunciado hacia el final del día (sobre las 21:30 UTC), siendo la pendiente de la fase descendente mayor que la de la fase de ascenso. En invierno el ciclo es débil, con una amplitud de sólo $0.67 \mathrm{~mm}$; el máximo se alcanza antes del mediodía (sobre las 10:30 UTC). La primavera presenta también un ciclo diurno débil, con la misma amplitud que en el invierno pero con un comportamiento diferente. En primavera el PWV comienza a aumentar más tarde que en invierno, el PWV decrece lentamente desde la media noche hasta las 11:30 UTC aproximadamente, y a partir de esa hora aumenta hasta la tarde cuando un máximo redondeado tiene lugar entre las 17:30 UTC y las 20:30 UTC, para finalmente disminuir de forma pronunciada hasta la media noche. El otoño presenta un comportamiento más similar al del verano, pero con un cierto desfase, el valor máximo y mínimo del ciclo diurno tienen lugar más pronto en otoño que en verano, y con una amplitud menor, tomando un valor intermedio entre el invierno y el verano $(0.99 \mathrm{~mm})$.

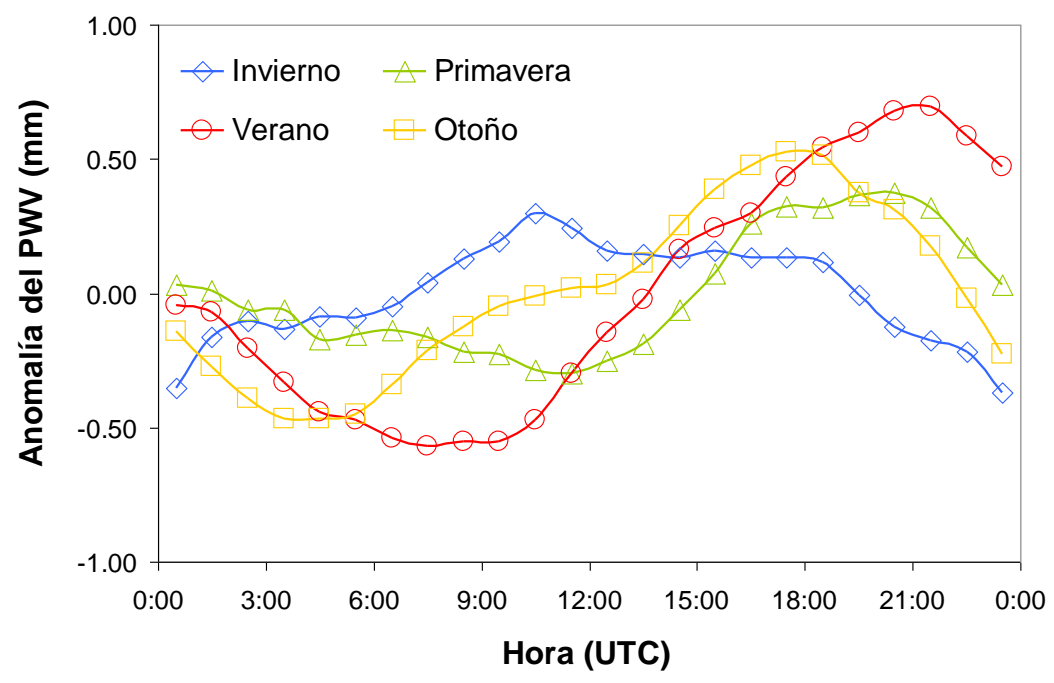

Figura 5.4 - Ciclos diurnos estacionales promedios de todos los emplazamientos.

De acuerdo a Wang et al. (2007), el ciclo diurno del PWV para la región europea, obtenido en base a la media de 110 estaciones GPS repartidas por todo el continente, presenta la oscilación más pronunciada en verano, con una amplitud de aproximadamente $1.2 \mathrm{~mm}$, mientras que en invierno y otoño la oscilación es algo más débil, y en primavera es prácticamente despreciable. El pico máximo de PWV se alcanza sobre las 11:00 LST en invierno, entre las 16 y las 18 LST en otoño, y entre las 20 y las 22 LST en verano. Los 
resultados obtenidos en el presente estudio para la Península Ibérica están en buena concordancia con estos otros para el verano, el otoño y el invierno, tanto en la forma de ciclo como en la hora a la que tiene lugar el máximo valor, pero la amplitud es ligeramente mayor en la Península en verano y otoño. En primavera, el ciclo diurno obtenido por Wang para la región europea es bastante más débil que el obtenido para la Península.

\subsection{Análisis de armónicos}

Al igual que se hizo con el ciclo anual, el ciclo diurno también se ha descompuesto en armónicos simples siguiendo las expresiones 4.1 y 4.2 , pero en este caso con periodos de 24horas $\left(\mathrm{S}_{1}\right)$, 12-horas $\left(\mathrm{S}_{2}\right)$, 8-horas $\left(\mathrm{S}_{3}\right)$, y 6 -horas $\left(\mathrm{S}_{4}\right)$ (Figura 5.5). La semiamplitud (mitad de la amplitud valle-pico), la fase (hora UTC del primer pico) y la varianza explicada por cada armónico están recogidas en la Tabla 5.4.

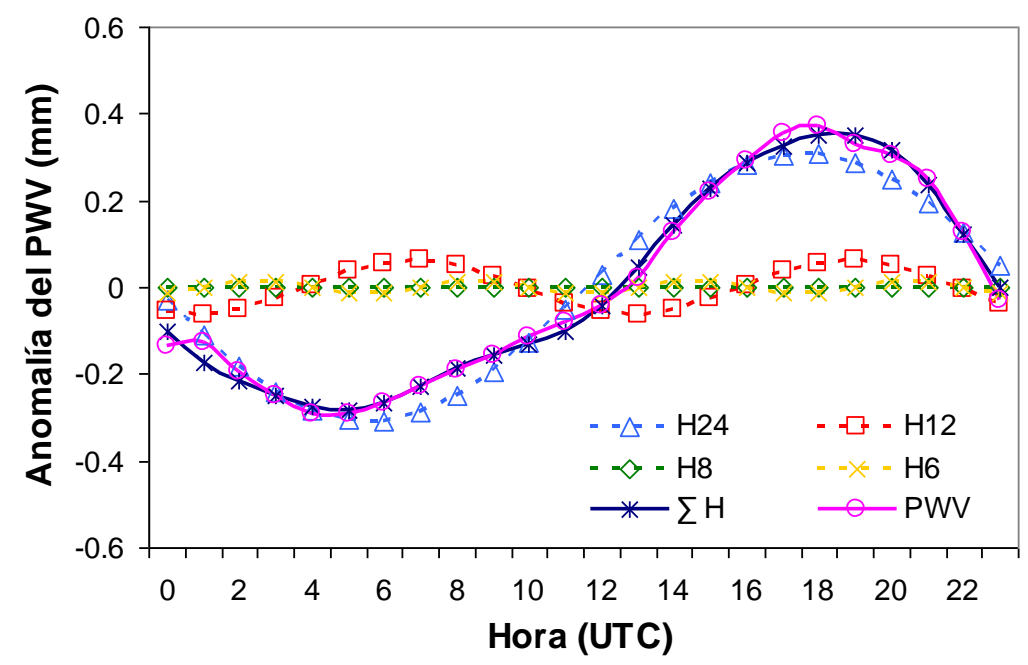

Figura 5.5 - Descomposición en armónicos simples del ciclo diurno promediado anualmente para todos los emplazamientos.

$\mathrm{S}_{1}$ es el armónico dominante en todos los emplazamientos. No obstante, hay diferencias entre los distintos emplazamientos. Así, la varianza explicada por este armónico oscila entre un $74 \%$ en Coruña y un $96 \%$ en Cáceres. $S_{2}$ es el segundo armónico dominante también para todos los emplazamientos, con una varianza explicada que oscila en este caso entre el $1.5 \%$ en Cáceres y el $21.5 \%$ en Coruña. Así, $S_{1}$ y $S_{2}$ juntos explican prácticamente toda la varianza, un $97 \%$. Solamente en la mitad de los emplazamientos la varianza explicada por $S_{3}$ es mayor de un $1 \%$, tomando un valor máximo de un $4 \%$ en Yebes. Por su parte la varianza explicada por $\mathrm{S}_{4}$ es mayor de un $1 \%$ sólo en Coruña (1.4\%). En término medio, $S_{1}$ explica el $85 \%$ de la varianza, $S_{2}$ el $11 \%, S_{3}$ solamente el $1 \%$, y la de $S_{4}$ es despreciable.

La semiamplitud de $S_{1}$ es más del doble de la de $S_{2}$, y en algunos emplazamientos incluso mucho más, mientras que la semiamplitud de $S_{3}$ y $S_{4}$ son prácticamente despreciables. La fase 
de $S_{1}$ oscila desde las 9:45 UTC en San Fernando a las 21:15 UTC en Yebes, aunque para la mayoría de los emplazamientos se encuentra entre las 17:00 UTC y las 20:30 UTC. Para $\mathrm{S}_{2}$ se da una mayor dispersión en los valores de la fase que en el caso de $S_{1}$, oscilando entre las 3:45 y las 10:45 UTC.

\begin{tabular}{lccccccccccccc}
\hline & \multicolumn{3}{c}{ 24-h Periodo } & \multicolumn{3}{c}{ 12-h Periodo } & \multicolumn{3}{c}{ 8-h Periodo } & \multicolumn{3}{c}{ 6-h Periodo } \\
Estación & A & F & V & A & F & V & A & F & V & A & F & V & V T \\
\hline Alicante & 0.46 & 17.28 & 87.56 & 0.15 & 7.94 & 9.39 & 0.05 & 0.58 & 1.11 & 0.03 & 3.30 & 0.49 & 98.54 \\
Almería & 0.63 & 17.12 & 94.32 & 0.13 & 8.45 & 3.99 & 0.05 & 3.61 & 0.51 & 0.00 & 0.00 & 0.00 & 98.82 \\
Cáceres & 0.28 & 15.64 & 96.08 & 0.04 & 10.12 & 1.50 & 0.02 & 0.00 & 0.52 & 0.00 & 0.00 & 0.00 & 98.10 \\
Coruña & 0.23 & 14.31 & 74.00 & 0.12 & 3.67 & 21.54 & 0.00 & 0.00 & 0.00 & 0.03 & 2.95 & 1.42 & 96.95 \\
Creus & 0.40 & 16.97 & 84.10 & 0.15 & 5.60 & 11.74 & 0.07 & 0.75 & 2.32 & 0.02 & 3.17 & 0.33 & 98.49 \\
Roquetes & 0.67 & 17.16 & 95.80 & 0.12 & 3.82 & 2.91 & 0.03 & 7.04 & 0.17 & 0.00 & 0.00 & 0.00 & 98.88 \\
San Fernando & 0.25 & 9.72 & 75.34 & 0.13 & 10.74 & 21.06 & 0.03 & 4.39 & 1.23 & 0.00 & 0.00 & 0.00 & 97.63 \\
Santander & 0.38 & 20.16 & 81.46 & 0.17 & 5.89 & 16.71 & 0.00 & 0.00 & 0.00 & 0.03 & 2.43 & 0.40 & 98.57 \\
Valencia & 0.56 & 20.37 & 82.80 & 0.24 & 7.81 & 14.61 & 0.06 & 1.42 & 1.09 & 0.04 & 3.18 & 0.32 & 98.81 \\
Villafranca & 0.16 & 18.62 & 76.33 & 0.08 & 5.51 & 16.85 & 0.04 & 1.74 & 3.80 & 0.00 & 0.00 & 0.00 & 96.99 \\
Yebes & 0.18 & 21.29 & 91.44 & 0.03 & 6.23 & 2.25 & 0.04 & 2.95 & 4.01 & 0.00 & 0.00 & 0.00 & 97.71 \\
\hline MEDIA & $\mathbf{0 . 3 8}$ & $\mathbf{1 7 . 1 5}$ & $\mathbf{8 5 . 3 8}$ & $\mathbf{0 . 1 2}$ & $\mathbf{6 . 8 9}$ & $\mathbf{1 1 . 1 4}$ & $\mathbf{0 . 0 4}$ & $\mathbf{2 . 0 4}$ & $\mathbf{1 . 3 4}$ & $\mathbf{0 . 0 1}$ & $\mathbf{1 . 3 7}$ & $\mathbf{0 . 2 7}$ & $\mathbf{9 7 . 8 7}$ \\
\hline
\end{tabular}

Tabla 5.4 - Análisis de armónicos del ciclo diurno promedio anual del PWV: (A) Semiamplitud (mm), mitad de la amplitud de pico-valle; (F) fase, hora UTC del máximo; (V) varianza explicada; (VT) varianza total explicada por los cuatro armónicos juntos.

Estos resultados están en consonancia con los obtenidos por Dai et al., (2002). Ellos descompusieron el ciclo diurno del PWV de 54 estaciones de Norte América en armónicos simples, también de periodos 24, 12, 8 y 6 horas, y encontraron que el ciclo diurno estaba bien representado con sólo los dos primeros armónicos. En su caso, $S_{1}$ explicaba más del $50 \%$ de la varianza, mientras que $S_{2}$ explicaba menos del $25 \%$. Ambos armónicos juntos explicaban más del $80 \%$ de la varianza para la mayoría de los emplazamientos.

También los ciclos diurnos estacionales fueron descompuestos en armónicos simples. Las Tablas 5.5, 5.6, 5.7 y 5.8 contienen los parámetros de este análisis para cada uno de los emplazamientos.

En invierno $S_{1}$ es siempre el armónico dominante, pero se da una gran dispersión en la varianza explicada por este armónico. Así, en Valencia es de sólo un 37\%, mientras que en Almería llega al 93\%, aunque en sólo dos emplazamientos la varianza explicada queda por debajo del $70 \%$, Valencia y Santander. Es precisamente en estos dos emplazamientos donde $\mathrm{S}_{2}$ explica más varianza, un $21 \%$ y un $30 \%$ respectivamente. Por el contrario, este armónico no explica ninguna varianza en Villafranca y Roquetas. Por su parte, $\mathrm{S}_{3}$ es muy significativo en Valencia, explicando un $34 \%$ de la varianza. En término medio $S_{2}$ y $S_{3}$ explican la misma 
varianza en el invierno, sobre un $8 \% . \mathrm{S}_{4}$ sólo tiene una contribución significativa en Coruña, Santander, y Roquetes donde explica del orden de un $2 \%$ de la varianza (Tabla 5.5).

\begin{tabular}{lccccccccccccc}
\hline & \multicolumn{3}{c}{ 24-h Periodo } & \multicolumn{3}{c}{ 12-h Periodo } & \multicolumn{3}{c}{ 8-h Periodo } & \multicolumn{3}{c}{ 6-h Periodo } \\
Estación & $\mathbf{A}$ & $\mathbf{F}$ & $\mathbf{V}$ & $\mathbf{A}$ & $\mathbf{F}$ & $\mathbf{V}$ & $\mathbf{A}$ & $\mathbf{F}$ & $\mathbf{V}$ & $\mathbf{A}$ & $\mathbf{F}$ & $\mathbf{V}$ & V T \\
\hline Alicante & 0.32 & 13.99 & 79.70 & 0.08 & 5.79 & 4.94 & 0.13 & 1.41 & 12.84 & 0.02 & 2.88 & 0.53 & 98.01 \\
Almería & 0.48 & 14.41 & 93.39 & 0.07 & 5.07 & 2.37 & 0.07 & 1.73 & 1.95 & 0.00 & 0.00 & 0.00 & 97.71 \\
Cáceres & 0.31 & 10.67 & 92.02 & 0.06 & 10.46 & 3.97 & 0.00 & 0.00 & 0.00 & 0.00 & 0.00 & 0.00 & 96.00 \\
Coruña & 0.26 & 10.66 & 72.68 & 0.09 & 14.58 & 7.79 & 0.09 & 2.54 & 8.81 & 0.05 & 4.89 & 2.66 & 91.93 \\
Creus & 0.27 & 11.77 & 76.57 & 0.09 & 6.17 & 8.46 & 0.09 & 1.89 & 7.78 & 0.00 & 0.00 & 0.00 & 92.81 \\
Roquetes & 0.25 & 11.54 & 84.96 & 0.00 & 15.00 & 0.00 & 0.06 & 1.32 & 4.75 & 0.04 & 3.08 & 2.76 & 92.47 \\
San Fernando & 0.26 & 11.17 & 89.77 & 0.07 & 13.09 & 6.80 & 0.03 & 2.97 & 1.40 & 0.00 & 0.00 & 0.00 & 97.98 \\
Santander & 0.21 & 9.54 & 51.91 & 0.16 & 5.75 & 29.53 & 0.09 & 2.18 & 9.88 & 0.04 & 3.14 & 2.65 & 93.97 \\
Valencia & 0.13 & 13.90 & 36.83 & 0.10 & 7.32 & 20.79 & 0.13 & 2.06 & 34.01 & 0.00 & 0.00 & 0.00 & 91.63 \\
Villafranca & 0.23 & 11.79 & 90.10 & 0.00 & 15.00 & 0.00 & 0.06 & 2.79 & 6.29 & 0.02 & 3.19 & 0.87 & 97.27 \\
Yebes & 0.13 & 10.72 & 76.92 & 0.03 & 8.01 & 4.33 & 0.03 & 2.88 & 5.26 & 0.00 & 0.00 & 0.00 & 86.51 \\
\hline MEDIA & $\mathbf{0 . 2 6}$ & 11.83 & $\mathbf{7 6 . 8 0}$ & $\mathbf{0 . 0 7}$ & $\mathbf{9 . 6 6}$ & $\mathbf{8 . 0 9}$ & $\mathbf{0 . 0 7}$ & $\mathbf{1 . 9 8}$ & $\mathbf{8 . 4 5}$ & $\mathbf{0 . 0 2}$ & $\mathbf{1 . 5 6}$ & $\mathbf{0 . 8 6}$ & $\mathbf{9 3 . 3 5}$ \\
\hline
\end{tabular}

En primavera vuelve a ser $S_{1}$ el armónico dominante, salvo en Coruña y San Fernando donde su contribución es del $9 \%$ y $12 \%$ respectivamente, mientras que la de $\mathrm{S}_{2}$ es en estos emplazamientos del $70 \%$ y $79 \%$ respectivamente. Este armónico es también importante en Alicante y Creus, con unos porcentajes superiores al $20 \%$. $\mathrm{S}_{3}$ y $\mathrm{S}_{4}$ sólo tienen una contribución por encima del $5 \%$ en Coruña (Tabla 5.6).

\begin{tabular}{lccccccccccccc}
\hline & \multicolumn{3}{c}{ 24-h Periodo } & \multicolumn{4}{c}{ 12-h Periodo } & \multicolumn{3}{c}{ 8-h Periodo } & \multicolumn{3}{c}{ 6-h Periodo } \\
Estación & $\mathbf{A}$ & $\mathbf{F}$ & $\mathbf{V}$ & $\mathbf{A}$ & $\mathbf{F}$ & $\mathbf{V}$ & $\mathbf{A}$ & $\mathbf{F}$ & $\mathbf{V}$ & $\mathbf{A}$ & $\mathbf{F}$ & $\mathbf{V}$ & V T \\
\hline Alicante & 0.37 & 18.16 & 74.51 & 0.19 & 6.86 & 20.38 & 0.05 & 0.96 & 1.54 & 0.00 & 0.00 & 0.00 & 96.43 \\
Almería & 0.44 & 18.13 & 83.66 & 0.18 & 6.89 & 13.27 & 0.05 & 3.60 & 1.09 & 0.00 & 0.00 & 0.00 & 98.01 \\
Cáceres & 0.32 & 17.09 & 92.18 & 0.06 & 7.41 & 3.65 & 0.03 & 0.00 & 0.85 & 0.00 & 0.00 & 0.00 & 96.68 \\
Coruña & 0.05 & 14.20 & 8.94 & 0.15 & 3.92 & 70.08 & 0.06 & 7.35 & 9.92 & 0.04 & 2.69 & 5.17 & 94.12 \\
Creus & 0.26 & 21.13 & 68.04 & 0.15 & 5.15 & 22.90 & 0.06 & 0.60 & 3.21 & 0.00 & 0.00 & 0.00 & 94.15 \\
Roquetes & 0.38 & 19.10 & 81.73 & 0.16 & 5.29 & 14.10 & 0.00 & 2.00 & 0.00 & 0.04 & 1.06 & 0.75 & 96.59 \\
San Fernando & 0.07 & 1.75 & 11.80 & 0.18 & 9.20 & 78.95 & 0.00 & 0.00 & 0.00 & 0.00 & 0.00 & 0.00 & 90.75 \\
Santander & 0.43 & 21.46 & 84.88 & 0.17 & 5.85 & 13.16 & 0.00 & 0.00 & 0.00 & 0.03 & 2.41 & 0.46 & 98.51 \\
Valencia & 0.45 & 21.83 & 85.13 & 0.17 & 7.03 & 11.44 & 0.05 & 1.05 & 0.90 & 0.04 & 3.03 & 0.62 & 98.08 \\
Villafranca & 0.42 & 19.63 & 89.23 & 0.13 & 5.24 & 7.74 & 0.05 & 0.57 & 1.47 & 0.00 & 0.00 & 0.00 & 98.44 \\
Yebes & 0.38 & 21.17 & 92.36 & 0.09 & 5.31 & 5.44 & 0.03 & 2.88 & 0.61 & 0.00 & 0.00 & 0.00 & 98.41 \\
\hline MEDIA & $\mathbf{0 . 3 2}$ & 17.60 & $\mathbf{7 0 . 2 2}$ & $\mathbf{0 . 1 5}$ & $\mathbf{6 . 1 9}$ & $\mathbf{2 3 . 7 4}$ & $\mathbf{0 . 0 3}$ & $\mathbf{1 . 7 3}$ & $\mathbf{1 . 7 8}$ & $\mathbf{0 . 0 1}$ & $\mathbf{0 . 8 4}$ & $\mathbf{0 . 6 4}$ & $\mathbf{9 5 . 7 4}$ \\
\hline
\end{tabular}

Tabla 5.6 - Análisis de armónicos del ciclo diurno de la primavera.

En verano $S_{1}$ es el armónico dominante en todos los emplazamientos, y $S_{2}$ el segundo salvo en Yebes que es $\mathrm{S}_{3}$. La contribución de $\mathrm{S}_{4}$ es despreciable en todos los casos (Tabla 5.7). 


\begin{tabular}{lccccccccccccc}
\hline & \multicolumn{3}{c}{ 24-h Periodo } & \multicolumn{3}{c}{ 12-h Periodo } & \multicolumn{3}{c}{ 8-h Periodo } & \multicolumn{3}{c}{ 6-h Periodo } \\
Estación & $\mathbf{A}$ & $\mathbf{F}$ & $\mathbf{V}$ & $\mathbf{A}$ & $\mathbf{F}$ & $\mathbf{V}$ & $\mathbf{A}$ & $\mathbf{F}$ & $\mathbf{V}$ & $\mathbf{A}$ & $\mathbf{F}$ & $\mathbf{V}$ & V T \\
\hline Alicante & 0.82 & 19.45 & 77.32 & 0.40 & 9.47 & 18.28 & 0.13 & 6.17 & 1.95 & 0.06 & 3.51 & 0.37 & 97.92 \\
Almería & 0.97 & 18.51 & 81.40 & 0.41 & 9.60 & 14.39 & 0.17 & 4.56 & 2.48 & 0.04 & 3.25 & 0.12 & 98.39 \\
Cáceres & 0.43 & 18.77 & 91.70 & 0.08 & 11.31 & 3.46 & 0.06 & 0.00 & 1.53 & 0.00 & 0.00 & 0.00 & 96.69 \\
Coruña & 0.46 & 15.77 & 84.06 & 0.12 & 3.71 & 5.91 & 0.12 & 5.20 & 5.51 & 0.00 & 0.00 & 0.00 & 95.48 \\
Creus & 0.91 & 17.85 & 90.87 & 0.26 & 5.30 & 7.34 & 0.06 & 7.10 & 0.41 & 0.00 & 0.00 & 0.00 & 98.62 \\
Roquetes & 1.58 & 17.70 & 95.52 & 0.26 & 2.33 & 2.54 & 0.14 & 5.38 & 0.71 & 0.00 & 0.00 & 0.00 & 98.78 \\
San Fernando & 0.56 & 7.82 & 69.69 & 0.32 & 11.75 & 23.32 & 0.13 & 5.03 & 3.95 & 0.00 & 0.00 & 0.00 & 96.97 \\
Santander & 1.03 & 20.31 & 93.98 & 0.21 & 5.90 & 4.00 & 0.09 & 5.26 & 0.71 & 0.00 & 0.00 & 0.00 & 98.68 \\
Valencia & 1.37 & 21.17 & 88.92 & 0.46 & 8.18 & 9.72 & 0.06 & 7.24 & 0.20 & 0.06 & 3.39 & 0.15 & 98.98 \\
Villafranca & 0.24 & 23.13 & 68.06 & 0.15 & 4.67 & 26.36 & 0.03 & 4.37 & 1.40 & 0.00 & 0.00 & 0.00 & 95.82 \\
Yebes & 0.32 & 23.25 & 87.34 & 0.00 & 15.00 & 0.00 & 0.10 & 3.96 & 8.23 & 0.02 & 0.18 & 0.60 & 96.17 \\
\hline MEDIA & $\mathbf{0 . 7 9}$ & $\mathbf{1 8 . 5 2}$ & $\mathbf{8 4 . 4 4}$ & $\mathbf{0 . 2 4}$ & $\mathbf{7 . 9 3}$ & $\mathbf{1 0 . 4 8}$ & $\mathbf{0 . 1 0}$ & $\mathbf{4 . 9 3}$ & $\mathbf{2 . 4 6}$ & $\mathbf{0 . 0 2}$ & $\mathbf{0 . 9 4}$ & $\mathbf{0 . 1 1}$ & $\mathbf{9 7 . 3 9}$ \\
\hline
\end{tabular}

Tabla 5.7 - Análisis de armónicos del ciclo diurno del verano.

En otoño es también $S_{1}$ el armónico más importante para todos los emplazamientos, explicando en todos ellos por encima de un $70 \%$ de la varianza. $S_{2}$ explica aproximadamente un $20 \%$ de la varianza en Coruña y Santander, y en otros tres emplazamientos por encima del $10 \%$, mientras que en Cáceres es de un $0 \% . S_{3}$ sólo tiene una contribución superior al $5 \%$ en tres emplazamientos (Creus, Villafranca y Yebes) y $S_{4}$ es siempre despreciable (Tabla 5.8).

\begin{tabular}{lccccccccccccc}
\hline & \multicolumn{3}{c}{ 24-h Periodo } & \multicolumn{3}{c}{ 12-h Periodo } & \multicolumn{3}{c}{ 8-h Periodo } & \multicolumn{3}{c}{ 6-h Periodo } \\
Estación & $\mathbf{A}$ & $\mathbf{F}$ & $\mathbf{V}$ & $\mathbf{A}$ & $\mathbf{F}$ & $\mathbf{V}$ & $\mathbf{A}$ & $\mathbf{F}$ & $\mathbf{V}$ & $\mathbf{A}$ & $\mathbf{F}$ & $\mathbf{V}$ & V T \\
\hline Alicante & 0.61 & 15.84 & 89.80 & 0.17 & 6.65 & 6.75 & 0.09 & 0.91 & 1.94 & 0.00 & 0.00 & 0.00 & 98.50 \\
Almería & 0.82 & 16.28 & 97.41 & 0.08 & 7.37 & 0.88 & 0.05 & 1.70 & 0.32 & 0.00 & 0.00 & 0.00 & 98.61 \\
Cáceres & 0.50 & 14.59 & 97.72 & 0.00 & 15.00 & 0.00 & 0.03 & 0.00 & 0.39 & 0.03 & 0.00 & 0.33 & 98.43 \\
Coruña & 0.29 & 14.96 & 73.14 & 0.15 & 3.95 & 20.53 & 0.04 & -0.02 & 1.22 & 0.00 & 0.00 & 0.00 & 94.89 \\
Creus & 0.56 & 15.86 & 87.35 & 0.13 & 6.42 & 4.71 & 0.14 & 0.76 & 5.41 & 0.04 & 1.21 & 0.45 & 97.93 \\
Roquetes & 0.73 & 16.30 & 93.73 & 0.15 & 5.03 & 3.86 & 0.09 & 7.84 & 1.35 & 0.00 & 0.00 & 0.00 & 98.94 \\
San Fernando & 0.36 & 12.32 & 83.41 & 0.15 & 9.25 & 14.29 & 0.04 & 1.65 & 1.00 & 0.00 & 0.00 & 0.00 & 98.71 \\
Santander & 0.30 & 18.65 & 72.76 & 0.16 & 6.10 & 19.45 & 0.06 & 0.28 & 2.43 & 0.00 & 0.00 & 0.00 & 94.64 \\
Valencia & 0.67 & 19.15 & 82.60 & 0.28 & 7.93 & 14.09 & 0.09 & 1.11 & 1.60 & 0.03 & 3.28 & 0.18 & 98.47 \\
Villafranca & 0.23 & 17.09 & 70.78 & 0.09 & 7.54 & 10.16 & 0.10 & 1.11 & 12.28 & 0.00 & 0.00 & 0.00 & 93.22 \\
Yebes & 0.21 & 19.60 & 82.41 & 0.04 & 8.10 & 2.55 & 0.07 & 1.36 & 7.85 & 0.00 & 0.00 & 0.00 & 92.81 \\
\hline MEDIA & $\mathbf{0 . 4 8}$ & 16.42 & $\mathbf{8 4 . 6 5}$ & $\mathbf{0 . 1 3}$ & $\mathbf{7 . 5 8}$ & $\mathbf{8 . 8 4}$ & $\mathbf{0 . 0 7}$ & $\mathbf{1 . 5 2}$ & $\mathbf{3 . 2 5}$ & $\mathbf{0 . 0 1}$ & $\mathbf{0 . 4 1}$ & $\mathbf{0 . 0 9}$ & $\mathbf{9 6 . 7 4}$ \\
\hline
\end{tabular}

Tabla 5.8 - Análisis de armónicos del ciclo diurno del otoño.

En el ciclo diurno promedio de todos los emplazamientos (Tabla 5.9), los cuatro armónicos juntos explican aproximadamente el mismo porcentaje de la variabilidad intradía para las cuatro estaciones, entre un $96 \%$ y un $98 \%$, pero no siempre en la misma proporción para cada una de ellas. $\mathrm{S}_{1}$ es siempre por mucho el armónico dominante, pero explica un poco más varianza en 
verano y otoño (92-95\%) que en invierno y primavera (84-86\%). La semiamplitud de $S_{1}$ es en verano más del doble que la del invierno o la primavera, y su fase tiene lugar al mediodía en invierno, a primeras horas de la tarde en otoño, y al final de la tarde en primavera y verano. $S_{2}$ es más significativo en primavera, explicando un 13\% de la varianza en esa estación, mientras que en las otras estaciones explica sólo entre un $1 \%$ y un $4 \%$. La varianza explicada por $\mathrm{S}_{3}$ es sólo significativa en invierno, con un $7 \%$, seguida del otoño con un $2 \%$; y la de $\mathrm{S}_{4}$ es siempre despreciable. No obstante, hay que recalcar que existe una gran dispersión entre los distintos emplazamientos en la varianza explicada por cada armónico para cada estación.
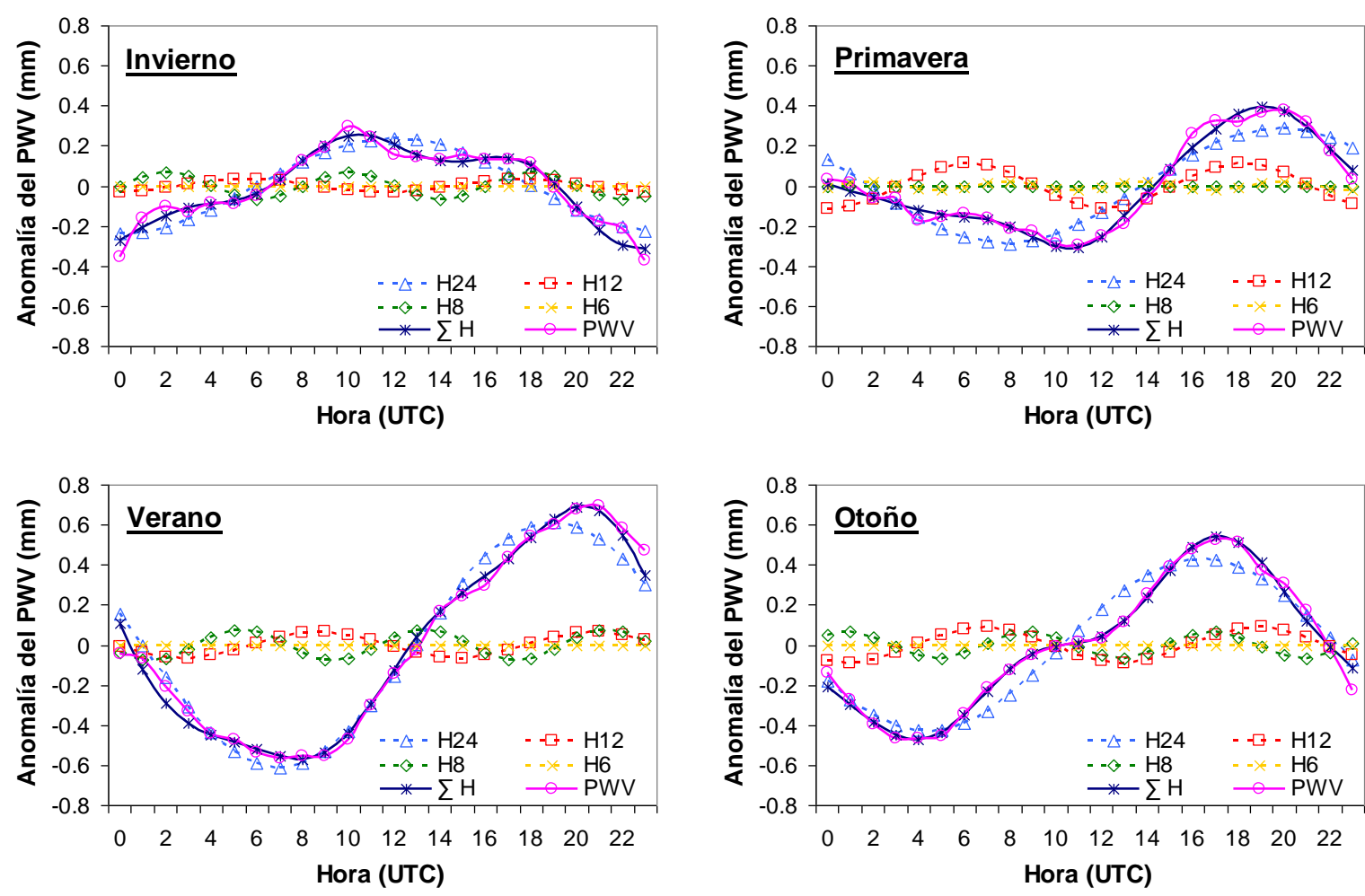

Figura 5.6 - Descomposición en armónicos de los ciclos diurnos promediados estacionales.

\begin{tabular}{lccccccccccccc}
\hline & \multicolumn{3}{c}{ 24-h Periodo } & \multicolumn{3}{c}{ 12-h Periodo } & \multicolumn{3}{c}{ 8-h Periodo } & \multicolumn{3}{c}{ 6-h Periodo } \\
Estación & $\mathbf{A}$ & $\mathbf{F}$ & $\mathbf{V}$ & $\mathbf{A}$ & $\mathbf{F}$ & $\mathbf{V}$ & $\mathbf{A}$ & $\mathbf{F}$ & $\mathbf{V}$ & $\mathbf{A}$ & $\mathbf{F}$ & $\mathbf{V}$ & V T \\
\hline Anual & 0.31 & 17.62 & 94.25 & 0.06 & 6.82 & 3.85 & 0.00 & 10.00 & 0.00 & 0.02 & 2.52 & 0.28 & 98.38 \\
Invierno & 0.24 & 12.02 & 86.47 & 0.03 & 5.61 & 1.95 & 0.07 & 2.09 & 7.14 & 0.00 & 0.00 & 0.00 & 95.56 \\
Primavera & 0.29 & 19.81 & 84.05 & 0.11 & 6.18 & 12.76 & 0.00 & 2.00 & 0.00 & 0.02 & 0.00 & 0.47 & 97.29 \\
Verano & 0.61 & 18.98 & 95.42 & 0.07 & 8.75 & 1.07 & 0.08 & 5.31 & 1.46 & 0.00 & 0.00 & 0.00 & 97.95 \\
Otoño & 0.43 & 16.36 & 91.83 & 0.09 & 6.84 & 4.10 & 0.07 & 0.83 & 2.10 & 0.00 & 0.00 & 0.00 & 98.03 \\
\hline
\end{tabular}

Tabla 5.9 - Análisis de armónicos de los ciclos diurnos medios estacionales.

\subsection{Ciclo diurno del año 2008}

La compleja orografía de la Península impide afirmar si los ciclos diurnos obtenidos en los apartados anteriores son representativos de toda la geografía peninsular. Afortunadamente, en 
los últimos años, especialmente en 2007, el número de receptores GPS ha aumentado de forma considerable. Por ello, en este apartado se va a estudiar el ciclo diurno exclusivamente con los datos del año 2008. De esta manera se dispone de un total de veintidós estaciones, las once estudiadas anteriormente más otras once nuevas: Albacete, Burriana, Córdoba, Huelva, León, Logroño, Málaga, Salamanca, Sonseca, Vigo, y Zaragoza. Al disponer de un mayor número de estaciones, y por comparación de sus ciclos diurnos, se espera poder valorar hasta que punto los ciclos obtenido con las series más largas de datos de un reducido número de estaciones son representativos de toda una zona más amplia, o si por el contrario están fuertemente influenciados por efectos muy locales y sólo son representativos de las cercanías del emplazamiento donde está ubicado el receptor.

Para una mayor claridad a la hora de representar los resultados obtenidos, se han agrupado las estaciones por proximidad geográfica en cinco zonas: cantábrica (costa cantábrica y atlántica norte), levante, sur (Andalucía), centro norte (meseta norte y valle del Ebro), centro sur (meseta sur y Extremadura) (Figura 5.7).

Para cuantificar las discrepancias o similitudes del ciclo diurno entre dos emplazamientos se ha calculado la diferencia media definida como,

$$
D_{i, j}=\sqrt{\frac{\sum_{z=1}^{24}\left(A_{i, z}-A_{j, z}\right)^{2}}{24}}
$$

donde $A_{i, z}$ representa la anomalía del PWV de la estación i de la hora z.

De la simple inspección visual de las gráficas se desprende que en la costa norte las estaciones de Coruña y Vigo siguen el mismo patrón, no así la de Santander. El valor de $\mathrm{D}_{\mathrm{i}, \mathrm{j}}$ entre Coruña y Vigo es de $0.10 \mathrm{~mm}$, mientras que entre Vigo y Santander es de $0.18 \mathrm{~mm}$ y entre Santander y Coruña de $0.22 \mathrm{~mm}$. La buena armonía de las dos primeras, a pesar de distar $150 \mathrm{Km}$ entre ellas, apunta a que el patrón de comportamiento de Coruña se podría extrapolar a la zona de la costa atlántica gallega.

En la costa mediterránea sólo se encuentra un comportamiento similar entre Valencia y Burriana por un lado $\left(D_{i, j}=0.08 \mathrm{~mm}\right)$, y entre Alicante y Creus por otro $\left(D_{i, j}=0.13 \mathrm{~mm}\right)$, mientras que el resto de comparativas presentan unos valores de $D_{i, j}$ superiores a los $0.23 \mathrm{~mm}$, llegando incluso a los $0.47 \mathrm{~mm}$ entre Roquetes y Valencia.

Destaca la buena concordancia entre las estaciones de Huelva y Málaga $\left(D_{i, j}=0.11 \mathrm{~mm}\right) \mathrm{a}$ pesar de la distancia entre ellas, y sobre todo por encontrarse una en el Mediterráneo y la otra en el Atlántico. De hecho, el ciclo de Málaga se asemeja más al de Huelva que al resto de las estaciones mediterráneas. Sin embargo, no ocurre lo mismo con San Fernando y Huelva. Esto 
confirma el comportamiento discrepante que se había obtenido en el apartado anterior para la estación de San Fernando, que parece que se encuentra muy afectada por efectos muy locales por su proximidad al estrecho de Gibraltar, por lo que su ciclo sólo se puede considerar representativo exclusivamente de esa zona. Tampoco el ciclo de las estaciones costeras del sur parece extrapolable al valle del Guadalquivir. En la comparativa de Córdoba o San Fernando entre sí o con Huelva o Málaga se han obtenido valores de $D_{i, j}$ superiores a $0.33 \mathrm{~mm}$ en todos los casos.
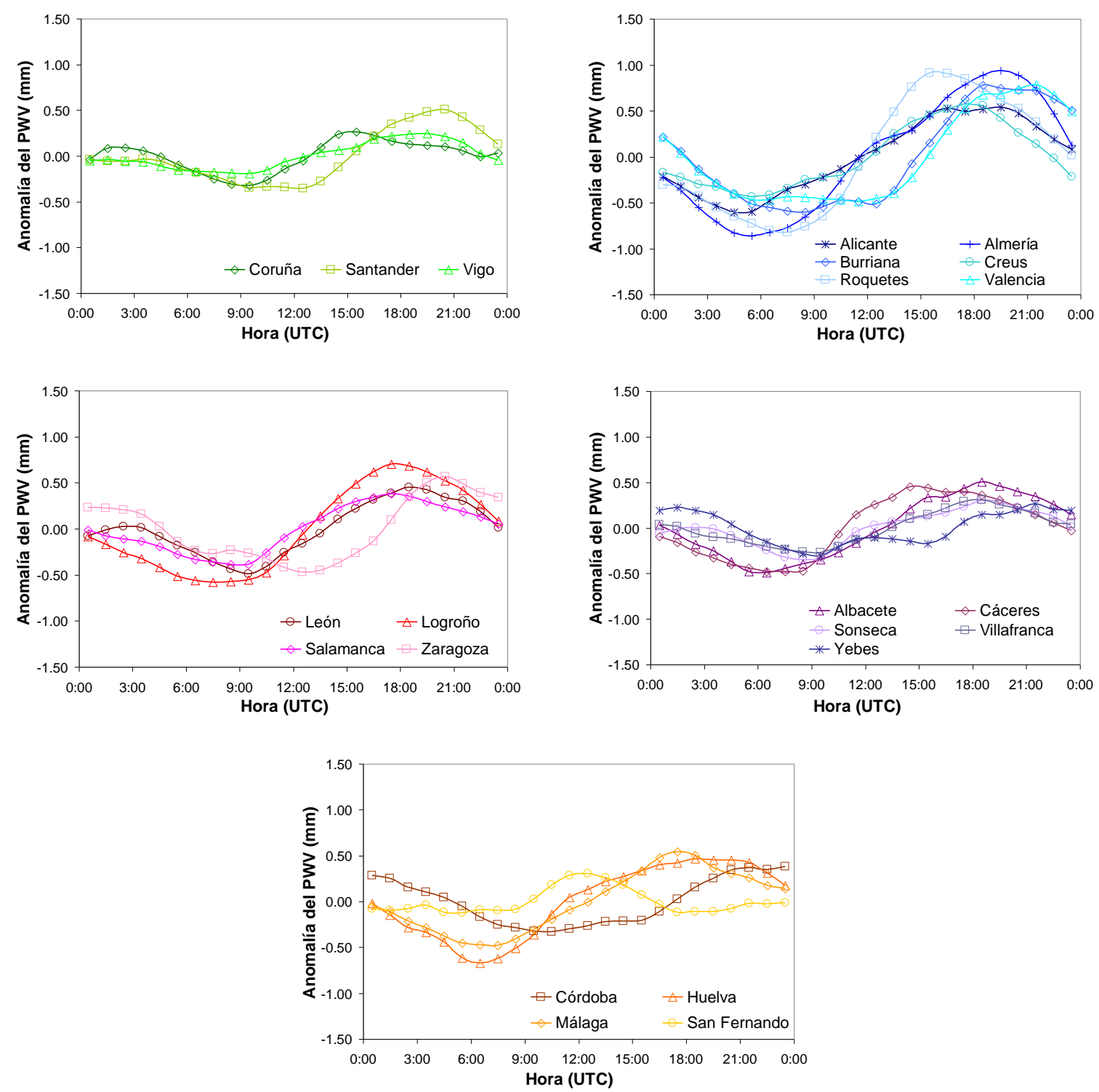

Figura 5.7 - Ciclo diurno del PWV exclusivamente con los datos del año 2008.

En el interior peninsular es donde más ha aumentado el número de estaciones GPS, pudiéndose apreciar distintas formas del ciclo diurno, lo que viene a indicar, como era de esperar, que los ciclos obtenidos en el apartado 5.1 para Cáceres, Villafranca, y Yebes no son representativos de toda la zona, siendo esta bastante heterogénea. En concreto, se da un ciclo similar en las dos estaciones de la meseta norte, León y Salamanca, con un valor de $D_{i, j}$ de 
$0.11 \mathrm{~mm}$, y también entre Villafranca y Sonseca $\left(D_{i, j}=0.06 \mathrm{~mm}\right)$, incluso estas cuatro estaciones presentan un ciclo muy similar entre ellas, a pesar de situarse en distintas mesetas separadas por el sistema central. Sin embargo, el resto de estaciones presentan ciclos con rasgos diferenciales. Este es el caso de Albacete, Cáceres, Logroño, Yebes, y Zaragoza, que caracterizan zonas distintas, como el alto Ebro, los valles del Ebro o del Tajo, etc.

Es curioso que estaciones distantes y con climatologías distintas presenten un ciclo diurno del PWV similar. Tal es el caso de Córdoba y Yebes $\left(D_{i, j}=0.09 \mathrm{~mm}\right)$, Albacete y Málaga $\left(D_{i, j}=0.06\right.$ $\mathrm{mm})$ o Villafranca y Vigo $\left(D_{i, j}=0.05 \mathrm{~mm}\right)$, mientras que estaciones de la zona mediterránea presentan ciclos dispares. Estas últimas estaciones junto con Córdoba, San Fernando y Zaragoza son las que muestran los ciclos diurnos menos semejantes con otras estaciones. En término medio, cuanto mayor es la amplitud del ciclo mayores son también las discrepancias con otras estaciones.

El estudio de los ciclos diurnos estacionales permite analizar con mayor detalle las diferencias y similitudes entre emplazamientos (Figuras $5.8,5.9,5.10,5.11$ y 5.12 ).
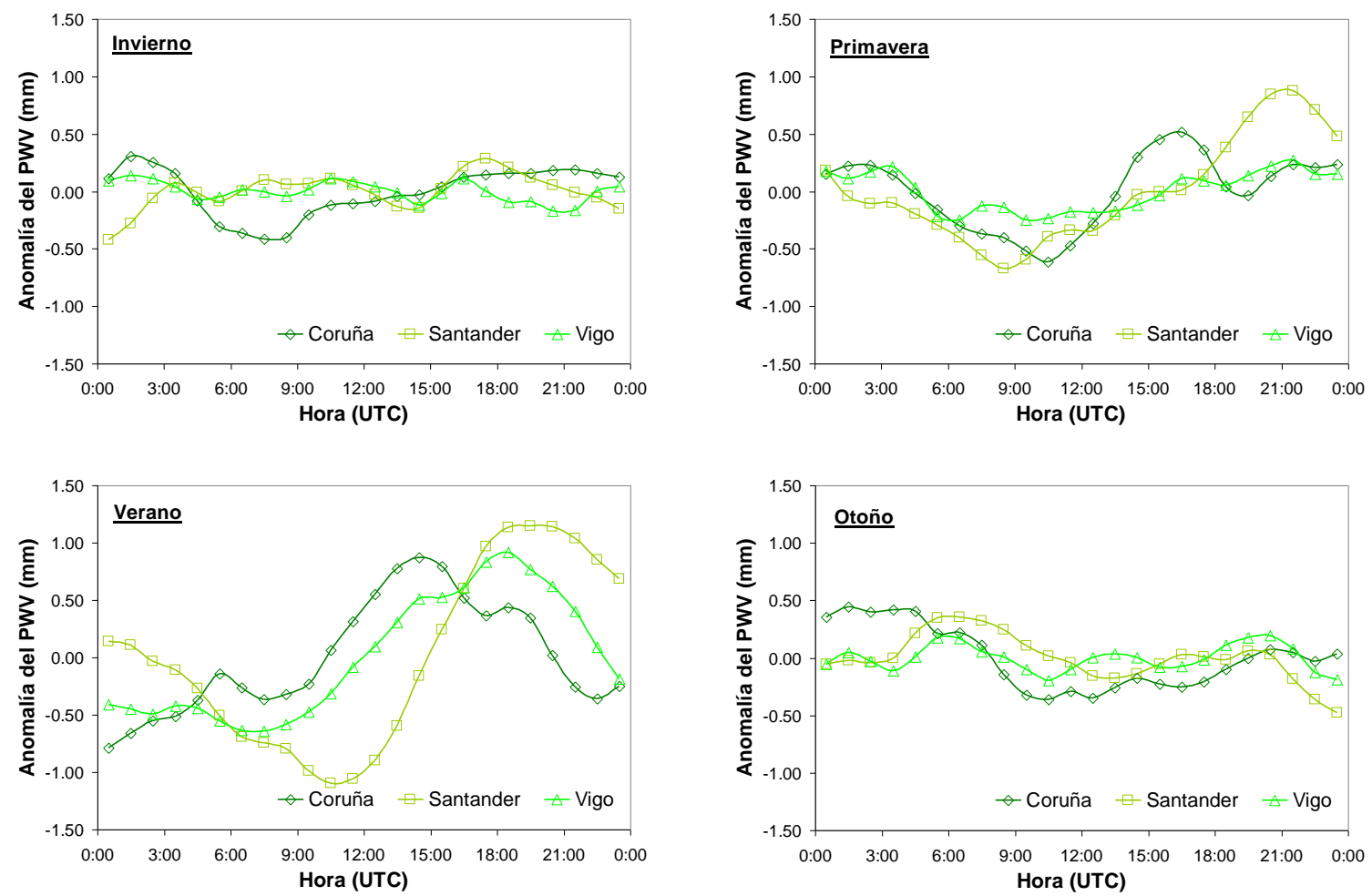

Figura 5.8 - Ciclos diurnos estacionales del año 2008 de las estaciones de la zona cantábrica.

En la zona Cantábrica, los ciclos diurnos de los tres emplazamientos presentan menores discrepancias en invierno y otoño que en las otras dos estaciones. En invierno y otoño los ciclos de Santander y Vigo se asemejan un poco más que los de Coruña y Vigo. Sin embargo, en verano y a últimas horas del día en primavera Santander muestra un comportamiento más 
dispar (Figura 5.8). En general los ciclos anuales se asemejan más ( $D_{i, j}$ toma menores valores) que los ciclos estacionales.
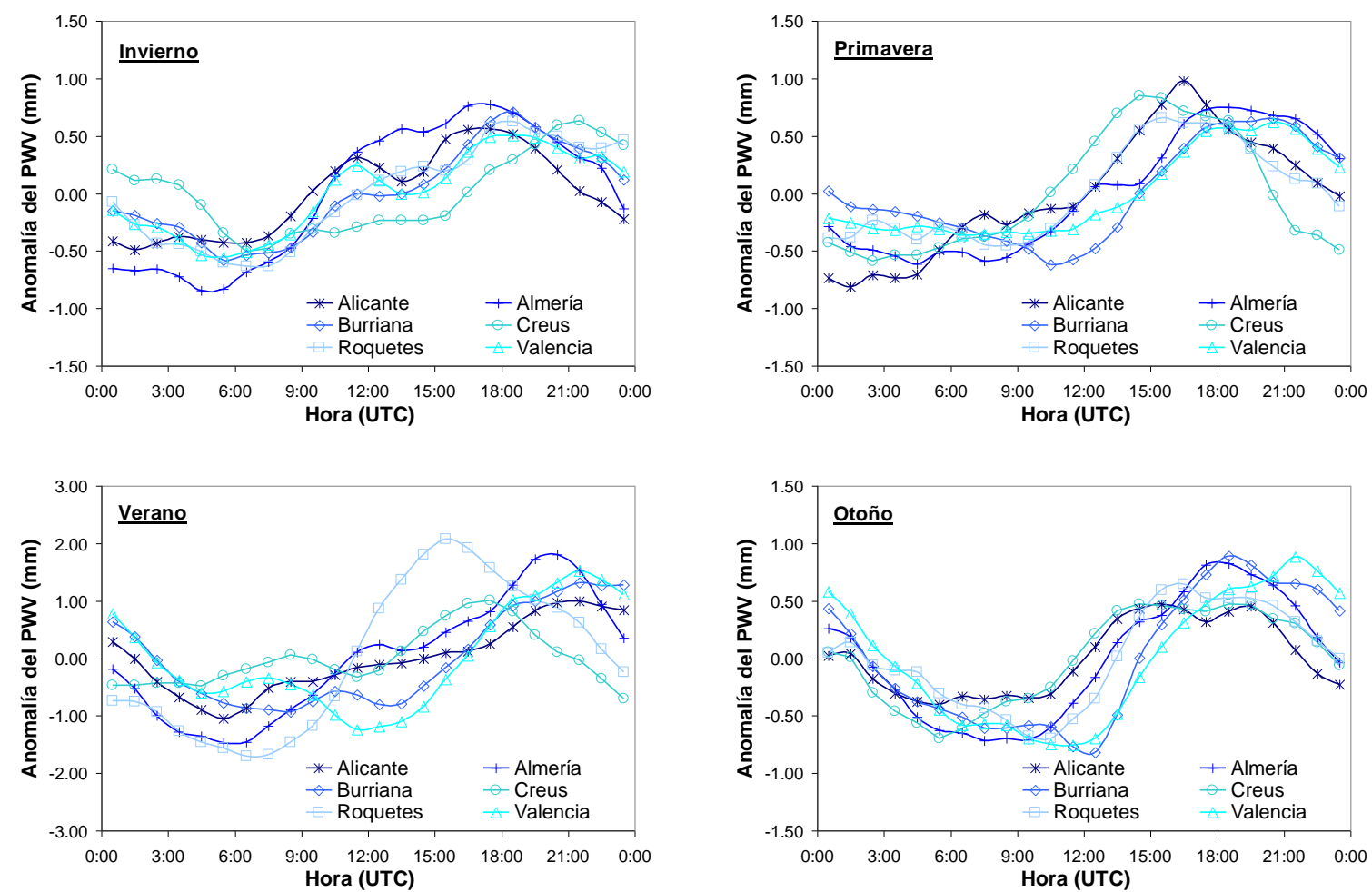

Figura 5.9 - Ciclos diurnos estacionales del año 2008 de las estaciones de la zona del levante.
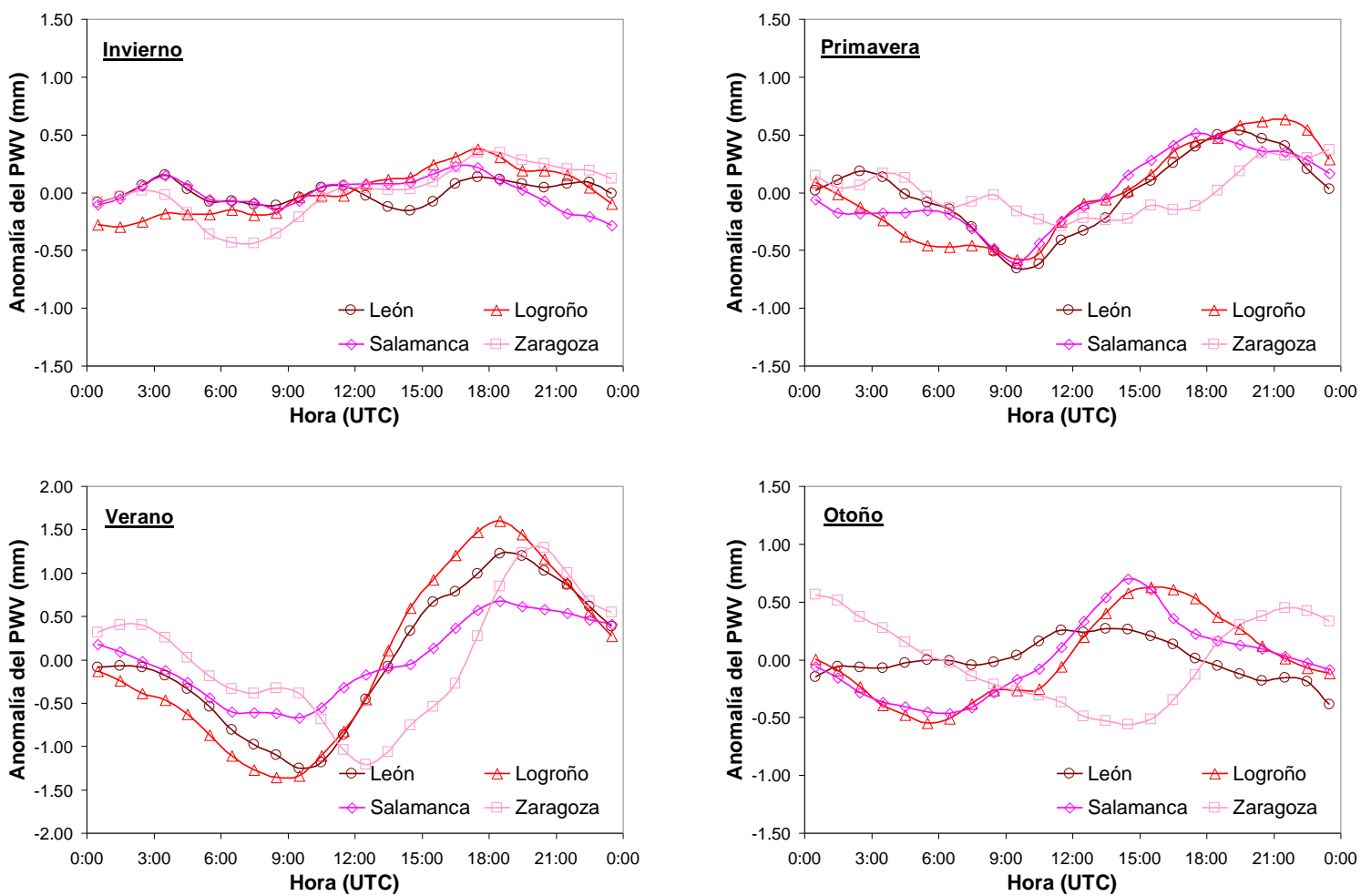

Figura 5.10 - Ciclos diurnos estacionales del año 2008 de las estaciones de la zona centro norte. 

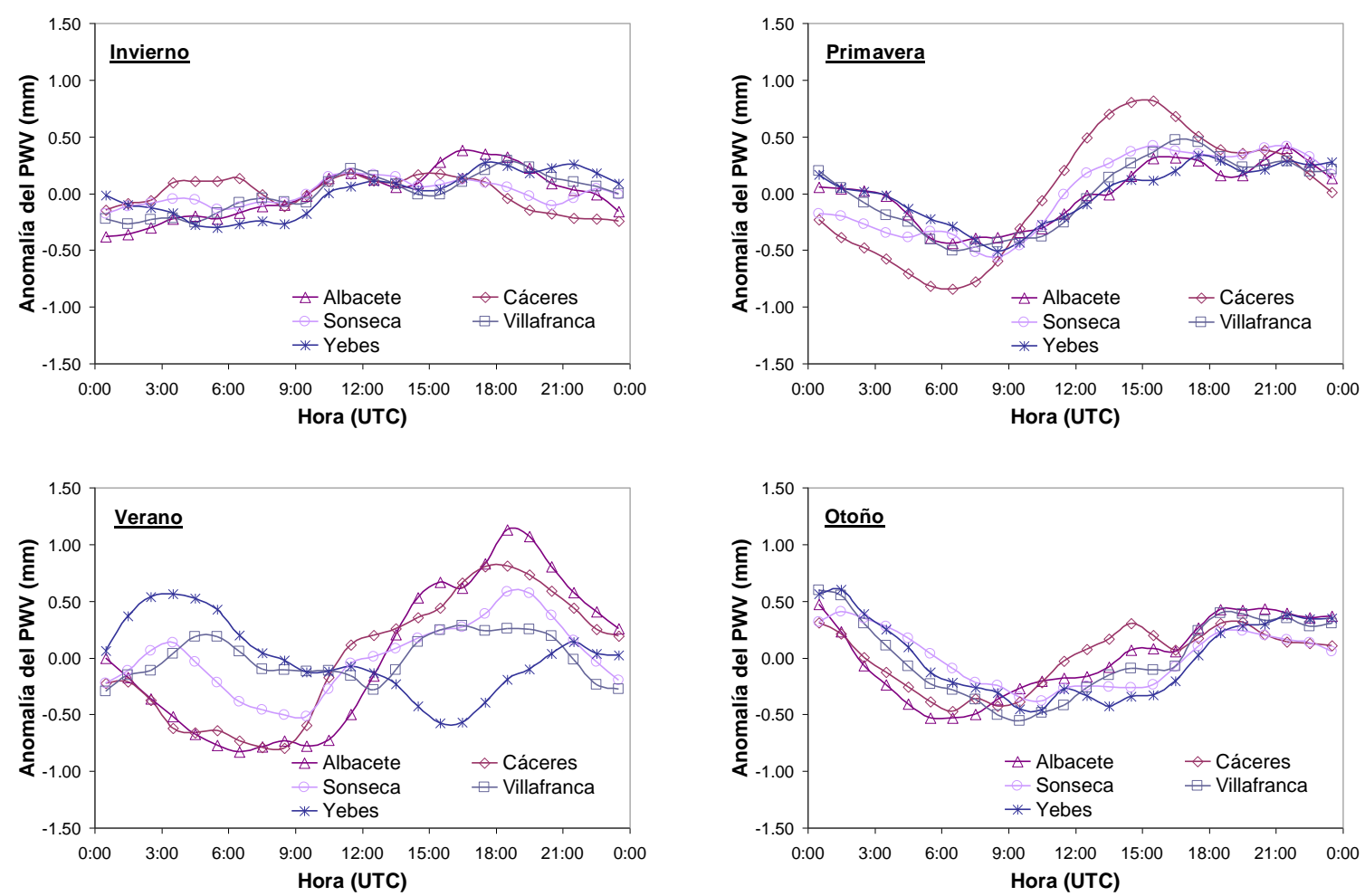

Figura 5.11 - Ciclos diurnos estacionales del año 2008 de las estaciones de la zona centro sur.
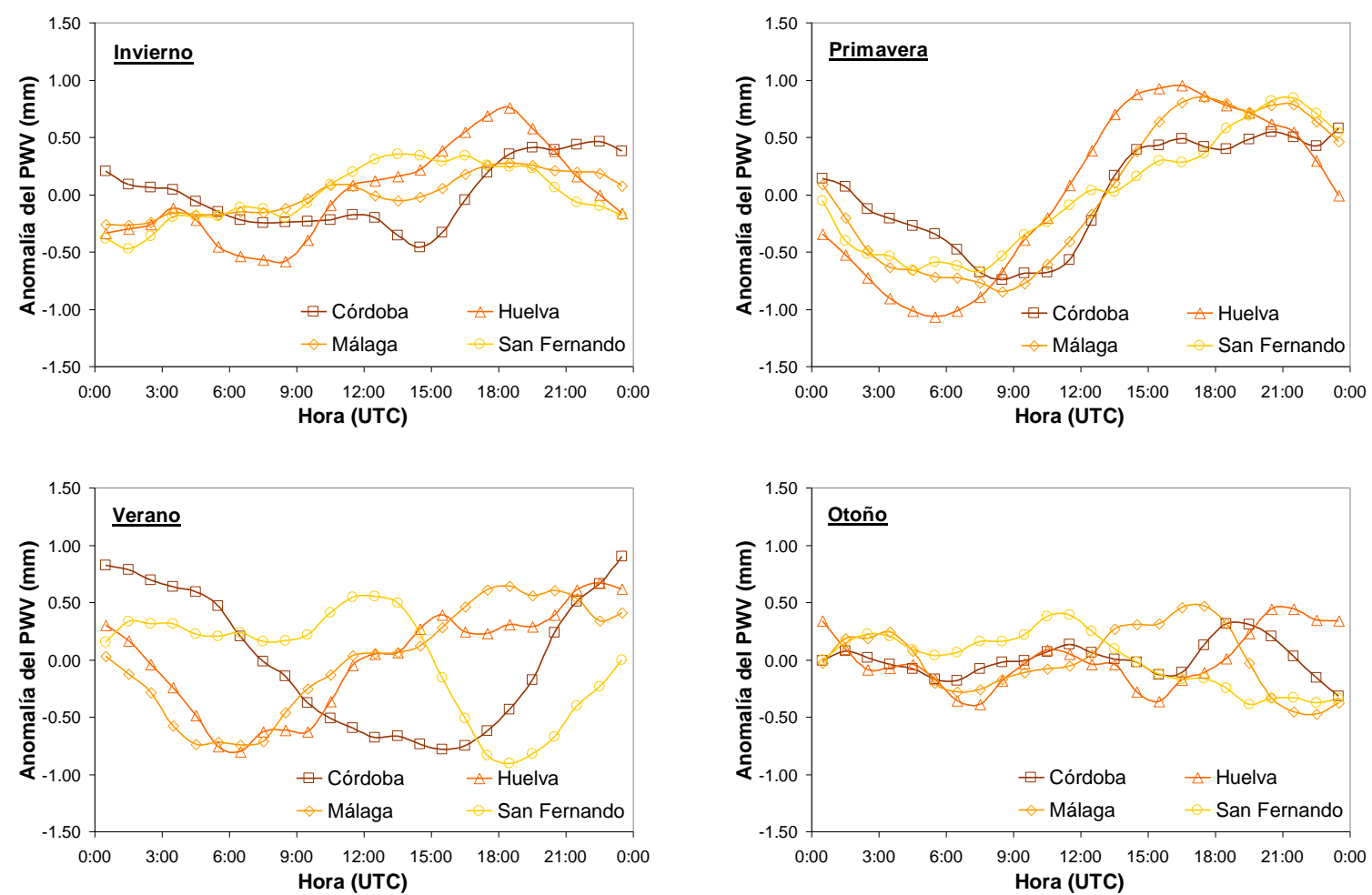

Figura 5.12 - Ciclos diurnos estacionales del año 2008 de las estaciones de la zona sur.

En la costa levantina las discrepancias estacionales son notables, sobre todo en verano (Figura 5.9). Sólo las estaciones de Valencia y Burriana presentan un ciclo similar en las cuatro 
estaciones, aunque con valores de $\mathrm{D}_{\mathrm{i}, \mathrm{j}}$ superiores a los de la comparativa del ciclo diurno anual en todas los casos. Estos resultados muestran que no se puede considerar uniforme esta zona desde el punto de vista del comportamiento diurno del PWV.

Las estaciones situadas en la zona centro norte presentan un ciclo diurno más semejante en invierno y primavera que en verano y otoño, incluso dos emplazamientos como León y Salamanca que en el cómputo anual concordaban bastante, presentan diferencias significativas en estas estaciones. Zaragoza es el emplazamiento con el comportamiento más dispar en todas las estaciones, lo que está indicando que representa a una zona, como es el valle del Ebro, con una climatología del ciclo diurno del PWV distinta (Figura 5.10).

Para las estaciones localizadas en la zona centro sur, exceptuando Cáceres, las discrepancias entre sus ciclos diurnos son sólo importantes en verano (Figura 5.11). Queda claro que Cáceres está ubicada en una zona con un comportamiento del ciclo diurno del PWV más diferente al de las otras estaciones. En verano, la estación de Yebes es la que presenta el comportamiento más dispar, pero hay que recordar que se encuentra a una altitud más elevada respecto al resto. Sonseca y Villafranca son las que presentan los ciclos más parecidos, pero con valores de $D_{i, j}$ superiores a los del computo anual.

Las cuatro estaciones de la zona sur presentan discrepancias entre sus ciclos diurnos estaciones, incluso Málaga y Huelva que seguían el mismo patrón de comportamiento en media anual (Figura 5.12). Las mayores discrepancias se producen en verano en San Fernando y Córdoba, mientras que el ciclo de Málaga y Huelva se ajusta mejor en verano que en las otras tres estaciones del año.

De lo visto anteriormente, se puede concluir que los ciclos diurnos de los diferentes emplazamientos son más parecidos en el computo anual que en el estacional. No obstante, también presentan grandes similitudes en el invierno, y en menor medida en la primavera y el otoño. Sin embargo, en verano, y principalmente durante el día, el ciclo diurno está muy matizado por efectos locales, aumentando de forma considerable las discrepancias entre emplazamientos.

\subsection{Factores del ciclo diurno}

Los mecanismos que producen variaciones en el contenido de PWV se pueden clasificar en tres tipos: cambio de masa de aire a gran escala, evaporación y condensación en el seno de la masa de aire, y advecciones húmedas o secas por vientos locales. Las variaciones debidas a los cambios a gran escala de la masa de aire no siguen el patrón de un ciclo diurno, sino que están regidas por la situación sinóptica. Al promediar el ciclo diurno de un gran número de días, en este caso siete años, las fluctuaciones de mayor periodo producidas por los cambios en la 
situación sinóptica se suavizan y desparecen, permaneciendo sólo aquellas con periodos inferiores a las veinticuatro horas, que están relacionadas con el ciclo diurno de la intensidad de la radiación solar incidente (Wu et al., 2003). Esta es la causa última de los factores que determinan el ciclo diurno del PWV, como son: la temperatura superficial, la evapotranspiración (Dai et al., 1999b), las circulaciones locales del aire (Dai \& Deser, 1999), la condensación y la precipitación (Dai et al., 1999a; Dai, 2001), o los movimientos verticales (Dai et al., 1999a). El ciclo diurno del PWV estará determinado por la suma de las contribuciones de cada uno de estos factores.

En este apartado se intentan explicar, de una manera cualitativa, los principales rasgos que presenta el ciclo diurno del PWV en función de la temperatura del aire, la precipitación, el transporte de humedad por vientos locales, y la mezcla en la vertical por movimientos turbulentos. La temperatura es quizás es factor con más peso en el sumatorio. El calentamiento diurno activa la evaporación, aumentando la cantidad de vapor de agua en la atmósfera. Además, conforme a la ecuación de Clausius-Clapeyron's, cuanto mayor es la temperatura del aire mayor es la cantidad de vapor de agua que este puede contener sin que sobrevenga la condensación por saturación en su seno. Por la noche, el enfriamiento nocturno provoca la condensación y por tanto la disminución del PWV.

Otro factor importante es el viento. Este favorece la evaporación en las capas bajas junto al suelo, y actúa como agente transportador de humedad de unas zonas a otras. El régimen diurno del viento, una vez substraída la componente media determinada por la situación sinóptica, viene determinado por el movimiento del sol y los efectos geográficos locales. A escala local, la velocidad del viento en su régimen diurno arrecia durante el día y amaina por la noche. El calentamiento del suelo durante el día desencadena los movimientos turbulentos, lo que favorece la propagación de la mayor velocidad del viento de las capas altas a las capas bajas junto al suelo. Durante la noche no hay turbulencia térmica, y el enfriamiento nocturno favorece la estratificación de las capas bajas de la atmósfera, y por tanto la estabilidad al disminuir la turbulencia dinámica, tendiendo las capas junto al suelo a permanecer en reposo. La dirección del viento está también influencia por el ángulo de elevación solar. El viento tiende a soplar hacia la vertical del sol por la depresión térmica que este genera. Es decir, por la mañana los vientos serían del oeste, rolando hacia el sur al mediodía y al este por la tarde. Las brisas, tanto de mar como de montaña, son un claro ejemplo de un régimen local de viento. Su mecanismo es el resultado del calentamiento diferencial entre la tierra y el mar, o entre el valle y la montaña, que origina un gradiente de presión que genera el viento. Durante el día las brisas soplan de mar a tierra al encontrarse ésta más caliente, son las 'brisas de mar', por tanto son vientos húmedos que aportan vapor de agua. Por la noche, el mayor enfriamiento de la tierra provoca que el régimen de las brisas se invierta, soplando de tierra a mar, 'brisa de tierra'. La brisa de tierra advecta hacia la costa el aire húmedo, previamente advectado hacia tierra durante el día por la brisa de mar, después de haber experimentado un enfriamiento y 
una condensación, por lo que serán vientos más secos. La aparición de las brisas, así como la hora de su comienzo y la extensión vertical de la capa afectada, dependerá de la situación sinóptica general (Bastin et al., 2007). La variación diurna del PWV parece estar fuertemente condicionada por las circulaciones térmicas locales generadas por la topografía (Li et al., 2008). El desfase en la consecución del máximo diario de PWV entre algunos emplazamientos puede explicarse por este mecanismo sobre la base del transporte de humedad.

También los movimientos verticales favorecen el intercambio y difusión del vapor de agua. Los movimientos ascendentes transportan vapor de las capas bajas a las altas, favoreciendo la evaporación. El vapor de agua se incorpora a la atmósfera desde la superficie terrestre por evaporación, acumulándose en la capa junto al suelo. Con la salida del sol, el calentamiento diurno produce movimientos turbulentos en la vertical que transportan el vapor de agua hacia capas más altas. El espesor de esta capa de mezcla aumenta con la intensidad de la radiación solar incidente. Cuando hacia el mediodía se generan las corrientes ascendentes la humedad específica junto al suelo disminuye, pero el PWV aumenta (Wu et al., 2003). Las variaciones del vapor de agua por encima de la capa de mezcla tienen que ser atribuidas a otro mecanismo, como la advección de humedad por circulaciones locales inducidas por calentamientos diferenciales (Kimura et al., 1997).

En la Figura 5.13 se ha representado para cada estación el ciclo diurno del PWV junto con el de la temperatura. En estas gráficas se puede observar como para la mayoría de los emplazamientos el mínimo de ambos ciclos tiene lugar dentro de un intervalo de una hora, no así el máximo, donde el desfase es mayor (Li et al., 2008). Solamente en Cáceres y Coruña el máximo de ambos ciclos está aproximadamente en fase. Sin embargo, en las estaciones de la costa mediterránea, así como en Santander, el máximo de PWV se alcanza entre cuatro y seis horas más tarde que el de la temperatura. San Fernando es un caso especial, es el único emplazamiento donde el máximo de PWV tiene lugar antes que el de la temperatura. De las gráficas se desprende que el ciclo de la temperatura por si sólo no explica el ciclo del PWV, especialmente durante el día. El desfase temporal entre los máximos del PWV y la temperatura es más acusado en las estaciones costeras. En estas estaciones el ciclo diurno del PWV está fuertemente influenciado por la advección de humedad por las brisas marinas, provocando que el PWV continúe aumentando incluso después que la temperatura empieze a disminuir. Por ejemplo, para una estación típica de la zona como es Valencia se puede apreciar en las gráficas de las frecuencias relativas del ciclo diurno de la dirección del viento (Figura 5.14) como el régimen de brisas marinas (vientos del segundo cuadrante) se establece en las cuatro estaciones del año. No obstante, debido a la mayor insolación el régimen de brisas en verano se establece antes, dura más y es más intenso. Por ello, el desfase entre el máximo de PWV y de temperatura es precisamente mayor en verano, cuando el régimen de brisas es más intenso. 

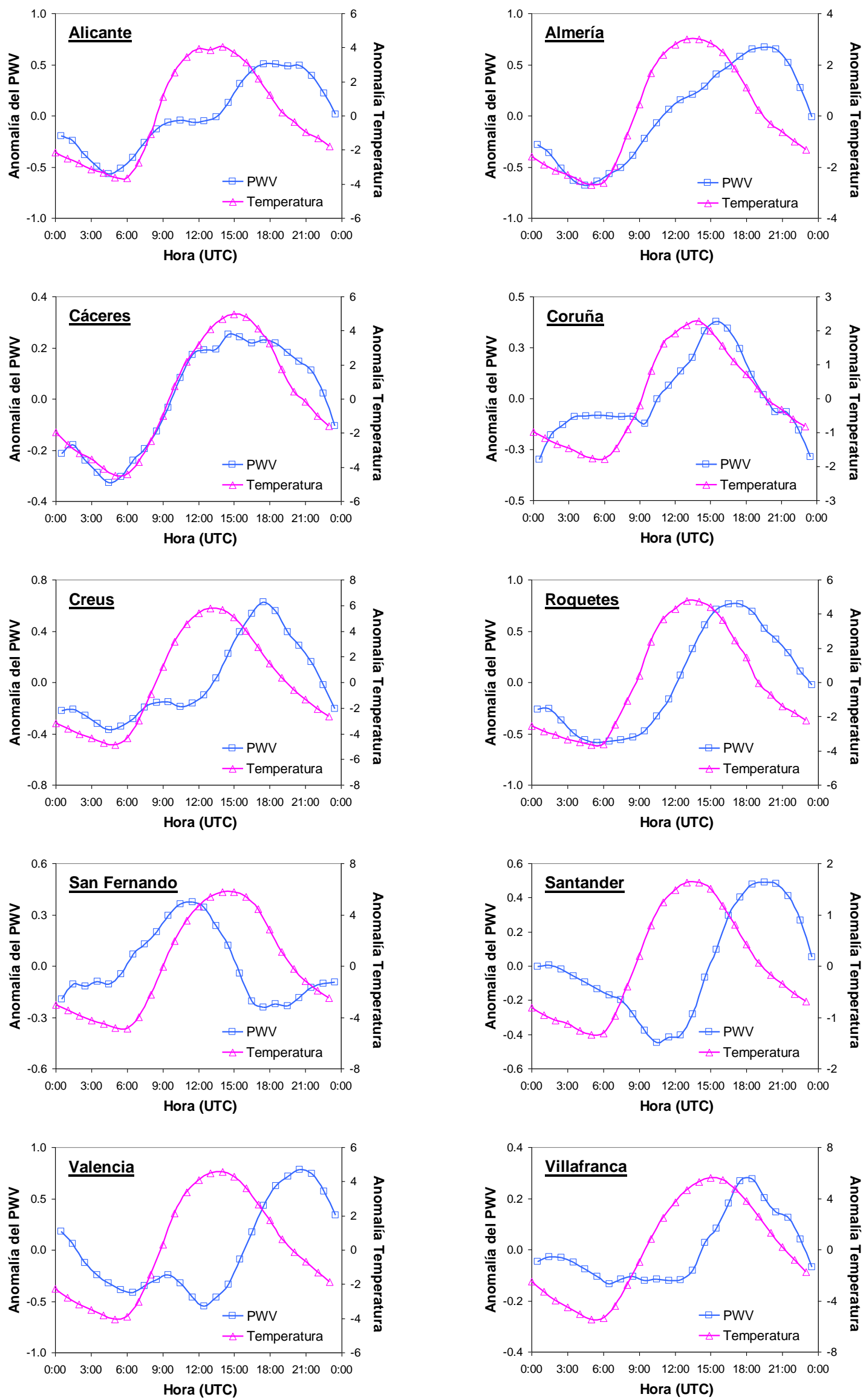

Figura 5.13 - Ciclos diurnos medios anuales del PWV y de la temperatura para cada estación. 
Comparando los ciclos diurnos estacionales del PWV (Figura 5.2) y de la frecuencia relativa del viento (Figura 5.14), se observa que para las cuatro estaciones el máximo de PWV se alcanza aproximadamente a la misma hora a la que el régimen de brisas deja de soplar de mar a tierra. Estas observaciones confirman que las brisas son en este emplazamiento el principal factor responsable del desfase entre el ciclo del PWV y de la temperatura durante el día.
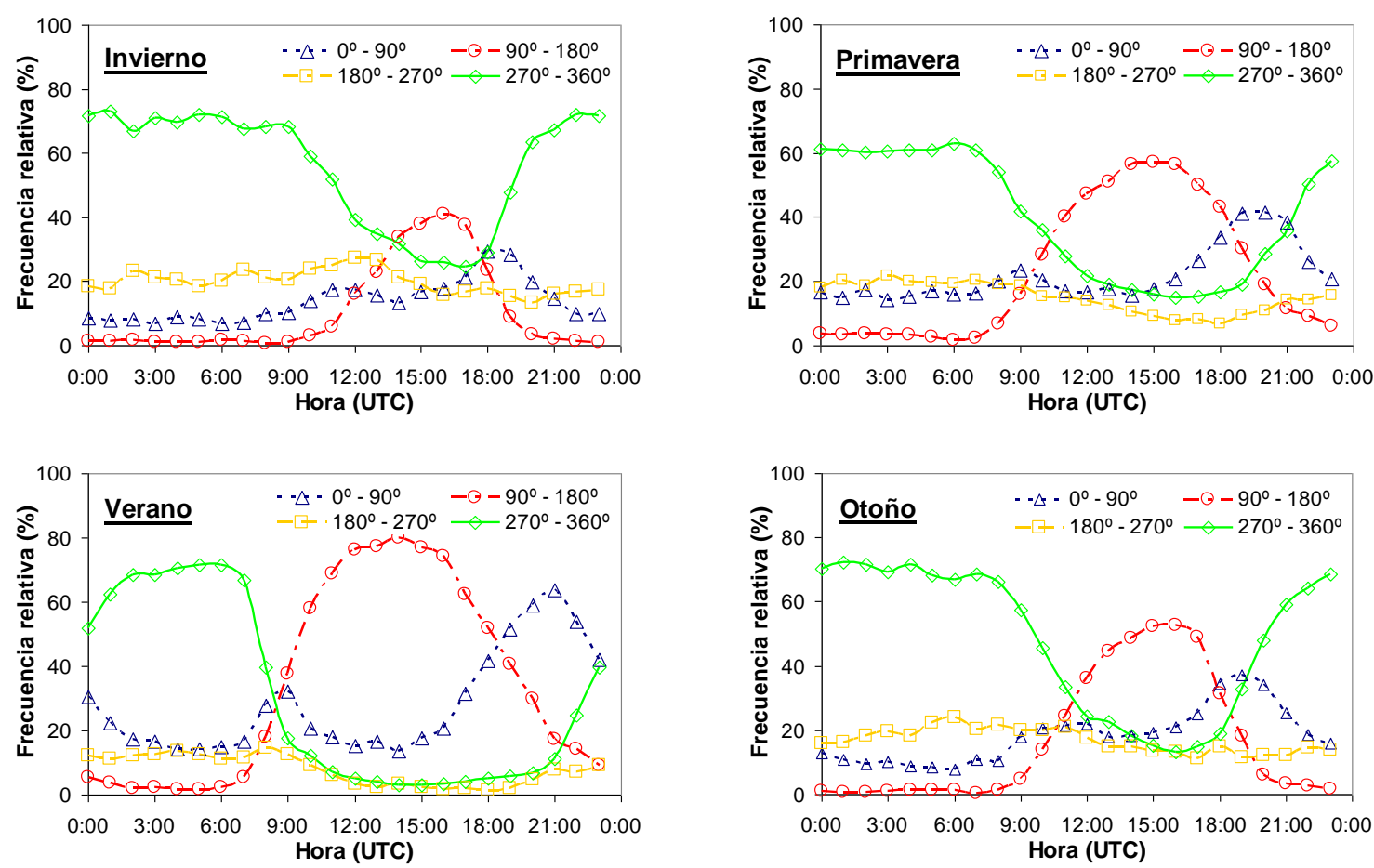

Figura 5.14 - Ciclos diurnos estacionales de la dirección del viento en la estación de Valencia.

También el mínimo relativo de PWV que tiene lugar justo después del mediodía puede ser atribuido a las brisas. Dos son los mecanismos que podrían producir esta disminución del PWV: 1) un ritmo de condensación en el seno de la masa de aire mayor que el de la evaporación; 2) la sustitución de la masa de aire por una más seca. La Figura 5.15 muestra que no hay un aumento significativo ni de la nubosidad total ni de la de tipo bajo entre las observaciones de las 7 y las 13 UTC. Aún más, en verano, cuando la disminución del PWV al mediodía es más acusada, la nubosidad disminuye ligeramente. Por tanto, la explicación debe venir más por el segundo mecanismo. Esto puede verse claramente en las gráficas del ciclo diurno del PWV y de la dirección del viento del verano. Después de la salida del sol, cuando el PWV ya ha comenzado a aumentar, se produce una disminución en el PWV coincidiendo aproximadamente con la hora a la que el régimen de brisas marinas se establece. En ese momento, cuando el viento comienza a soplar de mar a tierra, ésta se encuentra más caliente que el mar, y el aire cálido en contacto con ella, que ha evaporado la humedad superficial, se eleva y es reemplazado por aire de origen marino, pero aún no lo suficientemente cálido para transportar la misma o más humedad de la que tenía el aire original. Pasado el mediodía, 
conforme el mar se calienta lo suficiente, la brisa marina se convierte en un importante agente transportador de humedad hacia el interior, por lo que el contenido de PWV se incrementa hasta que la brisa finalmente se debilita. El hecho de que este mínimo no aparezca en todas los emplazamientos puede estar relacionado con la cantidad de humedad disponible en cada tipo de terreno.
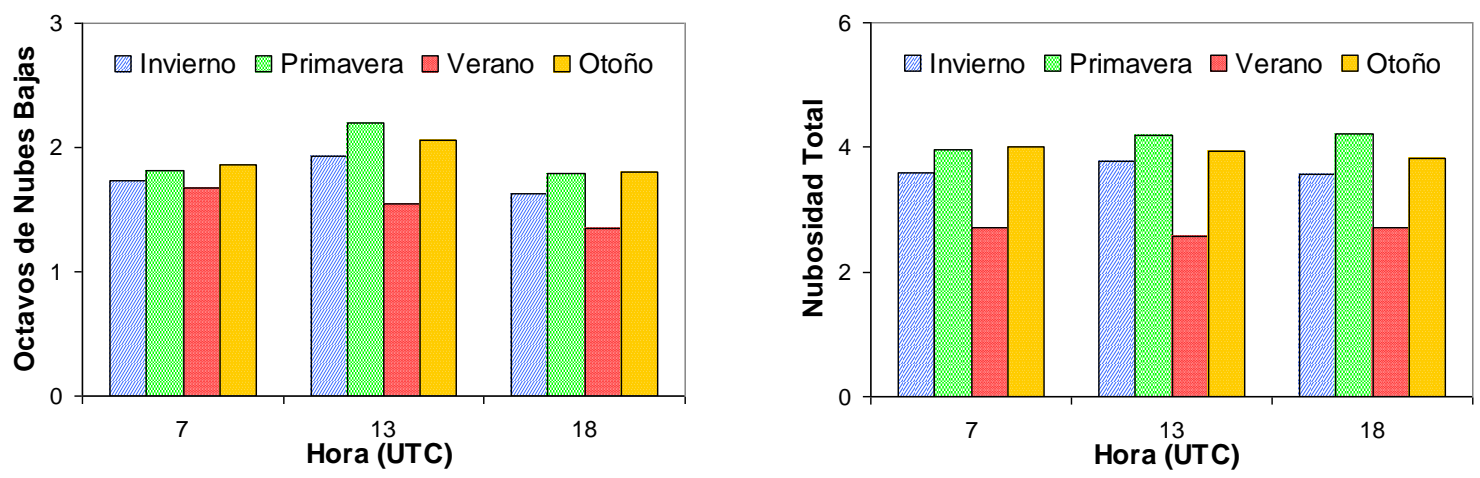

Figura 5.15 - Nubosidad total (derecha) y de tipo bajo (izquierda) en octavos de cielo cubierto en las observaciones de las 7, 13 y 18 UTC de la estación de Valencia.

Aunque Coruña es una estación costera con régimen de brisas, éste no es tan intenso como en las estaciones de la costa mediterránea al ser la insolación menor. Además, el océano Atlántico se encuentra más frío que el mediterráneo, haciendo todo ello que las brisas marinas en esta zona no aporten tanta humedad como en la costa mediterránea. Así, el ciclo del PWV y de la temperatura queda en el cómputo anual prácticamente en fase.
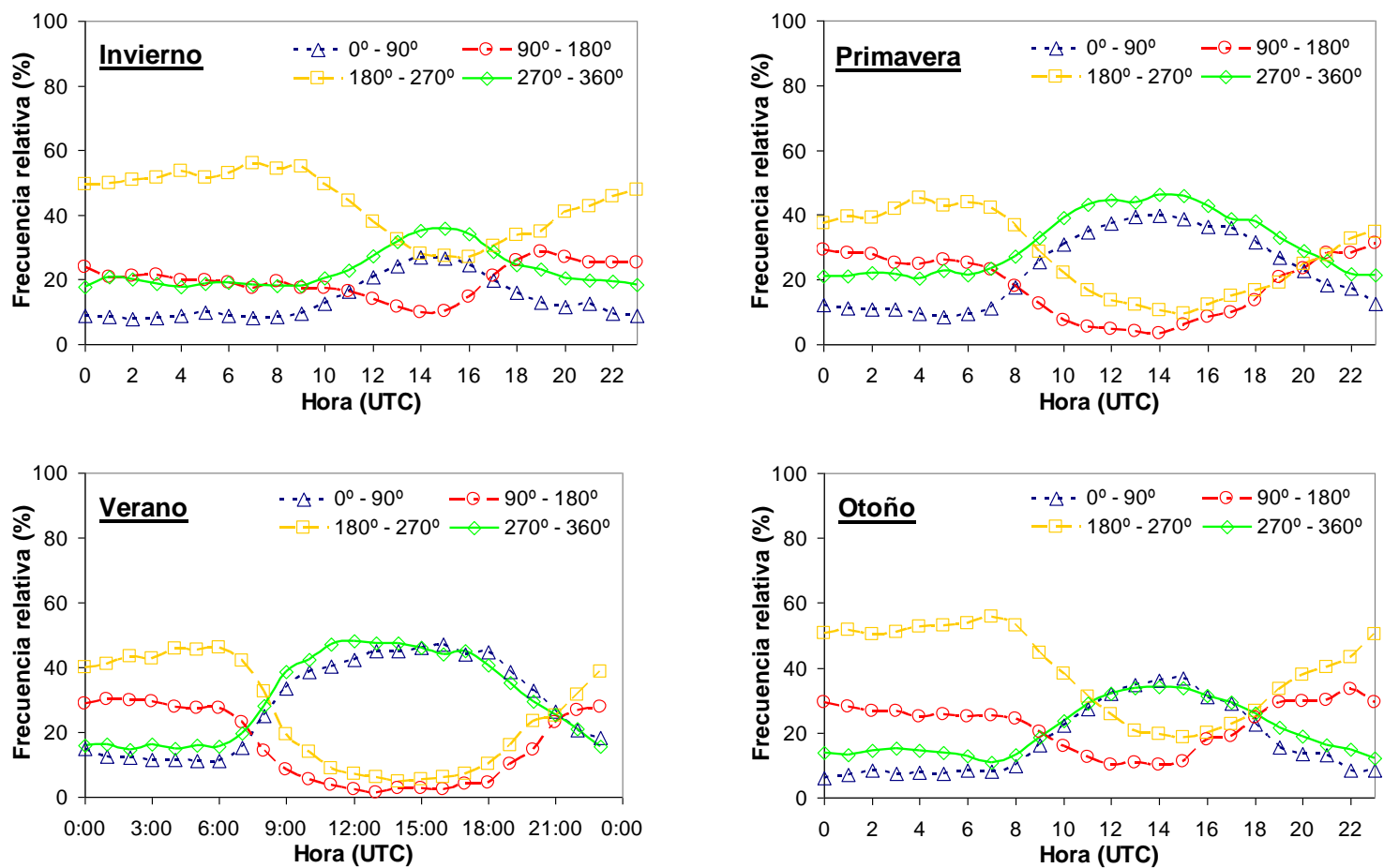

Figura 5.16 - Ciclos diurnos estacionales de la dirección del viento en la estación de Santander. 
Sin embargo, Santander, aunque se encuentra también en la costa cantábrica, muestra un comportamiento más parecido al de cualquiera de las estaciones de la costa mediterránea que al de Coruña. Esto puede ser debido a su situación geográfica en la falda de la cordillera cantábrica, que se extiende paralela a la línea de costa, de forma que las brisas marinas son reforzadas por los vientos anabáticos de las brisas de valle (Ohtani, 2001; Sasaki y Kiruma, 2001). Esta convergencia de vientos podría explicar también otro de los rasgos típicos del ciclo diurno del PWV de Santander, como es el comienzo tardío del incremento del PWV por la mañana. Durante la noche, los vientos catabáticos procedentes de la cordillera transportan aire más frío y seco hacia el valle, y se ven favorecidos por las brisas que soplan de tierra a mar, haciendo que el PWV no comience a aumentar hasta entrada la mañana cuando este sistema de vientos se invierte. Por ejemplo, en la Figura 5.16 se observa como el régimen de brisas se establece con más fuerza en primavera y verano. Durante la noche los vientos dominantes son del segundo y tercer cuadrante (componente sur), que son vientos del interior y por tanto más secos. A partir de las nueve el régimen de brisas se ha establecido, soplando los vientos del primer y cuarto cuadrante (componente norte); son vientos húmedos de origen marino. A las veintiuna horas el régimen de brisas se invierte, disminuyendo el PWV.
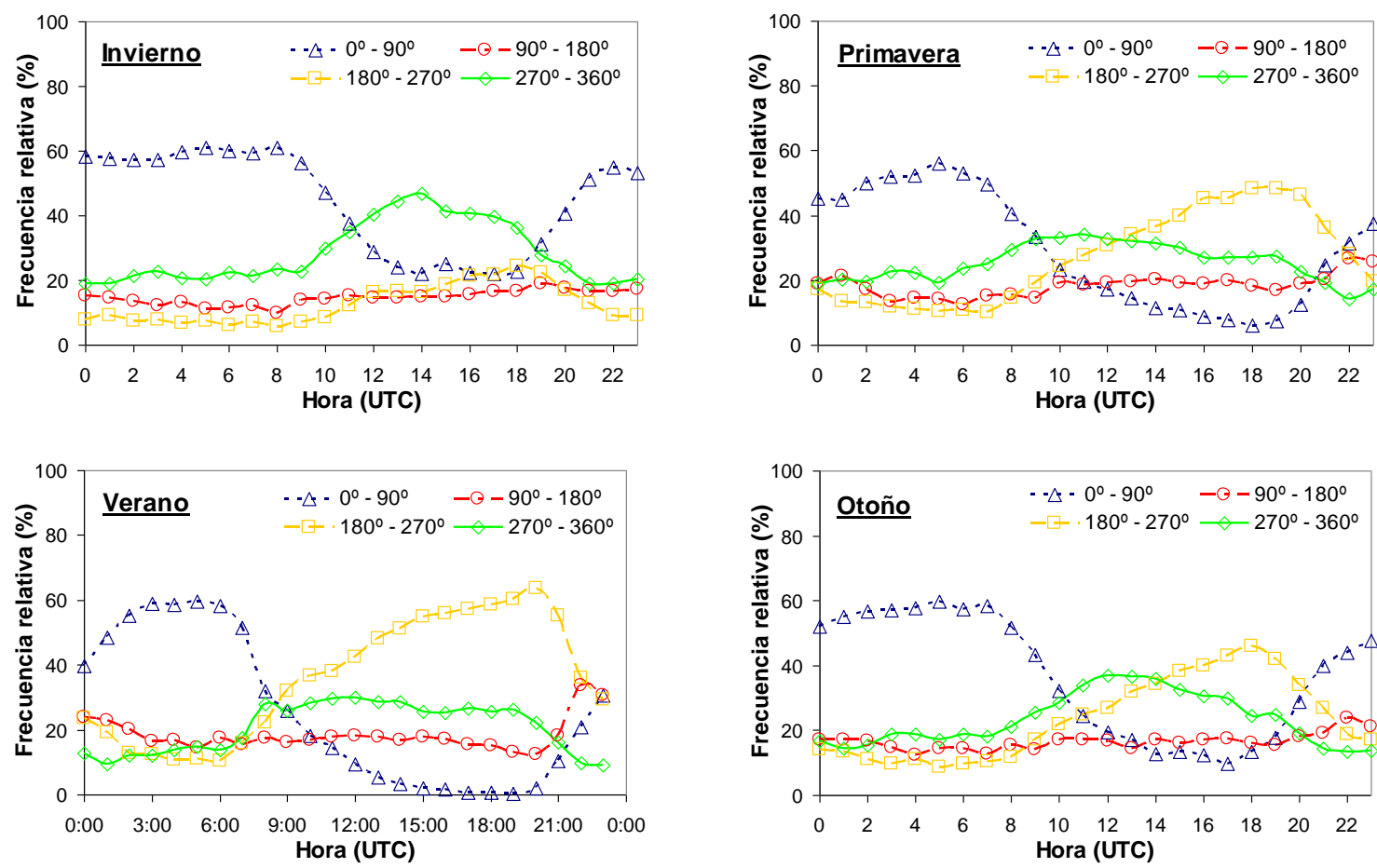

Figura 5.17 - Ciclos diurnos estacionales de la dirección del viento en la estación de Jerez (próxima a San Fernando). Para la representación gráfica, la dirección del viento se ha agrupado por cuadrantes.

En las estaciones del interior el ciclo diurno medio anual del PWV y el de la temperatura parecen estar más acoplados, al no darse ningún régimen diurno de vientos dominante que module sustancialmente el contenido de PWV. Sin embargo, si se estudian los ciclos diurnos estacionales sí se aprecia un desfase, pero de signo opuesto en invierno y en verano. En invierno el máximo de PWV se alcanza antes que el de la temperatura, mientras que en verano 
ocurre a la inversa. La explicación de porque en invierno el máximo de PWV se alcanza antes que el de la temperatura podría radicar en los movimientos verticales. Durante el invierno la estratificación de la atmósfera es mayor, desarrollándose además la inversión de subsidencia típica de los anticiclones invernales, que actúa a modo de tapadera inhibiendo los movimientos verticales. Al estar muy limitada la mezcla turbulenta en la vertical, la evaporación se dificulta al alcanzar la humedad relativa cerca de la superficie cierto valor, aún cuando la temperatura continúe subiendo.

Mención especial merece la estación de San Fernando, donde incluso en verano el máximo de PWV se alcanza antes que el de temperatura, cuando por su situación geográfica el régimen de brisas marinas debería continuar aportando humedad hasta el final de la tarde. La explicación de esta peculiaridad puede estar en su localización próxima al estrecho de Gibraltar, entre el frío océano Atlántico y el cálido mar Mediterráneo. Durante la noche, en esa zona el viento sopla del sureste (Figura 5.17), es decir del Mediterráneo, pero antes del mediodía se estable el régimen de brisas y empieza a soplar del oeste, es decir desde el océano Atlántico, resultando que la masa de aire sobre la estación es reemplazada por otra más fría y con menor contenido de humedad. Esto justificaría también que en verano el máximo de precipitación se alcance en la franja horaria entre las 7-13 UTC, y que la nubosidad disminuya por la tarde (Figura 5.18). Cuando al final del día la brisa marina se debilita y se intensifica la de tierra, los vientos del este trasportan más humedad, incrementando el PWV incluso aunque la temperatura este disminuyendo.

No se ha encontrado una correlación clara entre el ciclo diario de la precipitación y el del PWV. Es verdad que el calentamiento diurno está muy relacionado con el contenido de PWV, y que al mismo tiempo actúa como factor disparador de la convección. Sin embargo, a las latitudes a las que se encuentra la Península las precipitaciones más numerosas no son por convección térmica sino de origen frontal, determinadas por la situación sinóptica que no sigue un régimen diurno. Solamente la estación de Valencia en otoño presenta un incremento significativo en la precipitación durante la segunda mitad del día, cuando el PWV es mayor (Figura 5.19), y al contrario en San Fernando, donde las precipitaciones son más numerosas en la primera mitad del día (Figura 5.18). Esto último está de acuerdo con el hecho de que el máximo valor de PWV tenga lugar en esa estación antes del mediodía. También se ha observado un mínimo de precipitación durante el verano en Santander sobre el mediodía, coincidiendo con el mínimo de PWV (Figura 5.19).

El ciclo diurno del PWV puede estar también influenciado por la nubosidad. Por ello, se han dividido los datos en dos grupos, uno correspondiente a los días con la mayor amplitud térmica (mayoritariamente días soleados), y otro con los de menor amplitud térmica (mayoritariamente días nubosos). Como regla general se ha encontrado que para los emplazamientos costeros cuanto mayor es la amplitud térmica del día mayor es la amplitud del ciclo diurno del PWV, en 
todas las estaciones excepto en invierno. Por su parte, en los emplazamientos del interior cuanto mayor es la amplitud térmica menor es la amplitud del ciclo para todas las estaciones del año. Parece que la amplitud térmica juega un papel más relevante en la amplitud el ciclo diurno del PWV cuando hay una fuente ilimitada de vapor de agua y la intensidad de la radiación solar es alta. Estas condiciones no se dan en invierno y en los emplazamientos del interior. En estos casos, otros factores como podrían ser el tipo de masa de aire o la inestabilidad de la atmósfera son más determinantes, resultando que los días con más baja oscilación térmica presentan mayor variación del PWV.
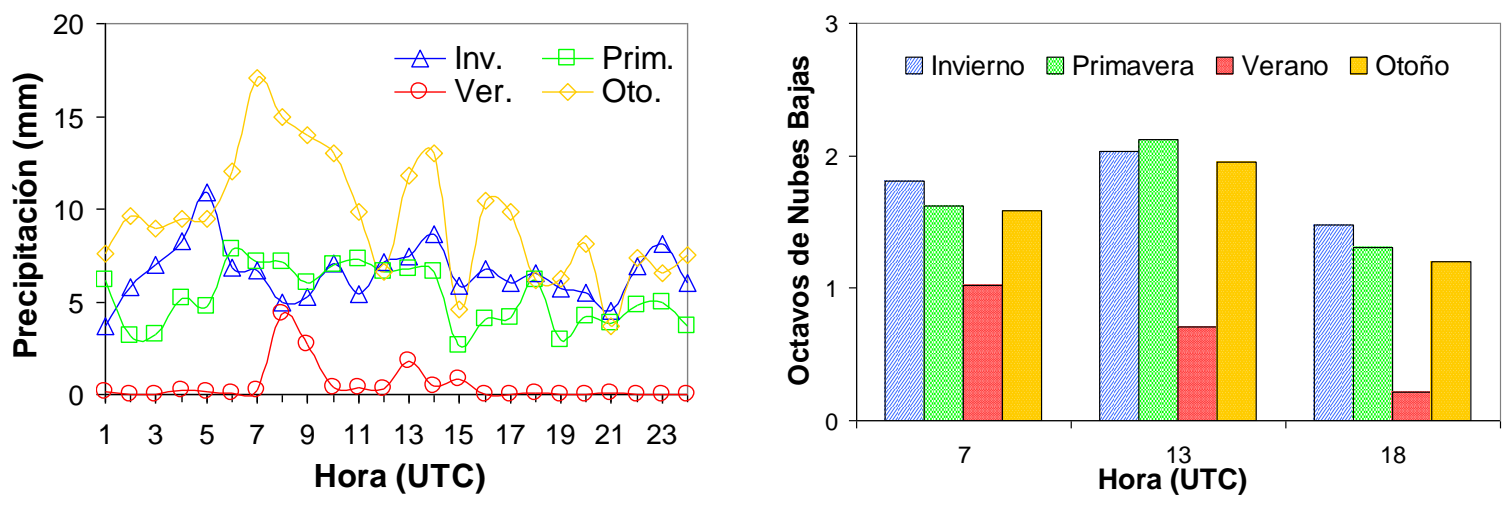

Figura 5.18 - Distribución horaria de la precipitación acumulada media estacional (izquierda), y de la nubosidad de tipo bajo en octavos de cielo cubierto a las 7, 13 y 18 UTC (derecha) para la zona de San Fernando, en base a los datos meteorológicos del aeropuerto de Jerez.

Entre los factores mencionados anteriormente, la temperatura y las brisas presentan un ciclo de periodo veinticuatro horas. Así, el armónico $S_{1}$ debe deberse principalmente a la suma de las contribuciones de estos dos factores. La dispersión en la fase de este armónico indicaría el peso diferente de cada uno de ellos en cada emplazamiento y estación climatológica. Las brisas son menos intensas en invierno en que verano, por ello, en invierno $S_{1}$ es más similar al ciclo diurno de la temperatura.
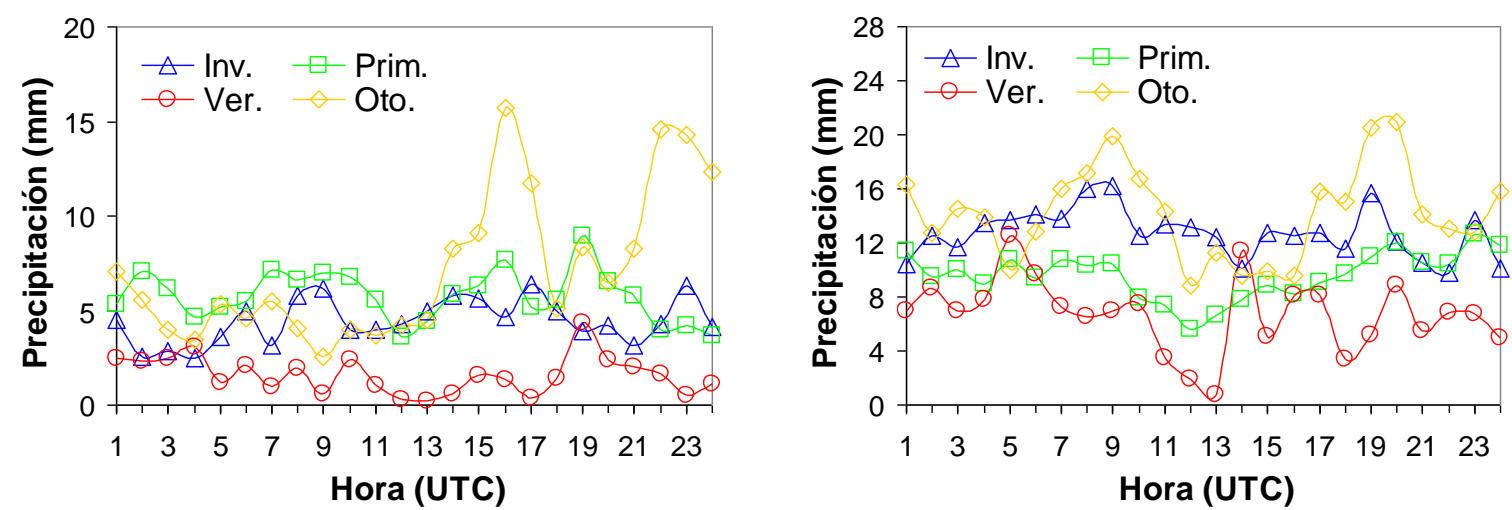

Figura 5.19 - Distribución temporal de la precipitación acumulada media estacional en Valencia (izquierda) y Santander (derecha). 
En algunos casos el PWV empieza a aumentar antes de que lo haga la temperatura. Esto indica que en principio este incremento no estaría relacionado con la intensificación de la evaporación por radiación. Pero puede ocurrir que la propia evaporación en sí produzca un enfriamiento del aire, evitando que la temperatura del aire en las capas bajas junto al suelo aumente a esas primeras horas de la mañana.

En las estaciones localizadas en zonas urbanas otro factor que puede modular el ciclo diurno del PWV es el cambio antropogénico de la superficie. En las áreas urbanas la evaporación esta limitada durante el verano por la escasez de fuentes de humedad, mientras que durante el invierno el vapor de agua es producido por la combustión. Aún más, el efecto isla de calor puede establecer brisas urbanas similares a las brisas marinas (Champollion et al., 2009).

Todas las teorías expuestas en este apartado requieren de un análisis más profundo para comprender mejor los mecanismos que entran en juego y cuantificar la contribución de cada factor al PWV total en base a modelos de flujos de humedad. En este punto, datos de los modelos numéricos de los flujos de calor latente serían muy útiles para corroborar y cuantificar la relación entre la temperatura, el estado de la capa límite y las variaciones de PWV, porque realmente la evaporación depende de estos, y estos no dependen sólo de la temperatura. 


\section{Capítulo 6}

\section{VARIABILIDAD TEMPORAL}

Uno de los rasgos característicos del contenido de vapor de agua atmosférico es su alta variabilidad, tanto espacial como temporal. Esta variabilidad no está bien cuantificada debido a la falta de datos con la suficiente resolución. En este capítulo se pretende caracterizar la variabilidad temporal del PWV para periodos de un día y de una hora a partir de los datos de la red de receptores GPS.

La variabilidad diaria se definirá como la dispersión de los datos horarios respecto al valor medio de cada día. No debe confundirse variabilidad diaria con ciclo diurno. La existencia de un ciclo diurno implica una variabilidad sistemática, pero ésta puede ser también debida a cambios en la situación meteorológica que no siguen un patrón de comportamiento de un ciclo diurno, y que como se verá conllevan unas variaciones mayores del PWV. Al igual que en capítulos anteriores, para que los resultados obtenidos tengan un cierto carácter climatológico se ha trabajado sólo con las estaciones GPS con las series de datos más largas. La variabilidad horaria se definirá como la dispersión de los datos de una hora con respecto al valor medio de la hora. Para esta parte del estudio se dispone de los datos cinco-minutales de ZTD desde el año 2007 generados por el IGS para cuatro estaciones peninsulares: San Fernando, Roquetes, Villafranca y Yebes.

Para describir la variabilidad, diaria u horaria, se han utilizado los siguientes estadísticos: el rango, definido como el valor máximo del periodo menos el mínimo (se ha expresado en valor absoluto y en porcentaje respecto del valor medio); la desviación típica de los valores del día o la hora según el caso; y el coeficiente de variación o dispersión de Pearson.

\subsection{Variabilidad diaria}

En la caracterización de la variabilidad diaria se ha seguido el siguiente procedimiento. Para cada día se han calculando los estadísticos comentados anteriormente a partir de los datos horarios. En este proceso se han considerado sólo los días con las veinticuatro observaciones horarias. A continuación, para cada mes de cada año se ha obtenido el valor medio, el máximo, y el mínimo de los valores diarios de los cuatro estadísticos mencionados. Posteriormente se han promediado para cada mes los valores mensuales de todos los años. Los meses con 
menos de la mitad de los días con datos no han sido considerados para los promedios. Finalmente, se han obtenido las medias anuales de los promedios de los valores mensuales.

\subsubsection{Variabilidad diaria por estación}

Siguiendo el procedimiento descrito anteriormente, los valores promedios mensuales obtenidos para la media, la media de los máximos, y la media de los mínimos de los cuatro estadísticos seleccionados para cada emplazamiento se recogen en las Tablas 6.1, 6.2 y 6.3 respectivamente. Para ilustrar mejor el comportamiento de la variabilidad diaria del PWV a lo del año, se han representado en las Figuras 6.1 a 6.4 los valores correspondientes al rango. Para su interpretación, y por una mayor claridad, se han agrupado las estaciones por área geográfica, distinguiendo cuatro grandes zonas: Cantábrico, Mediterráneo, Interior y Atlántico.
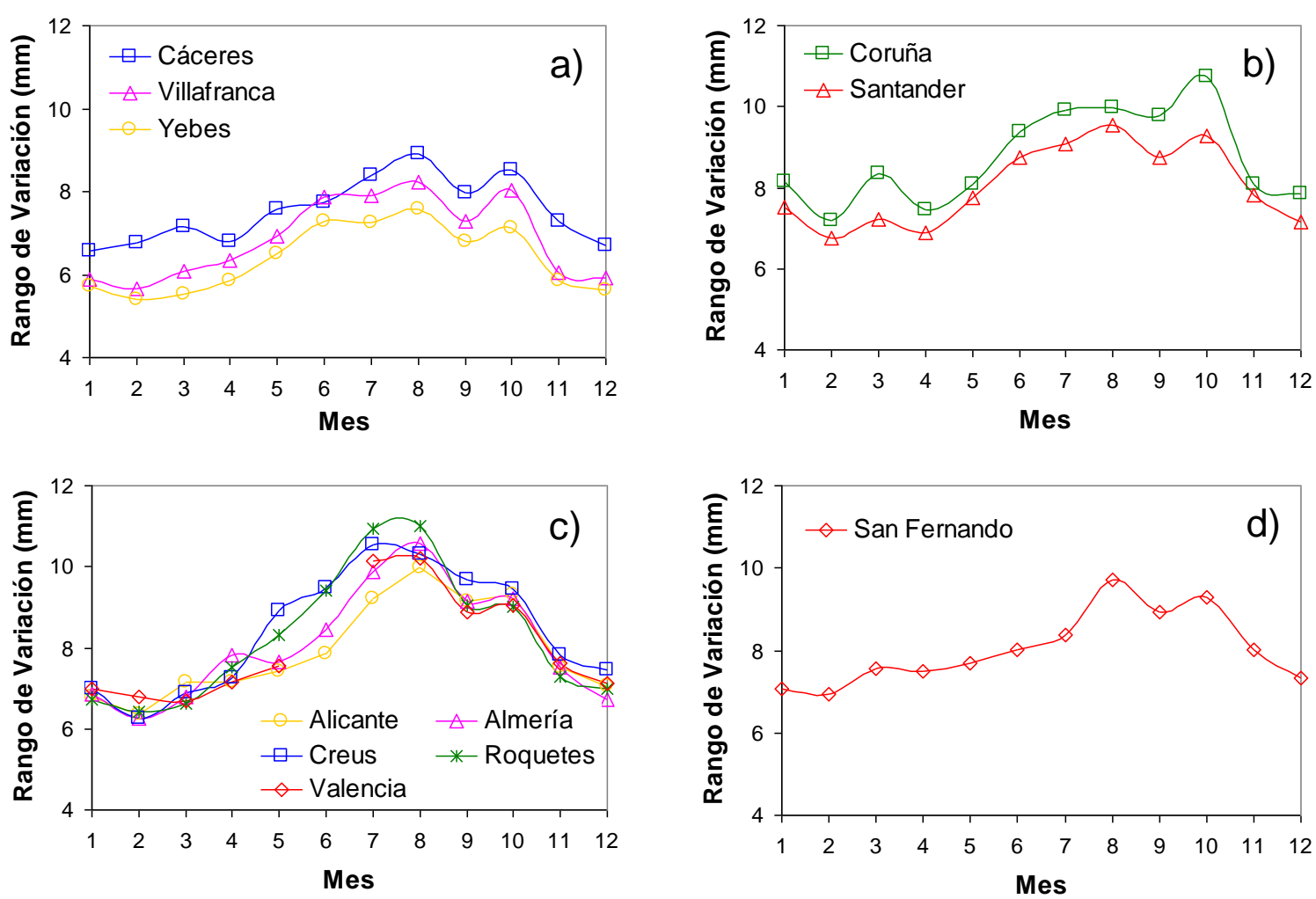

Figura 6.1 - Rango medio mensual de la variación diaria del PWV para cada estación.

Los valores más bajos del rango se dan en las estaciones del interior (Figura 6.1a), mientras que las los más altos tienen lugar en la costa mediterránea (Figura 6.1c). El comportamiento anual es semejante en todas las estaciones; el valor más bajo se registra en el mes de febrero, destacando Yebes con $5.40 \mathrm{~mm}$, aumenta hasta el final del verano principio del otoño presentándose dos máximos, uno en agosto y otro en octubre, con un mínimo relativo en septiembre. El máximo del verano es mayor que el de octubre (salvo en Coruña), especialmente en la costa mediterránea donde en Roquetes se alcanzan hasta los $11 \mathrm{~mm}$ de rango medio de variación diaria en agosto. La diferencia entre el valor máximo y mínimo anual es mayor en las costas (especialmente en la mediterránea) que en el interior. 


\begin{tabular}{|c|c|c|c|c|c|c|c|c|c|c|c|c|c|}
\hline Estación & & Ene & Feb & Mar & Abr & May & Jun & Jul & Ago & Sep & Oct & Nov & Dic \\
\hline \multirow[t]{4}{*}{ Alicante } & std & 1.92 & 1.81 & 2.06 & 2.08 & 2.11 & 2.28 & 2.61 & 2.87 & 2.65 & 2.72 & 2.23 & 2.06 \\
\hline & Coef. Var. & 0.16 & 0.15 & 0.15 & 0.12 & 0.10 & 0.09 & 0.09 & 0.10 & 0.09 & 0.11 & 0.14 & 0.15 \\
\hline & rango & 6.78 & 6.35 & 7.16 & 7.14 & 7.43 & 7.85 & 9.21 & 9.97 & 9.15 & 9.30 & 7.53 & 7.04 \\
\hline & rango $\%$ & 57.26 & 52.65 & 50.83 & 42.88 & 36.29 & 30.79 & 32.47 & 33.11 & 31.84 & 38.24 & 46.08 & 50.47 \\
\hline \multirow[t]{4}{*}{ Almería } & std & 1.92 & 1.78 & 1.91 & 2.23 & 2.25 & 2.43 & 2.88 & 3.15 & 2.68 & 2.70 & 2.21 & 1.93 \\
\hline & Coef. Var. & 0.16 & 0.14 & 0.14 & 0.14 & 0.11 & 0.10 & 0.11 & 0.12 & 0.10 & 0.11 & 0.14 & 0.14 \\
\hline & rango & 6.86 & 6.25 & 6.77 & 7.82 & 7.64 & 8.43 & 9.89 & 10.56 & 9.13 & 9.22 & 7.50 & 6.73 \\
\hline & rango $\%$ & 56.51 & 48.21 & 49.74 & 47.73 & 38.69 & 35.23 & 39.49 & 39.06 & 33.62 & 39.17 & 45.94 & 48.22 \\
\hline \multirow[t]{4}{*}{ Cáceres } & std & 1.89 & 1.97 & 2.06 & 1.94 & 2.19 & 2.20 & 2.39 & 2.58 & 2.32 & 2.48 & 2.12 & 1.95 \\
\hline & Coef. Var. & 0.17 & 0.18 & 0.17 & 0.14 & 0.13 & 0.11 & 0.13 & 0.13 & 0.11 & 0.13 & 0.15 & 0.16 \\
\hline & rango & 6.55 & 6.78 & 7.15 & 6.81 & 7.59 & 7.73 & 8.40 & 8.90 & 7.98 & 8.54 & 7.27 & 6.71 \\
\hline & rango $\%$ & 61.48 & 62.99 & 59.94 & 48.71 & 46.44 & 39.25 & 45.43 & 43.10 & 39.50 & 44.77 & 52.61 & 56.65 \\
\hline \multirow[t]{4}{*}{ Coruña } & std & 2.30 & 2.00 & 2.41 & 2.17 & 2.32 & 2.72 & 2.88 & 2.89 & 2.80 & 3.16 & 2.31 & 2.29 \\
\hline & Coef. Var. & 0.15 & 0.15 & 0.15 & 0.13 & 0.11 & 0.11 & 0.11 & 0.11 & 0.12 & 0.14 & 0.13 & 0.15 \\
\hline & rango & 8.14 & 7.20 & 8.34 & 7.46 & 8.10 & 9.36 & 9.92 & 9.98 & 9.78 & 10.75 & 8.08 & 7.85 \\
\hline & rango $\%$ & 53.85 & 53.41 & 53.87 & 45.79 & 40.09 & 39.16 & 37.23 & 38.20 & 40.37 & 46.68 & 46.06 & 51.06 \\
\hline \multirow[t]{4}{*}{ Creus } & std & 1.96 & 1.81 & 1.98 & 2.01 & 2.50 & 2.70 & 2.99 & 2.92 & 2.76 & 2.75 & 2.26 & 2.17 \\
\hline & Coef. Var. & 0.18 & 0.17 & 0.15 & 0.12 & 0.12 & 0.11 & 0.11 & 0.10 & 0.11 & 0.12 & 0.15 & 0.16 \\
\hline & rango & 7.00 & 6.25 & 6.88 & 7.25 & 8.90 & 9.46 & 10.54 & 10.32 & 9.66 & 9.44 & 7.82 & 7.46 \\
\hline & rango $\%$ & 63.68 & 57.78 & 53.64 & 44.84 & 43.37 & 36.98 & 37.88 & 36.02 & 39.14 & 42.70 & 51.75 & 56.67 \\
\hline \multirow[t]{4}{*}{ Roquetes } & std & 1.97 & 1.87 & 1.90 & 2.23 & 2.40 & 2.73 & 3.24 & 3.25 & 2.60 & 2.62 & 2.16 & 2.06 \\
\hline & Coef. Var. & 0.16 & 0.16 & 0.14 & 0.14 & 0.12 & 0.10 & 0.11 & 0.11 & 0.10 & 0.11 & 0.14 & 0.15 \\
\hline & rango & 6.73 & 6.41 & 6.62 & 7.51 & 8.33 & 9.40 & 10.93 & 11.00 & 9.04 & 9.02 & 7.30 & 6.98 \\
\hline & rango $\%$ & 57.41 & 55.46 & 49.08 & 45.93 & 40.30 & 35.56 & 37.02 & 38.30 & 34.25 & 39.33 & 47.55 & 52.33 \\
\hline \multirow[t]{4}{*}{ S. Fernando } & std & 2.06 & 2.00 & 2.26 & 2.14 & 2.19 & 2.28 & 2.39 & 2.90 & 2.56 & 2.69 & 2.35 & 2.10 \\
\hline & Coef. Var. & 0.17 & 0.15 & & & 12 & 10 & & 13 & 0.10 & 12 & 0.14 & 0.14 \\
\hline & rango & 7.07 & 6.93 & 7.57 & 7.49 & 7.69 & 8.03 & 8.38 & 9.70 & 8.92 & 9.30 & 8.03 & 7.33 \\
\hline & rango $\%$ & 57.31 & 50.98 & 54.92 & 48.93 & 43.04 & 36.50 & 41.05 & 41.76 & 36.36 & 40.23 & 49.32 & 48.71 \\
\hline \multirow[t]{4}{*}{ Santander } & std & 2.21 & 1.96 & 2.11 & 2.01 & 2.25 & 2.56 & 2.63 & 2.73 & 2.54 & 2.73 & 2.27 & 2.10 \\
\hline & Coef. Var. & 0.16 & 0.15 & 0.15 & 0.12 & 0.11 & 0.10 & 0.10 & 0.10 & 0.11 & 0.13 & 0.13 & 0.15 \\
\hline & rango & 7.50 & 6.74 & 7.22 & 6.88 & 7.75 & 8.74 & 9.09 & 9.54 & 8.74 & 9.27 & 7.81 & 7.15 \\
\hline & rango $\%$ & 55.62 & 53.21 & 52.16 & 42.31 & 37.86 & 34.38 & 33.00 & 33.77 & 36.35 & 42.50 & 45.94 & 50.52 \\
\hline \multirow[t]{4}{*}{ Valencia } & std & 2.01 & 1.93 & 1.96 & 2.11 & 2.19 & - & 2.88 & 2.93 & 2.57 & 2.69 & 2.25 & 2.13 \\
\hline & Coef. Var. & 0.17 & 0.16 & 0.15 & 0.12 & 0.11 & - & 0.10 & 0.10 & 0.09 & 0.11 & 0.15 & 0.16 \\
\hline & rango & 6.99 & 6.78 & 6.68 & 7.15 & 7.54 & - & 10.13 & 10.22 & 8.88 & 9.05 & 7.61 & 7.11 \\
\hline & rango $\%$ & 60.02 & 55.86 & 49.71 & 41.23 & 37.82 & - & 33.96 & 33.57 & 32.40 & 38.50 & 49.60 & 53.24 \\
\hline \multirow[t]{4}{*}{ Villafranca } & std & 1.70 & 1.66 & 1.73 & 1.80 & 1.97 & 2.24 & 2.24 & 2.33 & 2.07 & 2.31 & 1.74 & 1.71 \\
\hline & Coef. Var. & 0.17 & 0.17 & 0.16 & 0.14 & 0.12 & 0.11 & 0.12 & 0.12 & 0.11 & 0.13 & 0.14 & 0.15 \\
\hline & rango & 5.89 & 5.67 & 6.07 & 6.33 & 6.94 & 7.89 & 7.89 & 8.21 & 7.29 & 8.04 & 6.04 & 5.93 \\
\hline & rango \% & 60.53 & 57.12 & 56.44 & 48.38 & 42.07 & 38.84 & 41.63 & 40.85 & 38.42 & 44.62 & 48.86 & 54.20 \\
\hline \multirow[t]{4}{*}{ Yebes } & std & 1.64 & 1.58 & 1.59 & 1.69 & 1.84 & 2.05 & 2.03 & 2.14 & 1.93 & 2.06 & 1.67 & 1.62 \\
\hline & Coef. Var. & 0.20 & 0.19 & 0.18 & 0.15 & 0.13 & 0.12 & 0.12 & 0.12 & 0.11 & 0.13 & 0.16 & 0.18 \\
\hline & rango & 5.72 & 5.40 & 5.53 & 5.86 & 6.49 & 7.29 & 7.24 & 7.58 & 6.80 & 7.12 & 5.84 & 5.62 \\
\hline & rango $\%$ & 72.33 & 67.19 & 61.28 & 52.56 & 46.60 & 41.57 & 42.78 & 42.56 & 39.91 & 45.32 & 55.28 & 62.38 \\
\hline \multirow[t]{4}{*}{ MEDIA } & std & 1.80 & 1.70 & 1.83 & 1.87 & 2.02 & 2.20 & 2.43 & 2.56 & 2.29 & 2.41 & 1.97 & 1.84 \\
\hline & Coef. Var. & 0.15 & 0.15 & 0.14 & 0.12 & 0.11 & 0.10 & 0.10 & 0.10 & 0.10 & 0.11 & 0.13 & 0.14 \\
\hline & rango & 6.27 & 5.90 & 6.33 & 6.48 & 7.03 & 7.65 & 8.47 & 8.83 & 7.95 & 8.25 & 6.74 & 6.33 \\
\hline & rango \% & 54.67 & 51.24 & 49.30 & 42.44 & 37.71 & 33.48 & 35.16 & 35.02 & 33.51 & 38.50 & 44.92 & 48.70 \\
\hline
\end{tabular}

Tabla 6.1 - Medias mensuales (2002/2008) de la desviación típica, el coeficiente de dispersión, y el rango (en valor absoluto y en porcentaje) de la variabilidad diaria. 


\begin{tabular}{|c|c|c|c|c|c|c|c|c|c|c|c|c|c|}
\hline Estación & & Ene & Feb & Mar & Abr & May & Jun & Jul & Ago & Sep & Oct & Nov & Dic \\
\hline \multirow[t]{4}{*}{ Alicante } & std & 4.96 & 4.41 & 5.03 & 5.53 & 4.62 & 4.95 & 5.15 & 6.28 & 5.74 & 6.75 & 5.73 & 6.08 \\
\hline & Coef. Var. & 0.38 & 0.38 & 0.35 & 0.30 & 0.26 & 0.22 & 0.19 & 0.24 & 0.24 & 0.29 & 0.37 & 0.40 \\
\hline & rango & 16.22 & 14.12 & 15.91 & 16.18 & 14.45 & 16.02 & 17.17 & 18.83 & 18.18 & 20.06 & 16.65 & 17.29 \\
\hline & rango $\%$ & 120.05 & 136.40 & 104.86 & 98.48 & 80.18 & 73.76 & 63.92 & 73.91 & 75.76 & 88.21 & 113.83 & 120.99 \\
\hline \multirow[t]{4}{*}{ Almería } & std & 4.58 & 4.42 & 4.55 & 5.50 & 5.99 & 5.44 & 6.38 & 7.67 & 6.35 & 6.76 & 5.12 & 5.39 \\
\hline & Coef. Var. & 0.37 & 0.32 & 0.38 & 0.32 & 0.32 & 0.26 & 0.27 & 0.29 & 0.24 & 0.29 & 0.30 & 0.36 \\
\hline & rango & 15.04 & 13.80 & 14.86 & 17.41 & 17.11 & 16.98 & 20.17 & 23.20 & 18.97 & 20.65 & 15.78 & 16.18 \\
\hline & rango \% & 136.45 & 108.84 & 121.71 & 101.36 & 90.72 & 80.68 & 86.86 & 88.53 & 75.81 & 87.78 & 100.45 & 113.67 \\
\hline \multirow[t]{4}{*}{ Cáceres } & std & 4.89 & 4.60 & 5.20 & 5.48 & 5.12 & 5.72 & 6.16 & 6.60 & 6.22 & 7.06 & 5.95 & 5.36 \\
\hline & Coef. Var. & 0.40 & 0.47 & 0.42 & 0.34 & 0.31 & 0.31 & 0.29 & 0.28 & 0.30 & 0.37 & 0.42 & 0.39 \\
\hline & rango & 14.74 & 14.43 & 15.88 & 16.16 & 16.22 & 17.43 & 18.68 & 20.15 & 20.34 & 20.90 & 18.46 & 17.90 \\
\hline & rango \% & 135.15 & 158.97 & 137.31 & 105.04 & 97.86 & 98.96 & 91.57 & 88.28 & 97.83 & 133.71 & 131.57 & 133.03 \\
\hline \multirow[t]{4}{*}{ Coruña } & std & 5.65 & 4.73 & 5.86 & 5.63 & 5.93 & 6.04 & 7.43 & 7.90 & 6.83 & 8.52 & 5.93 & 6.37 \\
\hline & Coef. Var. & 0.33 & 0.31 & 0.38 & 0.31 & 0.30 & 0.27 & 0.27 & 0.28 & 0.29 & 0.32 & 0.29 & 0.35 \\
\hline & rango & 17.76 & 15.79 & 17.33 & 16.67 & 17.62 & 19.67 & 23.38 & 23.58 & 21.35 & 25.90 & 18.06 & 18.48 \\
\hline & rango $\%$ & 120.14 & 108.23 & 116.99 & 94.74 & 90.22 & 84.33 & 86.60 & 84.95 & 92.37 & 105.13 & 98.82 & 107.13 \\
\hline \multirow[t]{4}{*}{ Creus } & std & 4.51 & 5.28 & 5.46 & 4.44 & 5.30 & 6.14 & 6.68 & 5.25 & 6.75 & 6.55 & 5.42 & 5.43 \\
\hline & Coef. Var. & 0.37 & 0.41 & 0.41 & 0.28 & 0.28 & 0.24 & 0.25 & 0.21 & 0.27 & 0.33 & 0.38 & 0.37 \\
\hline & rango & 13.95 & 15.49 & 16.01 & 14.59 & 19.22 & 19.31 & 22.08 & 18.39 & 22.07 & 20.84 & 17.33 & 16.59 \\
\hline & rango $\%$ & 137.80 & 135.09 & 136.96 & 94.44 & 100.96 & 79.28 & 79.08 & 66.69 & 88.33 & 109.45 & 120.81 & 117.39 \\
\hline \multirow[t]{4}{*}{ Roquetes } & std & 5.03 & 4.90 & 4.41 & 5.06 & 4.74 & 5.99 & 6.86 & 7.36 & 5.93 & 6.30 & 6.30 & 5.73 \\
\hline & Coef. Var. & 0.39 & 0.39 & 0.32 & 0.34 & 0.27 & 0.25 & 0.28 & 0.28 & 0.28 & 0.28 & 0.38 & 0.38 \\
\hline & rango & 15.49 & 15.12 & 13.95 & 15.25 & 15.55 & 18.42 & 22.19 & 21.66 & 18.71 & 20.03 & 17.62 & 16.81 \\
\hline & rango $\%$ & 129.93 & 125.01 & 105.90 & 100.81 & 95.05 & 82.06 & 86.54 & 82.93 & 92.89 & 92.37 & 113.48 & 119.16 \\
\hline \multirow[t]{4}{*}{ S. Fernando } & std & 5.94 & 4.52 & 6.75 & 5.27 & 4.97 & 5.83 & 5.55 & 7.08 & 6.00 & 7.35 & 7.00 & 6.57 \\
\hline & Coef. Var. & 0.46 & & 0.44 & 37 & & 0. & 0.25 & 0.27 & 0.27 & 33 & 0.40 & 0.43 \\
\hline & rango & 18.14 & 15.22 & 18.20 & 16.83 & 16.76 & 18.25 & 17.53 & 21.38 & 20.33 & 22.79 & 20.88 & 19.63 \\
\hline & rango $\%$ & 147.27 & 116.11 & 143.02 & 122.17 & 93.77 & 87.29 & 82.06 & 83.77 & 96.54 & 111.82 & 121.10 & 130.35 \\
\hline \multirow[t]{4}{*}{ Santander } & std & 5.32 & 5.11 & 4.93 & 5.02 & 5.49 & 5.61 & 6.18 & 6.47 & 6.11 & 7.61 & 5.65 & 5.70 \\
\hline & Coef. Var. & 0.43 & 0.47 & 0.37 & 0.32 & 0.25 & 0.26 & 0.23 & 0.24 & 0.24 & 0.36 & 0.33 & 0.38 \\
\hline & rango & 15.74 & 15.77 & 16.14 & 15.24 & 16.61 & 18.05 & 18.78 & 22.24 & 18.74 & 22.14 & 17.73 & 16.87 \\
\hline & rango $\%$ & 137.28 & 155.93 & 113.16 & 93.70 & 79.06 & 86.72 & 68.87 & 73.28 & 75.81 & 104.35 & 103.45 & 112.12 \\
\hline \multirow[t]{4}{*}{ Valencia } & std & 5.16 & 4.70 & 4.62 & 5.20 & 4.46 & - & 5.39 & 5.90 & 5.83 & 7.75 & 5.92 & 5.72 \\
\hline & Coef. Var. & 0.42 & 0.42 & 0.37 & 0.29 & 0.27 & - & 0.20 & 0.28 & 0.25 & 0.32 & 0.39 & 0.42 \\
\hline & rango & 16.20 & 15.36 & 14.30 & 14.85 & 14.36 & - & 18.47 & 19.94 & 18.59 & 22.10 & 17.35 & 16.19 \\
\hline & rango $\%$ & 142.64 & 144.75 & 115.92 & 85.55 & 94.56 & - & 70.67 & 88.88 & 83.45 & 97.84 & 124.03 & 130.15 \\
\hline \multirow[t]{4}{*}{ Villafranca } & std & 4.19 & 4.67 & 4.27 & 4.91 & 4.44 & 5.38 & 4.80 & 5.60 & 5.13 & 5.95 & 4.80 & 4.71 \\
\hline & Coef. Var. & 0.41 & 0.40 & 0.35 & 0.35 & 0.28 & 0.27 & 0.24 & 0.29 & 0.30 & 0.33 & 0.37 & 0.40 \\
\hline & rango & 13.40 & 13.53 & 13.54 & 14.67 & 14.58 & 16.92 & 15.46 & 17.83 & 15.92 & 18.25 & 14.68 & 15.19 \\
\hline & rango \% & 136.14 & 126.94 & 116.07 & 102.59 & 91.48 & 86.12 & 80.91 & 93.96 & 98.23 & 116.73 & 111.05 & 130.27 \\
\hline \multirow[t]{4}{*}{ Yebes } & std & 4.02 & 4.50 & 4.05 & 4.89 & 4.58 & 4.97 & 4.39 & 5.13 & 4.89 & 5.71 & 4.30 & 4.41 \\
\hline & Coef. Var. & 0.50 & 0.49 & 0.42 & 0.38 & 0.32 & 0.31 & 0.25 & 0.30 & 0.30 & 0.35 & 0.39 & 0.46 \\
\hline & rango & 13.14 & 12.85 & 12.38 & 13.98 & 15.46 & 15.77 & 14.23 & 17.64 & 15.01 & 16.96 & 13.53 & 13.19 \\
\hline & rango $\%$ & 170.90 & 159.09 & 140.90 & 114.85 & 108.65 & 96.38 & 86.49 & 98.07 & 96.75 & 112.66 & 124.56 & 147.86 \\
\hline \multirow[t]{4}{*}{ MEDIA } & std & 4.52 & 4.32 & 4.59 & 4.74 & 4.64 & 5.10 & 5.41 & 5.94 & 5.48 & 6.36 & 5.18 & 5.12 \\
\hline & Coef. Var. & 0.37 & 0.37 & 0.35 & 0.30 & 0.26 & 0.24 & 0.23 & 0.25 & 0.25 & 0.30 & 0.33 & 0.36 \\
\hline & rango & 14.15 & 13.46 & 14.04 & 14.32 & 14.83 & 16.07 & 17.34 & 18.74 & 17.35 & 19.22 & 15.67 & 15.36 \\
\hline & rango \% & 126.15 & 122.95 & 112.73 & 92.81 & 85.21 & 77.78 & 73.63 & 76.94 & 81.15 & 96.67 & 105.26 & 113.51 \\
\hline
\end{tabular}

Tabla 6.2 - Media de los máximos mensuales (2002/2008) de la desviación típica, el coeficiente de dispersión, y rango (en valor absoluto y en porcentaje) de la variabilidad diaria. 


\begin{tabular}{|c|c|c|c|c|c|c|c|c|c|c|c|c|c|}
\hline Estación & & Ene & Feb & Mar & Abr & May & Jun & Jul & Ago & Sep & Oct & Nov & Dic \\
\hline \multirow[t]{4}{*}{ Alicante } & std & 0.65 & 0.65 & 0.69 & 0.68 & 0.82 & 0.90 & 1.22 & 1.14 & 0.90 & 0.88 & 0.77 & 0.68 \\
\hline & Coef. Var. & 0.05 & 0.04 & 0.04 & 0.04 & 0.04 & 0.03 & 0.04 & 0.04 & 0.03 & 0.04 & 0.05 & 0.04 \\
\hline & rango & 2.49 & 2.44 & 2.70 & 2.52 & 3.24 & 3.46 & 4.60 & 4.16 & 3.46 & 3.51 & 2.80 & 2.52 \\
\hline & rango $\%$ & 19.95 & 15.75 & 15.90 & 14.95 & 14.34 & 11.93 & 14.24 & 13.82 & 11.41 & 13.70 & 16.54 & 14.32 \\
\hline \multirow[t]{4}{*}{ Almería } & std & 0.72 & 0.72 & 0.78 & 0.75 & 0.87 & 0.94 & 1.18 & 1.16 & 0.99 & 0.96 & 0.77 & 0.68 \\
\hline & Coef. Var. & 0.06 & 0.05 & 0.04 & 0.05 & 0.04 & 0.03 & 0.04 & 0.04 & 0.03 & 0.04 & 0.04 & 0.04 \\
\hline & rango & 2.88 & 2.85 & 2.94 & 2.93 & 3.32 & 3.41 & 4.49 & 4.56 & 3.65 & 3.84 & 2.91 & 2.59 \\
\hline & rango \% & 22.72 & 18.67 & 16.69 & 17.65 & 13.82 & 12.62 & 16.52 & 15.18 & 12.84 & 14.02 & 16.80 & 15.33 \\
\hline \multirow[t]{4}{*}{ Cáceres } & std & 0.64 & 0.71 & 0.72 & 0.68 & 0.77 & 0.83 & 0.92 & 0.80 & 0.68 & 0.77 & 0.65 & 0.57 \\
\hline & Coef. Var. & 0.06 & 0.06 & 0.06 & 0.05 & 0.04 & 0.04 & 0.04 & 0.04 & 0.03 & 0.04 & 0.05 & 0.05 \\
\hline & rango & 2.47 & 2.71 & 2.62 & 2.76 & 3.04 & 3.22 & 3.48 & 3.07 & 2.52 & 2.79 & 2.40 & 2.30 \\
\hline & rango $\%$ & 19.87 & 22.43 & 21.33 & 17.60 & 16.50 & 14.50 & 16.13 & 14.51 & 13.54 & 14.66 & 16.80 & 18.92 \\
\hline \multirow[t]{4}{*}{ Coruña } & std & 0.72 & 0.75 & 0.64 & 0.57 & 0.70 & 0.89 & 0.82 & 0.97 & 0.86 & 0.94 & 0.68 & 0.66 \\
\hline & Coef. Var. & 0.05 & 0.06 & 0.05 & 0.04 & 0.04 & 0.04 & 0.03 & 0.04 & 0.03 & 0.04 & 0.04 & 0.04 \\
\hline & rango & 3.01 & 2.84 & 2.75 & 2.28 & 2.77 & 3.27 & 3.31 & 3.78 & 3.45 & 3.78 & 2.71 & 2.51 \\
\hline & rango $\%$ & 19.66 & 21.54 & 18.77 & 15.59 & 15.52 & 13.79 & 12.93 & 16.85 & 13.41 & 15.41 & 16.81 & 16.22 \\
\hline \multirow[t]{4}{*}{ Creus } & std & 0.73 & 0.74 & 0.68 & 0.92 & 0.99 & 1.02 & 1.23 & 1.22 & 1.05 & 0.93 & 0.80 & 0.70 \\
\hline & Coef. Var. & 0.06 & 0.05 & 0.05 & 0.05 & 0.04 & 0.04 & 0.04 & 0.04 & 0.03 & 0.04 & 0.05 & 0.05 \\
\hline & rango & 2.64 & 2.79 & 2.44 & 3.46 & 4.01 & 4.38 & 4.59 & 4.31 & 3.97 & 3.77 & 3.06 & 2.62 \\
\hline & rango $\%$ & 23.77 & 19.81 & 18.88 & 19.44 & 18.02 & 15.13 & 15.05 & 13.51 & 13.74 & 13.53 & 18.44 & 18.21 \\
\hline \multirow[t]{4}{*}{ Roquetes } & std & 0.57 & 0.62 & 0.59 & 0.82 & 1.01 & 1.02 & 1.32 & 1.18 & 0.96 & 0.74 & 0.68 & 0.52 \\
\hline & Coef. Var. & 0.05 & 0.04 & 0.04 & 0.04 & 0.04 & 0.04 & 0.04 & 0.04 & 0.03 & 0.03 & 0.04 & 0.04 \\
\hline & rango & 2.11 & 2.44 & 2.21 & 3.00 & 3.95 & 3.82 & 5.03 & 4.30 & 3.97 & 2.86 & 2.65 & 2.13 \\
\hline & rango $\%$ & 19.20 & 16.02 & 15.08 & 16.72 & 16.33 & 13.68 & 14.94 & 14.25 & 12.63 & 11.15 & 16.68 & 15.33 \\
\hline \multirow[t]{4}{*}{ S. Fernando } & std & 0.68 & 0.72 & 0.74 & 0.77 & 0.79 & 0.96 & 0.97 & 0.91 & 0.95 & 0.78 & 0.76 & 0.61 \\
\hline & Coef. Var. & 0.05 & 0.05 & & & 0.04 & & & 0.04 & $0 . C$ & 0.03 & 0.04 & 0.04 \\
\hline & rango & 2.50 & 2.52 & 2.79 & 2.83 & 3.06 & 3.63 & 3.58 & 3.58 & 3.58 & 3.02 & 2.91 & 2.40 \\
\hline & rango $\%$ & 19.61 & 18.11 & 17.89 & 18.40 & 14.04 & 15.79 & 16.55 & 15.93 & 14.68 & 12.83 & 15.23 & 14.33 \\
\hline \multirow[t]{4}{*}{ Santander } & std & 0.70 & 0.49 & 0.68 & 0.68 & 0.78 & 0.86 & 0.99 & 0.87 & 0.84 & 0.80 & 0.70 & 0.57 \\
\hline & Coef. Var. & 0.05 & 0.04 & 0.05 & 0.04 & 0.03 & 0.03 & 0.04 & 0.03 & 0.03 & 0.03 & 0.04 & 0.04 \\
\hline & rango & 2.82 & 2.03 & 2.63 & 2.62 & 3.18 & 3.38 & 3.68 & 3.35 & 3.06 & 3.11 & 2.74 & 2.17 \\
\hline & rango $\%$ & 18.70 & 18.04 & 18.49 & 15.92 & 14.33 & 10.79 & 15.25 & 12.40 & 12.78 & 13.36 & 15.28 & 16.93 \\
\hline \multirow[t]{4}{*}{ Valencia } & std & 0.59 & 0.70 & 0.71 & 0.89 & 0.67 & - & 1.20 & 1.11 & 1.04 & 0.98 & 0.74 & 0.69 \\
\hline & Coef. Var. & 0.05 & 0.05 & 0.05 & 0.05 & 0.03 & - & 0.04 & 0.03 & 0.03 & 0.04 & 0.04 & 0.04 \\
\hline & rango & 2.32 & 2.77 & 2.58 & 3.34 & 2.76 & - & 4.72 & 3.91 & 4.02 & 3.79 & 2.99 & 2.60 \\
\hline & rango $\%$ & 18.81 & 17.90 & 17.44 & 18.44 & 13.97 & - & 14.60 & 11.30 & 12.39 & 13.00 & 16.70 & 15.45 \\
\hline \multirow[t]{4}{*}{ Villafranca } & std & 0.63 & 0.52 & 0.61 & 0.65 & 0.71 & 0.92 & 0.82 & 0.76 & 0.72 & 0.67 & 0.59 & 0.54 \\
\hline & Coef. Var. & 0.06 & 0.05 & 0.05 & 0.05 & 0.04 & 0.04 & 0.04 & 0.03 & 0.04 & 0.04 & 0.05 & 0.05 \\
\hline & rango & 2.35 & 1.99 & 2.38 & 2.66 & 2.57 & 3.45 & 3.07 & 2.80 & 2.72 & 2.67 & 2.21 & 2.21 \\
\hline & rango \% & 22.80 & 17.23 & 18.84 & 19.91 & 15.05 & 14.98 & 15.14 & 12.42 & 14.53 & 14.39 & 16.97 & 19.44 \\
\hline \multirow[t]{4}{*}{ Yebes } & std & 0.49 & 0.55 & 0.60 & 0.55 & 0.69 & 0.81 & 0.86 & 0.84 & 0.66 & 0.61 & 0.53 & 0.52 \\
\hline & Coef. Var. & 0.06 & 0.06 & 0.06 & 0.05 & 0.04 & 0.04 & 0.04 & 0.05 & 0.04 & 0.04 & 0.05 & 0.05 \\
\hline & rango & 1.89 & 2.02 & 2.23 & 2.09 & 2.63 & 3.10 & 3.22 & 3.11 & 2.55 & 2.32 & 2.00 & 2.11 \\
\hline & rango $\%$ & 21.32 & 20.92 & 20.29 & 17.73 & 15.47 & 17.29 & 16.55 & 17.26 & 14.18 & 15.72 & 19.24 & 21.12 \\
\hline \multirow[t]{4}{*}{ MEDIA } & std & 0.59 & 0.60 & 0.62 & 0.66 & 0.73 & 0.83 & 0.96 & 0.91 & 0.80 & 0.75 & 0.64 & 0.56 \\
\hline & Coef. Var. & 0.05 & 0.04 & 0.04 & 0.04 & 0.04 & 0.03 & 0.04 & 0.04 & 0.03 & 0.03 & 0.04 & 0.04 \\
\hline & rango & 2.29 & 2.28 & 2.35 & 2.54 & 2.88 & 3.19 & 3.65 & 3.41 & 3.08 & 2.95 & 2.45 & 2.18 \\
\hline & rango $\%$ & 18.87 & 17.20 & 16.63 & 16.03 & 13.95 & 12.77 & 13.99 & 13.12 & 12.18 & 12.65 & 15.46 & 15.47 \\
\hline
\end{tabular}

Tabla 6.3 - Media de los mínimos mensuales (2002/2008) de la desviación típica, el coeficiente de dispersión, y rango (en valor absoluto y en porcentaje) de la variabilidad diaria. 
Las estaciones del interior presentan un comportamiento muy paralelo, con valores más bajos cuanto mayor es la altitud. Por su parte, las estaciones de la costa mediterránea tienen un comportamiento semejante en otoño e invierno, aumentando las diferencias entre ellas en primavera y verano. Un rasgo diferenciador de las estaciones de las costas atlánticas (y en menor medida en Cáceres) es el máximo relativo que tiene lugar en el mes de marzo. Este puede deberse a la mayor inestabilidad de la atmósfera en el paso del invierno a la primavera.
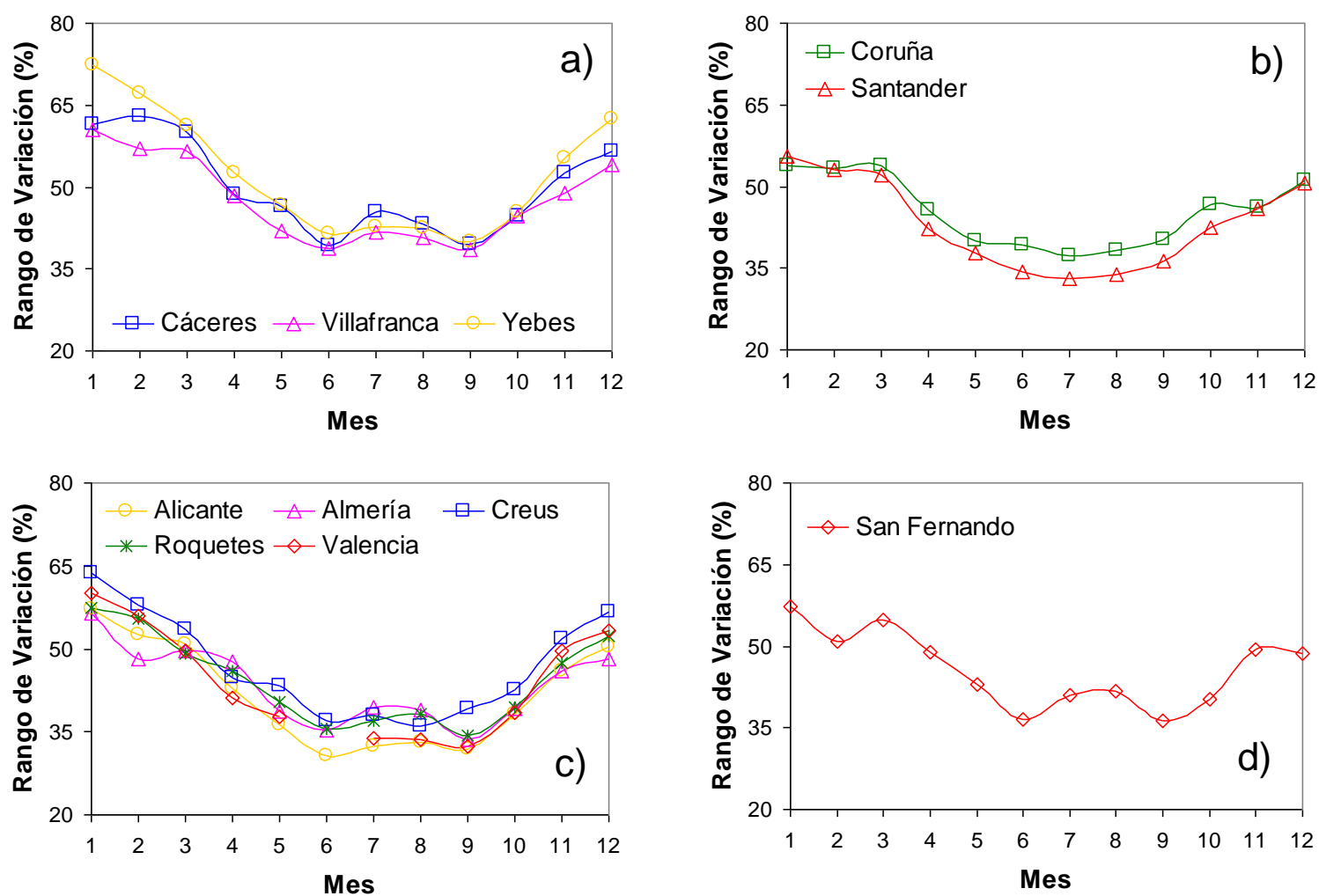

Figura 6.2 - Rango medio en valor relativo (\%) de la variación diaria del PWV para cada estación.

El comportamiento entre estaciones del rango en términos relativos (Figura 6.2) es más parecido que en términos absolutos, tanto en la forma de la evolución a lo largo del año como en los valores. Las gráficas presentan forma de 'U', con mínimos en verano y máximos en enero y diciembre. Excepto en la zona cantábrica, se observa una pequeña ondulación de junio a septiembre, alcanzándose el mínimo en estos meses, mientras que en julio y agosto aparece un pequeño máximo relativo. Este efecto parece más acusado cuanto más al sur, apreciándose claramente en San Fernando, Almería y Cáceres. Al contrario que con el rango en valor absoluto, los valores más altos del rango en porcentaje se dan en las estaciones del interior. La variación oscila desde un $72 \%$ en Yebes en enero, hasta un 31\% en Alicante en junio.

La desviación típica (no mostrada, ver Tabla 6.1) presenta una evolución similar a la del rango. Oscila entre los $3.25 \mathrm{~mm}$ de Roquetes en agosto, y los $1.58 \mathrm{~mm}$ de Yebes en febrero. Por su parte, el coeficiente de variación sigue el mismo patrón de comportamiento que el del rango en valor relativo, oscilando entre 0.20 para enero (Yebes) y 0.09 para junio (Alicante). 
El promedio de los máximos mensuales del rango de variación (Figura 6.3) presenta una evolución anual bastante similar a la de los valores medios. Los menores valores se dan en febrero, y los mayores al principio del otoño, presentando oscilaciones secundarias en los meses estivales. La mayor discrepancia radica en que los valores más altos tienen lugar para la mayoría de las estaciones en octubre, o se presentan dos máximos, uno en octubre y otro en agosto. Sólo Roquetes presenta un máximo destacado en julio, mientras que los mayores valores de la media mensual del rango se alcanzaban en julio-agosto para las estaciones mediterráneas, y en octubre y agosto en el resto. Los valores límite oscilan entre los $12.38 \mathrm{~mm}$ de Yebes en marzo y los $25.90 \mathrm{~mm}$ de Coruña en octubre. Estos valores duplican y sobrepasan los del rango medio. En cuanto a su distribución geográfica, los mayores valores se dan en las estaciones de las costas norte y sur, destacando Coruña, y los menores en la zona centro.

En términos porcentuales, al igual que en el caso del rango medio, los menores valores se dan en los meses de verano y los mayores en diciembre y enero, siendo mayores en las estaciones del interior y menores en las de la costa mediterránea. Estos valores oscilan entre un $64 \%$ en julio en Alicante y un $171 \%$ en enero en Yebes. La evolución anual es similar a la del rango medio en valores relativos, con la salvedad de que no tiene lugar la oscilación secundaria entre los meses de junio a septiembre, registrándose los valores mínimos en julio.
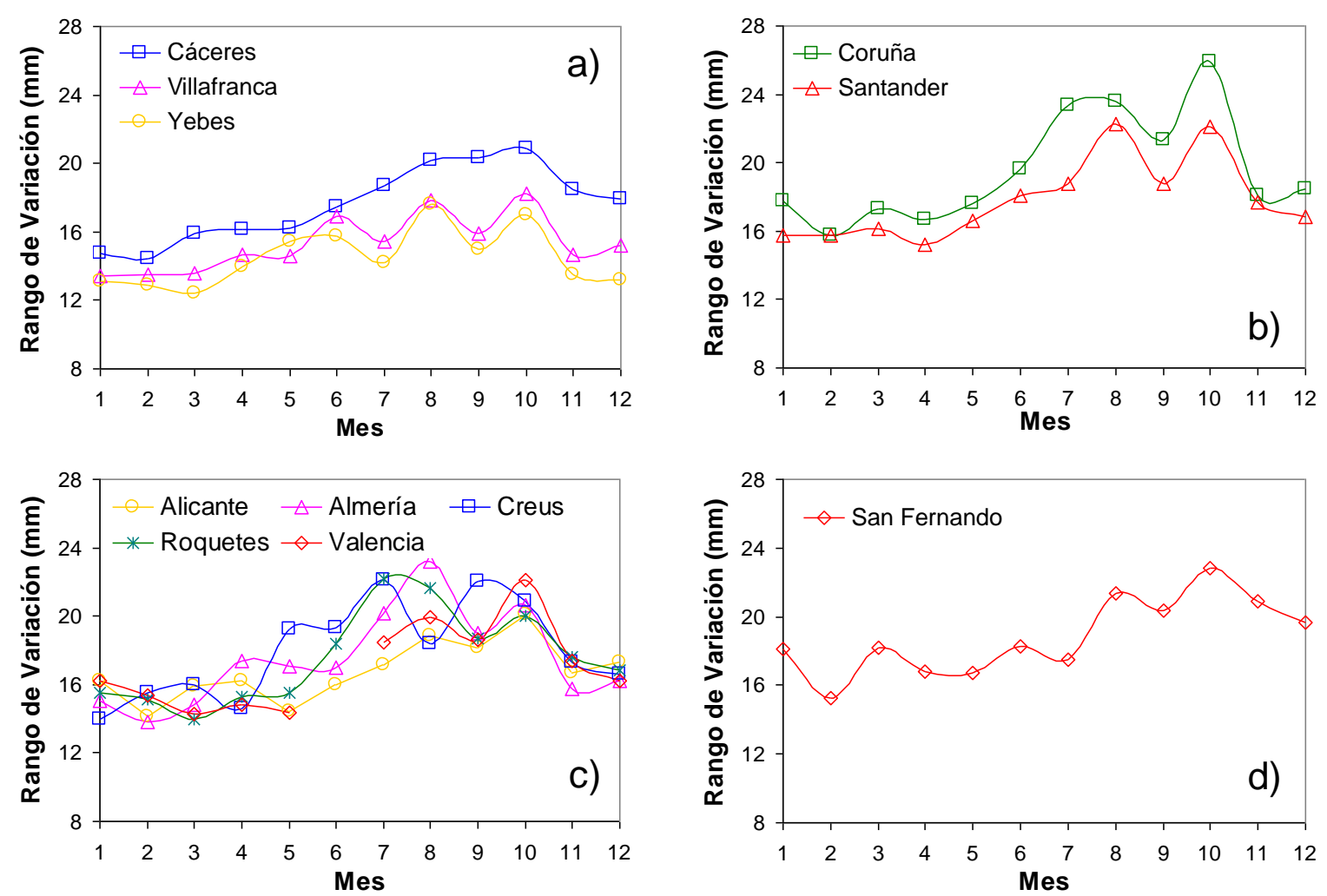

Figura 6.3 - Media de los máximos mensuales del rango diario de variación del PWV. 
Por último, la media de los mínimos mensuales del rango presenta una mayor uniformidad a lo largo del año (Figura 6.4), describiendo un ciclo con valores mínimos en invierno y máximos en verano, aunque con poca amplitud, sólo algo mayor en las estaciones mediterráneas. Los valores extremos oscilan entre los $1.89 \mathrm{~mm}$ de Yebes en enero y los $5.03 \mathrm{~mm}$ de Roquetes en julio. Estos valores son menos de la mitad de los valores obtenidos para el rango medio. En términos porcentuales estos límites se invierten, y se sitúan entre un $11 \%$ para junio en Santander y un $24 \%$ para enero en Creus.
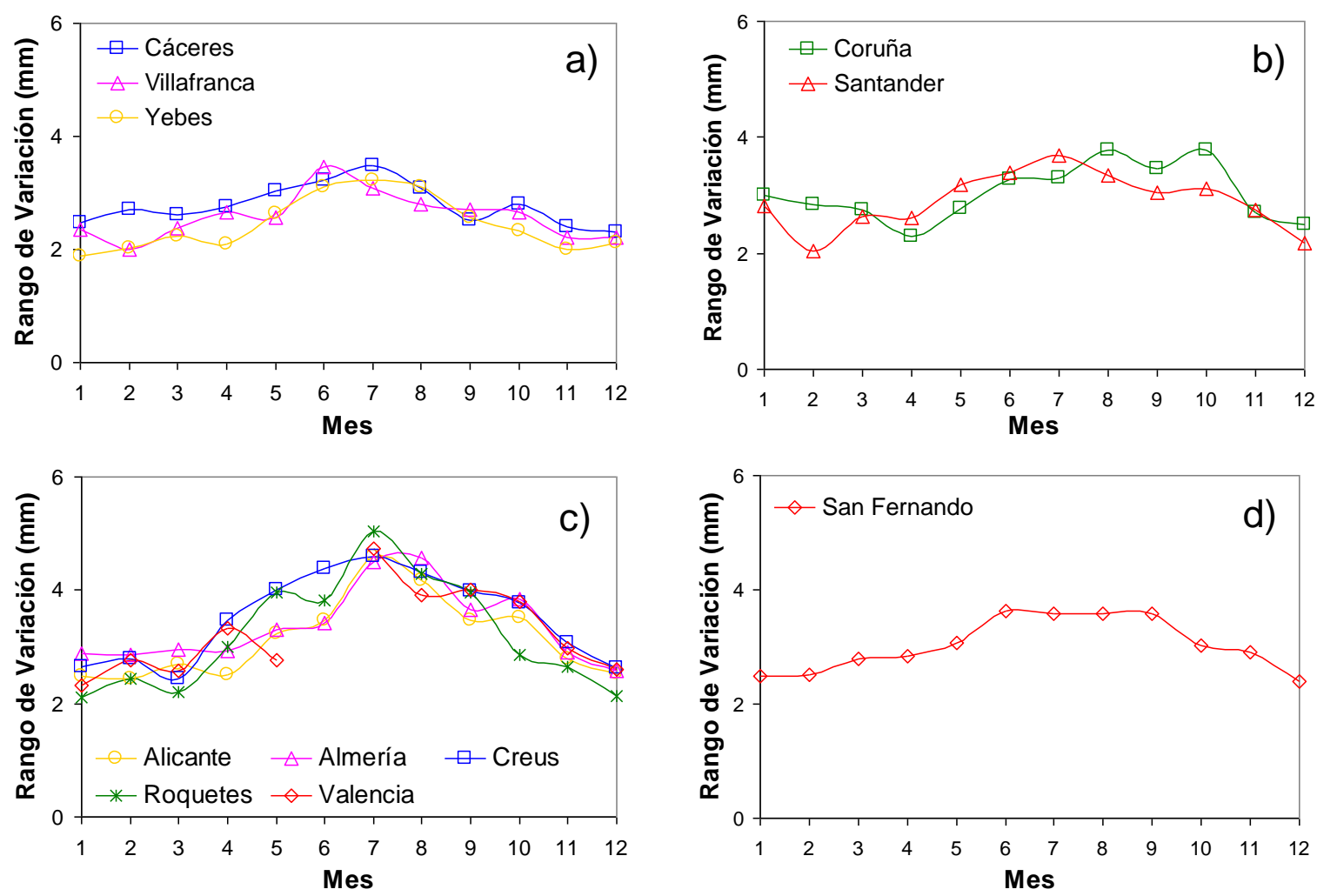

Figura 6.4 - Media de los mínimos mensuales del rango diario de variación del PWV.

En el promedio anual (Tabla 6.4) el rango en valor absoluto oscila entre los $6.38 \mathrm{~mm}$ de Yebes y los $8.75 \mathrm{~mm}$ de Coruña. Los valores más bajos se registran en las estaciones del interior situadas a mayor altitud. Las discrepancias entre las estaciones próximas a la costa, situadas todas ellas por debajo de los $100 \mathrm{~m}$ de altitud, son menores de un milímetro. En valor relativo, el rango varía entre el $42 \%$ de Alicante y el $53 \%$ de Yebes. En este caso es en las estaciones a mayor altitud, con menor PWV, donde se obtienen las variaciones más altas. Considerando sólo las ocho estaciones próximas a la costa, las diferencias entre ellas son como mucho de un $5 \%$. De la misma manera, la desviación típica es menor en las estaciones a mayor altitud, variando entre los 1.82 de Yebes y los 2.52 de Coruña, mientras que con el coeficiente de variación ocurre al revés, situándose entre los 0.12 de Alicante y los 0.15 de Yebes.

Respecto a la media de los máximos mensuales, se han obtenido valores poco dispares entre estaciones, siendo una vez más en las situadas a mayor altitud donde se dan las menores 
variaciones en valor absoluto (rango y desviación típica) y las mayores en valor relativo (rango en \% y coeficiente de variación). El rango en valor absoluto varía entre los $14.51 \mathrm{~mm}$ de Yebes y los $19.63 \mathrm{~mm}$ de Coruña, y en valor relativo varía entre un $96 \%$ de Alicante y un $121 \%$ de Yebes. Estas medias de los máximos mensuales son más del doble de los valores medios, mientras que las medias de los mínimos mensuales son del orden de la mitad o la tercera parte.

\begin{tabular}{|c|c|c|c|c|c|c|c|c|c|c|c|c|}
\hline & \multicolumn{4}{|c|}{ MEDIA } & \multicolumn{4}{|c|}{ MEDIA DE LOS MÁXIMOS } & \multicolumn{4}{|c|}{ MEDIA DE LOS MÍNIMOS } \\
\hline & $\begin{array}{l}\text { Rango } \\
(\mathrm{mm})\end{array}$ & $\begin{array}{c}\text { Rango } \\
\%\end{array}$ & $\begin{array}{l}\text { Desv. } \\
\text { Típica }\end{array}$ & $\begin{array}{c}\text { Coef. } \\
\text { Disper. }\end{array}$ & $\begin{array}{c}\text { Rango } \\
\text { (mm) }\end{array}$ & $\begin{array}{c}\text { Rango } \\
\%\end{array}$ & $\begin{array}{l}\text { Desv. } \\
\text { Típica } \\
\end{array}$ & $\begin{array}{l}\text { Coef. } \\
\text { Disper. }\end{array}$ & $\begin{array}{c}\text { Rango } \\
\text { (mm) }\end{array}$ & $\begin{array}{c}\text { Rango } \\
\%\end{array}$ & $\begin{array}{l}\text { Desv. } \\
\text { Típica }\end{array}$ & $\begin{array}{c}\text { Coef. } \\
\text { Disper. }\end{array}$ \\
\hline Alicante & 7.91 & 41.9 & 2.28 & 0.12 & 16.76 & 95.9 & 5.43 & 0.30 & 3.16 & 14.7 & 0.83 & 0.04 \\
\hline Almería & 8.07 & 43.5 & 2.34 & 0.13 & 17.51 & 99.4 & 5.68 & 0.31 & 3.36 & 16.1 & 0.88 & 0.04 \\
\hline Cáceres & 7.53 & 50.1 & 2.18 & 0.14 & 17.61 & 117.4 & 5.70 & 0.36 & 2.78 & 17.2 & 0.73 & 0.05 \\
\hline Coruña & 8.75 & 45.5 & 2.52 & 0.13 & 19.63 & 99.1 & 6.40 & 0.31 & 3.04 & 16.4 & 0.77 & 0.04 \\
\hline Creus & 8.42 & 47.0 & 2.40 & 0.13 & 17.99 & 105.5 & 5.60 & 0.32 & 3.50 & 17.3 & 0.92 & 0.05 \\
\hline Roquetes & 8.27 & 44.4 & 2.42 & 0.13 & 17.57 & 102.2 & 5.72 & 0.32 & 3.21 & 15.2 & 0.84 & 0.04 \\
\hline San Fernando & 8.04 & 45.8 & 2.33 & 0.13 & 18.83 & 111.3 & 6.07 & 0.34 & 3.03 & 16.1 & 0.80 & 0.04 \\
\hline Santander & 8.04 & 43.1 & 2.34 & 0.13 & 17.84 & 100.3 & 5.76 & 0.32 & 2.90 & 15.2 & 0.75 & 0.04 \\
\hline Valencia & 8.01 & 44.2 & 2.33 & 0.13 & 17.06 & 107.1 & 5.51 & 0.33 & 3.25 & 15.5 & 0.85 & 0.04 \\
\hline Villafranca & 6.85 & 47.7 & 1.96 & 0.14 & 15.33 & 107.5 & 4.90 & 0.33 & 2.59 & 16.8 & 0.68 & 0.04 \\
\hline Yebes & 6.38 & 52.5 & 1.82 & 0.15 & 14.51 & 121.4 & 4.65 & 0.37 & 2.44 & 18.1 & 0.64 & 0.05 \\
\hline MÁXIMO & 8.75 & 52.5 & 2.52 & 0.15 & 19.63 & 121.4 & 6.40 & 0.37 & 3.50 & 18.1 & 0.92 & 0.05 \\
\hline MÍNIMO & 6.38 & 41.9 & 1.82 & 0.12 & 14.51 & 95.9 & 4.65 & 0.30 & 2.44 & 14.7 & 0.64 & 0.04 \\
\hline
\end{tabular}

Tabla 6.4 -Valores medios anuales del rango, la desviación típica, y el coeficiente de dispersión.
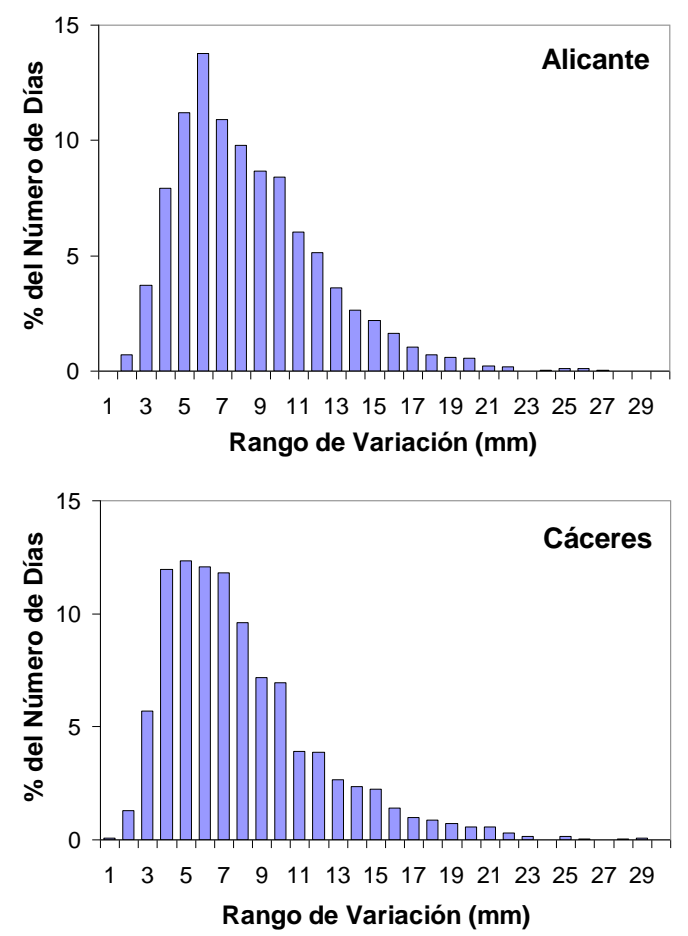
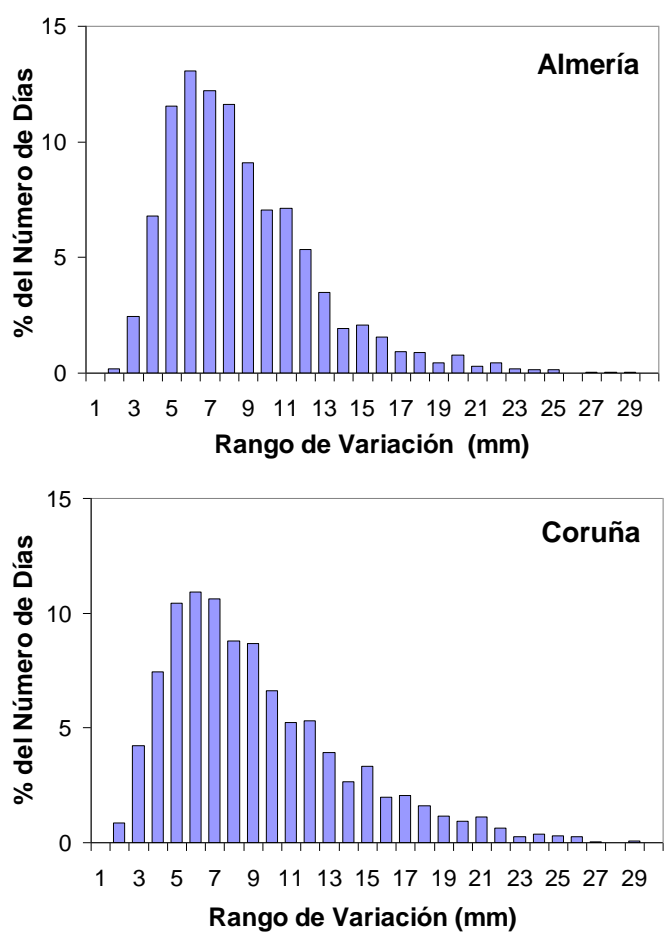

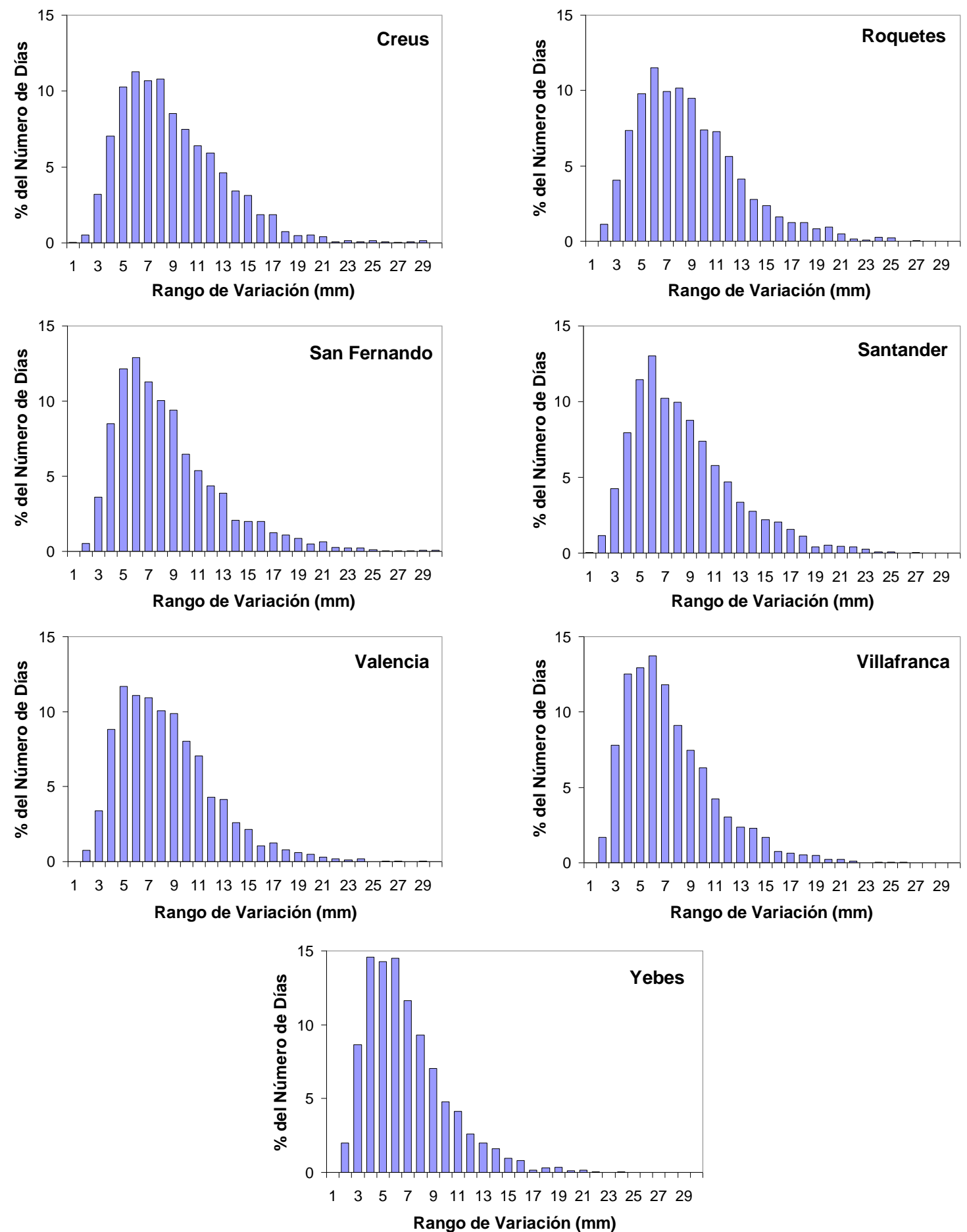

Figura 6.5 - Histogramas de frecuencias del rango de variación diaria del PWV para cada estación.

Para estudiar la distribución de los valores del rango de la variación diaria, estos se han agrupado en clases por intervalos de un milímetro de anchura; de 0 a $1 \mathrm{~mm}$, de 1 a $2 \mathrm{~mm}$, y así sucesivamente. Los histogramas de frecuencias de estas clases muestran un comportamiento muy similar para todas las estaciones (Figura 6.5).

La frecuencia incrementa rápidamente al aumentar el rango para valores bajos de este, hasta alcanzar la clase modal con unas frecuencias del 11 al 15\%. La clase modal se corresponde 
principalmente con el intervalo 5 a $6 \mathrm{~mm}$ ( 25 a $40 \%$ en términos relativos). Después de la clase modal la frecuencia disminuye lentamente, presentando la distribución una pronunciada asimétrica a derechas. Para rangos por encima de los 11 a $12 \mathrm{~mm}$ (variaciones del 60 al $70 \%$ ), la frecuencia cae por debajo del $5 \%$ para la mayoría de las estaciones. Coruña presenta las variaciones más altas con frecuencias superiores al 1\%. En esta estación la frecuencia cae por debajo del $1 \%$ a partir de un rango de 21 a $22 \mathrm{~mm}$. En el lado opuesto se encuentran Villafranca y Yebes, donde la frecuencia baja del $1 \%$ a partir de los $15-16 \mathrm{~mm}$, mientras que en la mayoría de las estaciones esto tiene lugar entre los 17 y $19 \mathrm{~mm}$. La frecuencia acumulada supera el $50 \%$ para rangos mayores de $7 \mathrm{~mm}$ en las estaciones costeras y de $6 \mathrm{~mm}$ en las del interior. En valores relativos, la mediana de la distribución se sitúa entre una variación del 35 al $40 \%$. De la misma manera se ha obtenido la distribución de frecuencias de la desviación estándar y del coeficiente de dispersión. En ellas, la moda se sitúa mayoritariamente en el intervalo $1-1.5 \mathrm{~mm}$ y 0.06-0.08, y la mediana en el intervalo $1.5-2 \mathrm{~mm}$ y 0.08-0.1 respectivamente. En general, la mediana se encuentra ligeramente a la derecha de la moda para todas las distribuciones.
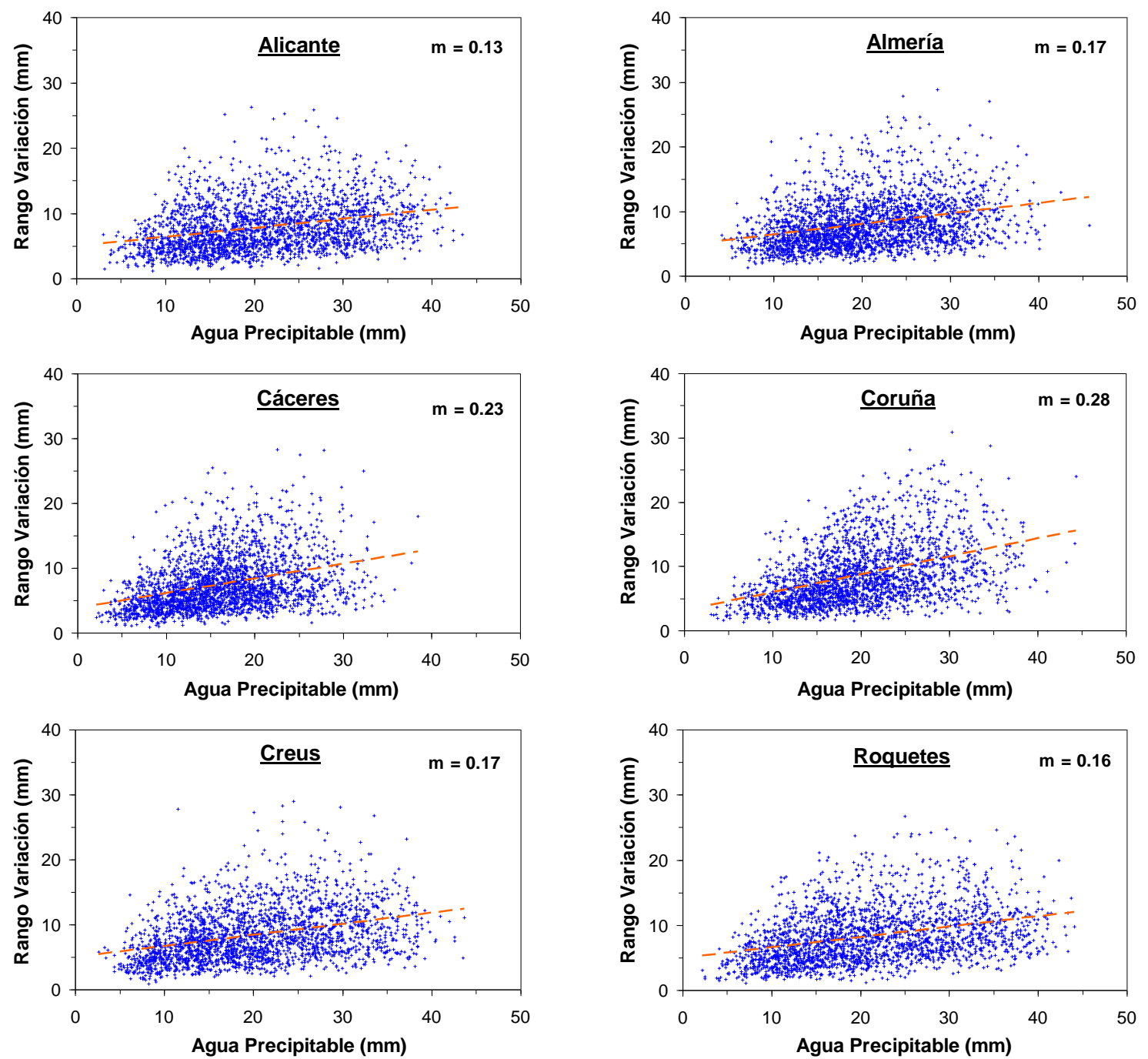

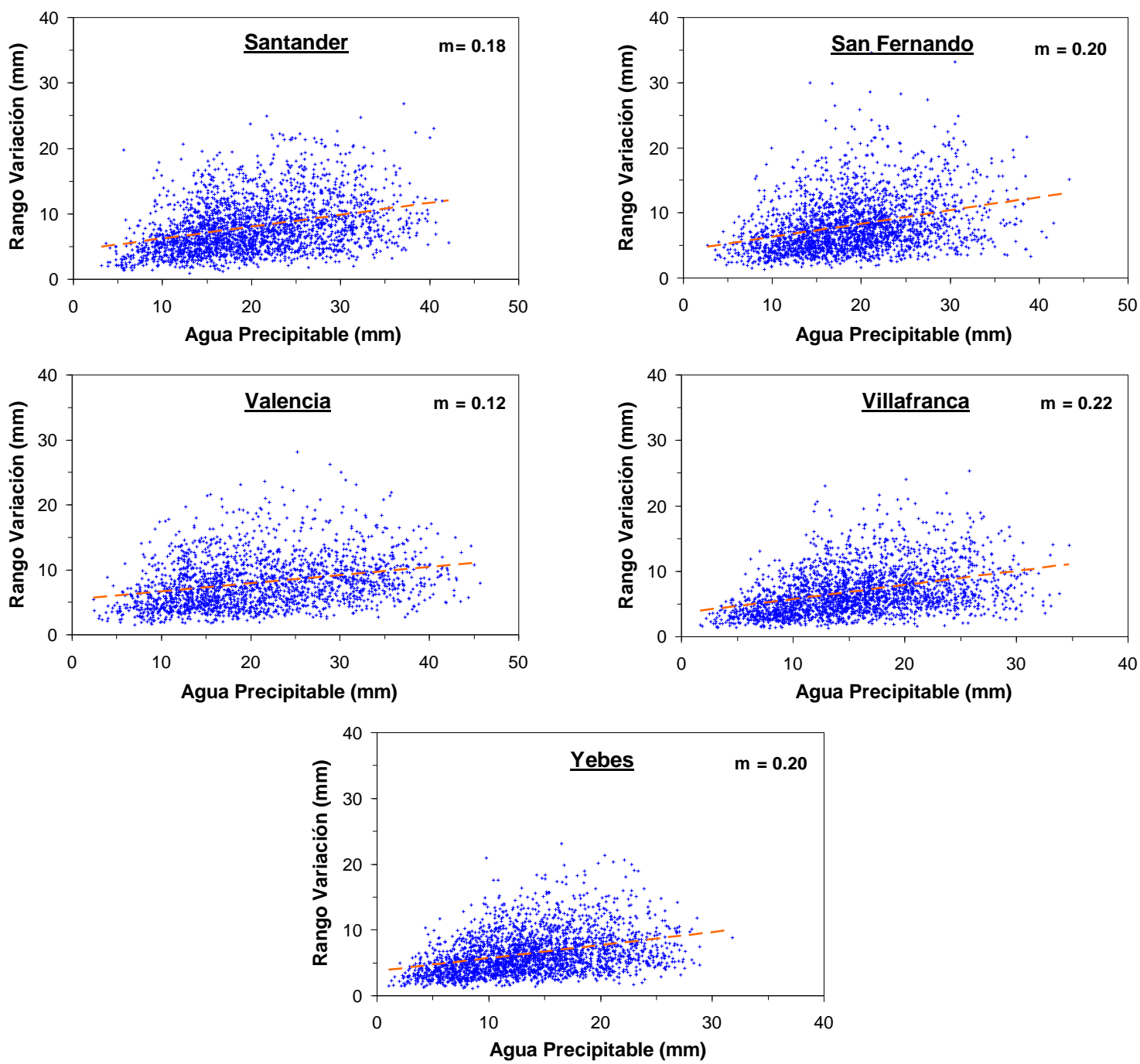

Figura 6.6 - Diagramas de dispersión del rango diario de variación frente a la media diaria del PWV. El valor de ' $m$ ' representa la pendiente de la recta de regresión (recta en trazos discontinuos).

En la Figura 6.6 se ha representado el rango diario de variación del PWV frente al valor medio del PWV. Para ninguna estación se ha encontrado una correlación significativa, sólo se observa una ligera tendencia a aumentar el rango cuando aumenta el PWV. El valor de la pendiente de la recta de regresión es muy similar para todas las estaciones, con la particularidad de que en las estaciones costeras (salvo en Coruña), y especialmente en las del arco mediterráneo, es donde la pendiente toma los valores más bajos.
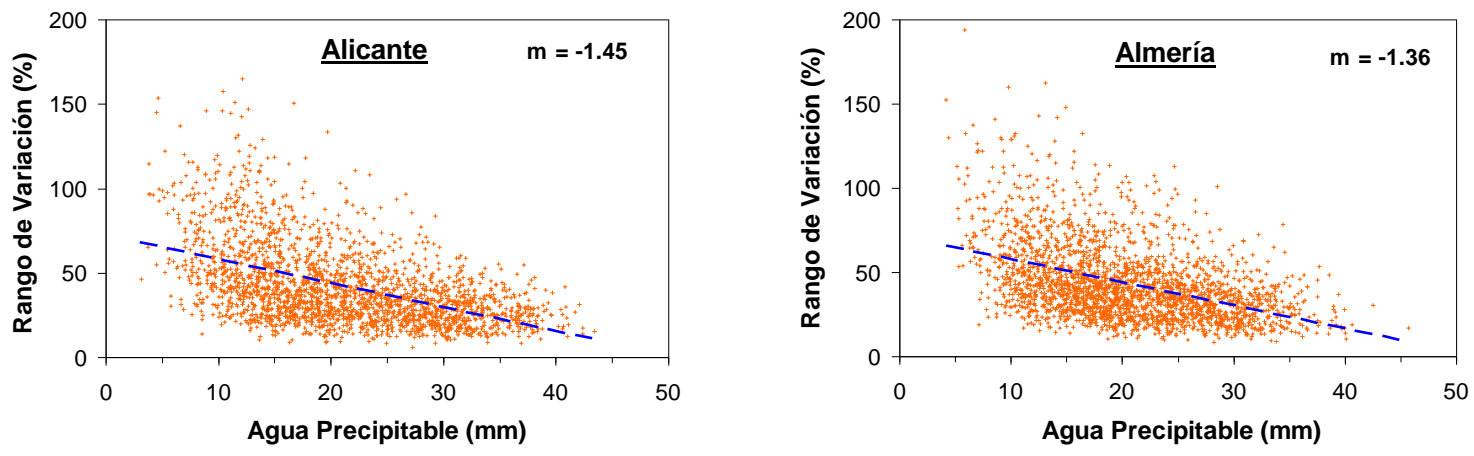

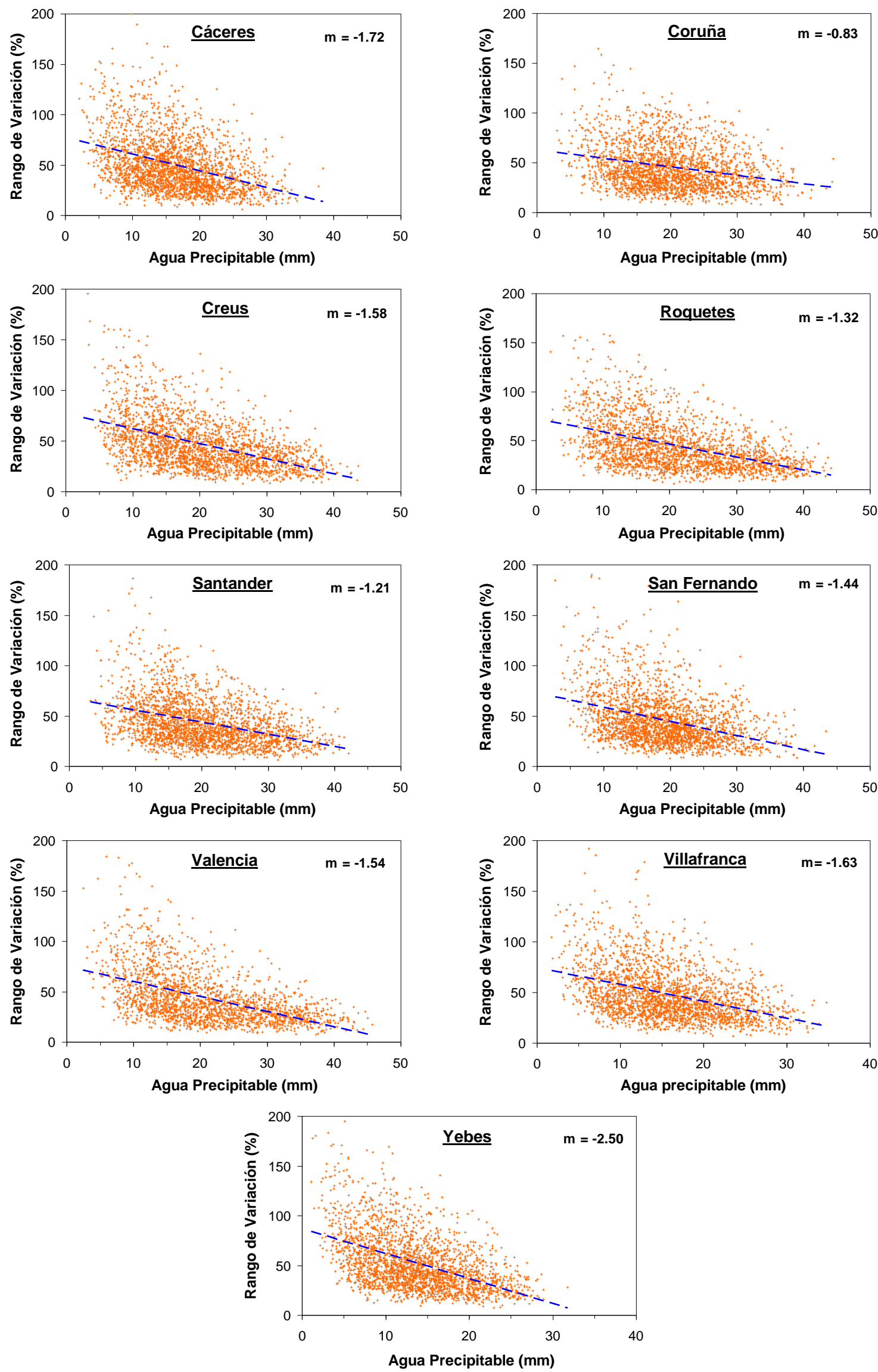

Figura 6.7 - Diagramas de dispersión del rango diario de variación en \% frente al valor medio del PWV. El valor de ' $m$ ' representa la pendiente de la recta de regresión (recta en trazos discontinuos). 
La Figura 6.7 es similar a la Figura 6.6, pero en este caso el rango de variación está expresado en valor relativo. En ella se observa como el rango tiende a disminuir con el aumento del PWV, siendo en las estaciones del interior donde esta tendencia es más pronunciada, aunque sólo de forma muy ligera.

\subsubsection{Variabilidad diaria media peninsular}

Unos valores medios para toda la Península de los estadísticos usados para caracterizar la variabilidad diaria se han obtenido promediando los de todos los emplazamientos disponibles.

La amplitud de la variación media diaria del PWV es de $7.84 \mathrm{~mm}$, un $46 \%$ sobre el valor medio del día, con una desviación típica de 2.26 mm, y con máximos mensuales de 17.31 mm (106\%) y mínimos de $3.02 \mathrm{~mm}(16 \%)$ (Tabla 6.5).

\begin{tabular}{|c|c|c|c|c|c|c|c|c|c|c|c|}
\hline \multicolumn{4}{|c|}{ MEDIA } & \multicolumn{4}{|c|}{ MEDIA DE LOS MÁXIMOS } & \multicolumn{4}{|c|}{ MEDIA DE LOS MÍNIMOS } \\
\hline $\begin{array}{c}\text { Rango } \\
(\mathrm{mm})\end{array}$ & $\begin{array}{c}\text { Rango } \\
\%\end{array}$ & $\begin{array}{l}\text { Desv. } \\
\text { Típica }\end{array}$ & $\begin{array}{l}\text { Coef. } \\
\text { Disper. }\end{array}$ & $\begin{array}{c}\text { Rango } \\
(\mathrm{mm})\end{array}$ & $\begin{array}{c}\text { Rango } \\
\%\end{array}$ & $\begin{array}{l}\text { Desv. } \\
\text { Típica }\end{array}$ & $\begin{array}{l}\text { Coef. } \\
\text { Disper. }\end{array}$ & $\begin{array}{c}\text { Rango } \\
\text { (mm) }\end{array}$ & $\begin{array}{c}\text { Rango } \\
\%\end{array}$ & $\begin{array}{l}\text { Desv. } \\
\text { Típica }\end{array}$ & $\begin{array}{l}\text { Coef. } \\
\text { Disper. }\end{array}$ \\
\hline 7.84 & 45.9 & 2.26 & 0.13 & 17.31 & 105.8 & 5.57 & 0.33 & 3.02 & 16.2 & 0.79 & 0.04 \\
\hline
\end{tabular}

Tabla 6.5 - Valores medios de los estadísticos usados para caracterizar la variabilidad diaria.

La variabilidad media en valor absoluto, es mínima en febrero, aumenta lentamente hasta agosto cuando alcanza su máximo, y posteriormente disminuye de manera más acusada hasta febrero, con la singularidad del mes de octubre cuando se produce un máximo relativo. Por el contrario, la variabilidad en valor relativo es máxima en enero y mínima entre junio y septiembre. La amplitud media del ciclo es $2.94 \mathrm{~mm}$, aproximadamente un $21 \%$ de variación entre el máximo y el mínimo. Para la desviación típica y el coeficiente de dispersión la amplitud del ciclo es de $0.86 \mathrm{~mm}$ y 0.06 respectivamente.

Respecto a la media de los máximos, de febrero a octubre la variabilidad incrementa lentamente, con la salvedad de septiembre donde se produce un pequeño descenso, para luego sufrir una caída brusca en noviembre, sólo ligeramente inferior a toda la subida experimentada de febrero a octubre. En términos relativos, la mayor variabilidad se da en enero y la mínima en julio. La amplitud del ciclo del rango es de $5.76 \mathrm{~mm}$ ( 53\%), de $2.04 \mathrm{~mm}$ para el de la desviación típica y de 0.15 para el del coeficiente de dispersión. Esta amplitud es mayor del doble que la de los valores medios.

Por su parte las medias de las mínimas describen un ciclo de una amplitud de $1.47 \mathrm{~mm} \mathrm{(} \mathrm{7 \% ),}$ con el valor mínimo en diciembre y el máximo en julio. 


\section{Valores medios}
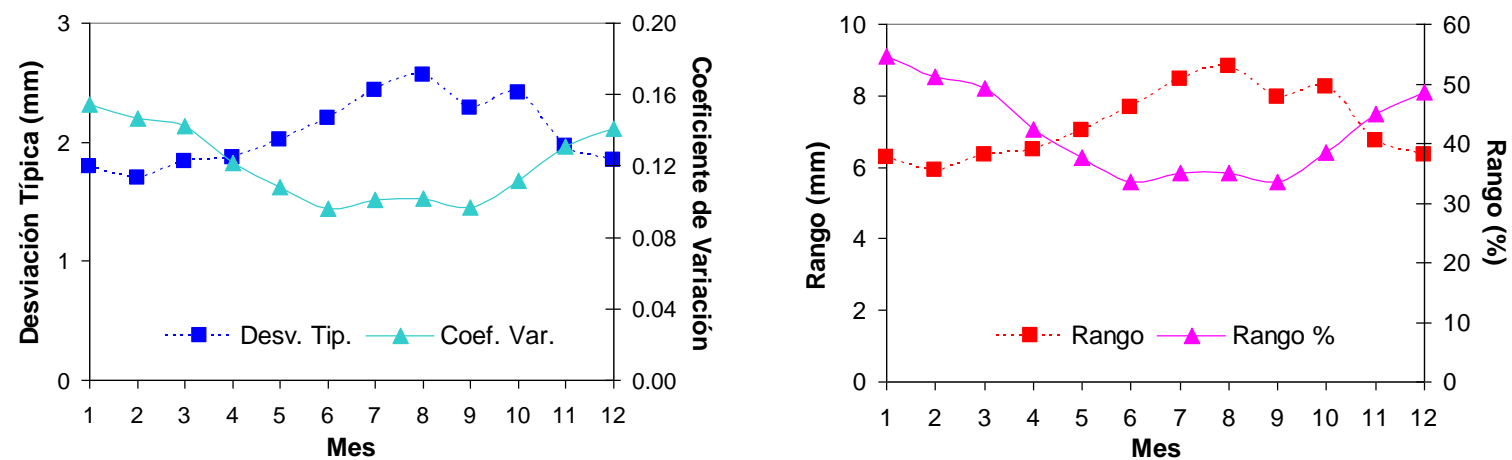

Medias de los valores máximos mensuales
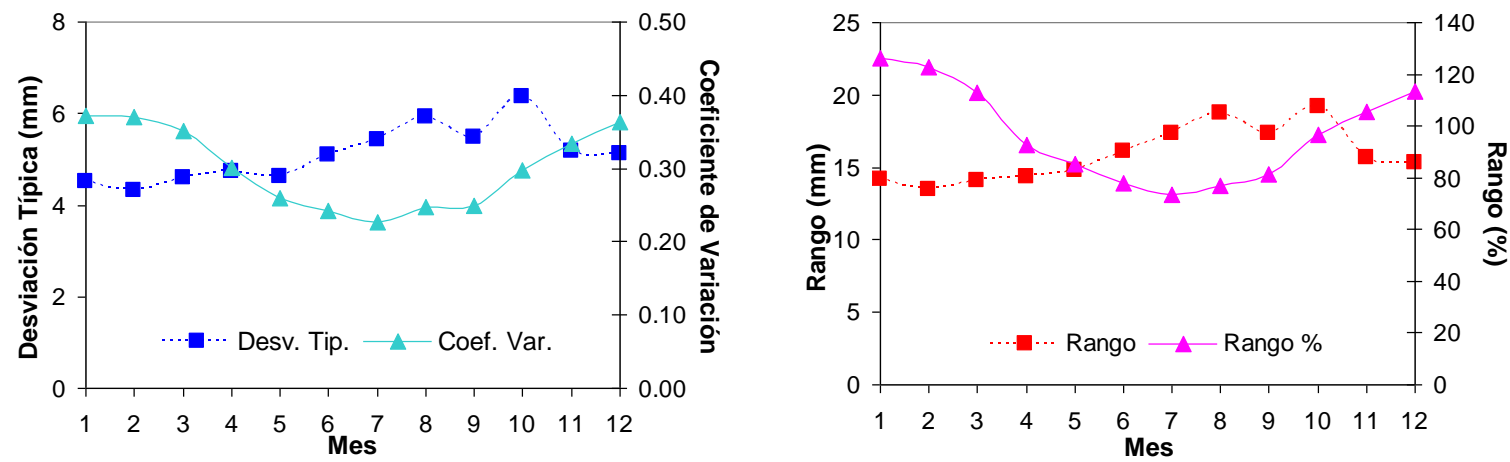

Medias de los valores mínimos mensuales
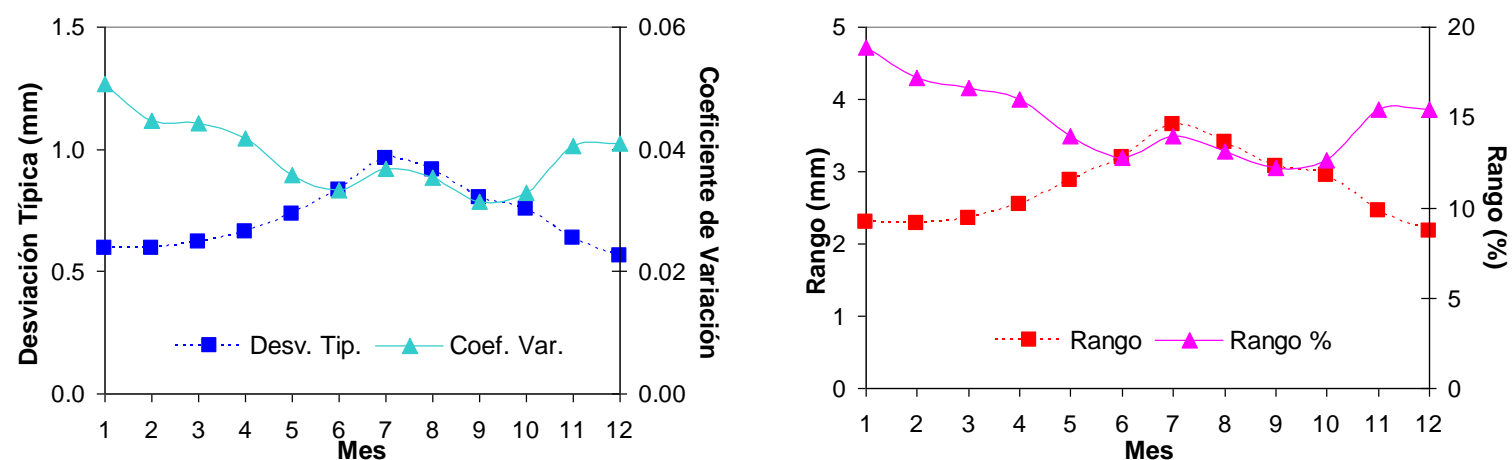

Figura 6.8 - Evolución anual media de la media, la media de los máximos y la media de los mínimos de los valores diarios de la desviación típica, el coeficiente de variación y el rango.

Para estudiar la distribución de frecuencias del rango de la variabilidad diaria para la Península se ha tratado de manera global el conjunto de datos de todas las estaciones, y se ha procedido igual que en el caso de estación a estación (Figura 6.9). La distribución de frecuencias del rango diario de variación presenta una pronunciada asimetría a derechas. La clase modal de la distribución es el intervalo 5-6 mm (25-30\%), mientras que la mediana es $7 \mathrm{~mm}$ (40\%). Eliminando las colas de la distribución, el $50 \%$ de los días la variación oscila aproximadamente entre 5 y $10 \mathrm{~mm}$ en términos absolutos (entre un 28 y un $57 \%$ en términos relativos), y para el $90 \%$ lo hace entre 3 y $16 \mathrm{~mm}$ (entre un 17 y un $96 \%$ ). 

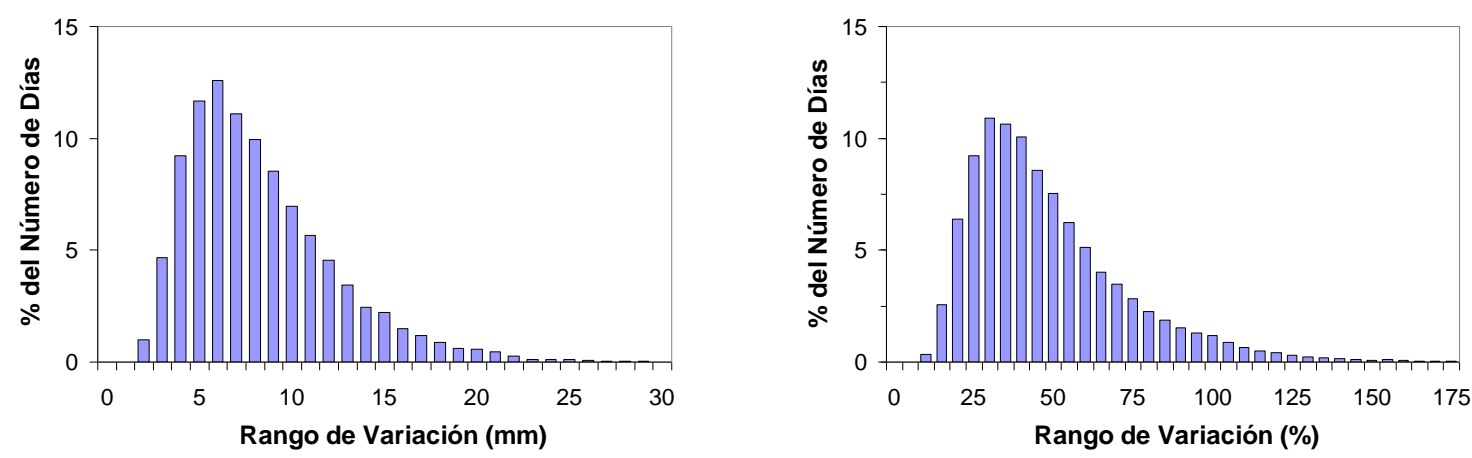

Figura 6.9 - Histogramas de frecuencias de la distribución del rango diario de variación del PWV en milímetros (izquierda) y en porcentaje respecto del valor medio diario (derecha).

El diagrama de dispersión del rango diario de variación frente al PWV (Figura 6.10) muestra como al incrementar el PWV se aprecia una ligera tendencia (líneas punteadas) a aumentar el rango de variación en valor absoluto, y a disminuir en términos de porcentaje, pero no existe una correlación definida entre ambas variables. También se observa cómo para valores bajos del contenido de vapor de agua la dispersión en el rango de variación es pequeña, mientras que para valores altos la nube de puntos se va abriendo presentando una mayor dispersión. En términos de porcentaje ocurre lo contrario, para valores bajos la nube de puntos presenta una gran dispersión, y conforme aumenta el contenido de vapor de agua tiende a converger.
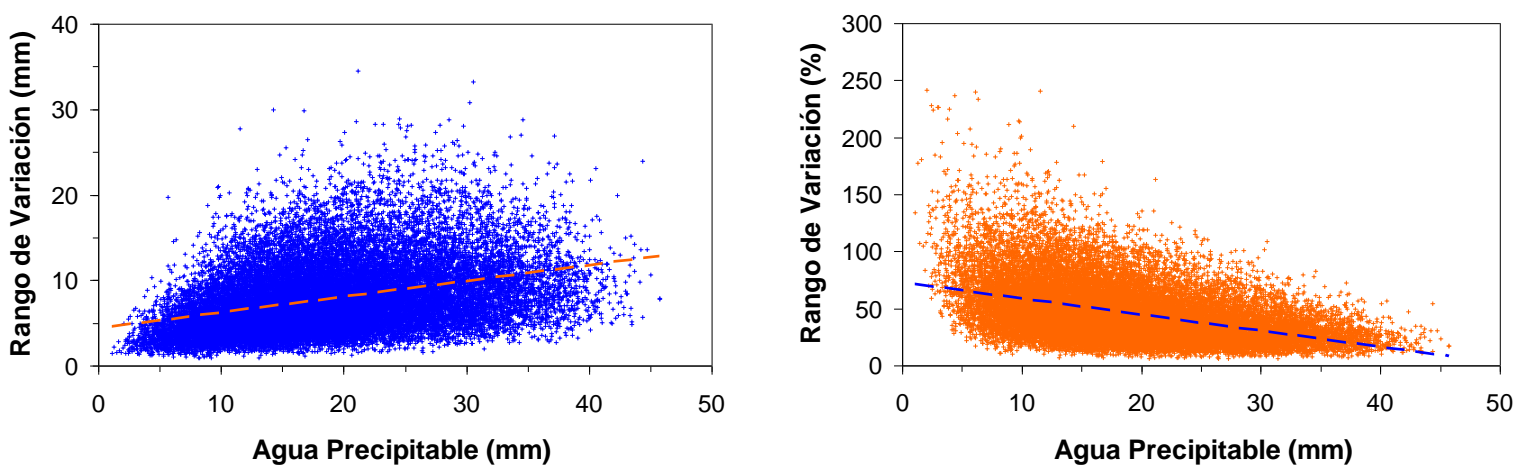

Figura 6.10 - Distribución del rango de variación diaria en valor absoluto (izquierda) y en porcentaje (derecha) frente al PWV. Las líneas punteadas representan la línea de tendencia de la nube de puntos.

La distribución estacional de la variabilidad diaria (Tabla 6.6) muestra como ésta crece del invierno al verano con el aumento del contenido medio de PWV, pero de una manera más suave que este, por lo que en términos de porcentaje el rango diario de la variación del PWV disminuye desde el $56 \%$ del invierno al $38 \%$ del verano.

Los histogramas de frecuencias del rango de variación estacional (Figura 6.11) presentan un máximo más pronunciado que en el conjunto global del año. La cola de la distribución es más corta en el invierno y la primavera que en el otoño y el verano. La mediana de la distribución queda a la derecha de la clase modal, y a la izquierda de la media para las cuatro estaciones. 


\begin{tabular}{|c|c|c|c|c|c|c|c|c|c|c|}
\hline & $\begin{array}{c}\text { Rango } \\
(\mathrm{mm})\end{array}$ & $\begin{array}{c}\text { Rango } \\
\%\end{array}$ & $\begin{array}{l}\text { Desv. } \\
\text { Típica } \\
\end{array}$ & $\begin{array}{c}\text { Coef. } \\
\text { Disper. }\end{array}$ & $\begin{array}{c}\text { Intervalo } \\
\text { Modal }\end{array}$ & Mediana & $\begin{array}{c}\text { Percentil } \\
5\end{array}$ & $\begin{array}{c}\text { Percentil } \\
25 \\
\end{array}$ & $\begin{array}{c}\text { I Percentil } \\
75 \\
\end{array}$ & $\begin{array}{c}\text { I Percentil } \\
95 \\
\end{array}$ \\
\hline Invierno & 6.71 & 56.0 & 1.94 & 0.16 & $4-5$ & 5.74 & 2.42 & 3.97 & 8.54 & 14.14 \\
\hline Primavera & 7.22 & 47.2 & 2.08 & 0.14 & $5-6$ & 6.52 & 3.00 & 4.74 & 9.02 & 13.80 \\
\hline Verano & 9.09 & 37.9 & 2.62 & 0.11 & $7-8$ & 8.31 & 3.84 & 6.09 & 11.23 & 17.04 \\
\hline Otoño & 8.30 & 42.5 & 2.41 & 0.12 & $5-6$ & 7.35 & 3.06 & 5.11 & 10.54 & 16.99 \\
\hline
\end{tabular}

Tabla 6.6 -Valores medios estacionales de la variabilidad diaria para toda la Península.

En invierno el $50 \%$ de los días presentan una variación entre 3.97 y $8.54 \mathrm{~mm}$, y el $90 \%$ entre $2.42 \mathrm{~mm}$ y $14.14 \mathrm{~mm}$, mientras que en verano estos intervalos aumentan a los $6.09-11.23 \mathrm{~mm}$, y los 3.84-17.04 $\mathrm{mm}$ respectivamente.
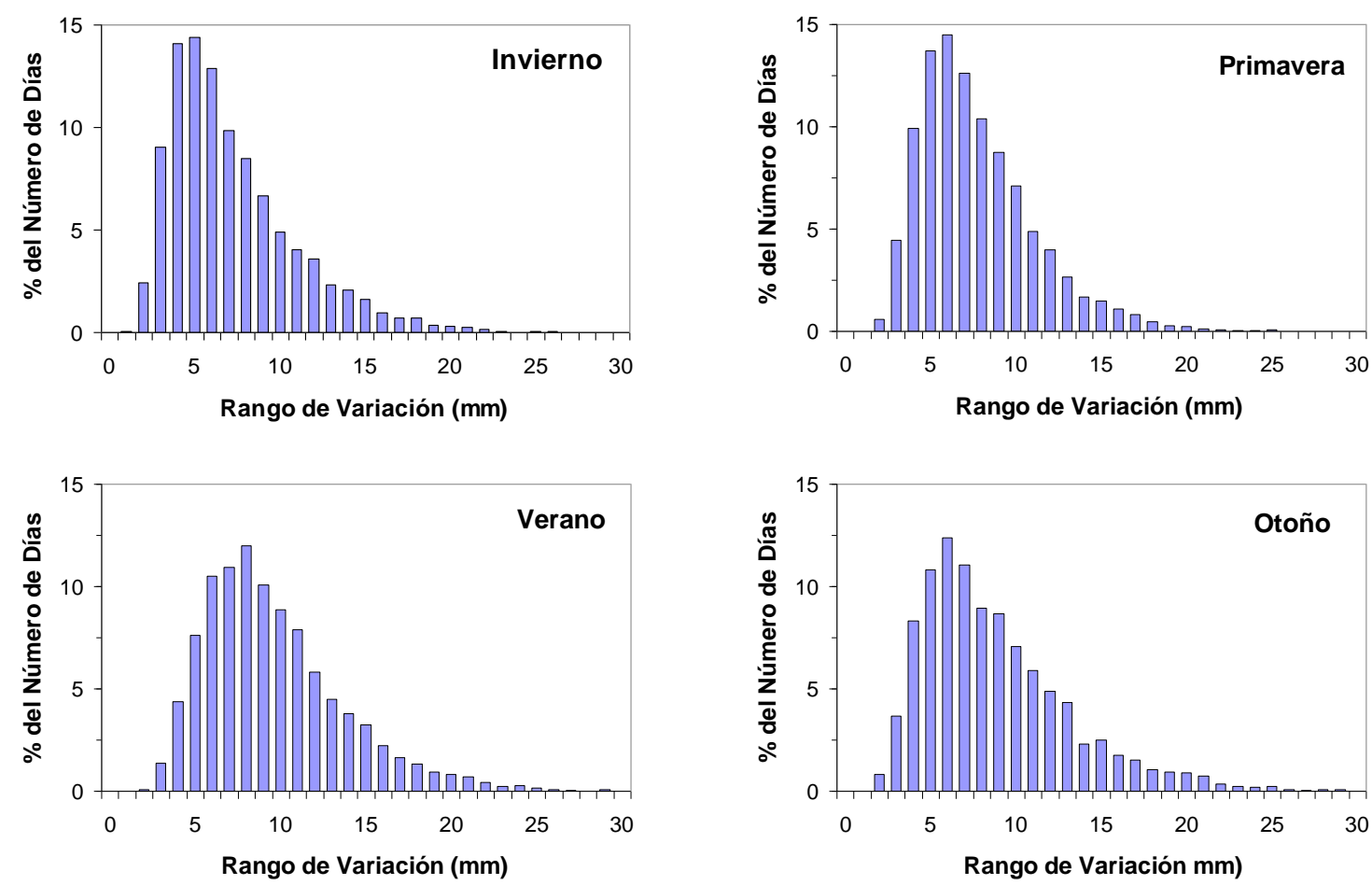

Figura 6.11 - Histogramas de frecuencias de la distribución estacional del rango diario de variación.

Los papeles entre las estaciones del año se intercambian en valores relativos del rango (Figura 6.12). El verano presenta una clase modal más pronunciada y una menor asimetría que el invierno. En verano el $90 \%$ de los valores del rango relativo se encuentran en el intervalo central entre el 16 y el $73 \%$, y el $50 \%$ lo hacen entre el 25 y el $47 \%$. Mientras que en invierno estos intervalos van del 20 al $114 \%$ y del 34 al $71 \%$ respectivamente.

Respecto a la relación entre el rango de la variabilidad y el PWV no se observa correlación significativa para ninguna de las cuatro estaciones. Solamente cabe destacar que la ligera tendencia al incremento de la variabilidad en valor absoluto (o disminución en valor relativo) con el aumento del PWV es más pronunciada en el invierno que en el verano. 

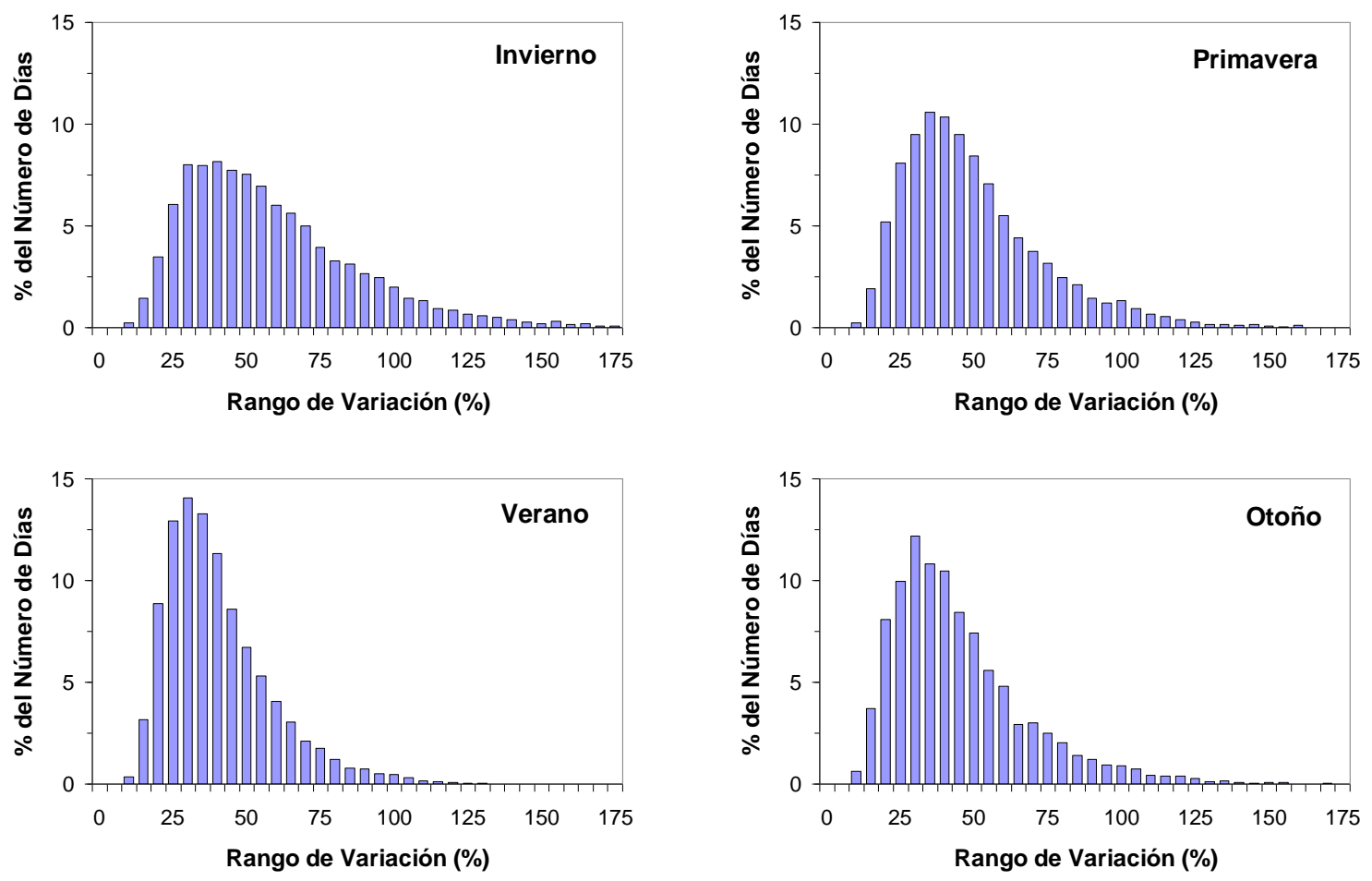

Figura 6.12 - Histogramas de frecuencias de la distribución estacional del rango diario de variación en \%.

\subsection{Variabilidad horaria}

Desde el año 2007 el IGS calcula el ZTD con una resolución temporal de cinco minutos para las estaciones de seguimiento de los satélites GPS. Sobre la Península hay cuatro de ellas: Roquetes, San Fernando, Villafranca, Yebes. La resolución temporal de estos datos permite analizar la variabilidad horaria del PWV. Esta también se podría estudiar a partir de los datos de los fotómetros, pero el número de datos por hora no es siempre constante sino que depende de la hora del día y de las condiciones meteorológicas, y sólo durante las horas de sol.

El procedimiento seguido para obtener la variabilidad horaria ha sido similar al empleado para estudiar la variabilidad diaria, utilizando los mismos estadísticos para caracterizarla. Los resultados obtenidos para los dos años de datos disponibles (2007/2008) muestran unos valores similares de la variabilidad horaria en todas las estaciones (Tabla 6.7). Las variables en valor absoluto (rango y desviación típica) toman valores más bajos en las estaciones del interior, y las expresadas en valor relativo (rango \% y coeficiente de dispersión) en las costeras.

\begin{tabular}{|c|c|c|c|c|c|c|c|c|c|c|}
\hline & $\begin{array}{l}\text { Rango } \\
(\mathrm{mm})\end{array}$ & $\begin{array}{c}\text { Rango } \\
\%\end{array}$ & $\begin{array}{l}\text { Desv. } \\
\text { Típica } \\
\end{array}$ & $\begin{array}{c}\text { Coef. } \\
\text { Disper. }\end{array}$ & $\begin{array}{c}\text { Intervalo } \\
\text { Modal }\end{array}$ & Mediana & $\begin{array}{c}\text { Percentil } \\
5 \\
\end{array}$ & $\begin{array}{c}\text { Percentil } \\
25 \\
\end{array}$ & $\begin{array}{c}\text { Percentil } \\
75 \\
\end{array}$ & $\begin{array}{c}\text { Percentil } \\
95 \\
\end{array}$ \\
\hline San Fernando & 0.67 & 4.62 & 0.22 & 0.02 & $0.25 / 0.375$ & 0.53 & 0.15 & 0.31 & 0.86 & 1.70 \\
\hline Roquetes & 0.76 & 4.70 & 0.25 & 0.02 & $0.375 / 0.50$ & 0.60 & 0.18 & 0.37 & 0.97 & 1.85 \\
\hline Villafranca & 0.62 & 5.51 & 0.20 & 0.02 & $0.25 / 0.375$ & 0.50 & 0.16 & 0.31 & 0.80 & 1.52 \\
\hline Yebes & 0.61 & 6.03 & 0.20 & 0.02 & $0.25 / 0.375$ & 0.49 & 0.16 & 0.31 & 0.77 & 1.46 \\
\hline
\end{tabular}

Tabla 6.7 - Valores medios de la variabilidad horaria. 
El valor medio del rango de la variación horaria se sitúa en $0.67 \mathrm{~mm}$, o aproximadamente un $5 \%$ sobre el valor medio de la hora. No obstante, se dan situaciones con cambios muy sustanciales en el PWV en muy poco tiempo. Así, se han llegado a registrar variaciones máximas de casi $10 \mathrm{~mm}$ o de un 190\% en una hora (Tabla 6.8). En el Capítulo 9 se verá un caso de estudio de estas situaciones. Las variaciones altas en porcentaje están asociadas a situaciones con muy bajo contenido de PWV, donde una pequeña variación en valor absoluto implica un porcentaje elevado en valor relativo. Por otro lado, las variaciones mínimas son prácticamente igual a cero.

\begin{tabular}{lrrrrrrrrr}
\hline & \multicolumn{3}{c}{ Variabilidad MÁXIMA } & \multicolumn{4}{c}{ Variabilidad MíNIMA } \\
& $\begin{array}{l}\text { Rango } \\
(\mathbf{m m})\end{array}$ & $\begin{array}{r}\text { Rango } \\
\%\end{array}$ & $\begin{array}{c}\text { Desv. } \\
\text { Típica }\end{array}$ & $\begin{array}{c}\text { Coef. } \\
\text { Disper. }\end{array}$ & $\begin{array}{c}\text { Rango } \\
(\mathbf{m m})\end{array}$ & $\begin{array}{c}\text { Rango } \\
\%\end{array}$ & $\begin{array}{c}\text { Desv. } \\
\text { Típica }\end{array}$ & $\begin{array}{c}\text { Coef. } \\
\text { Disper. }\end{array}$ \\
\hline San Fernando & 9.98 & 126.6 & 3.22 & 0.49 & 0.04 & 0.18 & 0.01 & 0.00 \\
Roquetes & 6.43 & 76.7 & 2.11 & 0.26 & 0.03 & 0.14 & 0.01 & 0.00 \\
Villafranca & 5.06 & 171.4 & 1.70 & 0.48 & 0.01 & 0.05 & 0.01 & 0.00 \\
Yebes & 5.52 & 190.5 & 1.80 & 0.57 & 0.03 & 0.14 & 0.01 & 0.00 \\
\hline
\end{tabular}

Tabla 6.8 - Valores máximos y mínimos registrados de la variabilidad horaria.
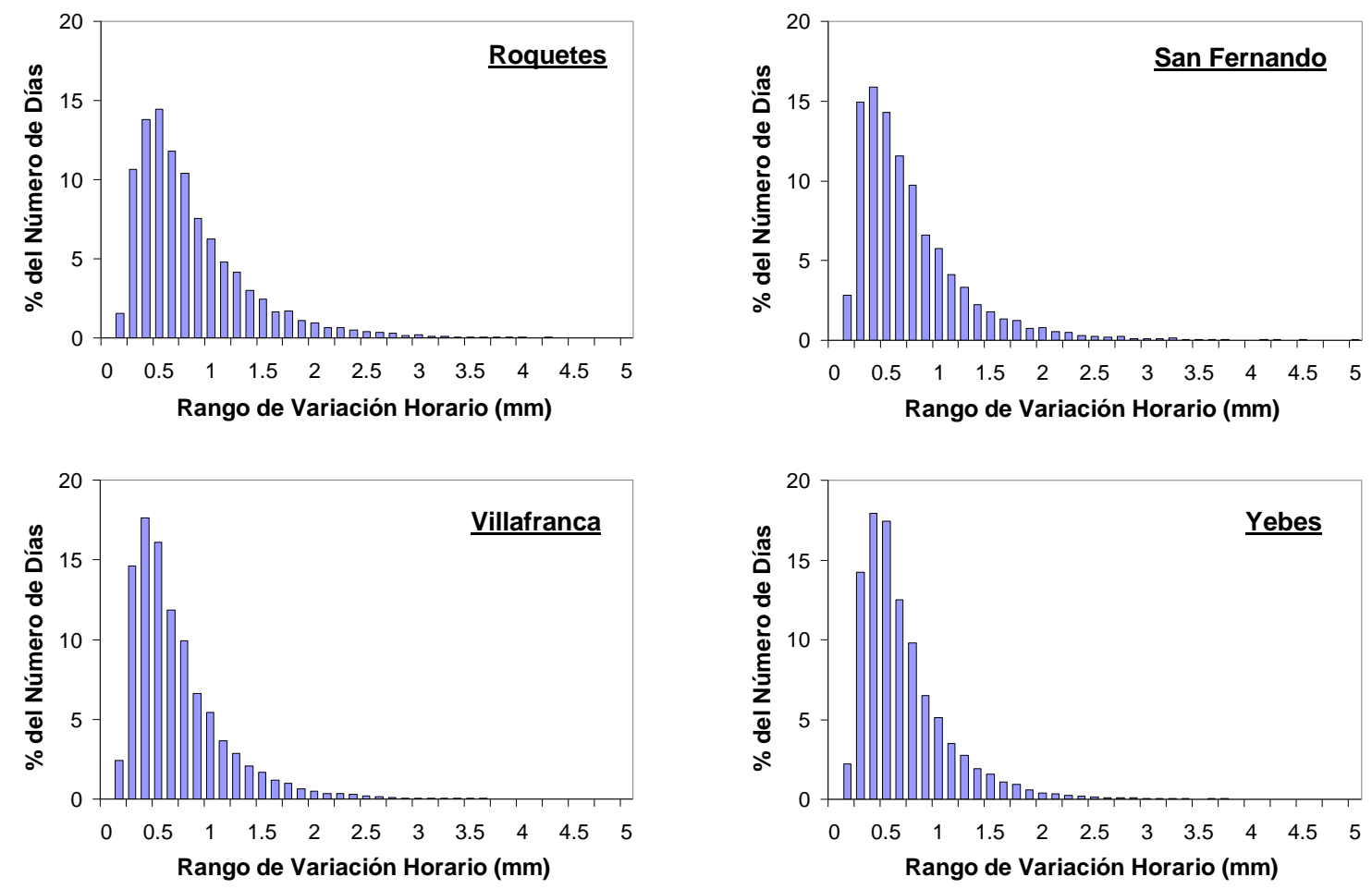

Figura 6.13 - Histogramas de frecuencias de la distribución del rango de variación horario del PWV.

La distribución de frecuencias es similar a la de la variabilidad diaria (Figura 6.13). La frecuencia aumenta muy rápidamente para valores bajos de la variabilidad hasta alcanzar su valor modal. A partir de ese valor la frecuencia disminuye muy lentamente, registrándose 
valores muy altos de la variabilidad aunque con baja frecuencia. Esto hace que la media de la distribución quede a la derecha de la mediana, que a su vez está a la derecha de la moda (Tabla 6.7). En término medio, el $50 \%$ de los datos del rango de variación se encuentra en el intervalo $0.33-0.85 \mathrm{~mm}$ alrededor de la mediana, y el 90\% lo hace en el intervalo 0.16-1.63 $\mathrm{mm}$. Estos límites se sitúan en el 2 al $6 \%$ y en el 1 al $14 \%$ respectivamente para el rango en valor relativo de porcentaje.

Al igual que ocurría con la variabilidad diaria, no se ha obtenido una correlación significativa entre la variabilidad horaria y el valor medio del PWV. La variabilidad se mueve en el mismo intervalo de valores para todos los posibles valores del PWV. Sólo para el caso de las variables en valor relativo (rango \% y coeficiente de dispersión), los valores muy altos de la variabilidad se dan sólo para valores bajos del PWV.
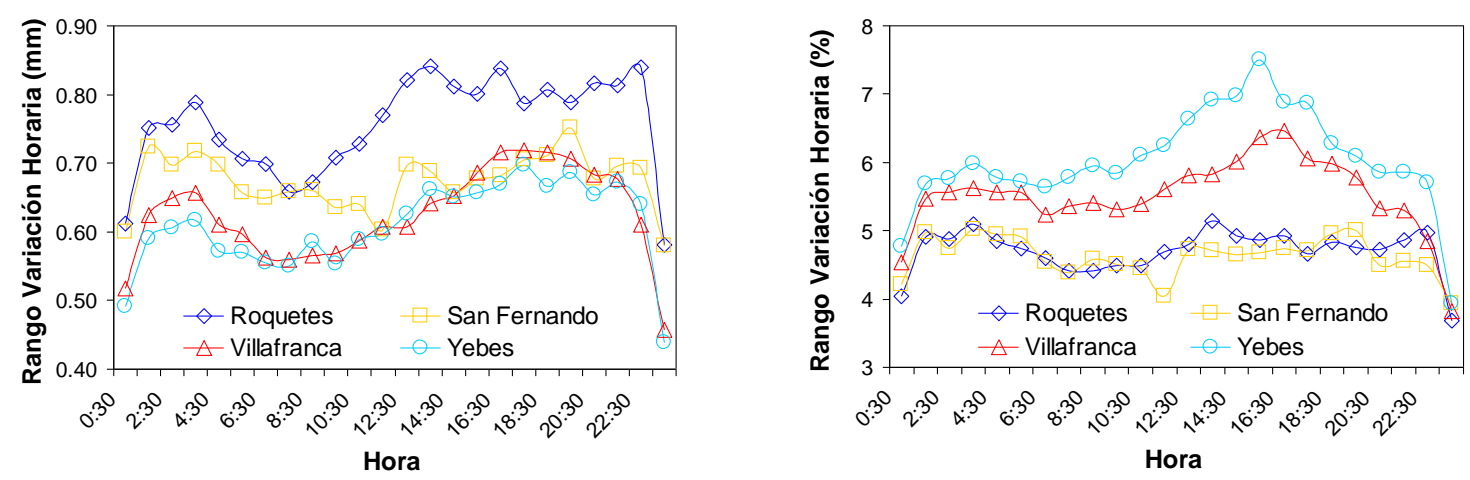

Figura 6.14 - Evolución diaria media del rango de la variación horaria del PWV en milímetros (izquierda) y en porcentaje respecto del valor medio de la hora (derecha).

A lo largo del día la variabilidad no presenta una clara tendencia (Figura 6.14). Sólo en las estaciones del interior se aprecia una tendencia a aumentar por la tarde. La amplitud media del ciclo es de $0.24 \mathrm{~mm}$, aproximadamente un $36 \%$ respecto de la variabilidad media horaria.
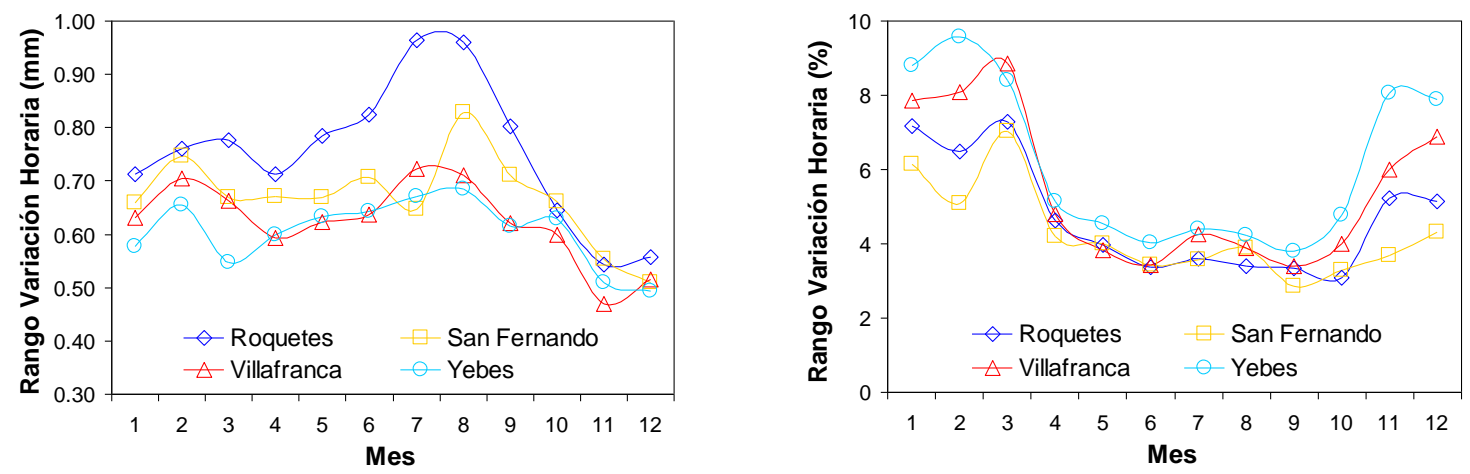

Figura 6.15 - Evolución anual media del rango de la variación horaria del PWV en milímetros (izquierda) y en porcentaje respecto del valor medio de la hora (derecha). 
A lo largo del año (Figura 6.15), la variabilidad absoluta sólo muestra una tendencia a tomar sus valores mínimos en noviembre, y un máximo en verano en las estaciones costeras. La amplitud media del ciclo es de $0.30 \mathrm{~mm}$, aproximadamente un $44 \%$ respecto de la variabilidad media horaria. En valores relativos el ciclo es más claro y más semejante entre estaciones, la variabilidad es mínima de abril a octubre, y máxima de noviembre a marzo. La diferencia media entre el valor máximo mensual y el mínimo es de un $5 \%$.

La desviación típica y el coeficiente de dispersión tienen el mismo comportamiento que el rango en valor absoluto y relativo respectivamente, tanto en su evolución diaria como anual. 
- 202 - 


\section{Capítulo 7}

\section{COMPARATIVA ENTRE TÉCNICAS}

En este capítulo se presenta una comparativa entre las medidas de PWV obtenidas con diferentes técnicas en aquellos emplazamientos en los que en ellos o en sus proximidades se dispone de más de un tipo de instrumentación. Por un lado, se han comparado los valores medios diarios y mensuales de las mismas series de datos utilizadas en la caracterización climatológica del Capítulo 3. El objetivo de esta comparación es conocer las desviaciones producidas en los resultado por la utilización de técnicas distintas para la medición del PWV, y así poder hacerlos comparables. Por otro lado, también se han comparado los pares de medidas instantáneas coincidentes en el tiempo. Esta otra comparación se ha realizado para valorar la calidad de las medidas proporcionadas por las distintas técnicas. Para esta comparativa se han utilizado sólo datos del año 2008, puesto que a lo largo de todo el periodo que abarca este estudio ha habido cambios en la instrumentación y/o en los algoritmos de procesamiento de las medidas, y se pretende comparar con las mismas condiciones instrumentales y con las últimas versiones de los algoritmos de cálculo.

A la hora de interpretar los resultados de las comparativas hay que tener en cuenta las siguientes consideraciones:

* Duración de cada medida. El dato de PWV de los sondeos no es una medida instantánea en el tiempo, sino el resultado de la integración de la humedad absoluta de las capas atmosféricas sondeadas durante el tiempo de vuelo del globo, que oscila entre hora y media y dos horas. No obstante, en la primera media hora tras el lanzamiento la sonda recorre las capas atmosféricas más bajas, donde se encuentra presente prácticamente la totalidad del PWV. Los datos proporcionados por los sondeos no se pueden considerar como una medida instantánea, pero en forma estricta tampoco como la media del PWV en un intervalo de tiempo, pues en cada instante la sonda explora una capa de atmósfera distinta. Por el contrario, las medidas de los fotómetros y de los GPS se pueden considerar instantáneas, si bien en el caso de estos últimos el algoritmo de cálculo utiliza los datos del tiempo de vuelo de las señales de los satélites GPS de las doce horas anteriores.

* La frecuencia de muestreo. Este factor es sólo importante cuando se comparan medias diarias o mensuales. Lo normal es que de los sondeos sólo se disponga de dos datos al 
día, de los receptores GPS uno cada hora, y en el caso de los fotómetros la frecuencia no es uniforme, variando de dos a treinta minutos entre el orto y el ocaso siempre que las condiciones meteorológicas sean favorables. La baja frecuencia de los lanzamientos de los sondeos no es suficiente para reflejar la alta variabilidad temporal del PWV (Capítulo 6). Por ello, la media diaria puede mostrar importantes discrepancias con la real en los días con grandes variaciones del PWV en poco tiempo, como ocurre al paso de sistemas frontales (Capítulo 9). Además, las medias diarias de los sondeos y las de los fotómetros pueden presentar un ligero sesgo debido al propio ciclo diurno del PWV (Capítulo 5).

* La capa atmosférica muestreada. Las medidas no se toman a lo largo del mismo camino atmosférico para las tres técnicas: los fotómetros miden apuntando al Sol, los receptores GPS a los satélites de la constelación GPS, y los sondeos según la trayectoria descrita por el globo en su ascensión, la cual dependerá de los vientos reinantes a cada altura, que generalmente no coincide con la vertical.

* El emplazamiento de la instrumentación. Para una misma localización, los emplazamientos de las estaciones de radiosondeo, GPS, o fotométricas no se encuentran exactamente a la misma altitud.

* Los cambios en la instrumentación y los algoritmos de cálculo a lo largo del periodo de comparación. Como se verá en el Capítulo 8, el algoritmo de procesamiento de los datos de los GPS experimentó en noviembre del año 2006 una modificación que apunta a una mejora en la precisión de los mismos. Los fotómetros solares son recalibrados regularmente y sus filtros sustituidos al sufrir una degradación con el paso del tiempo. También el modelo de los sensores de humedad de los sondeos ha cambiado durante el periodo de estudio, el modelo RS92-KL utilizado en la red de estaciones de AEMET fue reemplazado por el RS92-SGP durante el año 2005 (2006 en la estaciones de Coruña y Santander).

* Las limitaciones y los errores inherentes de cada una de las técnicas empleadas. Ejemplo de esto es la contaminación de las medidas de los fotómetros por la presencia de nubosidad, aún cuando se someten a un proceso de cloud-screening, o el sesgo día-noche que presentan algunas sondas debido al calentamiento del propio sensor por la radiación solar (Capítulo 8).

El capítulo se ha organizado en tres apartados: comparativa sondeos-GPS, comparativa sondeos-fotómetros, y comparativa GPS-fotómetros. Dentro de cada apartado se presentan los resultados de la comparación entre las medidas instantáneas, entre las medias diarias y entre las mensuales. 
Para caracterizar las comparativas se ha utilizado: el sesgo (bias), el error cuadrático medio (rmse), la media de los valores absolutos de las diferencias (mae), la desviación típica (std), la media de las diferencias relativas en valor absoluto $(r m d a)$ y el coeficiente de correlación $\left(R^{2}\right)$. La formulación de todos estos parámetros se recoge en el Anexo II.

\subsection{Comparativa Sondeos - GPS}

Se dispone de cinco ubicaciones con estación de radiosondeo y receptor GPS: Coruña, Santander, Madrid, Zaragoza y Lisboa. Con la excepción de Zaragoza, donde el GPS comenzó a funcionar en junio del 2006, para los otros cuatro emplazamientos la serie común de datos de ambos instrumentos abarca todo el periodo de estudio.

\subsubsection{Comparativa medidas instantáneas}

Las primeras capas que atraviesan los globos sonda son las que más contribuyen al contenido total de PWV. Así, la medida de PWV registrada durante los primeros treinta minutos de vuelo de la sonda difiere muy poco de la final. Además, es en la capa junto al suelo donde el PWV cambia más rápidamente. De esta manera, el PWV total registrado durante el vuelo de la sonda se asemejará más al del instante del lanzamiento del globo sonda. En base a ello, a la hora de comparar las medidas de los sondeos con las de los GPS, cada medida de radiosondeo se ha emparejado con la medida GPS de la hora del lanzamiento del globo sonda, que es treinta minutos antes de la hora nominal del mismo. Como se ha visto en el Capítulo 6, el rango medio de la variación del PWV en una hora es de $0.67 \mathrm{~mm}$ (aprox. 5\%), si bien se han registrado variaciones de hasta $10 \mathrm{~mm}$. En base a estos resultados y considerando una variación lineal del PWV en esas escalas de tiempo, se podría establecer el valor de $0.34 \mathrm{~mm}$ para la discrepancia media máxima debida a la distinta duración de ambas medidas.

Emparejando los datos de la manera anteriormente expuesta se han obtenido del orden de 700 pares de datos para los emplazamientos de Madrid y Coruña, 577 para Santander, y sólo 400 para Zaragoza. La estación de Lisboa presenta numerosas lagunas durante el año 2008 por lo que se ha excluido de esta comparativa.

El histograma de frecuencias de las diferencias de los pares de datos sondeo-GPS (Figura 7.1) muestra una distribución compatible con una normal, excepto para Zaragoza. La clase modal, la media, y la mediana prácticamente coinciden. En Santander y Coruña la clase modal está centrada, es la clase 0 (de -0.25 a $+0.25 \mathrm{~mm}$ ), mientras que en Madrid y Zaragoza está desplazada hacia la derecha, siendo el desplazamiento mayor en esta última estación donde además la clase modal es más pronunciada. Aproximadamente el $95 \%$ de los datos se encuentran comprendidos en el intervalo de la media más/menos dos veces la desviación típica de la distribución, y el $99 \%$ en el intervalo de la media más/menos tres veces la desviación típica. 

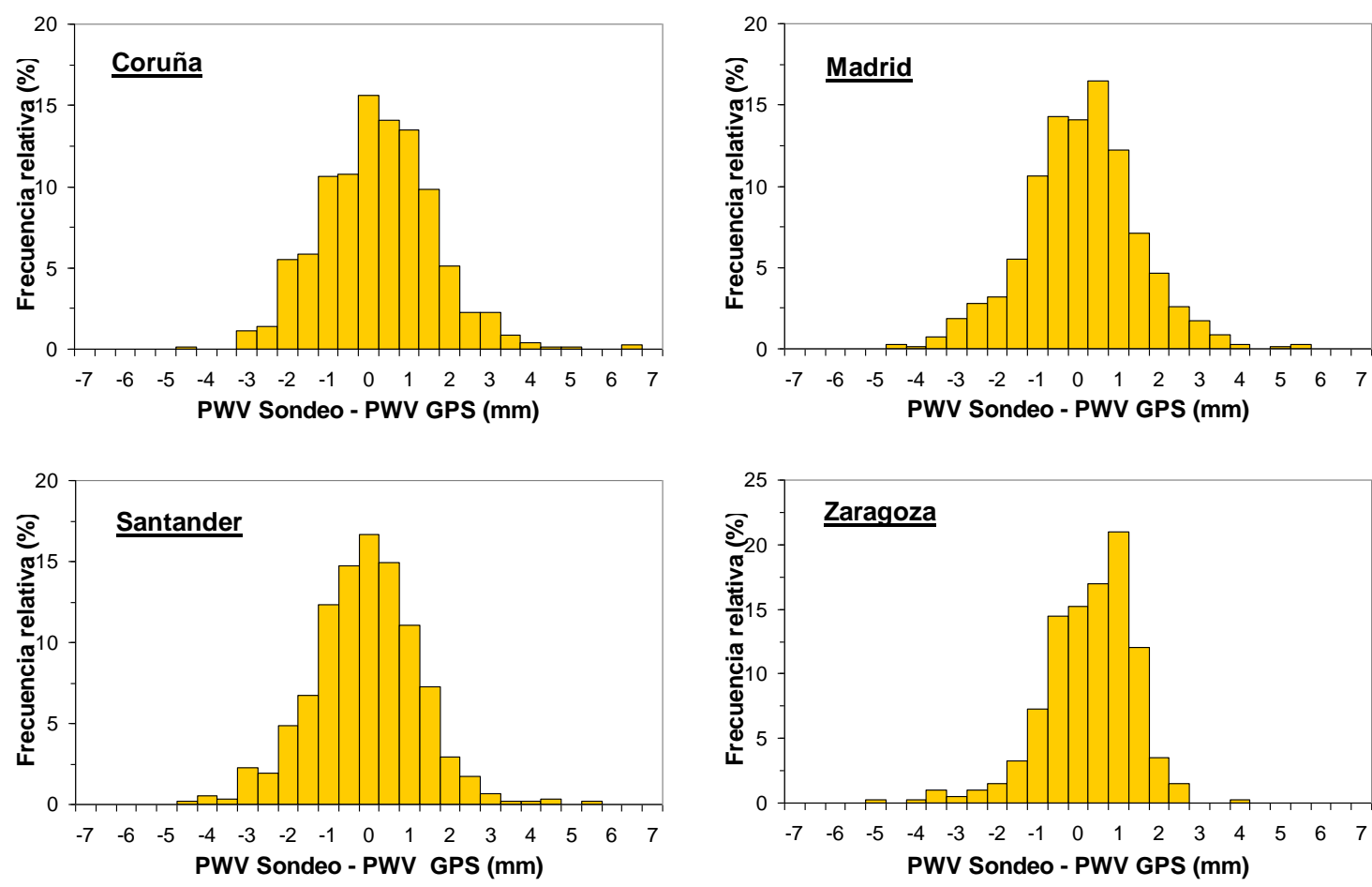

Figura 7.1 - Histograma de frecuencias de las diferencias entre el PWV del sondeo y del GPS. Para obtener estos histogramas los valores de las diferencias se han agrupado en clases por intervalos de 0.5 $\mathrm{mm}$ de amplitud centrados en la marca de clase.

De los resultados de la comparativa (Tabla 7.1) se desprende que la correlación es muy alta, con un coeficiente $\mathrm{R}^{2}$ de 0.95 en el peor de los casos. Las bias se pueden considerar despreciables, inferiores siempre al medio milímetro, por lo que se puede afirmar que no existe un sesgo o error sistemático en una de las técnicas respecto de la otra. El rmse está entre $1.1 \mathrm{y}$ $1.4 \mathrm{~mm}$, el mae supera sólo ligeramente el milímetro, y el rmda oscila entre un 6 y $9 \%$. El rmse y el std prácticamente coinciden al ser las bias despreciables. Estos valores de la dispersión son compatibles con las limitaciones propias de cada técnica mencionadas anteriormente.

\begin{tabular}{lccccccccc}
\hline Estación & $\begin{array}{c}\text { PWV } \\
\text { Sondeo }\end{array}$ & $\begin{array}{c}\text { PWV } \\
\text { GPS }\end{array}$ & BIAS & RMSE & MAE & STD & $\begin{array}{c}\text { RMDA } \\
\%\end{array}$ & R $^{2}$ & $\begin{array}{c}\text { № } \\
\text { Datos }\end{array}$ \\
\hline Coruña & 18.86 & 18.63 & 0.23 & 1.41 & 1.10 & 1.39 & 6.57 & 0.96 & 704 \\
Madrid & 14.42 & 14.33 & 0.09 & 1.42 & 1.09 & 1.41 & 8.63 & 0.95 & 687 \\
Santander & 19.69 & 19.77 & -0.08 & 1.31 & 1.01 & 1.31 & 5.50 & 0.97 & 577 \\
Zaragoza & 14.88 & 14.61 & 0.27 & 1.16 & 0.91 & 1.12 & 7.25 & 0.97 & 400 \\
\hline
\end{tabular}

Tabla 7.1 - Estadísticos de la comparativa de los pares de medidas Sondeo-GPS del año 2008.

En la bibliografía se encuentran muchos resultados de comparativas entre datos de GPS y de sondeos, aunque la mayoría están realizados sobre campañas o cortos periodos de tiempo. En ellos, el rmse suele oscilar entre 1 y 2 mm (Elgered et al. 1997; Emardson et al. 1998; Li et al. 2003; Ohtani \& Naito 2000; Wang et al. 2007; Wang y Zhang 2008; Schneider et al. 2009). Los resultados obtenidos en este estudio son comparables con los de la bibliografía. 

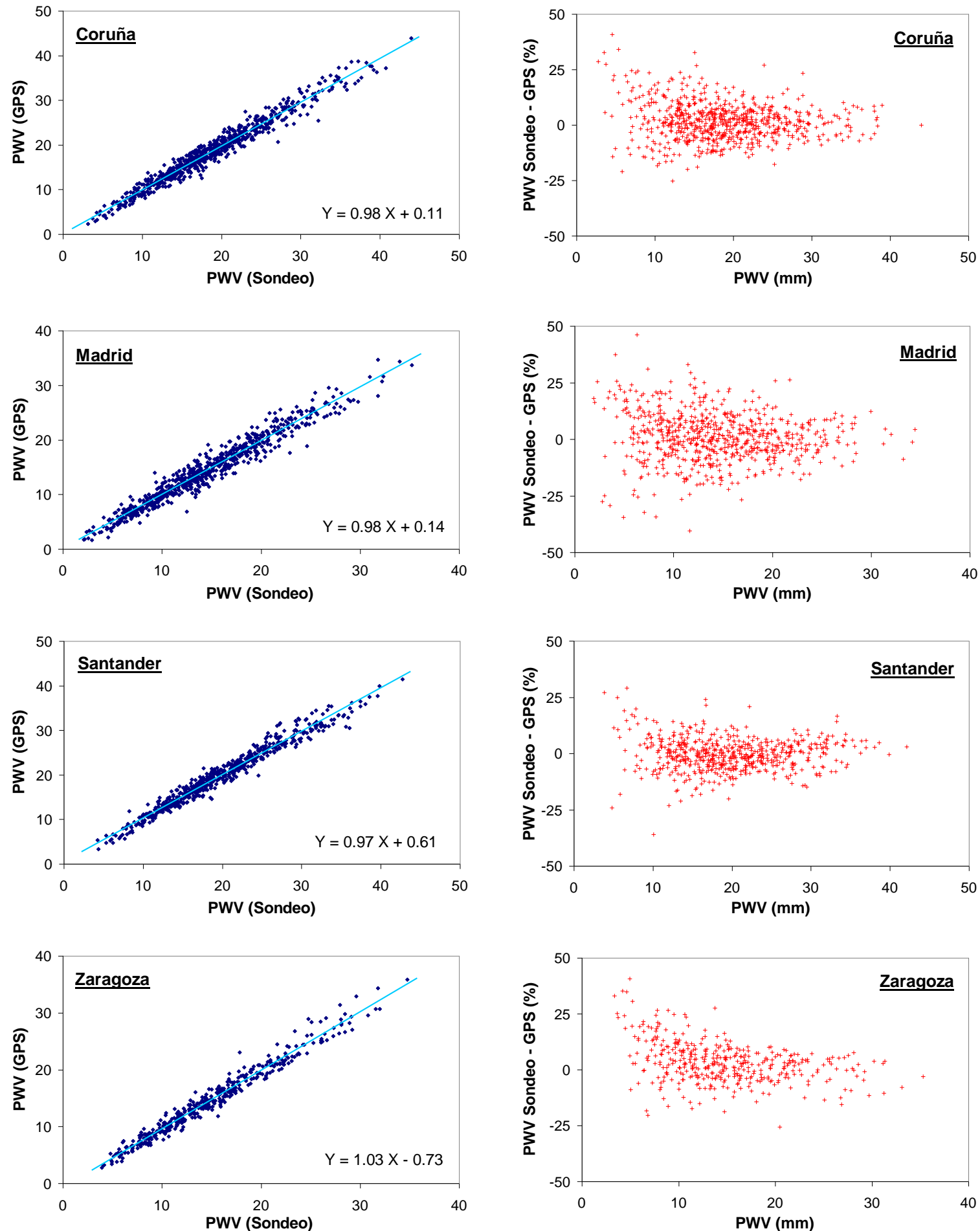

Figura 7.2 - Comparativa entre los pares de medidas Sondeo-GPS del año 2008. Las gráficas de la izquierda representan la nube de pares de puntos junto con la recta de regresión del ajuste por mínimos cuadrados. Las gráficas de la derecha representan la distribución de las diferencias de los pares de valores Sondeo-GPS, expresadas en términos relativos de porcentaje respecto del valor medio de PWV, frente al valor medio de PWV, calculado como la media aritmética del dato del sondeo y del GPS.

La representación gráfica de la nube de pares de puntos Sondeo-GPS (Figura 7.2) muestra como estos se distribuyen bastante uniformemente a lo largo de la recta de regresión, quedando prácticamente todos ellos comprendidos entre dos rectas paralelas distanciadas de 
la recta de regresión dos veces el valor del rmse. La dispersión de la nube de puntos es similar en todos los emplazamientos, como así lo recogen los estadísticos de la Tabla 7.1, no apreciándose ninguna tendencia significativa en la misma al aumentar o disminuir el PWV. Sin embargo, si se representa la diferencia entre el PWV del sondeo y del GPS frente al valor medio del PWV de las dos técnicas, se observa una ligera tendencia al incremento de las diferencias en valor absoluto al aumentar el PWV, del orden de $0.3 \mathrm{~mm}$ por cada $10 \mathrm{~mm}$ de aumento en el PWV. En valor relativo las diferencias tienden a ser mayores para los valores bajos del PWV, como recogen las gráficas de la derecha de la Figura 7.2, creciendo de manera exponencial para valores muy pequeños del PWV. Esto marca un límite inferior al contenido de PWV por debajo del cual la precisión de al menos una de las técnicas empleadas es muy pobre. Este límite se puede estimar en unos $5 \mathrm{~mm}$.

En valores relativos la estación de Madrid presenta la mayor dispersión. Así, el $50 \%$ de los datos se encuentra en el intervalo $(-5 \%, 8 \%)$ y el $90 \%$ en el intervalo $(-17 \%, 20 \%)$, mientras que en el otro extremo se sitúa Santander donde estos intervalos son $(-5 \%, 4 \%)$ y $(-11 \%, 11 \%)$ respectivamente. En general se aprecia una tendencia, más pronunciada en Zaragoza, hacia diferencias positivas (mayor valor del sondeo que del GPS) para valores bajos del PWV.
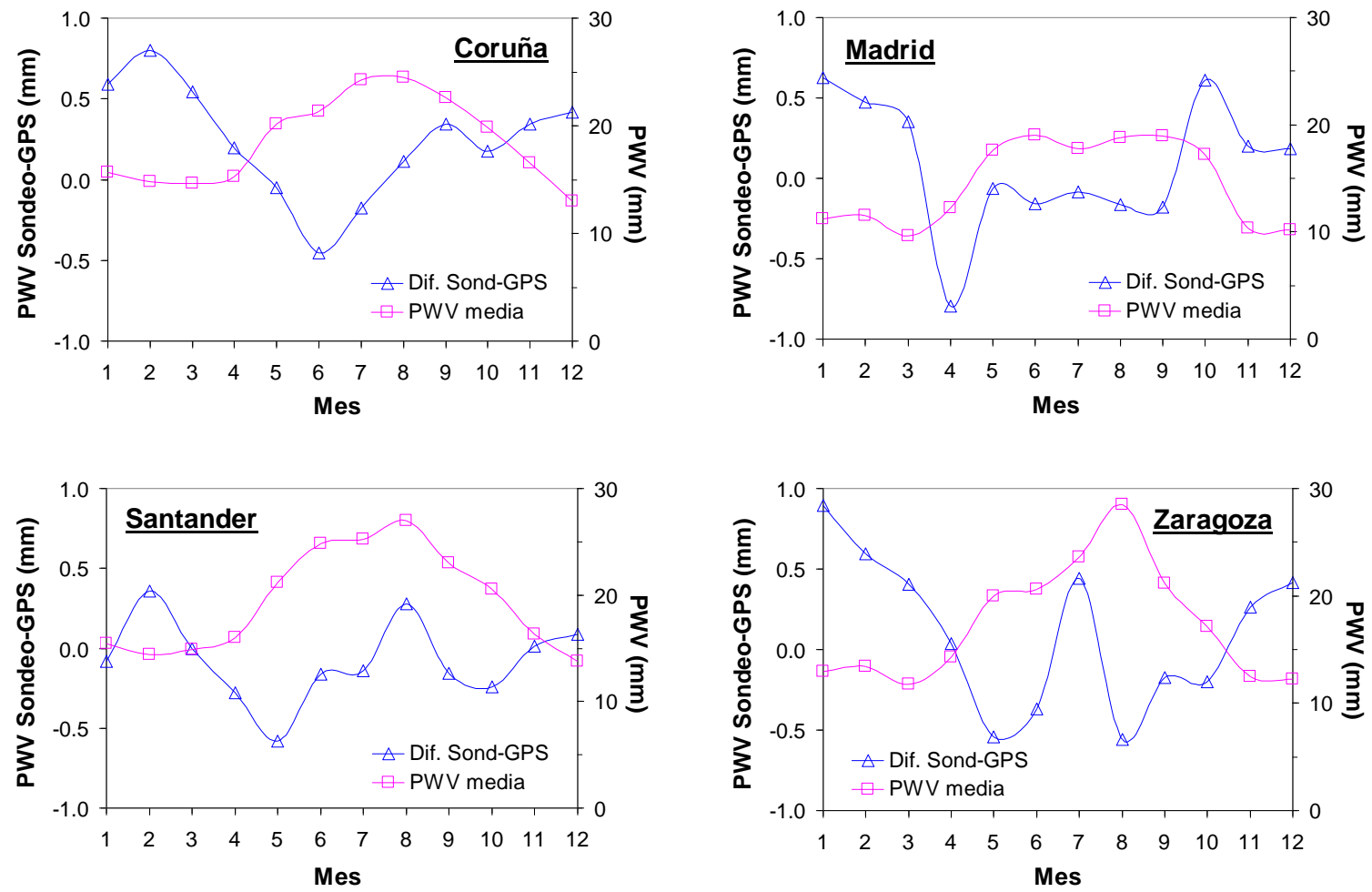

Figura 7.3 - Valores medios mensuales de las diferencias entre el PWV del sondeo y del GPS.

Si se representan las medias mensuales de las diferencias entre los pares de datos (Figura 7.3), no se aprecia un patrón claro de comportamiento a lo largo del año común a todos los emplazamientos. 


\subsubsection{Comparativa medias diarias}

Como se ha comentado anteriormente, en esta comparativa se han utilizado las series de datos completas, desde el año 2002 al 2008. La Figura 7.4 muestra el histograma de frecuencias de las diferencias entre el PWV medio diario del sondeo y del GPS. La distribución es bastante simétrica en casi todas las estaciones, con valores de la media, la mediana y la moda muy próximos entre sí. El $50 \%$ de las diferencias se localizan aproximadamente entre -4 y $0 \mathrm{~mm}$, y el $90 \%$ entre -7 y $3 \mathrm{~mm}$, excepto en Zaragoza que lo hacen entre -1.6 y $1.5 \mathrm{~mm}$ y -4 y $4 \mathrm{~mm}$ respectivamente. La clase modal y la mediana se encuentran desplazadas hacia la izquierda entre 1 y $2 \mathrm{~mm}$, excepto en Zaragoza donde están centradas. El motivo de este desplazamiento hay que buscarlo en el sesgo húmedo que presenta los datos GPS anteriores al 6 de noviembre del 2006 (Capítulo 8). Como la estación GPS de Zaragoza empezó a funcionar en junio del 2006 son pocos los datos afectados por este problema.
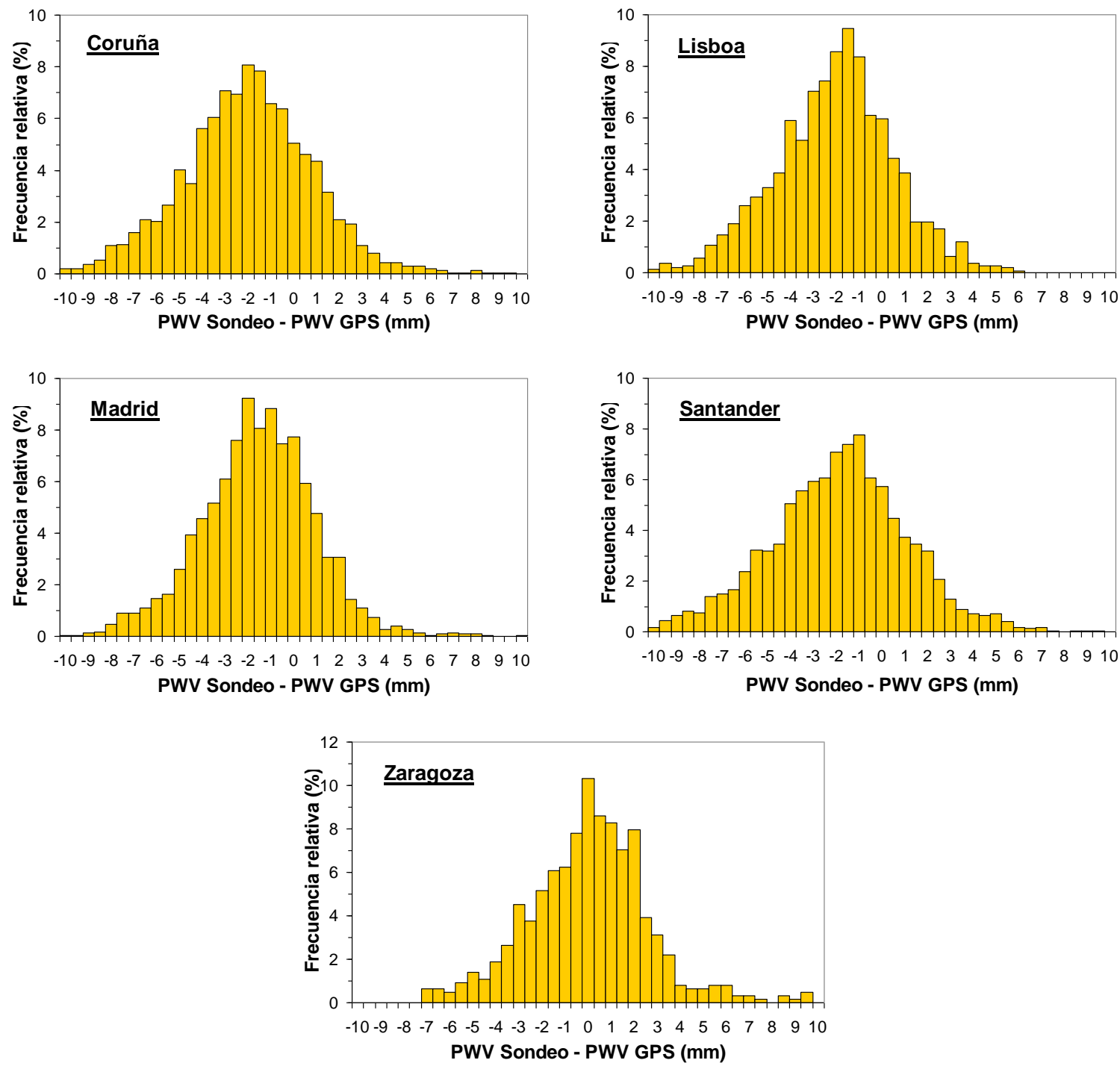

Figura 7.4 - Histograma de frecuencias de la diferencia entre el PWV medio diario del sondeo y del GPS. Para obtener estos histogramas los valores de las diferencias se han agrupado en clases por intervalos de $0.5 \mathrm{~mm}$ de amplitud. 
La comparativa de las medias diarias arroja peores resultados que la de las medidas instantáneas. Los estadísticos de la comparación (Tabla 7.2) reflejan unas bias húmedas en las medidas del GPS del orden de los $2 \mathrm{~mm}$ (excepto en Zaragoza), la std y el rmse son mayores que la de la comparativa de las medidas instantáneas, la primera de 1 a $2 \mathrm{~mm}$, y la segunda de 1.5 a $2 \mathrm{~mm}$. El coeficiente de correlación también empeora disminuyendo en torno a un 0.1. Esto último parece quedar justificado por el distinto número de medidas disponibles de cada técnica para obtener las medias diarias y por los valores típicos de la variación intradía del PWV. Los valores medios diarios de los datos GPS se han obtenido como la media de los veinticuatro datos con frecuencia horaria, y por tanto se pueden considerar como representativos del valor medio real del día. Sin embargo, en el caso de los sondeos normalmente sólo se dispone de dos datos, que no son suficientes para reflejar la variabilidad del PWV. En el Capítulo 6, se obtuvo un valor medio para la amplitud de la variación media diaria del PWV de $7.84 \mathrm{~mm}$ y una desviación típica de $2.26 \mathrm{~mm}$. Es de esperar que esta dispersión se traslade en cierta medida a los resultados de la comparación de las medias diarias de sondeos y receptores GPS. En situaciones meteorológicas de alta variabilidad del PWV las discrepancias entre ambas medias diarias pueden ser muy importantes. En este estudio se han registrado variaciones de hasta $10 \mathrm{~mm}$ en una hora, o de $35 \mathrm{~mm}$ en un día. Además, la existencia de un ciclo diurno del PWV puede dar lugar a un sesgo en las medias obtenidas en base a sólo dos sondeos diarios. De la forma del ciclo y la amplitud del mismo (Capítulo 5) se obtiene que el sesgo medio al considerar sólo las medidas de las 0 y 12 UTC es muy pequeño, del orden de $0.1 \mathrm{~mm}$, aunque en las estaciones de la costa sur (San Fernando o Almería) en verano se produce una sobreestimación media de casi $1 \mathrm{~mm}$.

\begin{tabular}{lccccccccc}
\hline Estación & $\begin{array}{c}\text { PWV } \\
\text { Sondeo }\end{array}$ & $\begin{array}{c}\text { PWV } \\
\text { GPS }\end{array}$ & BIAS & RMSE & MAE & STD & $\begin{array}{c}\text { RMDA } \\
\%\end{array}$ & R $^{2}$ & $\begin{array}{c}\text { № } \\
\text { Días }\end{array}$ \\
\hline Coruña & 18.28 & 20.32 & -2.04 & 3.60 & 2.84 & 2.97 & 15.41 & 0.83 & 2116 \\
Lisboa & 17.49 & 19.59 & -2.10 & 3.39 & 2.68 & 2.66 & 15.10 & 0.85 & 1425 \\
Madrid & 14.40 & 15.96 & -1.57 & 2.95 & 2.31 & 2.49 & 16.25 & 0.84 & 2186 \\
Santander & 18.63 & 20.64 & -2.00 & 3.78 & 2.92 & 3.20 & 15.96 & 0.82 & 2230 \\
Zaragoza & 17.31 & 17.30 & 0.01 & 2.59 & 1.96 & 2.59 & 12.28 & 0.89 & 640 \\
\hline
\end{tabular}

Tabla 7.2 - Estadísticos de la comparativa de las medias diarias de PWV de los sondeos y del GPS.

La evolución de la diferencia de las medias diarias a lo largo del tiempo (Figura 7.5) muestra como a partir de finales del año 2006 estas oscilan entorno a cero al desaparecer el sesgo de las medidas GPS, pero el orden de magnitud de la dispersión de las mismas se mantiene.

También se aprecia una tendencia a seguir las diferencias un ciclo anual con mínimos en los meses de verano (diferencias más negativas) y máximos en los de invierno. Cuanto mayor es el PWV mayor es la diferencia entre los valores medios diarios de las dos técnicas. Este efecto queda reflejado más claramente en las estaciones de Coruña y Madrid. En valores medios 
mensuales la amplitud de este ciclo anual oscila entre los $1.40 \mathrm{~mm}$ de Santander y los $2.93 \mathrm{~mm}$ de Zaragoza.
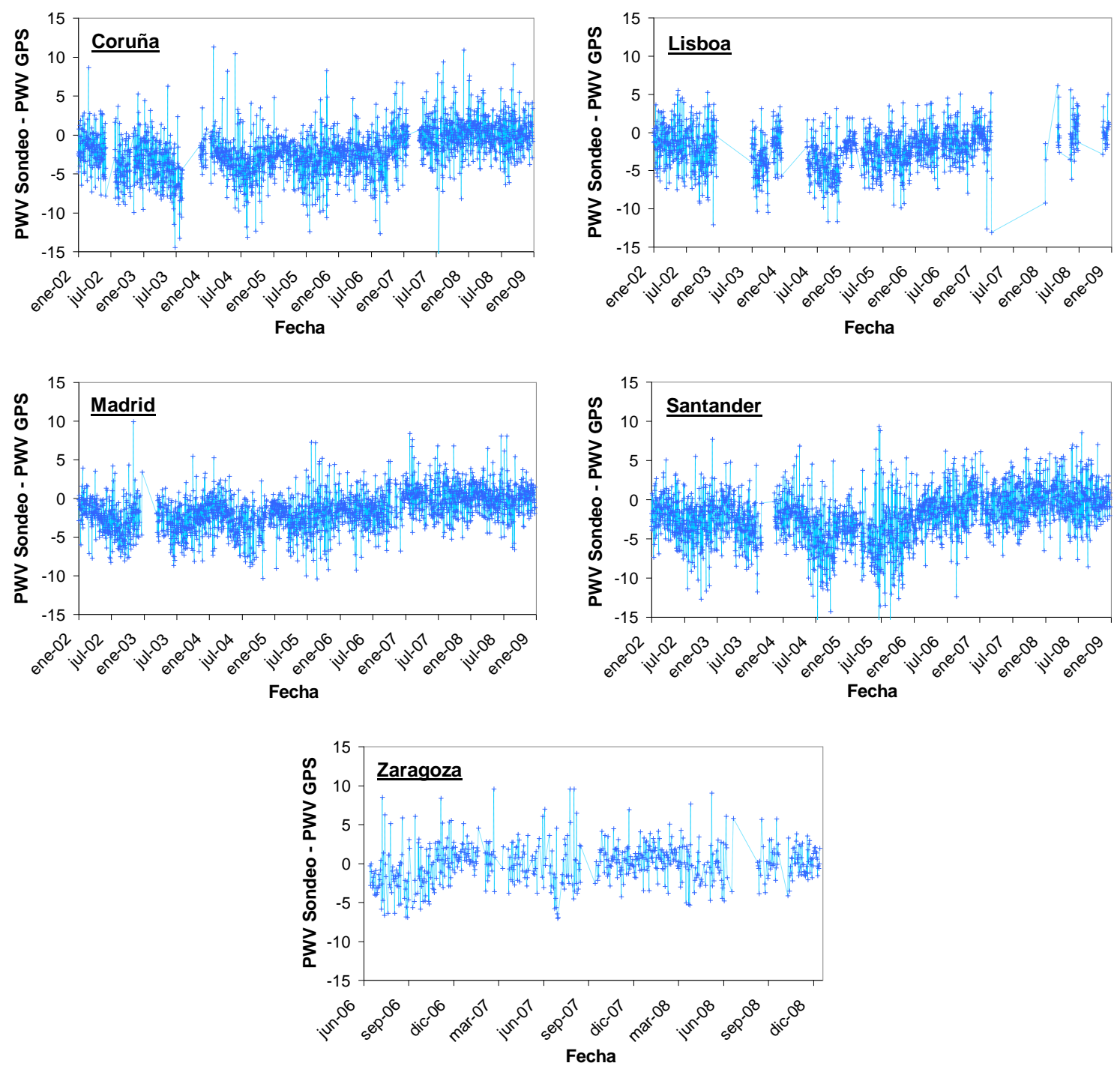

Figura 7.5 - Evolución temporal de las diferencias absolutas $(\mathrm{mm})$ entre la media diaria del PWV de los datos de los sondeos y de los receptores GPS.

\subsubsection{Comparativa medias mensuales}

Para caracterizar esta comparativa se han calculado los mismos estadísticos que en los apartados anteriores (Tabla 7.3). En este calculo no se han considerado aquellos meses para los cuales faltan datos de más de la mitad de los días de alguna de las dos técnicas.

Las medias mensuales de los GPS muestran unas bias húmedas ligeramente inferiores o similares a las que presentaban las medias diarias, midiendo los GPS entorno a un $10 \%$ más en media que los sondeos, excepto en Zaragoza, como ya se ha comentado en el punto anterior. El std y el rmse son menores que en la comparativa de las medias diarias, lo que indica que en términos mensuales las discrepancias diarias se compensan en parte, disminuyendo así la dispersión. 


\begin{tabular}{lccccccccc}
\hline Estación & $\begin{array}{c}\text { PWV } \\
\text { Sondeo }\end{array}$ & $\begin{array}{c}\text { PWV } \\
\text { GPS }\end{array}$ & BIAS & RMSE & MAE & STD & $\begin{array}{c}\text { RMDA } \\
\%\end{array}$ & R $^{2}$ & $\begin{array}{c}\text { № } \\
\text { Meses }\end{array}$ \\
\hline Coruña & 18.25 & 20.06 & -1.81 & 2.46 & 2.03 & 1.66 & 10.58 & 0.89 & 77 \\
Lisboa & 17.44 & 19.55 & -2.10 & 2.63 & 2.19 & 1.57 & 11.62 & 0.89 & 49 \\
Madrid & 14.36 & 15.94 & -1.58 & 2.21 & 1.75 & 1.55 & 11.44 & 0.89 & 80 \\
Santander & 18.48 & 20.15 & -1.66 & 2.40 & 1.91 & 1.73 & 10.18 & 0.92 & 81 \\
Zaragoza & 17.53 & 17.67 & -0.14 & 0.94 & 0.81 & 0.93 & 4.73 & 0.99 & 24 \\
\hline
\end{tabular}

Tabla 7.3 - Comparativa de las medias mensuales de PWV del sondeo y del GPS.
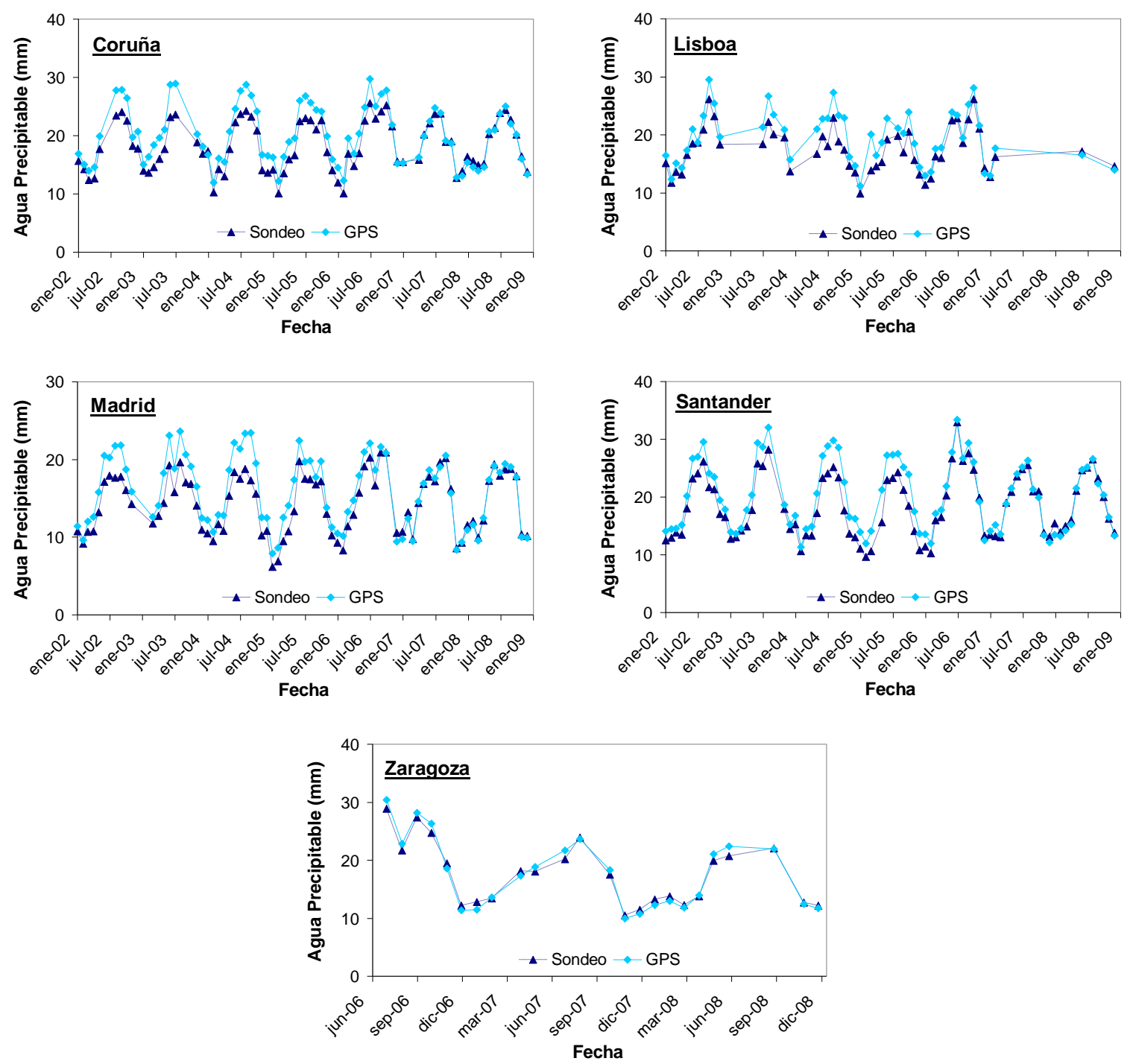

Figura 7.6 - Evolución temporal de las medias mensuales de PWV del sondeo y del GPS.

La evolución temporal de las medias mensuales (Figura 7.6) muestra claramente la sobrestimación de los GPS hasta el año 2007, a partir del cual las medias de los GPS y de los sondeos son prácticamente coincidentes. Esta sobreestimación es mayor en verano, cuando los valores del PWV son mayores, y menor en invierno. 


\subsection{Comparativa Sondeos - Fotómetros}

Sólo se dispone de dos emplazamientos dotados con estación de radiosondeo y fotómetro, estos son Lisboa y Barcelona, aunque de este último sólo se dispone de un año escaso de datos de ambas técnicas.

\subsubsection{Comparativa medidas puntuales}

Siguiendo en el mismo razonamiento de la comparativa entre sondeos y GPS, cada dato de sondeo se ha emparejado con la medida del fotómetro más próxima posterior a la hora del lanzamiento del sondeo. De esta manera, con los datos del año 2008 se han obtenido 82 pares de datos para Lisboa y 114 para Barcelona, todos ellos para el sondeo de las 12 UTC puesto que los fotómetros no miden por la noche.

El histograma de frecuencias de la diferencia entre los pares de datos sondeo-fotómetro (Figura 7.7) presenta una asimetría a derechas en ambos emplazamientos, más acusada en Barcelona. Es decir, las medias de PWV de los sondeos son generalmente mayores que las de los fotómetros.
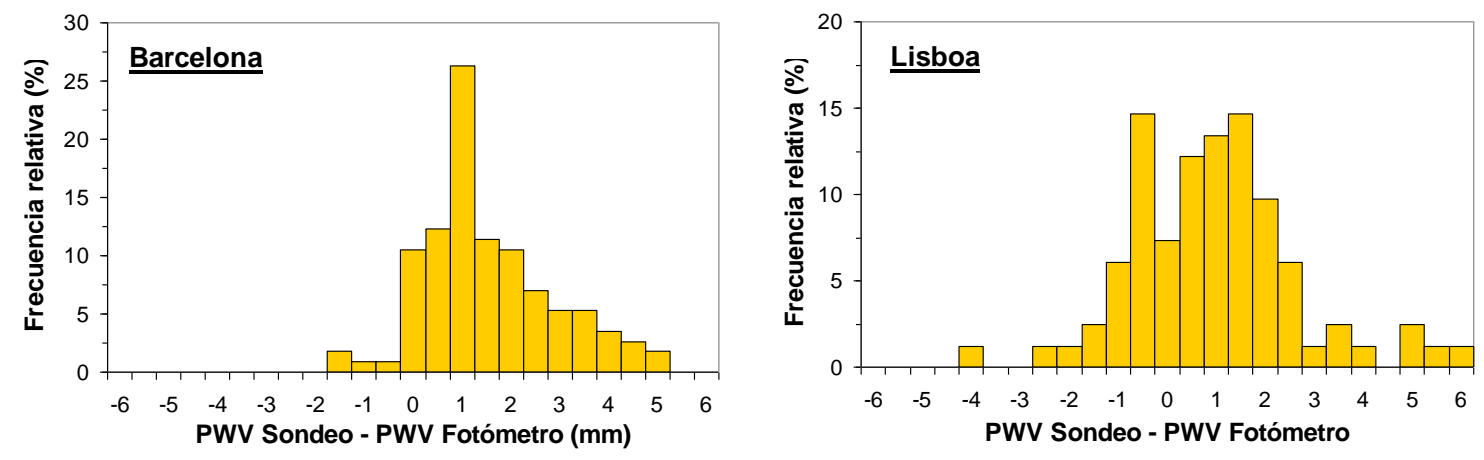

Figura 7.7 - Histograma de frecuencias de la diferencia entre el PWV del sondeo y del fotómetro. Los valores de las diferencias se han agrupado en clases por intervalos de $0.5 \mathrm{~mm}$ de amplitud.

En Barcelona la clase modal se destaca de forma importante respecto al resto, con una frecuencia del $26 \%$. A la derecha de la clase modal las frecuencias van cayendo lentamente, mientras que a la izquierda lo hacen de forma brusca, siendo prácticamente todas las diferencias positivas. La moda y la mediana coinciden, mientras que la media se encuentra desplazada más a la derecha. El 50\% de las diferencias se encuentran entre 0.75 y $2.28 \mathrm{~mm}$, y el $90 \%$ entre -0.15 y $4.09 \mathrm{~mm}$. En Lisboa hay dos clases modales situándose la mediana y la media (que prácticamente coinciden) entre ambas. El 50\% de las diferencias se sitúan entre 0.28 y $1.79 \mathrm{~mm}$, y el $90 \%$ entre -1.54 y $4.01 \mathrm{~mm}$.

Los resultados de la comparativa (Tabla 7.4) muestran una correlación muy alta, llegando en Barcelona el coeficiente de correlación $\mathrm{R}^{2}$ hasta un valor de 0.99. Los sondeos registran más 
cantidad de PWV que los fotómetros en ambos emplazamientos, con unas bias de 1 a $1.5 \mathrm{~mm}$. El rmse se sitúa en los $2 \mathrm{~mm}$, pero mientras que en Lisboa son menores las bias y mayor el std en Barcelona ocurre a la inversa. Hay que tener en cuenta que la incertidumbre de las medidas de los fotómetros está muy ligada con los errores en la calibración de los mismos y es propia para cada instrumento. También son aplicables a esta comparativa los errores debidos a la variabilidad del PWV durante el tiempo requerido por los sondeos para muestrear la atmósfera, como se ha comentado en el punto anterior.

\begin{tabular}{lccccccccc}
\hline Estación & $\begin{array}{c}\text { PWV } \\
\text { Sondeo }\end{array}$ & $\begin{array}{c}\text { PWV } \\
\text { Fotómetro }\end{array}$ & BIAS & RMSE & MAE & STD & $\begin{array}{c}\text { RMDA } \\
\%\end{array}$ & R $^{2}$ & $\begin{array}{c}\text { No } \\
\text { Datos }\end{array}$ \\
\hline Lisboa & 17.97 & 17.05 & 0.91 & 1.94 & 1.47 & 1.72 & 8.54 & 0.93 & 82 \\
Barcelona & 17.34 & 15.78 & 1.56 & 2.04 & 1.65 & 1.32 & 9.97 & 0.99 & 114 \\
\hline
\end{tabular}

Tabla 7.4 - Estadísticos de la comparativa de los pares de medidas Sondeo-Fotómetro del año 2008.

Otros autores han obtenido resultados parecidos a los de este estudio para la comparativa entre datos de sondeos y fotómetros (Campmany et al. 2010).
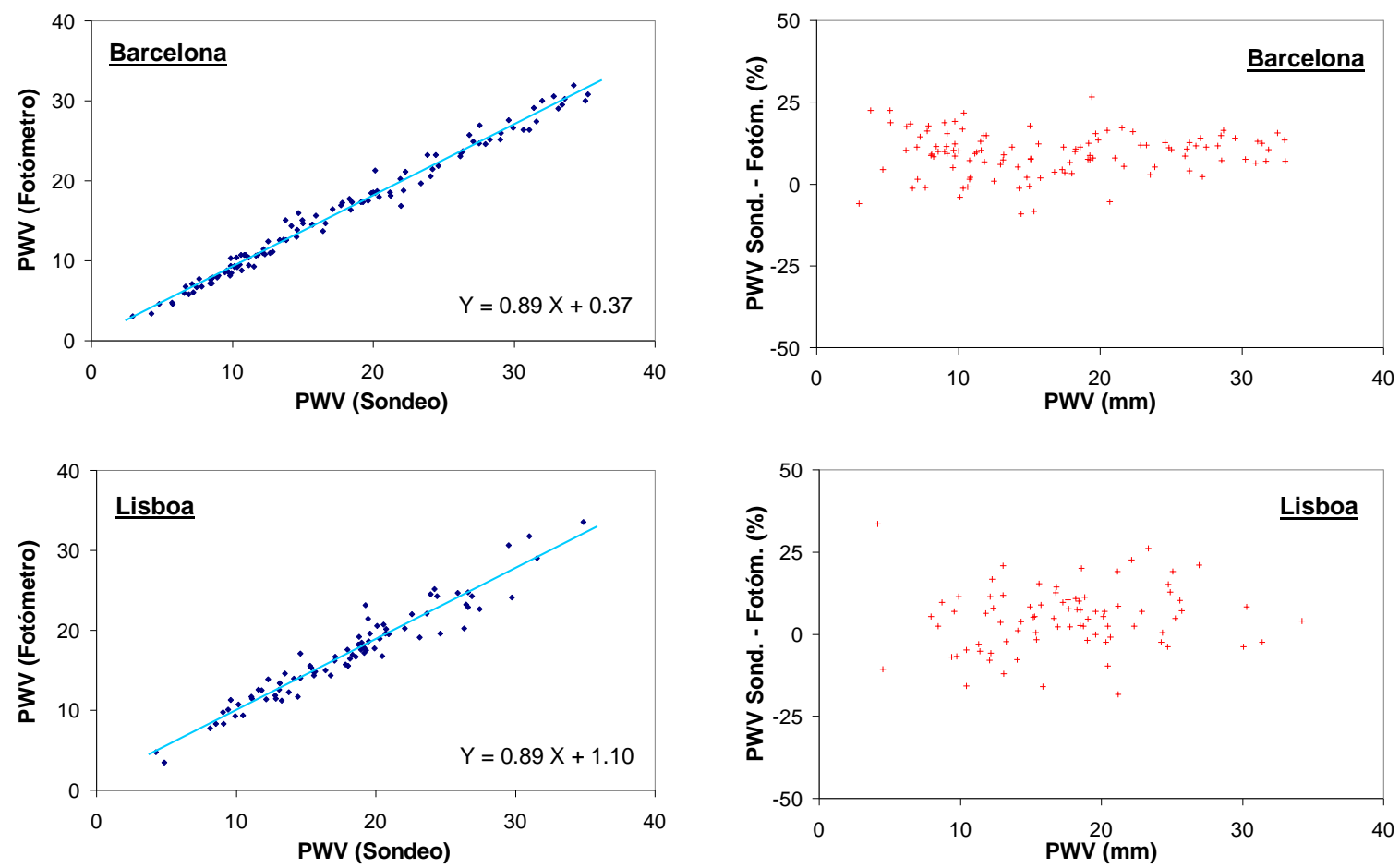

Figura 7.8 - Comparativa sondeo-fotómetro: rectas de regresión (izquierda), y distribución de las diferencias relativas en porcentaje respecto del valor medio frente al propio valor medio del PWV, calculado como la media aritmética del dato del sondeo y del fotómetro (derecha).

La representación gráfica de la nube de puntos de PWV sondeo-fotómetro (Figura 7.8) muestra como en Barcelona estos se distribuyen uniformemente a lo largo de la recta de regresión. Por el contrario, en Lisboa se aprecia una mayor dispersión para valores de PWV por encima de los $20 \mathrm{~mm}$. Si se representa la diferencia entre el PWV del sondeo y del fotómetro frente al valor medio del PWV, se observa una tendencia al incremento de las diferencias en valor absoluto al 
aumentar el PWV del orden de $1 \mathrm{~mm}$ por cada $10 \mathrm{~mm}$ de aumento en el PWV. En el caso de la comparativa entre sondeos y GPS este incremento era de sólo $0.03 \mathrm{~mm}$. Sin embargo, en valores relativos no se presenta ninguna tendencia significativa, tan sólo en Barcelona la dispersión aumenta para valores bajos del PWV. Para valores muy pequeños del PWV las diferencias relativas no se disparan como ocurría en la comparativa de los sondeos con los GPS, lo que podría indicar que son estos últimos los que pierden más precisión para atmósferas secas. En Barcelona el 50\% de las diferencias en valores relativos se encuentran en un intervalo del 6 al $13 \%$ y el $90 \%$ en un intervalo del -1 al 19\%, mientras que en Lisboa se encuentran en un intervalo del -2 al $10 \%$ y del -11 al $21 \%$ respectivamente.
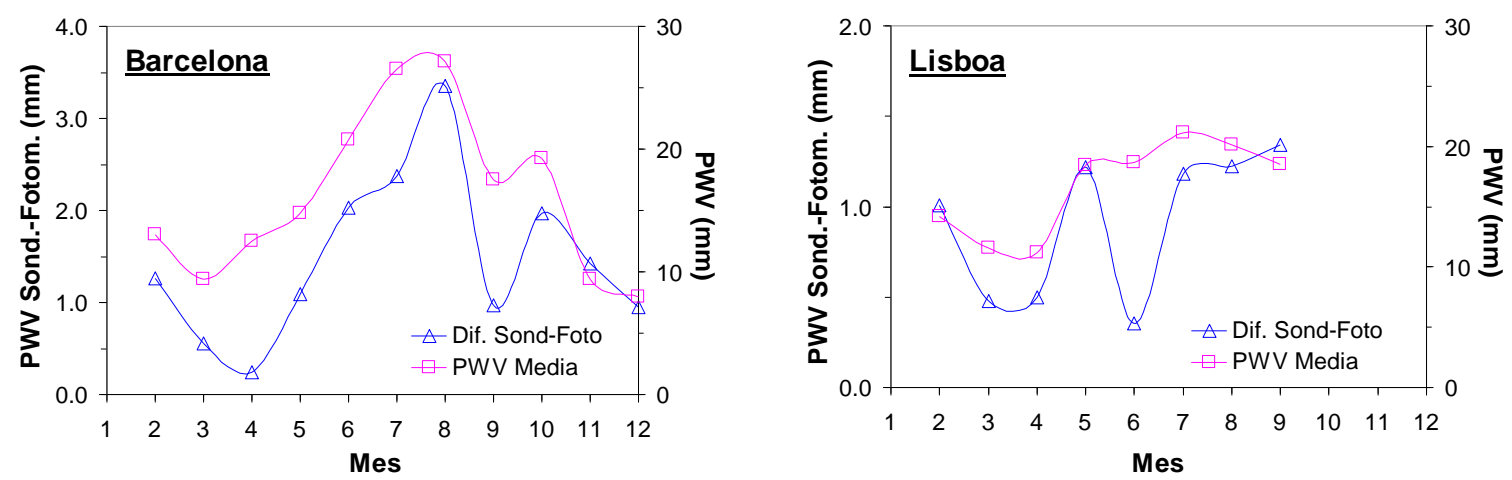

Figura 7.9 - Valores medios mensuales de la diferencia entre el PW del sondeo y del fotómetro.

Si se representan los valores medios mensuales de las diferencias entre el PWV del sondeo y del fotómetro (Figura 7.9), se observa que en Barcelona el ciclo anual de las diferencias se ajusta bastante bien al del contenido de PWV. Cuanto mayor es el PWV mayor es la diferencia entre ambas técnicas, manteniéndose bastante constante la diferencia en valores relativos de porcentaje respecto del contenido de PWV.

\subsubsection{Comparativa medias diarias}

Ninguna de las dos técnicas, sondeos y fotómetros, posee una frecuencia adecuada para reflejar la variabilidad temporal del PWV. Así, es de esperar que parte de la desviación típica de los valores intradiarios del PWV se traslade a los resultados de la comparación de las medias diarias, incrementando las medidas de la dispersión de la distribución, especialmente en situaciones meteorológicas con alta variabilidad del PWV. Además, se podría pensar que las medias de los fotómetros pueden presentan un sesgo hacia valores más altos, puesto que estos sólo miden durante las horas de sol cuando en término medio los valores del PWV son más elevados (Capítulo 8). Sin embargo, según se desprende de los resultados presentados en el Capítulo 5, este sesgo tomaría valores medios muy pequeños, del orden de $0.15 \mathrm{~mm}$, siendo algo mayores en las estaciones de la costa mediterránea donde la amplitud del ciclo es mayor. En el caso de los sondeos, el ciclo diurno del PWV prácticamente no afecta al estar su efecto equilibrado entre las medidas de las 00 y 12 UTC, si bien en el caso de Lisboa desde el año 2004 sólo se lanza un sondeo al día, el de las 12 UTC. 

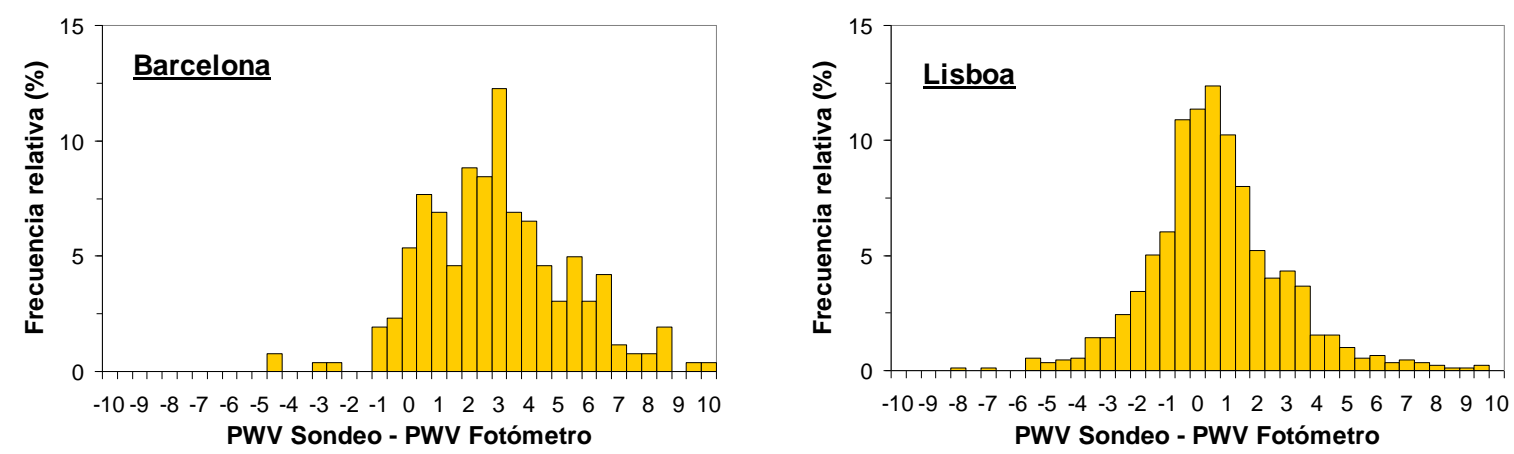

Figura 7.10 - Histograma de frecuencias de las diferencias entre el valor medio diario del PWV obtenido de las medidas de los sondeos y del fotómetro.

La Figura 7.10 muestra el histograma de frecuencias de las diferencias de las medias diarias.

En Barcelona la distribución se encuentra totalmente desplazada a la derecha, sólo un $8 \%$ de las diferencias toman valores negativos. La moda, la mediana y la media se encuentran en el intervalo 2.75 a $3.25 \mathrm{~mm}$. Más del $50 \%$ de los datos se encuentran entre 1 y $4.5 \mathrm{~mm}$, y más del $90 \%$ entre -0.5 y $8 \mathrm{~mm}$. En Lisboa la distribución está más centrada entorno al cero. La moda, la mediana, y la media se encuentran en el intervalo 0.25 a $0.75 \mathrm{~mm}$, encontrándose el $50 \%$ de los datos entre -0.6 y $1.8 \mathrm{~mm}$, y el $90 \%$ entre -2.8 y $4.7 \mathrm{~mm}$.

Los resultados de la comparación (Tabla 7.5) reflejan un sesgo húmedo en las medidas de los sondeos que llega a ser del orden de $3 \mathrm{~mm}$ en Barcelona mientras que en Lisboa es de sólo $0.73 \mathrm{~mm}$. La std en ambos emplazamientos difieren poco, sin embargo el rmse de Barcelona casi duplica el de Lisboa debido a la diferencia en las bias.

\begin{tabular}{lccccccccc}
\hline Estación & $\begin{array}{c}\text { PWV } \\
\text { Sondeo }\end{array}$ & $\begin{array}{c}\text { PWV } \\
\text { Fotómetro }\end{array}$ & BIAS & RMSE & MAE & STD & $\begin{array}{c}\text { RMDA } \\
\%\end{array}$ & R $^{2}$ & $\begin{array}{c}\text { No } \\
\text { Días }\end{array}$ \\
\hline Lisboa & 16.97 & 16.24 & 0.73 & 2.55 & 1.77 & 2.44 & 10.62 & 0.85 & 898 \\
Barcelona & 20.58 & 17.55 & 3.03 & 3.95 & 3.21 & 2.54 & 17.62 & 0.92 & 261 \\
\hline
\end{tabular}

Tabla 7.5 - Estadísticos de la comparativa de las medias diarias de los sondeos y los fotómetros.

Casi todos los estadísticos representados empeoran respecto de la comparación de las medidas instantáneas. Esto puede ser consecuencia de la diferente distribución temporal de las medidas de ambas técnicas y del diferente número de medidas disponibles utilizadas para calcular las medias diarias, las medidas de los fotómetros poseen muchas lagunas por el desarrollo de nubosidad. Mientras que en Lisboa las bias disminuyen ligeramente pasando de 0.91 a $0.73 \mathrm{~mm}$, en Barcelona se duplican, pasando de 1.56 a $3.03 \mathrm{~mm}$. Además, en este último emplazamiento los datos de los sondeos reflejan que el PWV medio a las 00 UTC es mayor que a las 12 UTC. Al no operar el fotómetro por la noche, la medias diarias de sus datos no reflejan este hecho, y por tanto son menores que las de los datos del sondeo. Los otros estadísticos aumentan en los dos emplazamientos, pero siempre de forma más acusada en Barcelona. 
De la evolución de las diferencias a lo largo del tiempo (Figura 7.11) se aprecia una ligera tendencia en Barcelona a aumentar las diferencias en los meses de verano, cuando la cantidad de PWV en la atmósfera es mayor, pero manteniéndose constantes en valores relativos. Esta tendencia se hace más palpable en la representación de los valores medios mensuales. Sin embargo, en Lisboa no se aprecia ninguna tendencia significativa, si bien esta estación presenta numerosas lagunas de datos.
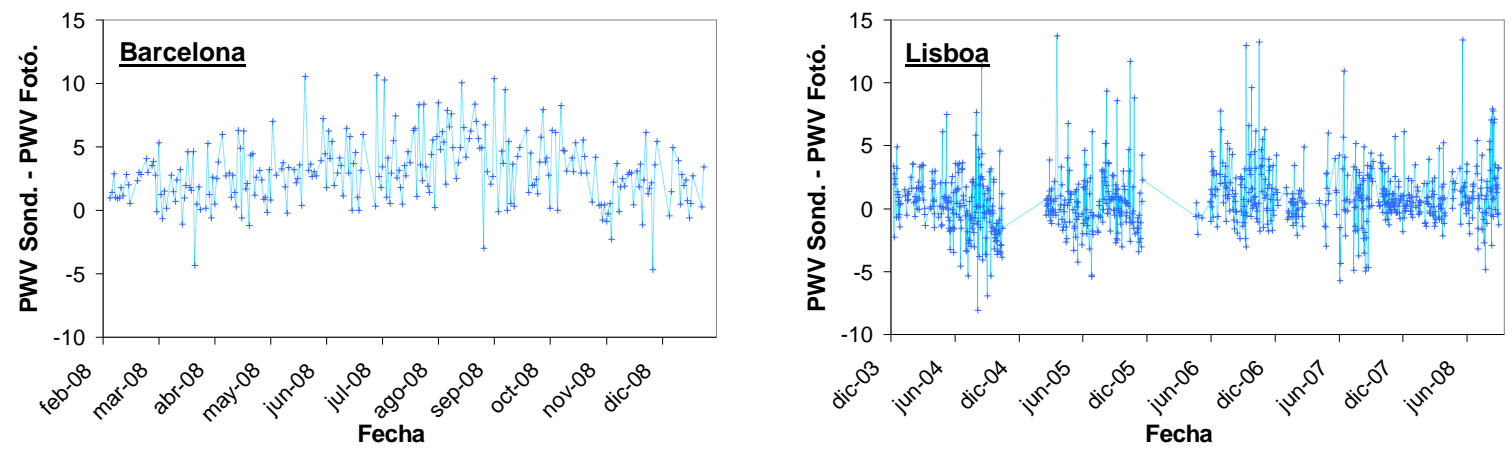

Figura 7.11 - Evolución temporal de la diferencia entre la media diaria de PWV obtenida de los datos del sondeo y de los fotómetros.

\subsubsection{Comparativa medias mensuales}

Al igual que en el caso de la comparativa entre datos de sondeos y GPS, para esta comparativa de las medias mensuales no se han considerado aquellos meses para los cuales faltan datos de más de la mitad de los días. Los resultados de la comparativa se muestran en la Tabla 7.6. Las medidas de los sondeos presentan una sobreestimación del PWV con respecto a la de los fotómetros, de un $10 \%$ en Lisboa, y de hasta un $21 \%$ en Barcelona. La dispersión de las diferencias se compensa en parte en los términos mensuales respecto a la comparativa de las medias diarias, disminuyendo el std. Sin embargo, las bias aumentan, resultando al final un rmse también mayor.

\begin{tabular}{lccccccccc}
\hline Estación & $\begin{array}{c}\text { PWV } \\
\text { Sondeo }\end{array}$ & $\begin{array}{c}\text { PWV } \\
\text { Fotómetro }\end{array}$ & BIAS & RMSE & MAE & STD & $\begin{array}{c}\text { RMDA } \\
\%\end{array}$ & R $^{2}$ & $\begin{array}{c}\text { № } \\
\text { Meses }\end{array}$ \\
\hline Barcelona & 21.01 & 17.18 & 3.83 & 3.99 & 3.83 & 1.12 & 20.89 & 0.99 & 11 \\
Lisboa & 17.72 & 16.25 & 1.47 & 1.90 & 1.63 & 1.21 & 10.14 & 0.88 & 37 \\
\hline
\end{tabular}

Tabla 7.6 - Estadísticos de la comparativa de las medias mensuales de los sondeos y de los fotómetros.

La evolución temporal de las medias mensuales (Figura 7.12) muestra claramente en el caso de Barcelona la sobrestimación de los sondeos con respecto al fotómetro para todos los meses del año, pero mayor en los meses del verano y menor en invierno. En Lisboa, si bien la media del sondeo está por encima de la del fotómetro prácticamente en todos los meses, no se observa un patrón claro de variación anual. En este caso hay que tener en cuenta que durante el periodo de medidas el fotómetro puede haber sufrido cambios y calibraciones, además del envejecimiento de los filtros. Estos aspectos se analizarán en el Capítulo 8. 

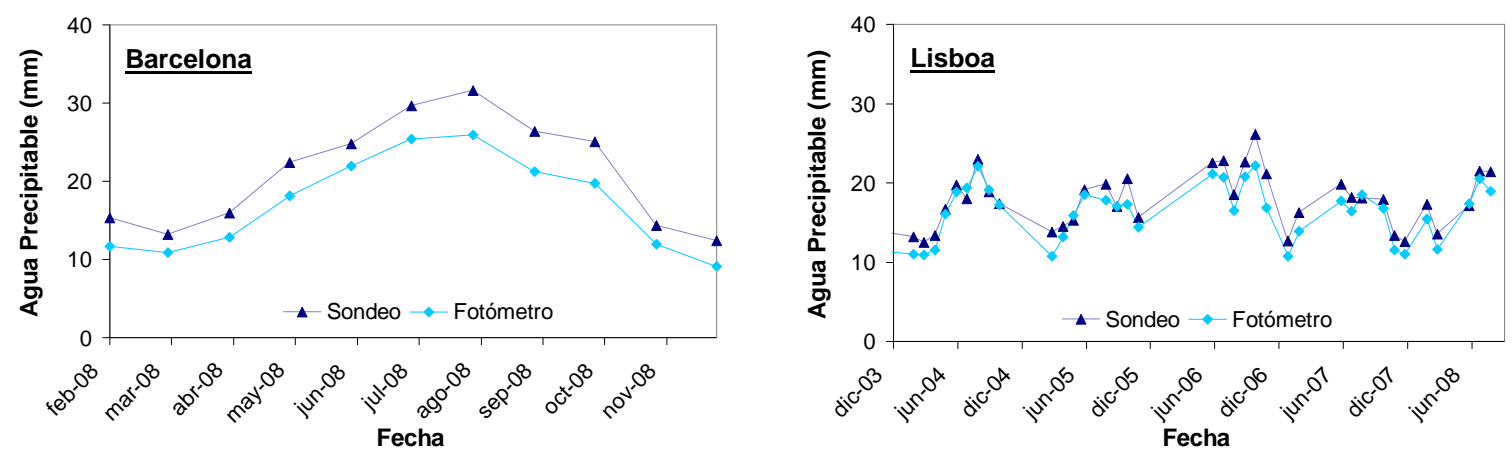

Figura 7.12 - Evolución de la media mensual de PW obtenido del sondeo y de los fotómetros.

\subsection{Comparativa GPS - Fotómetros}

Se disponen de cuatro emplazamientos con receptor GPS y fotómetro: Valencia, Cáceres, Huelva y Lisboa. Aunque esta última estación posee las series más largas de datos de ambas técnicas (desde el año 2003) presenta numerosas lagunas. Las estaciones GPS de Huelva y Valencia son muy recientes (finales del 2007) pero para los propósitos de la comparativa de medidas instantáneas son muy valiosas.

\subsubsection{Comparativa medidas instantáneas}

Tanto las medidas de los fotómetros como de los receptores GPS se pueden considerar como instantáneas en el tiempo, por ello para esta comparativa se han seleccionado los pares de valores de ambas técnicas que no diferían más de quince minutos. Como la variabilidad media del PWV es de $0.67 \mathrm{~mm} /$ hora (Capítulo 6), este criterio de selección podría introducir una discrepancia media máxima del orden de $0.17 \mathrm{~mm}$ por el posible desfase temporal de las medidas. No obstante, se ha probado también disminuyendo el intervalo a sólo cinco minutos y los estadísticos de la comparativa no han mejorado, por lo que se ha optado por los quince minutos para disponer de un mayor número de pares de valores. De esta manera se han obtenido del orden de 2000 pares de valores para los emplazamientos de Cáceres y Huelva, del orden de 1000 para Valencia (sólo hay datos del fotómetro hasta el mes de agosto), y sólo 169 para Lisboa.

Los histogramas de frecuencias de las diferencias entre los pares de valores (Figura 7.13) presentan un desplazamiento a la derecha (medida del GPS mayor que la del fotómetro) en todos los emplazamientos, salvo en Cáceres que ocurre al contrario.

La mediana de la distribución cae dentro de los límites de la clase modal en los cuatro emplazamientos, y también la media en Lisboa, no así en las otras tres donde cae a la derecha de esta, y de forma más acusada en Cáceres. En todos los casos, el $50 \%$ de las diferencias se 
sitúan en un intervalo de 1.5 a 2 mm de amplitud centrado en la mediana. Para abarcar el $90 \%$ de la diferencias la amplitud del intervalo aumenta a los 3.75 a $4.75 \mathrm{~mm}$.
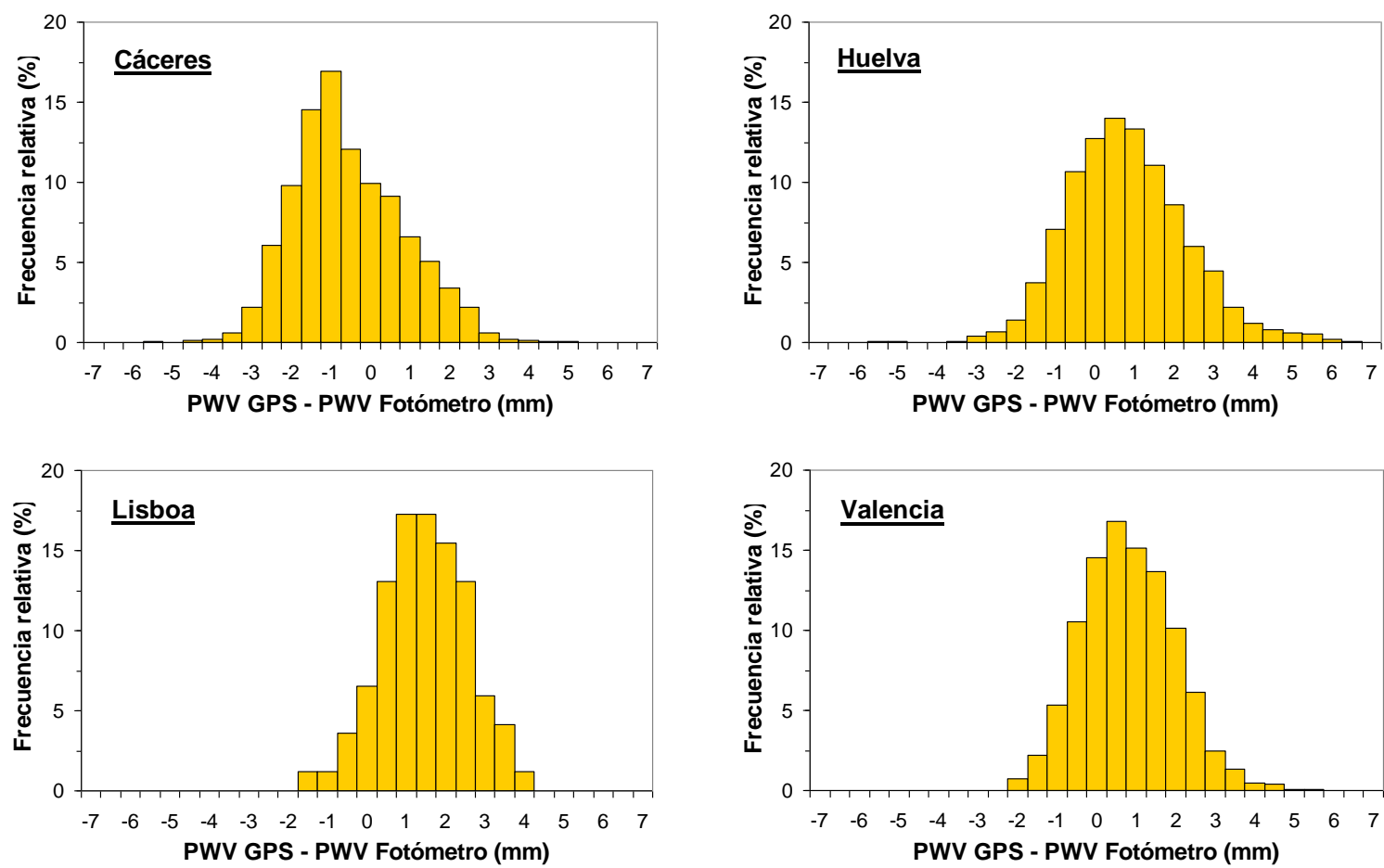

Figura 7.13 - Histograma de frecuencias de la diferencia entre el PWV del GPS y del fotómetro.

Los estadísticos de la comparativa (Tabla 7.7) arrojan una correlación muy buena entre ambas técnicas, con valores del coeficiente $R^{2}$ de al menos 0.95 . Contrario a lo que ocurría en las otras comparativas, las bias no presentan siempre el mismo signo, lo que apunta a que el sesgo depende del instrumento en concreto y no sólo de las técnicas. Hay que recordar que la obtención del dato de PWV de los fotómetros está muy condicionada por la constante de calibración de cada instrumento. No obstante, este sesgo no es muy importante, sólo en Lisboa supera $1 \mathrm{~mm}$. El rmse y la std toman valores similares en todos los emplazamientos, el primero se sitúa por debajo de los $2 \mathrm{~mm}$ y la std entre 1 y $1.5 \mathrm{~mm}$.

\begin{tabular}{lccccccccc}
\hline Estación & $\begin{array}{l}\text { PWV } \\
\text { GPS }\end{array}$ & $\begin{array}{c}\text { PWV } \\
\text { Fotómetro }\end{array}$ & BIAS & RMSE & MAE & STD & $\begin{array}{c}\text { RMDA } \\
\%\end{array}$ & R $^{2}$ & $\begin{array}{c}\text { № } \\
\text { Datos }\end{array}$ \\
\hline Cáceres & 14.01 & 14.56 & -0.55 & 1.49 & 1.25 & 1.39 & 10.35 & 0.95 & 1927 \\
Huelva & 16.75 & 15.93 & 0.82 & 1.71 & 1.31 & 1.50 & 8.43 & 0.95 & 2029 \\
Lisboa & 19.56 & 18.11 & 1.45 & 1.80 & 1.55 & 1.07 & 8.08 & 0.97 & 168 \\
Valencia & 18.30 & 17.48 & 0.82 & 1.43 & 1.13 & 1.17 & 6.89 & 0.98 & 1055 \\
\hline
\end{tabular}

Tabla 7.7 - Estadísticos de la comparativa de los pares de medidas GPS-Fotómetro del año 2008.

El posible error por la diferencia de altitud entre los emplazamientos de las dos instrumentaciones no es significativo, salvo en Lisboa. De hecho esta estación presenta las bias positivas más altas, posiblemente por encontrarse el fotómetro $113 \mathrm{~m}$ por encima de la altitud del receptor GPS. 
Otras comparativas GPS-fotómetros de la bibliografía (Bokoye et al. 2003, Santangelo et al. 2003) presentan resultados semejantes.
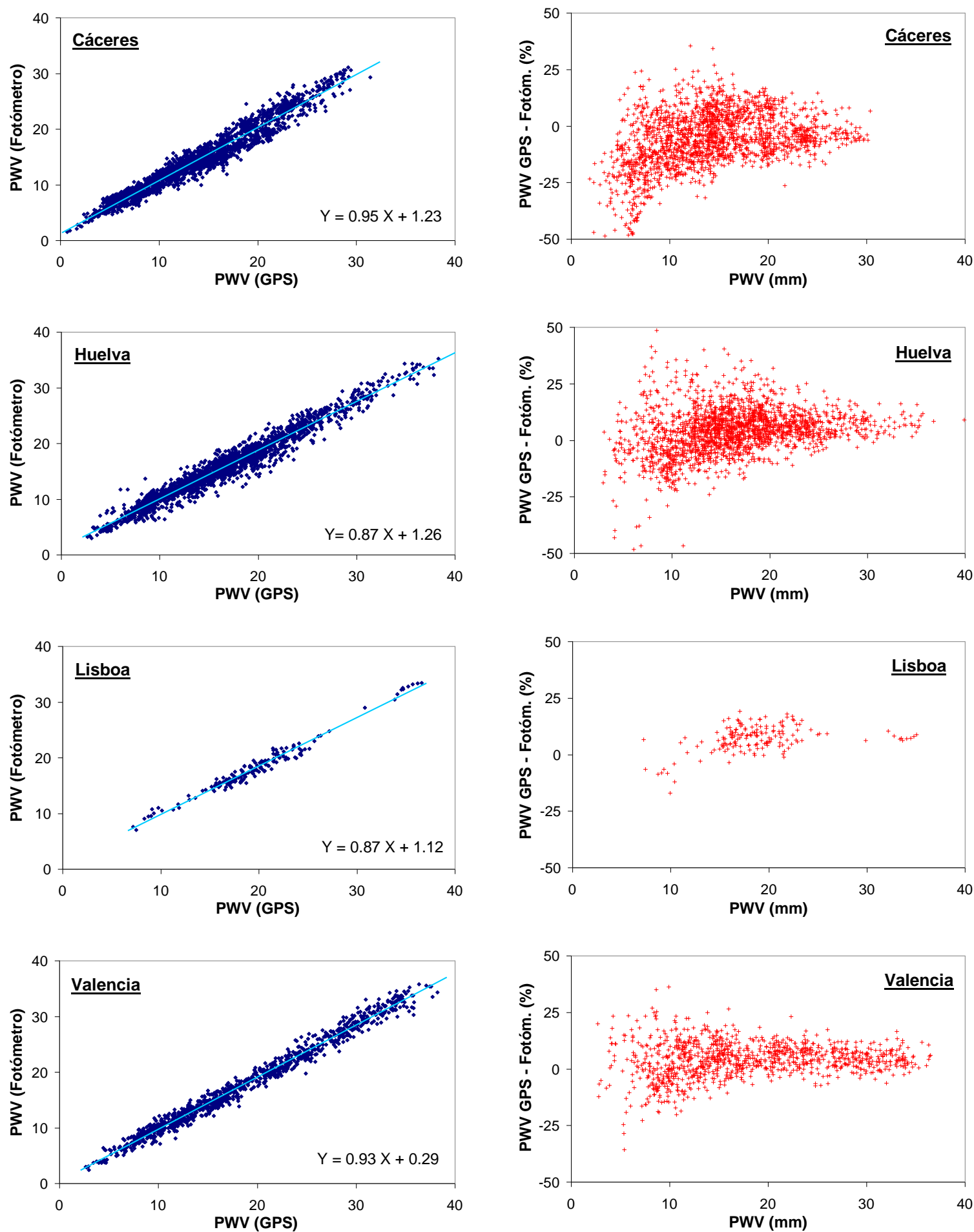

Figura 7.14 - Gráficas de la comparativa entre los pares de medidas GPS-fotómetro. Las gráficas de la izquierda representan las rectas de regresión, y las de la derecha la distribución de las diferencias relativas respecto del valor medio del PWV frente al propio valor medio del PWV, calculado como la media aritmética del dato del GPS y del fotómetro. 
La representación gráfica de la nube de pares de puntos PWV GPS-fotómetro (Figura 7.14) muestra cómo estos se distribuyen bastante uniformemente a lo largo de la recta de regresión, con una dispersión ligeramente mayor en Cáceres y Huelva como así lo recogen los valores de la std (Tabla 7.11).

La representación gráfica de las diferencias entre el PWV del GPS y del fotómetro frente a su valor medio muestra una ligera tendencia al aumento de la dispersión de la nube de puntos con el aumento del PWV en Cáceres, mientras que en los otros emplazamientos lo que se observa es una tendencia al incremento de las diferencias con el aumento del PWV del orden de 0.5 a 1 $\mathrm{mm}$ por cada $10 \mathrm{~mm}$ de aumento en el PWV. Sin embargo, las diferencias en valores relativos se incrementan sustancialmente al disminuir el PWV, especialmente por debajo de los $10 \mathrm{~mm}$ cuando la mayoría de las diferencias se vuelven negativas. Es como si para valores bajos del PWV los fotómetros sobreestimaran las medidas de PWV y/o los GPS la subestimaran (Figura 7.14). Exceptuando la estación de Lisboa por disponer de pocos datos, el $50 \%$ de las diferencias en valor relativo se mueven en un intervalo asimétrico en torno a la mediana de una amplitud media de $12 \%$. Para poder abarcar hasta el $90 \%$ de las diferencias, la amplitud del intervalo tiene casi que triplicarse. Cáceres es la estación que presenta una mayor dispersión en de las diferencias en valor relativo y Valencia la menor. Así, en Cáceres el $50 \%$ de las diferencias se sitúan entre el -12.7 y el $2.8 \%$, y en Valencia entre el 0.0 y el $8.8 \%$, mientras que el $90 \%$ lo hacen entre el -25.4 y el $12.2 \%$, y el -8.8 y el $15.6 \%$ respectivamente.

Si se representan los valores medios mensuales de las diferencias entre el PWV del GPS y del fotómetro de Cáceres y Huelva, por ser las únicas con suficientes datos durante todo el año, no se obtiene ninguna tendencia que sea común a ambos emplazamientos (Figura 7.15).
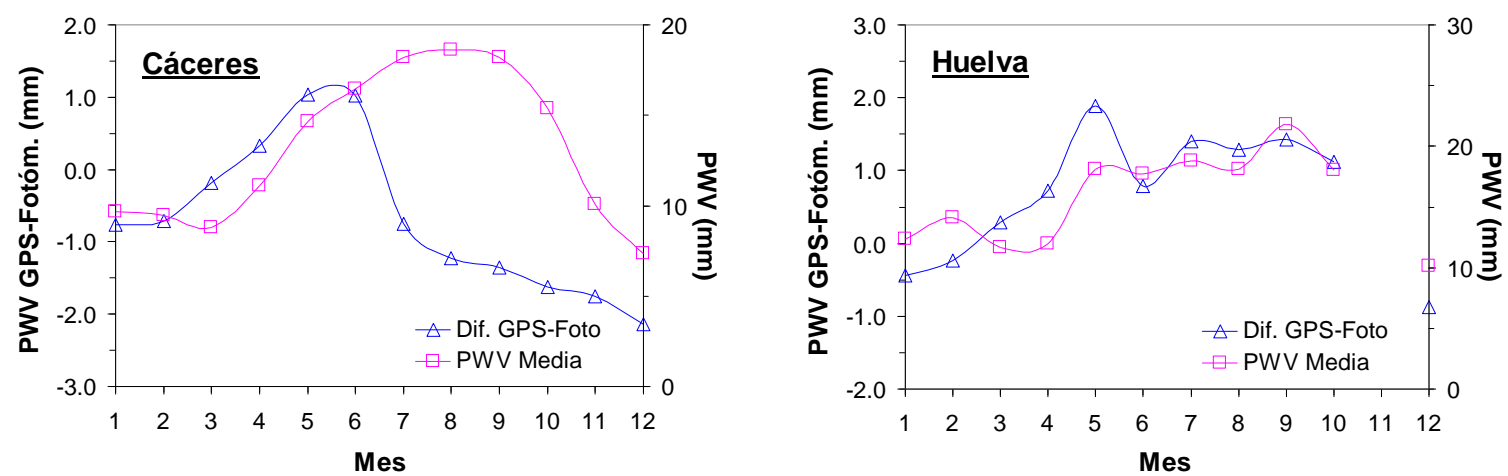

Figura 7.15 - Valores medios mensuales de la diferencia entre el PWV del GPS y del fotómetro.

\subsubsection{Comparativa medias diarias}

Mientras que para calcular el valor medio diario del PWV de los datos de los GPS se dispone de 24 medidas uniformemente distribuidas a lo largo del día, en el caso de los fotómetros el número de datos disponibles para cada día dependerá de las condiciones meteorológicas y 
siempre sólo durante las horas de luz solar. No obstante, el sesgo que podría introducir el ciclo diurno del PWV es prácticamente despreciable en términos medios. Sin embargo, en días de alta variabilidad del PWV las diferencias entre ambas medias si pueden ser importantes, lo que se reflejaría como un aumento de la dispersión en la serie de las diferencias.

La Figura 7.16 muestra la distribución del histograma de frecuencias de las diferencias de las medias diarias de ambas técnicas. Todos ellos muestran un desplazamiento hacia la derecha, mucho más acusado en Valencia y Lisboa, incluso en la estación de Cáceres que en la comparativa de las medidas instantáneas presentaba un desplazamiento de signo opuesto. La mediana se encuentra o bien en el intervalo de la clase modal, como en Huelva y Cáceres, o a la derecha de este. Por su parte, la media es mayor que la mediana y siempre queda a la derecha de la clase modal. El 50\% de las diferencias queda en un intervalo de 2 a $2.7 \mathrm{~mm}$ de amplitud centrado en la mediana y el $90 \%$ en otro de 4.7 a $6.6 \mathrm{~mm}$ de amplitud. Como se observa en la gráfica, Valencia es la estación que presenta una menor dispersión de las diferencias, y Lisboa la que mayor.
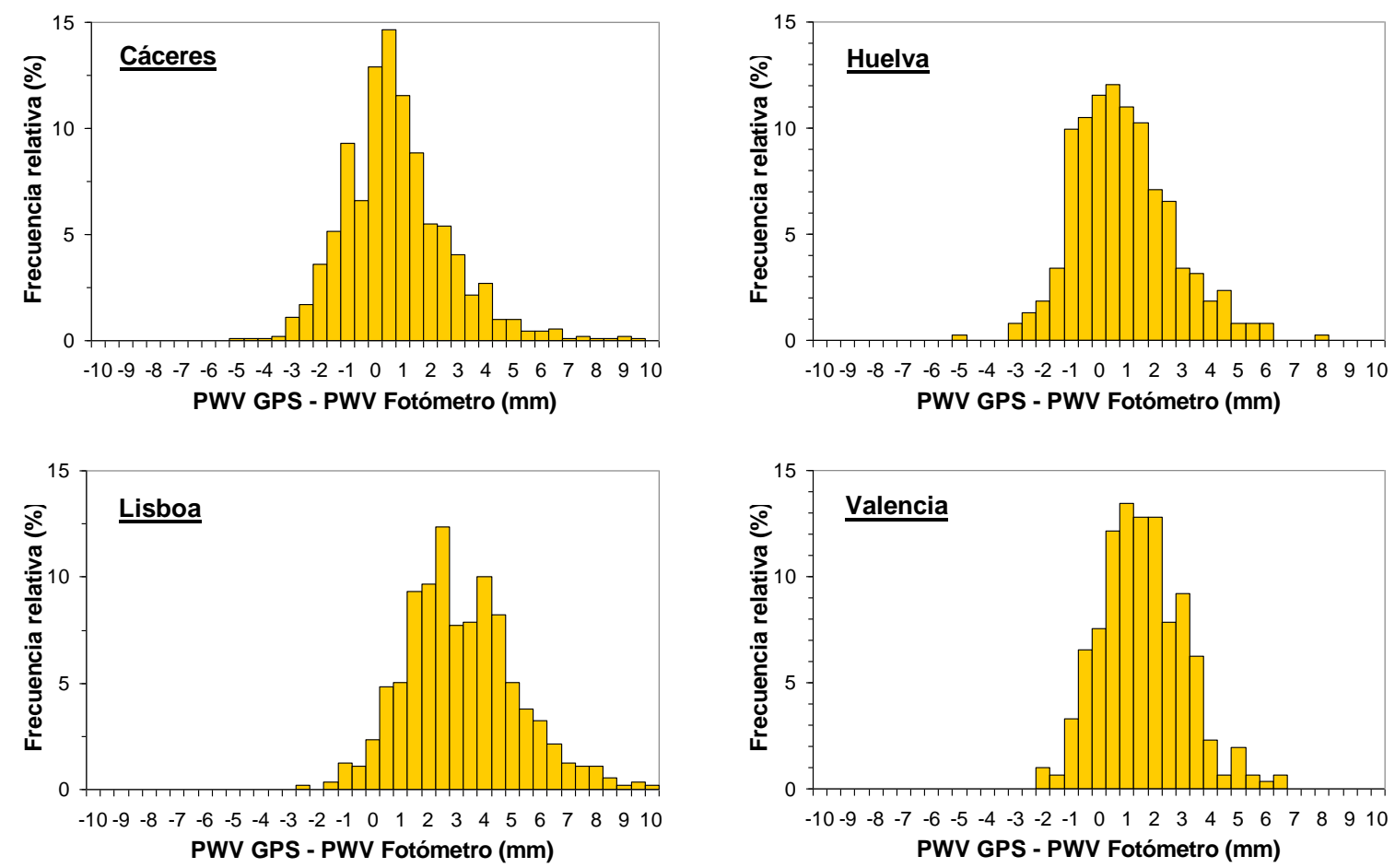

Figura 7.16 - Histograma de frecuencias de la diferencia de la media diaria del PWV de los GPS y de los fotómetros.

Todos los estadísticos de la comparativa (Tabla 7.8) empeoran respecto a los de la comparativa de las medidas instantáneas, aunque en Huelva lo hacen en menor medida y en Lisboa de una manera más acusada. Esto se debe en parte por la diferente distribución temporal de las medidas de ambas técnicas, y en parte también porque al ampliar el periodo de comparación se están computando medidas anteriores al cambio en la calibración del centro de fase de las antenas GPS, lo que implica un sesgo importante. Este hecho sólo afecta a las 
estaciones de Lisboa y Cáceres, que son las únicas con datos anteriores a dicho cambio. Esto explica que en Cáceres las bias pasen de ser negativas a ser positivas. Excluyendo la estación de Lisboa, en las otras tres la std aumenta en la misma medida, mientras que las bias aumentan en mayor medida en Cáceres por el motivo ya expuesto.

\begin{tabular}{lccccccccc}
\hline Estación & $\begin{array}{l}\text { PWV } \\
\text { GPS }\end{array}$ & $\begin{array}{c}\text { PWV } \\
\text { Fotómetro }\end{array}$ & BIAS & RMSE & MAE & STD & $\begin{array}{c}\text { RMDA } \\
\%\end{array}$ & R $^{2}$ & $\begin{array}{c}\text { № } \\
\text { Días }\end{array}$ \\
\hline Cáceres & 14.79 & 14.04 & 0.76 & 2.05 & 1.50 & 1.91 & 11.10 & 0.90 & 893 \\
Huelva & 17.33 & 16.47 & 0.87 & 1.97 & 1.49 & 1.77 & 9.12 & 0.93 & 381 \\
Lisboa & 20.81 & 17.57 & 3.24 & 3.89 & 3.29 & 2.15 & 17.00 & 0.89 & 558 \\
Valencia & 19.99 & 18.43 & 1.56 & 2.18 & 1.75 & 1.52 & 9.52 & 0.96 & 305 \\
\hline
\end{tabular}

Tabla 7.8 - Resultados de la comparativa de las medidas diarias GPS-Fotómetro.

En la evolución temporal de las diferencias para la estación de Cáceres (Figura 7.17) se aprecia claramente que estas presentan un ciclo anual con mínimos en invierno y máximos en verano, tal y como ocurría también en la comparativa sondeo-GPS.
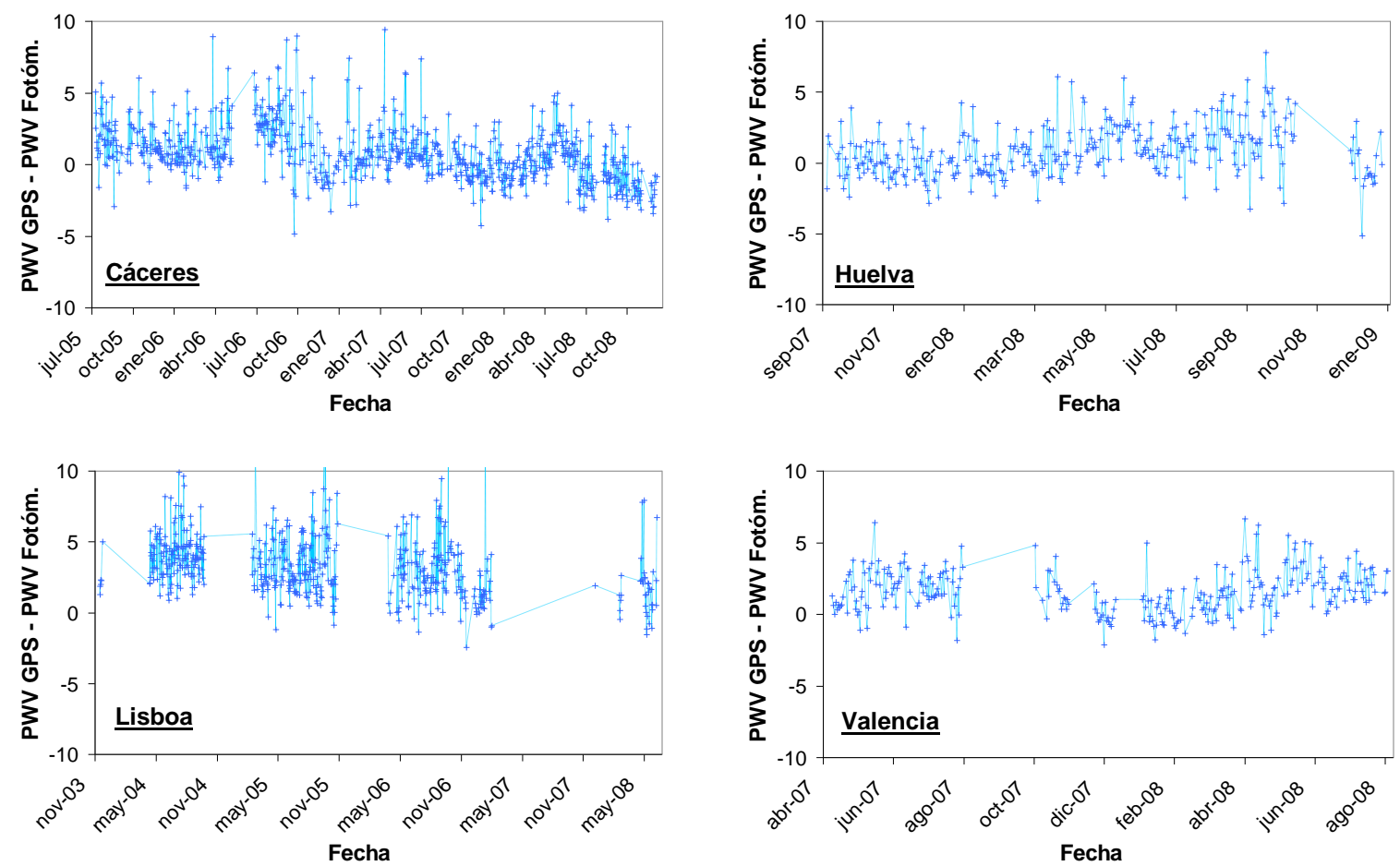

Figura 7.17 - Diferencias entre la media diaria del PWV de los datos de los GPS y de los fotómetros.

\subsubsection{Comparativa medias mensuales}

Los resultados de esta comparación se muestran en la Tabla 7.9. Las medidas de los GPS presentan en todos los casos una sobreestimación del PWV con respecto a la de los fotómetros, y además con un valor de las bias del orden de 0.5 a $1 \mathrm{~mm}$ superior al de la comparación de las medias diarias, sin embargo el std disminuye unos $0.5 \mathrm{~mm}$. 


\begin{tabular}{lccccccccc}
\hline Estación & $\begin{array}{c}\text { PWV } \\
\text { GPS }\end{array}$ & $\begin{array}{c}\text { PWV } \\
\text { Fotómetro }\end{array}$ & BIAS & RMSE & MAE & STD & $\begin{array}{c}\text { RMDA } \\
\%\end{array}$ & R $^{2}$ & $\begin{array}{c}\text { No } \\
\text { Meses }\end{array}$ \\
\hline Cáceres & 15.52 & 13.99 & 1.53 & 2.07 & 1.70 & 1.40 & 11.28 & 0.89 & 34 \\
Huelva & 18.20 & 16.71 & 1.49 & 1.78 & 1.51 & 0.98 & 8.74 & 0.95 & 15 \\
Lisboa & 21.10 & 17.06 & 4.03 & 4.41 & 4.10 & 1.79 & 21.95 & 0.74 & 25 \\
Valencia & 19.89 & 17.75 & 2.14 & 2.33 & 2.14 & 0.94 & 11.67 & 0.98 & 11 \\
\hline
\end{tabular}

Tabla 7.9 - Resultados de la comparativa de las medidas mensuales GPS-Fotómetro.

La evolución temporal de las medias mensuales (Figura 7.18) muestra una vez más la reducción del sesgo a partir de noviembre de 2006, pero además muestra también como este no es constante a lo largo del tiempo, sino que va cambiando como consecuencia de la degradación de los filtros de los fotómetros con el tiempo y de la recalibración de los equipos.
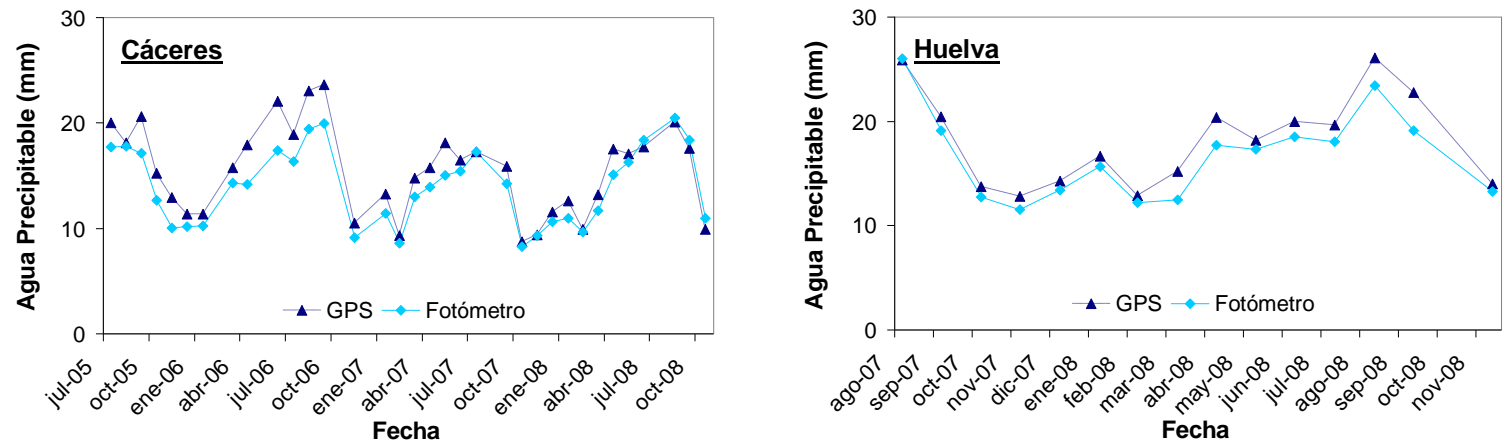

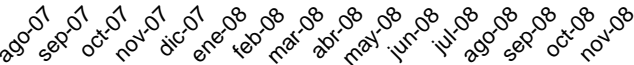
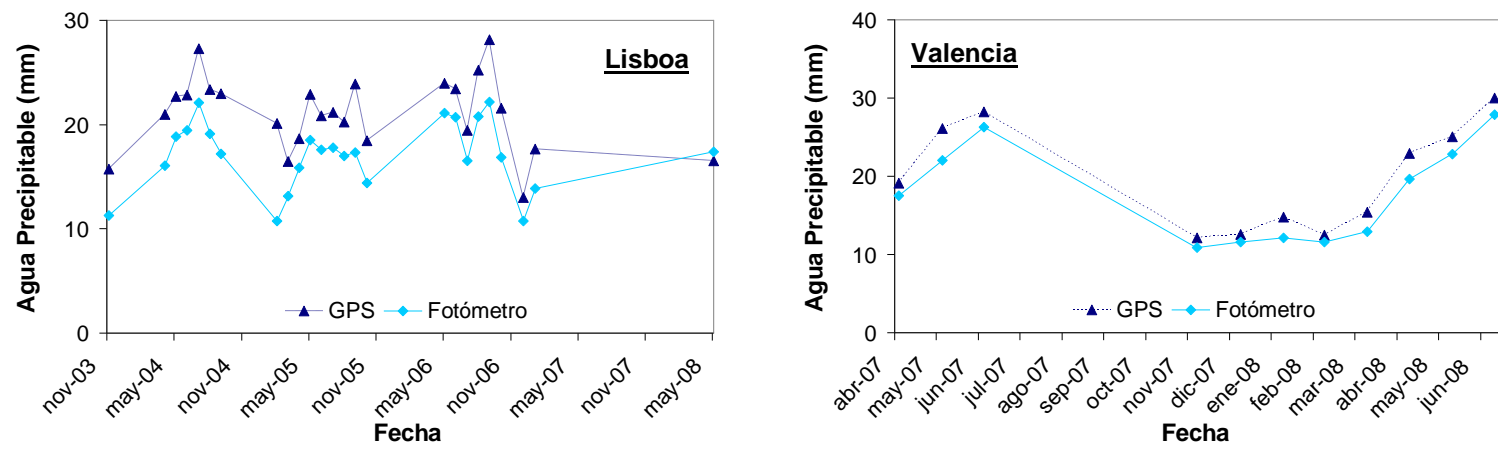

Figura 7.18 - Evolución de la media mensual de PWV de los GPS y de los fotómetros. 


\section{Capítulo 8}

\section{SINERGIAS}

Como ejemplo de las sinergias que pueden existir entre las distintas técnicas usadas para medir el PWV, en este capítulo se estudiarán algunas posibles aplicaciones de la comparativa de datos provenientes de diferentes instrumentos en un mismo emplazamiento. En concreto, se verá su utilidad para el estudio de cuatro fenómenos: 1) la influencia de la radiación solar en las medidas de los sondeos; 2) la mejora en la precisión del posicionamiento con el sistema GPS, después de que el IGS adoptara una calibración absoluta de las variaciones del centro de fase de las antenas; 3) la validación de la calibración de los filtros de los fotómetros solares; 4) el sesgo en los datos de los fotómetros solares al medir sólo en condiciones de cielo despejado.

\subsection{Diferencia día-noche en las medias de los sondeos}

Está ampliamente reportado en la literatura que las medidas de humedad de los sondeos pueden presentar un sesgo seco durante el día como consecuencia del calentamiento de los sensores por la radiación solar (Turner et al., 2003; Smout et al., 2005; Pathack et al., 2005; Ciesielski et al., 2009). Durante el día los sensores se calientan debido a la radiación solar incidente, lo que implica que la temperatura que registran sea mayor que la del aire que les rodea. La cantidad de vapor de agua que admite el aire seco antes de alcanzar la saturación depende de la temperatura, mientras mayor sea ésta mayor es la cantidad de vapor de vapor que el aire admite. Como la humedad relativa viene definida como la razón entre la cantidad de vapor que contiene el aire y la máxima que podría contener, si la temperatura se determina por exceso también se estará haciendo lo mismo con el denominar de este cociente, y por tanto se estará subestimando la humedad relativa. Aunque los fabricantes son concientes de este problema y han introducido modificaciones en el diseño de los sensores, un buen test para conocer si el problema persiste y cuantificarlo es comparar las medidas de los sondeos con las de otros equipos cuyas medidas no estén afectadas por este problema, como pueden ser los receptores GPS.

En este apartado se han comparado por separado las medidas de PWV de las 00 y de las 12 UTC de los sondeos y los receptores GPS en cuatro emplazamientos dotados de ambas instrumentaciones: Coruña, Madrid, Santander y Zaragoza. Para ello se han utilizado los datos de los días con medidas a ambas horas de los años 2007 y 2008. Durante este periodo la 
sonda utilizada en estas estaciones de radiosondeo fue siempre del modelo RS92-SGP de Vaisala.
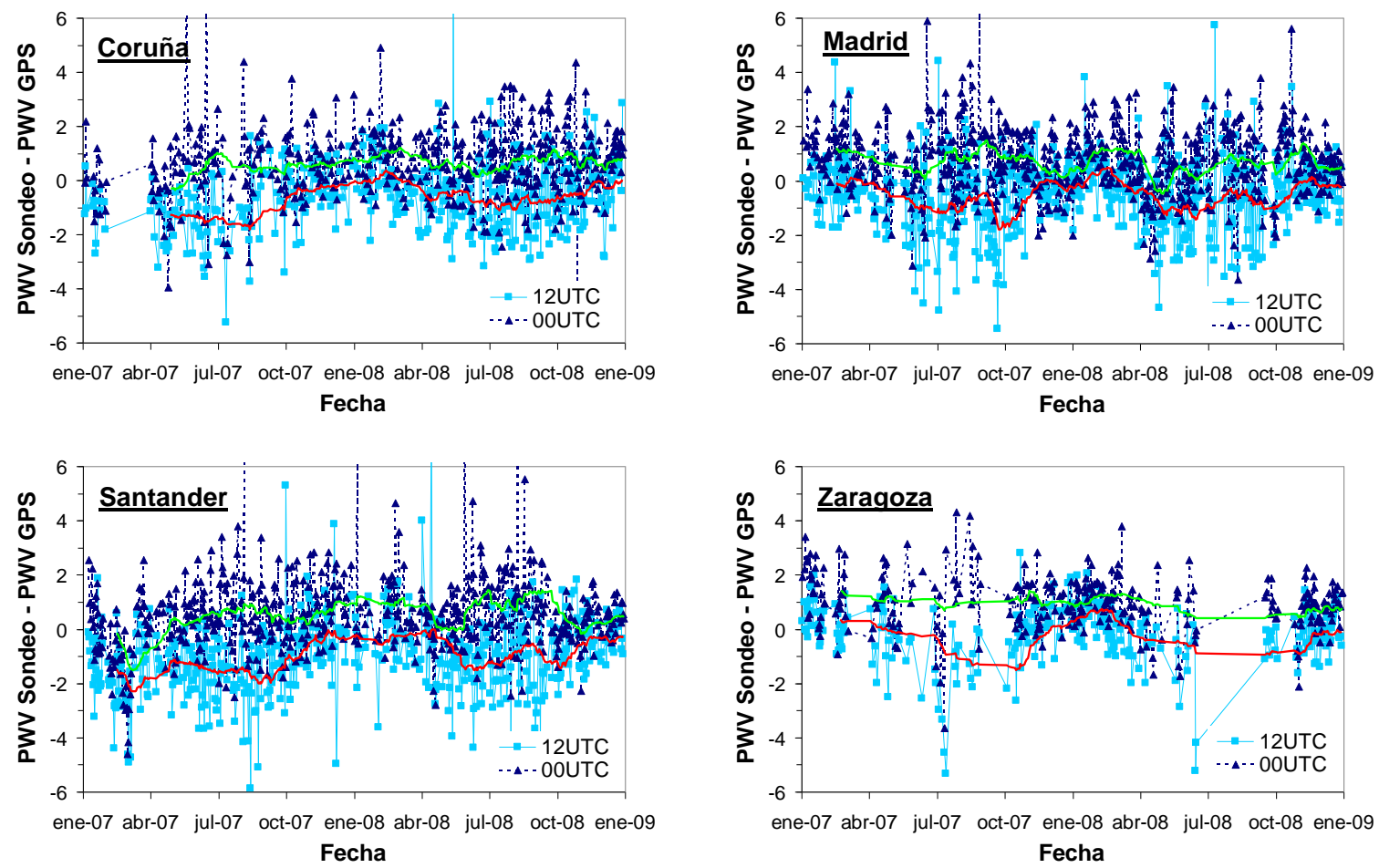

Figura 8.1 - Diferencias en el PWV de las medidas de los sondeos y del GPS en cuatro emplazamientos dotados de ambas instrumentaciones. Las líneas verde y roja representan la media móvil de treinta días de las series de datos de las 00 y 12 UTC respectivamente.

En la Figura 8.1 se han representado las diferencias del PWV entre los pares de datos del sondeo y del GPS para la serie de las observaciones de las 00 y de las 12 UTC de forma independiente. En ella, se puede observar un claro desplazamiento vertical entre ambas series en torno al cero. Durante el día (12 UTC) las diferencias son mayoritariamente negativas, el sondeo registra menos PWV que el GPS, mientras que por la noche (00 UTC) ocurre a la inversa. Esta distribución no aleatoria de las diferencias indica un comportamiento de las medidas de los sondeos relativo a las del GPS sesgado durante el día y la noche. Si se parte del hecho de que las medidas del GPS no presentan ningún sesgo entre el día y la noche, este tiene que se achacable a los sondeos.

Los valores numéricos (Tabla 8.1) muestran que los sondeos de las 12 UTC registran con respecto a los de las 00 UTC menores cantidades de PWV. Las diferencias entre los valores medios de ambas horas oscilan entre los $-1.27 \mathrm{~mm}$ en Madrid y los $-1.87 \mathrm{~mm}$ en Santander. Estas diferencias son del orden de un 8 a $9 \%$ del valor medio del PWV. Sin embargo, las medidas de los GPS toman valores medios muy semejantes para ambas horas, registrándose una máxima diferencia de $-0.39 \mathrm{~mm}$ en Santander, lo que supone una variación del 1.97\%. Estos últimos resultados están más en concordancia con el débil ciclo diurno del PWV tal y como se ha visto en el Capítulo 5. 


\begin{tabular}{lcccccccc}
\hline \multirow{2}{*}{ Estación } & \multicolumn{4}{c}{ PWV Sondeo } & \multicolumn{4}{c}{ PWV GPS } \\
& Media & 00 UTC & $\mathbf{1 2}$ UTC & Dif. & Media & 00 UTC & 12 UTC & Dif. \\
\hline Coruña & 18.77 & 19.46 & 18.08 & -1.38 & 18.76 & 18.84 & 18.68 & -0.15 \\
Madrid & 14.42 & 15.06 & 13.79 & -1.27 & 14.35 & 14.37 & 14.33 & -0.04 \\
Santander & 19.79 & 20.72 & 18.85 & -1.87 & 20.05 & 20.25 & 19.85 & -0.39 \\
Zaragoza & 14.48 & 15.12 & 13.84 & -1.28 & 14.07 & 14.14 & 14.00 & -0.14 \\
\hline
\end{tabular}

Tabla 8.1 - Valores medios del PWV de los radiosondeos y de los GPS para las medidas de las 00 UTC y de las 12 UTC. La columna 'Dif.' representa la diferencia entre las medidas de las 12 y las 00 UTC.

Se ha definido la diferencia entre las medias del día y la noche $D_{D / N}$ como,

$$
D_{D / N}=1-\frac{\overline{P W V_{D}}}{\overline{P W V_{D+N}}}
$$

donde el numerador es la media del PWV obtenida sólo con las medidas de las 12 UTC, y el denominador la media total obtenida con las medidas de las 12 y las 00 UTC. Valores positivos de $D_{D / N}$ indican un sesgo seco durante el día y valores negativos un sesgo húmedo.

\begin{tabular}{lcc}
\hline Estación & $\mathrm{D}_{\mathrm{D} / \mathrm{N}}$ Sond. & $\mathrm{D}_{\mathrm{D} / \mathrm{N}} \mathrm{GPS}$ \\
\hline Coruña & 0.037 & 0.004 \\
Madrid & 0.044 & 0.002 \\
Santander & 0.047 & 0.010 \\
Zaragoza & 0.044 & 0.005
\end{tabular}

Tabla 8.2 - Valores del coeficiente $\mathrm{D}_{\mathrm{D} / \mathrm{N}}$ para las medidas de los sondeos y de los GPS.

En los cuatro emplazamientos, los datos de los sondeos presentan un sesgo seco en las medidas de las 12 UTC, con valores del coeficiente $D_{D / N}$ muy parecidos (Tabla 8.2). Por el contrario, los datos de los GPS no presentan un sesgo significativo entre el día y la noche.

Los resultados obtenidos de la comparativa entre las medidas de los sondeos y los GPS a las 00 y las 12 UTC (Tabla 8.3) muestran que los sondeos sobrestiman el PWV para las observaciones de las 00 UTC en valores que van desde los $0.47 \mathrm{~mm}$ en Santander a los 0.98 $\mathrm{mm}$ en Zaragoza. Para las observaciones de las 12 UTC esta sobrestimación pasa a ser una subestimación, con valores que en este caso oscilan entre $-0.16 \mathrm{~mm}$ en Zaragoza y $-1.00 \mathrm{~mm}$ en Santander. Por tanto, la variación total entre las medidas del sondeo a las 00 y las 12 UTC será igual a la suma de la subestimación de las medidas de las 12 UTC más la sobrestimación de las medidas de las 00 UTC. De esta forma se han obtenido unos valores para las diferencias día-noche en las medidas de los sondeos que oscilan entre los $-1.14 \mathrm{~mm}$ de Zaragoza y los $-1.47 \mathrm{~mm}$ de Santander. En término medio esto supone una subestimación de aproximadamente un $7.5 \%$ en las medidas de PWV de las 12 UTC de los sondeos. Estos resultados concuerdan con los obtenidos por otros autores en distintas inter-comparaciones (Vömel et al., 2007; Yoneyama et al., 2008). 
En el computo global de todas las medidas unas diferencias tienden a compensarse con otras, de forma que las bias totales son pequeñas o prácticamente cero como en Coruña y Madrid. Tanto la std como el rmse de ambas series de datos son muy similares en todos los emplazamientos.

\begin{tabular}{lcccccc}
\hline & \multicolumn{2}{c}{ BIAS } & \multicolumn{2}{c}{ RMSE } & \multicolumn{2}{c}{ MAE } \\
Estación & 00 UTC & 12 UTC & 00 UTC & 12 UTC & 00 UTC & 12 UTC \\
\hline Coruña & 0.62 & -0.61 & 1.47 & 1.39 & 1.11 & 1.09 \\
Madrid & 0.68 & -0.54 & 1.42 & 1.45 & 1.11 & 1.08 \\
Santander & 0.47 & -1.00 & 1.63 & 1.71 & 1.07 & 1.34 \\
Zaragoza & 0.98 & -0.16 & 1.41 & 1.11 & 1.16 & 0.78 \\
\hline
\end{tabular}

Tabla 8.3 - Resultados de la comparativa entre los datos de PWV de los sondeos y del GPS para las observaciones de las 00 y 12 UTC de forma independiente.

Repitiendo el cálculo para la estación de Madrid, pero en este caso con los datos de los años 2002/2003 cuando el modelo de sonda utilizado era el RS80, se obtienen unas bias menores entre las medidas del día y la noche. El problema del calentamiento en la sonda RS92-SGP es más acusado que en otros modelos como el RS80, al estar estos últimos provistos de un abrigo protector contra la radiación solar incidente (Miloshevich et al., 2006; Cady-Pereira et al., 2008). El uso de estas cubiertas también tiene inconvenientes como la reducción de la ventilación y el aumento del tiempo de respuesta del sensor al limitar el flujo de aire exterior.

\subsection{Calibración absoluta del centro de fase de las antenas GPS}

El posicionamiento con el sistema GPS se basa en una triangulación de la distancia entre el receptor GPS en tierra y las antenas emisoras de los satélites de la constelación GPS. Estas distancias se calculan en base al tiempo de vuelo de la señal de radio emitida por los satélites, y están referidas al centro de fase de la antena que es el punto donde se emite y recibe la señal. Pero el centro de fase de una antena depende de la frecuencia de la señal, y no es un punto estable sino que varía con los ángulos de elevación y de azimut de la señal de una manera distinta para cada modelo de antena (Rothacher et al., 1995). Para corregir este problema, las antenas deben ser calibradas. Este proceso consiste en calcular las variaciones del centro de fase (PCVs, del inglés Phase Centre Variations) con respecto a un punto de referencia, como un conjunto de offsets aplicables a cada ángulo y modelo de antena.

Básicamente existen dos métodos de calibrar las antenas, los modelos relativos y los absolutos. Un modelo de calibración relativo de antenas se basa en tomar un modelo de antena como de referencia, con una corrección cero, y calcular las correcciones para los otros modelos de antena por comparación con la antena de referencia. Este método tiene el inconveniente del error sistemático asociado con las PCVs de la antena de referencia (Schmid, 
2004), al tratarse de correcciones relativas. Mientras que la calibración absoluta consiste en la determinación para cada ángulo de las PCVs absolutas propias de cada modelo de antena, proporcionando un conjunto de offsets 3D (Wübbena et al., 2000).

En noviembre del año 2006, el IGS adoptó un modelo de calibración absoluta de las PCVs de las antenas en la rutina de generación de las orbitas precisas de los satélites y de las coordenadas de las estaciones, en lugar del modelo de variaciones relativas que se había usado hasta entonces (IGSMail-5438, 2006). Esta modificación debería suponer un aumento de la precisión en el posicionamiento (Schmid, 2005), y por consiguiente en los subproductos de post-proceso como es el ZTD. Conforme al procedimiento descrito en la metodología para calcular el PWV de los receptores GPS, cualquier error en la determinación de la distancia entre los satélites GPS y los receptores en tierra se propaga al ZTD, y por consiguiente al PWV, y a la inversa cualquier mejora en la precisión del posicionamiento debería implicar otra en la estimación del PWV.

En este punto se demostrará, por comparación con las otras técnicas (sondeos y fotómetros), que las medidas de PWV del GPS son más precisas desde el 6 de noviembre del 2006, lo que lleva a afirmar que el cambio del modelo relativo al absoluto en la determinación de las PCVs ha sido una mejora. Para la comparativa se han seleccionado los emplazamientos de receptores GPS en los que en su cercanía existía una estación equipada con alguna de las otras dos instrumentaciones, y que al mismo tiempo dispusiera de series suficientemente largas. Con estos requisitos se tienen cuatro emplazamientos, tres de ellos equipados con GPS y sondeos (Coruña, Santander y Madrid), y otro con GPS y fotómetro (Cáceres). Para que la comparativa fuera homogénea y así evitar cualquier sesgo, se ha seleccionado un periodo de dos años antes y después del 6 de noviembre de 2006, del 6/11/04 al 5/11/06 y del 6/11/06 al 5/11/08, excepto en el caso de la estación fotométrica de Cáceres que empezó a funcionar en julio del 2005, pero se ha querido incluir esta estación al ser la única dotada de fotómetro para ilustrar los resultados de la comparación con varias técnicas distintas. En la comparación se han usado sólo los pares de datos coincidentes en el tiempo.

Con anterioridad a la adopción del modelo de calibración absoluta de las PCVs (Tabla 8.4), el PWV obtenido de los receptores de GPS es siempre mayor que el obtenido por cualquiera de las otras técnicas en los cuatro emplazamientos. Este sesgo húmedo varía entre 1.75 y 3.04 mm (entre un 10.49 y un 17.71\%). Después del 6 de noviembre del 2006 (Tabla 8.5) este sesgo prácticamente se hace cero para todas las estaciones (menos de un $2 \%$ en términos relativos en el peor de los casos). También el rmad y el rmse experimentan una importante disminución, el primero de ellos disminuye alrededor de un $39 \%$, desde un rango de variación del 12.36 al $18.73 \%$ a otro del 6.50 al $8.64 \%$, mientras que el segundo lo hace alrededor de un $47 \%$, desde un rango de 2.51 a $4.30 \mathrm{~mm}$ a otro de 1.25 a $1.64 \mathrm{~mm}$. Con estos números parece claro que el modelo de calibración relativo sobreestimaba el PWV en unos 2 a $3 \mathrm{~mm}$. 


\begin{tabular}{lccccccc}
\hline & & \multicolumn{5}{c}{ Anterior al 6 de noviembre de 2006 } \\
Estación & Técnicas & $\begin{array}{c}\text { PWV } \\
\text { GPS }\end{array}$ & $\begin{array}{c}\text { PWV } \\
\text { S / F }\end{array}$ & BIAS & BIAS \% & $\begin{array}{c}\text { RMAD } \\
\%\end{array}$ & RMSE \\
\hline Cáceres & $\begin{array}{c}\text { GPS } \\
\text { Fotómetro }\end{array}$ & 16.56 & 14.81 & 1.75 & 10.49 & 12.36 & 2.51 \\
Coruña & $\begin{array}{c}\text { GPS } \\
\text { Sontander }\end{array}$ & 21.18 & 18.56 & 2.61 & 14.48 & 15.13 & 3.22 \\
Madrid & $\begin{array}{c}\text { GPS } \\
\text { Gondeo }\end{array}$ & 21.68 & 18.64 & 3.04 & 17.71 & 18.73 & 4.30 \\
\hline & $\begin{array}{c}\text { GPS } \\
\text { Sondeo }\end{array}$ & 15.81 & 13.92 & 1.89 & 15.37 & 16.74 & 2.59 \\
\hline
\end{tabular}

Tabla 8.4 - Estadísticas de la comparativa entre el PWV de los datos GPS y de los sondeos (o fotómetro) con las series de dos años de datos anteriores al 6 de noviembre del 2006. La columna Técnica representa las dos Fuentes de datos comparadas.

\begin{tabular}{lccccccc}
\hline & & \multicolumn{5}{c}{ Posterior al 6 de noviembre de 2006 } \\
Estación & Técnicas & $\begin{array}{c}\text { PWV } \\
\text { GPS }\end{array}$ & $\begin{array}{c}\text { PWV } \\
\text { S / F }\end{array}$ & BIAS & BIAS \% & $\begin{array}{c}\text { RMAD } \\
\%\end{array}$ & RMSE \\
\hline Cáceres & $\begin{array}{c}\text { GPS } \\
\text { Fotómetro }\end{array}$ & 13.74 & 13.80 & -0.06 & -1.82 & 8.00 & 1.25 \\
Coruña & $\begin{array}{c}\text { GPS } \\
\text { Santander } \\
\text { GPS }\end{array}$ & 19.06 & 19.02 & 0.04 & -0.05 & 6.50 & 1.59 \\
Madrid & $\begin{array}{c}\text { Sondeo } \\
\text { GPS }\end{array}$ & 19.76 & 19.59 & 0.17 & 0.84 & 6.84 & 1.64 \\
\hline
\end{tabular}

Tabla 8.5 - Estadísticas similares a la de la Tabla 8.4 pero con las series de dos años de datos posteriores al 6 de noviembre del 2006.

La Figura 8.2 muestra la recta de regresión de las series comparadas antes y después del 6 de noviembre del 2006. Se puede observar como después de esta fecha las rectas de regresión se ajustan mejor a la diagonal, el coeficiente de correlación aumenta ligeramente, y la pendiente se aproxima a la unidad y la ordenada en el origen al cero (Tabla 8.6).

\begin{tabular}{lccccccc}
\hline & & \multicolumn{3}{c}{ Antes $\mathbf{6}$ nov 2006} & \multicolumn{3}{c}{ Después 6 nov 2006} \\
Estación & Técnicas & $\mathbf{R}^{2}$ & $\mathbf{m}$ & $\mathbf{b}$ & $\mathbf{R}^{2}$ & $\mathbf{m}$ & $\mathbf{b}$ \\
\hline Cáceres & $\begin{array}{c}\text { GPS } \\
\text { Cotómetro }\end{array}$ & 0.93 & 1.11 & 0.05 & 0.95 & 1.01 & -0.21 \\
Santana & $\begin{array}{c}\text { GPS } \\
\text { Sondeo } \\
\text { Madrid }\end{array}$ & 0.94 & 1.02 & 2.33 & 0.95 & 0.98 & 0.42 \\
& $\begin{array}{c}\text { GPS } \\
\text { Gondeo }\end{array}$ & 0.87 & 0.92 & 4.60 & 0.95 & 0.96 & 0.99 \\
\hline Sondeo & 0.94 & 0.99 & 2.01 & 0.94 & 0.98 & 0.18 \\
\hline
\end{tabular}

Tabla 8.6 - Pendiente $(\mathrm{m})$ y ordenada en el origen de la recta de regresión (b), y coeficiente de correlación $\left(R^{2}\right)$ antes y después del 6 de noviembre del 2006.

En la Figura 8.3, donde se han ploteado las diferencias frente al valor medio del PWV, se observa un desacoplamiento entre las diferencias anteriores y posteriores a noviembre del 2006. La forma de la nube de puntos es similar pero con un desplazamiento vertical entre ambas series. Si se estudia la evolución temporal de las diferencias en el PWV entre las técnicas comparadas (Figura 8.4), se observa también una discontinuidad significativa en la 
fecha en cuestión. La nube de puntos experimenta un desplazamiento vertical oscilando alrededor de cero después del 6 de noviembre del 2006.
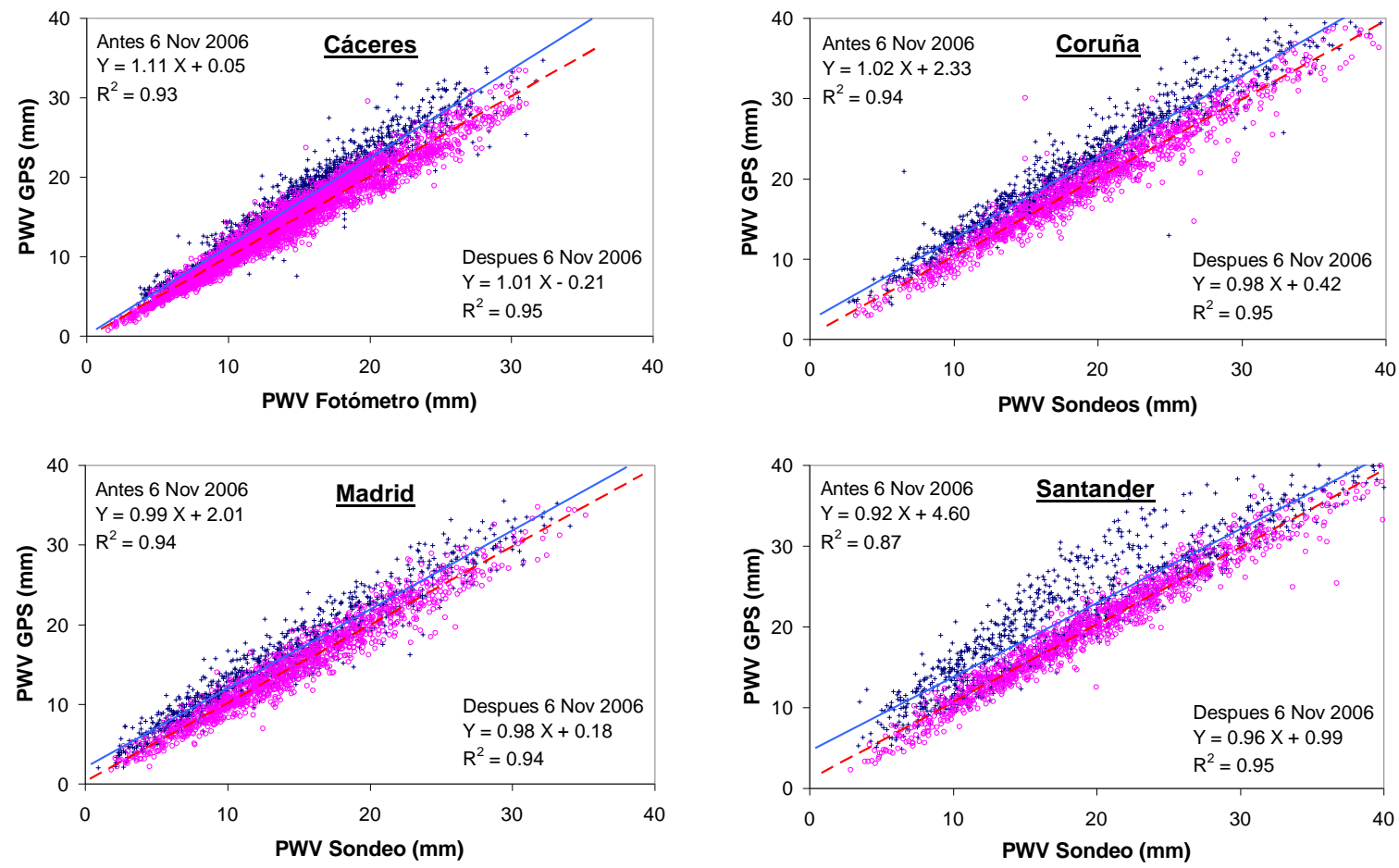

Figura 8.2 - Recta de regresión y coeficiente de correlación $\left(R^{2}\right)$ entre las series de datos de PWV de los GPS y de los sondeos (o fotómetro). Las cruces azules y la línea sólida azul representan datos anteriores al 6 de noviembre del 2006, y los círculos rosas y la línea roja discontinua datos posteriores a dicha fecha.
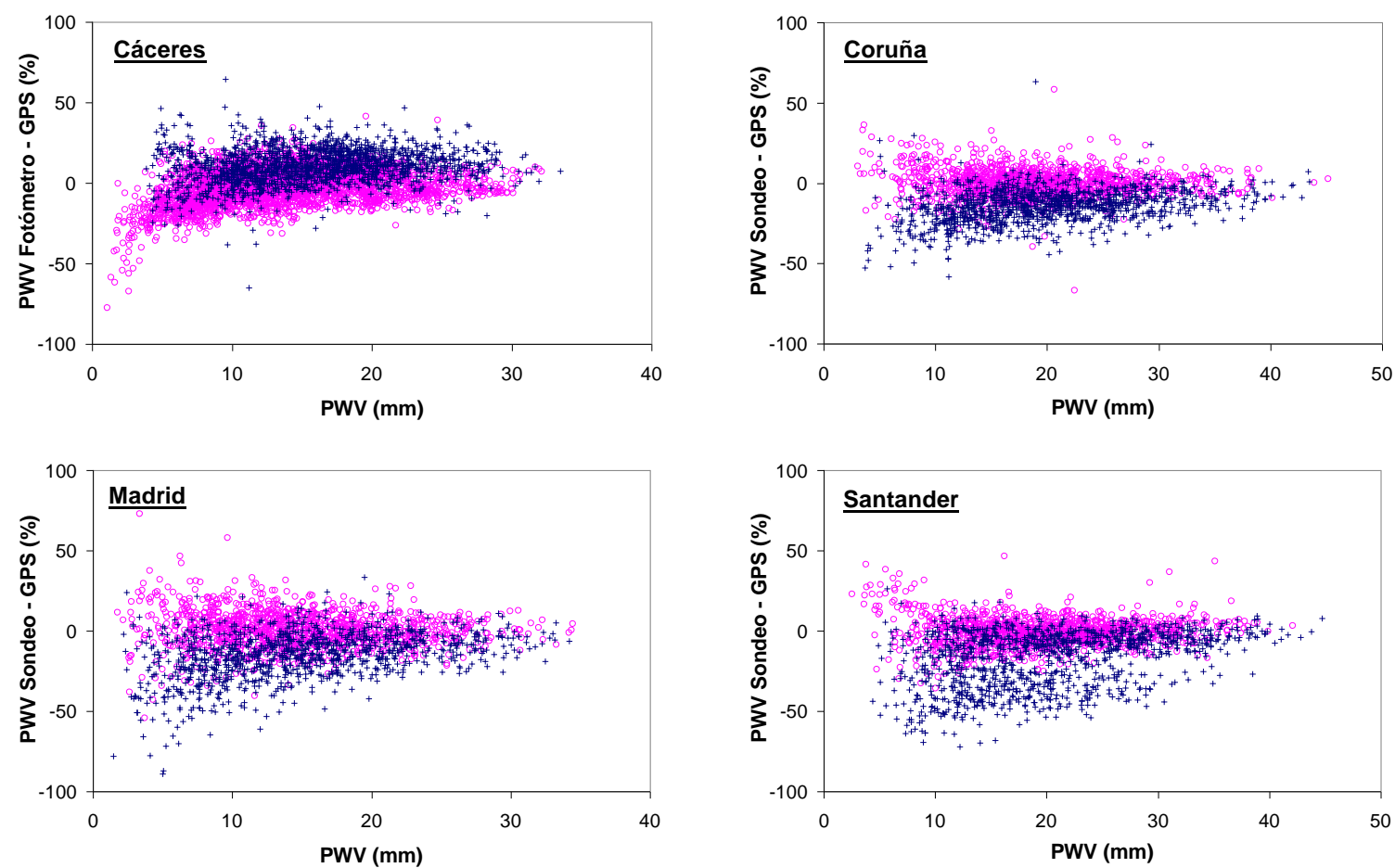

Figura 8.3 - Ploteo de las diferencias relativas entre el PWV del GPS y de los sondeos (o fotómetro) frente al valor medio del PWV. Las cruces azules y los círculos rosas representan los datos anteriores y posteriores al 6 Nov 2006 respectivamente. 

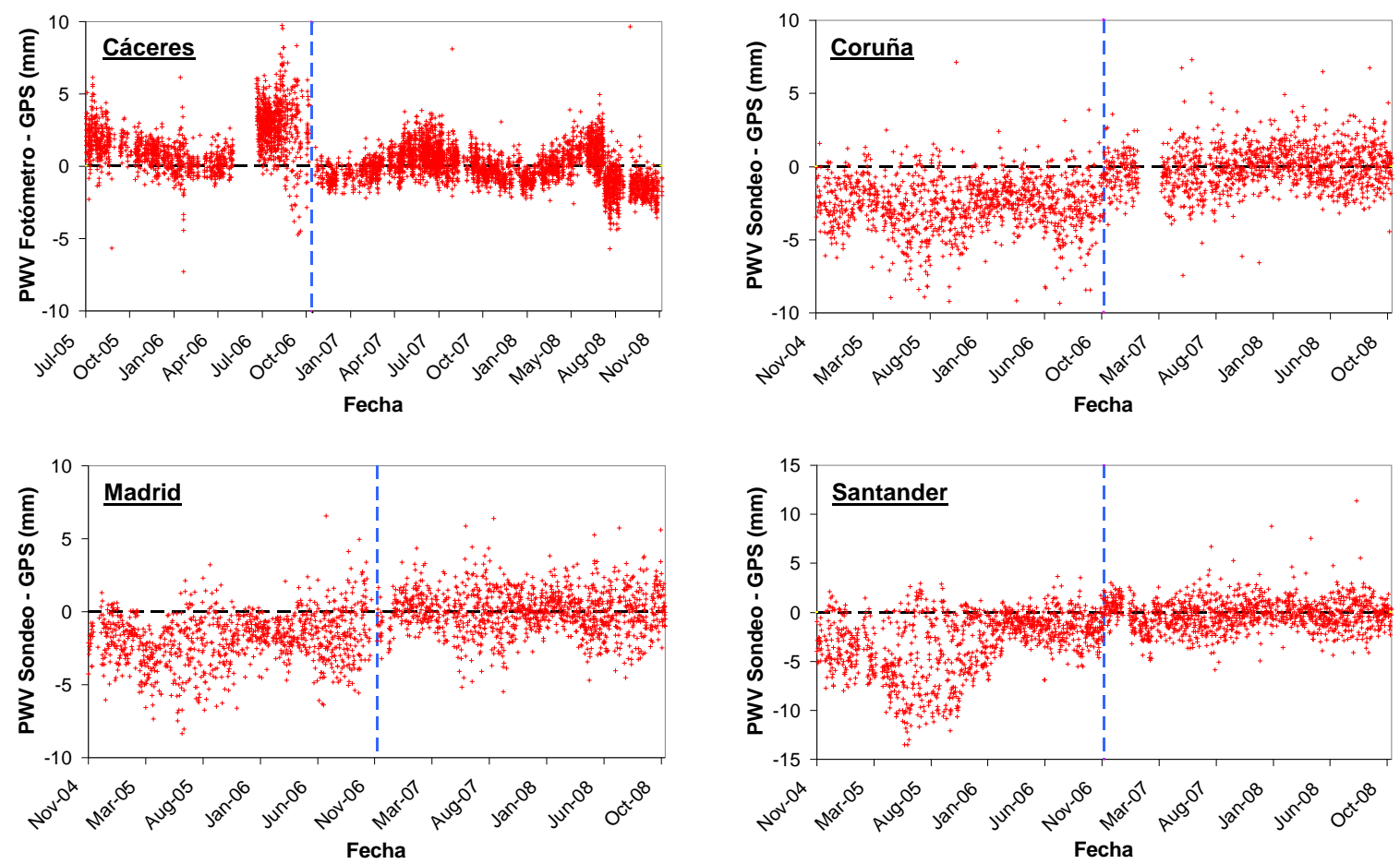

Figura 8.4 - Evolución temporal de las diferencias entre el PWV de los datos GPS y de la otra técnica (sondeo o fotómetro). La línea vertical azul discontinua marca la fecha del 6 de noviembre del 2006.

Con el paso del modelo de calibración relativo al absoluto algunos autores apuntan diferencias en las coordenadas de las estaciones (mayores en la vertical) y en el ZTD, que oscilan en termino medio entre 5 y 15 mm (Schmid, 2006; Bruyninx, 2006; Fotiou, 2008; Byun y BarServer, 2009). Teniendo en cuenta que $1 \mathrm{~mm}$ de PWV produce un retardo expresado en términos de longitud de aproximadamente $6.35 \mathrm{~mm}$, las cifras anteriores supondrían unas diferencias en el PWV del orden de las que se han encontrado en este estudio. Por tanto, se puede concluir que las medidas de PWV de los GPS presentaban un error sistemático, una sobreestimación que ha sido eliminada con la adopción del modelo absoluto de calibración de los PCVs de las antenas.

En el caso de la estación de Cáceres se observa como las diferencias siguen una onda anual con un pico en verano y un valle en invierno. Aún más, en verano las diferencias son mayores y positivas (valores del GPS más altos), mientras que en invierno las diferencias son menores y negativas (valores del fotómetro más altos). Que las diferencias sean mayores en verano que en invierno es algo general que ocurre en todas las estaciones, y que está relacionado con el hecho de que éstas son mayores cuanto mayor es el contenido de PWV. Sin embargo, el cambio de tendencia tan marcado en el signo de las diferencias es algo que puede estar relacionado con las medidas fotométricas, ya que no se presenta en la comparación entre el GPS y los sondeos. Desafortunadamente, no se dispone de otra estación dotada de GPS y fotómetro con una serie larga de datos que permita constatar este fenómeno. 


\subsection{Validación de las calibraciones de los fotómetros}

El envejecimiento de los filtros de los fotómetros solares altera sus coeficientes de transmisión, lo que obliga a que tengan que ser recalibrados periódicamente. La principal fuente de error de las medidas de los fotómetros solares radica precisamente en la determinación de las constantes de calibración de los filtros (Reagan et al., 1987; Bruegge et al., 1992), que son propias de cada instrumento. Así, la incertidumbre asociada a las medidas de PWV con los fotómetros solares es muy dependiente del instrumento y puede variar con el tiempo. De la comparativa de las medidas del fotómetro con las del GPS se puede extraer información sobre los cambios de instrumento, las calibraciones de los filtros de los fotómetros, o el envejecimiento de los filtros (Torres et al., 2010).

En este apartado se comparan las series temporales de los datos de PWV de los años 2007 al 2008 del fotómetro y del GPS en la estación de Cáceres. Durante este periodo, en dicho emplazamiento estuvo operativo el fotómetro Cimel nº 341 hasta el 8 de julio de 2008, cuando fue retirado para su calibración y sustituido por el Cimel n 353 . Si se representa la evolución temporal de la diferencia entre ambas medidas (Figura 8.5) se observa un salto en julio del 2008 que coincide con el cambio de instrumento.

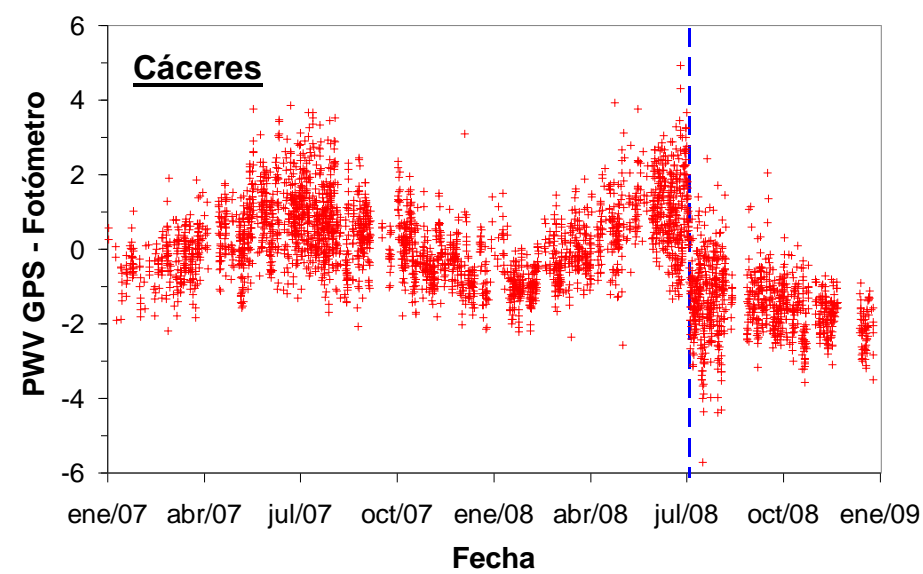

Figura 8.5 - Diferencias entre las medidas de PWV del GPS y del fotómetro en Cáceres. La línea vertical azul indica un cambio de fotómetro en este emplazamiento.

En el capítulo anterior se vió un ejemplo de cómo las diferencias entre las medidas del GPS y del fotómetro en Huelva aumentaban con la degradación de los filtros (Fig. 7.18), y como estas disminuían con la recalibración del fotómetro.

\subsection{Sesgo en las medidas de cielo despejado}

Los fotómetros solares sólo proporcionan medidas válidas en ausencia de nubosidad en la trayectoria entre el sol y el instrumento. La toma de medidas bajo esta limitación de cielo 
despejado puede conducir a un sesgo seco en las medidas de los fotómetros (Gaffen y Elliot, 1993). En este apartado se han utilizado los datos de los GPS para cuantificar el sesgo seco de las medidas fotométricas en los emplazamientos equipados con ambos instrumentos. Para ello se ha calculado el coeficiente definido por Gaffen y Elliot,

$$
S_{C D}=1-\frac{\overline{P W V_{C D}}}{\overline{P W V}}
$$

donde el numerador representa el contenido medio de PWV en condiciones de cielo despejado y el denominador el contenido medio en todas las condiciones. El numerador se ha obtenido promediando las medidas del GPS coincidentes en el tiempo con las medidas del fotómetro, y el denominador se ha calculado promediando todas las medidas del GPS para el mismo periodo de tiempo que las del numerador. Los fotómetros, además de medir bajo condiciones de cielo despejado lo hacen también sólo durante el día. Para cuantificar en que medida el sesgo de las medidas fotométricas se debe al requerimiento de cielo despejado o al propio ciclo diurno del PWV al medir sólo durante el día, se ha calculado también el coeficiente $D_{D / N}$ definido en el apartado 8.1 de este capítulo, considerado como medidas diurnas las realizadas entre las 06 y 18 UTC. La Tabla 8.7 recoge los valores obtenidos para los coeficientes $S_{C D}$ y $D_{D / N}$ con la serie de datos del año 2008.

\begin{tabular}{lcc}
\hline Estación & Coef. $\mathrm{S}_{\mathrm{CD}}$ & Coef. $\mathrm{D}_{\mathrm{D} / \mathrm{N}}$ \\
\hline Cáceres & 0.03 & -0.006 \\
Huelva & 0.05 & 0.001 \\
Valencia & 0.08 & 0.011 \\
\hline
\end{tabular}

Los valores positivos del coeficiente $\mathrm{S}_{\mathrm{CD}}$ en los tres emplazamientos indican la existencia de un sesgo seco. El PWV en condiciones de cielo despejado es en término medio aproximadamente un $5 \%$ menor que el valor medio de todos los días. El sesgo es mayor en las dos estaciones costeras, y especialmente en Valencia, que en la del interior. Ello apunta a que la atmósfera contiene una mayor humedad en las situaciones meteorológicas de cielos nubosos que en las de cielos despejados sobre los emplazamientos costeros que sobre los del interior. Los valores del coeficiente $D_{D / N}$ son un orden de magnitud menor que los del $S_{C D}$, por lo que el efecto del ciclo diurno al medir sólo durante el día puede considerar despreciable. 


\section{Capítulo 9}

\section{CASOS DE ESTUDIO}

La buena resolución espacial y temporal que proporcionan las actuales redes de receptores de GPS permite seguir con detalle los movimientos de los sistemas de masas de aire (Elgered et al., 1997). En este capítulo se estudiarán algunas situaciones meteorológicas de días con una gran variabilidad del PWV, en las que los datos de la red GPS son de gran utilidad por su mejor resolución. En concreto, se analizarán las situaciones para el periodo de estudio en las que el PWV ha presentado la mayor variación en un día, en valor absoluto y en valor relativo respecto al valor medio del día, y aquellas con la mayor variación en una hora. También se estudiará la evolución del PWV al paso de un sistema frontal y en un día de tormentas.

\subsection{Alta variabilidad diaria en valor absoluto}

El episodio con la mayor variación del PWV en veinticuatro horas, para el periodo de estudio, tuvo lugar en la estación de San Fernando entre los días 13 y 14 de septiembre de 2006. La Figura 9.1 muestra la evolución del PWV entre las 06 UTC del día 13 y las 18 UTC del día 14, obtenida de las medidas horarias del GPS. En tres horas el PWV disminuyó $33.22 \mathrm{~mm}$, desde los $48.93 \mathrm{~mm}$ que se registraban a las 0:30 UTC a los $15.71 \mathrm{~mm}$ de las 3:30 UTC.

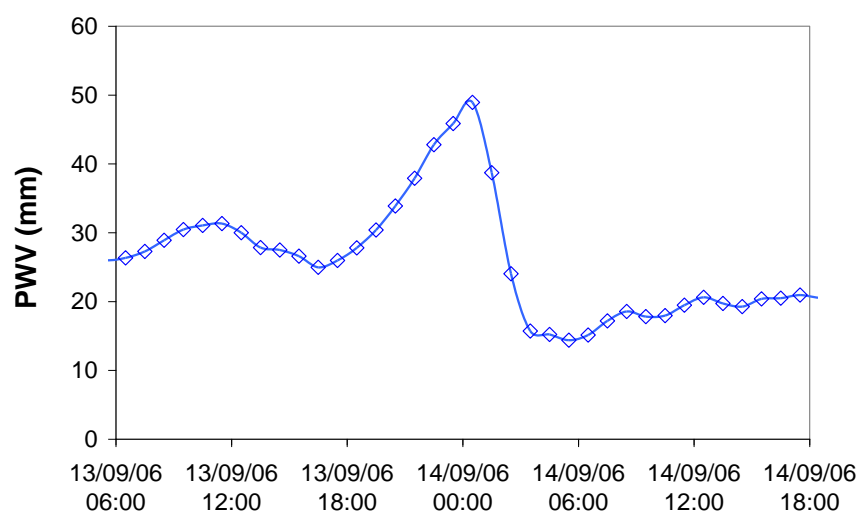

Figura 9.1 - Evolución del PWV durante los días 13 y 14 septiembre de 2006 en San Fernando.

En el sondeo de Gibraltar de las 12 UTC del día 13 (Figura 9.2) se aprecia como la línea de estado de la temperatura y la del punto de rocío están muy distantes, esto indica una atmósfera bastante seca. Sólo en niveles bajos aparece una capa relativamente húmeda. La presencia de 
una pequeña inversión térmica a los 850 mb, típica de las situaciones anticiclónicas (inversión de subsidencia), limitaba los movimientos verticales, y por tanto la difusión del PWV hacia las capas altas. A las 00 UTC del día 14 la inversión está más reforzada y la capa junto al suelo se encuentra más húmeda, sin embargo, en niveles medios y altos la masa seca ha sido reemplazada por otra muy húmeda. A las 12 UTC del día 14 nos encontramos de nuevo con una masa húmeda junto al suelo y una capa muy seca a partir de los $850 \mathrm{mb}$.
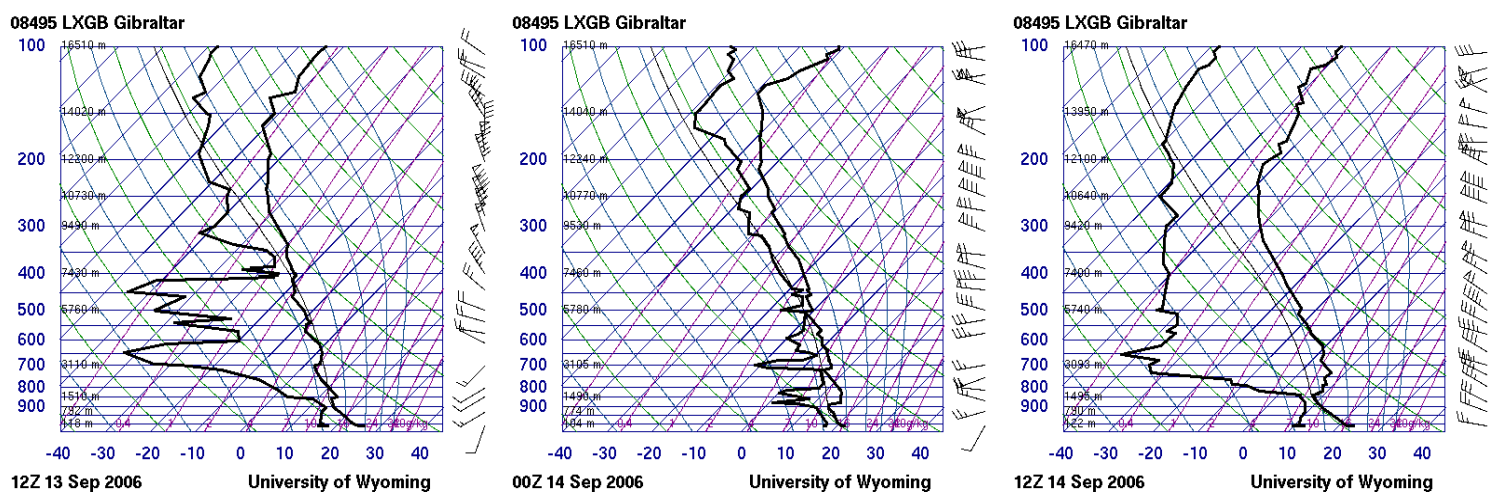

Figura 9.2 - Diagramas Skew-T de los sondeos de Gibraltar de las 12 UTC del día 13 a las 12 UTC del día 14. Para cada nivel de presión en escala logarítmica (eje $Y$ ) se representa la temperatura del termómetro seco y la del punto de rocío (eje $X$ rotado $45^{\circ}$ en sentido horario). En este tipo de diagramas se muestran las isobaras (líneas horizontales azules), las isotermas (líneas diagonales azules), las adiabáticas secas (líneas curvas verdes), las adiabáticas húmedas o saturadas (líneas curvas azules), y las líneas de proporción de mezcla constante (líneas rectas violetas).

El análisis de superficie de esos días (Figura 9.3) muestran un anticiclón centrado al suroeste de las islas Azores, extendiendo su influencia hasta la zona del golfo de Cádiz con presiones de 1012 mb. La situación en superficie varía poco en la zona de interés durante el transcurso del episodio, como ha quedado reflejado en el sondeo de Gibraltar.
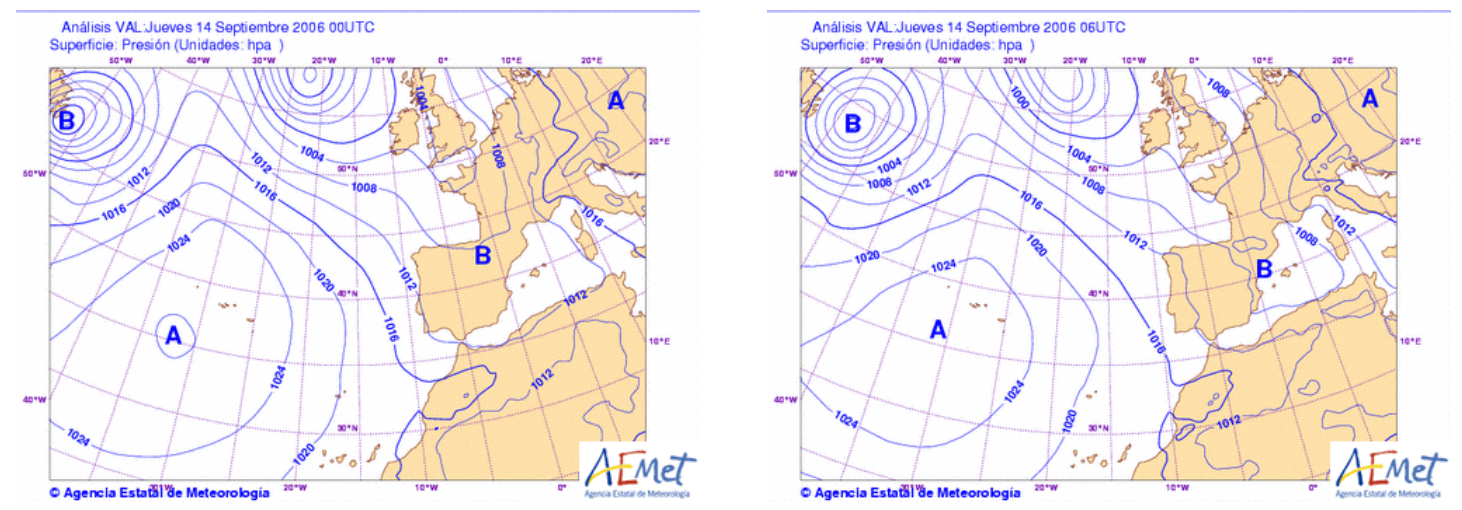

Figura 9.3 - Análisis de superficie del modelo Hirlam de las 00 y 06 UTC del día 14.

Sin embargo, los mapas de altura (Figura 9.4) muestran el paso de una vaguada. La cola de un frente, asociado a una profunda borrasca centrada al noroeste de Irlanda, pasa sobre la zona del golfo de Cádiz a las 00 UTC del día 14, provocando el cambio de masa de aire que se observa en el sondeo y produciendo el máximo de PWV recogido por el GPS. Tras el paso del 
frente, en los niveles altos de la atmósfera se produce una irrupción de aire frío y seco de origen estratosférico. La imagen de vapor de agua del satélite Meteosat (Figura 9.5) refleja una zona oscura que denota esta irrupción de aire seco en altura.
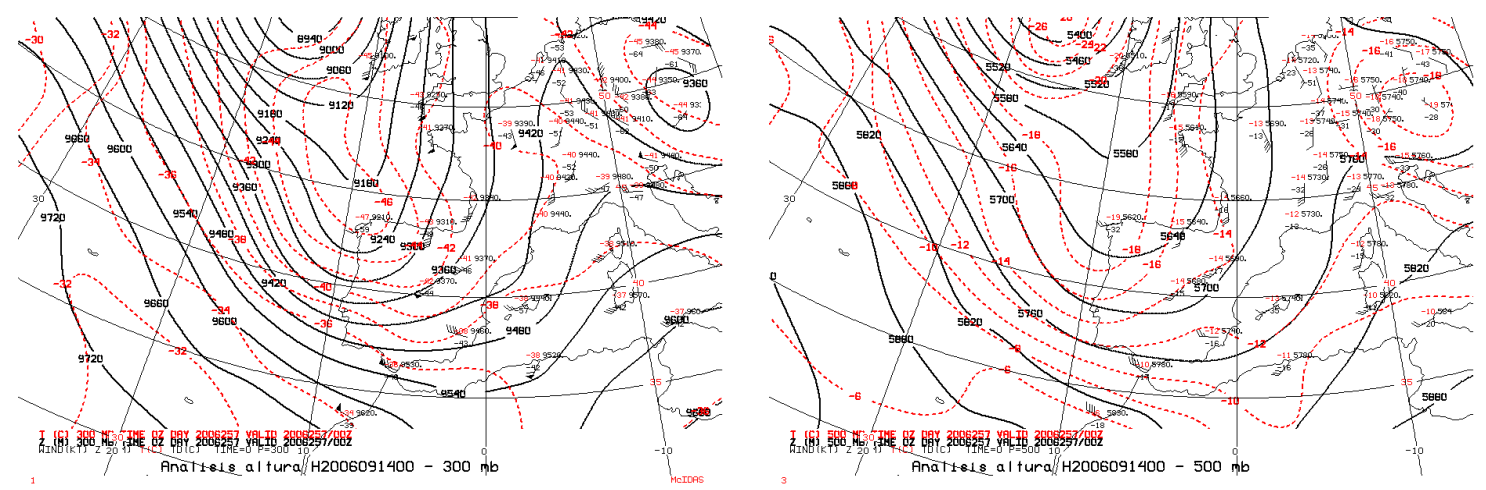

Figura 9.4 - Análisis de altura del modelo Hirlam de los niveles de 300 mb y 500 mb de las 00 UTC del 14 de septiembre de 2006.

A las 06 UTC el frente ya ha rebasado el Estrecho de Gibraltar, y la intrusión de aire seco se sitúa sobre la vertical de San Fernando, coincidiendo con el mínimo de PWV.
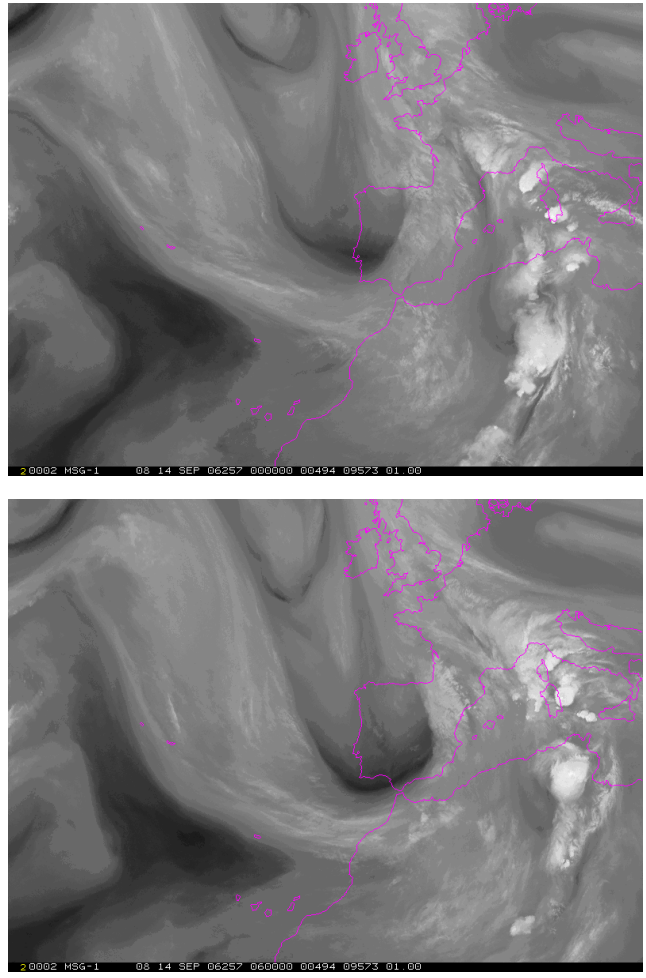
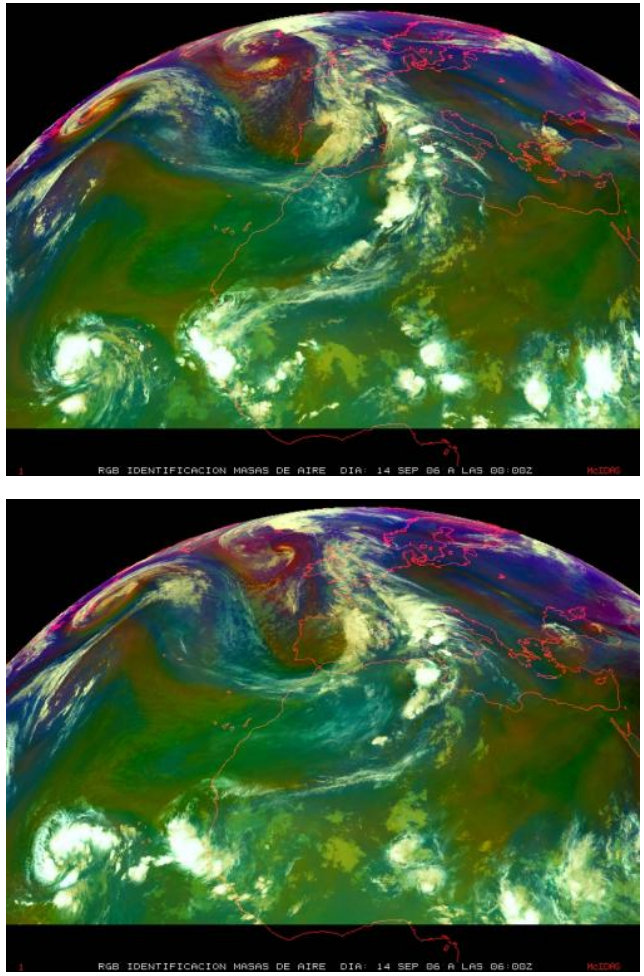

Figura 9.5 - Imágenes del satélite Meteosat de las 00 y 06 UTC del día 14 en el canal de vapor de agua (izquierda) y composición RGB de masas de aire (derecha).

El análisis del campo vapor de agua total en columna del modelo ECMWF (Figura 9.6) refleja claramente la situación descrita. La variación de PWV observada con el GPS de San Fernando concuerda con los análisis de los modelos de predicción. Los datos del GPS ilustran al detalle la evolución de la situación. 

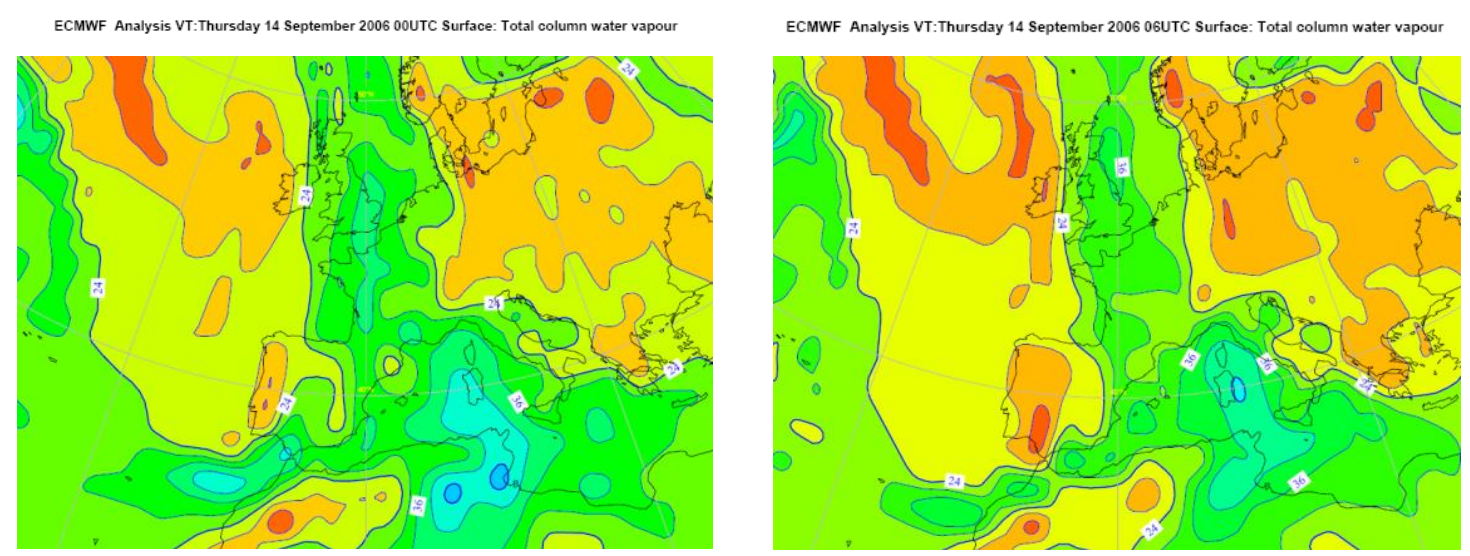

Figura 9.6 - Análisis del campo Vapor de Agua Total en Columna del modelo del Centro Europeo de Predicción (ECMWF) para las 00 y 06 UTC del día 14 de septiembre de 2006.

\subsection{Alta variabilidad diaria en valor relativo}

El 15 de febrero de 2007 el GPS de la estación de Santander registró el episodio con la mayor variación del PWV en términos relativos, con un porcentaje del $350 \%$ sobre el valor medio del día que fue de $5.64 \mathrm{~mm}$. El PWV alcanzó un valor máximo de $20.74 \mathrm{~mm}$ y un valor mínimo de $1.01 \mathrm{~mm}$, lo que supone una variación en términos absolutos de $19.73 \mathrm{~mm}$. Esta última queda lejos de los $26.88 \mathrm{~mm}$ alcanzados en la misma estación el 24 de agosto de 2002. El motivo de esta altísima variación en términos relativos radica en el bajo contenido medio de PWV ese día, producido por los vientos del sur que provocaron un importante efecto Föehn en la vertiente norte de la cordillera Cantábrica.

El análisis de las 06 UTC muestra una amplia vaguada en altura sobre el Atlántico, con un chorro delantero del SW de $140 \mathrm{Kt}$ sobre Irlanda y otro posterior del NW de $120 \mathrm{Kt}$. En superficie (Figura 9.7), un profundo sistema de bajas presiones se sitúa al sur de Islandia con un sistema frontal asociado que se extiende hacia el sur a lo largo de un extenso surco de bajas presiones. Otro sistema de bajas presiones menos profundo se centra sobre Córcega y Cerdeña, mientras que sobre la Península se sitúan altas presiones que se extienden por centro Europa. La aproximación del sistema frontal por el oeste y las altas presiones que se mantienen en el área mediterránea aumentan el gradiente de presión en la Península. Con esta situación los vientos reinantes sobre la cordillera Cantábrica son intensos y de componente sur, llegando secos y recalentados a la vertiente norte por efecto Föehn. Ese día se alcanzaron $21.2 \stackrel{\circ}{\circ}$ en Santander, cuando la media de las máximas para un mes de febrero es de $13.8 \stackrel{\circ}{\circ}$, según la serie climatológica de referencia 1971/2000. La atmósfera se fue secando con la entrada del aire seco que dejó los cielos despejados.

El análisis de las 18 UTC muestra el sistema frontal asociado a la baja del Atlántico norte adentrándose sobre la Península, girando los vientos a componente oeste y produciendo que la masa de aire que llega a Santander lo haga cargada de humedad tras un recorrido marítimo. 

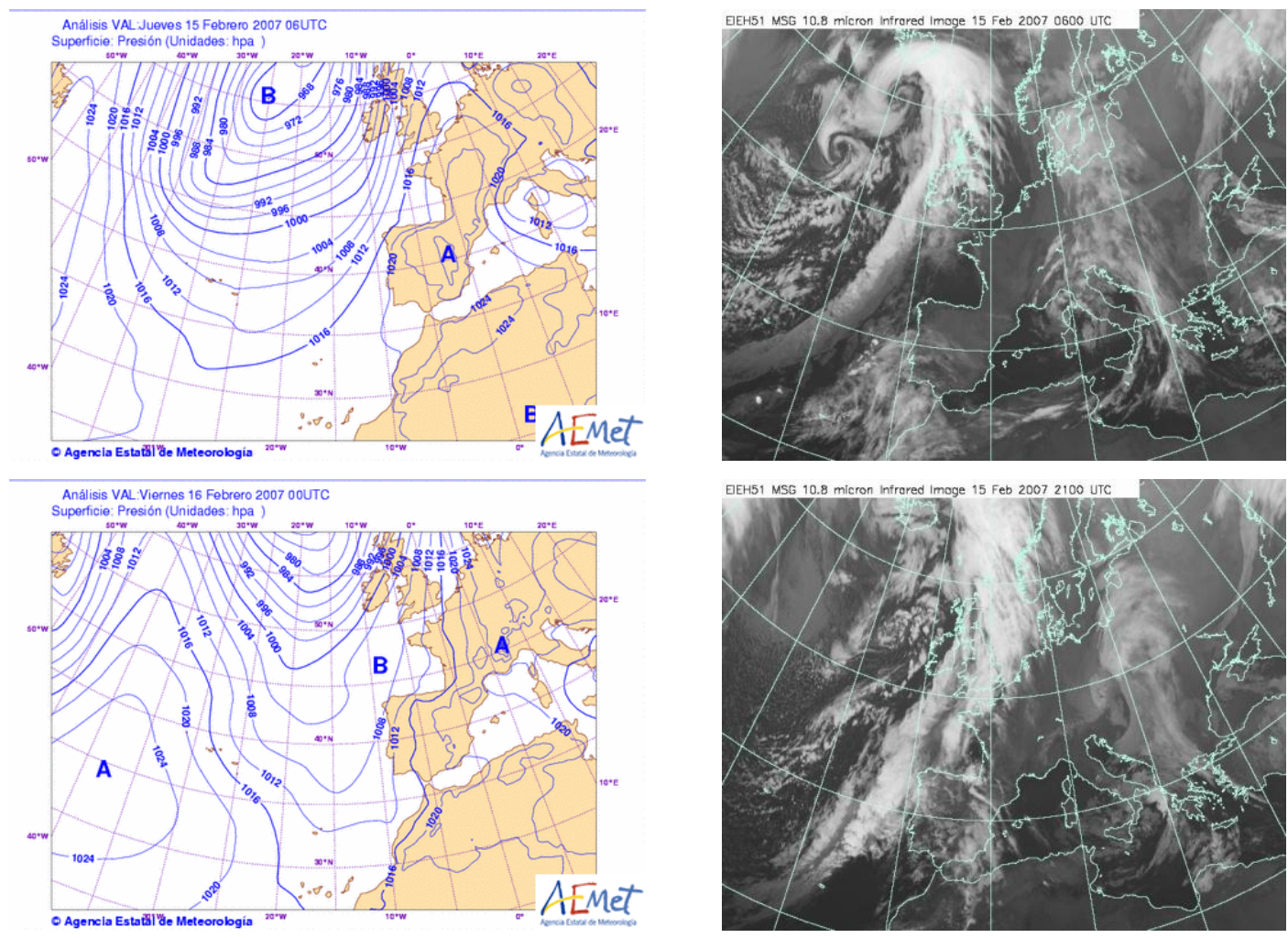

Figura 9.7 - Izquierda: análisis de superficie del modelo Hirlam para las 06 UTC del día 15 de febrero de 2007 (arriba) y para las 00 UTC del día 16 (abajo). Derecha: imágenes del canal infrarrojo de $10.8 \mu \mathrm{m}$ del satélite Meteosat MSG para las 06 UTC (arriba) y las 21 UTC (abajo).

El sondeo de las 12 UTC del día 15 (Figura 9.8) muestra una atmósfera estable y seca a todos los niveles, especialmente en la capa entre los 900 y los $600 \mathrm{mb}$, con vientos moderados de componente sur en niveles bajos. Por su parte el sondeo de las 00 UTC del día 16 muestra la entrada de una masa de aire húmeda en niveles medios y altos debido a la aproximación del sistema frontal, que hace que los vientos arrecien y empiecen a rolar a componente oeste.
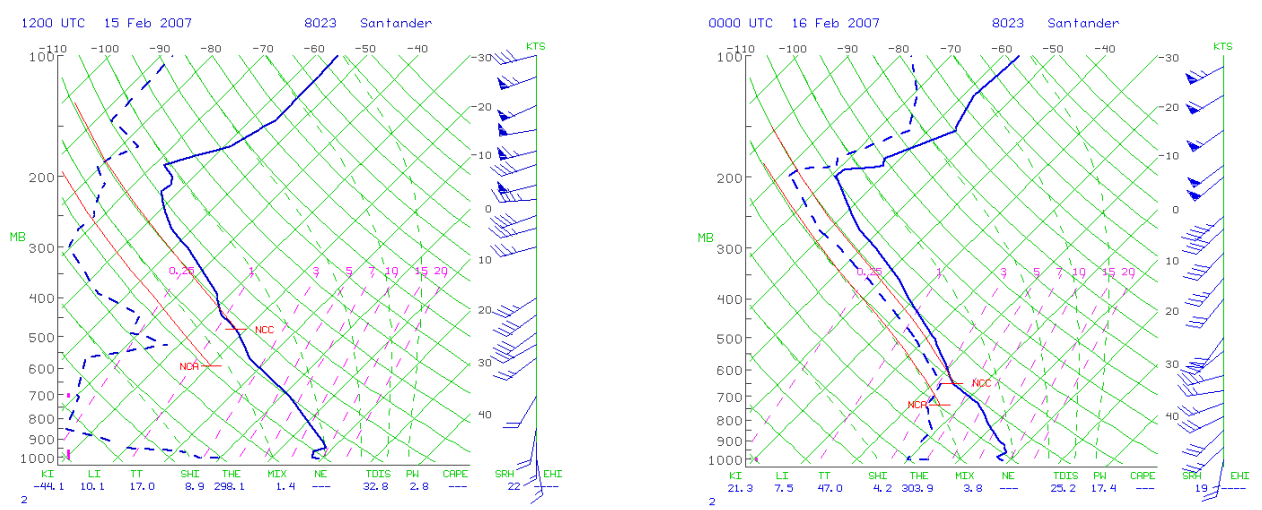

Figura 9.8 - Sondeo de Santander del día 15 a las 12 UTC y del día 16 a las 00 UTC. El diagrama de la izquierda muestra una atmósfera seca, línea de estado (azul sólida) y la del termómetro húmedo (azul discontinua) muy separadas, mientras que el de la derecha muestra una atmósfera muy húmeda por encima de los $700 \mathrm{mb}$, línea de estado y del termómetro húmedo muy próximas.

El análisis del ECMWF (Figura 9.9) refleja la acusada variación del PWV durante el episodio. 

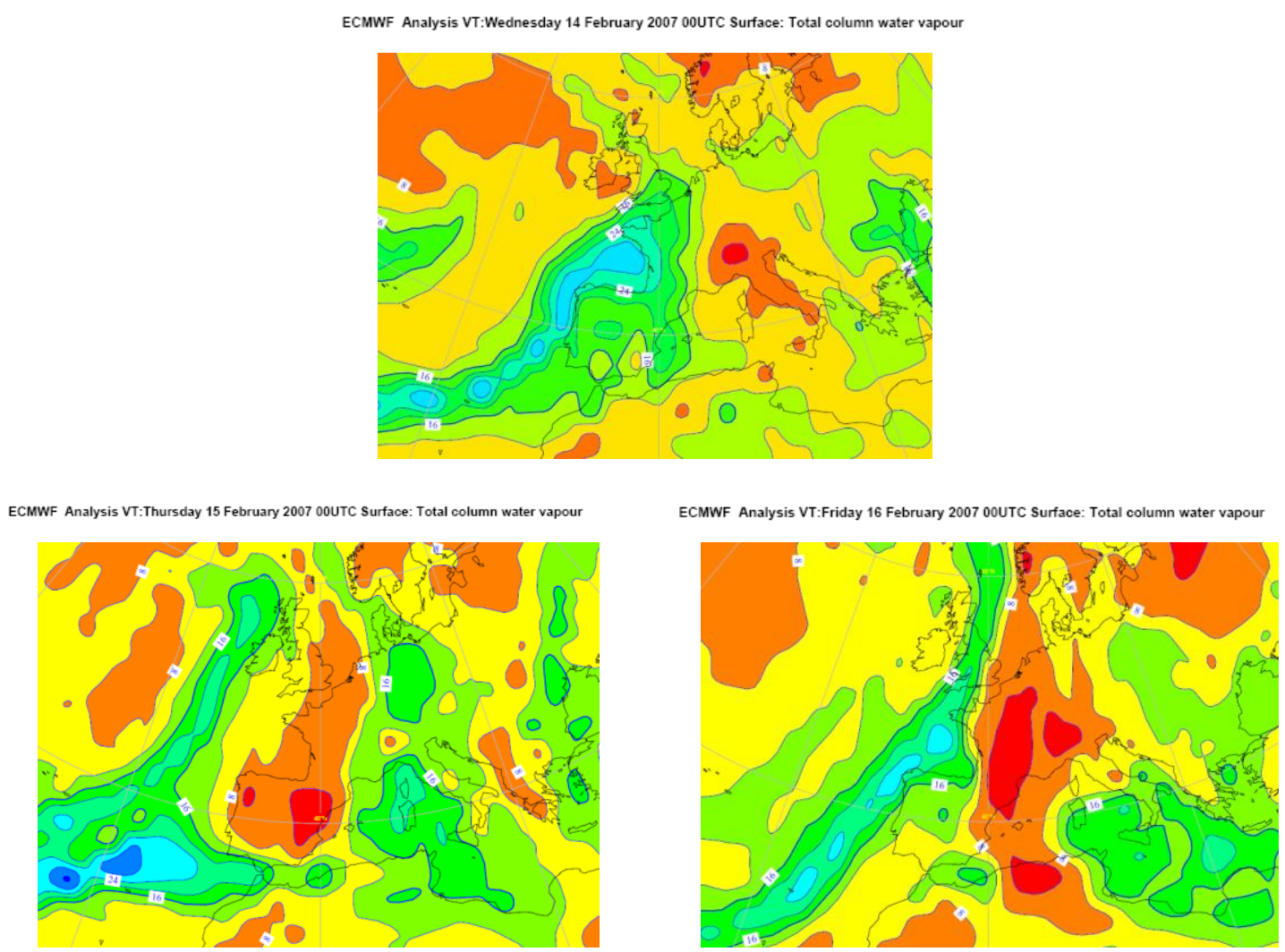

Figura 9.9 - Análisis del campo Vapor de Agua Total en Columna del modelo del Centro Europeo de Predicción (ECMWF) para las 00 UTC de los días 14 a 16 de febrero de 2007.

La evolución del PWV durante el episodio recogida por el GPS (Figura 9.10) presenta un valor alto durante la madrugada del día 14, como consecuencia del paso de un sistema frontal que el día 15 se encuentra ya en el Mediterráneo. Durante la mañana del día 14 y hasta el mediodía del 15 el PWV disminuye hasta alcanzar un valor mínimo muy bajo por la llegada a la estación de vientos secos de componente sur, precursores de un nuevo sistema frontal que se acerca por el oeste. Con la entrada de este último, el PWV aumenta hasta la media noche del día 16.

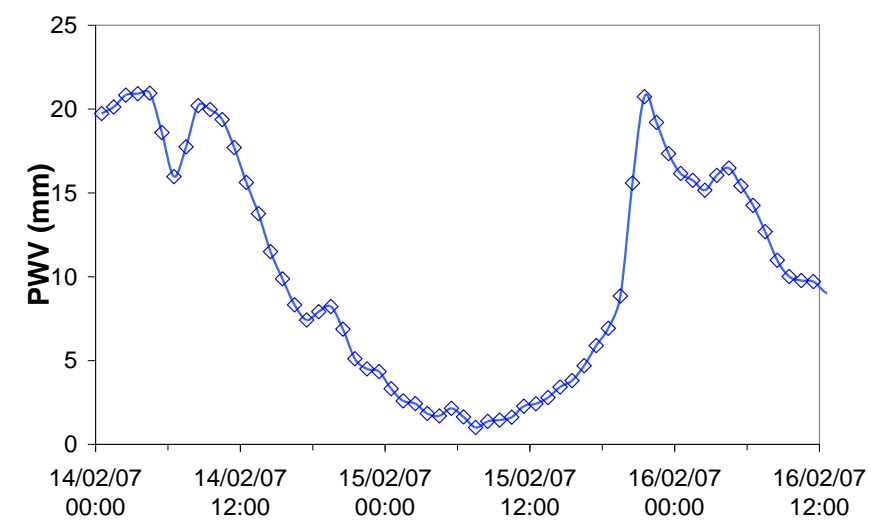

Figura 9.10 - Evolución del PWV durante los días 14 al 16 de febrero de 2007 en Santander. 


\subsection{Alta variabilidad horaria}

Con los datos analizados en este estudio, los episodios con las mayores variaciones en pocas horas del PWV han sido siempre de disminuciones bruscas del PWV, no de incrementos. Un ejemplo es el día 12 de febrero de 2007, cuando se registró en la estación GPS de Villafranca una disminución del PWV de $14.37 \mathrm{~mm}$ en cuatro horas y de $5.03 \mathrm{~mm}$ en sólo una hora, entre las 10 y las 11 UTC (Figura 9.11).

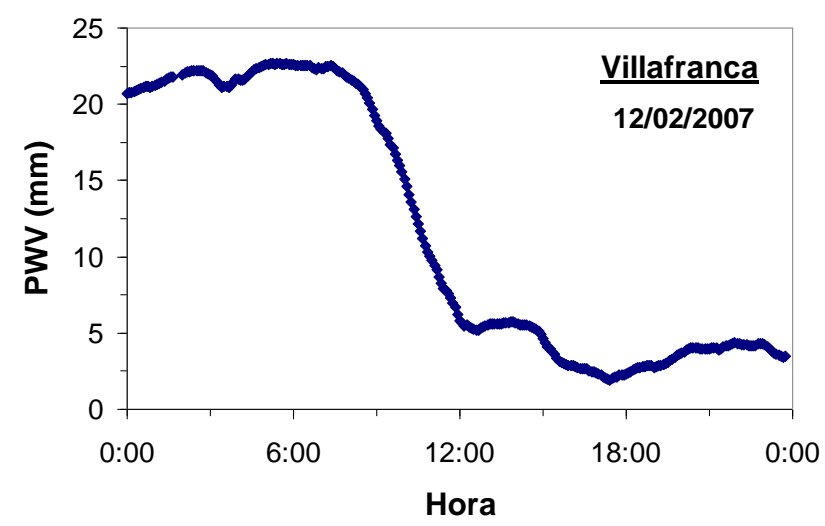

Figura 9.11 - Evolución del PWV el día 12 de febrero de 2007 en la estación GPS de Villafranca.

La causa de este importante descenso en poco tiempo se debe al paso rápido de un sistema frontal muy bien delimitado, como se observa en la imagen de intensidad de precipitación ( $\mathrm{mm} / \mathrm{h}$ ) de la composición nacional de la red de radares de AEMET (Figura 9.12). En la imagen del canal de vapor de agua del satélite Meteosat para la misma hora se aprecia una banda negra detrás del sistema frontal, que denota la presencia de una masa de aire seca en niveles medios y altos (Figura 9.12).
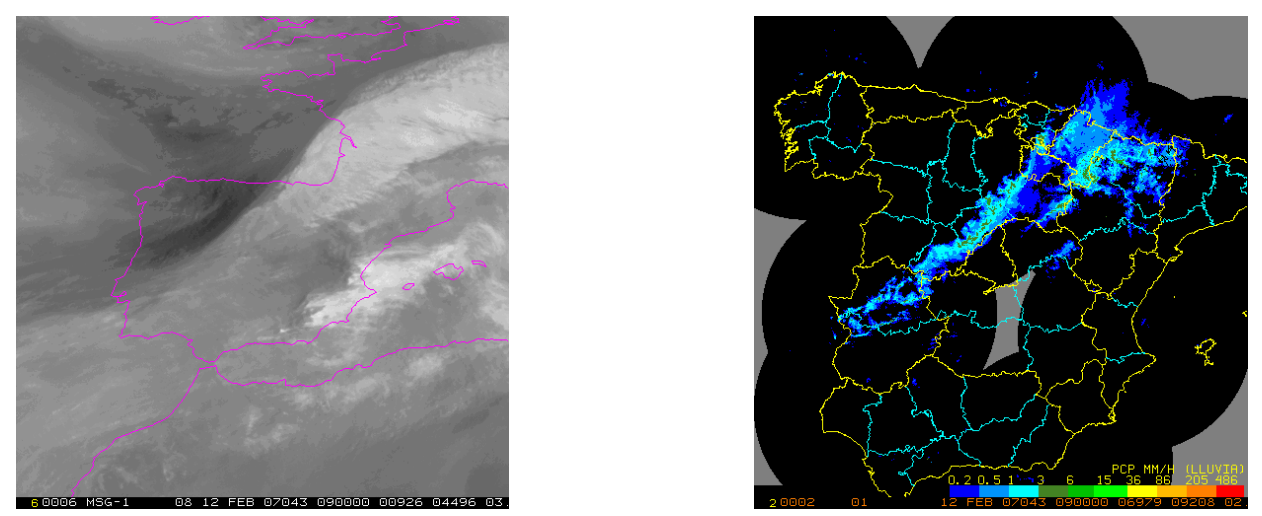

Figura 9.12 - Imagen del canal de vapor de agua del Meteosat de las 09 UTC (izquierda), y composición nacional de la red de radares de AEMET de las 09 UTC (derecha).

Los sondeos de Barajas de las 00 y 12 UTC de ese día (Figura 9.13) reflejan también el importante cambio de masa de aire al paso del frente, pasando de una atmósfera muy húmeda a las 00 UTC a una atmósfera muy seca a las 12 UTC. 

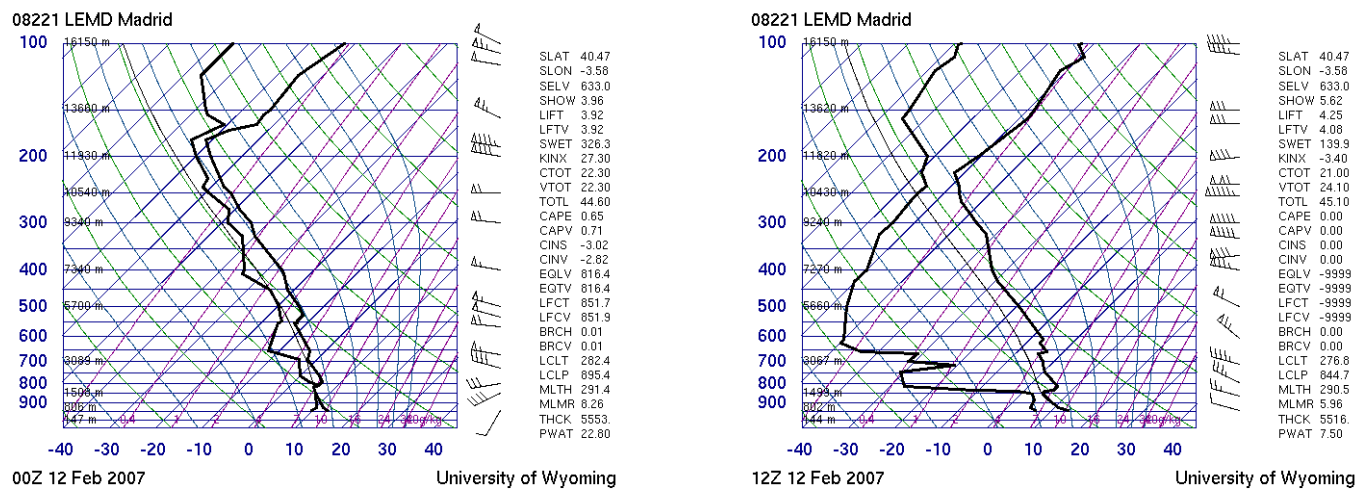

Figura 9.13 - Sondeos de Barajas del 12/02/2007 a las 00 y 12 UTC.

Una situación con una variación aún mayor del PWV se registró en San Fernando el día 7 de marzo del 2007, cuando el PWV disminuyó 9.98 mm en sólo una hora (aprox. un 68\%), y 17.62 $\mathrm{mm}$ en dos (Figura 9.14). Este es el episodio con la mayor variación del PWV registrada.

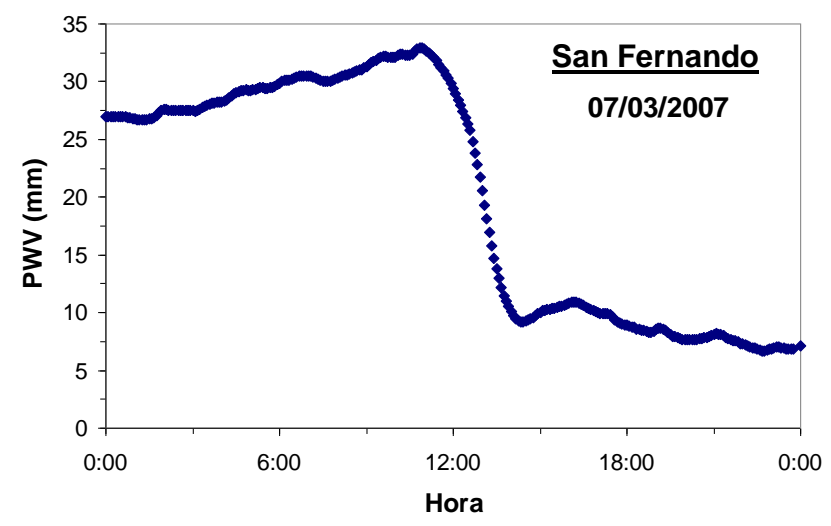

Figura 9.14 - Evolución del PWV durante el día 7 de marzo de 2007 en San Fernando.

Los sondeos de Gibraltar de las 00 UTC del día 7 y 8 reflejan claramente el cambio de masa de aire que se produjo esos días, pasando de una atmósfera húmeda a una atmósfera seca (Figura 9.15). El sondeo de las 12 UTC del día 7, justo cuando tiene lugar la disminución del PWV, muestra como la atmósfera comienza a desecarse por las capas medias-altas, mientras que por debajo de 750 mb aún está saturada en esos momentos.

En la imagen de composición RGB de masas de aire del Meteosat de las 06 UTC (Figura 9.16), se aprecia sobre la península, y más claramente sobre al Atlántico, la frontera entre las dos masas de aire distintas. Más tarde, esta frontera se desplazaría rápidamente hacia el sur empujada por los intensos vientos reinantes, según se recoge en los mapas isobáricos de superficie y altura (500 mb) de las 12 UTC (Figura 9.17). El campo de las líneas de igual fuerza del viento (isotacas) en $300 \mathrm{mb}$ muestra una corriente en chorro con vientos máximos de 160 Kt de dirección noroeste. A las 12 UTC el sistema frontal que separa las dos masas de aire se sitúa sobre la vertical de San Fernando, como queda reflejado por el importante gradiente en el campo de contenido de vapor de agua del análisis del ECMWF (Figura 9.18). 

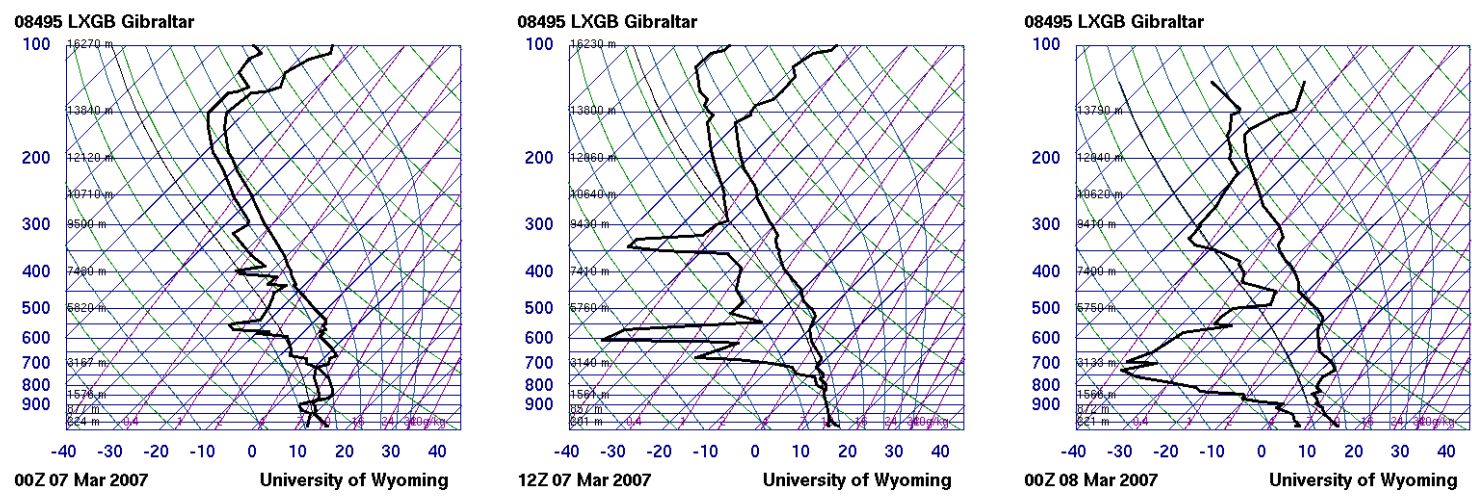

Figura 9.15 - Sondeos de Gibraltar de las 00 y 12 UTC del día 7 y de las 00 UTC del día 8.

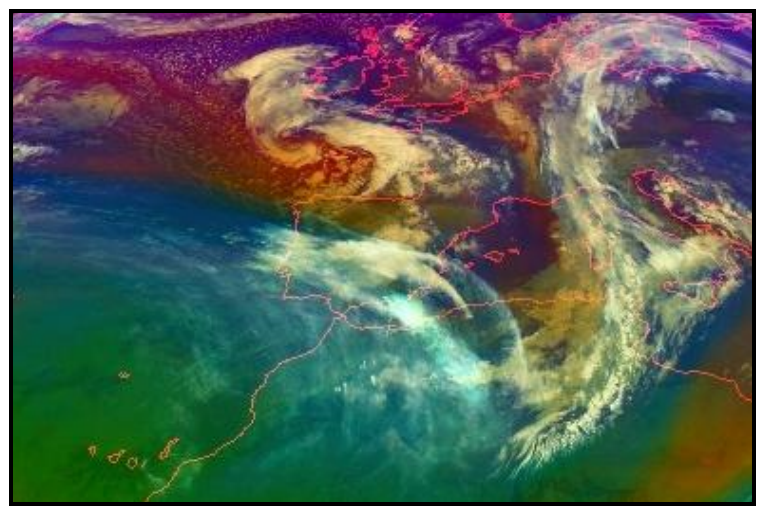

Figura 9.16 - Composición RGB de masas de aire del Meteosat para las 06 UTC del día 7. Los colores rojizos indican aire seco de origen estratosférico, y las de color verdoso corresponden a masas tropicales.
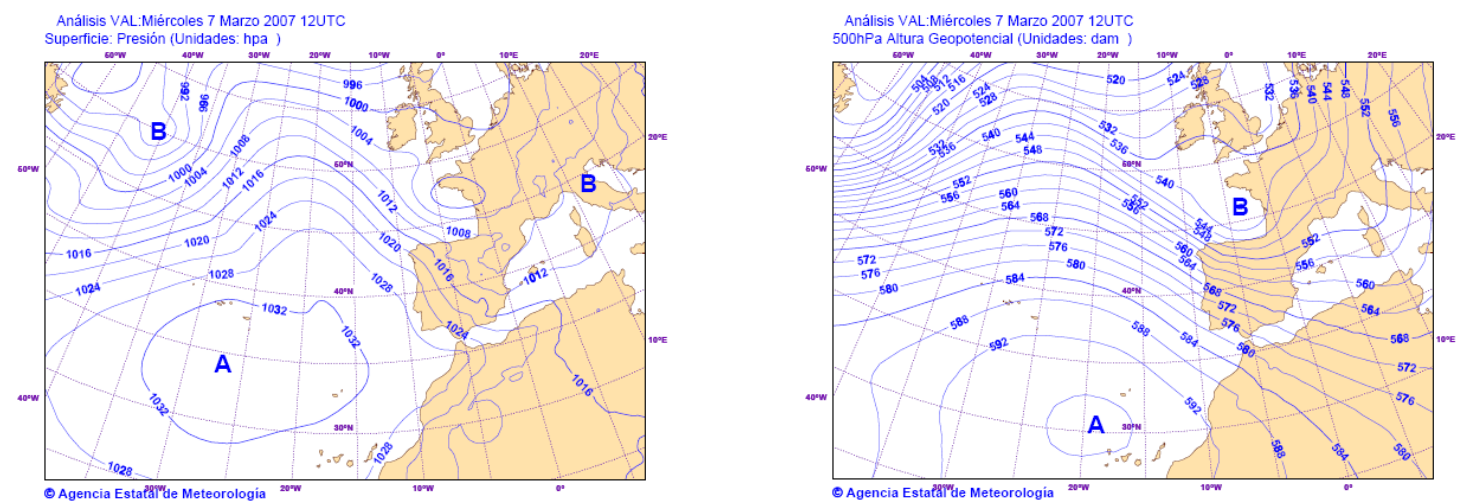

Figura 9.17 - Análisis de las 12 UTC: superficie (izquierda) y geopotencial de 500 mb (derecha).

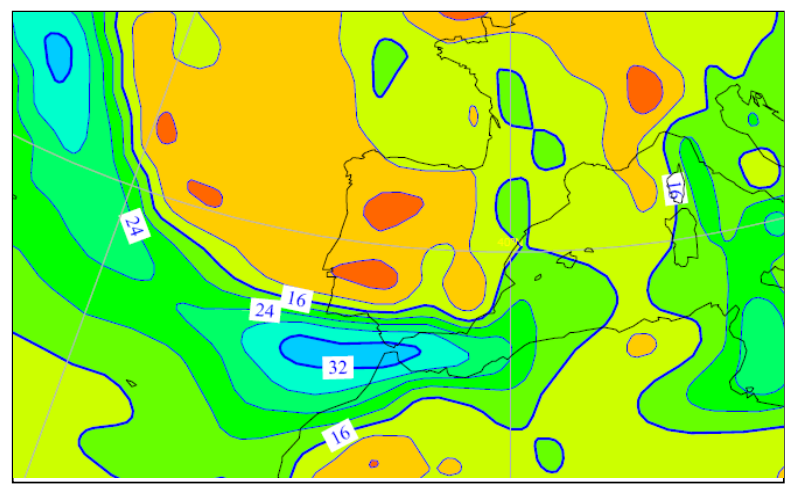

Figura 9.18 - Análisis de las 12 UTC del campo PWV del ECMWF. 


\subsection{Paso de un sistema frontal}

En este apartado se estudia el desplazamiento de un sistema frontal que atravesó la Península el día 23 de julio de 2007. La Figura 9.19 recoge la situación meteorológica para ese día. A las 18 UTC del día 22 el anticiclón de las Azores se encuentra al oeste de estas islas, mientras que un sistema de bajas presiones de $992 \mathrm{mb}$ se sitúa al sur de Irlanda frente a la Bretaña francesa, quedando la Península bajo la influencia de las bajas presiones. A esas horas un frente asociado a dicha depresión entra por el noroeste peninsular. A las 00 UTC del día 24 las bajas presiones se han desplazado hacia el este, mientras que el anticiclón gana terreno y se adentra sobre el noroeste peninsular en forma de cuña. El frente asociado, ya muy debilitado, comienza a abandonar la Península por el sureste. El desplazamiento del sistema frontal se observa claramente en las imágenes del satélite Meteosat (Figura 9.20)
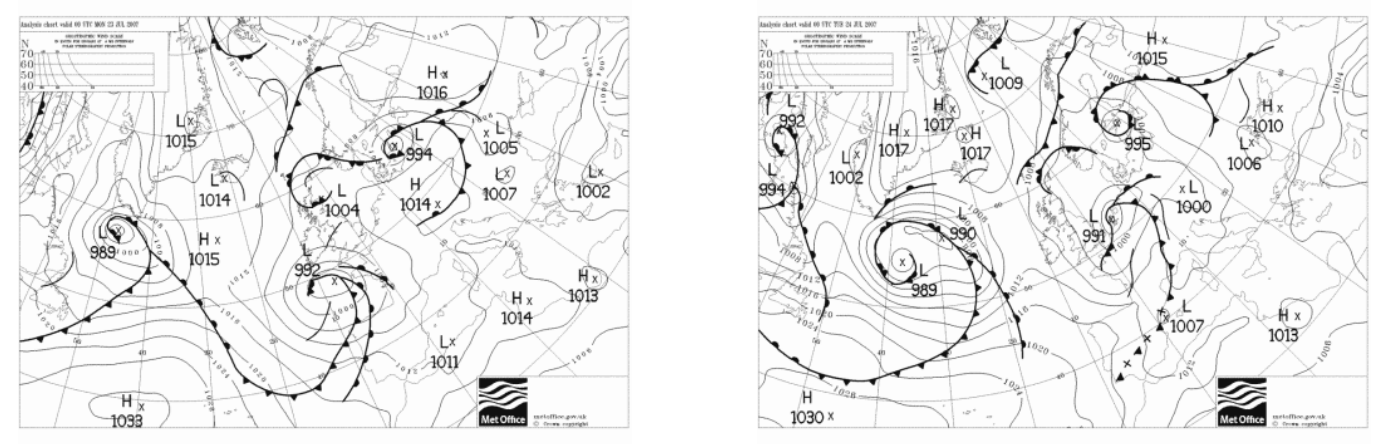

Figura 9.19 - Análisis de superficie del MetOffice de las 00 y las 18 UTC del día 23 de julio de 2007.

Los datos de precipitación muestran como a las 00 UTC del día 23 llovía sobre Galicia. A las 06 UTC las precipitaciones se extendían por la cornisa Cantábrica y Castilla y León, mientras que en Galicia se abrían grandes claros. Hacia las 12 UTC las precipitaciones habían remitido, quedando sólo chubascos por la descarga fría posfrontal en Galicia. Durante la tarde, el frente ya muy debilitado terminó de atravesar la Península sin dejar precipitaciones en el resto de las regiones.
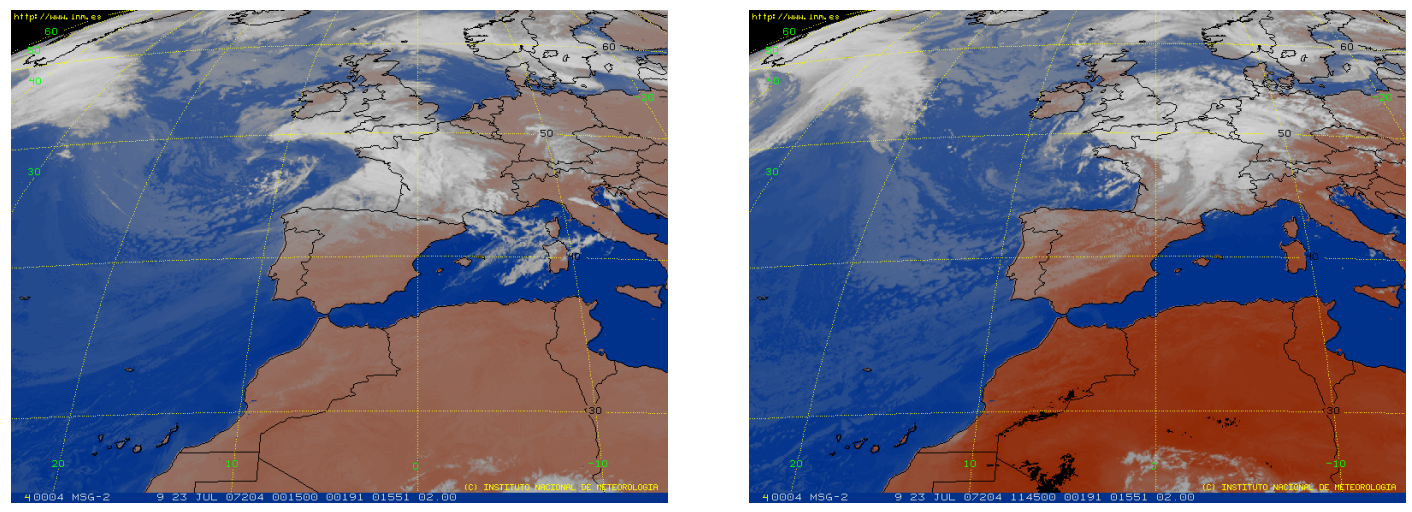

Figura 9.20 - Imágenes del satélite Meteosat de las 00 y las 18 UTC del día 23 de julio de 2007. 
Los sondeos no tienen la suficiente resolución temporal para recoger fielmente los cambios en el PWV que acompañaron el paso del sistema frontal, no así los GPS. Esto se observa claramente en la Figura 9.21 que muestra la evolución temporal del PWV medido con ambas técnicas para los días 22 y 23 en Santander y Madrid. El frente pasa sobre Santander a las 00 UTC, coincidiendo con la hora de lanzamiento del sondeo, por lo que la evolución del PWV en esta estación queda suficientemente bien reflejada. Sin embargo, sobre Madrid el frente pasa a las 06 UTC, justo entre los dos lanzamientos de sondeos. Por ello, el pico de PWV queda muy suavizado en los datos de los sondeos, mientras que los GPS lo recogen muy bien.

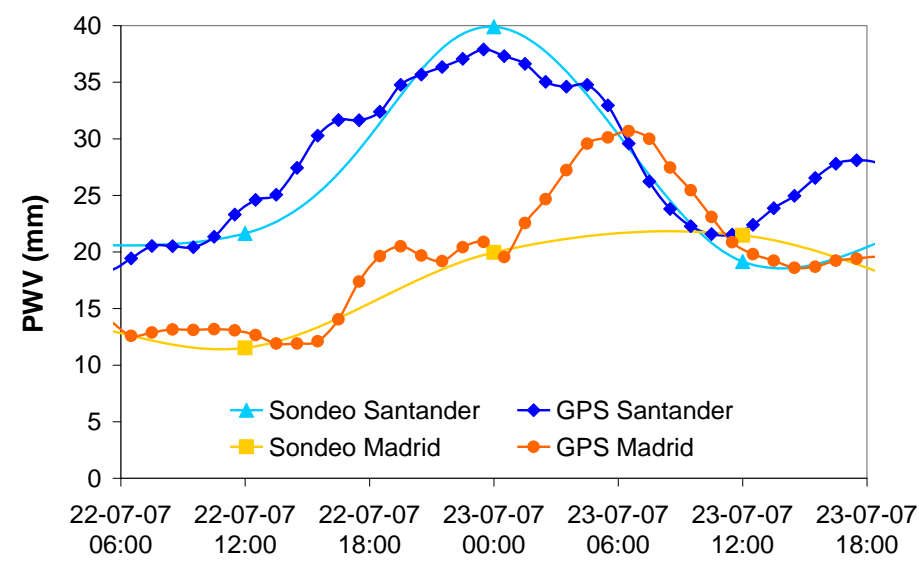

Figura 9.21 - Evolución del PWV durante los días 22 y 23 de julio de 2007 sobre Santander y Madrid.

La Figura 9.23 muestra el campo PWV del análisis del modelo del ECMWF en intervalos de seis horas. El sistema frontal queda delimitado por la banda de altos valores de PWV representada en colores azulados. Sobre los mares el frente está mejor delimitado, debilitándose y desdibujándose al entrar en tierra. Si se compara la hora de paso de esta banda con los picos en el PWV recogidos por los GPS en varias estaciones distribuidas a lo largo de la Península (Figura 9.22), se observa como estos reflejan muy fielmente el movimiento del sistema frontal.

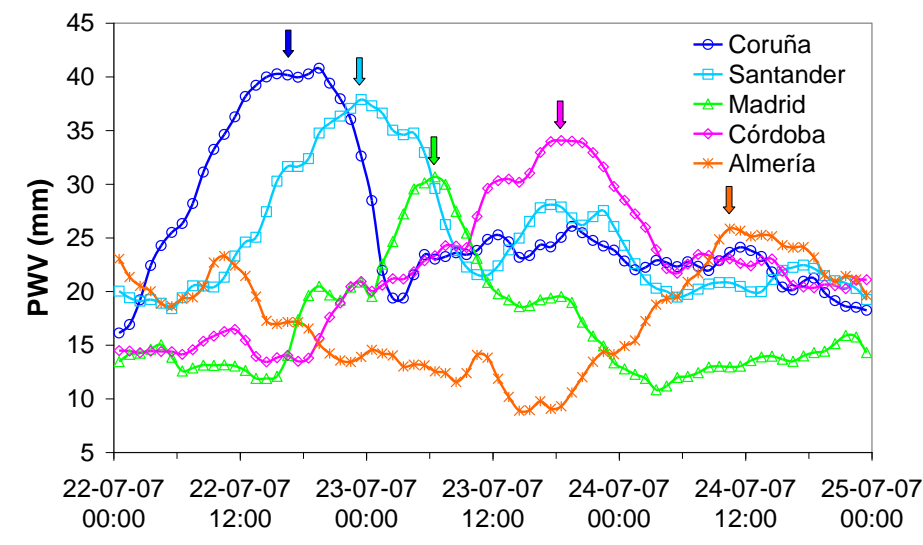

Figura 9.22 - Evolución del PWV durante los días 22 al 24 de julio de 2007 sobre la Península. 

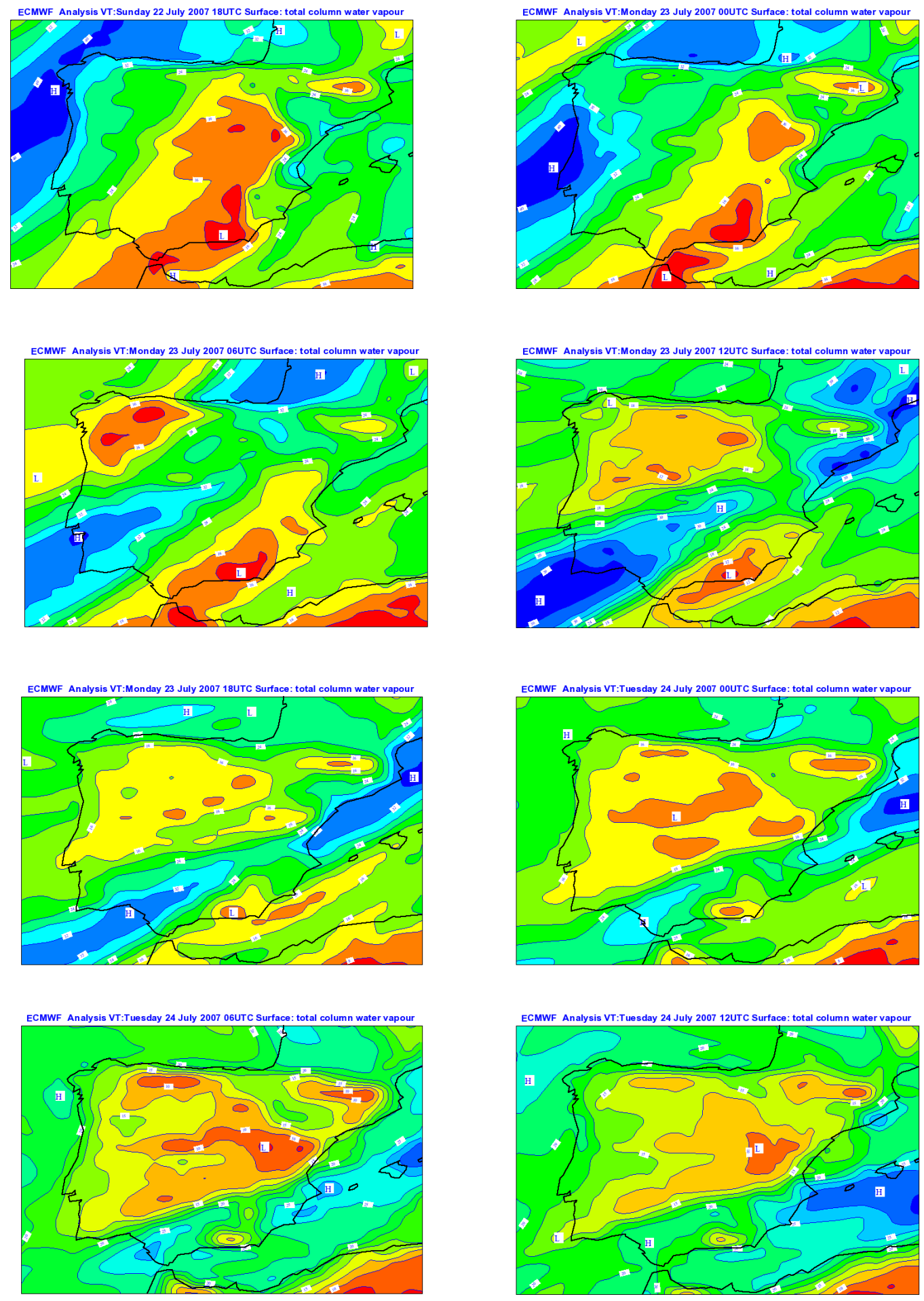

Figura 9.23 - PWV del análisis del modelo del ECMWF desde las 18 UTC del día 22 a las 12 UTC del día 24 de julio de 2007.

La velocidad del sistema frontal se puede calcular a través del intervalo temporal entre los máximos de PWV en distintos emplazamientos. De esta manera, se ha obtenido una velocidad media de unos $35 \mathrm{Km} / \mathrm{h}$ en la primera mitad de su recorrido a lo largo de la Península, disminuyendo a los $23 \mathrm{Km} / \mathrm{h}$ en la segunda mitad. 
Si se representan los datos de la precipitación recogida por los pluviómetros de las estaciones junto con el PWV de los GPS (Figura 9.24), se obtiene que los máximos de PWV coinciden con las mayores intensidades de precipitación.

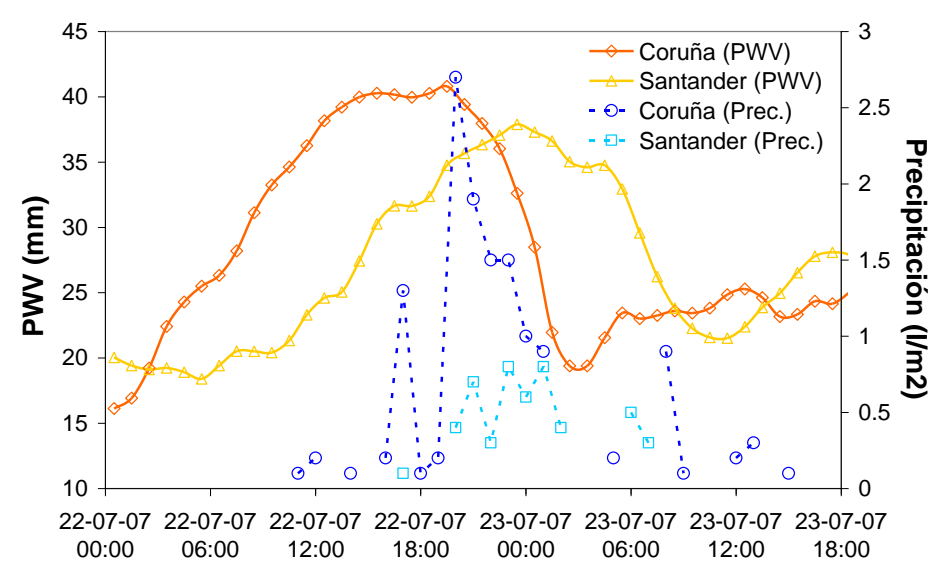

Figura 9.24 - Evolución del PWV y la precipitación durante el paso del sistema frontal sobre las estaciones de Coruña y Santander. Las precipitaciones expresan las cantidades recogidas en los diez minutos anteriores a la observación. En el resto de estaciones no se registraron precipitaciones.

Los datos de PWV de los GPS no sólo nos ayudan a estudiar el desplazamiento de los sistemas frontales, sino que además la combinación de estos datos con la temperatura de brillo de las imágenes de los canales del infrarrojo y vapor de agua de los satélites proporciona una indicación de su distribución vertical (De Haan et al., 2004).

\subsection{Situaciones de precipitaciones}

Las redes de receptores GPS se han mostrado ser una buena herramienta para la monitorización de la evolución de sistemas convectivos (Champollion et al., 2004; Seco et al., 2009). En este apartado se verán unos ejemplos de cómo varía el PWV durante un episodio de precipitaciones debido al paso de un sistema frontal y otros debidos a situaciones de inestabilidad convectiva que produjeron tormentas.

Precipitaciones al paso de un sistema frontal.

El día 21 de octubre de 2008 un sistema frontal pasó sobre Galicia, dejando precipitaciones en la estación de Coruña donde se registraron $30.3 \mathrm{l} / \mathrm{m}^{2}$. Las precipitaciones comenzaron sobre las 3:30 UTC, coincidiendo con el máximo valor registrado del PWV. A continuación, la intensidad de las precipitaciones aumentó rápidamente hasta alcanzar su máximo valor sobre las 6:30 UTC. A esa hora el PWV había disminuido, pero sólo de forma muy ligera, menos de 1 mm. A partir de ese momento el PWV disminuyó de forma más acusada, y también la intensidad de las precipitaciones (Figura 9.25). 
Si para la misma estación, normalmente afectada por el paso de frentes, se representa un periodo más largo de tiempo en el que se hayan producido precipitaciones, se observa que estas tienen lugar coincidiendo con máximos del PWV, aunque no todos los máximos de PWV tienen siempre que llevar asociados precipitaciones (Figura 9.26).

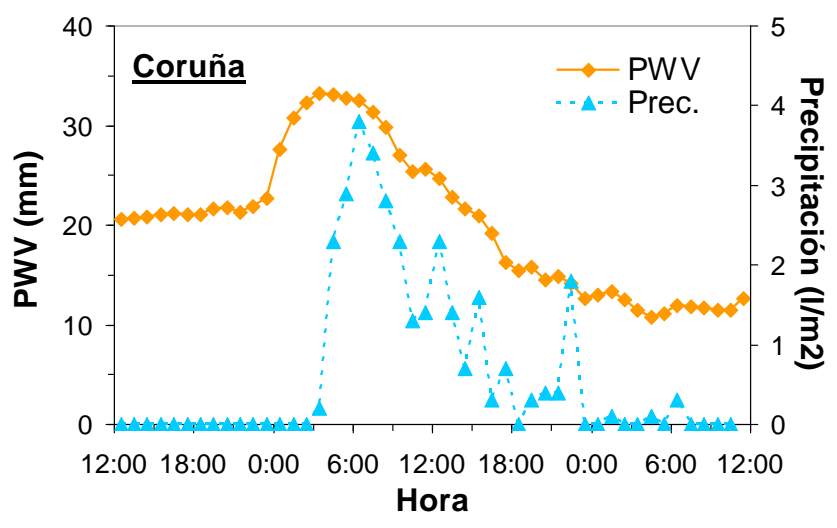

Figura 9.25 - Evolución del PWV y de las precipitaciones desde las 12 UTC del día 20 a las 12 UTC del día 22 de octubre de 2008 en Coruña.

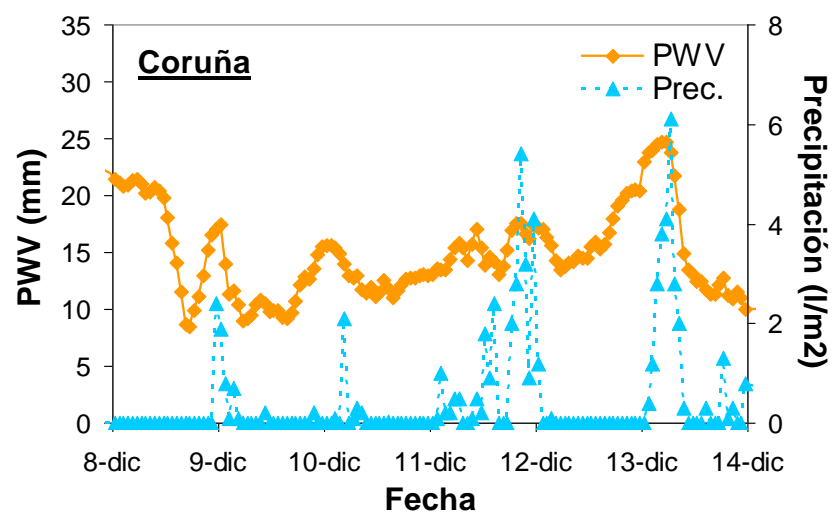

Figura 9.26 - Evolución del PWV y de las precipitaciones entre el día 8 al 14 de diciembre de 2008.

\section{Situaciones de tormentas.}

El día 23 de junio de 2008 la atmósfera se encontraba muy inestable, con un valor del índice Total de Totales de 52 sobre Castilla y León, debido al paso de una vaguada en altura con un embolsamiento de aire frío. Este índice de inestabilidad atmosférica se define como la diferencia entre la temperatura en grados Celsius a $850 \mathrm{mb}$ y a $500 \mathrm{mb}$, más la diferencia entre la temperatura del punto de rocío a $850 \mathrm{mb}$ y la temperatura a $500 \mathrm{mb}$.

Tras el calentamiento diurno se alcanzó la temperatura de disparo de la convección, y a las 18 UTC la nubes tormentosas se encontraban ya muy desarrolladas, como se aprecia en las imágenes de satélite (Figura 9.27). A partir de las 15 UTC el PWV experimentó un importante incremento hasta alcanzar su máximo valor de $32 \mathrm{~mm}$ a las 19:30 UTC, momento en que las nubes convectivas descargaron con su máxima intensidad sobre Salamanca (Figura 9.28). 

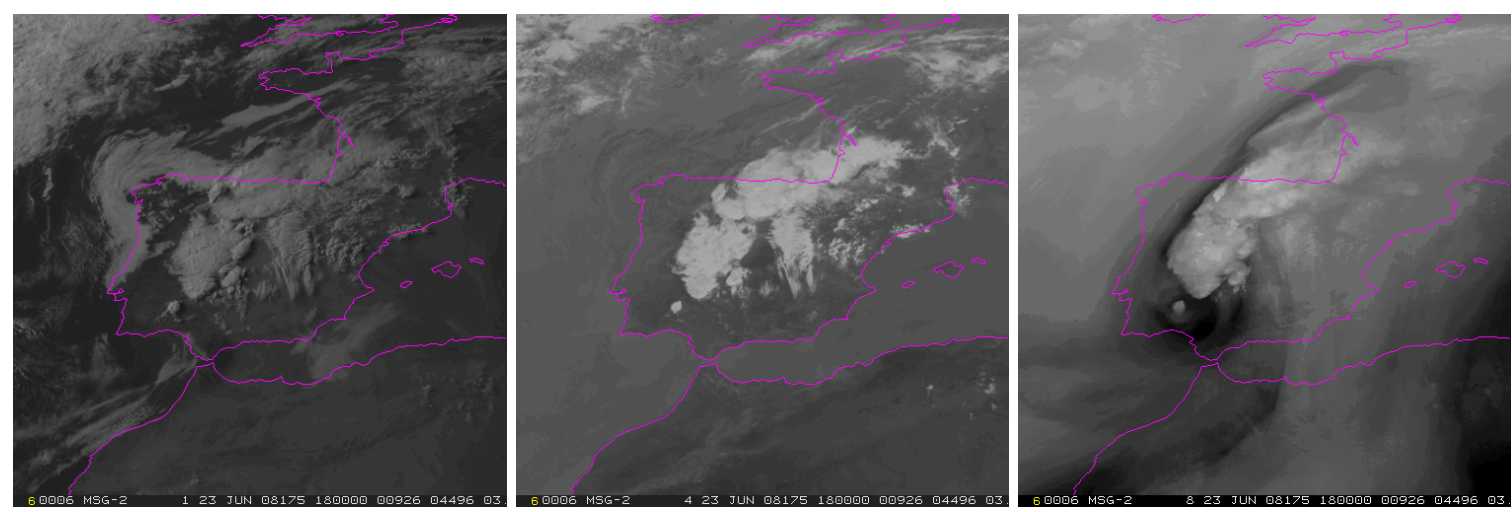

Figura 9.27 - Imágenes del satélite Meteosat en el canal visible (izquierda), infrarrojo (centro) y vapor de agua (derecha) de las 18 UTC del día 23 de junio de 2008.

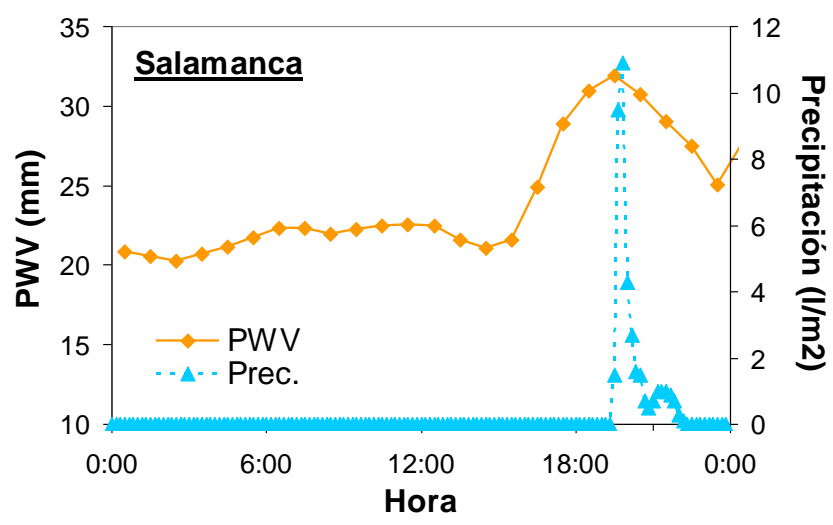

Figura 9.28 - Evolución del PWV y de las precipitaciones del día 23 de junio de 2008 en Salamanca.

Otras situaciones con precipitaciones intensas de carácter convectivo, como la del día 14 de septiembre de 2007 en Valencia o del día 29 del mismo mes en Almería donde se recogieron 54 y $35 \mathrm{l} / \mathrm{m}^{2}$ respectivamente en pocas horas (Figura 9.29), muestran el mismo patrón de comportamiento. Al tiempo que comienza a llover el PWV empieza a crecer de manera rápida (5-7 mm en 2-3 horas) hasta alcanzar su valor máximo con valores entre 40-45 mm, momento en el que las precipitaciones adquieren también su máxima intensidad para posteriormente disminuir ambos de forma pronunciada.
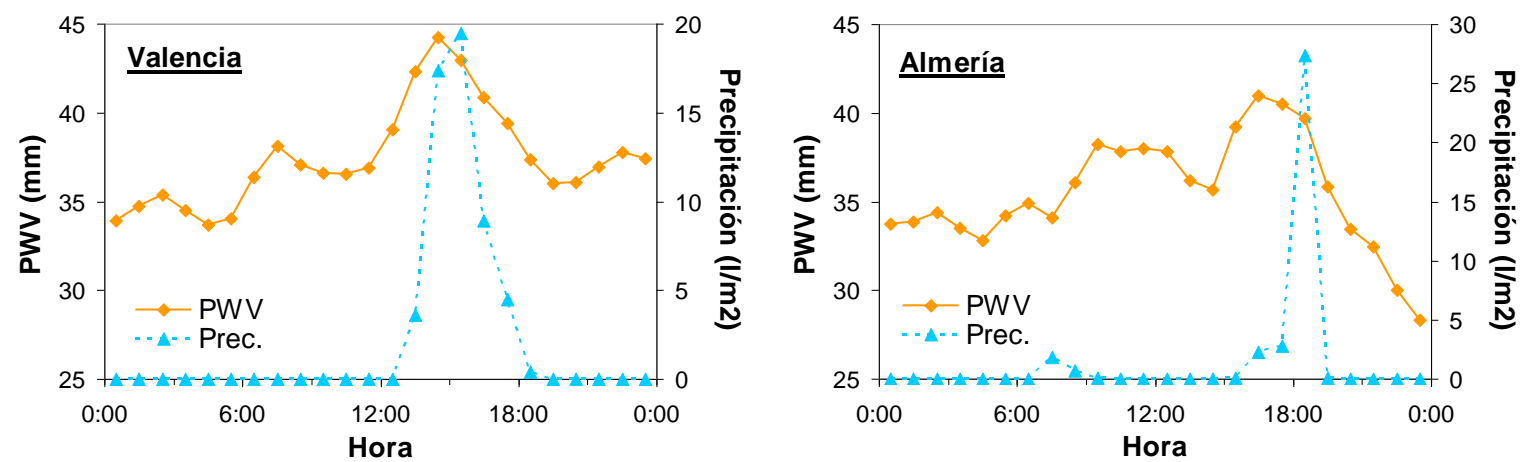

Figura 9.29 - Evolución del PWV y de las precipitaciones durante dos días de septiembre de 2007 con precipitaciones intensas en la zona mediterránea: día 14 en Valencia (izquierda), día 29 en Almería (derecha). 


\section{- 250 -}




\section{CONCLUSIONES Y LÍNEAS FUTURAS}

Este estudio constituye el primer trabajo de caracterización del agua precipitable sobre la Península Ibérica. Ha sido realizado a partir de siete años de datos (2002/2008) obtenidos principalmente de los receptores GPS de las estaciones de EUREF, y también de los radiosondeos y de los fotómetros solares de la red AERONET-RIMA. Las principales conclusiones que se han extraído son:

A.- Sobre la parte de metodología e instrumental:

1. El sistema GPS permite caracterizar la alta variabilidad del agua precipitable gracias a la densidad espacial de receptores GPS y la alta resolución temporal de los mismos. La calidad de estos datos ha sido validada por comparación con los datos de los sondeos, experimentado ésta un significativo aumento desde noviembre del 2006 cuando se adoptó un modelo de calibración absoluta del centro de fases de las antenas de los satélites y receptores GPS. EI modelo de calibración relativo sobreestimaba el agua precipitable en unos 2 a $3 \mathrm{~mm}$.

2. La obtención del agua precipitable con el sistema GPS es sensible a los errores en la medida de la presión, una incertidumbre de $1 \mathrm{hPa}$ produce aproximadamente un error del $2 \%$. Por ello, es muy recomendable disponer de datos precisos de presión en el mismo emplazamiento del GPS. Si se disponen de pocos datos de presión y se recurre a una interpolación lineal para obtener el dato de la presión a la hora de la observación del GPS, se introduce un ciclo diurno artificial en el agua precipitable debido a la marea barométrica.

3. La incertidumbre en las medidas del retraso húmedo troposférico marca un límite por debajo del cual la calidad de los datos de agua precipitable del sistema GPS disminuye significativamente. En el presente estudio este umbral se ha situado sobre los $5 \mathrm{~mm}$.

4. No se ha obtenido una mejora significativa en el algoritmo de cálculo al estimar la temperatura media atmosférica utilizando una expresión empírica diferente para cada emplazamiento, hora del día, o época del año.

5. La comparativa de medidas obtenidas con distintas técnicas proporciona una buena herramienta para analizar los inconvenientes inherentes a cada técnica. Se ha cuantificado la influencia de la radiación solar en las medidas de agua precipitable de los sondeos de las 12 UTC en una subestimación del 7.5\% para la sonda RS92-SGP de Vaisala. También se ha 
analizado la existencia de un sesgo seco de un $5 \%$ en los datos de los fotómetros solares al medir sólo en condiciones de cielo despejado.

6. De las tres técnicas utilizadas los fotómetros solares son los que presentan la mayor imprecisión en las medidas del agua precipitable, variando ésta con el tiempo y de un instrumento a otro. Las medidas de los fotómetros han presentando con respecto a la de los sondeos una subestimación, con unas bias entre 1 y $1.5 \mathrm{~mm}$ y unas diferencias en torno al 9$10 \%$, con una tendencia al incremento de estas al aumentar el agua precipitable. En la comparativa GPS-fotómetros las diferencias han estado entre el 8 y $10 \%$, pero las bias no han presentado siempre el mismo signo, lo que apunta a que este sesgo no depende sólo de la técnica sino también del fotómetro. Además, los fotómetros han sobreestimado las medidas respecto a las de los GPS para valores bajos del agua precipitable. Las medidas de los sondeos y los GPS no presentan, unas respecto de las otras, un sesgo o error sistemático con posterioridad a noviembre del 2006. Las diferencias han oscilado entre un 6 y $9 \%$, siendo mayores para valores bajos del agua precipitable, especialmente por debajo de unos $5 \mathrm{~mm}$.

\section{B.- Sobre el comportamiento del agua precipitable:}

1. Ha presentado una media anual global de $18.19 \mathrm{~mm}$. No obstante, este valor varía significativamente dependiendo de la localización geográfica. Así, para las estaciones del interior oscila entre 12 y $17 \mathrm{~mm}$, mientras que en las de costa lo hace entre 17 y $21 \mathrm{~mm}$.

2. En medias mensuales el agua precipitable describe un ciclo anual, registrando su valor mínimo en los meses del invierno y el máximo hacia finales del verano. La amplitud media de este ciclo es de unos $12 \mathrm{~mm}$, duplicando los valores del verano a los del invierno, y siendo máxima para las estaciones de la costa mediterránea y mínima en las del interior. El ciclo anual del agua precipitable sigue por regla general al ciclo anual de la temperatura. Como excepciones, existe un mínimo relativo en julio en las estaciones situadas al suroeste, y el máximo del agua precipitable se alcanza con posterioridad al de la temperatura principalmente en las estaciones de la costa mediterránea. El análisis de armónicos ha mostrado que el armónico de periodo 12 meses es el dominante en todas las estaciones, explicando en término medio el $96 \%$ de la varianza.

3. El agua precipitable describe un débil ciclo diurno con el valor mínimo próximo al amanecer y el máximo durante la tarde. En media anual la amplitud del ciclo diurno ha variado entre un 3 y un $7 \%$ del valor medio diario. Las mayores amplitudes se han registrado en los emplazamientos de la costa mediterránea, siendo más del doble que las de las estaciones del interior. Los ciclos diurnos de diferentes emplazamientos se asemejan más durante la noche que durante el día. Ello indica que los mecanismos que producen variaciones en el agua precipitable están más influenciados por los efectos locales durante el día. En invierno el ciclo 
diurno es bastante similar en todos los emplazamientos estudiados, mientras que en verano las diferencias son significativas. El análisis de armónicos ha mostrado que sólo los armónicos de periodo 24 y 12 horas tienen una contribución significativa. Juntos explican en término medio el $97 \%$ de la varianza, aunque el primero explica el $85 \%$ y el segundo el $11 \%$. Los principales rasgos del ciclo diurno del agua precipitable pueden explicarse sobre la base del ciclo diurno de la temperatura del aire, el trasporte de humedad por los vientos locales (brisas), y la mezcla turbulenta en la vertical. Además de esta variación cíclica, el agua precipitable ha presentado una variación media diaria de $7.84 \mathrm{~mm}$, un $46 \%$ sobre el valor medio del día, y una variación media horaria de $0.67 \mathrm{~mm}$, aproximadamente un $5 \%$ sobre el valor medio de la hora.

4. En los primeros $1500 \mathrm{~m}$ de altitud se localiza en promedio el $51 \%$ del total del agua precipitable, y por debajo de los $5 \mathrm{Km}$ el 93\%. La contribución media de las capas situadas por encima de los $7 \mathrm{Km}$ de altitud es sólo de un $2 \%$ ( $0.3 \mathrm{~mm}$ en valor absoluto), mientras que la contribución de las capas situadas por encima de los $9 \mathrm{Km}$ es de $0.05 \mathrm{~mm}$, prácticamente un $0 \%$.

5. Aunque las series de datos utilizadas no son lo suficientemente largas para hablar de una verdadera climatología, los valores medios obtenidos con las series de 25 años de sondeos de Coruña y Madrid no difieren significativamente $(\sim 0.5 \mathrm{~mm})$ con los valores aquí presentados.

\section{Líneas Futuras}

Como un objetivo general se pretende mantener abierta la línea de trabajo emprendida, incorporando los nuevos datos que se obtengan de las estaciones ya existentes para completar sus series, y los de las nuevas que se instalen. Como objetivos concretos, las principales líneas futuras de trabajo serán:

1. Validación de los productos satelitales de agua precipitable suministrados por diferentes plataformas, instrumentos, y técnicas. Dentro de este apartado se considera de gran interés el producto generado por el SAF (Satellite Application Facilities) de Nowcasting de EUMETSAT a partir de las medidas del instrumento SEVIRI embarcado en el Meteosat Segunda Generación.

2. Comparación de las medidas de agua precipitable obtenidas de datos de retraso troposférico generados por distintos centros de análisis para un mismo emplazamiento, en el que exista además una medida independiente como puede ser una estación de radiosondeo o fotométrica.

3. Validación de las medidas de retraso troposférico en tiempo cuasi-real. En concreto, se pretenden validar los datos generados por la red de receptores GPS del Instituto Tecnológico 
Agrario de Castilla y León para generar en tiempo cuasi-real productos derivados del agua precipitable con fines agrícolas.

4. Estudiar la posible tendencia al aumento del agua precipitable sobre la Península como consecuencia del incremento medio de las temperaturas por el Cambio Climático.

5. Validación de los análisis de los modelos. Precisamente en este punto los datos del sistema GPS pueden ser muy útiles al provenir de una fuente independiente, puesto que en la actualidad no son asimilados por los modelos numéricos de predicción.

6. Estudio de otros factores que pudieran determinar un comportamiento cíclico del agua precipitable. Por ejemplo, ciclo semanal en las zonas urbanas debido a la actividad humana (Champollion et al., 2009), o variaciones climáticas relacionadas con oscilaciones a gran escala como la NAO (North Atlantic Oscillation).

7. Estudio de las influencias o interacciones entre el vapor de agua y los aerosoles atmosféricos, ya que la humedad de las masas de aire es un factor extremadamente importante en el cambio del tamaño y composición de los aerosoles según la higroscopicidad de los mismos. 


\section{BIBLIOGRAFÍA}

AERONET, http://aeronet.gsfc.nasa.gov/

Baby HB, Gole P, Lavergnat J. 1988. A model for the troposheric excess path length of radio waves from surface meteorological measurements. Radio Science 23(6), 1023-1038.

Bastin S, Champollion C, Bock O, Drobinski P, Masson F. 2007. Diurnal Cycle of Water Vapor as Documented by a Dense GPS Network in a Coastal Area during ESCOMPTE IOP2. J. Appl. Meteor. Climatol., 46, 167-182.

Bennouna YS, Cachorro VE, Toledano C, Berjon A, Prats N, Fuertes D, Gonzalez R, Rodrigo R, Torres B, de Frutos AM. 2011. Comparison of atmospheric aerosol climatologies over southwestern Spain derived from AERONET, MODIS and OMI. Remote Sensing of Environement, Vol. 115, 1272-1284.

Beutler G, Rothacher M, Schaer S, Springer TA, Kouba J, Neilan RE. 1999. The International GPS Service (IGS): An Interdisciplinary Service in Support of Earth Sciences. Adv. Space Res. Vol. 23, No. 4, pp. 631-635.

Bevis M, Businger S, Herring TA, Rocken C, Anthes RA, Ware RH. 1992. GPS Meteorology: Remote Sensing of Atmospheric Water Vapor using the Global Positioning System. J. Geophys. Res. 97, 15787-15801.

Bevis M, Businger S, Chiswell S, Herring TA, Anthes RA, Rocken C, Ware RH. 1994. GPS Meteorology: Mapping Zenith Wet Delays onto Precipitable Water. J. App. Meteorology, 33, 379-386.

Bodhaine BA, Word NB, Dutton EG, Slusser JR. 1999. On Rayleigh Optical Depth Calculations. J.Atmos. and Ocean. Tech, 16, 1854-1861.

Bokoye Al, Royer A, O'Neill NT, Cliché P, McArthur LJB, Teillet PM, Fedosejevs G, Thériault JM. 2003. Multisensor analysis of integrated atmospheric water vapor over Canada and Alaska. J. Geophys. Res., 108(D15), 4480, DOI:10.1029/2002JD002721. 
Bokoye Al, Royer A, Cliché P, O'Neill NT. 2006. Calibration of Sun Radiometer-Based Atmospheric Water Vapor Retrievals Using GPS Meteorology. Journal of Atmospheric and Oceanic Technology, 24, 964-979.

Brown S, Desai S, Keihm S, Lu W, Ruf ChS. 2007. Ocean Water Vapor and Cloud Burden Trends Derived from the Topex Microwave Radiometer, IEEE International Geoscience and Remote Sensing Symposium, 23-27 July 2007, Barcelona, Spain.

Bruegge CJ, Conel JE, Green RO, Margolis JS, Holm RG, Toon G. 1992. Water vapor column abundance retrievals during FIFE. Journal of Geophysical Research, 97 (D17), 18759-18768.

Brunner FK, Gu M. 1991. An improved model for the dual frequency ionospheric correction of GPS observations. Manusc. Geod., 16, 205-214, 1991.

Bruyninx C, Brockmann E, Schaer S. 2006. How to tie the EPN to the ITRF2005. Proceedings of the EUREF TWG Meeting, November 6-7 2006, Frankfurt.

Byun SH, Bar-Server YE. 2009. A new type of troposphere zenith path delay product of the international GNSS service. J. Geod. 83:367-373. DOI: 10.1007/s00190-008-0288-8.

Cachorro VE. 1985. Medida y modelización de la radiación solar espectral. Tesis Doctoral, Departamento de Física Aplicada, Universidad de Valladolid.

Cachorro VE, De Frutos AM, Casanova JL. 1985. Comparison between various models of solar spectral irradiance and experimental data. Applied. Optic. 24, 3249-3253.

Cachorro VE, De Frutos AM, Casanova JL. 1986. Determination of the total vertical water vapor in the atmosphere. Atmospheric Research, 20, 67-74.

Cachorro VE, De Frutos AM, Casanova JL. 1987. Absorption by oxygen water vapor in the real atmosphere. Applied Optics, 26, 501-505.

Cachorro VE, Utrillas P, Vergaz R, Duran P, de Frutos AM, Martinez-Lozano JA. 1998. Determination of the atmospheric-water-vapor content in the $940-\mathrm{nm}$ absorption band by use of moderate spectral-resolution measurements of direct solar irradiance. Applied Optics, 37(21), 4678-4689.

Cady-Pereira KE, Shepherd MW, Turner DD, Mlawer EJ, Clough SA, Wagner TJ. 2008. Improved daytime column-integrated precipitable water vapor from Vaisala radiosonde humidity sensors. J. Atmos. Oceanic Technol., 25, 873-883. 
Campanelli M, Lupi A, Nakajima T, Malvestuto V, Tomasi C, Estellés V. 2010. Summertime columnar content of atmospheric water vapor from ground-based Sun-sky radiometer measurements through a new in situ procedure. J. Geophys. Res., 115, D19304.

Campmany E, Bech J, Rodríguez-Marcos J, Sola Y, Lorente J. 2010. A comparison of total precipitable water measurements from radiosonde and sunphotometers. Atmospheric Research, Vol. 97, No. 3, pp. 385-392.

Cess RD, Potter GL, Blanchet JP, Boer GJ, Del Genio AD, Déqué M, Dymnikov V, Galin V, Gates WL, Ghan SJ, Kiehl JT, Lacis AA, Le Treut H, Li ZX, Liang XZ, McAvaney BJ, Meleshko VP, Mitchell JFB, Morcrette JJ, Randall DA, Rikus L, Roeckner E, Royer JF, Schlese U, Sheinin DA, Slingo A, Sokolov AP, Taylor KE, Washington WM, Wetherald RT, Yagai I, Zhang MH. 1990. Intercomparison and interpretation of climate feedback processes in 19 atmospheric general circulation models. J. Geophys. Res., 95(D10), 16,601-16,615.

Champollion C, Masson F, Van Baelen J, Walpersdorf A, Chéry J, Doerflinger E. 2004. GPS monitoring of the tropospheric water vapor distribution and variation during the 9 September 2002 torrential precipitation episode in the Cévennes (southern France). J. Geophys. Res., 109, D24102, DOI:10.1029/2004JD004897.

Champollion C, Drobinski P, Haeffelin M, Bock O, Tarniewicz J, Bouin MN, Vautard R. 2009. Water vapor variability induced by urban/rural surface heterogeneities during convective conditions. Q. J. R. Meteorol. Soc. 135, 1266-1276, 2009. DOI: 10.1002/qj.446

Ciesielski PE, Johnson RH, Wang J. 2009. Correction of Humidity Biases in Vaisala RS80-H Sondes during NAME. J. Atmos. Oceanic Technol., 26, 1763-1780.

Cimel-Electronique. Sunphotometer user manual, version 4.6, 2004. http://www.Cimel.fr

Clough SA, lacono MJ, Moncet JL. 1992. Line-by-line calculation of atmospheric fluxes and cooling rates: Application to water vapor. J. Geophys. Res., 97, 15761-15785.

Cubasch U, Meehl GA, Boer GJ, Stouffer RJ, Dix M. 2001. Projections of future climate change. Climate Change 2001: The Scientific Basis, J. T. Houghton et al., Eds., Cambridge University Press, 525-582.

Dai A, Deser C. 1999. Diurnal and semidiurnal variations in global surface wind and divergence fields. J. Geophys. Res., 104, 31,109-31,125. 
Dai A, Giorgi F, Trenberth KE. 1999a: Observed and model-simulated precipitation diurnal cycle over the contiguous United States. J. Geophys. Res., 104, 6377-6402.

Dai A, Trenberth KE, Karl TR. 1999b. Effects of clouds, soil moisture, precipitation and water vapor on diurnal temperature range. J. Clim., 12, 2451-2473.

Dai A. 2001. Global precipitation and thunderstorm frequencies, II, Diurnal variations. J. Clim., $14,1112-1128$.

Dai A, Wang J, Ware RH, Van Hove T. 2002. Diurnal variation in water vapor over North America and its implications for sampling errors in radiosonde humidity. J. Geophys. Res., 107(D10), 4090, DOI:10.1029/2001JD000642.

Davidson JM, Trask DW. 1985. Utilization of mobile VLBI for geodetic measurements, IEEE Trans. Geosci. Remote Sens., GE-23, 426-437.

Davis JL, Herring TA, Shapiro II, Rogers AE, Elgered G. 1985. Geodesy by radio interferometry: Effects of atmospheric modelling errors on estimates of baseline length. Radio Sci., 20, 15931607.

De Haan S, Barlag S, Baltink HK, Debie F. 2004. Synergic use of GPS water vapor and Meteosat images for synoptic weather forecasting. J. Appl. Meteor., 43, 514-518.

De Haan S. 2006. National/regional operational procedures of GPS water vapor networks and agreed international procedures, WMO - World Meteorological Organization. Instruments and Observing Methods, Report No. 92.

Duan J, Bevis M, Fang P, Bock Y, Chiswell S, Businger S, Rocken C, Solheim F, van Hove T, Ware R, McClusky S, Herring TA, King RW. 1996. GPS Meteorology: Direct Estimation of the Absolute Value of Precipitable Water. J. Applied Meteorology, 35, 830-838, 1996.

Dubuisson P, Dessailly D, Vesperini M, Frouin R. 2004. Water vapor retrieval over ocean using near-infrared radiometry. J. Geophys. Res., 109, D19106, DOI:10.1029/ 2004JD004516.

Durán P. 1997. Spectrometer measurements for atmospheric components determination (ozone, water vapor and aerosols) and atmospheric radiative transfer modelling. Tesis Doctoral, Departamento de Física Aplicada, Universidad de Valladolid.

Elgered G, Davis JL, Herring TA, Shapiro II. 1991. Geodesy by radio interferometry: Water vapor radiometry for estimation of the wet delay. J. Geophys. Res., 96, 6541-6555, 1991. 
Elgered G. 1993. Tropospheric radio-path delay from ground-based microwave radiometry, Atmospheric Remote Sensing by Microwave Radiometry, Michael A. Janssen, Ed., John Wiley and Sons, 215-258.

Elgered G, Johansson JM, Rönnäng BO. 1997. Measuring regional atmospheric water vapor using the Swedish permanent GPS network. Geophysical R. Letters, vol. 24, pag. 2663-2666.

Elliott WP, Gaffen DJ. 1991. On the utility of radiosonde humidity archives for climate studies. $B$. Am. Meteorol. Soc., v. 72, n. 10, p. 1507-1520.

Emardson TR, Elgered G, Johansson JM. 1998. Three months of continuous monitoring of atmospheric water vapor with a network of Global Positioning System receivers. J. Geophysical Res., vol. 103, pag. 1807-1820.

Escudero M, Castillo S, Querol X, Avila A, Alarcón M, Viana MM, Alastuey A, Cuevas E, Rodríguez S. 2005. Wet and dry African dust episodes over eastern Spain. J. Geophys. Res., 110, D18S08, DOI:10.1029/2004JD004731.

Estellés V, Utrillas MP, Martínez-Lozano JA, Alcántara A, Olmo FJ, Alados-Arboledas L, Lorente J, Cachorro V, Horvath H, Labajo A, de la Morena B, Vilaplana JM, Díaz JP, Díaz AM, Elías T, Silva AM, Pujadas M, Rodríguez. 2004. Aerosol related parameters intercomparison of Cimel sunphotometers in the frame of the VELETA 2002 field campaign. Óptica Pura $y$ Aplicada, 37 (3), 3289-3295.

EUREF Permanent Network, http://epncb.oma.be/

Fotiou A, Pikridas C, Chatzinikos M. 2008. GPS antenna: from relative to absolute. Coordinates, vol IV, issue 3, pp. 28-30, March 2008.

Gaffen DJ, Robock A, Elliot WP. 1992. Annual cycle of tropospheric water vapour. J. Geophysical R., vol. 97, pag. 18185-18193.

Gaffen DJ, Elliot WP. 1993. Column Water Vapor Content in Clear and Cloudy Skies. J. Climate, 6, 2278-2287.

Gao BC, Chan PK, Li RR. 2004. A global water vapor data set obtained by merging the SSMI and MODIS data. Geophys. Res. Lett., vol. 31, no. 18, p. L18 103, Sep. 2004. 
Gardner CS. 1976. Effects of horizontal refractivity gradients on the accuracy of laser ranging to satellites. Radio Sci., 11, 1037-1044.

Gelb A. 1974. Applied Optimal Estimation, 374 pp., MIT Press, Cambridge, Mass.

Guerova G. 2003. Derivation of integrated water vapor (IWV) from the ground - based GPS estimates of Zenith Total Delay (ZTD). Research Report No 2003-08, Institute of Applied Physics, University of Berne, Switzerland.

Hagemann S, Bengtsson L, Gendt G. 2003. On the determination of atmospheric water vapor from GPS measurements. J. Geophys. Res., 108(D21), 4678.

Halthore RN, Eck TF, Holben BN, Markham BL. 1997. Sun photometric measurements of atmospheric water vapor column abundance in the 940nm band. J. Geophysical R., 102, 43434352.

Hauser JP. 1989. Effects of deviations from hydrostatic equilibrium on atmospheric corrections to satellite and lunar laser range measurements. J. Geophys. Res., 94:10 182-10 186.

Heise S, Bender M, Beyerle G, Dick G, Gendt G, Schmidt T, Wickert J. 2009. Integrated water vapor from IGS ground-based GPS observations: Initial results from a global 5-minute data set. Annales Geophysicae, 27, 7, 2851-2859.

Herring T, Davis JL, Shapiro II. 1990. Geodesy by radio interferometry: The application of Kalman filtering to the analysis of very long baseline interferometry data. J. Geophys. Res., 95, 12,561-12,581, 1990.

Hogg DC, Guiraud F, Decker M. 1981. Measurements of excess transmisión length on earthspace path. Astron. Astrophys., 95, 304-307.

Holben BN, Eck TF, Slutsker I, Tanré D, Buis JP, Setzer A, Vermote EF, Reagan JA, Kaufman YJ, Nakajima T, Lavenu F, Jankowiak I, Smirnov A. 1998. AERONET - A federated instrument network and data archive for aerosol characterization. Remote Sensing of Environment, 66(1), $1-16$.

Holben BN, Tanré D, Smirnov A, Eck TF, Slutsker I, Abuhassan N, Newcomb WW, Schafer JS, Chatenet B, Lavenu F, Kaufman YJ, Vande Castle J, Setzer A, Markham B, Clark D, Frouin R, Halthore R, Karneli A, O’Neill NT, Pietras C, Pinker RT, Voss K, Zibordi G. 2001. An emerging ground-based aerosol climatology: Aerosol Optical Depth from AERONET. J. Geophys. Res., 106, 12067-12097. 
IGS International GNSS Service, http://igscb.jpl.nasa.gov/

IGSMail-5438 (2006): IGS switch to absolute antenna model and ITRF2005. IGS International GNSS Service.

Ingold T, Schmid B, Mätzler C, Demoulin P, Kämpfer N. 2000. Modeled and empirical approaches for retrieving columnar water vapor from solar transmittances measurements in 0.72, 0.82 and 0.94 um absorption bands. J. Geophysical R., 105(D19), 24327-24344.

Jakobson E, Ohvril H, Elgered G. 2009. Diurnal variability of precipitable water in the Baltic region, impact on transmittance of the direct solar radiation. Boreal Env. Res. 14: 45-55.

Jin SG, Luo OF. 2009. Variability and climatology of PWV from global 13-year GPS observations, IEEE Trans. Geosci. Remote Sens., Vol. 47, NO. 7, July 2009, DOI: 10.1109/TGRS.2008.2010401.

Kasten F, Young AT. 1989. Revised optical air mass tables and approximation formula. Appl. Opt., 28, 4735-4738, 1989.

Kimura F, Tanikawa R, Yoshizaki M. 1997. Diurnal variation of precipitable water in clear days over the northern mountains in Kanto plain (in Japanese). Tenki, 44, 799-807.

Kneizys FX, Shettle EP, Abreu LW, Chetwynd JH Jr., Anderson GP, Gallery WO, Selby JEA, Clough SA. 1988. User's Guide to LOWTRAN 7. Air Force Geophysics Laboratory Rep. AFGLTR-88-0177, $137 \mathrm{pp}$.

Kruse L, Sierk B, Springer T, Cocard M. 1999. GPSMeteorology: Impact of Predicted Orbits on Precipitable Water Estimates. Geophys. Res. Let., Vol. 24, No. 14, pp. 2045-2048.

Kuo Y-H, Guo Y-R, Westwater E. 1993. Assimilation of Precipitable Water Measurements into a Mesoscale Numerical Model. Mon. Wea. Rev. 121, 1215-1238, 1993.

Li Z, Muller JP, Cross P. 2003. Comparison of precipitable water vapor derived from radiosonde, GPS, and Moderate Resolution Imaging Spectroradiometer measurements. J. Geophys. Res., 108(D20), 4651, DOI:10.1029/2003JD003372.

Li G, Kimura F, Sato T, Huang D. 2008. A composite analysis of diurnal cycle of GPS precipitable water vapor in central Japan during Calm Summer Days. Theor. Appl. Climatol., 92, 15-29, DOI:10.1007/s00704-006-0293-x. 
Lichten SM, Border JS. 1987. Strategies for high precision global positioning system orbit determination. J. Geophys. Res., 92, 12,751-12,762.

Michalsky JJ, Liljegren JC, Harrison LC. 1995. A comparison of sun photometer derivations of total column water vapor and ozone to standard measures of same at the Southern Great Plains Atmospheric Radiation Measurement site. J. Geophys. Res., 100, 25,995-26,003.

Miloshevich LM, Vömel H, Whiteman DN, Lesht BM, Schmidlin FJ, Russo F. 2006. Absolute accuracy of water vapor measurements from six operational radiosonde types launched during AWEX-G and implications for AIRS validation. J. Geophys. Res., 111, D09S10.

Mockler SB. 1995. Water Vapor in the Climate System, Special Report, American Geophysical Union (AGU), 2000 Florida Ave., N.W., Washington, DC 20009, ISBN 0-87590-865-9, December 1995; http://www.agu.org/sci_soc/mockler.html.

Morland J, Collaud Coen M, Hocke K, Jeannet P, Mätzler C. 2009. Tropospheric water vapour above Switzerland over the last 12 years. Atmos. Chem. Phys., 9, 5975-5988, 2009.

Mote PW, Frey R. 2006. Variability of clouds and water vapor in low latitudes: View from Moderate Resolution Imaging Spectroradiometer (MODIS). J. Geophys. Res., 111, D16101.

Ohtani R, Naito I. 2000. Comparisons of GPS-derived precipitable water vapors with radiosonde observations in Japan. J. Geophys. Res., 105(D22), 26,917-26,929.

Ohtani R. 2001. Detection of water vapor variations driven by thermally induced local circulations using the Japanese continuous GPS array. Geophys. Res. Lett., 28, 151-154.

Ortiz de Galisteo JP, Toledano C, Cachorro VE, Torres B. 2010. Improvement in PWV estimation from GPS due to the absolute calibration of antenna phase center variation. GPS Solut., 14, 389-395, 2010. DOI 10.1007/s10291-010-0163-y.

Pathack B, Nash J, Smout R, Kurnosenko S. 2005. Preliminary results of WMO intercomparison of high quality radiosonde systems, Mauritus, February 2005. World Meteorological Organization Technical Conference on Meteorological and Environmental Instruments and Methods of Observation - TECO 2005.

Paukkunen A. 1995. Sensor Heating to Enhance Reliability of Radiosonde Humidity Measurement. Ninth AMS Symposium on Meteorological Observations and Instrumentation, Charlotte, North Carolina, pp. 65-69. 
Rapp-Arrarás I, Domingo-Santos JM. 2008. Extinction, refraction, and delay in the atmosphere. J. Geophys. Res., 113, D20116, DOI:10.1029/2008JD010176.

Ray RD, Ponte RM. 2003. Barometric tides from ECMWF operational analyses. Ann. Geophys., 21, 1897-1910, 2003. DOI: 10.5194/angeo-21-1897-2003.

Reagan JA, Thome K, Herman B, Gall R. 1987. Water vapor measurements in the 0.94 micron absorption band: calibration, measurements and data applications. In Proceeding of IGARSS '87 Symposium, pp. 63-67, IEEE Pres, Piscataway N.J., 1987.

Reitan $\mathrm{CH}$. 1960. Mean monthly values of precipitable water over the United States, 1946-56, Monthly Weather Review, January 1960.

Resch GM. 1984. Water vapor radiometry in geodetic applications, in Geodetic Refraction, edited by F. K. Brunner, pp. 53-84, Springer-Verlag, New York.

Richner H, Phillips PD. 1982. The radiosonde intercomparison SONDEX, spring 1981, Payerne. Pure and Appl. Geophys., 120, 852-913.

Rocken C, Johnson JM, Neilan RE, Cerezo M, Jordan JR, Falls MJ, Nelson LD, Ware RH, Hayes M. 1991. The measurement of atmospheric water vapor: Radiometer comparison and spatial variations, IEEE Trans. Geosci. Remote Sens., 29, 3-8.

Rocken C, Ware R, Van Hove T, Solheim F, Alber C, Johnson J. 1993. Sensing atmospheric water vapor with the global positioning system. Geophysical R. Letters, vol. 20, pag. 2631-2634, 1993.

Rocken C, Van Hove T, Johnson J, Solheim F, Ware R. 1995. GPS/STORM-GPS sensing of atmospheric water vapor for meteorology. J. Atmos. Oceanic Technol., 12:468-478.

Rothacher M, Schaer S, Mervart L, Beutler G. 1995. Determination of Antenna Phase Center Variations using GPS Data. In: Gendt, G. Dick (Eds.); Special Topics and New Directions, Proceedings of the 1955 IGS Work-Shop, Potsdam, 15-17 May, pp. 205-220.

Saastamoinen J. 1972. Atmospheric correction for the troposphere and stratosphere in radio ranging of satellites, in The Use of Artificial Satellites for Geodesy. Geophys. Monogr. Ser., vol. 15, edited by S. W. Henriksen, et al., pp. 247-251, AGU, Washington, D.C., 1972. 
Santangelo R, Pugnaghi S, Corradini S, Lombroso L, Teggi S. 2003. Continuous photometric observations at ENEA base in Lampedusa to estimate precipitable water. Ann. Geophy., Vol. 46, N. 2, DOI:10.4401/ag-3413.

Sasaki T, Kimura F. 2001. Diurnal variation of water vapor content over the Kanto area during clear summer days observed through GPS precipitable water (in Japanese). Tenki, 48, 65-74.

Schmid B, Thome KJ, Demoulin P, Peter R, Mätzler C, Sekler J. 1996. Comparison of modeled and empirical approaches for retrieving columnar water vapor from solar transmittance

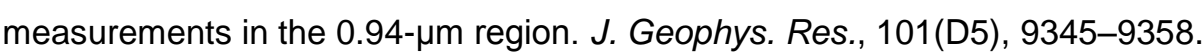

Schmid R, Mader G, Herring T. 2004. From relative to absolute antenna phase center corrections. Proceedings of the IGS Workshop and Symposium 2004: Celebrating a Decade of the International GPS Service IGS. Berne, Switzerland, March 1-5, 2004.

Schmid R, Rothacher M, Thailer D, Steigenberger P. 2005. Absolute phase center corrections of satellite and receiver antennas. Impact on global GPS solutions and estimation of azimuthal phase center variations of the satellite antenna. GPS Solutions, Vol. 9, $\mathrm{Nr} 4$, pp 283-293.

Schmid R, Steigenberger P, Rothacher M, Gendt G, Ge M, Tesmer V. 2006. Absolute antenna phase center corrections and their impact on GPS results. Proceeding of the 2006 UNAVCO Science Workshop, March 14-16, Denver, Colorado, USA.

Schneider M, Romero PM, Hase F, Blumenstock T, Cuevas E, Ramos R. 2009. Quality assessment of Izaña's upper-air water vapor measurement techniques: FTIR, Cimel, MFRSR, GPS, and Vaisala RS92. Atmos. Meas. Tech. Discuss., 2, 1625-1662, 2009.

Seco A, González PJ, Ramírez F, García R, Prieto E, Yagüe C, Fernández J. 2009. GPS monitoring of the tropical storm Delta along the Canary Islands track, November 28-29, 2005. Pure Appl. Geophys. 166, no 8/9, 1519-1531. DOI:10.1007/s00024-009-0502-5.

Smirnov A, Holben BN, Eck TF, Dubovick O, Slutsker I. 2000. Cloud screening and quality control algorithms for the AERONET database. Rem. Sens. Environ.

Smirnov A, Holben BN, Lyapustin A, Slutsker I, Eck TF. 2004. AERONET processing algorithms refinement, AERONET Workshop, May 10-14, 2004, El Arenosillo, Spain.

Smith EK, Weintraub S. 1953. The constants in the equation for atmospheric refractive index at radio frequencies, Proc. IRE, 41, 1035-1037. 
Smout R, Nash J, Hewison T, Smees M. 2005. Results of the RS92 Acceptance Test performed by the Met Office (UK). World Meteorological Organization Technical Conference on Meteorological and Environmental Instruments and Methods of Observation - TECO 2005.

Spilker JJ. 1980. GPS signal structure and performance characteristics, in Global Positioning System, vol. 1, The Institute of Navigation, Washington, D.C., 1980.

Thayer GD. 1974. An improved equation for the radio refractive index of air. Radio Sci., 9(10), 803-807.

Toledano C, Cachorro VE, de Frutos AM, Sorribas M, Prats N, de la Morena BA. 2007. Inventory of African desert dust events over the southwestern Iberian Peninsula in 2000-2005 with an AERONET Cimel Sun photometer. J. Geophys. Res.,112, D21201, 2007.

Toledano C, Cachorro VE, de Frutos AM, Torres B, Sorribas M, de la Morena B. 2009. Air mass classification and analysis of aerosol types at El Arenosillo (Spain). J. Appl. Met. Climat. 48, 5, 962-981, 2009.

Torres B, Cachorro VE, Toledano C, Ortiz de Galisteo JP, Berjón A, de Frutos AM, Bennouna Y, Laulainen N. 2010. Precipitable water vapor characterization in the gulf of Cadiz region (southwestern Spain) based on sun photometer, GPS and radiosonde data. J. Geophys. Res., 115, D18103, DOI:10.1029/2009JD012724.

Tralli DM, Dixon TH, Stephens SA. 1988. Effect of wet tropospheric path delays on estimation of geodetic baselines in the Gulf of California using the global positioning system. J. Geophys. Res., 93, 6545-6557, 1988.

Tralli DM, Lichten SM. 1990. Stochastic estimation of tropospheric path delays in global positioning system geodetic measurements. Bull. Geod., 64, 127-159, 1990.

Trenberth KE, Fasullo J, Smith L. 2005. Trends and variability in column integrated atmospheric water vapor. Climate Dynamics, 24: 741-758, DOI 10.1007/s00382-005-0017-4.

Treuhaft RN, Lanyi GE. 1987. The effects of the dynamic wet troposphere on radio interferometric measurements. Radio Sci., 22,251-265.

Turner DD, Lesht BM, Clough SA, Liljegren JC, Revercomb HE, Tobin DC. 2003. Dry bias and variability in Vaisala RS80-H radiosondes: The ARM experience. J. Atmos. Ocean. Technol., 20, 117-132. 
Vömel H, Selkirk H, Miloshevich L, Valverde-Canossa J, Valdés J, Kyrö E, Kivi R, Stolz W, Peng G, Diaz JA. 2007. Radiation dry bias of the Vaisala RS92 humidity sensor. J. Atmos. Oceanic Technol., 24, 953-963.

Wang J, Cole HL, Carlson DJ, Miller ER, Beierle K, Paukkunen A, Laine TK. 2002. Corrections of Humidity Measurement Errors from the Vaisala RS80 Radiosonde-Application to TOGA COARE Data. J. Atmos. Oceanic Technol., 19, 981-1002.

Wang J, Zhang L, Dai A. 2005. Global estimates of water-vapor-weighted mean temperature of the atmosphere for GPS applications. J. Geophys. Res., 110, D21101.

Wang J, Zhang L, Dai A, Van Hove T, Van Baelen J. 2007. A near-global, 2-hourly data set of atmospheric precipitable water from ground-based GPS measurements. J. Geophys. Res., 112, D11107, DOI:10.1029/2006JD007529

Wang J, Zhang L. 2008. Systematic errors in global radiosonde precipitable water data from comparisons with ground-based GPS measurements. J. Climate, 21, 2218-2238.

Wu P, Hamada J, Mori S, Tauhid YI, Yamanaka MD, Kimura F. 2003. Diurnal variation of precipitable water over a mountainous area of Sumatra Island. J. Appl. Meteor., 42, 1107-1115

Wübbena G, Schmitz M, Menge F, Boder V, Seeber G. 2000. Automated absolute field calibration of GPS antennas in real-time. Proceedings of the $13^{\text {th }}$ International Technical Meeting of the satellite Division of the Institute of Navigation, ION GPS-2000, Salt Lake City, Utah, USA, 19-22 September, pp. 2512-2522.

Yoneyama K, Fujita M, Sato N, Fujiwara M, Inai Y, Hasebe F. 2008. Correction for radiation dry bias found in RS92 radiosonde data during the MISMO field experiment. SOLA, 4. 
ANEXOS 
- 268 - 


\section{ANEXO I}

\section{ACRÓNIMOS}

AEMET - Agencia Estatal de Meteorología

AERONET - AErosol RObotic NETtwork

AOD - Espesor Óptico de Aerosoles (Aerosol Optical Depth)

ECMWF -European Centre for Medium-Range Weather Forecasts

EUMETNET - Network of European Meteorological Services

EUREF - European Reference Frame

FTIR - Fourier Transform Infrared

GCOS - Sistema de Observación del Clima Mundial

GNSS - Global Navigation Satellite System

GPS - Sistema de Posicionamiento Global (Global Position System)

GOA - Grupo de Óptica Atmosférica de la Universidad de Valladolid

HIRLAM - High Resolution Local Area Modeling

IGN - Instituto Geográfico Nacional

IGS - International GNSS Service

INM - Instituto Nacional de Meteorología

IPCC - Panel Intergubernamental para el Cambio Climático

LAC - Centro Local de Análisis de Datos GPS (Local Analysis Center)

LBLRTM - Line-By-Line Radiative Transfer Model

LOWTRAN - Low Resolution Transmission Model

LST - Hora Solar Local (Local Solar Time)

MAE - Media de los valores absolutos de las diferencias

MODIS - Moderate-Resolution Imaging Spectroradiometer

MSG - Meteosat Second Generation

NAO - North Atlantic Oscillation

OMM - Organización Meteorológica Mundial

PCV - Variación del Centro de Fase de las Antenas (Phase Centre Variation)

PRN - Ruido Pseudo-aleatorio (Pseudo Random Noise)

PWV - Agua Precipitable (Precipitable Water Vapor)

RIMA - Red Ibérica de Medida Fotométrica de Aerosoles

RMDA - Media de las diferencias relativas en valor absoluto

RMSE - Error cuadrático medio

SAF - Satellite Application Facilities

SINEX - Solution INdependent EXchange format 
SSA - Single Scattering Albedo

STD - Desviación Estándar (Standard Deviation)

UNFCCC - Convección de Naciones Unidas para el Cambio Climático

UTC - Tiempo Universal Coordinado (Coordinated Universal Time)

WVR - Radiómetros de microondas

ZHD - Retraso Cenital Hidrostático (Zenith Hydrostatic Delay)

ZTD - Retraso Cenital Total (Zenith Total Delay)

ZWD - Retraso Cenital Húmedo (Zenith Wet Delay) 


\section{ANEXO II}

\section{FÓRMULAS}

\section{Estadísticos}

- Coeficiente de variación o de dispersión de Pearson

$$
\text { Coef_Var }=\frac{\sigma}{\bar{X}}=\frac{\sqrt{\frac{\sum_{i=1}^{N}\left(X_{i}-\bar{X}\right)^{2}}{N}}}{\frac{\sum_{i=1}^{N} X_{i}}{N}}
$$

- Media de las diferencias (Sesgo o Bias)

$$
B I A S=\frac{\sum_{i=1}^{N} P W V_{i}^{(x)}-P W V_{i}^{(y)}}{N_{\text {datos }}}
$$

- Media de las diferencias relativas (Bias relativas)

$$
B I A S_{-} \text {relativas }=\frac{\sum_{i=1}^{N} 2 \cdot \frac{P W V_{i}^{(x)}-P W V_{i}^{(y)}}{P W V_{i}^{(x)}+P W V_{i}^{(y)}}}{N_{\text {datos }}} \cdot 100
$$

- Media de las diferencias relativas en valor absoluto (RMDA)

$$
R M D A=\frac{\sum_{i=1}^{N} 2 \cdot \frac{\left|P W V_{i}^{(x)}-P W V_{i}^{(y)}\right|}{P W V_{i}^{(x)}+P W V_{i}^{(y)}}}{N_{\text {datos }}} \cdot 100
$$

- Error cuadrático medio (RMSE)

$$
R M S E=\sqrt{\frac{\sum_{i=1}^{N}\left(P W V_{i}^{(x)}-P W V_{i}^{(y)}\right)^{2}}{N_{\text {datos }}}}
$$


- Media de los valores absolutos de las diferencias (MAE)

$$
M A E=\frac{\sum_{i=1}^{N}\left|P W V_{i}^{(x)}-P W V_{i}^{(y)}\right|}{N_{\text {datos }}}
$$

- Desviación estándar (STD)

$$
S T D=\sqrt{(R M S E)^{2}-(B I A S)^{2}}
$$

Los subíndices $x$ e $y$ denotan series de datos de diferente instrumentación o emplazamiento. 


\section{ANEXO III}

\section{PROGRAMAS INFORMÁTICOS}

Para extraer el dato de PWV de los ficheros originales, convertirlos a un mismo formato, y procesar el gran volumen de datos tratados en este trabajo, se han desarrollado varios programas informáticos con el lenguaje de programación VBasic 6.0 bajo un entorno de Windows XP, y se ha trabajado con la hoja de cálculo Microsoft Office Excel 2003.

\section{Tratamiento de los datos de AERONET}

El programa PWV_AERONET.EXE extrae el dato de PWV de los ficheros generados por AERONET.

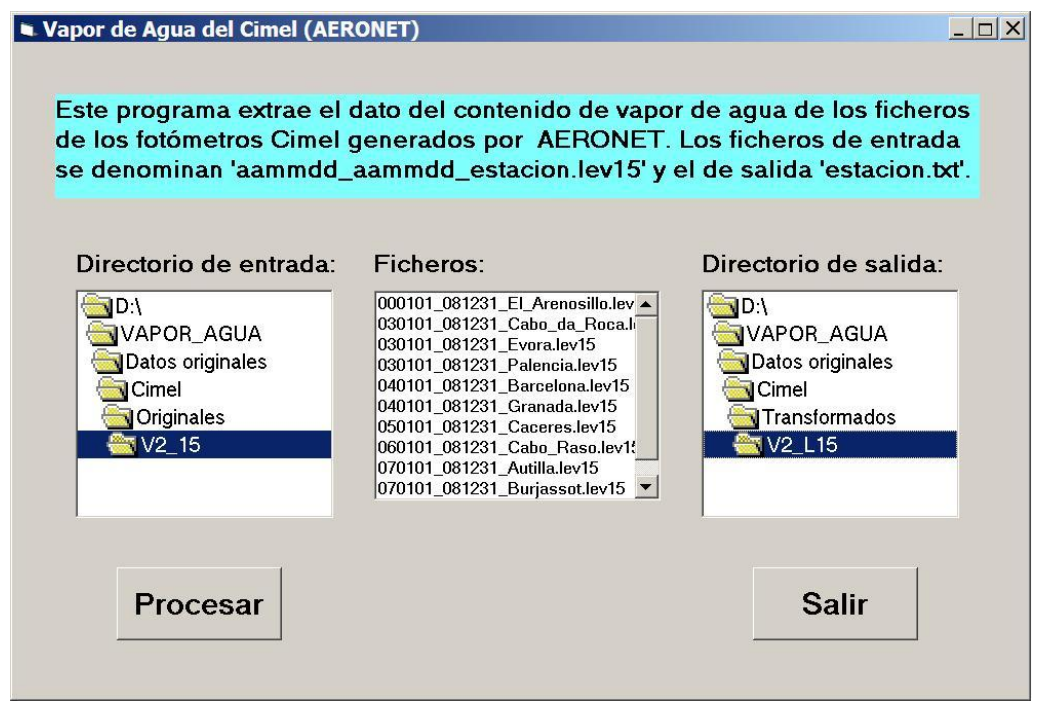

Formulario del programa PWV_AERONET.EXE.

Para cada estación se dispone de un fichero denominado aammdd_aammdd_estación.lev15, donde aammdd son la fecha inicial y final del periodo de datos contenido en el fichero, estación es el nombre de la estación según consta en el fichero maestro de AERONET, y lev15 indica que los datos corresponden al nivel de calidad 1.5. Estos ficheros contienen, además del dato de PWV, los datos del AOD para cada uno de los canales del fotómetro Cimel, el parámetro alfa de Angstrom, y otras variables de interés. El programa recorre el directorio de entrada y para cada fichero genera otro nuevo en el directorio de salida denominado estación.txt, que contiene únicamente los datos de fecha, hora y PWV. 


\section{Tratamiento de los datos de los sondeos}

El programa PWV_SONDEOS.EXE extrae el dato de PWV de los ficheros de los sondeos descargados de la Universidad de Wyoming.

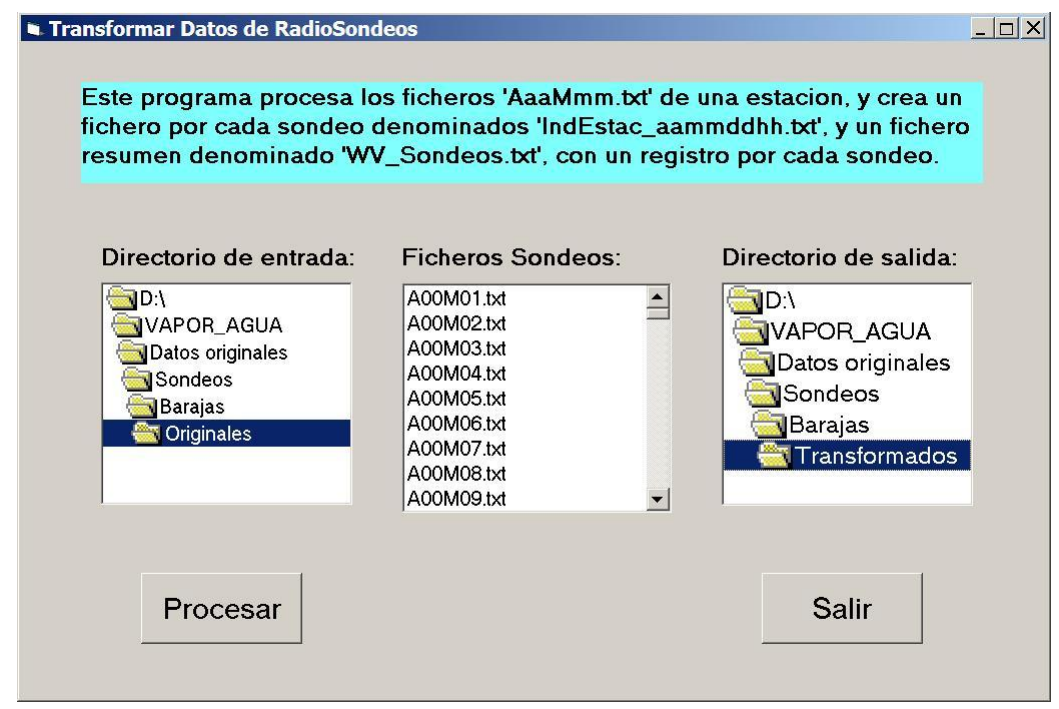

Formulario del programa PWV_SONDEOS.EXE.

Para cada estación de sondeo se dispone de un fichero por mes y año que contiene todos los sondeos del mes en cuestión. De cada sondeo se tiene el valor de las variables medidas a cada altitud y un resumen con ciertos índices y parámetros, entre ellos el PWV.

Los ficheros originales se denominan AaaMMmm.txt, donde aa es el año, y $\mathrm{mm}$ el mes. El programa recorre el directorio de entrada, que deberá contener los ficheros originales de una única estación con la nomenclatura anterior, y genera en el directorio de salida un fichero para cada sondeo individual que consta de un registro por cada nivel sondeado. Estos ficheros se denominan iiiii_aammddhh.txt, donde iiiii es el indicativo sinóptico de la estación de sondeo, aa el año, $m m$ el mes, $d d$ el día y $h h$ la hora, Así mismo, el programa genera un único fichero resumen de todos los sondeos denominado $W V \_$Sondeos.txt, que contendrá un registro por cada sondeo con la fecha, la hora, el PWV, la temperatura al nivel de la superficie, la temperatura media del sondeo pesada por el contenido de vapor de agua, la altitud del primer dato, la altitud máxima alcanzada, y el número de niveles.

El programa SONDEO_MED.EXE obtiene el perfil vertical medio a partir de un conjunto de sondeos de una estación. El programa lee de un fichero de entrada denominado Sondeos_iiiii.txt, donde iiiii es el indicativo de la estación, la fecha y hora de los sondeos que se quieren promediar, y va recorriendo el directorio de entrada donde se encontrarán los ficheros iiiii_aammddhh.txt con los datos de los sondeos generados por el programa anterior. El programa produce dos ficheros: uno con el sondeo medio calculado para unos niveles fijos de 
altitud (SondMed1_iiiii.txt), y otro para niveles de presión (SondMed2_iiiii.txt). En el caso de los niveles de altitud se ha dividido la atmósfera en capas de $100 \mathrm{~m}$ entre los 0 y los $3 \mathrm{Km}$, de 200 $\mathrm{m}$ entre los 3 y los $9 \mathrm{Km}$, de $500 \mathrm{~m}$ hasta los $14 \mathrm{Km}$, y de $1 \mathrm{Km}$ a partir de aquí, correspondiéndose los niveles de referencia con los puntos medios de las capas. En el caso de los niveles de presión se han utilizado los niveles estándar: 1013, 1000, 975, 950, 925, 900, 850, 800, 750, 700, 650, 600, 650, 500, 450, 400, 350, 300, 250, 200, 150, 100, 50, 20, 0 hPa. Para calcular el valor medio de cada variable para cada nivel tipo de altitud o presión el programa asigna cada medida del sondeo al nivel de referencia más cercano, y finalmente promedia todas las medidas asignadas a cada nivel.

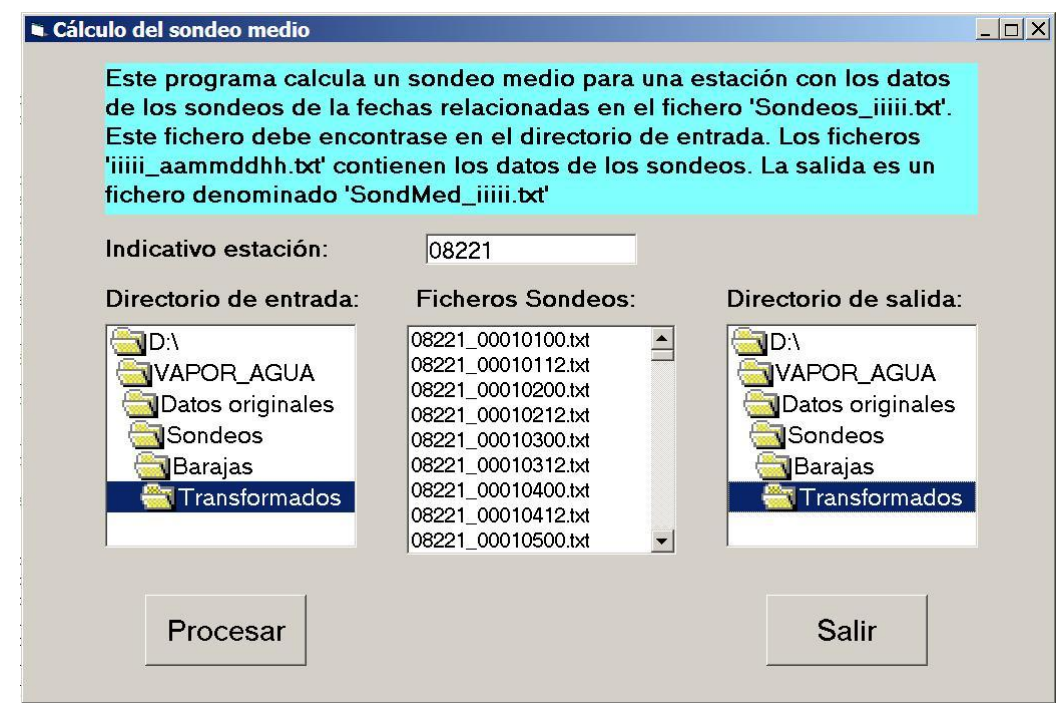

Formulario del programa SONDEO_MED.EXE.

El sondeo medio contendrá para cada nivel: la altitud, la presión, la temperatura, el punto de rocío, la humedad relativa, la razón de mezcla, la tensión de vapor, la humedad absoluta y el número de medidas consideradas en el promedio.

Además del sondeo medio total los ficheros de salida contendrán también un sondeo medio para cada uno de los meses del año.

\section{Tratamiento de los datos GPS}

El programa PWV_GPSIGN.EXE transforma los ficheros del retraso troposférico generados por el IGN. Estos ficheros se denomina 'IGEssssd.TRO', donde 'ssss' es la semana GPS, y 'd' el día de la semana. Cada fichero contiene los datos horarios de un día de todas las estaciones GPS procesadas por el IGN. El programa procesa todos los ficheros *.tro del directorio de entrada, y crea un fichero de salida para cada estación con sus datos del ZTD. Estos ficheros se denominan ZTD_iiii.txt, donde iiii es el indicativo de la estación GPS. 


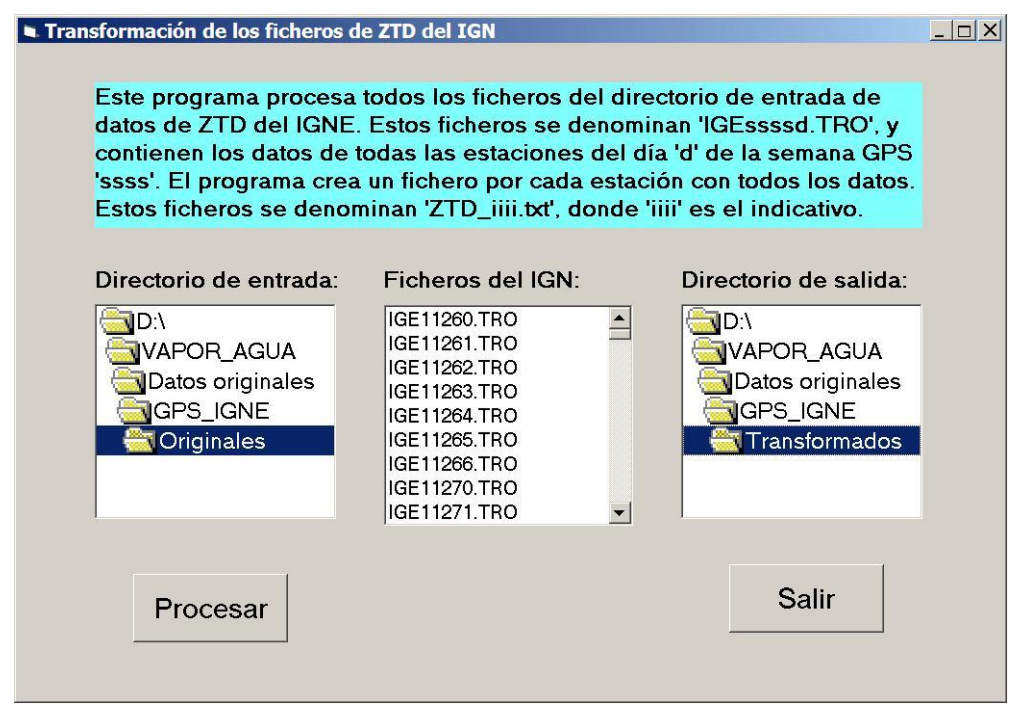

Formulario del programa PWV_GPSIGN.EXE.

El programa ZTD_MET.EXE asocia a cada medida de ZTD los valores de presión y temperatura de la estación meteorológica más próxima. El programa fusiona los ficheros ZTD_iiii.txt, con los retrasos troposféricos, y los ficheros $M E T$ _iiiii.txt de datos meteorológicos. El fichero maestro de estaciones Est_GPS.txt contiene el indicativo y las coordenadas de la estación meteorológica asociada a cada estación GPS. Las observaciones de presión y temperatura se interpolan para calcular su valor a la hora de la medida del ZTD, y se reducen a la altitud de la estación GPS. Los ficheros de salida se denominan ZTDMET_iiii.txt, y contendrán los valores de la presión $(\mathrm{hPa})$, la Temperatura $\left({ }^{\circ} \mathrm{C}\right)$ y el ZTD $(\mathrm{mm})$.

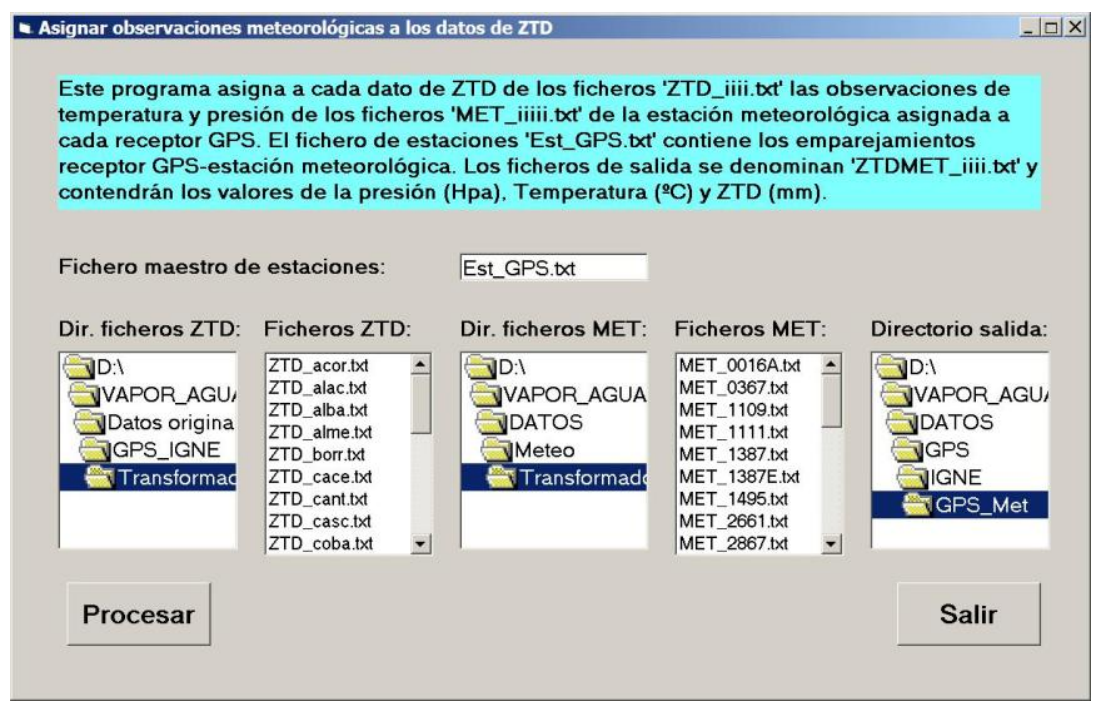

Formulario del programa ZTD_MET.EXE.

El programa GPS_PWV.EXE calcula el PWV a partir del ZTD y de los datos meteorológicos en superficie de presión y temperatura. Los ficheros de entrada se denominan ZTDMET_iiii.txt y

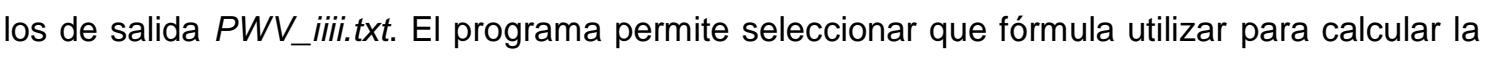
temperatura media atmosférica a partir de la temperatura al nivel de la superficie. 


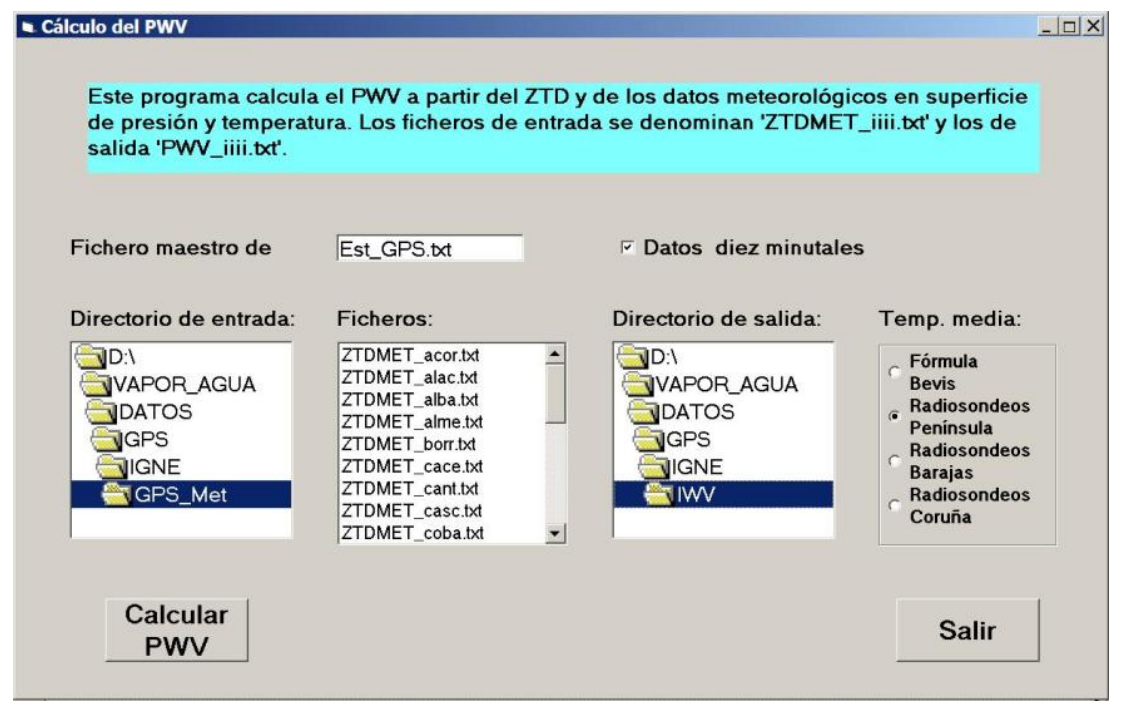

Formulario del programa GPS_PWV.EXE.

Public Function PWV(lat, alt, ts, ps, ztd As Double) As Double

'Cálculo del PWV en Kgr/m2 o mm $(10 \mathrm{~kg} / \mathrm{m} 2=1 \mathrm{gr} / \mathrm{cm} 2$ ó $10 \mathrm{~mm}=1 \mathrm{~cm})$

'Datos entrada: ZTD $(\mathrm{mm}), \operatorname{Ps}(\mathrm{HPa})$, lat $\left({ }^{\circ}\right)$, alt $(\mathrm{m})$ (sobre el elipsoide), y $\mathrm{Ts}\left({ }^{\circ} \mathrm{C}\right)$

'latitud en grados y altitud en $\mathrm{Km}$

'salida PWV en $\mathrm{Kgr} / \mathrm{m} 2$ o mm

Const $\mathrm{c} 1=2.2779$ 'Bevis 1992

Const $\mathrm{c} 2=0.00266$

Const $\mathrm{c} 3=0.00028$

Const pi $=3.1416$

Const $\mathrm{Rv}=461.51$ 'Constante del vapor de agua en $\mathrm{J} / \mathrm{kg}$ 으

Const $\mathrm{k} 3=3.739^{*} 10^{\wedge} 5$ 'Constante de la refractividad en ${ }^{\circ} \mathrm{K} 2 / \mathrm{mb}$ (Bevis 1994)

Const $\mathrm{k} 2=22.1$ 'Constante $\mathrm{k}$ '2 de la refractividad en ${ }^{\circ} \mathrm{K} / \mathrm{mb}$ (Bevis 1994)

Dim tm As Double 'temperatura media atmosférica en ํㅡ

Dim zhd As Double 'zenit hydrostatic delay en $\mathrm{mm}$

Dim ef As Double 'factor de corrección de la gravedad

Dim ak As Double 'constante de conversión

alt $=$ alt $/ 1000$ 'para pasar de metros a Km

If ps <> -9999 And ts <> -99 And ztd $<>0$ Then

ef $=1 \#-c 2$ * $\operatorname{Cos}(2 *$ lat * pi / 180) - c3 * alt 'corrección de gravedad por latitud y altitud sobre elipsoide

'Selecciono la formula a utilizar para el calculo de la temperatura media

Select Case formTM

Case 0

$\mathrm{tm}=70.2+0.72 *(\mathrm{ts}+273.15)$ 'formula Bevis

Case 1

$\mathrm{tm}=61.92+0.75^{*}(\mathrm{ts}+273.15)$ 'radiosondeos Península

Case 2

$\mathrm{tm}=91.17+0.64 *(\mathrm{ts}+273.15)$ 'radiosondeos Barajas

Case 3

$\mathrm{tm}=24.74+0.88 *(\mathrm{ts}+273.15)$ 'radiosondeos Coruña

End Select

ak $=10 \#{ }^{\wedge} 5 /\left((\mathrm{k} 3 / \mathrm{tm}+\mathrm{k} 2){ }^{*} \mathrm{Rv}\right)$ 'en unidades de $\mathrm{Kg} / \mathrm{m} 2 \mathrm{~mm}$

$\mathrm{zhd}=\mathrm{c} 1{ }^{*} \mathrm{ps} / \mathrm{ef}$ 'en $\mathrm{mm}$

$P W V=a k^{*}(z t d-z h d)$ 'en $\mathrm{Kg} / \mathrm{m} 2$

$P W V=$ Round $(P W V, 2)$ 'valor en $\mathrm{mm}$ con 2 decimales Else

PWV $=-999$

End If

End Function

Subrutina del cálculo del PWV a partir de los datos de ZTD. 


\section{Tratamiento de los datos meteorológicos y otras utilidades}

El programa METEO.EXE lee el fichero de datos meteorológicos, y genera un fichero para cada estación con un registro por día con sus datos de presión a las horas tipo (00, 07, 12 y 18 UTC) y la temperatura horaria.

El programa EMPAREJAR.EXE fusiona dos ficheros de entrada con datos de PWV obtenidos con distintas técnicas para un mismo emplazamiento, generando un fichero con los pares de datos dentro de un intervalo temporal configurable.

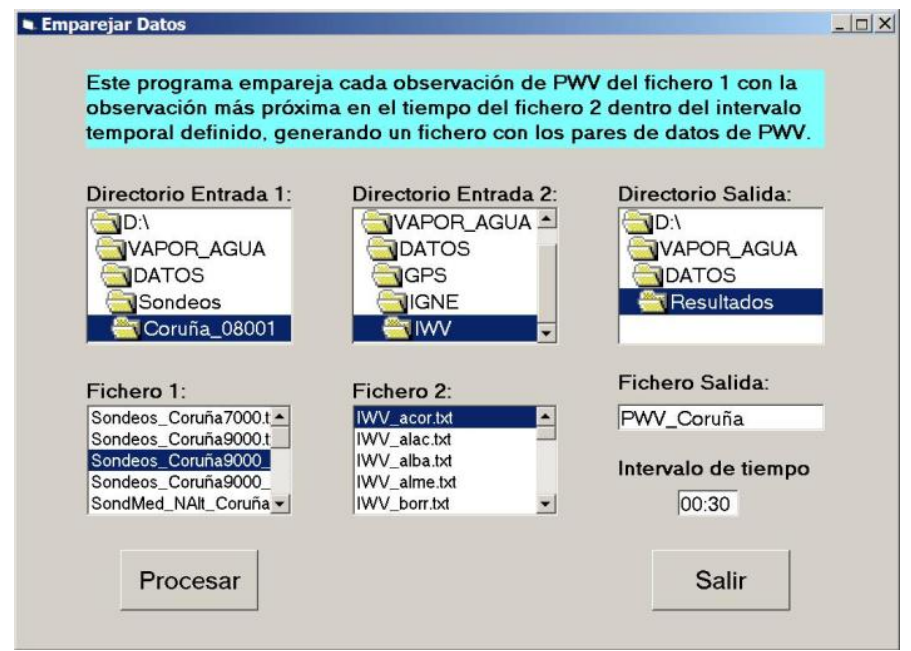

Formulario del programa EMPAREJAR.EXE.

El programa PROMEDIAR.EXE calcula el promedio del PWV según el criterio seleccionado: horario, diario, mensual, de los datos contenidos en el fichero de entrada. El fichero de salida contendrá además del valor medio, el máximo, el mínimo, la desviación estándar, y el número de datos promediados para cada intervalo de tiempo definido. En el caso del promedio horario el dato resultante se asigna a la hora y media.

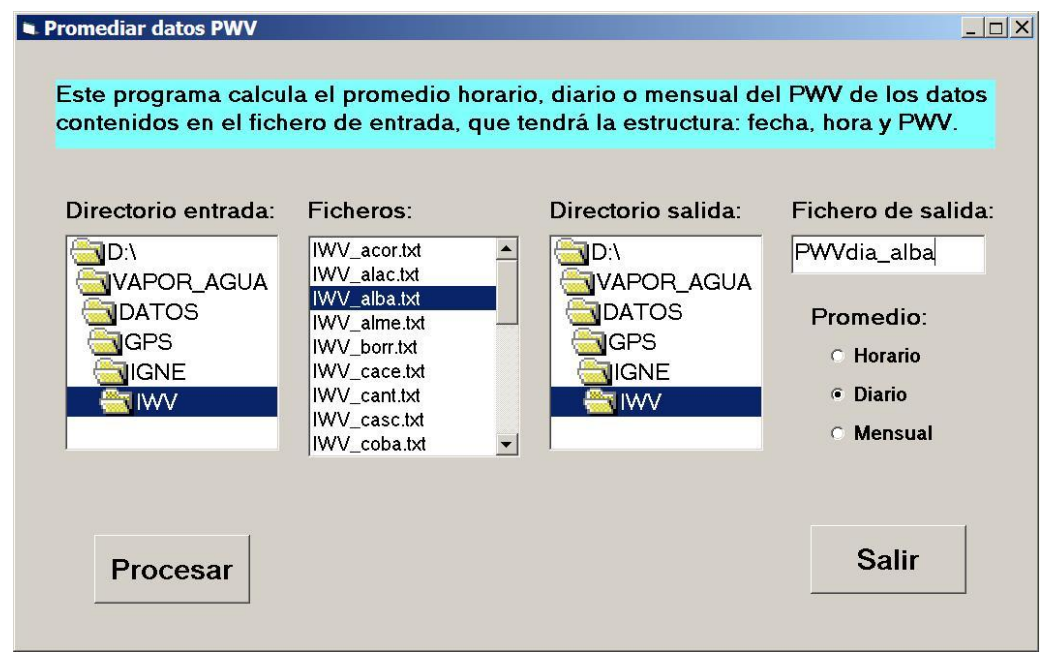

Formulario del programa PROMEDIAR.EXE. 


\title{
ANEXO IV
}

\section{ARTÍCULO I: Improvement in PWV estimation from GPS due to the absolute calibration of antenna phase center variations}

\author{
J. P. Ortiz de Galisteo ${ }^{1,2}$, C. Toledano ${ }^{1}$, V. Cachorro', B. Torres ${ }^{1}$ \\ ${ }^{1}$ Group of Atmospheric Optics, University of Valladolid, Spain. \\ ${ }^{2}$ Meteorological State Agency (AEMET), Spain.
}

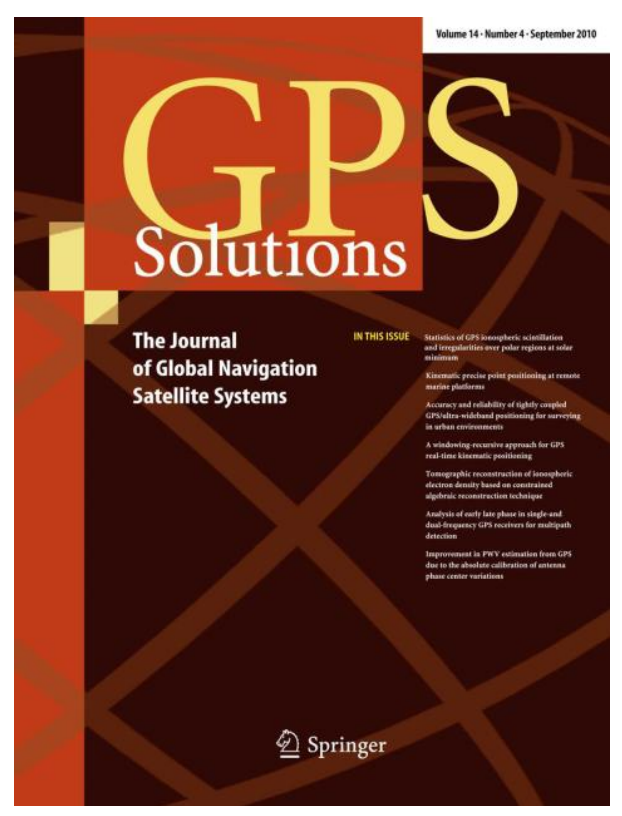

Publicado en: GPS Solutions, the Journal of Global Navigation Satellite Systems.

GPS Solut (2010) 14:389-395

ISSN 1080-5370, Volume 14, Number 4

DOI 10.1007/s10291-010-0163-y

Recibido: 2 septiembre 2009 / Aceptado: 16 febrero 2010 / Publicado online: 13 marzo 2010 



\title{
Improvement in PWV estimation from GPS due to the absolute calibration of antenna phase center variations
}

\author{
J. P. Ortiz de Galisteo $\cdot$ C. Toledano • \\ V. Cachorro $\cdot$ B. Torres
}

Received: 2 September 2009/ Accepted: 16 February 2010

(C) Springer-Verlag 2010

\begin{abstract}
Climatology of column-integrated atmospheric water vapor over Spain has been carried out by means of three techniques: soundings, sun photometers and GPS receivers. Comparing data from stations equipped with more than one of these instruments, we found that a large discontinuity occurred on November 6, 2006, in the differences between the data series from GPS receivers and those from the other two techniques. Prior to that date, the GPS data indicate a wet bias of $2-3 \mathrm{~mm}$ for all stations when compared with sounding or photometer data, whereas after that date this bias practically reduces to zero. The root mean square error also decreases about half of its value. On November 6, 2006, the International GNSS Service adopted an absolute calibration model for the antennas of the GPS satellites and receivers instead of the relative one. This change is expected to be an improvement, increasing the accuracy of station position determination and consequently benefiting postprocessing products such as zenith total delay from which the atmospheric water vapor content is calculated.
\end{abstract}

Keywords Phase center variations - GPS - Water vapor

\section{Introduction}

When carrying out climatology of total column-integrated atmospheric water vapor content over Spain with

J. P. Ortiz de Galisteo $(\bowtie) \cdot$ C. Toledano · V. Cachorro .

B. Torres

Group of Atmospheric Optics, University of Valladolid,

Valladolid, Spain

e-mail: jportiz@goa.uva.es; jportiz@inm.es

J. P. Ortiz de Galisteo

Meteorological State Agency (AEMET), Valladolid, Spain soundings, sun photometers and GPS receivers, we find that on November 6, 2006, a great jump occurs in the differences between the data series from GPS receivers and those of the other two techniques.

Positioning by the Global Position System (GPS) is based on the distances between the electrical phase center of the ground receiver antenna and the GPS satellites antenna. It is well known that the antenna phase center depends on the wavelength of the signal and that it is not a stable point, but it varies with the elevation and azimuth angle of the outgoing and incoming radiation (Rothacher et al. 1995).

In order to overcome the phase center variation problem, antennas must be calibrated. Basically, there are two ways to do this: the relative and the absolute calibration. The relative calibration is based on taking one antenna as a reference and calculating the corrections for other antennas in comparison with the reference one. This method cannot correct for systematic error associated with the phase center variation (PCV) of the reference antenna (Schmid et al. 2004), thus only relative corrections can be obtained. The absolute calibration method is based on the determination of the absolute PCV of each antenna model (Wübbena et al. 2000). GPS antennas are a very critical error source, and a transition from relative to absolute PCVs would be an improvement, increasing the accuracy of station position determination (Schmid et al. 2005). On November 6, 2006, the International GNSS Service (IGS) adopted a model of absolute calibration to correct for PCV. This calibration is included in the procedure to calculate precise satellite orbits and the station coordinates (IGSMail-5438 2006; http://www.igscb.jpl.nasa.gov/mail/ igsmail/2006/maillist.html).

The atmosphere increases the optical path length between GPS satellites and ground receivers, introducing a 
delay in the arrival time compared to signal propagation in vacuum. The tropospheric total zenith delay (ZTD) has two components: the zenith hydrostatic delay (ZHD) and the zenith wet delay (ZWD). The ZHD is proportional to the amount of air and can be modeled and removed by knowing the surface atmospheric pressure at station level; and the wet ZWD is due to the presence of water vapor (Bevis et al. 1992). The ZTD can be calculated from GPS measurements using complicated geodetic inversions (Tralli et al. 1988; Herring et al. 1990). Subtracting the ZHD from the ZTD, the ZWD is obtained. Subsequently, this can be converted into total precipitable water vapor (PWV). One millimeter of PWV approximately produces a delay of $6.35 \mathrm{~mm}$ (Bevis et al. 1994). Thus, the GPS receiver network can be used to estimate the PWV (De Haan 2006).

According to the procedure described above, any error in the distance between GPS satellites and ground receivers is propagated to the travel time of the signal and consequently affects the accuracy of the ZTD and the PWV. It follows that an improvement in positioning should improve the PWV estimation accuracy. This study demonstrates this last statement by comparing PWV data before and after November 6, 2006, from GPS with the values provided by other techniques like soundings and sun photometers.

The following section presents the stations and data used. In Section "Result," we compare the PWV amounts measured by the three different techniques and discuss the

Table 1 Geographic coordinates of the stations in latitude (north), longitude (west) and elevation in meters above sea level

\begin{tabular}{lllllllr}
\hline Station & \multicolumn{2}{l}{ GPS station } & & \multicolumn{3}{l}{ Sounding/photometer station } \\
\cline { 2 - 3 } \cline { 7 - 8 } \cline { 7 - 8 } & Lat. & Lon. & Elev. & & Lat. & Lon. & Elev. \\
\hline Cáceres & $39^{\circ} 29^{\prime}$ & $6^{\circ} 21^{\prime}$ & 384 & & $39^{\circ} 29^{\prime}$ & $6^{\circ} 21^{\prime}$ & 397 \\
Coruña & $43^{\circ} 22^{\prime}$ & $8^{\circ} 24^{\prime}$ & 12 & & $43^{\circ} 22^{\prime}$ & $8^{\circ} 25^{\prime}$ & 58 \\
Santander & $43^{\circ} 28^{\prime}$ & $3^{\circ} 48^{\prime}$ & 48 & & $43^{\circ} 29^{\prime}$ & $3^{\circ} 48^{\prime}$ & 52 \\
Madrid & $40^{\circ} 27^{\prime}$ & $3^{\circ} 57^{\prime}$ & 596 & & $40^{\circ} 28^{\prime}$ & $3^{\circ} 35^{\prime}$ & 631 \\
\hline
\end{tabular}

results. The most important results are summarized in Section "Conclusions".

\section{Stations and data}

We have used the data from the radio sounding stations run by the Meteorological State Agency of Spain (AEMET), sun photometers of the Aerosol Robotic Network (AERONET), and GPS receivers of the European Reference Frame (EUREF).

We selected four GPS receiver stations with a long data series and equipped, in the same location or in the near-by vicinity, with any of the other two instruments. Three GPS stations are supplied with radio sounding equipment (Coruña, Santander and Madrid), and the other one with a sun photometer (Cáceres). Table 1 shows the geographical coordinates of the locations of the stations.

PWV data from the radio soundings have been downloaded from the Web site of the University of Wyoming (http://www.weather.uwyo.edu/upperair/sounding.html). In the case of sun photometers, we have used the quality level 1.5 (cloud-screened) water vapor data from AERONET version 2 processing algorithm (http://www.aeronet.gsfc. nasa.gov/). Although level 2.0 data are quality assured, we have chosen level 1.5 because level 2.0 dataset has many gaps. Finally, for GPS receivers, the ZTD data have been obtained from EUREF Permanent Network Web site (http://www.epncb.oma.be/). From all the Analysis Centers of EUREF, we have selected the data generated by the National Geographic Institute of Spain (IGE) using the Bernese V5.0 software. Within the routine analysis of a network of ground-based GPS receivers, the tropospheric parameters are a by-product of the parameter estimation. In order to achieve the highest accuracy, the ZTD data is calculated with the final precise orbits of the satellites provided by the IGS (Kruse et al. 1999). The IGE processes the ZTD at all of its stations over Spain on an hourly basis. The ZTD is transformed in PWV knowing the pressure and temperature from a nearby meteorological station (Guerova 2003).

Table 2 Statistics of the comparison for 2 year data before November 6, 2006

\begin{tabular}{|c|c|c|c|c|c|c|c|}
\hline \multirow[t]{2}{*}{ Station } & \multirow[t]{2}{*}{ Instruments } & \multicolumn{6}{|c|}{ Before November 6, 2006} \\
\hline & & Mean GPS & Mean S/F & BIAS & Relative BIAS \% & RMAD \% & RMSE \\
\hline Cáceres & GPS/photometer & 16.92 & 14.91 & 2.01 & 12.3 & 13.5 & 2.72 \\
\hline Coruña & GPS/sounding & 21.19 & 18.56 & 2.63 & 14.5 & 15.2 & 3.25 \\
\hline Santander & GPS/sounding & 21.69 & 18.64 & 3.05 & 17.8 & 18.8 & 4.33 \\
\hline Madrid & GPS/sounding & 15.82 & 13.92 & 1.91 & 15.4 & 16.9 & 2.64 \\
\hline
\end{tabular}

The column Instruments indicates the two data sources. The statistics shown are the mean water vapor content in millimeters from GPS receivers (Mean GPS), the mean of the other techniques (Mean S/F), the difference (BIAS), the relative mean difference (Relative BIAS) and the relative mean absolute difference (RMAD) expressed in percentage, and the root mean square error (RMSE) 
Soundings are usually launched twice a day, at 00 and 12 UTC. The soundings last approximately an hour and a half, but it takes to the balloon $30 \mathrm{~min}$ to pass across the lower 7,000 $\mathrm{m}$ of the troposphere, where most of the water vapor is present. Therefore, soundings provide a PWV data which is not an instantaneous measurement but a kind of average from the launch time (about 30-45 min before the nominal hour) to the final stage. It is not an actual average because in each instant a different atmospheric layer is measured.

The ability of soundings to provide accurate PWV data is limited, in fact, among all soundings data the relative humidity is the least reliable (Richner and Phillips 1982).
The sounding PWD data are also affected by errors in temperature and pressure data and can present a dry bias in daytime caused by solar heating of the sensor (Miloshevich et al. 2006). Most soundings measure relative humidity with a precision of about 3.5\% (Elliott and Gaffen 1991) and PWV with an accuracy of a few millimeters.

The photometer PWV is derived from direct solar transmittance measures in the 940-nm strong water vapor absorption band (Schmid et al. 1996; Halthore et al. 1997; Cachorro et al. 1998). The main error sources associated with this retrieval procedure depend on the determination of the calibration constant (Reagan et al. 1987; Bruegge et al. 1992) and in the modeling of water

Table 3 Statistics for 2-year data after November 6, 2006

\begin{tabular}{|c|c|c|c|c|c|c|c|}
\hline \multirow[t]{2}{*}{ Station } & \multirow[t]{2}{*}{ Instruments } & \multicolumn{6}{|c|}{ After November 6, 2006} \\
\hline & & Mean GPS & Mean S/F & BIAS & Relative BIAS \% & RMAD \% & RMSE \\
\hline Cáceres & GPS/photometer & 14.03 & 14.04 & -0.01 & -1.4 & 8.0 & 1.29 \\
\hline Coruña & GPS/sounding & 19.07 & 19.02 & 0.05 & 0.0 & 6.6 & 1.60 \\
\hline Santander & GPS/sounding & 19.77 & 19.59 & 0.18 & 0.9 & 6.9 & 1.66 \\
\hline Madrid & GPS/sounding & 14.76 & 14.78 & -0.03 & -0.6 & 8.8 & 1.54 \\
\hline
\end{tabular}

See Table 2 for additional explanation
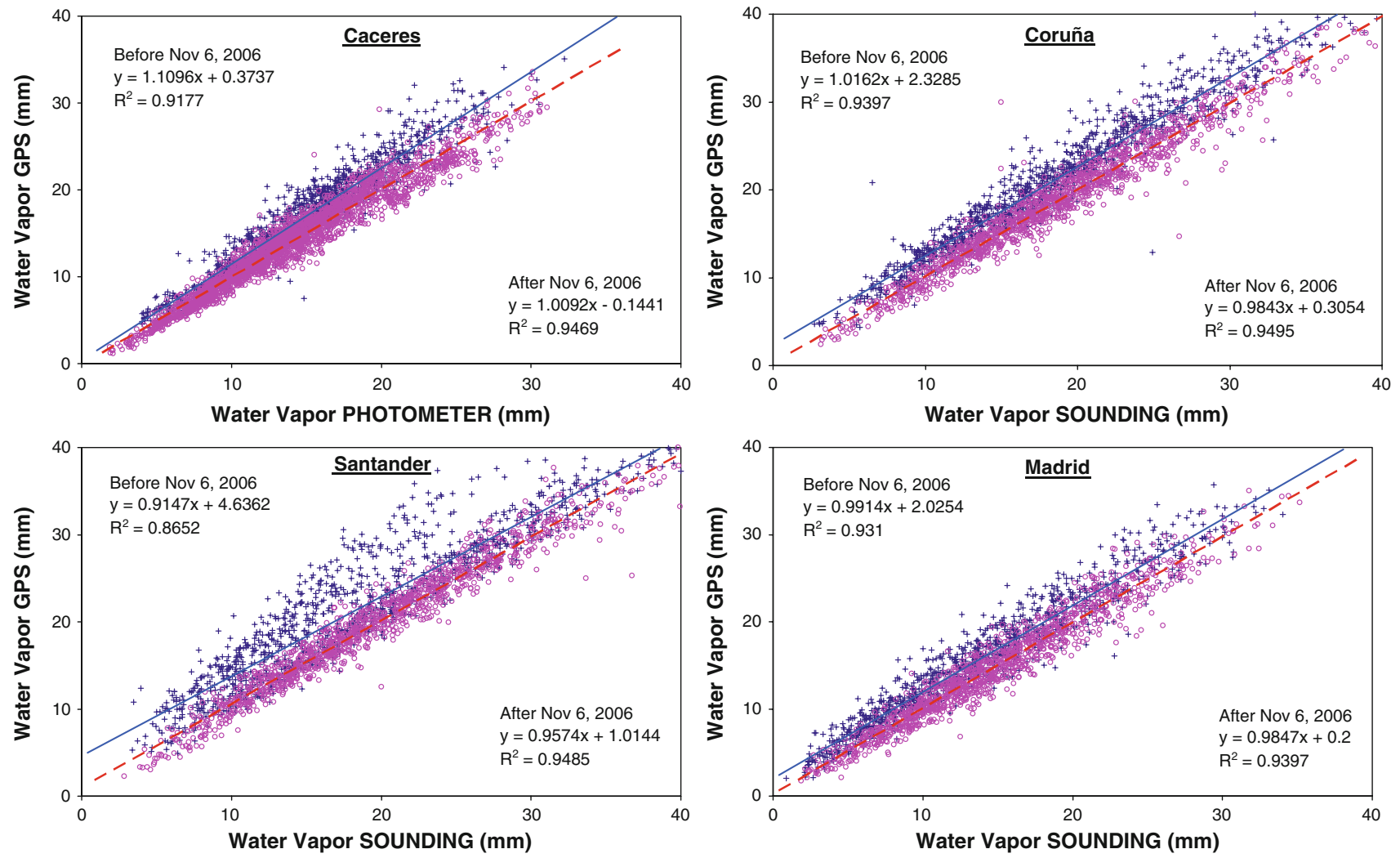

Fig. 1 Regression line and correlation coefficient $R^{2}$ of the PWV data series obtained from GPS receivers and from soundings or sun photometers. The blue crosses and the blue solid line represent the

data before November 6, 2006 and the pink circles and the red dash line the data after this date 
vapor transmittance (Ingold et al. 2000). There are others related issues like cloudiness contamination, instrument characteristics, filter shape, filter aging, or filter central wavelength (Boyoke et al. 2006). In the case of AERONET (Smirnov et al. 2004) or similar photometers, the PWV retrieved for this technique is about $10 \%$, but the uncertainty is very variable depending on the specific instrument used to measure the solar radiation in this band.

We selected 2 years of data before and after the change from relative to absolute antenna calibration to compare two series of the same length to avoid a bias. This is not the true of the Cáceres station, which began operating in July 2005. However, we include this station because is the only one equipped with a sun photometer in order to be able to illustrate the comparison with this technique.

In order to carry out the comparison, each sounding data has been paired with the closest GPS data after the actual time of the sounding launch, and each sun photometer data has been matched up with the closest GPS data taken at an interval of $\pm 5 \mathrm{~min}$. Thus, about 2,300 pairs of GPSsounding data for each station and 3,750 pairs of GPSphotometer have been compared.
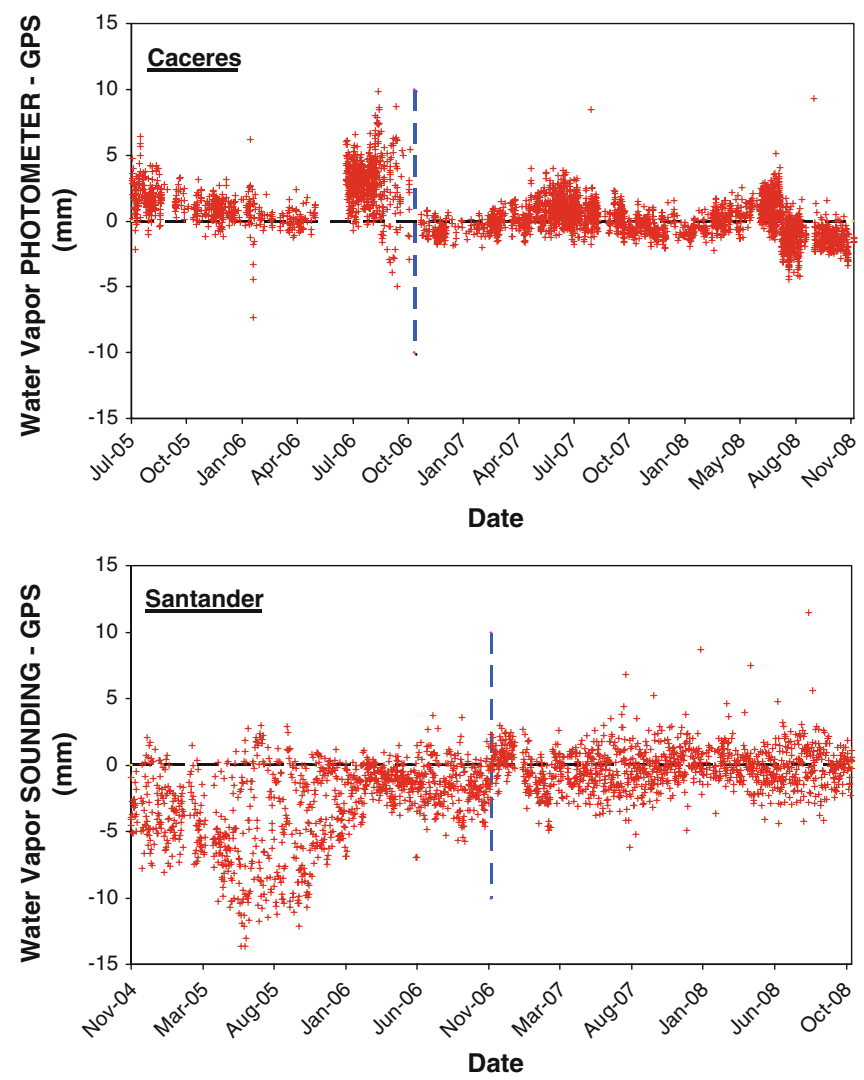

\section{Results}

We compared for each location the GPS series data with the sounding or photometer series data and calculated the mean PWV, the mean difference (BIAS), the relative mean difference (Relative BIAS), the relative mean absolute difference (RMAD), and the root mean square error (RMSE). The mathematical expressions of these statistics can be found in the "Appendix".

Before the adoption of the absolute calibration model of PCVs (Table 2), the PWV obtained from GPS receivers is higher than the one obtained from the soundings or photometer in the four locations. This wet bias ranges between 1.91 and $3.05 \mathrm{~mm}$ and the relative bias between 12.3 and $17.8 \%$. After November 6, 2006, (Table 3), the bias practically decreases to zero for all four sites, ranging between -0.03 and $0.18 \mathrm{~mm}$. Also the RMAD and the RMSE decrease, the RMAD from a range of $13.5-18.8 \%$ to another of 6.6-8.8\%, and the RMSE from $2.64-4.33 \mathrm{~mm}$ to $1.29-1.66 \mathrm{~mm}$. On average, both quantities experience a drop of about $52 \%$. These figures seem to indicate that the antenna relative calibration model overestimated the PWV GPS data by $2-3 \mathrm{~mm}$.
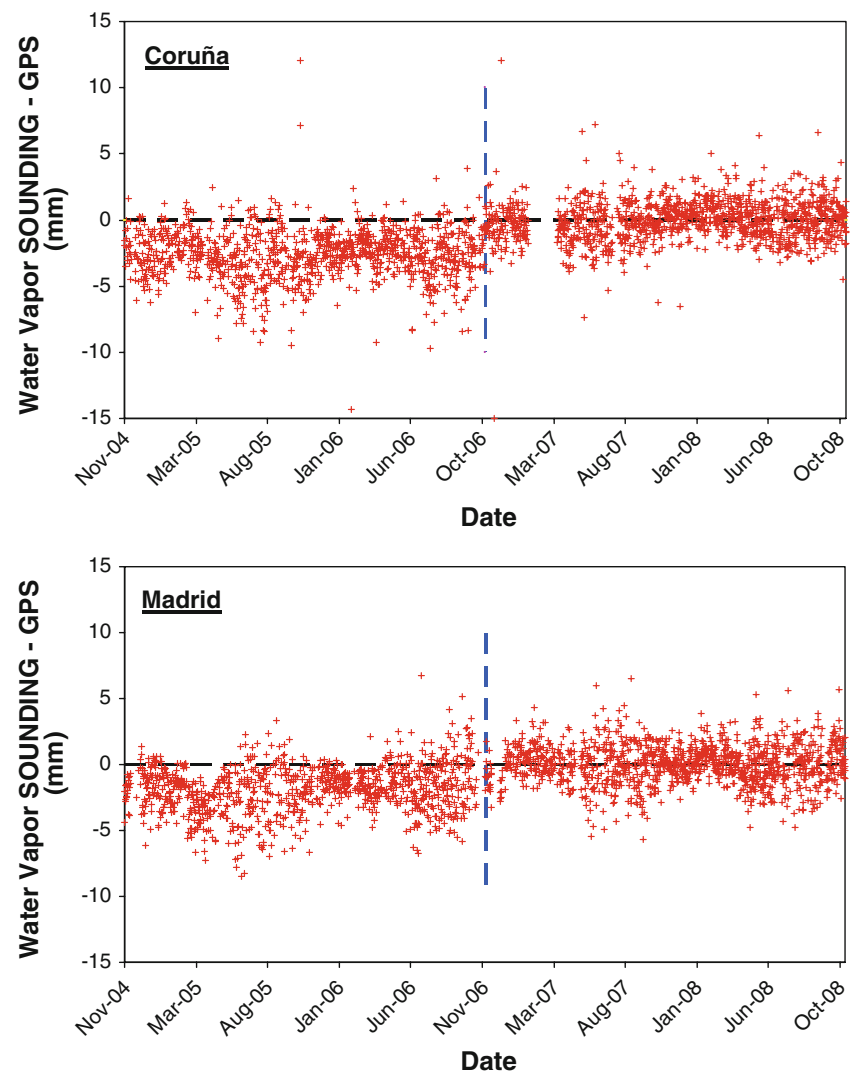

Fig. 2 Time series of the PWV differences (expressed in millimeters) calculated from GPS data and the other techniques (sounding or sun photometer). The vertical dash line marks the November 6, 2006, date 

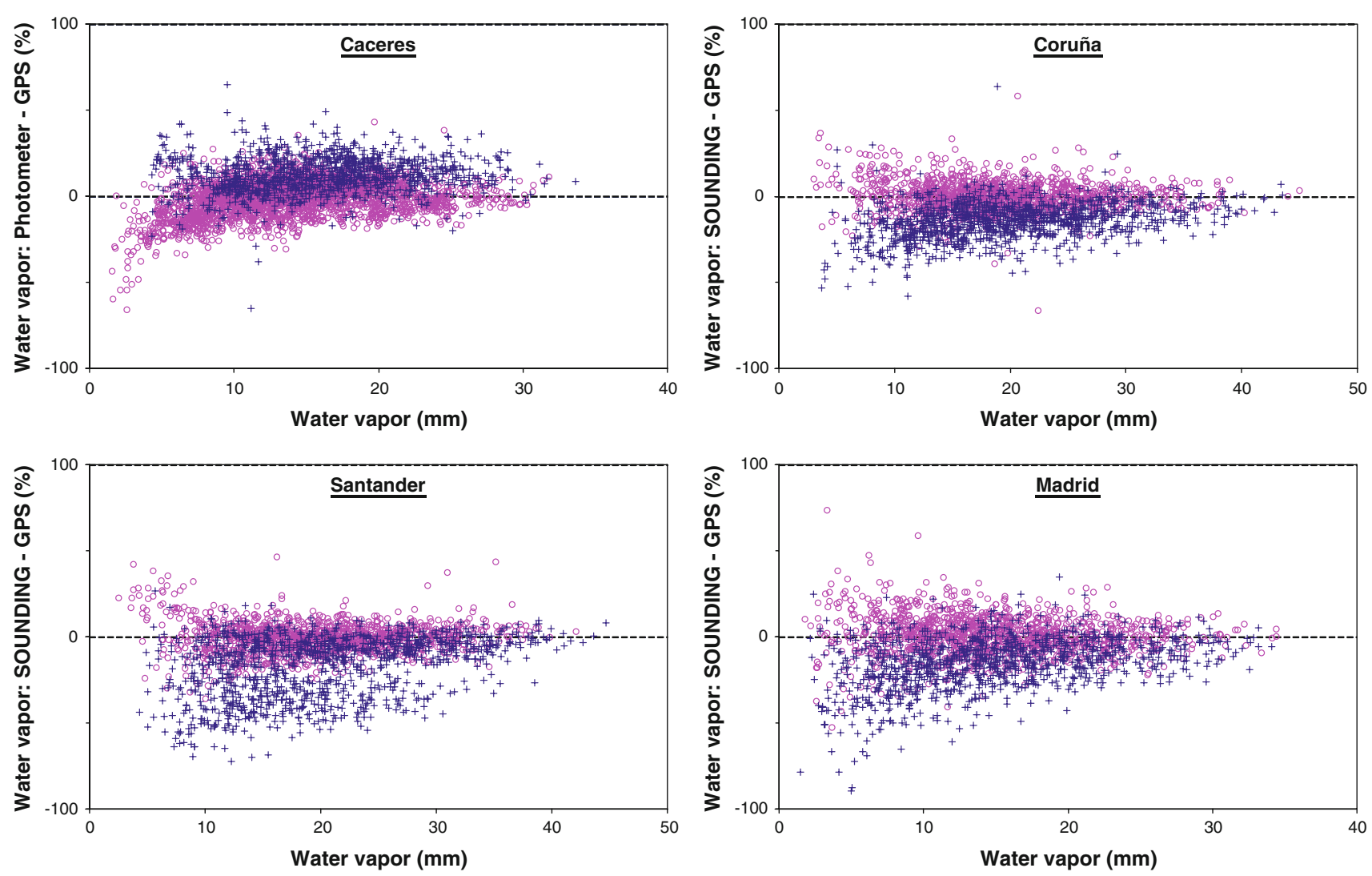

Fig. 3 Relative differences (expressed as a percentage of the average) between the PWV data from the GPS receiver and from the other instrument versus the mean PWV. The blue crosses represent the data before November 6, 2006, and the pink circles the data after this date

Figure 1 shows the regression lines between the compared series before and after November 6 for each site. It can be observed how after this date the regression lines fit better to the diagonal. The figure also contains the values of the correlation coefficient $\left(R^{2}\right)$, as well as the equation of the regression lines. After the cited date, the $R^{2}$ coefficients increase slightly, whereas the slopes of the regression lines are closer to the unit, and the Y-intercept values decrease.

If we plot the time series of the PWV differences from GPS data and the other techniques (Fig. 2), a significant jump can be observed. The data points experienced a shift and are oscillating around zero after November 6 . This can also be observed in Fig. 3, where the differences are plotted versus the mean PWV. The shapes of the data points are similar, but there is a vertical shift.

In addition to the intrinsic error sources mentioned above, we have to keep in mind the different temporal resolution and the fact that they do not check the same atmospheric layer when comparing the PWV data from GPS, soundings or photometers. For GPS receivers and photometers, the measures are taken pointing toward the satellite constellation and the sun, respectively, and are subsequently projected onto the vertical, whereas soundings are drifted by the wind. All these produce noise in the comparisons of GPS-sounding and GPS-photometer (Fig. 2). We emphasize that in this study we are interested in a relative comparison before and after the change in the calibration model of PCVs rather than in an absolute one. Nevertheless, the root mean square errors obtained are in good agreement with the published ones by other authors (Ohtani and Naito 2000; Bokoye et al. 2003; Schneider et al. 2009).

As a result of switching from relative to absolute antenna calibration models, other authors point out differences in the station coordinates (higher in the vertical) and in the ZTD (Schmid et al. 2006; Bruyninx et al. 2006; Fotiou et al. 2008; Byun and Bar-Server 2009) ranging between 5 and $15 \mathrm{~mm}$. Taking into account that $1 \mathrm{~mm}$ of PWV produces a delay in the incoming signal of approximately $6.35 \mathrm{~mm}$ when expressed in units of length, these figures can explain the differences in the PWV that we have found.

\section{Conclusions}

A detailed comparison between PWV from GPS receivers, radio soundings and photometers in four different locations 
in Spain has been carried out using 2 years of data before and after November 6, 2006. At that date, the calibration model for the GPS antenna phase center variations was switched from relative to absolute.

Regardless of the technique used to compare with GPS data, the results show an improvement in PWV data after the absolute calibration model was established. Before November 6, 2006, the data calculated with the GPS ground receivers contained a systematic error, overestimating the PWV in 2-3 mm. After November 6, 2006, this wet bias practically decreases to zero. Also the root mean square error and the relative mean absolute differences reduce by one half, and the correlation coefficient increases slightly.

The results provide strong evidence that the new absolute calibration model is clearly unbiased as opposed to the relative calibration previously used. Thus, GPS technique appears to be a key method for water vapor monitoring, providing data with a better temporal and spatial resolution.

\section{Appendix}

Definitions of statistics

BIAS $=\frac{\sum_{i=1}^{N} \mathrm{PWV}_{i}^{(\mathrm{GPS})}-\mathrm{PWV}_{i}^{(\text {Sound } / \text { Photo })}}{N_{\text {data }}}$
RelativeBIAS $=\frac{\sum_{i=1}^{N} 2 \times \frac{\mathrm{PWV}_{i}^{(\mathrm{GPS})}-\mathrm{PWV}_{i}^{(\text {Sound/Photo })}}{\mathrm{PWV}_{i}^{(\mathrm{GPS})}+\mathrm{PWV}_{i}^{(\text {Sound/Photo })}}}{N_{\text {data }}} \times 100$

$\mathrm{RMDA}=\frac{\sum_{i=1}^{N} 2 \times \frac{\left|\mathrm{PWV}_{i}^{(\mathrm{GPS})}-\mathrm{PWV}_{i}^{\text {(Sound/Photo })}\right|}{\mathrm{PWV}_{i}^{(\mathrm{GPS})}+\mathrm{PWV}_{i}^{\text {(Sound/Photo })}}}{N_{\text {data }}} \times 100$

$\mathrm{RMSE}=\sqrt{\frac{\sum_{i=1}^{N}\left(\mathrm{PWV}_{i}^{(\mathrm{GPS})}-\mathrm{PWV}_{i}^{(\text {Sound } / \text { Photo })}\right)^{2}}{N_{\text {data }}}}$

\section{References}

Bevis M, Businger S, Herring TA, Rocken C, Anthes RA, Ware RH (1992) GPS meteorology: remote sensing of atmospheric water vapor using the global positioning system. J Geophys $\mathrm{R}$ 97:15787-15801

Bevis M, Businger S, Chiswell S, Herring TA, Anthes RA, Rocken C, Ware RH (1994) GPS meteorology: mapping zenith wet delays onto precipitable water. J App Meteorol 33:379-386

Bokoye AI, Royer A, O’Neill NT, Cliché P, McArthur LJB, Teillet PM, Fedosejevs G, Thériault JM (2003) Multisensor analysis of integrated atmospheric water vapor over Canada and Alaska. J Geophys Res 108(D15):4480. doi:10.1029/2002JD002721

Boyoke AI, Royer A, Cliche P, O'Neill N (2006) Calibration of sun radiometer-based atmospheric water vapor retrievals using GPS meteorology. J Atmos Oceanic Technol 24:964-979
Bruegge CJ, Conel JE, Green RO, Margolis JS, Holm RG, Toon G (1992) Water vapor column abundance retrievals during FIFE. J Geophys Res 97(D17):18759-18768

Bruyninx C, Brockmann E, Schaer S (2006) How to tie the EPN to the ITRF2005. Proceedings of the EUREF TWG Meeting, 6-7 Nov 2006, Frankfurt

Byun SH, Bar-Server YE (2009) A new type of troposphere zenith path delay product of the international GNSS service. J Geod 83(2009):367-373. doi: 10.1007/s00190-008-0288-8

Cachorro VE, Utrillas P, Vergaz R, Duran P, de Frutos AM, Martinez-Lozano JA (1998) Determination of the atmosphericwater-vapor content in the $940-\mathrm{nm}$ absorption band by use of moderate spectral-resolution measurements of direct solar irradiance. Appl Opt 37(21):4678-4689

De Haan S (2006) National/regional operational procedures of GPS water vapor networks and agreed international procedures. WMO-World Meteorological Organization. Instruments and Observing Methods, Report No. 92

Elliott WP, Gaffen DJ (1991) On the utility of radiosonde humidity archives for climate studies. Bull Amer Meteor Soc 72:15071520

Fotiou A, Pikridas C, Chatzinikos M (2008) GPS antenna: from relative to absolute. Coordinates vol IV, issue 3, pp. 28-30, March 2008

Guerova G (2003) Derivation of integrated water vapor (IWV) from the ground-based GPS estimates of Zenith Total Delay (ZTD). Research Report No 2003-08, Institute of Applied Physics, University of Berne, Switzerland

Halthore NR, Thomas FE, Holben BN, Markham BL (1997) Sun photometric measurements of atmospheric water vapor column abundance in the 940-nm band. J Geophys Res 102(D4):43434352

Herring T, Davis JL, Shapiro II (1990) Geodesy by radio interferometry: the application of Kalman filtering to the analysis of very long baseline interferometry data. J Geophys Res 95:12561-12581

IGSMail-5438 (2006) IGS switch to absolute antenna model and ITRF2005. IGS International GNSS Service

Ingold T, Schmid B, Mätzler C, Demoulin P, Kämpfer N (2000) Modeled and empirical approaches for retrieving columnar water vapor from solar transmittances measurements in $0.72,0.82$ and 0.94 um absorption bands. J Geophys Res 105(D19):2432724344

Kruse L, Sierk B, Springer T, Cocard M (1999) GPSMeteorology: impact of predicted orbits on precipitable water estimates. Geophys Res Let 24(14):2045-2048

Miloshevich LM, Vömel H, Whiteman DN, Lesht BM, Schmidlin FJ, Russo F (2006) Absolute accuracy of water vapor measurements from six operational radiosonde types launched during AWEX-G and implications for AIRS validation. J Geophys Res 111:D09S10. doi:10.1029/2005JD006083

Ohtani R, Naito I (2000) Comparisons of GPS-derived precipitable water vapors with radiosonde observations in Japan. J Geophys Res 105(D22):26917-26929

Reagan JA, Thome K, Herman B, Gall R (1987) Water vapor measurements in the 0.94 micron absorption band: calibration, measurements and data applications. In: Proceeding of IGARSS '87 Symposium, pp 63-67. IEEE Pres, Piscataway N.J

Richner H, Phillips PD (1982) The radiosonde intercomparison SONDEX Spring 1981, Payerne. Pure Appl Geophys 120:8521198

Rothacher M, Schaer S, Mervart L, Beutler G (1995) Determination of antenna phase center variations using GPS data. In: Gendt G, Dick G (eds) Special topics and new directions, proceedings of the 1955 IGS work-shop, Potsdam, 15-17 May, pp 205-220 
Schmid B, Thome KJ, Demoulin P, Peter R, Mätzler C, Sekler J (1996) Comparison of modeled and empirical approaches for retrieving columnar water vapor from solar transmittance measurements in the $0.94-\mu \mathrm{m}$ region. J Geophys Res 101(D5): 9345-9358

Schmid R, Mader G, Herring T (2004) From relative to absolute antenna phase center corrections. In: Proceedings of the IGS workshop and symposium 2004: celebrating a decade of the international GPS service IGS. Berne, Switzerland, 1-5 March 2004

Schmid R, Rothacher M, Thailer D, Steigenberger P (2005) Absolute phase center corrections of satellite and receiver antennas. Impact on global GPS solutions and estimation of azimuthal phase center variations of the satellite antenna. GPS Solutions, Vol. 9, Nr 4, pp 283-293. doi: 10.1007/s10291-005-0134-x

Schmid R, Steigenberger P, Rothacher M, Gendt G, Ge M, Tesmer V (2006) Absolute antenna phase center corrections and their impact on GPS results. In: Proceeding of the 2006 UNAVCO Science Workshop, 14-16 March, Denver, Colorado, USA

Schneider M, Romero PM, Hase F, Blumenstock T, Cuevas E, Ramos R (2009) Quality assessment of Izaña's upper-air water vapor measurement techniques: FTIR, Cimel, MFRSR, GPS, and Vaisala RS92. Atmos Meas Tech Discuss 2:1625-1662

Smirnov A, Holben BN, Lyapustin A, Slutker I, Eck TF (2004) AERONET processing algorithm refinement. In: Proceeding “AERONET Workshop 2004". El Arenosillo, Spain

Tralli DM, Dixon TH, Stephens SA (1988) Effect of wet tropospheric path delays on estimation of geodetic baselines in the Gulf of California using the global positioning system. J Geophys Res 93:6545-6557

Wübbena G, Schmitz M, Menge F, Boder V, Seeber G (2000) Automated absolute field calibration of GPS antennas in realtime. In: Proceedings of the 13th international technical meeting of the satellite division of the institute of navigation, ION GPS2000, Salt Lake City, Utah, USA, 19-22 Sep, pp 2512-2522

\section{Author Biographies}

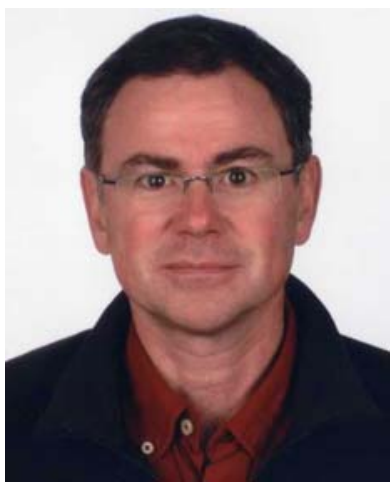

Mr. José Pablo Ortiz de Galisteo graduated in physics at the Complutense University in Madrid (1986). He obtained the Certificate of Advanced Studies at the University of Valladolid (2006). $\mathrm{He}$ is a member of the Group of Atmospheric Optics, University of Valladolid (Spain), researching on atmospheric water vapor content. A meteorologist at the Spanish Meteorological State Agency (AEMET), he holds the current position of Territorial

Delegate for the Castilla y León region, and was in a previous position of Chief of the Basic Systems Unit.

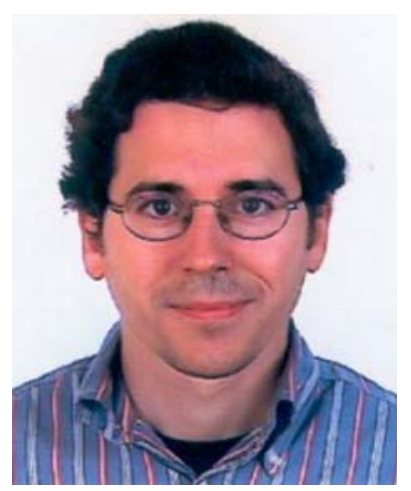

Dr. Carlos Toledano graduated in physics at the Complutense University in Madrid (1999) and holds a $\mathrm{PhD}$ from the University of Valladolid (2005). For 2 years, he was Postdoctoral Fellow at the Meteorological Institute, University of Munich (Germany). Currently, he is a postdoctoral researcher at the Group of Atmospheric Optics, University of Valladolid (Spain). His research concentrates on the investigation of atmospheric aerosol by optical methods, aerosol characterization, data quality assurance and field campaigns.

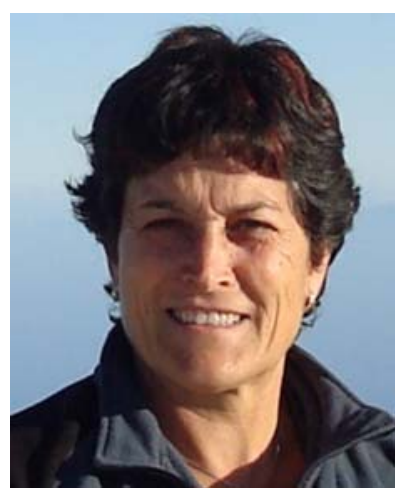

Dra Victoria E. Cachorro is a graduate in physics (1978), $\mathrm{PhD}$ in sciences (1985) and Professor at the University of Valladolid (Spain). V. Cachorro is an expert in spectral radiation measurements and calibration procedures in radiometry, radiative transfer modelling, and remote sensing techniques for aerosol parameters retrieval and analysis. Having about 80 peer reviewer articles in collaboration with different institutions, V. Cachorro is Manager of RIMA (Red Ibérica de Medida Fotométrica de Aerosoles) federated into AERONET, Member of the USP for ARI and eARI projects, Member of "Consejo Asesor de Medio Ambiente" of the Regional Government of Castilla y León and Member of the International Radiation Commission (IRS).

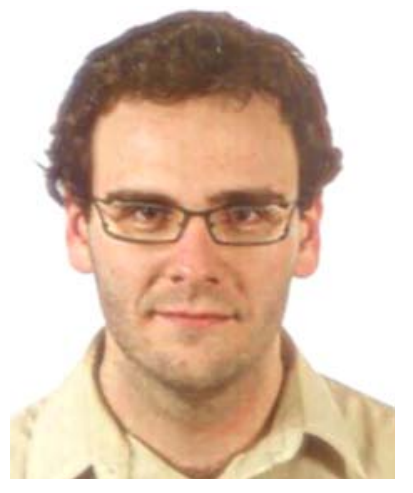

Benjamin Torres is a graduate in physics at the Valladolid University (2006) and holds an MSc (experimental techniques in physics) from the Valladolid University (2006). He is currently a $\mathrm{PhD}$ researcher in the Group of Atmospheric Optics, University of Valladolid (Spain). His research is focused on the investigation of atmospheric aerosols using optical methods, aerosol characterization, data quality assurance and field campaigns. 



\section{ANEXO V}

\section{ARTÍCULO II: Diurnal cycle of precipitable water vapor over Spain}

J. P. Ortiz de Galisteo ${ }^{1,}{ }^{2}$, V. Cachorro ${ }^{1}$, C. Toledano ${ }^{1}$, B. Torres ${ }^{1}$, N. Laulainen ${ }^{3}$, Y. Bennouna $^{1}$, A. de Frutos ${ }^{1}$

${ }^{1}$ GOA-UVA, Group of Atmospheric Optics, University of Valladolid, Spain.

${ }^{2}$ AEMET, Meteorological State Agency, Territorial Delegation of Castilla y León, Spain.

${ }^{3}$ PNNL, Pacific Northwest National Laboratory, Richland, WA, USA.

\section{RMetS}

Royal Meteorological Society

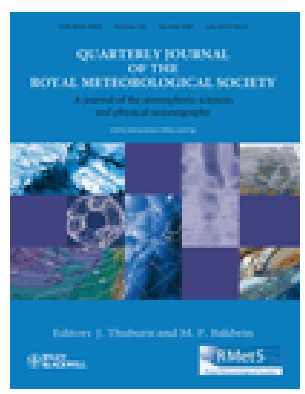

Publicado en: Quarterly Journal of the Royal Meteorological Society.

Recibido: 5 agosto 2010 / Revisado: 11 febrero 2011 / Aceptado: 22 febrero 2011 / Publicado online en Wiley Online. DOI: 10.1002/qj.811. 



\title{
RMetS
}

Royal Meteorological Society

\section{Diurnal cycle of precipitable water vapor over Spain}

\author{
J. P. Ortiz de Galisteo, ${ }^{\mathrm{a}, \mathrm{b} \star}$ V. Cachorro, ${ }^{\mathrm{a}}$ C. Toledano, ${ }^{\mathrm{a}}$ B. Torres, ${ }^{\mathrm{a}}$ N. Laulainen, ${ }^{\mathrm{c}}$ \\ Y. Bennouna ${ }^{\mathrm{a}}$ and A. de Frutos ${ }^{\mathrm{a}}$ \\ ${ }^{a}$ GOA-UVA, Group of Atmospheric Optics, University of Valladolid, Spain \\ ${ }^{\mathrm{b}}$ AEMET, Meteorological State Agency, Territorial Delegation of Castilla y León, Spain \\ 'Pacific Northwest National Laboratory, Richland, Washington, USA \\ ${ }^{*}$ Correspondence to: J. P. Ortiz de Galisteo, Grupo de Óptica Atmosférica, Prado de la Magdalena, Facultad de Ciencias, \\ Universidad de Valladolid, Valladolid 47014, Spain. E-mail: jportiz@goa.uva.es
}

Knowledge of the diurnal cycle of precipitable water vapor (PWV) is very limited owing to the lack of data with sufficient temporal resolution. Currently, GPS receivers have proven to be a suitable technique to determine PWV diurnal variations. In this study, the annual and seasonal diurnal cycles of PWV have been obtained from GPS data for 10 locations over Spain. The minimum value of PWV is reached approximately at the same time at all the stations, $\sim 0430-0530$ UTC, whereas the maximum is reached in the second half of the day, but with a larger dispersion of its occurrence between stations. The annual sub-daily variability ranges from 0.41 to $1.35 \mathrm{~mm}(3-7 \%)$. The highest values are recorded at the stations on the Mediterranean coast, with a doubling of the values of the stations on the Atlantic coast or inland. The winter cycle is quite similar at all locations, whereas in summer local effects are felt strongly, making the diurnal cycle quite different between stations. The PWV mean diurnal cycle is strongest in summer and weakest in spring, with a sub-daily variability of 1.34 and $0.66 \mathrm{~mm}$ respectively. Harmonic analysis shows that the first two harmonics can explain $97 \%$ of the variance. The diurnal $(24 \mathrm{~h})$ harmonic explains $85 \%$ of the variance, has mean amplitude of $0.40 \mathrm{~mm}$, and the peak time is from early afternoon to evening. The semi-diurnal $(12 \mathrm{~h})$ harmonic is weaker, with an amplitude of $0.13 \mathrm{~mm}$, and peak time between 0400 and 1000 UTC. The diurnal cycle of temperature alone would be a proxy for PWV cycle during the night, but not during the daytime. The breeze regime is the main factor responsible for the phase lag between PWV and temperature cycles during daytime. No clear correlation between the daily cycle of precipitation and PWV has been found. Copyright (c) 2011 Royal Meteorological Society

Key Words: PWV; atmospheric water vapor content; diurnal regime; GPS

Received 5 August 2010; Revised 11 February 2011; Accepted 22 February 2011; Published online in Wiley Online Library

Citation: Ortiz de Galisteo JP, Cachorro V, Toledano C, Torres B, Laulainen N, Bennouna Y, de Frutos A. 2011. Diurnal cycle of precipitable water vapor over Spain. Q. J. R. Meteorol. Soc. DOI:10.1002/qj.811

1. Introduction

Precipitable water vapor (PWV) is the most abundant greenhouse gas, and plays a crucial role in many atmospheric processes such as radiative balance, hydrological cycle, the transport of large amounts of latent heat energy or instability and convective activity. Thus precise knowledge of PWV distribution is important in meteorology for both numerical weather forecasting and climatological studies. Nevertheless, and despite its importance, knowledge of its 
behaviour is very limited owing to the lack of data with sufficient spatial and temporal resolution.

Considering the high temporal and spatial variability of PWV, conventional observation systems are not suited to provide sufficient information. Thus additional PWV data from new observation techniques are highly desirable to achieve adequate observation coverage. In recent years many networks of GPS ground receivers have been established, from which PWV can be measured (Bevis et al., 1992). Such instruments provide data with high temporal resolution in all weather conditions and all hours of the day. This allows the systematic study of the diurnal cycle of this atmospheric component, which can be applied to a better modelling of the water vapor attenuation of the direct solar radiation (Jakobson et al., 2009) and of the physical parametrizations in numerical weather models.

The determination of PWV from GPS receivers is based on the delay produced by the atmosphere in the arrival time of the signal of the GPS satellites. This delay can be divided into ionospheric and tropospheric components. The ionospheric delay is dispersive, such that the GPS satellites emit in two frequencies in order to quantify and remove this effect in the propagation of the signal (Spilker, 1980; Brunner and $\mathrm{Gu}, 1991)$. On the other hand, the troposphere is non-dispersive. In this layer, the delay is determined by the refractive index along the path of the signal. The refractivity of the atmosphere is a function of temperature, pressure, and water vapor content. Water vapor is a unique atmospheric gas in the troposphere, having its own dipolar momentum that contributes to the dipolar component of the atmospheric refractivity. Thus the zenith tropospheric delay (ZTD) can be divided into a hydrostatic (ZHD) component, associated with the dipolar momentum induced in the atmosphere, and a wet delay (ZWD) component, associated with the permanent dipolar momentum of water vapor (Saastamoinen, 1972). ZHD is an order of magnitude larger than ZWD, but ZWD is usually far more variable. Thus the daily variability of ZWD usually exceeds that of ZHD by an order of magnitude (Elgered et al., 1991). From measurements obtained by the GPS system and by use of complex inversion algorithms, the ZTD can be calculated (Tralli and Lichten, 1990; Herring et al., 1990; Rocken et al., 1993; Duan et al., 1996). The ZHD can be modelled knowing the atmospheric pressure at the surface. Subtracting the ZHD from the ZTD, the ZWD is obtained, which can be transformed into PWV knowing the watervapor-weighted mean temperature of the atmosphere. This can be derived from the temperature at station level (Davis et al., 1985; Bevis et al., 1992). Approximately $1 \mathrm{~mm}$ of PWV produces a $6.35 \mathrm{~mm}$ delay, but this factor can vary by about $20 \%$ with respect to location, altitude, season of the year, and meteorological conditions (Bevis et al., 1994). Thus a GPS network can be used to estimate the PWV (de Haan, 2006).

The quality of GPS PWV data has been demonstrated through intercomparison with different instruments and techniques (Ohtani and Naito, 2000; Bokoye et al., 2003; Schneider et al., 2009). In addition, on 6 November 2006, the International GNSS Service adopted an absolute calibration model for the antennas of GPS satellites and receivers instead of the relative one. This change has involved an improvement, increasing the accuracy of station position determination, and, consequently, benefiting postprocessing products such as ZTD and PWV (Ortiz de

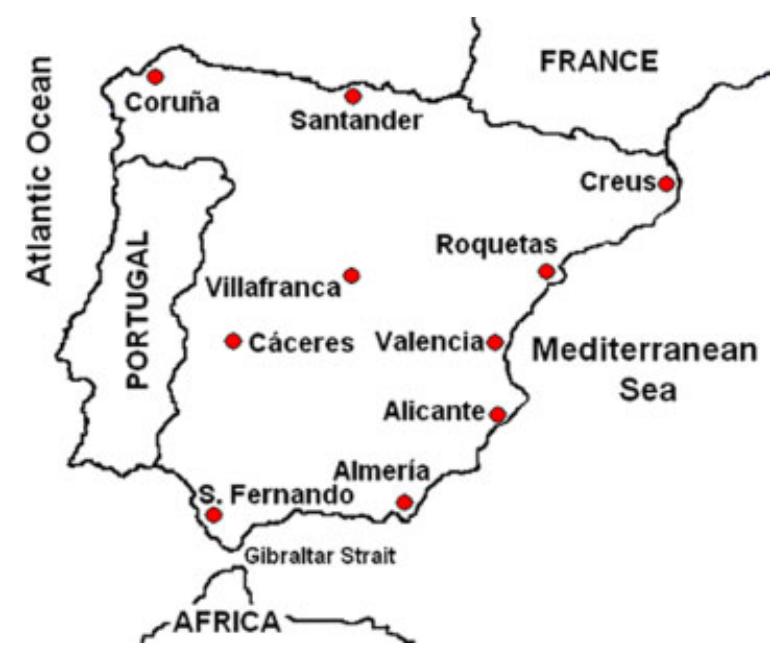

Figure 1. Location of the GPS ground receivers. This figure is available in colour online at wileyonlinelibrary.com/journal/qj

Galisteo et al., 2010). Some authors have compared the PWV diurnal cycle from GPS and microwave radiometer (MWR) data. They suggest that GPS is suitable for studying the diurnal variations of PWV (Dai et al., 2002; Morland et al., 2009).

\section{Methodology and data}

GPS stations on the Spanish mainland as a part of EUREF (European Reference Frame; http://epncb.oma.be/), have been used in this study. In order that the study has a climatologic character, only stations with the longest series of data have been selected. These stations are: Coruña, Alicante, Almería, Cáceres, Santander, Creus, Roquetes, San Fernando, Valencia, and Villafranca (Table I). The stations of Coruña and Santander are located on the north Atlantic coast; San Fernando on the south Atlantic coast (near the Strait of Gibraltar); Alicante, Almería, Creus, Roquetes and Valencia are situated on the Mediterranean coast; and Cáceres and Villafranca inland (Figure 1). Owing to the geographical situation of Spain between two seas with different characteristics - the Atlantic Ocean and the Mediterranean Sea - and to its abrupt and complicated physical relief with several mountain ranges, valleys of large rivers, and two large plateaus, several areas with different PWV climatologies can be expected.

The GPS data have been processed by the Geographic National Institute of Spain (IGNE) for all stations. The selected stations have data from August 2001; however, only the data from January 2002 to December 2008 have been used, to avoid any kind of bias for not considering whole years. ZTD data have an hourly frequency and have been calculated using the software Bernese V5.0, with the precise orbits of satellites provided by the IGS (International GNSS Service). The ZTD data were transformed into PWV according to the procedure described by Bevis et al. (1992). For that, the pressure at surface level $P_{\mathrm{s}}$ and the water vapor weighted mean temperature of the atmosphere $T_{\mathrm{m}}$ (Davis et al., 1985) are required. $T_{\mathrm{m}}$ was computed from the surface temperature $T_{\mathrm{s}}$ from the expression

$$
T_{\mathrm{m}}=61.9+0.75 T_{\mathrm{s}}
$$

instead of a similar expression obtained by Bevis et al. (1992). This expression was obtained based on the analysis of 37179 
Table I. GPS sites. (Lat.) latitude (north), (Lon.) longitude (positive west, negative east), (Elev.) elevation in meters above sea level, (V) sub-daily variability in absolute value, and (\%) relative to mean PWV.

\begin{tabular}{lccccc}
\hline Station & Lat. & Lon. & Elev. & V & $\%$ \\
\hline Alicante & $38^{\circ} 20^{\prime}$ & $0^{\circ} 29^{\prime}$ & 10 & 1.08 & 5.1 \\
Almería & $36^{\circ} 51^{\prime}$ & $2^{\circ} 28^{\prime}$ & 77 & 1.35 & 6.7 \\
Cáceres & $39^{\circ} 29^{\prime}$ & $6^{\circ} 21^{\prime}$ & 384 & 0.58 & 3.5 \\
Coruña & $43^{\circ} 22^{\prime}$ & $8^{\circ} 24^{\prime}$ & 12 & 0.68 & 3.4 \\
Creus & $42^{\circ} 19^{\prime}$ & $-3^{\circ} 19^{\prime}$ & 84 & 0.99 & 4.9 \\
Roquetes & $40^{\circ} 49^{\prime}$ & $-0^{\circ} 30^{\prime}$ & 58 & 0.35 & 6.4 \\
S. Fernando & $36^{\circ} 28^{\prime}$ & $6^{\circ} 12^{\prime}$ & 40 & 0.94 & 3.2 \\
Santander & $43^{\circ} 28^{\prime}$ & $3^{\circ} 48^{\prime}$ & 48 & 1.33 & 4.6 \\
Valencia & $39^{\circ} 29^{\prime}$ & $0^{\circ} 20^{\prime}$ & 28 & 0.41 & 6.2 \\
Villafranca & $40^{\circ} 27^{\prime}$ & $3^{\circ} 57^{\prime}$ & 596 & & 2.6 \\
\hline
\end{tabular}

radiosonde profiles spanning a 9-year interval from seven radiosonde stations over the Iberian Peninsula. The linear regression has a bias of $0.06 \mathrm{~mm}$ and a root mean square error (RMSE) of $3.19 \mathrm{~mm}$. A comparison between the $T_{\mathrm{m}}$ computed from $T_{\mathrm{s}}$ and the $T_{\mathrm{m}}$ from the soundings was carried out at 0000 and 1200 UTC, to check the possible artificial diurnal cycle in PWV introduced by the $T_{\mathrm{m}}-T_{\mathrm{s}}$ relationship, because this takes no account of the fact that $T_{\mathrm{s}}$ has a much higher diurnal cycle amplitude than temperatures higher in the atmosphere (Wang et al., 2005). A dry bias in $T_{\mathrm{m}}$, and subsequently in PWV, was obtained at night, and a wet bias at daytime. At 0000 UTC Eq. (1) underestimated $T_{\mathrm{m}}$ by $1.08 \mathrm{~K}$, and at 1200 UTC Eq. (1) overestimated $T_{\mathrm{m}}$ by $1.09 \mathrm{~K}$. That means a variation of $\sim 2 \mathrm{~K}$ produces an artificial mean difference in PWV between those hours of around 1\%. This difference will be higher between the peak hours of the maximum and minimum $T_{\mathrm{s}}$. To remove this artificial cycle, $T_{\mathrm{s}}$ was damped according to the expression

$$
T_{\mathrm{sd}}=0.25 T_{\mathrm{s}}+0.75 T_{\mathrm{sm}}
$$

where $T_{\mathrm{sm}}$ is the daily mean surface air temperature (Morland et al., 2009).

Meteorological data $\left(P_{\mathrm{s}}\right.$ and $\left.T_{\mathrm{s}}\right)$ for each station were obtained from the nearest station of the Spanish Meteorological State Agency (AEMET). There is a meteorological station in the same city for all the GPS stations except San Fernando, Villafranca and Creus. For the first two the meteorological station is $25 \mathrm{~km}$ away and for the third it is $50 \mathrm{~km}$. If needed, we have corrected the meteorological data by the difference of altitude between the GPS and the meteorological stations. Temperature data are hourly, but there are only four pressure data per day. To avoid introducing an artificial PWV cycle, the 6-hourly pressure data were interpolated at the ZDT hours taking into account the barometric tide, which presents over Spain a semi-diurnal cycle with maximum values of atmospheric pressure around 1000 and 2200 UTC and minimum ones around 0400 and 1600 UTC, with a mean amplitude of $0.5 \mathrm{mb}$ (Ray and Ponte, 2003). PWV calculation is very sensitive to pressure uncertainties; an error of $0.5 \mathrm{mb}$ in pressure produces a $1 \%$ error in PWV (Hagemann et al., 2003).

To calculate the diurnal cycle we proceeded as follows. First, we calculated the mean PWV for each day by averaging the 24-hourly data. Subsequently, the hourly anomalies for each day were obtained by subtracting the daily mean from the hourly PWV values. In this manner, the mean contribution to the PWV due to the synoptical situation is removed, with only the contribution of the factors which vary following a diurnal cycle remaining (Jakobson et al., 2009). Finally, the annual mean diurnal cycle of each station was obtained by averaging for each hour the anomalies of all days. A similar procedure was used to obtain the seasonal cycles. In this case, however, a diurnal cycle for each month was obtained first and the seasonal diurnal cycles were calculated by averaging the monthly diurnal cycles of the months of each season, where winter includes December, January and February, spring is from March to May, summer from June to August, and autumn from September to November. The annual and seasonal mean diurnal cycles over Spain were obtained from the average of the cycles of all the stations. The time is always expressed in Coordinated Universal Time (UTC) and not in True Solar Time, but it should be noted that the Greenwich meridian passes over Spain, and the maximum correction due to the longitude of the stations is only $34^{\prime}$.

The annual and seasonal diurnal cycles obtained are presented in section 3, together with a harmonic analysis. Finally, section 4 shows an attempt to explain in a qualitative way the shape of the diurnal cycle on the basis of the factors that cause condensation, evaporation, and transport of water vapor.

\section{Results}

To put the diurnal cycle into context, first the annual and seasonal mean values of PWV for each station are discussed briefly. The annual mean ranges between $15.76 \mathrm{~mm}$ at Villafranca and $21.37 \mathrm{~mm}$ at Valencia, with the mean of all stations being $19.55 \mathrm{~mm}$. The lowest values of the annual mean of PWV are registered at the inland stations and the highest ones at the stations on the Mediterranean coast. With respect to the stations on the Atlantic coast, the two in the north (Coruña and Santander) register values similar to the lowest values of the stations on the Mediterranean coast, but the one located in the south (San Fernando) registers a lower value. As to the seasonal behaviour, winter shows the lowest values and summer the highest, with a mean value $(26.01 \mathrm{~mm})$, about twice the winter value $(13.28 \mathrm{~mm})$. Similar summer-winter doubling differences are noticed for individual stations, ranging in summer between $20.31 \mathrm{~mm}$ 
at Cáceres and $30.06 \mathrm{~mm}$ at Valencia, and in winter between $10.78 \mathrm{~mm}$ at Villafranca and $15.02 \mathrm{~mm}$ at Coruña. Spring and autumn have values that are intermediate between winter and summer, with spring being more similar to winter and autumn more similar to summer. The stations situated inland register the lowest values in all seasons, whereas the highest values are registered at the stations on the Atlantic coast in winter and at those on the Mediterranean coast and at Santander (Atlantic coast) in the summer.

\subsection{Annual diurnal cycle}

According to the above-mentioned procedure, Figure 2 shows the annual average of the diurnal cycle for each station. One observed characteristic is that there is more dispersion in the PWV data among stations during daytime than during the night. This result suggests that the mechanisms changing the PWV are more influenced by local effects during daytime than during night. The minimum value of PWV is reached approximately at the same time at most stations (around 0430-0530 UTC), whereas the maximum is reached in the second half of the day, but with a larger dispersion in its occurrence, varying from 1130 UTC at San Fernando to 2030 UTC at Alicante or Valencia. At most of the stations it is reached between 1730 and 2030 UTC. Only in the three most western stations (Coruña, Cáceres and San Fernando) is the maximum reached earlier.

The three stations on the Atlantic coast show a quite different diurnal cycle. However, the stations on the Mediterranean coast show cycles more similar to each other. The shape of the cycle at the inland stations is more similar to the one of Coruña station on the Atlantic coast.

The sub-daily variability (the difference between the maximum and minimum value of the deviation from the mean) ranges between $0.41 \mathrm{~mm}$ at Villafranca and $1.35 \mathrm{~mm}$ at Almería and Roquetes (Table I). The highest values are found at the stations on the Mediterranean coast, ranging between 0.99 and $1.35 \mathrm{~mm}$, whereas the lowest values are found at the inland stations, ranging between 0.41 and $0.58 \mathrm{~mm}$. The sub-daily variability relative to the annual mean value of PWV ranges between $6.7 \%$ at Almería and $2.6 \%$ at Villafranca. The highest values always occur at all the stations on the Mediterranean coast.

The diurnal mean cycle, obtained by averaging the cycles of all stations, has a sub-daily variability of $0.71 \mathrm{~mm}$. It decreases during the night to a minimum value of the anomaly of $-0.32 \mathrm{~mm}$ at about 0500 UTC. Thereafter, the PWV increases slowly until it reaches its maximum value of $0.39 \mathrm{~mm}$ at about 1830 UTC. Finally, the PWV decreases more quickly until it reaches again the nightly minimum. The shape of the mean annual diurnal cycle resembles an asymmetric sinusoid, with the descending branch shorter and more pronounced than the ascending one (Figure 3). The height of the maximum is slightly greater than the depth of the minimum.

\subsection{Seasonal diurnal cycle}

From a visual comparison of the graphs of the seasonal averaged diurnal cycles (Figure 2) it is noticed that the cycle is clearly stronger in summer than in any other season. In general, the maximum sub-daily variability occurs in summer. Only at inland stations is it larger in autumn (Cáceres) or spring (Villafranca). The lowest values of the sub-daily variability occur in winter; also the differences between stations are lowest in winter, while in summer there is a larger dispersion (Table II). In spring the subdaily variability is larger or slightly lower than in winter, except at Coruña, where it is reduced more than half of its winter value. In autumn, the sub-daily variability has values between spring and summer, except at Santander and at inland stations. The sub-daily variability ranges in summer from $0.62 \mathrm{~mm}$ at Villafranca to $3.19 \mathrm{~mm}$ at Valencia, with the lowest values at inland stations and the highest ones at the stations on the Mediterranean coast and at Santander; whereas in winter it ranges from $0.61 \mathrm{~mm}$ at San Fernando to $1.07 \mathrm{~mm}$ at Almería; in spring from $0.45 \mathrm{~mm}$ at Coruña to $1.15 \mathrm{~mm}$ at Valencia, with the lowest values at the western stations; and in autumn from $0.72 \mathrm{~mm}$ at Villafranca to $1.77 \mathrm{~m}$ at Almería, with the highest values at the stations on the Mediterranean coast.

Concerning the shape of the cycle, in winter it is quite similar at all locations despite their geographical situation. The dispersion increases in spring, and even more in autumn. In summer, local effects are felt strongly, making the diurnal cycle quite different among stations. At least two distinctly different cycles appear at all stations: one in winter and another in summer. At some stations spring and autumn show transitional intermediate shapes between winter and summer, as at the stations on the Mediterranean coast, whereas at others they are similar to the winter cycle (San Fernando) or to the summer one (Coruña).

Averaging the cycles of all stations (Figure 4), summer is characterized by the highest sub-daily variability $(1.34 \mathrm{~mm})$, describing a curve with a wide minimum between 0630 UTC and 0930 UTC and a sharper maximum around 2130 UTC, with the slope of the decreasing phase greater than the increasing phase. In winter the cycle is weaker, the sub-daily variability is only $0.69 \mathrm{~mm}$, and the maximum is reached around 1030 UTC. The lowest sub-daily variability is found in spring $(0.66 \mathrm{~mm})$ - slightly lower than in winter. In that season the increase of PWV starts later than in winter and the PWV decreases slightly from midnight to 1130 UTC; thereafter it increases until evening, where a wide maximum takes place (1730-2030 UTC), and finally it decreases pronouncedly until midnight. Autumn shows a behaviour more similar to summer, but with a phase lag; minimum and maximum values occur earlier in autumn than in summer, and there is a lower sub-daily variability $(1.06 \mathrm{~mm})$, almost half way between winter and summer.

According to Wang et al. (2007), the mean diurnal cycle for the European region, based on an average of 110 GPS stations distributed over the entire continent, is strongest in summer, with a sub-daily variability of $\sim 1.2 \mathrm{~mm}$, weaker in winter and autumn, and practically negligible in spring. The PWV maximum is reached at 1100 Local Solar Time (LST) in winter, around 1600-1800 LST in autumn, and between 2000 and 2200 LST in summer. The results obtained in the present study are in good agreement with the results of Wang et al. (2007) in summer, autumn and winter, both in the shape of the cycle and the in time of the maximum, but with slightly higher-amplitude values in Spain than in the rest of Europe in summer and autumn. In spring, the mean cycle for Spain is stronger than for the Europe region. 

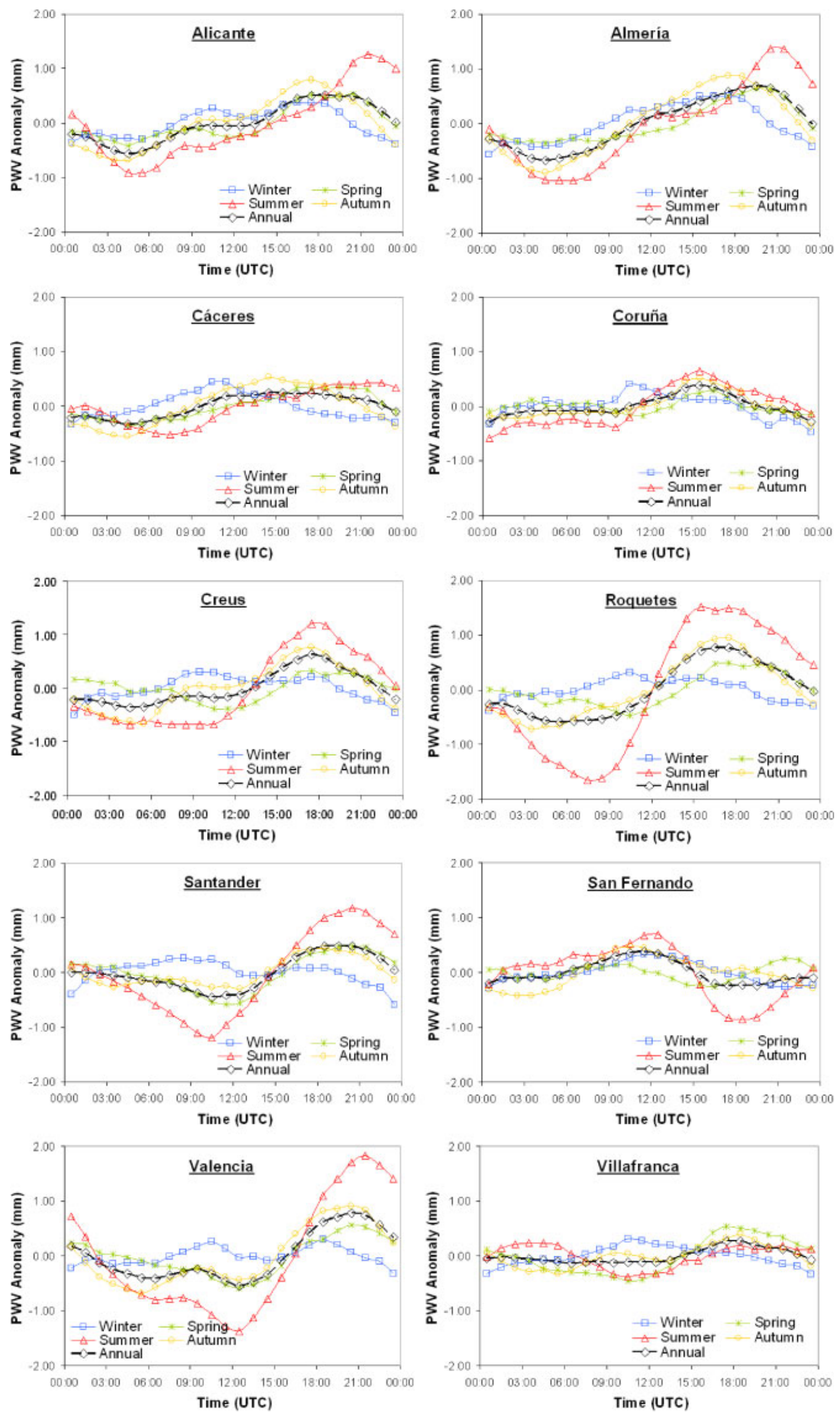

Figure 2. Annual and seasonal diurnal cycles for each station. This figure is available in colour online at wileyonlinelibrary.com/journal/qj 
Table II. Seasonal mean sub-daily variability ( $\mathrm{mm})$.

\begin{tabular}{lcccc}
\hline Station & Winter & Spring & Summer & Autumn \\
\hline Alicante & 0.76 & 0.95 & 2.16 & 1.47 \\
Almería & 1.07 & 1.00 & 2.41 & 1.77 \\
Cáceres & 0.77 & 0.70 & 0.94 & 1.08 \\
Coruña & 0.88 & 0.45 & 1.23 & 0.89 \\
Creus & 0.81 & 0.71 & 1.89 & 1.06 \\
Roquetes & 0.69 & 0.95 & 3.16 & 1.66 \\
S. Fernando & 0.61 & 0.51 & 1.55 & 0.90 \\
Santander & 0.84 & 1.06 & 2.38 & 0.74 \\
Valencia & 0.63 & 1.15 & 3.19 & 1.59 \\
Villafranca & 0.64 & 0.99 & 0.62 & 0.72 \\
\hline
\end{tabular}

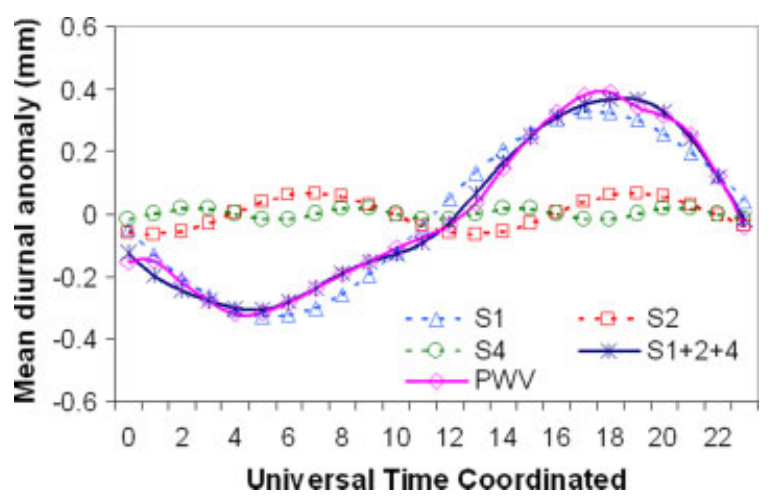

Figure 3. Annual mean diurnal cycle (PWV) and the result of the harmonic analysis: S1, S2 and S4 are the harmonics of 24, 12 and 6-h periods, and $\mathrm{S} 1+2+4$ represents the sum of the three harmonics. The harmonic of $8-\mathrm{h}$ period (S3) is not shown because it is negligible. This figure is available in colour online at wileyonlinelibrary.com/journal/qj

\subsection{Harmonic analysis}

The PWV annual diurnal cycle at each GPS station was subjected to a harmonic analysis. The amplitude (half of the peak-to-peak amplitude), phase (UTC time at the maximum) and variance of the four first harmonics with periods 24, 12, 8 and $6 \mathrm{~h}$ are represented in Table III. The $24 \mathrm{~h}$ period harmonic (S1) explains an average over $85 \%$ of the sub-daily variance, whereas the $12 \mathrm{~h}$ period harmonic (S2) explains over $12 \%$, the 8 -h period one (S3) only $1 \%$, and the $6 \mathrm{~h}$ period (S4) is negligible. S1 is the dominant harmonic for all the stations. The variance explained by this harmonic ranges from $74 \%$ at Coruña to $96 \%$ at Cáceres. S2 is the second dominant harmonic for all the stations, with an explained variance ranging from $1.5 \%$ at Cáceres to $22.5 \%$ at Coruña. Thus S1 and S2 together explain most of the variance (97\%). Only at half of the stations is the variance explained by S3 higher than $1 \%$, being its maximum value $3.8 \%$ at Villafranca, while S4 explains more than $1 \%$ only at Coruña (1.4\%).

The amplitude of S1 is more than twice the amplitude of S2, and at some stations even much more, whereas the amplitudes of S3 and S4 are negligible. The dispersion of the phases of S2 is higher than that of S1. The phase of S1 ranges from 0930 UTC at San Fernando to 2030 UTC at Valencia, although at most of the stations it ranges from 1700 UTC to 2030 UTC. In contrast, the phase of S2 is approximately between 0330 and 1030 UTC.
These results agree with those obtained by Dai et al. (2002). They decomposed the diurnal cycle of PWV of 54 stations over North America into simple harmonics (with periods of 24, 12, 8 and $6 \mathrm{~h}$ ) and found that the diurnal cycle was well represented only with the first two harmonics. The $24 \mathrm{~h}$ period explained more than $50 \%$ of the variance, while the $12 \mathrm{~h}$ period explained less than $25 \%$. Both together explained more than $80 \%$ of the variance for most of the stations.

Also the seasonal diurnal cycles were subjected to a harmonic analysis (Figure 4). Table IV contains the parameters of this analysis for the average cycles of all stations. Together S1, S2 and S3 explain approximately the same variance for every season (96-98\%), but not always at the same rate. S1 is always by far the most dominant harmonic, but it explains a little more variance in summer and autumn (92-96\%) than in winter and spring $(83-86 \%)$. The amplitude of S1 is in summer more than twice that in winter or spring, and its phase is at noon in winter, in the afternoon in autumn and in the evening in spring and summer. S2 is more significant in spring, explaining $14 \%$ of the variance, while in the other seasons it explains between $1 \%$ and $4 \%$. The variance explained by S3 is only significant in winter (7\%), and S4 is always negligible. However, there is a great dispersion between stations in the variance explained by each harmonic for each season.

\section{Discussion}

The mechanisms producing variations in the PWV can be classified into three groups: large-scale changes of the air mass, evaporation and condensation within the air mass, and wet and dry advections (local winds). The variations due to the large-scale changes of the synoptical situation do not follow a diurnal cycle pattern, so that when averaging over a large number of days they are compensated, with only those variations related to the diurnal cycle of solar radiation remaining ( Wu et al., 2003). The latter is one of the main factors that determines the diurnal variations of PWV, as well as temperature, evapotranspiration (Dai et al., 1999b), local wind circulation (Dai and Deser, 1999), condensation and precipitation (Dai et al., 1999a; Dai, 2001), or vertical air motion (Dai et al., 1999a). The diurnal cycle of the PWV is determined by the sum of the contributions of each of these factors.

In this section some of the features of the PWV diurnal cycle - mainly on the basis of the air temperature, the transport of moisture by local winds, and the turbulent mixture in the vertical - are presented in a qualitative way. 

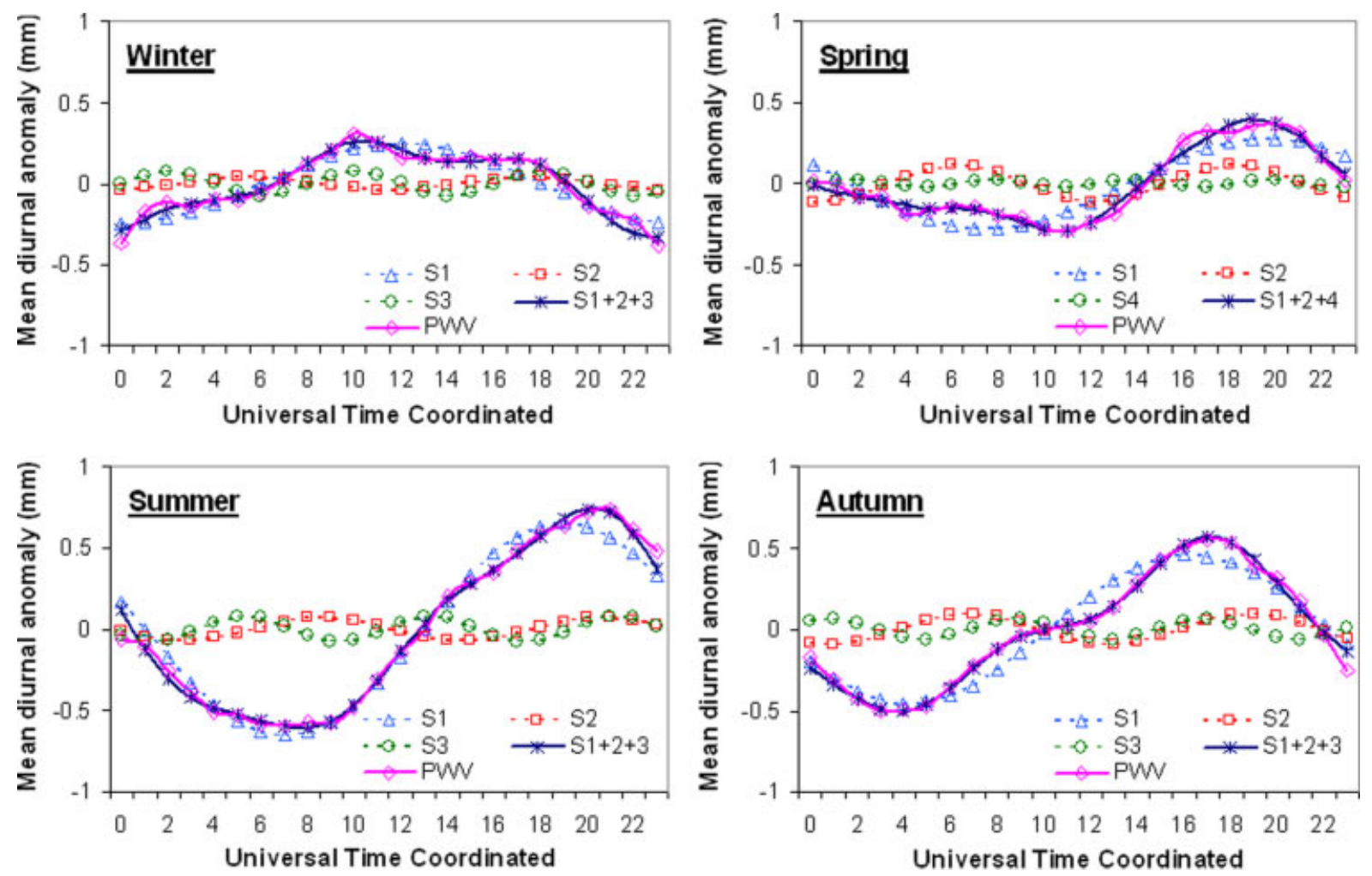

Figure 4. Seasonal mean diurnal cycle and harmonic analysis (see Figure 3). This figure is available in colour online at wileyonlinelibrary.com/journal/qj

Table III. Harmonic analysis of the PWV annual diurnal cycle. (A) amplitude (mm), (Ph) phase (UTC time at the maximum), (V) variance explained, and (VT) total variance explained by the four harmonics together.

\begin{tabular}{|c|c|c|c|c|c|c|c|c|c|c|c|c|c|}
\hline \multirow[b]{2}{*}{ Station } & \multicolumn{3}{|c|}{$24 \mathrm{~h}$ harmonic } & \multicolumn{3}{|c|}{$12 \mathrm{~h}$ harmonic } & \multicolumn{3}{|c|}{$8 \mathrm{~h}$ harmonic } & \multicolumn{3}{|c|}{$6 \mathrm{~h}$ harmonic } & \multirow[b]{2}{*}{ VT } \\
\hline & A & $\mathrm{Ph}$ & $\mathrm{V}$ & A & $\mathrm{Ph}$ & $\mathrm{V}$ & A & $\mathrm{Ph}$ & $\mathrm{V}$ & A & $\mathrm{Ph}$ & $\mathrm{V}$ & \\
\hline Alicante & 0.46 & 17.3 & 87.6 & 0.15 & 7.9 & 9.4 & 0.05 & 0.6 & 1.1 & 0.03 & 3.3 & 0.5 & 98.5 \\
\hline Almería & 0.63 & 17.1 & 94.3 & 0.13 & 8.5 & 4.0 & 0.05 & 3.6 & 0.5 & 0.00 & 0.0 & 0.0 & 98.8 \\
\hline Cáceres & 0.28 & 15.6 & 96.1 & 0.04 & 10.1 & 1.5 & 0.02 & 0.0 & 0.5 & 0.00 & 0.0 & 0.0 & 98.1 \\
\hline Coruña & 0.23 & 14.3 & 74.0 & 0.12 & 3.7 & 21.5 & 0.00 & 0.0 & 0.0 & 0.03 & 2.9 & 1.4 & 97.0 \\
\hline Creus & 0.40 & 17.0 & 84.1 & 0.15 & 5.6 & 11.7 & 0.07 & 0.7 & 2.3 & 0.02 & 3.2 & 0.3 & 98.5 \\
\hline Roquetes & 0.67 & 17.2 & 95.8 & 0.12 & 3.8 & 2.9 & 0.03 & 7.0 & 0.2 & 0.00 & 0.0 & 0.0 & 98.9 \\
\hline S. Fernando & 0.25 & 9.7 & 75.3 & 0.13 & 10.7 & 21.1 & 0.03 & 4.4 & 1.2 & 0.00 & 0.0 & 0.0 & 97.6 \\
\hline Santander & 0.38 & 20.2 & 81.5 & 0.17 & 5.9 & 16.7 & 0.00 & 0.0 & 0.0 & 0.03 & 2.4 & 0.4 & 98.6 \\
\hline Valencia & 0.56 & 20.4 & 82.8 & 0.24 & 7.8 & 14.6 & 0.06 & 1.4 & 1.1 & 0.04 & 3.2 & 0.3 & 98.8 \\
\hline Villafranca & 0.16 & 18.6 & 76.3 & 0.08 & 5.5 & 16.9 & 0.04 & 1.7 & 3.8 & 0.00 & 0.0 & 0.0 & 97.0 \\
\hline Mean & 0.40 & 16.7 & 84.8 & 0.13 & 7.0 & 12.0 & 0.03 & 2.0 & 1.1 & 0.01 & 1.5 & 0.3 & 97.9 \\
\hline
\end{tabular}

Table IV. Harmonic analysis of the PWV seasonal mean diurnal cycles (see Table III).

\begin{tabular}{|c|c|c|c|c|c|c|c|c|c|c|c|c|c|}
\hline \multirow[b]{2}{*}{ Season } & \multicolumn{3}{|c|}{$24 \mathrm{~h}$ harmonic } & \multicolumn{3}{|c|}{$12 \mathrm{~h}$ harmonic } & \multicolumn{3}{|c|}{$8 \mathrm{~h}$ harmonic } & \multicolumn{3}{|c|}{$6 \mathrm{~h}$ harmonic } & \multirow[b]{2}{*}{ VT } \\
\hline & A & $\mathrm{Ph}$ & $\mathrm{V}$ & A & $\mathrm{Ph}$ & $\mathrm{V}$ & A & $\mathrm{Ph}$ & $\mathrm{V}$ & A & $\mathrm{Ph}$ & $\mathrm{V}$ & \\
\hline Winter & 0.25 & 12.1 & 86.2 & 0.04 & 5.6 & 2.2 & 0.07 & 2.1 & 7.4 & 0.00 & 0.0 & 0.0 & 95.7 \\
\hline Spring & 0.28 & 19.6 & 82.6 & 0.12 & 6.3 & 13.9 & 0.00 & 2.0 & 0.0 & 0.02 & 0.0 & 0.6 & 97.0 \\
\hline Summer & 0.66 & 19.0 & 95.5 & 0.07 & 8.8 & 1.1 & 0.08 & 5.3 & 1.4 & 0.00 & 0.0 & 0.0 & 98.0 \\
\hline Autumn & 0.46 & 16.2 & 92.3 & 0.10 & 6.8 & 4.1 & 0.06 & 0.8 & 1.8 & 0.00 & 0.0 & 0.0 & 98.2 \\
\hline
\end{tabular}


Temperature should perhaps be the most important factor. Diurnal warming drives evaporation, which increases the PWV. Moreover, according to Clausisus-Clapeyron's equation, the higher the temperature the more water vapor the air can contain before condensation takes place. During the night, cooling causes a decrease of the PWV by condensation.

Another important factor is the wind. Wind enables evaporation in the lower atmospheric layers near the ground and acts like a conveyor belt of moisture. The diurnal variability of the wind, obtained by subtracting the mean component due to the synoptical situation, is determined by the movement of the sun and by local geographical effects. Owing to changes in solar elevation, the wind speed gets stronger during the daytime and weakens during the night. Wind direction is also influenced by solar position, with the wind tending to blow towards the point of the vertical of the sun due to the thermal depression that it generates, i.e. westerly wind in the morning veering to easterly wind in the afternoon. Breezes (both sea and mountain) are clear examples of local wind regimes. Its mechanism is well known. It is the result of differential warming between land and sea or between valley and mountain that establishes a gradient of pressure that generates the wind. During daytime sea breezes carry moisture inland. During the night the higher cooling of the land causes the breeze regime to reverse, blowing from land to sea (land breeze). The land breeze advects air previously advected inland by the sea breeze towards the coast, which after having undergone cooling and condensation is now drier. The appearance and onset time of the breezes and the vertical growth of the affected layer also depend on the general synoptical situation (Bastin et al., 2007). The diurnal variation of PWV seems to be strongly conditioned by local thermal circulations generated by the topography (Li et al., 2008). The phase lag between stations in the PWV diurnal cycle can be explained by this factor on the basis of moisture transport.

Vertical motion transports moisture from lower layers to upper layers, disperses PWV and enhances evaporation. Water vapor enters the atmosphere from the Earth's surface by evaporation and is accumulated in the layer closest to the ground. When the Sun rises, the diurnal warming triggers the turbulent and the vertical mixing. The thickness of the mixed layer increases with the intensity of the incident solar radiation. When updrafts are generated around noon, PWV increases, although the specific humidity next to the ground decreases (Wu et al., 2003). The variations of PWV above the mixed layer can be attributed to advections of moisture by local currents induced by differential warming (Kimura et al., 1997). During the night there is no thermal turbulence and cooling at night increases stability and stratification in the lower layers of the atmosphere.

Figure 5 shows the annual mean diurnal cycle of temperature, which is almost the same at all stations. It can be observed that at most stations the minima of PWV and temperature cycles occur nearly at $1 \mathrm{~h}$ intervals. However, the same does not occur with the maxima, where there is a longer phase lag (Li et al., 2008). Only at Cáceres and Coruña are the maxima of both cycles approximately in phase, whereas at the stations on the Mediterranean coast, as well as at Santander, the maximum PWV is reached between 4 and $6 \mathrm{~h}$ later than the temperature maximum. San Fernando is a special case: it is the only site where the maximum PWV occurs before the temperature maximum.

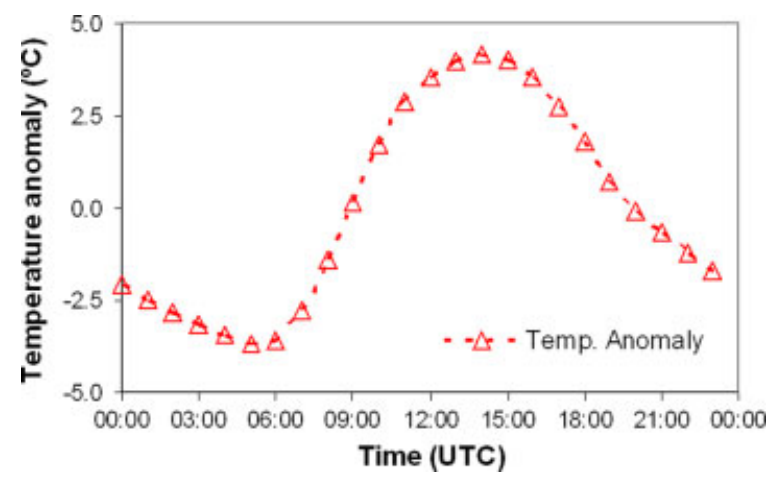

Figure 5. Annual average of the temperature diurnal cycle. This figure is available in colour online at wileyonlinelibrary.com/journal/qj
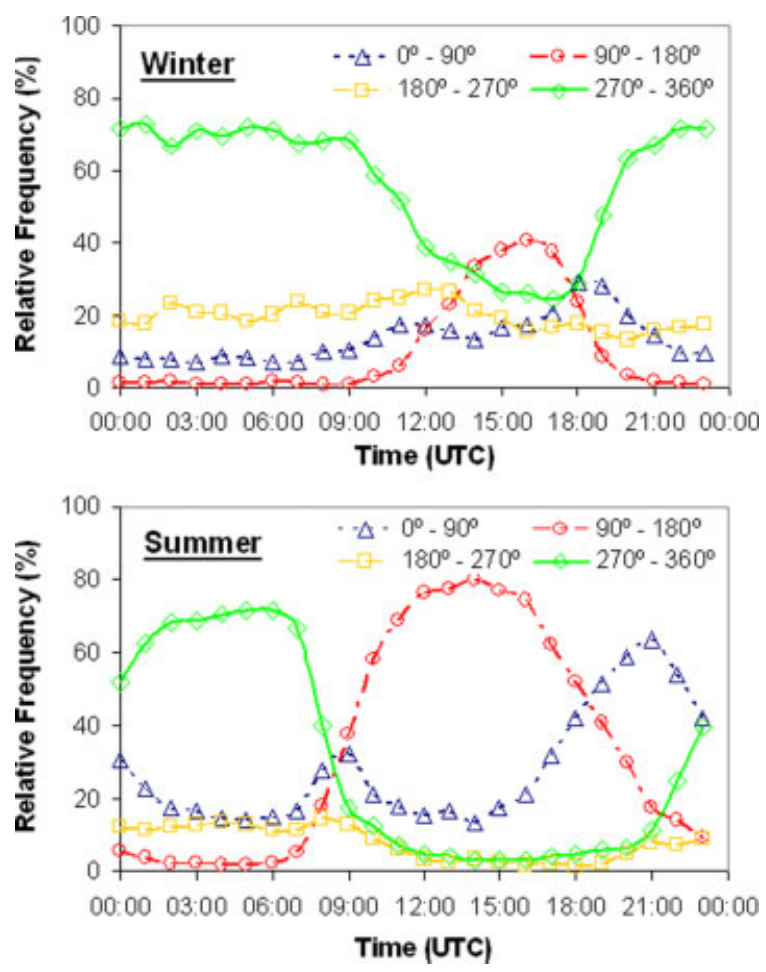

Figure 6. Seasonal diurnal cycles of the relative frequency (\%) of the wind direction at Valencia. The easterly winds blow from sea to land (sea breeze) and the westerly winds blow from land to sea (land breeze). This figure is available in colour online at wileyonlinelibrary.com/journal/qj

It is clear that the diurnal cycle of temperature alone would not be a proxy for PWV cycle, especially during daytime.

At coastal stations the diurnal cycle of PWV could be greatly influenced by the advection of moisture by sea breezes, causing the PWV to continue to increase even after the air temperature has already begun to decrease. For example, at a typical station of the Mediterranean coast, such as Valencia, it is seen how the sea breeze regime is established every season. Nevertheless, the see breeze regime sets in earlier, is stronger and lasts longer in summer than in winter, because of the higher insolation in this season (Figure 6). Comparing the seasonal diurnal cycles of PWV (Figure 2) and the relative frequency of the wind direction (Figure 6), it is observed that the maximum PWV is reached approximately at the same time the regime breeze turns from sea to land for all seasons. In general, the phase lag is much shorter in winter than in summer, when the sea breeze is stronger. These observations confirm that at this station the 


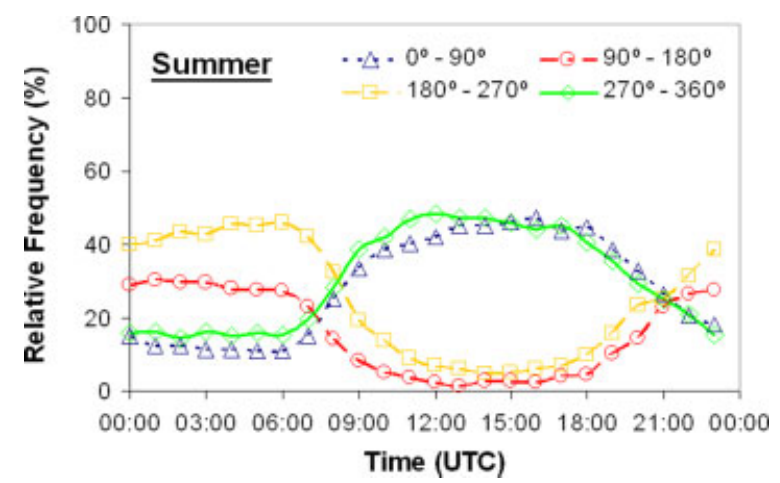

Figure 7. Summer diurnal cycle of the relative frequency (\%) of the wind direction at Santander. Northerly winds are of Atlantic origin. This figure is available in colour online at wileyonlinelibrary.com/journal/qj

breeze regime is the main factor responsible for the phase lag between PWV and temperature cycles during daytime. Also the relative minimum, which occurs at Valencia just after noon, coinciding with the temperature maximum, can be attributed to the breeze regime. This can be seen clearly in summer. Just after sunrise, a decrease in PWV occurs approximately at the onset time of the sea breeze. At this moment the land is hotter than the sea and the warm air above ground, which contains evaporated moisture from the surface, rises and is replaced by colder and drier air originating from the sea. In the afternoon, as the sea warms, it provides a continuous source of moisture to the air above it. Thus the sea breeze becomes an important conveyor of moisture towards inland, increasing the PWV until the sea breeze finally weakens. This minimum does not appear at all stations, because PWV also depends on the amount of moisture available in the soil.

Although there is a breeze regime at Coruña station (on the Atlantic coast), it is not as strong as the breeze effect at the stations on the Mediterranean coast. As a result, it transports less moisture due to the lower temperature of the Atlantic Ocean than the Mediterranean Sea, such that in the annual average PWV and temperature cycles are in phase at this station. However, Santander (also on the Atlantic coast) shows a behaviour more similar to any of the Mediterranean stations than to Coruña. This difference could arise from its location at the foot of the Cantábrica mountain range. This range ( $480 \mathrm{~km}$ long, $100 \mathrm{~km}$ wide and with a highest altitude of $2648 \mathrm{~m}$ ) extends parallel to the coastline. In this area, the sea breezes are enhanced by the valley breezes generated by the presence of the mountain range (Sasaki and Kimura, 2001; Ohtani, 2001), resulting in a more intensive breeze (Figure 7).

At the inland stations, the annual diurnal cycles of PWV and temperature seem to be more in phase, because there is not a dominant diurnal wind regime where the PWV has changed substantially. However, if we study the seasonal mean cycles, a phase lag is noticeable, but with opposite sign in winter and summer. In winter the PWV maximum is reached earlier in the day than the temperature maximum, whereas in summer it occurs the other way around. The reason why the maximum of PWV is reached before the maximum temperature in winter could be explained by the cessation of vertical mixing. During winter, the stratification of the atmosphere is greater - typical in the presence of a subsidence inversion. This inversion acts like a cap, inhibiting the vertical transport and limiting turbulent

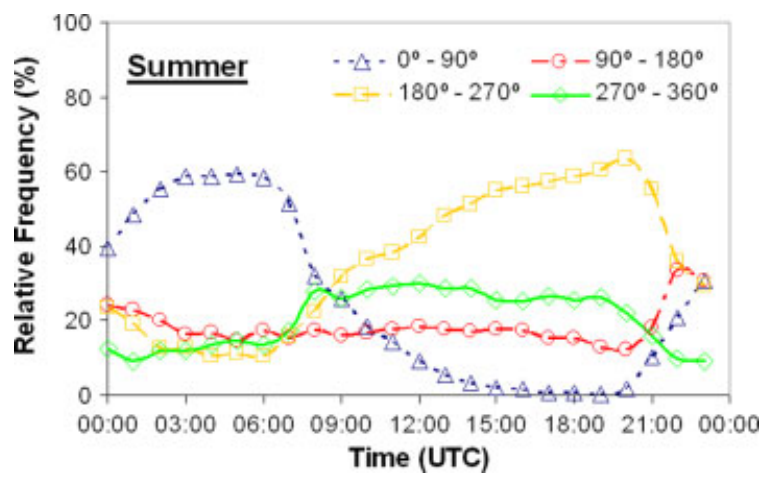

Figure 8. Summer diurnal cycle of the relative frequency of the wind direction at San Fernando. Westerly winds are of Atlantic origin and easterly winds have a Mediterranean influence. This figure is available in colour online at wileyonlinelibrary.com/journal/qj

mixing. Thus, even as the temperature continues to rise, evaporation stops.

At San Fernando, even in summer, the maximum PWV is reached early in the day, around noon. Owing to its geographical location on the coast, the sea breeze is already well established at noon (Figure 8). In contrast to the other stations on the coast, where the sea breeze should continue to provide moisture until late evening, this persistence does not seem to occur here. The explanation for this peculiarity could lie in the proximity of the station to the strait of Gibraltar, between the Atlantic and the Mediterranean. During the night the wind blows from land to sea, but the air mass over the land can be influenced by the Mediterranean Sea on the other side of the strait, so that it is warm and wet. After the sea breeze is established in the morning, the wind turns from east to west (from the Atlantic), which is colder than the Mediterranean, resulting in replacing the air mass over the station with another dryer air. When the sea breeze begins to weaken in the late evening, the easterly winds transport moisture and the PWV increases, even when the temperature is decreasing. However, additional analysis is needed to understand this more complicated situation.

No clear correlation between the daily cycle of precipitation and PWV has been found. It is true that the diurnal heating (related to the content of PWV) is a factor to trigger convection. However, at Spain's latitudes convective precipitation is not the most important but frontal precipitation determined by the synoptical situation, which does not follow a daily cycle. Only Valencia in autumn shows a significant increase in precipitation in the second half of the day when the PWV is higher (Figure 9), and the other way round at San Fernando in autumn and spring, where there is a greater amount of precipitation in the first half of the day (Figure 10). This also agrees with the fact that the maximum PWV occurs at that station before noon. Also at Santander in summer a minimum of precipitation has been found around noon, coinciding with the minimum of PWV.

PWV diurnal cycle can be influenced by cloudiness, so that we divided the data into two groups: one corresponding to the days with the highest temperature amplitude (mostly sunny days), and the other with the lowest temperature amplitude (mostly cloudy days). We have analyzed separately both data groups for each season. As a general rule we have found that at coastal locations the higher the temperature amplitude, the higher the PWV amplitude in all seasons except in winter. At inland locations, 


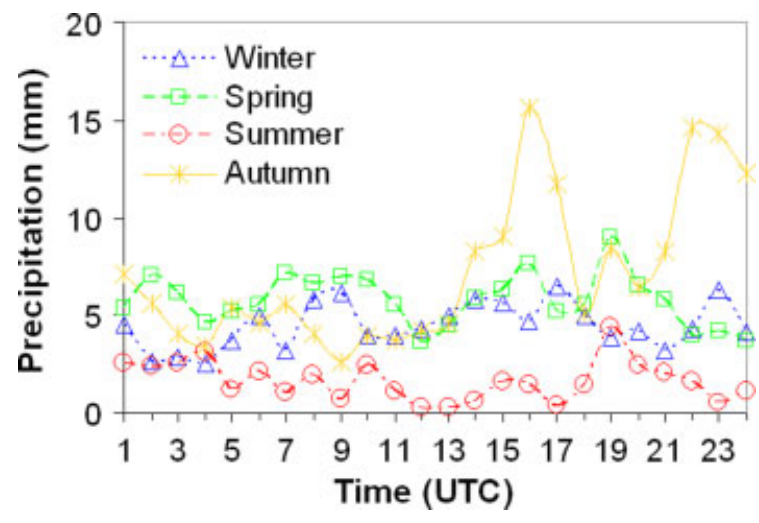

Figure 9. Time distribution of the mean cumulative seasonal rainfall at Valencia. This figure is available in colour online at wileyonlinelibrary.com/journal/qj

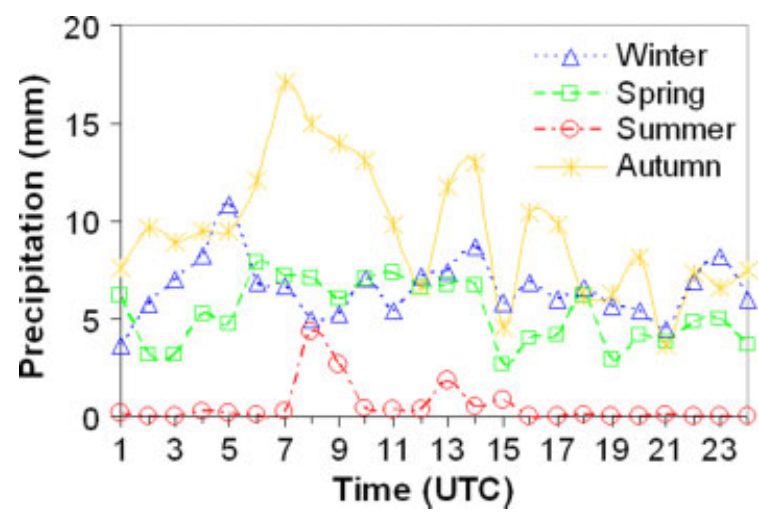

Figure 10. Time distribution of the mean cumulative seasonal rainfall at San Fernando. This figure is available in colour online at wileyonlinelibrary.com/journal/qj

the higher the temperature amplitude, the lower the PWV amplitude in all seasons. Thermal oscillation plays a major role in the PWV diurnal amplitude when there is an unlimited source of water vapor and the intensity of the solar radiation is high. However, these conditions do not occur in winter or at inland locations. In those cases, other factors such as air mass type or atmospheric instability are more determining, with the result that days with lower thermal oscillation present higher PWV variation.

Among the above-mentioned factors, temperature and local winds present a $24 \mathrm{~h}$ diurnal cycle. Thus the S1 harmonic must be mainly produced by the addition of their contributions. The dispersion in the phase of this harmonic indicates the different contribution of both factors in each station. Local winds are weaker in winter than in summer, so in winter S1 is more similar to the temperature diurnal cycle.

Another effect influencing the PWV diurnal cycle at the stations located in urban areas is the anthropogenic change of the surface. In urban areas, evaporation is limited by the lack of water sources during summer. During winter, water vapor is produced by combustion. Moreover, the urban heat island can establish an urban breeze similar to the sea breeze (Champollion et al., 2009).

\section{Conclusions}

The knowledge of the diurnal cycle of PWV can be applied to a better modelling of the water vapor attenuation of the direct solar radiation and subsequently improve atmospheric correction of the satellite images. The PWV temporal variation also provides a test bed for many aspects of the physical parametrizations in numerical weather models and subsequently improves convective activity forecasting. The GPS receivers have proven to be an appropriate technique to determine the PWV diurnal cycle. The annual and seasonal diurnal cycles of PWV have been studied at 10 stations over Spain using the data provided by the GPS receivers. In general, the minimum value of PWV is reached close to dawn, approximately at the same time at all the stations, whereas the maximum is reached in the afternoon or in the evening. Both the annual and the seasonal diurnal cycles at the different stations are more similar to each other during the night than during the afternoon. The mechanisms changing the PWV are influenced more by local effects during daytime than during the night. The annual sub-daily variability ranges from 0.41 to $1.35 \mathrm{~mm}$ $(3-7 \%)$. The highest values are recorded at the stations on the Mediterranean coast: more than twice the values of the inland stations. Also the amplitude of the cycle is higher in summer than in winter, often by factors of two or three times at the stations on the Mediterranean coast. The diurnal cycle in winter is quite similar at all locations, whereas in summer it is quite different. Summer is characterized by the highest sub-daily variability $(1.34 \mathrm{~mm})$ and a PWV maximum around 2130 UTC. In winter and spring the subdaily variability is the lowest ( 0.69 and $0.66 \mathrm{~mm}$ respectively), but the maximum is reached around 1030 UTC in winter and between 1730 UTC and 2030 UTC in spring. Autumn shows a behaviour more similar to summer, but with a phase lag and a lower sub-daily variability $(1.06 \mathrm{~mm})$. Harmonic analysis shows that only the first two harmonics with periods of 24 and $12 \mathrm{~h}$ have a significant contribution. The first one is dominant, explaining $85 \%$ of the variance, whereas the second one explains $12 \%$. The diurnal and semi-diurnal harmonics together can explain $97 \%$ of the variance. The diurnal harmonic explains a little more variance in summer and autumn than in winter and spring. Its amplitude in is summer more than twice that in winter or spring, and its phase is at noon in winter, in the afternoon in autumn and in the evening in spring and summer. The semi-diurnal harmonic explains more variance in spring than in any other season, whereas the $8 \mathrm{~h}$ period harmonic is only significant in winter. Although a more detailed analysis is needed to explain all the features at each station, as a result of the influence of local effects, the main features of the PWV diurnal cycle in the different locations can be explained in a general and qualitative way on the basis of the air temperature diurnal cycle, the transport of moisture by local winds (breezes) and the turbulent vertical mixing. Precipitation does not follow a significant diurnal cycle. Latent heat flux data from numerical models could enhance the affirmations concerning the relation between temperature, state of the boundary layer and PWV variations, because evaporation depends on the latent heat flux, which depends not only on temperature. The PWV diurnal cycle can exhibit a climatic variation related to large-scale oscillation such as the North Atlantic oscillation or a drift due to the increase in the mean temperature by global warming, but longer series are needed to study such correlations. Besides the sub-daily variability, described in this paper, PWV shows oscillations of longer period, such 
as the annual cycle, and it could even present a 7-day period cycle due to human activities.

\section{Acknowledgements}

The GOA-UVA is funded by CICYT projects CGL2008-05939-C03-01/CLI, CGL2009-05693-C03/CLI and CGL2010-09480-E, and under the project of Junta de Castilla y León Excellence Program. One of us (NL) was supported by the US Department of Energy under Contract DE-AC06-76RLO 1830. Pacific Northwest National Laboratory is operated for the US DOE by Battelle Memorial Institute.

\section{References}

Bastin S, Champollion C, Bock O, Drobinski P, Masson F. 2007. Diurnal cycle of water vapor as documented by a dense GPS network in a coastal area during ESCOMPTE IOP2. J. Appl. Meteor. Climatol. 46 : $167-182$

Bevis M, Businger S, Herring TA, Rocken C, Anthes RA, Ware RH. 1992. GPS meteorology: remote sensing of atmospheric water vapor using the Global Positioning System. J. Geophys. R. 97: 15787-15801.

Bevis M, Businger S, Chiswell S, Herring TA, Anthes RA, Rocken C, Ware RH. 1994. GPS meteorology: mapping zenith wet delays onto precipitable water. J. Appl. Meteorol. 33: 379-386.

Bokoye AI, Royer A, O'Neill NT, Cliché P, McArthur LJB, Teillet PM Fedosejevs G, Thériault JM. 2003. Multisensor analysis of integrated atmospheric water vapor over Canada and Alaska. J. Geophys. Res., 108: 4480, DOI: 10.1029/2002JD002721.

Brunner FK, Gu M. 1991. An improved model for the dual frequency ionospheric correction of GPS observations. Manusc. Geod. 16: 205-214.

Champollion C, Drobinski P, Haeffelin M, Bock O, Tarniewicz J, Bouin MN, Vautard R. 2009. Water vapour variability induced by urban/rural surface heterogeneities during convective conditions. $Q$. J. R. Meteorol. Soc. 135: 1266-1276.

Dai A. 2001. Global precipitation and thunderstorm frequencies. II. Diurnal variations. J. Clim. 14: 1112-1128.

Dai A, Deser C. 1999. Diurnal and semidiurnal variations in global surface wind and divergence fields. J. Geophys. Res. 104: 31109-31125.

Dai A, Giorgi F, Trenberth KE. 1999a. Observed and model-simulated precipitation diurnal cycle over the contiguous United States. J. Geophys. Res. 104: 6377-6402.

Dai A, Trenberth KE, Karl TR. 1999b. Effects of clouds, soil moisture, precipitation and water vapor on diurnal temperature range. J. Clim. 12: $2451-2473$.

Dai A, Wang J, Ware RH, van Hove T. 2002. Diurnal variation in water vapor over North America and its implications for sampling errors in radiosonde humidity. J. Geophys. Res. 107: 4090, DOI: 10.1029/2001JD000642.

Davis JL, Herring TA, Shapiro II, Rogers AE, Elgered G. 1985. Geodesy by radio interferometry: effects of atmospheric modeling errors on estimates of baseline length. Radio Sci. 20: 1593-1607.

de Haan S. 2006. 'National/regional operational procedures of GPS water vapor networks and agreed international procedures, WMO - World Meteorological Organization'. Instruments and Observing Methods, Report No. 92.

Duan J, Bevis M, Fang P, Bock Y, Chiswell S, Businger S, Rocken C, Solheim F, van Hove T, Ware R, McClusky S, Herring TA, King RW.
1996. GPS meteorology: direct estimation of the absolute value of precipitable water. J. Appl. Meteorol. 35: 830-838.

Elgered G, Davis JL, Herring TA, Shapiro II. 1991. Geodesy by radio interferometry: water vapor radiometry for estimation of the wet delay. J. Geophys. Res. 96: 6541-6555.

Hagemann S, Bengtsson L, Gendt G. 2003. On the determination of atmospheric water vapor from GPS measurements. J. Geophys. Res. 108: 4678, DOI: 10.1029/2002JD003235.

Herring T, Davis JL, Shapiro II. 1990. Geodesy by radio interferometry: the application of Kalman filtering to the analysis of very long baseline interferometry data. J. Geophys. Res. 95: 12561-12581.

Jakobson E, Ohvril H, Elgered G. 2009. Diurnal variability of precipitable water in the Baltic region, impact on transmittance of the direct solar radiation. Boreal Env. Res. 14: 45-55.

Kimura F, Tanikawa R, Yoshizaki M. 1997. Diurnal variation of precipitable water in clear days over the northern mountains in Kanto plain. Tenki 44: 799-807.

Li G, Kimura F, Sato T, Huang D. 2008. A composite analysis of diurnal cycle of GPS precipitable water vapor in central Japan during calm summer days. Theor. Appl. Climatol. 92: 15-29.

Morland J, Collaud Coen M, Hocke K, Jeannet P, Mätzler C. 2009. Tropospheric water vapour above Switzerland over the last 12 years. Atmos. Chem. Phys. 9: 5975-5988.

Ohtani R. 2001. Detection of water vapor variations driven by thermally induced local circulations using the Japanese continuous GPS array. Geophys. Res. Lett. 28: 151-154.

Ohtani R, Naito I. 2000. Comparisons of GPS-derived precipitable water vapors with radiosonde observations in Japan. J. Geophys. Res. 105: $26917-26929$

Ortiz de Galisteo JP, Toledano C, Cachorro V, Torres B. 2010. Improvement in PWV estimation from GPS due to the absolute calibration of antenna phase center variation. GPS Solut. 14: 389-395.

Ray RD, Ponte RM. 2003. Barometric tides from ECMWF operational analyses. Ann. Geophys. 21: 1897-1910.

Rocken C, Ware R, Van Hove T, Solheim F, Alber C, Johnson J. 1993. Sensing atmospheric water vapor with the global positioning system. Geophys. Res. Lett. 20: 2631-2634.

Saastamoinen J. 1972. Atmospheric correction for the troposphere and stratosphere in radio ranging of satellites. In The Use of Artificial Satellites for Geodesy, Henriksen SW, Chovitz BH, Mancini A (eds) Geophys. Monogr. Ser. 15: 247-251, AGU: Washington, DC.

Sasaki T, Kimura F. 2001. Diurnal variation of water vapor content over the Kanto area during clear summer days observed through GPS precipitable water. Tenki 48: 65-74.

Schneider M, Romero PM, Hase F, Blumenstock T, Cuevas E, Ramos R. 2009. Quality assessment of Izaña's upper-air water vapor measurement techniques: FTIR, Cimel, MFRSR, GPS, and Vaisala RS92. Atmos. Meas. Tech. Discuss. 2: 1625-1662.

Spilker JJ. 1980. GPS signal structure and performance characteristics. In Global Positioning System, Vol. 1, Institute of Navigation: Washington, DC.

Tralli DM, Lichten SM. 1990. Stochastic estimation of tropospheric path delays in global positioning system geodetic measurements. Bull. Geod. 64: 127-159.

Wang J, Zhang L, Dai A. 2005. Global estimates of water-vapor-weighted mean temperature of the atmosphere for GPS applications. J. Geophys. Res. 110: D21101, DOI: 10.1029/2005JD006215.

Wang J, Zhang L, Dai A, van Hove T, van Baelen J. 2007. A nearglobal, 2-hourly data set of atmospheric precipitable water from ground-based GPS measurements. J. Geophys. Res. 112: D11107, DOI: 10.1029/2006JD007529.

Wu P, Hamada J, Mori S, Tauhid YI, Yamanaka MD, Kimura F. 2003. Diurnal variation of precipitable water over a mountainous area of Sumatra Island. J. Appl. Meteor. 42: 1107-1115. 




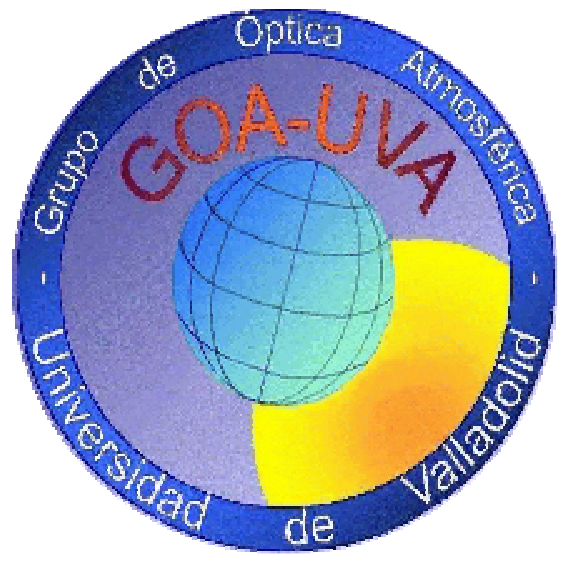

Este trabajo ha sido realizado en el Grupo de Óptica Atmosférica de la Universidad de Valladolid 